
WK 818 qJ83d 1923

41120530R

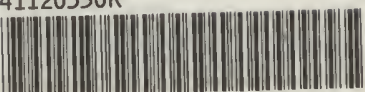

NLM ロ5말9 8

NATIONAL LIBRARY OF MEDICINE

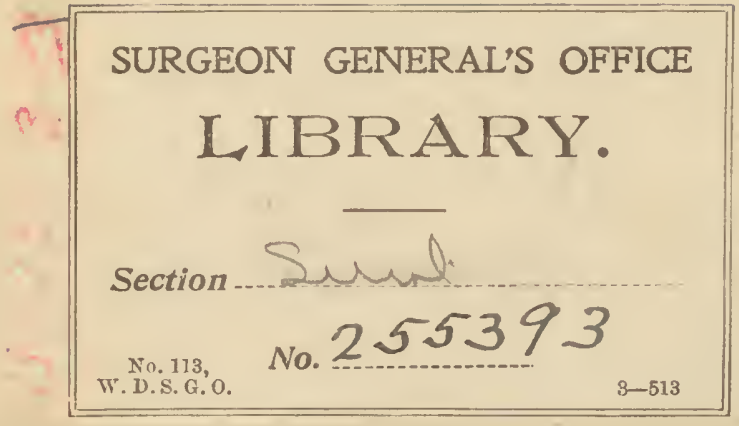




\section{DUE TWO WEEKS FROM LAST DATE}

L. WAY I 1952

GPO 881473 



\section{DIABETIC METABOLISM WITH HIGH AND LOW DIETS}

BY

ELLIOTT P. JOSLIN

11)

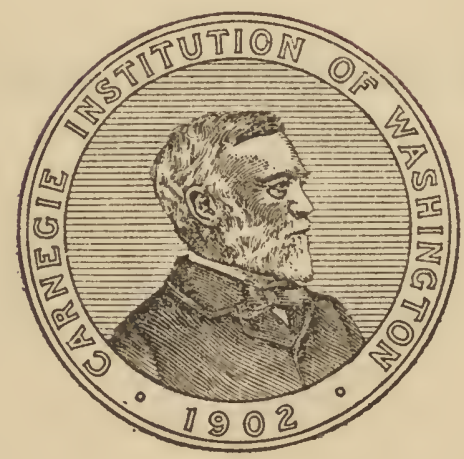

Published by the Carnegie Institution of Washington WASHINGTON, 1923

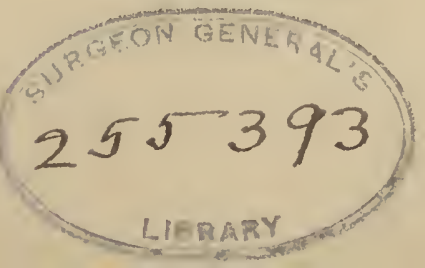




$$
\begin{aligned}
& W K \\
& 818 \\
& \text { J83d } \\
& 1923
\end{aligned}
$$

filmno. 9869 , Item 2

CARNEGIE INSTITUTION OF WASHINGTON Publication No. 323

JUDD \& DETWEILFR, INC.

WASHINGTON, D. C. 


\section{PREFACE.}

The early pages of this monograph and the summary at the end render a preface unnecessary save for the opportunity it affords to acknowledge help received.

First of all, to the thoroughly altruistic private patients, whether alive or dead, who furnished the facts, their doctor presents his heartfelt thanks. To the nurses who cared for these patients, to the assistants and technicians, whether associated with the Nutrition Laboratory or with the writer, he extends his gratitude for their cheerful cooperation, both in the collection of the original data and its later preparation. So many have been associated in the task that one can not mention all, but I must name four: Miss Anna Holt and Dr. Albert A. Hornor, who made the first statistical survey of the material, and especially Mr. W. H. Leslie, whose painstaking accuracy and discernment of any unusual features in the protocols and the data therefrom derived give me confidence in the figures recorded; and finally to Miss A. N. Darling for constant advice and heroic therapeutic treatment of the manuscript. I wish only that Dr. Francis G. Benedict, with whom I have been associated since 1908, who has been a constant inspiration, and without whom the work would not have been begun or completed, knew what these years have meant to me. 



\section{CONTENTS.}

Introduction . PAGE

Bibliography of recent research on metabolism in diabetes............ 1

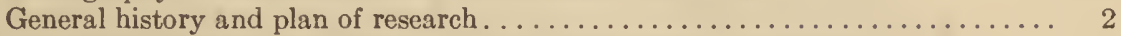

Apparatus cmployed for determining the metabolism of diabetics . . . . . . . 5

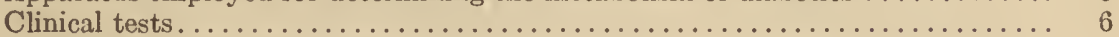

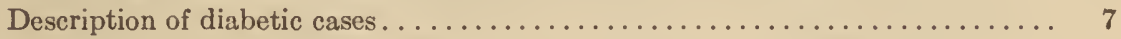

Sex. . . . . . . . . . . . . . . . . . . . . . . . . .

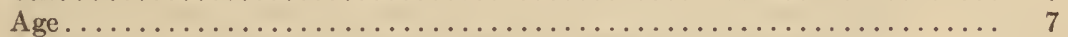

Maximum body-weight in diabetes and its etiological significance . . . . . 12

Greatest loss in weight of diabetic patients. . . . . . . . . . . . . 13

Extreme loss in weight. . . . . . . . . . . . . . . . . . . . . . 14

Loss in weight of pancrcas. . . . . . . . . . . . . . . 15

Duration of diabetes. . . . . . . . . . . . . . . . . . 16

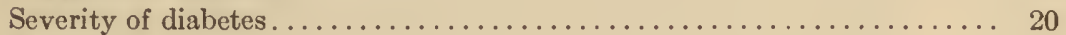

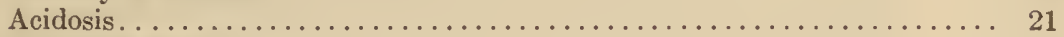

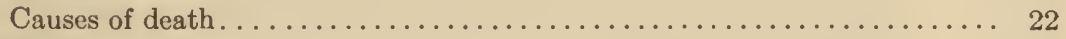

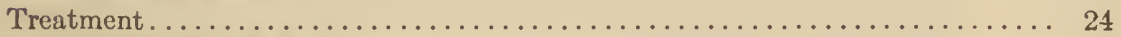

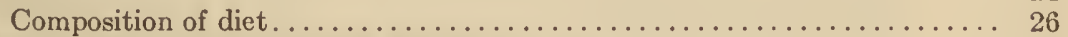

Detailed protocols for individual diabetics. . . . . . . . . . . . . . . . 26

Discussion of results . . . . . . . . . . . . . . . . . . . . . . . 28

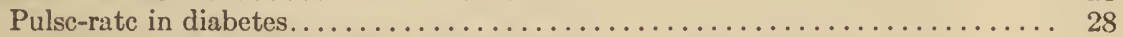

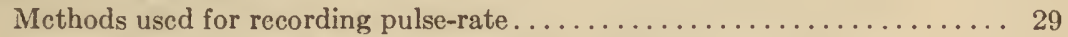

Summary of previous data upon pulse-ratc in diabetes. . . . . . . . . 30

Pulse-rate of diabetic patients treated before and since June, 1914 . . . . . . 31

Relation between loss in weight and pulse-rate.............. 32

Effect of loss in weight on pulse-rate of normal individuals. . . . . . . 32

Factors influencing relation betwcen pulse-rate and loss in weight..... 34

Effect of loss in weight on pulsc-rate of diabetics, and comparison with

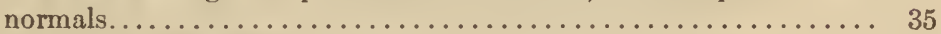

Effect of sex upon pulse-rate. . . . . . . . . . . . . . . . . . . 36

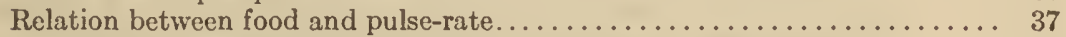

Relation between food and pulse-rate with normal individuals........ 38

Relation between food and pulse-rate with diabetics. . . . . . . . . . 39

Effect of levulose upon pulse-rate of diabetics............ 40

Comparison of effect of food on pulse-rate of normals and diabetics. . . 40

Variations in pulse-rate with certain individuals. . . . . . . . . . . 40

Relation of severity of diabetes to pulse-rate. . . . . . . . . . . . . 41

Relation of acidosis to pulsc-rate. . . . . . . . . . . . . . . . . . . 42

Relation of blood sugar and blood fat to pulse-rate............... 44

Metabolism of diabetics without food.................... 45

Normal standards. . . . . . . . . . . . . . . . . . . . . . . . 45

Computation of basal metabolism..................... 47

Varying metabolism in diabetes........................ 48

Metabolism of diabetic patients before and after June, $1914 \ldots . . \ldots \ldots \ldots . .49$

Effect on metabolism of using different types of apparatus, including changes

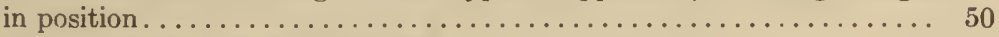

High and low metabolism in diabetes..................... 51

Changes in metabolism during intervals of more than one year ........ 54

Relation of age to inetabolism of diabetics. . . . . . . . . . . . . . 56

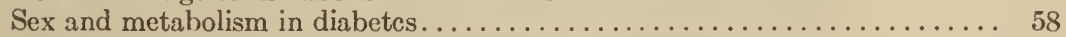

Pulse-rate as a measurc of basal metabolism in diabetes.............. 59

Relation betwcen pulse-rate and metabolism of different individuals... . 60

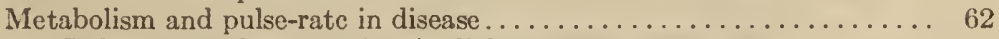

Pulse-rate and metabolism in diabetes................. 63 
Discussion of results-Continued.

Metabolism of diabeties without food-Continued.

Variations in body-weight and their relation to calculations of the metabolism

during observation.

Edema and calculations of metabolism

Caloric value of a kilogram of body-weight and hypothetical estimations connected therewith

Effect of sudden change in body-weight on calculation of metabolism....

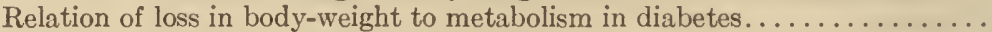

Relation of severity of diabetes to metabolism $\ldots \ldots \ldots \ldots \ldots \ldots \ldots \ldots \ldots \ldots \ldots$

Relation of acidosis to metabolism of diabetics............... 77

Variations in sane individual of acidosis and metabolism . . . . . . . 79

Acidosis, pulse-rate, and metabolism ................... 83

Acidosis, severity of the diabetes, and metabolism............. 83

Acidosis and metabolism of individual diabetics............... 85

Metabolism of young female diabetics without food . . . . . . . . . . . . 90

Variations in metabolism of diabctic girls, with influencing factors . . . . 95

Influcnce of liberal diet upon metabolism of severe cases. . . . . . . . 95

Influcnce of restricted dict upon metabolism of severc cases . . . . . . . . 96

Influence of acidosis upon metabolism of scvere cases. . . . . . . . . . 97

Mctabolism of moderately severe cases . . . . . . . . . . . . . . . . 97

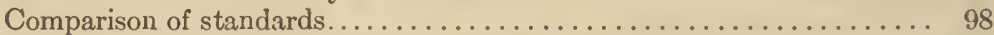

Relation between pulse-rate and metabolism of diabctic girls . . . . . . . 99

Comparison of metabolism and urinary nitrogen of diabetic girls...... 100

Respiratory quotients of diabetic girls.................... 101

Comparison of respiratory quotients and urinary nitrogen of diabetic

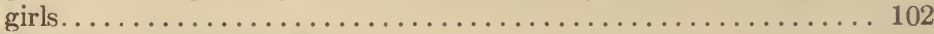

Body-weight of diabctic girls. . . . . . . . . . . . . . 103

Relation of various constitucnts of blood and urine to mctabolism in diabetes. 105

Relation between metabolism and percentage of sugar in the blood.... 105

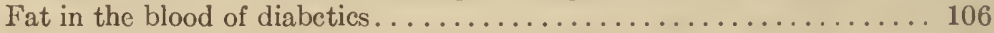

Relation of blood fat and scverity of diabetes............. 107

Relation between blood fat and acidosis................. 107

Relation between blood fat and metabolism.............. 107

Rclation between metabolism and non-protein nitrogen in the blood. . 109

Relation between metabolism and urinary sugar.............. 111

Nitrogen excretion in the urine . . . . . . . . . . . . . . . . . 112

Individual variations in excretion of urinary nitrogen .......... 114

Low nitrogen excretion. ............................ 114

High nitrogen excretion. ......................... 116

Rclation of excretion of urinary nitrogen in periods of overnutrition and undernutrition to severity of diabetes . ................. 117

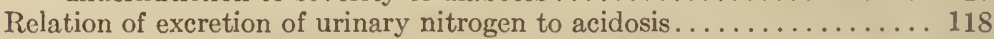

Relation between acidosis, urinary nitrogen, and body-wcight. . . . . . 119

Relation of excretion of urinary nitrogen to basal mctabolism . . . . . . . 120

Heat-production per kilogram of body-wcight as index of caloric needs of

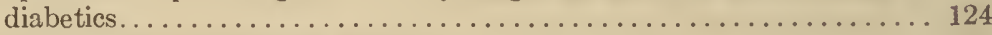

Fasting and undernutrition in health . . . . . . . . . . . . . . 127

Mctabolism of a healthy individual during a prolonged fast. . . . . . . 127

Metabolism of a healthy young woman undergoing the routine undernutrition treatment of a diabetic................. 131

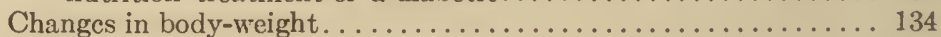

Pulse-ratc................................... 135

Volume of urine................................ 135

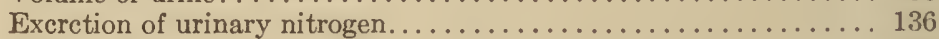

Blood sugar. . . . . . . . . . . . . . . . . . . . . . . . 137

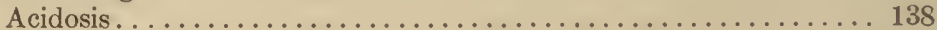

Basal metabolism. .............................. 140

Respiratory quoticnt........................ 140

Materials katabolized......................... 141

Summary of results with healthy woman under diabetic régime.... 141 
Discussion of results-Continued.

Metabolism of diabetics without food-Continued.

PAGE

Effect of extraneous factors upon metabolism in diabetes............ 142

Influence of catamenia, the menopause, and ovariotomy upon the metabolism of diabetic patients.................... 142

Diabetcs during pregnancy .......................... 143

Observations with Case No. $436 \ldots \ldots \ldots \ldots \ldots \ldots \ldots \ldots \ldots \ldots \ldots \ldots$

Observations with Case No. $1070 \ldots \ldots \ldots \ldots \ldots \ldots \ldots \ldots \ldots \ldots \ldots$

Observations with Case No. $1232 \ldots \ldots \ldots \ldots \ldots \ldots \ldots \ldots \ldots \ldots \ldots$

Conclusions regarding metabolism in diabetes with pregnancy . . . 151

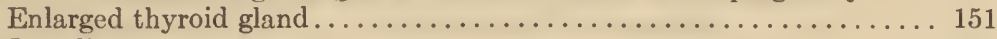

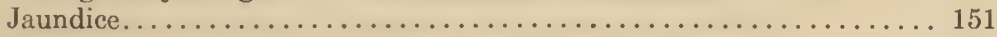

Influence of sodium bicarbonate upon the metabolism........... 152

Effect of overweight on metabolism of diabetics and normal individuals. . 153

Metabolism of diabetic patients within a month and a half of death...... 156

Metabolism of diabetics on verge of coma preceding death......... 158

Factors of influence in the prognosis of diabetes................. 160

Severity of diabetes and duration of life................. 162

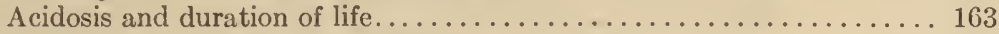

Duration of life and body-weight...................... 164

Respiratory quotient in diabetes................................. 165

Relation between respiratory quotient and metabolism of diabetics .... 165

Clinical importance of relation between respiratory quotient and metabolism. 167

Low and high respiratory quotients........................ 169

Low respiratory quotients in diabetes.......................... 171

Extremely low respiratory quotients in the literature......... 171

Extremely low respiratory quotients in this Laboratory......... 173

High respiratory quotients in diabetes.................... 178

Respiratory quotients with men of same height but of varying weight. ... 187

Respiratory quotient in relation to the different types of severity . . . . . . 187

Respiratory quotient in relation to the degree of acidosis............ 189

Respiratory quotient in relation to pulse-rate of diabetics........... 191

Respiratory quotient in relation to the glycosuria of preceding 24 hours.... 191

Relation between respiratory quotient and carbohydrate balance........ 193

Relation of constituents of the blood and respiratory quoticnt........... 194

Respiratory quotient in relation to blood sugar................ 194

Relation between respiratory quotient and blood fat............ 197

Effect of administering levulose and other foods to diabetics. . . . . . . . . . . . 198

General factors influencing normal metabolism ..................... 198

Incrcase in metabolism due to exercise ................... 198

Increasc in metabolism duc to ingestion of food................ 199

Effect of coffee upon metabolism................... 201

Factors decreasing the metabolism ..................... 202

Variations in metabolism due to pathological conditions........... 203

Effect of food on respiratory quotient of normal individuals............ 204

Effect of ingestion of carbohydrate upon respiratory quotients of normal individuals............................... 206

Methods employed in studying effect of food upon metabolism in diabetes. . 208

Comparison with basal metabolism..................... 208

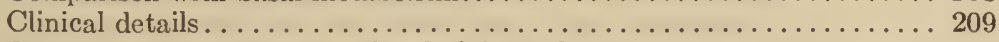

Quality and quantity of foods administered................ 209

Character of information supplied by experiments after food.......... 210

Expcriments following ingestion of levulose................... 211

Obscrvations with diabctics after levulose in present research....... 212

Utilization of levulose by diabetics..................... 214

Effect of ingestion of levulose upon metabolism.............. 214 Effect upon metabolism of variation in amounts of levulose...... 214 Effect of levulose in diabetes of different degrecs of severity... 215 Effect of levulose on metabolism with varying degrees of acidosis. . 217 
Discussion of results-Continued

Effect of administering levulose and other foods to diabetics-Continued.

Experiments following ingestion of levulose-Continued.

Effect of ingestion of levulose upon respiratory quoticnt.......... 217

Effect of levulose with basal quotients of different lcvels........ 217

Variations in quotients in different pcriods of basal cxperiments . . . 221

Variations in quotients in different periods of levulose cxpcriments. . 221

Comparison of basal respiratory quotients of diabetics with respiratory quotients after ingcstion of levulose............. 222

Effect on respiratory quotient of varying amounts of levulose per kilogram of body-wcight. . . . . . . . . . . . . . 222

Effect of levulosc on the respiratory quotient in successive half-lour

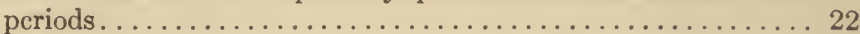

Levulose experiments in which the respiratory quotient remaincd

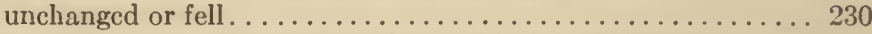

High respiratory quoticnts obtained after administration of lcvulose. 231

Effect of levulosc given on different occasions to the same paticnt. . 235

Carbohydratc balance in levulose experiments............ 237

Relation between metabolism and variations in excretion of sugar in urinc of diabetics after levulose................. 238

Effect of severity of diabetes on respiratory quotient after ingestion of levulose................................. 240

Effect of acidosis on respiratory quotient after ingestion of levulose 240

Blood sugar and ingestion of levulose................... 240

Effect of levulose on metabolism and respiratory quotient with varying

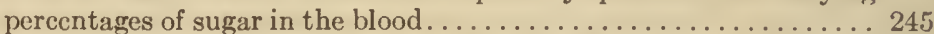

Relation of urinary nitrogen to metabolism and respiratory quotient of diabetics in levulose experiments. . . . . . . . . . . . . 246

Relation of non-protein nitrogen in the blood to total metabolism and respiratory quotient of diabetics in levulose cxpcriments....... 247

Relation of blood fat to total metabolism and respiratory quotient after administration of levulosc to diabctics ................. 248

Effect of ingestion of various carbohydrates.................. 249

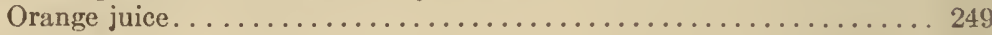

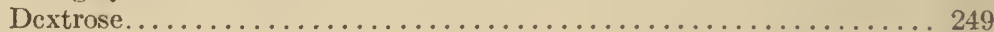

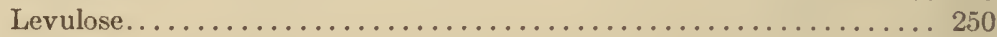

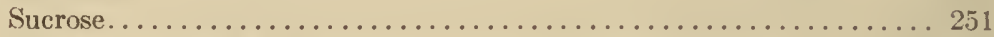

Effect of dextrose and bread on the metabolism of diabetics........ 251

Effect on diabetics of ingestion of carbohydrate with butter or olive oil. 251

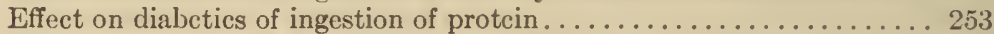

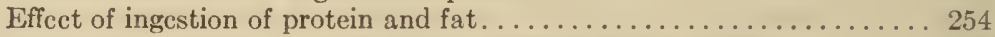

Effect of ingestion of beefsteak (protein) and fat by diabetics........ 256

Increascs in heat-production in various food expcriments at different

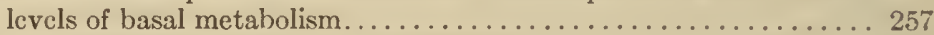

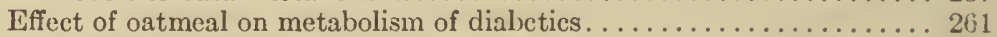

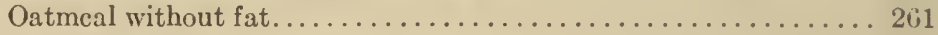

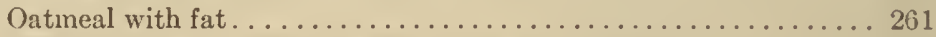

Metabolism on "oatmeal days"-single observations........... 262

Metabolism on "oatmeal days" -multiple obscrvations......... 263

Conclusions upon expcriments with oatmeal. . . . . . . . . 267

Metabolism of diabetics after ingestion of mixed diets.............. 268

Metabolism of diabetics after first meal of day (breakfast or dimncr). 268

Metabolism of diabetics after noon ineal preceded by breakfast... . 270

Metabolism of diabetics after two or thrce incals........... 271

Metabolism of diabetics after noon meal of carbohydrates and..

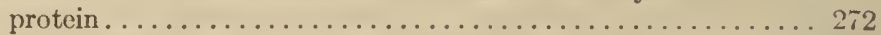

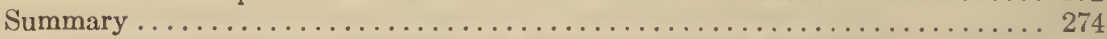

Appendix I. Abstract of clinical data and protocols of expcriments with 113 cases of diabctes mellitus . . . . . . . . . . . . . . . . . . . . 281

Appendix II. Sugar, fat and non-protein nitrogen in blood of diabctics in

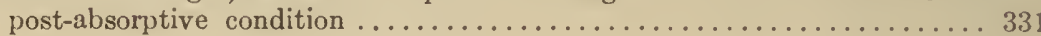




\section{DIABETIC METABOLISM WITH HIGH AND LOW DIETS.}

By Elimott P. Joslin. 


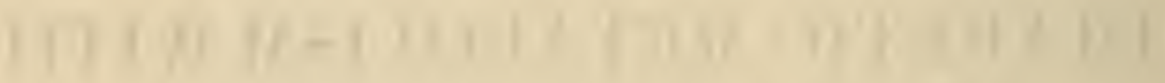

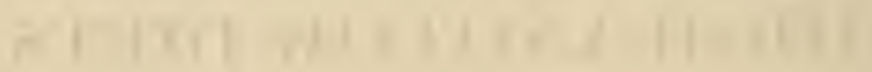




\title{
DIABETIC METABOLISM WITH HIGH AND LOW DIETS.
}

\author{
By Ellioto P. Joslin.
}

\section{INTRODUCTION.}

Two monographs on metabolism in diabetes have been published by the Nutrition Laboratory. In $1910^{a}$ a report was made of investigations based upon 13 cases of diabetes. With 10 of these cases, the diabetes was severe; with 2 it was moderately severe, and with 1 it was mild. Two years later, the results of further studies upon many of these original cases and upon 11 additional patients appeared in a second monograph, ${ }^{b}$ which dealt particularly with metabolism in severe diabetes. Between 1912 and 1917 other patients were studied, so that data from observations on 113 cases are now available.

\section{BIBLIOGRAPHY OF RECENT RESEARCH ON METABOLISM IN DIABETES.}

Since the second monograph on metabolism in diabetes was issued by the Nutrition Laboratory in 1912, an interest in the respiratory metabolism of diabetic patients has been manifested by workers in various laboratories. Of these investigations those in the laboratory of the Russell Sage Institute of Pathology are preeminent. For convenience, the bibliography of the more recent work is here assembled, though reference to the several reports will be deferred to appropriate places in the text. In general, however, it will be found that in this third monograph attention has been given to the presentation of work carried out at the Nutrition Laboratory rather than to the discussion of the work of investigators in other laboratories. The bibliography shows that but little research has been reported in this period, except in a few clinics in Germany and that already mentioned as having been carried on in New York, and recently at the Mayo Clinic.

Allen, Rôle of fat in diabetes. Harvey Society Lectures, 1916-1917, Philadelphia, 1918 ' p. 42.

Allen and Du Bors, Metabolism and treatment in diabetes. Arch. Intern. Med., 1916, 17, p. 1010.

Benedict and Joslin, Metabolism in diabetes mellitus. Carnegie Inst. Wash. Pub. No. $136,1910$.

—, A study of metabolism in severe diabetes. Carnegie Inst. Wash. Pub. No. 176, 1912.

Bernstern and Falta, Ueber den Einfluss der Ernährungsweise auf den Ruhenüchternumsatz bei normalen und diabetischen Individuen. Deutsch. Arch. f. klin. Med., 1916,121 , p. 95 .

${ }^{a}$ Benedict and Joslin, Carnegie Inst. Wash. Pub. No. 136, 1910.

Ibid. No. 176, 1912 . 
BreEd, Metabolism in diabetes, nephritis, and cholecystitis. Calif. State Med. Journ., 1918,16, p. 327.

FALTA, Zur Theorie u. Behandlung des Diabetes mellitus. Med. Klinik, 1914, 10, p. 9.

Gephart, Aub, Du Bois, and Lusk, Metabolism in three unusual cases of diabetes. Arch. Intern. Med., 1917, 19, p. 908.

Geyelin and Du BoIs, A case of diabetes of maximum severity with marked improvement: A study of blood, urine, and respiratory metabolism. Journ. Am. Med. Assoc., 1916, 66, p. 1532.

Grafe, Ueber Karamelkuren bei Diabetikern. München. Med. Wochenschr., 1914, 61, p. 1433.

- Ueber die Wirkung des Karamels im normalen und diabetischen Organismus. Deutsch. Arch. f. klin. Med., 1914, 116, p. 437.

Grafe and Wolf, Beiträge zur Pathologie und Therapie der schwersten Diabetesfälle. Deutsch. Arch.f. klin. Med., 1912, 107, p. 201.

Iwanoff, Experimentelle Beiträge zur Frage der Zuckerzerstörung bei Diabetes. Der respiratorische Quotient beim Pankreasdiabetes und die actuelles Blutreaction unter dem Einflusse von Strychnininjectionen. Zeitschr. f. exp. Path. u. Therapie, 1914,15, p. 359.

Ioffe, Poulton, and RyFrel, The respiratory metabolism in a case of prolonged undernutrition. Quart. Journ. Med., 1918-1919, 12, p. 334.

Johansson, Untersuchungen über den Kohlehydratstoffwechsel, Skand. Arch. f. Physiol., 1909,21, p. 1.

Johansson, Brliström, und Heisl, Die Kohlensäureabgabe bei Zufuhr verschiedener Zuckerarten. Skand. Arch. f. Physiol., 1904, 16, p. 263.

LöFrLer, Ueber das Verhalten des Gaswechsels beim Diabetes nach Zufuhr von reinen Eiweisskörpern und reinen Kohlehydraten. Zeitschr. f. klin. Med., 1919, 87, p. 309.

Lusk, On the diabetic respiratory quotient. Arch. Intern. Med., 1915, 15, p. 939.

MURLIN and KRAMER, Influence of alkali on respiratory metabolism after total and partial pancreatectomy. Journ. Biol. Chem., 1916, 27, p. 517.

Röver, Ueber Atmung des gesunden und säurevergifteten Menschen. Zeitschr. f. klin. Med., 1913, 77, p. 228.

Rотн, Ueber Mehltage bei Diabetes. Wien. klin. Wochenschr., 1912, 25, p. 1864 . Also Orvosi Hetilap, Budapest, 1913, 57, p. 155.

SchILling, Experimentelle Untersuchungen übe den respiratorischen Quotienten bei Diabetes mellitus nach Mehlkuren. Inaug.-Diss., Leipsic, 1911.

Sieb, Experimentelle Untersuchungen über den respiratorischen Gaswechsel bei Diabetes mellitus nach Eiweisszufuhr und bei Hyperthermie. Inaug.-Diss., Leipsic,1913. See, also, Zeitschr. f. Physiol., 1913-1914, 27, p. 930.

Wilder, Boотнв, and Beeler, Studies of the metabolism of diabetes. Journ. Biol. Chem., 1922, 51, p. 311.

\section{GENERAL HISTORY AND PLAN OF RESEARCH.}

Following the publication of the second monograph upon diabetes in 1912, experiments were continued in the Nutrition Laboratory to determine the effect of the administration of food to diabetics. This was in contrast to the earlier observations, which related chiefly to the study of the metabolism with the patient in the post-absorptive state (12 to 14 hours after the ingestion of food). Then came in June, 1914, the introduction of treatment by undernutrition and, in consequence, the entire aspect of the metabolism in diabetes changed. Thereupon observations upon patients were multiplied in number, and efforts were made to secure records of the metabolism under widely varying conditions of fasting and feeding.

The responsibility and the actual conduct of the determinations of the respiratory metabolism were assumed by the Nutrition Laboratory, while 
the responsibility for the clinical care of the cases and, save for the first few years, for the chemical tests, also, was taken by the writer and his assistants. This latter task was lightened through the advice of the Director of the Nutrition Laboratory and his staff, which was frequently sought and always freely given.

The cases whose metabolism is here recorded have been private patients of the writer and not patients taken from the public wards of a large general hospital. The experiments were performed with the patients rather than upon them, because throughout the research their cooperation was not only solicited, but secured. The investigators and the patients considered themselves united in a partnership, having for its object the accumulation of knowledge for the benefit of all diabetics rather than for the given individual under investigation in particular. This altruistic principle was thoroughly appreciated by the patients, who made suggestions which were helpful not only in treatment, but in the planning of the experiments. These statements are emphasized because they demonstrate, first, that private patients are especially desirable subjects for scientific investigation, and second, because cooperation and an intelligent understanding of what is the purport of an experiment considerably lessen the labor of supervision and are of the greatest assistance in preventing errors, whether wilful or unintentional.

The early observations of the metabolism, namely, those made between 1908 and the winter of $1914-15$, were carried out mainly at the Nutrition Laboratory. With but four exceptions, all of the patients studied were undergoing treatment at the New England Deaconess or the Corey Hill Hospitals, or had at one time or another been at these institutions. As most of the patients sharing in these experiments had been without food for some hours, they were transported from the hospital to the Laboratory to avoid unnecessary exertion. In no instance was a patient in such condition as to require an ambulance. Most of the cases came from the Deaconess Hospital, which is but an eighth of a mile from the Laboratory, whereas the Corey Hill Hospital is about 2 miles distant. During 1913 and 1914 a series of experiments was also carried out at the central building of the New England Deaconess Hospital. In December, 1915, a room was prepared and an apparatus installed for the metabolism experiments in Brodbeck Cottage, adjoining the Deaconess Hospital, in which the diabetic patients were then housed, and, beginning with January, 1916, the observations of the metabolism were generally made there. This special installation greatly facilitated the work and, in consequence, it was possible to double the number of experiments.

The results of the 150 experiments representing the work from 1908 to 1911 have already been reported in publications 136 and 176 of the Carnegie Institution of Washington, previously referred to. Mention was also made of several others in a Harvey lecture delivered in the spring of $1915,{ }^{a}$ while the remainder are published here for the first time.

In this monograph the attempt has been made to utilize the data of all experiments conducted by the Nutrition Laboratory upon diabetic patients. To present this mass of evidence satisfactorily and fairly, it was found necessary to separate the observations into two groups, those before and those after

a Joslin, The Harvey Lectures, 1914-15, Philadelphia, 1915, p. 290. 
June, 1914, this being the date when the patients studied began to feel the therapeutic influence of treatment by undernutrition proposed by F. M. Allen. ${ }^{a}$ This date will accordingly appear frequently in the tables and discussions of results in the present monograph.

TABLE 1.-General summary of observations on diabetics from 1908 to 191\%, inclusive.

\begin{tabular}{|c|c|c|c|c|}
\hline \multirow{2}{*}{$\begin{array}{c}\text { Period of } \\
\text { experimentation. }\end{array}$} & \multicolumn{2}{|c|}{ No. of experiments. } & \multicolumn{2}{|c|}{ No. of periods. } \\
\cline { 2 - 4 } & Without food. & With food. & Without food. & With food. \\
\hline $1908-1911^{1}$ & 105 & 45 & 350 & 149 \\
$1912-1917$ & 351 & 160 & 1,147 & 573 \\
$1908-1917$ & 456 & 205 & 1,497 & 722 \\
\hline
\end{tabular}

1 See Benedict and Joslin, Carnegie Inst.Wash. Pub. No. 136, 1910, and ibid., No.176, 1912.

Somewhat over two-thirds (456) of the observations with diabetics were conducted with patients in the post-absorptive state, and the remainder (205) were made shortly after administration of food. A general summary of all the observations with and without food is given in table 1 . In addition to the 661 metabolism experiments $(2,219$ periods) with these diabetics, there were 19 experiments, representing 61 periods, which were made with a normal individual. This subject, a nurse, assumed the rôle of a diabetic patient for a period of three weeks in order that the effect of the diabetic diet could be studied with a healthy subject. (See p. 131.)

TABLE 2.-Food materials used in experiments with diabetics.

\begin{tabular}{|c|c|c|c|}
\hline Food materials. & $\begin{array}{c}\text { No. of } \\
\text { experiments. }\end{array}$ & Food materials. & $\begin{array}{c}\text { No. of } \\
\text { experiments. }\end{array}$ \\
\hline 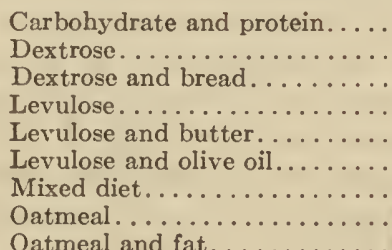 & $\begin{array}{r}15 \\
1 \\
4 \\
51 \\
1 \\
7 \\
51 \\
4 \\
34\end{array}$ & 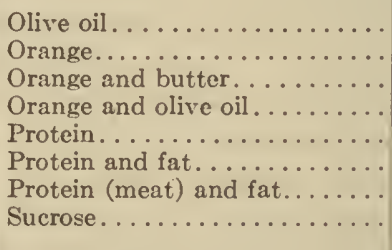 & $\begin{array}{r}1 \\
4 \\
1 \\
2 \\
4 \\
11 \\
13 \\
1\end{array}$ \\
\hline & & Total. . & 205 \\
\hline
\end{tabular}

In studying the diabetic metabolism after food, it was generally the practice to make use of a single food material or a combination of two special food materials for each experiment. Levulose was the special food material most frequently tested; next in number were the experiments with oatmeal or oatmeal and fat; and finally observations were made upon patients living upon various quantities of protein or carbohydrate, with or without fat. In addition, whenever the apparatus and the assistants had free time between more elaborately planned observations, routine experiments were undertaken after

a Allen, Journ. Am. Med. Assoc., 1914, 63, p. 939. 
the regular mixed meals prescribed in the course of treatment. The kinds of food included in the research are shown in table 2.

The summary in this table represents all experiments with food which are recorded in Appendix I, regardless of conditions at the time of the observation, or of suitable basal values for the computation of increase of heat-production following the ingestion of food.

\section{APPARATUS EMPLOYED FOR DETERMINING THE METABOLISM OF DIABETICS.}

The metabolism of the diabetics was determined at first in the Nutrition Laboratory by means of the chair calorimeter or the bed calorimeter. These apparatus measured directly the heat which was produced by the patient, as well as the carbon-dioxide production and oxygen consumption of the subject. In the studies without food, 32 experiments were made with the chair calorimeter and 27 experiments with the bed calorimeter; with food there were 14 with the chair calorimeter and 6 with the bed calorimeter. As the accuracy of the results obtained by indirect calorimetry became established by means of comparisons in various laboratories of the methods of direct and indirect calorimetry, the complicated methods of direct calorimetry were gradually discarded for the simpler indirect determination of the metabolism with the respiration apparatus and the respiration chamber. Accordingly, the Benedict universal respiration apparatus was used in experiments with diabetics at the Nutrition Laboratory as early as June, 1909, and it was employed for all of the experiments at the Deaconess Hospital during 1913 and 1914. With this apparatus 123 experiments were made with the patients in the post-absorptive condition, and 60 experiments after the patients had taken food. In the early part of 1915,12 experiments were also carried out with the respiratory-valve apparatus, and in 1914 one with the Douglas respiration apparatus, ${ }^{a}$ all without food. The simplicity of the Benedict universal respiration apparatus made it of great value. Undoubtedly the use of this apparatus would have been continued had not the clinical respiration chamber been devised and employed not only for observations with diabetics at the Nutrition Laboratory, but for the long series of experiments in Brodbeck Cottage previously referred to. The observations with the chamber apparatus, which were for the most part the final experiments of the series, consisted in all of 261 experiments with the subject without food and 125 experiments after the patient had taken food of various kinds.

The calorimeters employed in the earliest experiments were somewhat formidable in appearance and the technique required to operate them was so intricate as to excite apprehension. On the other hand, the clinical respiration chamber was admirably adapted for experiments of the type indicated with diabetic patients. The subject could lie down and rest throughout the observations. He was free from the annoyance of the adjustment and wearing of the nosepieces or mouthpiece required with the other forms of respiration apparatus. The couch and its cover, the methods of introducing oxygen and removing the carbon dioxide, the blower for the circulation of air in the chamber, and the pneumograph were all so simple that they were easily

a Douglas, Journ. Physiol., 1911, 42; Proc. Physiol. Soc., p. xvii. Douglas, Haldane, Henderson, and Schneider, Phil. Trans, 1913, 203, p. 217. 
comprehended and gave confidence. Practically no training of the subject was required to secure a successful observation, and, save for the ennui of lying quiet, the experiment was not objectionable to the individual. The results obtained with the clinical respiration chamber were the most satisfactory of any secured in the research.

It is unnecessary to describe each apparatus and the technique employed in using it, as these have been discussed in detail in previous publications from this Laboratory. ${ }^{a}$

\section{CLINICAL TESTS.}

The tests employed in the examination of the urine, blood, and alveolar air changed from time to time. The urinary analyses were usually made with the Folin ${ }^{b}$ methods for nitrogen and ammonia, ${ }^{c}$ and the S. R. Benedict method for sugar, ${ }^{d}$ but in the early experiments the Citron method, ${ }^{e}$ and later a method devised by A. W. Peters, ' of the Nutrition Laboratory staff, for the estimation of sugars, were employed. The estimation of the hydro-oxybutyric acid was originally made with Black's method." A general idea of the extent of acidosis was obtained by Gerhardt's diacetic acid reaction and recorded by the analyst in the customary manner, i. e., $0,+,++,+++,++++$. As recorded in this monograph, however, the two last are combined and recorded as +++ . These same symbols have likewise been employed in our records to represent the final conclusion upon the extent of acidosis, but such conclusions are based upon various factors and not upon Gerhardt's reaction alone. These conclusions are expressed according to the method used for the diacetic acid and are likewise given in four, not five, groups. (See p. 21, where the decision as to acidosis is discussed.)

Analyses of the blood for sugar were made first with Bang's method, ${ }^{h}$ and later with the Lewis-Benedict method, ${ }^{i}$ although now the Folin methods ${ }^{i}$ are employed. The analyses for fat in the blood were performed according to Bloor's suggestions; ${ }^{k}$ the determinations of the non-protein nitrogen were made according to the Folin-Denis ${ }^{l}$ description. The carbon dioxide in the blood was determined by the Van Slyke principle. ${ }^{m}$ In the estimation of the carbon dioxide in the alveolar air, the Fridericia ${ }^{n}$ apparatus was employed.

\footnotetext{
a For a description of the chair calorimeter and the bed calorimeter, see Benedict and Carpenter, Carnegie Inst. Wash. Pub. No. 123, 1910; Benedict, Riche, and Emmes, Am. Journ. Physiol., 1910, 26, p. 1. For the Benedict universal respiration apparatus, see Benedict, $A m$. Journ. Physiol., 1909, 24, p. 345; ibid., Deutsch. Arch. f. klin. Med., 1912, 107, p. 156; and Carpenter, Carnegie Inst. Wash. Pub. No. 216, 1915, p. 21. For the respiratory-valve apparatus, which was employed in a few experiments, see Hendry, Carpenter, and Emmes, Boston Med. and Surg. Journ., 1919, 181, p. 287. For the clinical respiration chamber, see Benedict and Tompkins, Boston Med. and Surg. Journ., 1916, 174, pp. 898 and 939.

bolin and Farmer, Journ. Biol. Chem., 1912, 11, p. 493.

c Folin and Macallum, Journ. Biol. Chem., 1912, 11, p. 523.

dS. R. Benedict, Journ. Am. Med. Asso., 1911, 57, p. 1193.

- Citron, Deutsch. med. Wochenschr., 1904, 30, p. 1602; ibid., 1909, 35, p. 1189.

$\checkmark$ Peters, Journ. Am. Chem. Soc., 1912, 34, p. 422; ibid., 1912, 34, p. 928.

- Black, Journ. Biol. Chem., 1908, 5, p. 207.

${ }^{n}$ Bang, Der Blutzucker, Wiesbaden, 1913.

Lewis-Benedict, Journ. Biol. Chem., 1915, 20, p. 61.

; Folin and Wu, Journ. Biol. Chem., 1919, 38, p. 106.

* Bloor, Journ. Biol. Chem., 1914, 17, p. 377.

${ }^{l}$ Folin and Denis, Journ. Biol. Chem., 1912, 11, p. 527.

$m$ Van Slyke, Journ. Biol. Chem., 1917, 30, p. 347. The method is described in detail in Joslin: Treatment of diabetes mellitus, 2d ed., Philadelphia, 1917, p. 217.

- Fridericia, Berl. klin. Wochenschr., 1914, 51, part 2, p. 1268; see, also, Joslin: Treatment of diabetes mellitus, 2d ed., Philadelphia, 1917, p. 233.
} 


\section{DESCRIPTION OF DIABETIC CASES.}

As already stated, the cases of diabetes under observation in the research conducted by the Nutrition Laboratory between the years 1908 and 1917 were private patients. They numbered 113 and represented all grades of society-male and female, young and old, the poor and the rich, the ignorant and the wise. With but one exception, these individuals and their relatives have manifested a keen interest in the observations and this has helped more than anything else to promote the acquiring of accurate data.

The number of experiments made with each of these 113 cases is given in table 3 , together with considerable clinical data regarding the patients. Detailed information concerning the individual observations is given in Appendix I. (See pp. 281 to 330.) The figures in the first column of table 3 represent the writer's private identification case numbers, which will be used throughout this report in designating the individual cases. This numerical designation appears desirable, as the same cases are discussed in various other publications. $^{a}$ The alphabetical designations used for the cases previously discussed in the two monographs on metabolism in diabetes issued by this Laboratory are likewise given in footnote 5 for further identification.

The sex, the age at the onset of diabetes, with date of onset, the duration of the disease, its severity, and the degree of acidosis, the maximum bodyweight, the greatest percentage loss in weight, the causes of death, and the method of treatment, are discussed in a general way in the pages immediately following. Their relations to the pulse-rate and to the metabolism are discussed more specifically in later sections.

\section{Sex.}

The number of males in the series was 67 and of females 46 . In June, 1921, 21 per cent of the males (14) and 22 per cent of the females (10) were alive. No distinction between the two sexes in the character of the diabetes has been noted. Catamenia is known to have ceased with 12 cases, presumably as a result of the disease, and the menopause to have occurred with 9 patients. In 17 instances, catamenia was uninterrupted. An ovariotomy had been performed upon one case 13 years previous to onset of diabetes. In 7 cases the history of catamenia is indefinite or unknown. The influence of the catamenia, the menopause, and the ovariotomy upon the metabolism is discussed on page 142 .

The metabolism of the two sexes will be considered later. (See p. 58.) In general, account of sex has been taken when diabetic metabolism is compared with normal standards, males being compared with males and females with females.

\section{AGE.}

The youngest male at the time of experimental observation was 14 years, and the youngest female 16 years. The oldest cases were, respectively, 72 and 64 years of age. It is partly on account of this wide range in age that it has been considered desirable to estimate variations in metabolism from some normal standard of corresponding age rather than to use the metabolism per kilogram of body-weight for a basis of comparison, as was done in the two

a Joslin, Treatment of diabetes mellitus, 2d ed., Philadelphia, 1917. A diabetic manual, 2d ed., Philadelphia, 1919. 


\begin{tabular}{|c|c|c|}
\hline \multirow{3}{*}{ 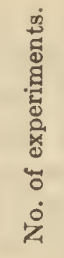 } & 密 & 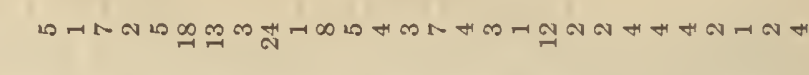 \\
\hline & 象宽 & 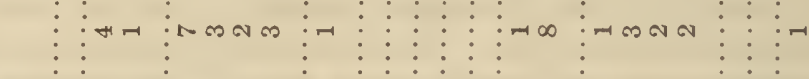 \\
\hline & 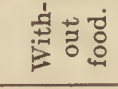 & 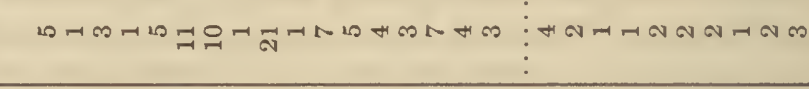 \\
\hline & 䄈 & 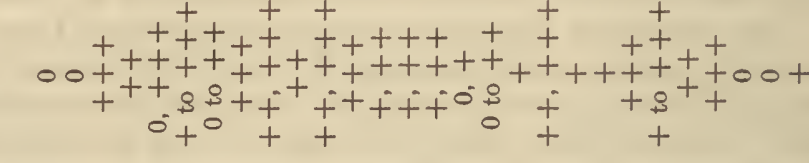 \\
\hline & 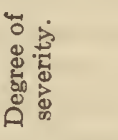 & 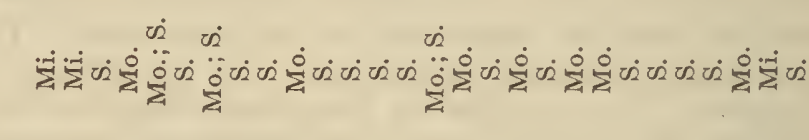 \\
\hline 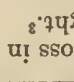 & 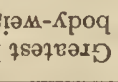 & త。ం 유 \\
\hline & 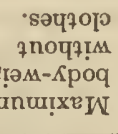 & 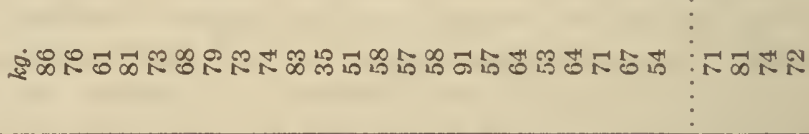 \\
\hline & 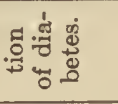 & 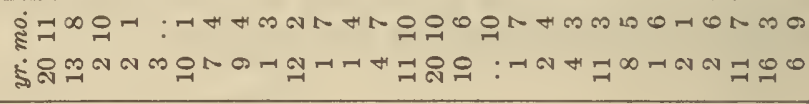 \\
\hline & 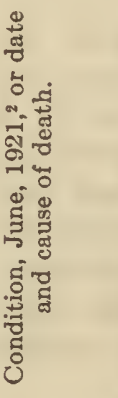 & $\begin{array}{l}0 \\
0 \\
0\end{array}$ \\
\hline 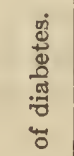 & 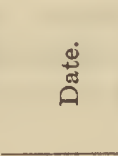 & 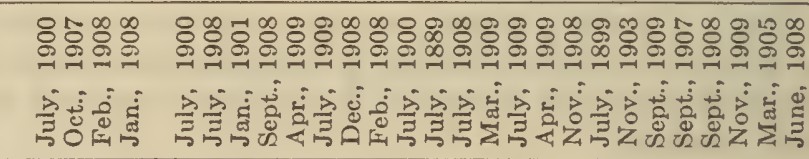 \\
\hline & 兽 & 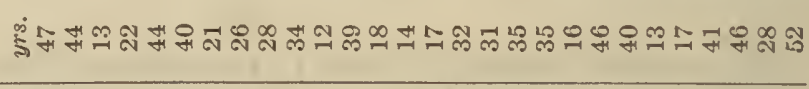 \\
\hline & 崖 & 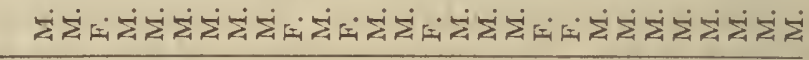 \\
\hline & 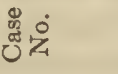 & 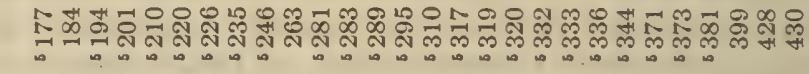 \\
\hline
\end{tabular}




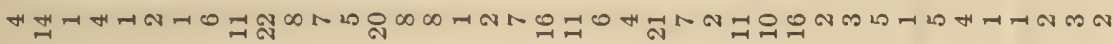
:o $\vdots \vdots \vdots$ : $\vdots$ :

H 52 म

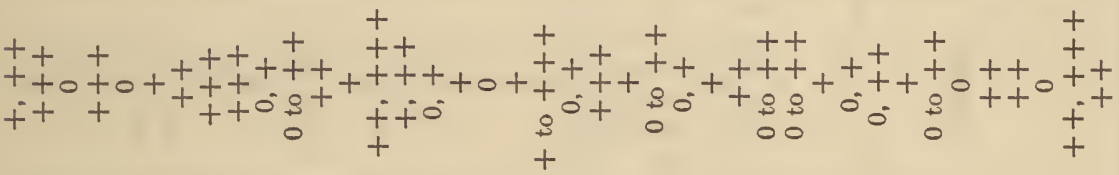

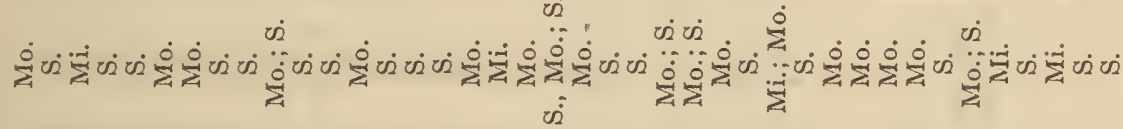

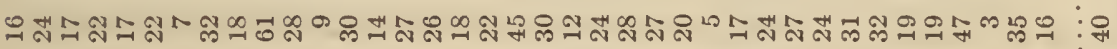

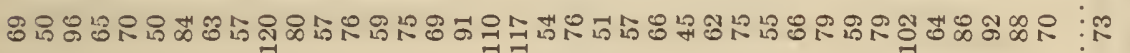

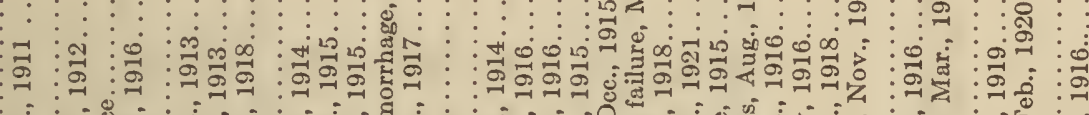

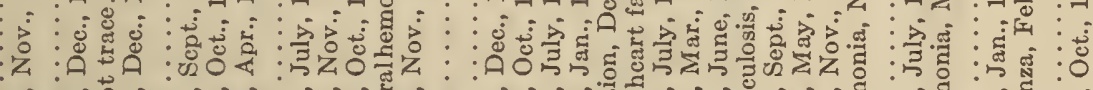

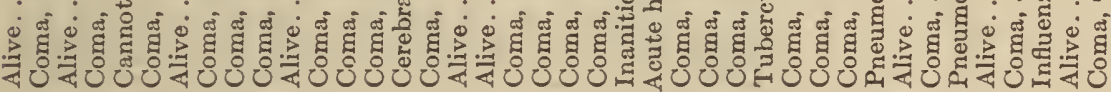

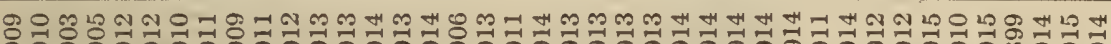

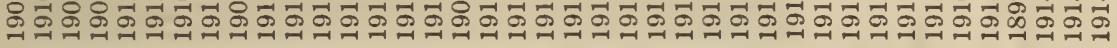

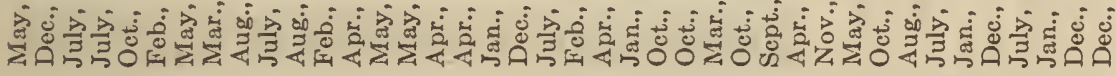

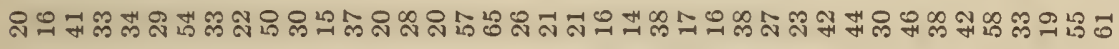

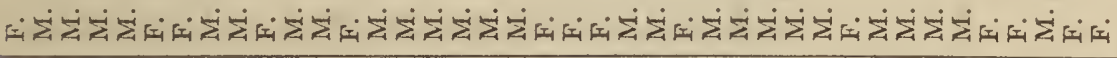

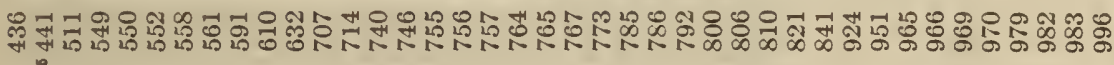




\begin{tabular}{|c|c|c|}
\hline \multirow{3}{*}{ 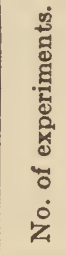 } & 涥 & NN⿻上丨 \\
\hline & 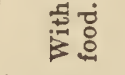 & 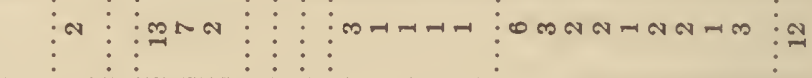 \\
\hline & 急范宫 & 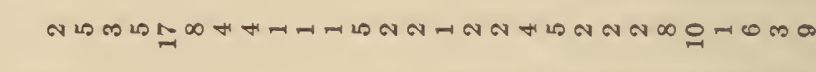 \\
\hline \multicolumn{2}{|r|}{ 兽 } & 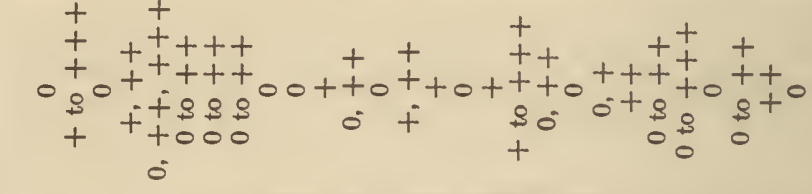 \\
\hline \multicolumn{2}{|r|}{ 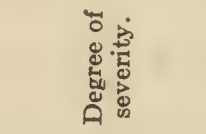 } & 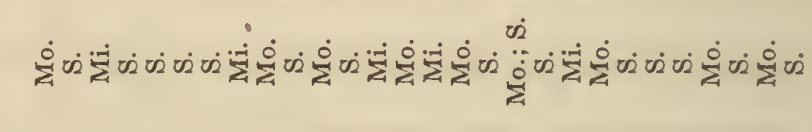 \\
\hline \multicolumn{2}{|c|}{ 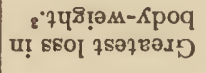 } & కீ \\
\hline \multicolumn{2}{|c|}{ 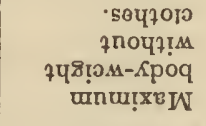 } & 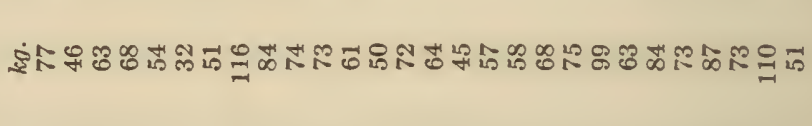 \\
\hline \multicolumn{2}{|c|}{ 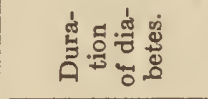 } & 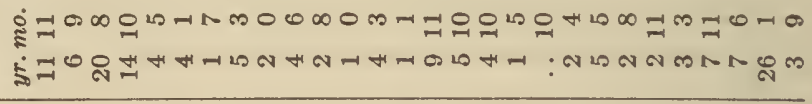 \\
\hline \multicolumn{2}{|r|}{ 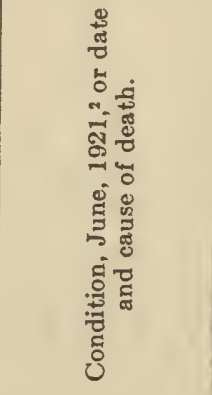 } & 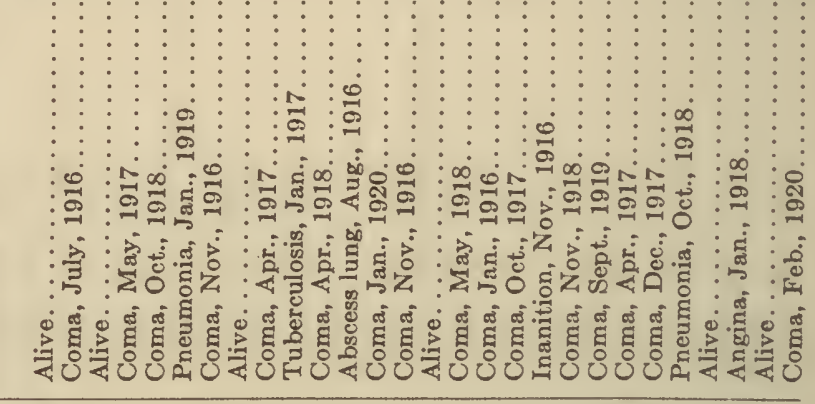 \\
\hline \multirow{2}{*}{ 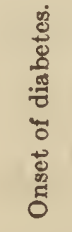 } & $\stackrel{5}{\oplus}$ & 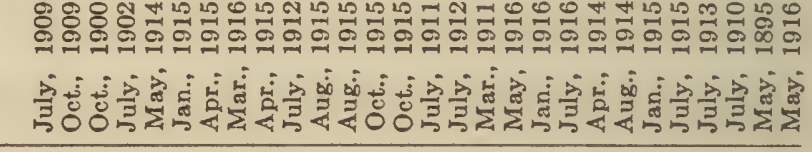 \\
\hline & $\stackrel{\$}{\sharp}$ & 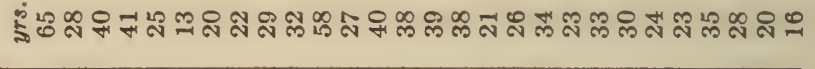 \\
\hline \multicolumn{2}{|r|}{ ஜீं } & 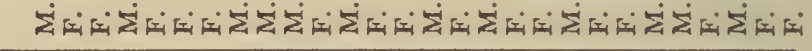 \\
\hline \multicolumn{2}{|r|}{ 总宗 } & 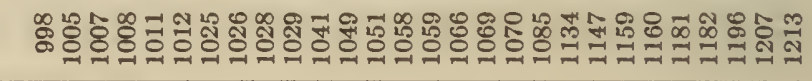 \\
\hline
\end{tabular}




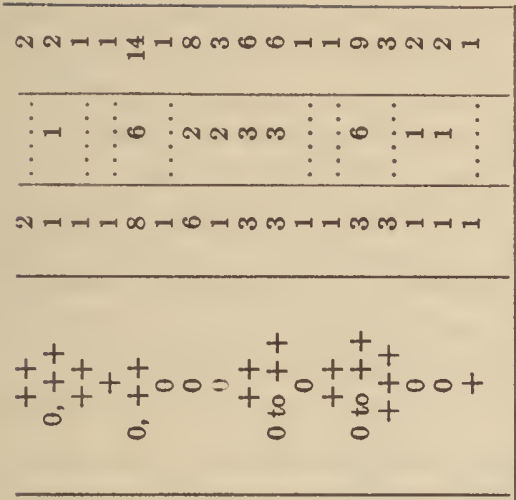

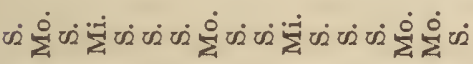

ผิ ผิ ผ

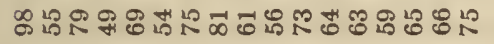

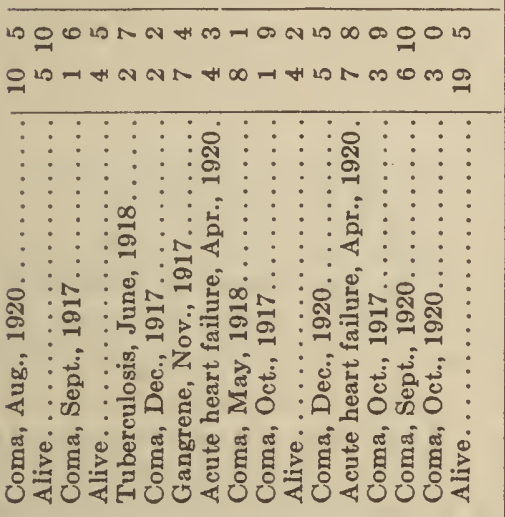

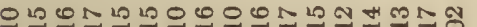

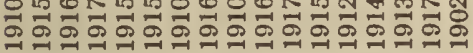

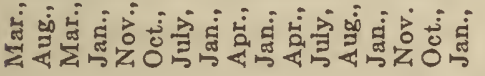

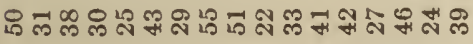

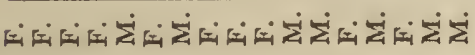

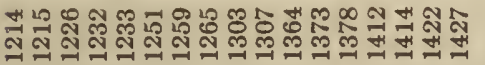

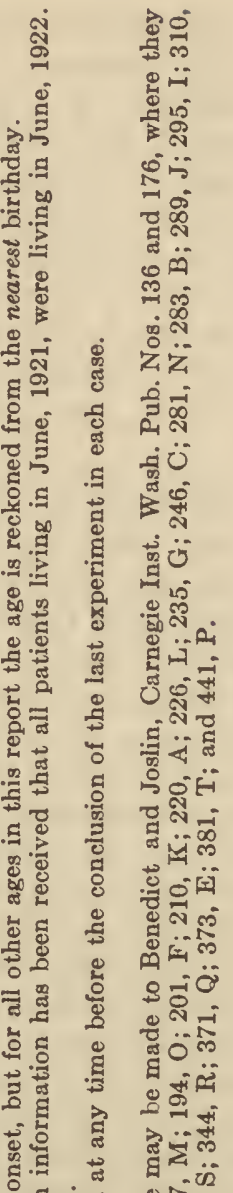

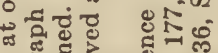
品

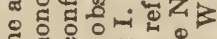
†

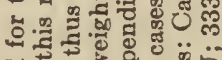

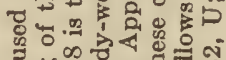
응

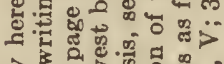
在

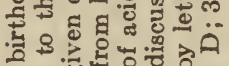

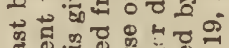

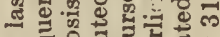
语品

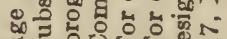

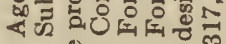

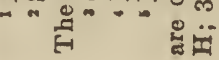


previous monographs. Throughout this publication it will be found that often, particularly when the pulse-rate is discussed, the cases are classified by age. This is more necessary in comparisons of the pulse-rate with the metabolism because elsewhere the metabolism is considered in relation to a standard of equivalent age as well as of sex. The onset of the diabetes occurred most frequently in the third decade of life (between 20 and 30 years of age) and the majority of the cases were in this and the two neighboring decades. (See tables 3 and 4.) These decades are particularly favorable for the study of uncomplicated diabetes in contradistinction to the fifth and sixth decades, in which obesity has been found to be so great a factor. ${ }^{a}$

\section{Maximum Body-weight in Diabetes and its Etiological Significance.}

The maximum weight given by the patient can be considered, as a rule, to be the weight in health and therefore preceding and not far from the date of the onset of diabetes. Occasionally there are exceptions to this rule and mild diabetes may develop when the patient is gaining and has not yet reached a maximum weight. In preparing table 4 the variations of maximum weight from the normal standard have been computed on the basis of age at onset, though the actual age at the time of the highest body-weight may have been somewhat less in many instances and even greater than at the date of onset. Of the cases studied at the Nutrition Laboratory, 55 per cent of the patients were more than 5 per cent overweight $t^{b}$ previous to the onset of diabetes, 22 per cent were more than 5 per cent underweight, and the remaining 23 per cent were within 5 per cent plus or minus of the normal. (See footnote 3 in table 4.) Obesity was equally common to the two sexes. There was no case in the group whose maximum weight before the onset of diabetes was more than 20 per cent below the standard weight.

These figures show obesity to be less of a factor than was found in a recent compilation of a larger series of 1,000 cases $^{c}{ }^{c}$ in which 73.4 per cent were more than 5 per cent overweight, 10.7 per cent were more than 5 per cent underweight, and 15.9 per cent were within 5 per cent plus or minus of the normal.

The percentage variations in the maximum weight above or below the standard are shown for the different age groups in table 4, the age at onset being used in grouping the patients. It will be seen that in all decades overweight is a factor in the onset of diabetes. That diabetes develops in the fourth decade ( 31 to 40 years), although the factor of overweight which is favorable to such development is far less marked, shows that the disease is more deep-seated in the cases studied at the Nutrition Laboratory in comparison with the larger group of 1,000 cases previously referred to. Beginning with the sixth decade ( 51 to 60 years), but one individual appears in the table whose maximum weight was more than 5 per cent below normal. This observation, here encountered for the first time, led to a further study of the connection between obesity and diabetes which brought out the importance of the avoidance of obesity in the prevention of diabetes.

\footnotetext{
a Joslin, Journ. Am. Med. Assoc., 1921, 76, p. 79.

${ }^{b}$ For standards employed to determine normal weight, see Medico-Actuarial Mortality Investigation. Compiled and published by Assoc. of Life Ins. Med. Directors and The Actuarial Soc. of Am., New York, 1912, 1, pp. 38 and 67. See, also, Joslin, Journ. Am. Med. Assoc., 1921, 76, p. 79.

'Joslin, Journ. Am. Med. Assoc., 1921, 76, p. 79, table 1.
} 


\section{Greatest Loss in Weight of Diabetic Patients.}

The average loss in weight for 111 of the entire group of 113 subjects, computed from their maximum weights (averaging $70 \mathrm{~kg}$.) and their minimum weights (averaging $52 \mathrm{~kg}$.), was $18 \mathrm{~kg}$., or 25 per cent. It should be noted that the minimum weights, as given in table 3 , represent the lowest weights observed at any time before the conclusion of the last experiment

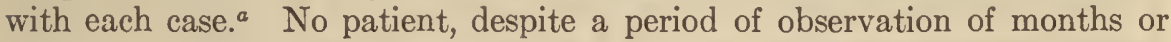

TABLE 4.-Percentage variations of maximum body-weight of 111 diabetics from standard normal weight.

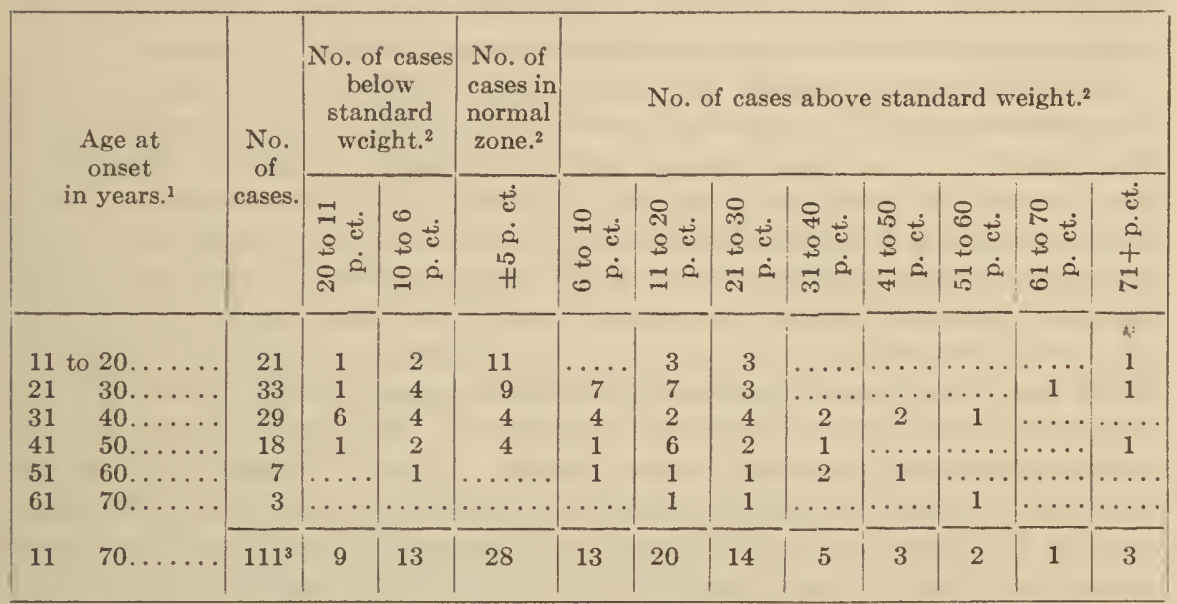

1 Age at last birthday here uscd.

${ }^{2}$ See Medico-Actuarial Mortality Investigation. Compiled and published by Assoc. of Life Ins. Med. Directors and The Actuarial Soc. of Am., New York, 1912, 1, pp. 38 and 67. See, also, Joslin, Diabetic manual, 2d ed., Phila., 1919, p. 115.

${ }^{3}$ No data for maximum weight were available for two cases. Of the rcmaining 111 patients, 22 cases were more than 5 per cent below standard weight (20 per cent); 61 cases were more than 5 per cent above standard weight ( 55 per cent); and 28 cases were within \pm 5 per cent of standard weight for their sexes, agcs, and heights (25 per cent).

years, is known to have gained up to his maximum weight previous to observation save Case No. 428. His highest known weight without clothing at the time of his first visit in July, 1911, was $71.7 \mathrm{~kg}$., but his weight on April 22, 1912, was $73.8 \mathrm{~kg}$.

The maximum weight of a larger group of patients (200), which included only 10 of the individuals studied by the Nutrition Laboratory, was given in a previous summary, ${ }^{b}$ together with the subsequent fall in weight. The average maximum weight for this group was $76 \mathrm{~kg}$., and the average fall in weight to minimum was $15 \mathrm{~kg}$. or 19 per cent. The greater percentage loss of the cases studied by the Nutrition Laboratory is another indication of the severity of the diabetes with the smaller group. Comparatively little of this loss of 19 per cent took place after these patients were first seen, because

a These percentage losses do not necessarily represent the greatest loss in weight in the course of the disease, as subsequent to the last obscrvation of the metabolism, greater loss in weight frequently took place.

${ }^{b}$ Benedict and Joslin, Carnegie Inst. Wash. Pub. No. 176, 1912, p. 99, table 116. 
when they first came for treatment the decline in weight had already reached $12 \mathrm{~kg}$., or 16 per cent of the maximum weight. These figures, which represent records obtained between 1898 and 1912, are significant of the type of treatment in this period, and show that loss in weight was limited during observation to slightly more than 3 per cent of the maximum weight.

For comparison, a second and a third series of 187 and 200 cases, respectively, more recently treated, have been compiled. In the second series the average maximum weight was $80.9 \mathrm{~kg}$. and the average weight at the first visit $66.3 \mathrm{~kg}$., representing a loss of 18 per cent, or essentially the same as in the first series. In the third and most recent series, the average maximum weight of 200 diabetics was $79.9 \mathrm{~kg}$., and at the first visit, oddly enough, the average weight for this group was $66.2 \mathrm{~kg}$., giving a loss of 17 per cent.

The maximum weights in the three series are essentially the same, as are also the losses up to the time of their first being seen. A comparison of the final weights in the three groups, and the average duration of life of each group, would be valuable in that it would give a hint for treatment. Such data are not yet available, because the recent cases have been too short a time under observation to permit of deductions. There are lessons in these statistics, however, which more than repay the labor of their collection. It is evident that cases do not come earlier for treatment to-day than they did a decade ago. As the early stages of the disease offer the best opportunity for treatment, this delay is greatly to be deplored. In a large measure it is due to the infrequency of urinary examinations. Thus, 77 recent case histories show that 30 patients had never had their urine examined prior to the diagnosis of the disease, and in 18 instances the interval since the previous examination was three or more years. ${ }^{a}$ The laity should be taught to have routine urinary and physical examinations, and to provide against their forgetting the advice, they should be urged to secure such examinations upon their birthdays. The significance of loss in weight should be emphasized and the necessity of urinary examinations at such periods, particularly in the case of fat individuals, given wider publicity. Physicians should take pride in diagnosing diabetes before their patients have lost 15 per cent of their body-weight.

\section{EXTREME LOSS IN WEIGHT.}

An illustration of a patient with an extreme loss of body-weight between onset and death is Case No. 1213. At the onset of diabetes in May, 1916, she weighed $44 \mathrm{~kg}$. Her previous highest weight was $51 \mathrm{~kg}$. at the age of 16 years in January, 1916. She left the hospital on April 17, 1917, with a weight of $32 \mathrm{~kg}$. From that time on, she lived upon a restricted diet, eventually developing a severe, acute pulmonary infection and furunculosis, until in July, 1918, her weight had fallen to approximately $27 \mathrm{~kg}$. At that time she had an attack of renal calculus and the stone was passed September, 1918. In September, 1919, a cough developed which persisted until the end. Whether or not this was of tubercular origin is unknown. From October, 1918, onward she discontinued dieting and ate without restriction in any way. In the last two weeks of her life she was chiefly troubled with dyspnœea, and during this time, for a period of 5 days, she showed a paralysis of the right

a Joslin, Journ. Am. Med. Assoc., 1921, 76, p. 79. 
arm and was nearly blind, but both of these symptoms ultimately disappeared. She finally succumbed to circulatory failure, being conscious to within 10 minutes of death upon February 14, 1920. Her weight at death was about $18 \mathrm{~kg}$., a loss of 65 per cent from the maximum weight.

Attention is directed to this extreme loss of weight upon an unrestricted diet, which is perhaps greater than any coming to the writer's notice with a patient undergoing treatment by undernutrition. Physicians are often reproached for much smaller percentage losses when they have treated their patients by sound dietetic principles on a restricted diet. The duration of life after onset for this patient ( 3 years and 9 months) should be compared with that of other cases living upon a rigid dietetic régime.

Cases Nos. 610 and 1085 also underwent extreme loss in weight, amounting to 61 per cent and 59 per cent, respectively. Case No. 610 developed diabetes in July, 1911. When she came for treatment in May, 1913, her weight had decreased from $120 \mathrm{~kg}$. (her greatest weight) and $108.9 \mathrm{~kg}$. (her weight at onset) to $76.2 \mathrm{~kg}$., a loss of $32.7 \mathrm{~kg}$., or $18 \mathrm{~kg}$. a year in about 2 years from the time of onset. In the next $41 / 2$ years, it decreased to $46.7 \mathrm{~kg}$., or a loss under treatment at the rate of about $7 \mathrm{~kg}$. a year. Her weight half a year later, when she died of coma, is unknown.

Case No. 1085 developed diabetes in January, 1916, or earlier, at which time her weight was $52.2 \mathrm{~kg}$., in contrast to previous maximum weight of 68.0 $\mathrm{kg}$. Six months after onset, when she came for treatment, her weight was $41.7 \mathrm{~kg}$., a loss of weight at the rate of $21 \mathrm{~kg}$. a year. She died 4 months later, and in those 4 months her weight fell to $27.7 \mathrm{~kg}$., a further loss of $14 \mathrm{~kg}$., the equivalent of $42 \mathrm{~kg}$. a year! This patient was the only one of the 113 cases in the series who died of undernutrition with a subnormal blood sugar. A discussion of this and three similar cases has elsewhere been published in detail. ${ }^{a}$

\section{LOSS IN WEIGHT OF PANCREAS.}

It is of importance to compare loss of body-weight with simultaneous loss in weight of the pancreas, because the theory has been advanced that when the diabetic loses weight there is proportionately more pancreatic tissue available to preserve the normal sugar mechanism. In an article upon the atrophy of human organs in inanition, Krieger ${ }^{b}$ has discussed the loss in weight of the pancreas, and cites Vierordt as stating that in the adult man the weight of the pancreas is 0.15 per cent of the body-weight, and the average weight of this gland 97.6 grams. Various other values are given from other writers, these ranging from 66 to 102 grams. Krieger found the greatest loss in weight of the pancreas with chronic dysentery, the actual weight of the organ under these conditions being 54 grams. The next greatest loss was with malignant disease when the average weight was 66 grams; with chronic infections, the average weight was 69.2 grams; and with tuberculosis 69.8 grams. With these four groups of diseased individuals, the weight varied from 0.16 to 0.19 per cent of the body-weight.

Of far more importance than the loss of weight itself would appear to be the loss of function which accompanied the loss in weight of the pancreas. Bern-

a Joslin, Med. Clin of North America, 1921, 4, p. 1723.

${ }^{b}$ Krieger, Zeitschr. f. angewand. Anat. u. Konstitutionslehre, 1921, 17, p. 87. 
stein and Heidenheim ${ }^{a}$ report that in fasting the secretion of pancreatic juice entirely ceases, which agrees essentially with the statements of Luciani. As a matter of fact, animal experiments with few exceptions show very great losses in weight of the pancreas during fasting. Chossat ${ }^{b}$ observed a loss of 64 per cent, Kumagawa ${ }^{b} 62$ per cent, Sedelmair ${ }^{b}$ in one experiment 39 per cent and in another 69 per cent, but Voit, ${ }^{b}$ on the other hand, only 17 per cent. Lasarew $^{b}$ studied the losses in weights during different periods of fasting in one group of animals in which the loss of weight was 10 per cent, in a second 20 per cent, in a third 30 per cent, and in a final group in which fasting was carried to a fatal termination. He observed that the pancreas decreased in weight from the beginning steadily but slightly as the period of fasting progressed, but that the greatest loss in weight did not occur until the third period was reached.

It would, therefore, appear that one may accept the doctrine that with progressive loss of weight the pancreas can more readily serve the body as it decreases in size, provided the loss of body-weight does not reach 30 per cent. When the loss of body-weight exceeds 30 per cent, the weight of the pancreas will also be materially affected and not only affected in weight but, of greater importance, in function. Though undernutrition gives far better results in the treatment of diabetes than overnutrition, the danger of extreme undernutrition is thus again brought to the front.

Very likely it will not be long before one will be able to prove with clinical observations at least the extent of the functional loss of external pancreatic secretion. Through the courtesy of Dr. Charles W. McClure, the following observation is available. Case No. 1542 developed diabetes in July, 1917, when she was 37 years of age. Her greatest weight without clothing was $68.5 \mathrm{~kg}$. Upon January 11, 1922, her weight had decreased to $32.9 \mathrm{~kg}$., a loss of 52 per cent. On that day she was given a meal of $40 \mathrm{c}$. c. of 20 per cent cream, to which was added sufficient barium sulphate to bring the mixture up to 50 c. c., and during the subsequent two hours the duodenal contents were collected. The material was examined by Dr. McClure, who reported the figures for the enzymatic activities of the duodenal contents as follows: Proteolytic activity, $2.6 \mathrm{mg}$. of non-protein nitrogen; lipolytic activity, 1 c. c. of $\mathrm{N} / 10 \mathrm{NaOH}$; amylolytic activity, $1.2 \mathrm{mg}$. of glucose. These figures are within normal limits.

\section{Duration of Diabetes.}

The duration of the diabetes up to June, 1921, is recorded seriatim in table 3. In table 5 the cases are classified in decades by age at onset, and the duration of life after onset of the living and fatal cases compared. In table 6 the fatal cases are further grouped according to the time of observation, i. e., whether they were studied before or after June, 1914, the date when treatment by undernutrition was begun with these patients. In all these tables the duration is stated as the period from the age at onset of diabetes up to the date of death, or to June, 1921, if the patient were alive at that time. Finally, for comparison, data collected between 1893 and 1919 in the author's private

a Bernstein and Heidenheim, cited by Krieger, loc. cit.

${ }^{b}$ Cited by M. Krieger, loc. cit., p. 28. 
practice have been grouped in table 7, according to the age at onset. ${ }^{a}$ The data for the cases studied at the Nutrition Laboratory, and given in tables 5 and 6 , form a part of this larger group.

TABLE 5.-Average duration of life after onset of diabetes of cases studied by the Nutrition Laboratory.

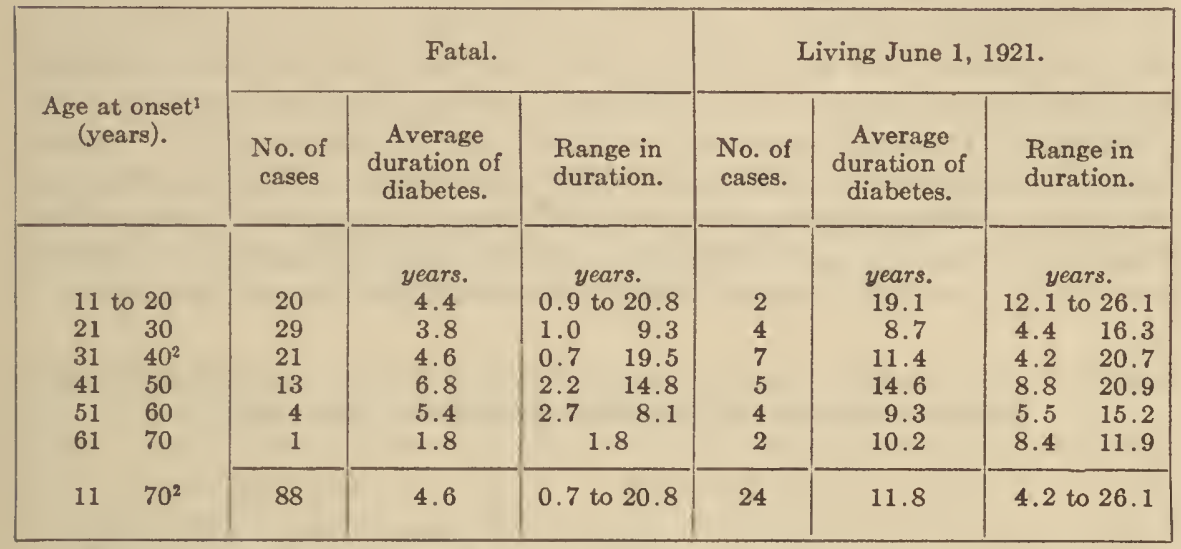

${ }_{1}$ Age here used represents the age on the last birthday. See table 3, p. 8 .

3 One patient (No. 550) not included, as his history could not be traced.

The duration of the diabetes with any given individual is by no means easy of determination, as anyone will testify who essays to take careful clinical histories. It is probable that in public records, based upon death certificates, the duration is understated, because so frequently diabetic patients and physicians have not been long associated. Coma, which is of brief duration, is the most frequent cause of the final illness, and for this any physician may be called in an emergency, and the occasion is not favorable for a careful investigation as to the onset of the disease. The date of demonstration of diabetes by clinical tests is by no means coincident with onset, as proved by both the clinical symptoms and the loss of weight prior to the tests. The interval of neglect varies between weeks and years, and even to-day routine urinary examinations are so shockingly rare that almost invariably the date of onset must be determined by such criteria as loss of weight, languor, pruritus pudendi, and the familiar polydipsia and polyuria.

It is therefore encouraging to note that in Boston during recent years the duration of the disease has increased as shown by the death certificates. Between 1895 and 1913 the average duration for 940 cases was 3.3 years; in 1915 for 117 cases, it was 4.3 years; and in 1920 for 116 cases, it was 5.3 years. How much longer these individuals might have lived if their disease had been earlier diagnosed can be surmised by the average duration of life of 24 cases, now dead, discovered by insurance examiners, which amounted to 12 years. Consider, further, that the insurance cases were found by accident, whereas it is in the power of any physician to discover cases by design and thus obtain a series of diabetics in the still earlier stages.

a Joslin, Oxford Medicine, Oxford University Press, London and New York, 1921, 4, p. 135. 
The longest duration of diabetes in the Laboratory series occurred with a female diabetic (No. 1207). This was 26 years and 1 month in June, 1921, with the patient still living. Two other cases of female diabetics with a duration of over 20 years were Nos. 310 and 1007. No. 310 succumbed to coma after 20 years and 10 months, but No. 1007 was still alive in June, 1921, with a duration of 20 years and 8 months. There was yet another female diabetic (No. 979) who died in coma after a duration of life of 19 years and 6 months. Four male cases (Nos. 177, 1427, 511, and 428) all living in June, 1921, had durations at that time of 20 years and 11 months, 19 years and 5 months, 17 years and 11 months, and 16 years and 3 months, respectively. The remainder of the cases had a duration of less than 16 years. The long durations with female diabetics above cited are in contrast to the general rule that the prognosis for males is more favorable. The favorable prognosis for males is possibly due to the fact that the disease is discovered at an earlier stage.

TABLE 6.-Average duration of life after onset of diabetes of fatal cases studied by the Nutrition Laboratory before and after beginning of treatment by undernutrition.

\begin{tabular}{|c|c|c|c|c|c|c|}
\hline \multirow{2}{*}{$\begin{array}{l}\text { Age at onset } \\
\text { (years). }\end{array}$} & \multicolumn{3}{|c|}{ Before June, 1914.} & \multicolumn{3}{|c|}{ After June, 1914.} \\
\hline & $\begin{array}{l}\text { No. of } \\
\text { cases. }\end{array}$ & $\begin{array}{c}\text { Average } \\
\text { duration of } \\
\text { diabetes. }\end{array}$ & $\begin{array}{l}\text { Range in } \\
\text { duration. }\end{array}$ & $\begin{array}{l}\text { No. of } \\
\text { cases. }\end{array}$ & $\begin{array}{l}\text { Average } \\
\text { duration of } \\
\text { diabetes. }\end{array}$ & $\begin{array}{l}\text { Range in } \\
\text { duration. }\end{array}$ \\
\hline $\begin{array}{ll}11 & \text { to } 20 \\
21 & 30 \\
31 & 40 \\
41 & 50 \\
51 & 60 \\
61 & 70\end{array}$ & $\begin{array}{l}10 \\
6 \\
9^{2} \\
3\end{array}$ & $\begin{array}{c}\text { years. } \\
5.2 \\
4.8 \\
5.0 \\
5.6 \\
\ldots \ldots \ldots\end{array}$ & \begin{tabular}{lr}
\multicolumn{2}{c}{ years. } \\
0.9 to 20.8 \\
1.3 & 9.3 \\
0.8 & 10.5 \\
2.5 & 11.3 \\
$\ldots \ldots \ldots \ldots \ldots$
\end{tabular} & $\begin{array}{r}10 \\
23 \\
12 \\
10 \\
4 \\
1\end{array}$ & $\begin{array}{c}\text { years. } \\
3.6 \\
3.4 \\
4.2 \\
7.1 \\
5.5 \\
1.8\end{array}$ & \begin{tabular}{lr}
\multicolumn{3}{c}{ years. } \\
1.4 to & 7.0 \\
10 & 7.0 \\
0.7 & 19.5 \\
2.2 & 14.8 \\
2.7 & 8.1 \\
\multicolumn{1}{c}{1.8} &
\end{tabular} \\
\hline 70 & 228 & 5.1 & 0.8 to 20.8 & 60 & ${ }^{3} 4.3$ & 0.7 to 19.5 \\
\hline
\end{tabular}

1 Age here used represents the age on the last birthday. See table 3, p. 8 .

2 One patient (No. 550) not included in those studied before June, 1914, as his history could not be traced.

${ }^{3}$ For explanation of apparent shorter duration of life after June, 1914, see p. 19.

It will be noted in the comparison of the fatal with the living cases in table 5 that the duration of the diabetes with the living cases was, on the average, more than twice as long as that with the fatal cases. Naturally, as time passes the average duration of the living cases will tend to increase, not necessarily because they are better treated, but rather because the number is smaller and a few individuals with diabetes of an especially long duration may dominate the group. It is a satisfaction, however, and justifiable to attribute a portion of the greater duration of life of the surviving cases to better treatment. The duration of the 88 fatal cases studied at the Nutrition Laboratory was approximately 4 years for the second, third, and fourth decades, and in the two subsequent decades about half again as long. (See table 5.) The duration of life of the living cases shows no general tendency for successive decades, save that the ratio of living cases to fatal cases invar- 
iably increased with each advancing ten years. The table presents hopeful data.

In table 6 , in which the fatal cases are classified by decades according to whether the individuals were studied before or after June, 1914, i. e., when overnutrition gave way to undernutrition, it is seen that, on the average, the duration of life after onset with the later group is shorter by 0.8 year. This does not at first thought speak well for modern treatment, but it should be realized that all but three of the cases studied before June, 1914, are now dead and those living allow little possibility for subsequent increase in the duration of life for the patients studied before the change in treatment. On the other hand, 21 of the cases studied after June, 1914, are still living and the average duration of life after onset for the fatal cases in this period may therefore be constantly lengthened until this comparatively large number of living cases die. These 21 cases were classified as 3 severe, 9 moderate, and

TABLE 7.-Average duration of 1,200 fatal and living cases of diabetes between 1893 and 1919 by decade of onset. ${ }^{1}$

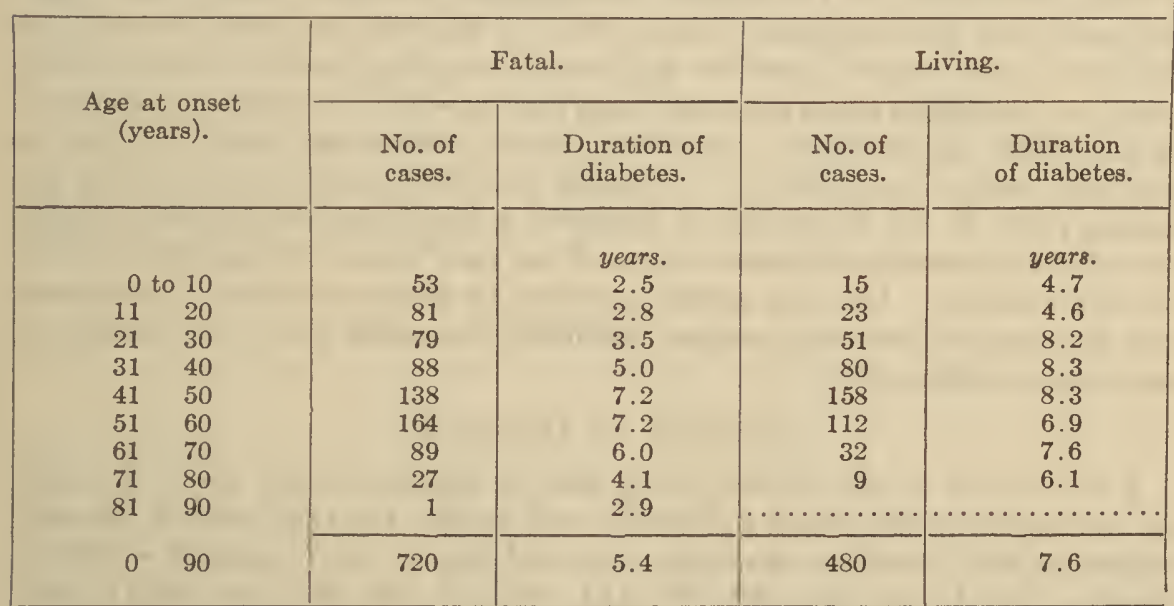

${ }^{1}$ See Joslin, Oxford Medicine, Oxford University Press, London and New York, 1921, 4, p. 135 , table 4 .

9 mild. It is not an easy matter, however, to judge of the effects of treatment statistically until all cases in a given period are dead. This would appear to imply that all cases of diabetes will die of the disease. Although this is not the case, it is probably safer at present to depend upon statistics collected from fatal cases than from an arbitrarily selected group of living cases.

The improvement in the duration of life which is generally found when onset occurs as age advances is brought out in table 7 , in which the data for 1,200 cases, both living and dead, are recorded. Perhaps one-half of these 1,200 cases have come under the influence of treatment by undernutrition. When tables 5 and 7 are compared, it will be seen that the duration of life of the 88 fatal cases of the series studied at the Nutrition Laboratory was 4.6 years, and of the 720 fatal cases in the larger series 5.4 years. Attention has pre- 
viously been called to the fact that the cases studied at the Laboratory were more severe than those included in the larger series of 1,000 cases which forms a part of this group of 1,200 cases. (See page 12.) In view of this difference, the fact that the Laboratory fatal cases attained an average duration within a year of that of the larger series is remarkable, and demands explanation. It would appear to be due to a closer supervision of the Laboratory cases rather than to the type of treatment employed.

The duration of life of the living cases in the Nutrition Laboratory series is somewhat longer than that in the larger series, being 11.8 years for the former and 7.6 years for the latter. The explanation for this is given in the comments on the living cases of the Laboratory series before and after June, 1914, in the discussion of table 6 on page 18. A critical and ofttimes too vivid recollection of these cases leads to the conviction that if these patients came for treatment to-day, their lives could be prolonged and the duration of the disease in many instances doubled.

To effect further statistical gains in duration, attention should be directed toward the discovery of the diabetic, and energetic treatment concentrated upon the cases when first diagnosed, because they are the ones most easily treated, yet most often mismanaged; upon the diffusion of knowledge relating to coma, gangrene, and infections which often needlessly destroy mild or moderately severe cases of potentially long duration; and finally, upon arrangements which will lead to prolonged medical supervision. To realize fully the improvements which are taking place in the treatment of diabetes, a physician should keep careful records and occasionally reread those of his fatal cases who succumbed five years previously. By such means it is easy to detect mistakes in treatment and to perceive how, with modern methods, life might have been prolonged and made comfortable.

\section{Severity of Diabetes.}

A decision as to the severity of a case of diabetes is not easily reached. At one period in the life of a diabetic, and usually the early period, he may appear to be of a mild or moderate type and later to have diabetes severe in degree. (See Cases Nos. 210, 226, 310, 610, 765, 810, 969, and 1070 in Appendix I.) Less often the change takes place in the opposite direction, there being but one instance in the series. The terms severe, moderate, and mild (indicated in Appendix I by S., Mo., and Mi.) will accordingly be used in this report to indicate the state of the patient on the actual date of the given experiment. Furthermore, in the early period of this investigation prior to June, 1914, cases were of ten considered severe and were actually severe which, under present methods of treatment, might be considered to be moderate, or even mild. As a matter of fact, such cases were severe not inherently, but artificially, this being brought about in an innocent manner by the methods of treatment then employed. These same remarks also apply to acidosis. One must seek to answer the question whether a case made artificially severe, as the victim of an artificial acidosis, behaves the same as one who develops this condition in the routine course of his malady.

The criteria of severity for each case at the time of each observation were based chiefly upon the carbohydrate balance, and this plan was adopted in the two previous monographs. When the tolerance for carbohydrate was 
10 grams or under the diabetes was considered severe; when between 10 and 50 grams it was considered moderate; but when over 50 grams it was classified as mild. Temporary changes in the carbohydrate balance as a result of the sudden ingestion of large quantities of carbohydrate, such as oatmeal, potato, or levulose, were not considered a reason for the alteration of the previously determined classification, for to-day it is better recognized that the carbohydrate balance without consideration of the total calories is an inadequate test of severity.

In determining the severity of the disease for this monograph, attention was given not only to the carbohydrate balance, but also to the age of the patient, the previous and subsequent course of the diabetes, the change in body-weight, and the conditions under which acidosis appeared. After a conclusion had been recorded as to the degree of severity for an individual case, Dr. A. A. Hornor, who was personally familiar with many of the patients, independently studied the appropriate material and recorded his opinion. The two opinions seldom differed and were easily brought into harmony by a closer examination of the protocols. In consequence of the estimation of severity on the new basis, revision was made in several instances of the severities given in the two previous monographs.

Most of the observations were made with cases of severe diabetes and but few with individuals of mild type. In 327 of the observations upon patients in the post-absorptive state, the diabetes was severe, in 101 it was moderately severe, and in 28 it was mild.

\section{Acidosis.}

In the 456 observations with the patients in the post-absorptive state there were 124 in which the subjects were without acidosis at the time, 93 with slight acidosis $(+), 169$ with moderately severe acidosis $(++)$, and 70 with acidosis of an extreme degree $(+++)$.

The acidosis was determined by one or more methods. As soon as the period was reached when alkalis were given up, namely, September, 1915, and tests of the carbon-dioxide content of the alveolar air or of the blood were begun, the estimation of the degree of acidosis was rendered less difficult. In a large proportion of the cases the quantity of ammonia in the urine was recorded and as a part of the routine the ferric-chloride test for diacetic acid was performed. In a few instances the amount of $\beta$-oxybutric acid was estimated. As a working hypothesis, the basis for differentiation of the acidosis was adopted which is shown in table 8 .

It has been impracticable to record all the data upon which the conclusions as to the degree of acidosis were reached, although frequently some of the additional information is given in footnotes to the protocols. The distinction between 0 acidosis and + acidosis is close and to a lesser extent between ++ and +++ acidosis, but the extremes, i. e., the first group and the last group, present good material for the discussion of the part played by acidosis in the metabolism.

Acidosis is an acquired rather than an inherent characteristic of diabetes and thus is amenable to alterations of intensity usually brought about by the relation of the combustion of carbohydrate to that of fat, including in 
this relation the antiketogenic and ketogenic factors obtained from carbohydrate, protein, and fat.

It would be expected that when the carbohydrate balance is low, the acidosis would be high, and vice versa. The records do not show this always to be the case. The method of determining the acidosis was often such as to represent the condition of the patient at a given moment; the method of registering the carbohydrate balance was based upon a 24-hour period.

TABLE 8.-Criteria for classification of acidosis.

\begin{tabular}{|c|c|c|c|}
\hline Degree of acidosis. ${ }^{1}$ & $\begin{array}{l}\text { Diacetic acid (ferric- } \\
\text { chloride test). }{ }^{1}\end{array}$ & $\begin{array}{c}\text { Ammonia in } 24 \\
\text { hours. }\end{array}$ & $\begin{array}{c}\text { Carbon-dioxide ten- } \\
\text { sion in alveolar air } \\
\text { or blood. }\end{array}$ \\
\hline $\begin{array}{r}0 \\
+ \\
++ \\
++\end{array}$ & $\begin{array}{r}0 \\
+ \\
++ \\
++\end{array}$ & $\begin{array}{c}\text { grams. } \\
\ldots \ldots \ldots \\
2.0 \\
3.0 \\
4.0\end{array}$ & 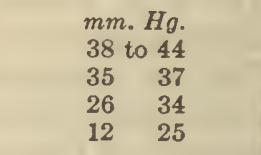 \\
\hline
\end{tabular}

${ }_{1}^{1}$ See p. 6 for explanation of method of recording.

\section{Causes of Death.}

The causes of death of the 88 fatal diabetic cases whose respiratory metabolism was investigated during the years 1908 to 1917 are summarized in table 9. Diabetic coma heads the list of fatalities with 67 deaths, constituting 76 per cent of the total mortality. This was perhaps the period with the greatest frequency of coma as a cause for death in diabetes for at least a generation. It indicates the zeal with which the low carbohydrate, high protein-fat, and particularly the high-calorie features of the diet were emphasized in the early part of the research. One would expect with a change to lower fat diets and the better understanding of the dependence of coma upon fat that the percentage of deaths from this cause would be reduced. This has been the case, and if one compares the mortality due to coma prior to June, 1914, with the deaths in coma since that date, it will be seen that 86 per cent of the fatal cases in the early period died in coma and 72 per cent in the later period. The change in conditions is more strikingly shown if one compares the total mortality from coma (76 per cent) for all the fatal cases of the Laboratory group with that for the deaths in a larger series of diabetics summarized successively for the more recent years, i. e., ending in 1915, 1916, 1917, and 1919. In these years the percentage of deaths due to coma fell successively from 64 to $60^{a}$ and 57 per cent, and by 1919 to 52 per cent. ${ }^{b}$ Actually, the decrease in the proportion of deaths from coma is greater because each of the four groups of the larger series upon which the statistics are based includes all previous deaths with the higher coma rate. In other words, in a series of fatal diabetic cases, two-thirds of the deaths prior to 1915 were due to coma, but in 1919 approximately one-half of the deaths were due to this cause.

- Joslin, Treatment of diabetes mellitus, 2d ed., Philadelphia, 1917, p. 65.

b Joslin, Oxford Medicine, 4, 1921, p. 153. 
The change which treatment has brought about in the type of diabetes during this period is greater than is often appreciated. What other disease has so altered its character? It is particularly fortunate that so many cases in the series studied at the Laboratory belonged to this vanishing type of diabetes. It is especially important to contrast the former and the present types and in every way possible to observe the effect upon the metabolism of acidosis which was the distinguishing feature of the earlier group. When one reads anew the protocols of the patients investigated between the years 1908 and 1914 , one can not but be impressed with the advances which the treatment of diabetes has made.

TABLE 9.-Causes of death of 88 fatal cases of diabetes studied by the Nutrition Laboratory. ${ }^{1}$

\begin{tabular}{|c|c|c|c|c|c|c|}
\hline \multirow[b]{2}{*}{ Cause of death. } & \multirow{2}{*}{$\begin{array}{c}\text { No. of } \\
\text { fatal cases, } \\
1908 \text { to } \\
1917 .\end{array}$} & \multirow{2}{*}{$\begin{array}{l}\text { Propor- } \\
\text { tion of } \\
\text { mortality } \\
\text { for whole } \\
\text { period. }\end{array}$} & \multicolumn{2}{|c|}{ Before June, 1914. } & \multicolumn{2}{|c|}{ After June, 1914.} \\
\hline & & & $\begin{array}{l}\text { No. of } \\
\text { fatal cases } \\
\text { in period. }\end{array}$ & $\begin{array}{l}\text { Propor- } \\
\text { tion of } \\
\text { mortality } \\
\text { in period. }\end{array}$ & $\begin{array}{c}\text { No. of } \\
\text { fatal cases } \\
\text { in period. }\end{array}$ & $\begin{array}{l}\text { Propor- } \\
\text { tion of } \\
\text { mortality } \\
\text { in period. }\end{array}$ \\
\hline $\begin{array}{l}\text { Coma.............. } \\
\text { Pneumonia........ } \\
\text { Tuberculosis........ } \\
\text { Acute heart failure... } \\
\text { Inanition.......... } \\
\text { Cerebral hemorrhage. } \\
\text { Abscess of lung..... } \\
\text { Angina pectoris..... } \\
\text { Influenza.......... } \\
\text { Gangrene......... }\end{array}$ & $\begin{array}{r}67 \\
7 \\
4 \\
3 \\
2 \\
1 \\
1 \\
1 \\
1 \\
1\end{array}$ & $\begin{array}{c}p . c t . \\
76 \\
8 \\
5 \\
3 \\
2 \\
1 \\
1 \\
1 \\
1 \\
1\end{array}$ & 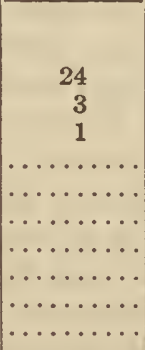 & 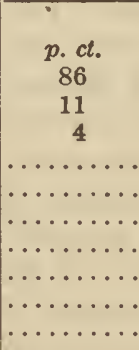 & $\begin{array}{r}43 \\
4 \\
3 \\
3 \\
2 \\
1 \\
1 \\
1 \\
1 \\
1\end{array}$ & $\begin{array}{c}\text { p. } c t . \\
72 \\
7 \\
5 \\
5 \\
3 \\
2 \\
2 \\
2 \\
2 \\
2\end{array}$ \\
\hline Total number. . & 88 & & 28 & $\cdots \cdots$ & 60 & $\cdots$ \\
\hline
\end{tabular}

1 One patient (Case No. 550), who was studied before June, 1914, but is probably dead, has not been included in this table, as his history could not be traced.

The low mortality from tuberculosis (see table 9) conforms to the lessening frequency of this disease. It deserves emphasis because it indicates that the methods of undernutrition recently employed have not led to an increase in the number of deaths from this cause. Landis has recorded his favorable experience with treatment of diabetes by undernutrition even though tuberculosis is present. ${ }^{\circ}$ The two deaths from inanition, occurring respectively in December, 1915, and in November, 1916, were the first with this diagnosis among all the diabetic cases of the author. Seven deaths from pneumonia would not be unusual, as well as the five from circulatory diseases. In the future a larger proportion of deaths from these two causes must be anticipated, because of the decrease in deaths from coma. The fact that there was but one death from gangrene deserves attention, since gangrene indicates a careless or neglected diabetic. The carefully treated and trained patient usually escapes it.

a Landis, Funk, and Montgomery, Am. Rev. of Tuberculosis, 1919, 2, p. 690. 


\section{TREATMENT.}

Reflection upon the early and late cases of the series suggests certain contrasts in physical appearance. The early patients appeared tense and ill, but fairly strong, while the later cases in contradistinction were frail and weak. The early cases were apt to have high color and to be mentally as acute as ever, though often emotionally unstrung, but the later patients were pale, sallow, or distinctly yellow, their mental activity was reduced far below normal, and they were seldom emotional. The former type was that of an individual stricken in health with a fatal disease, and the other that of one who had been an invalid for years. Individuals conforming to both descriptions might be found in each group. This by no means alters the rule, but rather emphasizes the general tendency. The transition from one class to the other was begun in June, 1914, and extended well into 1915.

The cause for a marked alteration in the aspect of the disease was surely adequate. Prior to 1914 diabetic patients were overfed, all cases being treated with a low-carbohydrate and high protein-fat diet. Excess of calories was encouraged. To guard against coma, gradual restrictions of diet were advised, and sodium bicarbonate was employed in large doses and continued for periods of months. Fat was given ad nauseam, and even such fatty foods as cheese and eggs were served, mixed with about equal proportions of butter. The good results of fasting days were often overlooked, Cantani's and von Noorden's recommendation, ${ }^{a}$ Naunyn's observation, ${ }^{b}$ and Weintraud's proof ${ }^{c}$ that diabetic patients could subsist upon remarkably few calories being considered more of scientific interest than of therapeutic significance. Hodgson, ${ }^{d}$ however, had grasped the principle and attained unusual success where others failed. It was at this time that Guelpa's conceptions of fastinge and of the waning severity of diabetes in the presence of an emaciating disease were recognized, utilized, and enlarged by Allens into a system of treatment based upon a reduced caloric intake.

In June, 1914, in consequence of the teachings of Allen, fasting and undernutrition were introduced, but it was not until well into 1915 that this practice became the rule. This change in the method of treatment profoundly affected the metabolism of the diabetics. As has already been said, on this account it has been necessary to separate the observations upon the patients in this research into two groups according to whether they were studied before or after June, 1914.

Patients given the fasting treatment when this procedure was first used were almost invariably underfed to a marked degree, because the hospital period was spent in securing quick results, and these were most readily obtained by extreme dietetic restrictions. In the period prior to June, 1914, to have employed the undernutrition treatment of diabetes as practiced to-day would have seemed quite as radical and dangerous a course as would

- Cited by von Noorden, Die Zuckerkrankheit, Berlin, 1917, 7 th ed., p. 456.

- Naunyn, Der Diabetes Mellitus, Vienna, 1906, p. 396.

- Weintraud, cited by Naunyn, loc. cit., p. 192.

d Hodgson, Journ. Am. Med. Assoc., 1911, 57, p. 1187.

- Guelpa, British Med. Journ., 1910, 2, p. 1050.

' Allen, Journ. Am. Med. Assoc., 1914, 63, p. 939 
now the adoption of the high protein-fat diet of the former period. One would hardly have had the fortitude at either period to design, much less carry out as an experiment the procedures therapeutically adopted in the other.

In 1915, fat was recognized as largely responsible for acidosis, and its omission at the beginning of treatment emphasized. Sodium bicarbonate was abandoned in September, 1915. The reduction of weight for therapeutic purposes was followed with some hesitancy, and lapses of treatment were more tolerated than at present. The last few patients in the Nutrition Laboratory series received treatment which differed but little from that outlined in the following summarized directions for the care of a diabetic:

Preparation for fasting.-In severe, long-standing, complicated, obese, and elderly cases, as well as in all cases with acidosis, or in any case if desired, without otherwise changing habits or diet, omit fat, after two days decrease protein, and halve the carbohydrates daily until the patient is taking 30 grams or less; then fast. In other cases, begin fasting at once.

Fasting.-Fast four days, unless earlier sugar-free. Allow water freely, tea, coffee, and thin clear meat broths as desired.

Intermittent fasting.-If glycosuria persists at the end of four days, give 1 gram protein or 0.5 gram carbohydrate per kilogram of body-weight for two days, and then fast again for three days unless earlier sugar-free. If glycosuria persists, repeat and then fast for one or two days as necessary. If there is still sugar, give protein as before for four days, then fast one, and then gradually increase the periods of feeding, one day each time, until fasting one day each week.

Carbohydrate tolerance. - When the 24-hour urine is free from sugar, give 5 or 10 grams carbohydrate (150 to 300 grams of vegetables containing 1 to 5 per cent carbohydrate, amounting to about 3 per cent in a mixture of vegetables selected from the so-called 5 per cent group; see table 10). Continue, or add 5 to 10 grams carbohydrate daily (more in mild cases) up to 50 grams or more until sugar appears, then fast until sugar-free.

Protein tolerance.-When the urine is again sugar-free, decrease the carbohydrate by one-third below the carbohydrate tolerance or at least 10 grams, and then add about 20 grams protein and thereafter 15 grams daily in the form of egg-white, fish, or lean meat (chicken) until the patient is receiving from 1 gram to 1.5 grams protein per kilogram of body-weight.

Fat tolerance.- It is usually desirable, especially in the young, to add no fat until the protein reaches 1 to 1.5 grams per kilogram of body-weight and the blood sugar is normal. Then add 5 to 25 grams daily according to previous acidosis until the patient ceases to lose weight or receives in the total diet 20 to 30 calories per kilogram of bodyweight.

Reappearance of sugar.-The return of sugar demands fasting for 24 hours, or until sugar-free, then resume the former diet, adding fat gradually and last of all, in order to maintain as high a carbohydrate tolerance as possible, even sacrificing body-weight for the purpose.

Weekly fast days. - Whenever the tolerance is less than 20 grams of carbohydrate, fasting should be practiced one day in seven; when the tolerance is over 20 grams of carbohydrate, cut the diet in half on one day in each week.

The foods commonly employed in determining the tolerance for carbohydrate and protein were 5 per cent vegetables, oranges or grape fruit, oatmeal or shredded wheat, potato, fish, chicken, lean meat, skimmed milk. 


\section{Composition of Diet.}

With this method of treatment, the diet consists largely of vegetables, meat, fish, cream, bacon, eggs, oatmeal, potato, fruit, and broths. The dietetic calculations for diabetics are made upon the basis indicated in tables 10 and 11 , no allowance being made for the food content of the clear broths, coffee, tea, cocoa shells, and cracked cocoa in the diet, or for the amount of water taken.

TABLE 10.-Approximate percentage of carbohydrate in food materials of diabetic diet. ${ }^{1}$

\begin{tabular}{|c|c|c|c|c|c|}
\hline & 5 p. ct. & & 10 p. ct. & $15 \mathrm{p} . \mathrm{ct}$. & 20 p. ct. \\
\hline $\begin{array}{l}\text { Lettuce. } \\
\text { Cucumbers. } \\
\text { Spinach. } \\
\text { Asparagus. } \\
\text { Rhubarb. } \\
\text { Endive. } \\
\text { Marrow. } \\
\text { Sorrel. } \\
\text { Sauerkraut. }\end{array}$ & $\begin{array}{l}\text { Bect grcens. } \\
\text { Dandelion greens. } \\
\text { Swiss chard. } \\
\text { Celery. } \\
\text { Mushrooms. } \\
\text { Tomatoes. } \\
\text { Brussels sprouts. } \\
\text { Water cress. } \\
\text { Sea kalc. }\end{array}$ & $\begin{array}{l}\text { Okra. } \\
\text { Cauliflower. } \\
\text { Egg plant. } \\
\text { Cabbage. } \\
\text { Radishes. } \\
\text { Leeks. } \\
\text { String beans, canned. } \\
\text { Broccoli. } \\
\text { Artichokes, } \\
\text { canned. }\end{array}$ & $\begin{array}{l}\text { String beans. } \\
\text { Pumpkiu. } \\
\text { Turnip. } \\
\text { Kohl-rabi. } \\
\text { Squash. } \\
\text { Beets. } \\
\text { Carrots. } \\
\text { Onions. } \\
\text { Green peas, } \\
\text { canned. }\end{array}$ & $\begin{array}{l}\text { Green peas. } \\
\text { Artichokes. } \\
\text { Parsnips. } \\
\text { Lima beans, } \\
\text { canned. }\end{array}$ & $\begin{array}{l}\text { Potatoes. } \\
\text { Shell beans. } \\
\text { Baked beans. } \\
\text { Green corn. } \\
\text { Boiled rice. } \\
\text { Boiled macaroni. }\end{array}$ \\
\hline \multicolumn{6}{|c|}{ Fruits. } \\
\hline \multicolumn{3}{|c|}{$\begin{array}{l}\text { Ripe olives ( } 20 \text { p. ct. fat). } \\
\text { Grape fruit. }\end{array}$} & $\begin{array}{l}\text { Watermelon. } \\
\text { Strawberries. } \\
\text { Lemons. } \\
\text { Cranberries. } \\
\text { Peaches. } \\
\text { Pineapple. } \\
\text { Blackberries. } \\
\text { Gooseberries. } \\
\text { Oranges. }\end{array}$ & $\begin{array}{l}\text { Raspberries. } \\
\text { Currants. } \\
\text { Apricots. } \\
\text { Pears. } \\
\text { Apples. } \\
\text { Huckleberries. } \\
\text { Blueberries. } \\
\text { Cherries. }\end{array}$ & $\begin{array}{l}\text { Plums. } \\
\text { Bananas. } \\
\text { Prunes. }\end{array}$ \\
\hline
\end{tabular}

1 Food materials arranged approximately according to content of carbohydrate. Carbohy. drates in the 5 per cent group vary from 2 to 5 per cent and in calculating the carbohydrate content of a diet, an average of 3 per cent should be used for foods in this group. Similarly, the 10 per cent group vary from 6 to 10 per cent, and an average of 6 per cent should be used.

TABLE 11.-Approximate composition of $\$ 0$ grams (1 ounce) of food materials commonly employed in diabetic diet.

\begin{tabular}{|c|c|c|c|c|c|c|c|c|c|}
\hline Food material. & 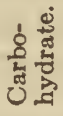 & $\begin{array}{l}\text { 명 } \\
\text { 范 } \\
\text { ค. }\end{array}$ & 它 & है & Food material. & 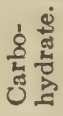 & 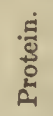 & 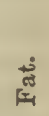 & 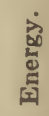 \\
\hline & $g m$. & $g m$. & $g m$. & cal. & & om. & $g m$. & $g m$. & cal. \\
\hline $\begin{array}{l}\text { Uatmeal, dry weight..... } \\
\text { Shredded wheat....... }\end{array}$ & $\begin{array}{l}20 \\
23\end{array}$ & $\begin{array}{l}5 \\
3\end{array}$ & $\begin{array}{l}2 \\
0\end{array}$ & $\begin{array}{l}118 \\
104\end{array}$ & $\begin{array}{l}\text { Cheese.. } \\
\text { Egg (1). }\end{array}$ & $\begin{array}{l}0 \\
0\end{array}$ & $\begin{array}{l}8 \\
6\end{array}$ & $\begin{array}{r}11 \\
6\end{array}$ & $\begin{array}{r}131 \\
78\end{array}$ \\
\hline Cream, 40 p. ct....... & 1 & 1 & 12 & 116 & Vegetables 5 p. ct. group..... & 1 & 0.5 & 0 & 6 \\
\hline Cream, 20 p. ct....... & 1 & 1 & 6 & 62 & Vegetables 10 p. ct. group... & 2 & 0.5 & 0 & 10 \\
\hline Milk. .......... & 1.5 & 1 & 1 & 19 & Potato............... & 6 & 1 & 0 & 28 \\
\hline Brazil nuts........... & 2 & 5 & 20 & 208 & Bread.............. & 18 & 3 & 0 & 84 \\
\hline Oysters, six.......... & 4 & 6 & 1 & 49 & Butter............... & 0 & 0 & 25 & 225 \\
\hline Meat (uncooked, lean). . & 0 & 6 & 3 & 51 & Oil... & 0 & 0 & 30 & 270 \\
\hline Meat (cooked, lean).... & 0 & 8 & 5 & 77 & Fish: cod, haddock (cooked). & $\mathbf{0}$ & 6 & 0 & 24 \\
\hline Chicken (cooked, lean).. & 0 & 8 & 3 & 59 & Broth $\ldots \ldots \ldots \ldots \ldots \ldots \ldots$ & 0 & 0.7 & 0 & 3 \\
\hline Bacon.......... & 0 & 5 & 15 & 155 & Fruit, 10 p. ct.......... & 3 & 0 & 0 & 12 \\
\hline
\end{tabular}




\section{DETAILED PROTOCOLS FOR INDIVIDUAL DIABETICS.}

The detailed data regarding the observations with the individual diabetics are given in Appendix I. This presents results for the experimental days only, except for such urinary analyses as are noted for the day preceding the determination of the metabolism and, in a few instances, for the following day. The apparatus used for the measurement of the metabolism is here given; the experimental conditions as to food, including the number of grams of each food element in the diet for the food experiments; the age, height without shoes, and body-weight without clothing of the patient on the days of the experiments; the average pulse-rate during each observation of the metabolism; the carbon-dioxide output and oxygen intake on a per minute basis, the respiratory quotient, and the heat-output per 24 hours, including both the total and the per kilogram values. A comparison is likewise made between the determined metabolism and the standard heat-output, i. e., the basal metabolism which would be expected for a subject of the specified sex, age, height, and body-weight, as computed by means of the Harris and Benedict

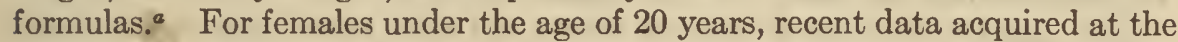
Laboratory in a study of Girl Scouts are used to supply a basis for such computation. $^{b}$ These six cases are discussed separately, and while their data are included in Appendix I, they do not form a part of the general tables which are based upon comparisons of the metabolism of diabetics with the Harris and Benedict standard.

In addition to the experimental results, information is given in Appendix I as to the amount of sodium bicarbonate when given, and for later experiments the carbon-dioxide tension in alveolar air. The urinary constituents, such as ammonia, ${ }^{c}$ diacetic acid, nitrogen, and sugar, are also included and conclusions presented as to the degree of acidosis and the severity of the diabetes for each subject. The results in Appendix I form the basis of the discussion in the following pages. In considering these data it should always be borne in mind that the experimental day was a 24 -hour day, beginning at approximately $7 \mathrm{a} . \mathrm{m}$. on the first date and ending at $7 \mathrm{a} . \mathrm{m}$. on the second date.

\footnotetext{
a Harris and Benedict, Carnegie Inst. Wash. Pub. No. 279, 1919, pp. 227 and 253 to 266 also, Harris and Benedict, Sci. Mo., 1919, 8, p. 385.

${ }^{b}$ Benedict and Hendry, Boston Med. and Surg.Journ., 1921, 184, pp. 217, 257, 282, 297, and 329. For data used for the 18-year-old girls, see Benedict, Boston Med. and Surg. Journ., 1923, 188, p. 127.

Ammonia is always expressed as $\mathrm{NH}_{3}$ and not as ammonia-nitrogen.
} 


\section{DISCUSSION OF RESULTS.}

The abundance of the material collected between 1908 and 1917 and here summarized allows a differentiation of it into many groups, each of notable size. The various degrees of severity and of acidosis are among the main subdivisions. It should be emphasized that severity and acidosis are by no means synonymous terms, because occasionally the severest type of diabetes is found independent of acidosis, and conversely, severe acidosis may exist temporarily in a patient with diabetes of moderate severity. On this account it has become possible to study the metabolism of these cases of diabetes under a great variety of conditions and to note the effect of both internal and external influences upon the different forms of the disease. Such, for example, are the variations in the amounts of sugar, fat, and non-protein nitrogen in the blood, the effect of undernutrition for longer or shorter periods with consequent changes in weight, and of feeding with various foods, notably levulose. As in the previous publications, emphasis is laid upon the respiratory metabolism and about it everything is centered.

The radical difference in the diet before and after June, 1914, must be constantly borne in mind. This is definitely shown by the fall in urinary nitrogen in the later period and in the presentation of the detailed data for several individual cases on pages 114 and 116. Most of the excessive diets of the early cases could not be given in the protocols, because the exact quantities of protein and fat in the years 1908 to 1914 were only approximately known and even in 1916 the proportions were not exactly known. Moreover, the carbohydrate was likewise less exactly estimated in the early period of the research than at the present time. The constituents of the diet eaten in connection with the observations after food have, however, for the most part been estimated with considerable accuracy and are recorded in Appendix I. Tables are also presented which give the relation of the metabolism to the urinary sugar, the carbohydrate balance, and the urinary nitrogen. These will assist in indicating differences in the results of treatment before and after June, 1914.

In the assembling of data in the following discussion from the protocols in Appendix I, different methods have been followed. If the matter under consideration relates specifically to the patients as individuals, as in table 13, page 36 , in which a question of age is involved, the data are grouped and averaged according to the number of subjects rather than according to the number of experimental days; otherwise the experimental days are taken as the basis for grouping. When two or more observations during a single day were made upon the same individual in the post-absorptive state, the average of the results is taken as the basal metabolism for that day. In many instances a patient exhibited different degrees of severity or of acidosis at different periods and on this account, the same individual may appear twice or more in the discussion of these problems.

\section{PULSE-RATE IN DIABETES.}

It is customary to take frequent records of the pulse-rate when the metabolism is determined. In conformity with this custom, in the course of the studies on the metabolism of diabetic subjects at the Nutrition Laboratory, between 7,000 and 8,000 records have been made of the pulse-rate. These 
observations are so numerous and their collection has required so much labor that they demand detailed analysis, not only for this, but for other investigations to show their value or the futility of further expenditure of time in this direction. This has been the purpose and even the excuse for the space devoted to the pulse-rate in the present monograph, in which an attempt has been made to bring out what an analysis of pulse-rate data can contribute to a study of the metabolism as compared with respiratory data. Subsequent sections of the monograph will show whether conclusions founded on the pulse are otherwise confirmed. In particular, in what follows it is the purpose to present all evidence available which will allow a conclusion to be reached as to whether the pulse-rate in diabetes is characteristic of the various phases of the disease as indicated by the relationships with variations in severity, acidosis, percentage of sugar or fat in the blood, loss of weight, and the reaction of the patient to foods; and also whether the data upon the pulse-rate in diabetes give evidence that this factor can be utilized more than heretofore has been the case, and depended upon as an index of metabolism in general.

While the relationship of the pulse-rate to various factors is discussed in the immediately following pages, the consideration of the second question, i. e., the relationship of the pulse-rate to the metabolism, is deferred to the section in which the post-absorptive metabolism in diabetes is considered. (See page 59.)

\section{Methods Used for Recording Pulse-Rate.}

In all of the studies on metabolism carried out by the Nutrition Laboratory, serious attempts have been made to secure reliable data upon the pulse-rate and the technique now employed has been slowly developed. It has been considered essential, first, that the subject should be unaware of the time when the rate was counted; second, that the observations should be multiple rather than single, extending throughout the period of the study of the metabolism; and third, in order to secure these records without disturbing the subject, the measurement should be of the heart-beats rather than of the pulse at the wrist. In several publications from this Laboratory electrocardiographic tracings of the heart beat have been employed.

Various endeavors have been made at this Laboratory to secure the pulserate independently of the observer. Thus, Dr. T. M. Carpenter secured the femoral pulse by placing a pneumograph around the thighs and recording the pulse-beats on smoked-paper drums. ${ }^{a}$ This procedure was successfully carried out, but for most studies it is impracticable. Other attempts have been made to secure the pulse-rate by means of an apparatus closely fitting the foot. Dodge and Benedict ${ }^{b}$ secured the pulse-rate from the hand by employing a Wiersma hand sphygmograph. Thus far, however, no method has been found satisfactory for use during prolonged experiments which has been equal to the attachment of a Bowles stethoscope to the chest by strips of plaster, using long leads to the earpieces, and making counts of the pulse-rate unknown to the subject at intervals of 5 or 10 minutes, or in short experi-

'Carpenter, Am. Journ. Physiol., 1917, 42, p. 605. The results of this research have not yet been published in detail.

b Dodge and Benedict, Carnegie Inst. Wash. Pub. No.'232, 1915, p. 190. 
ments even more frequently. This has been the routine practice in the respiration-calorimeter experiments and in all the gaseous metabolism experiments reported in this book.

It must be acknowledged that in many instances the subjects were asleep and at other times awake; furthermore, that in these, as in most experiments, there were certain psychical stimuli which caused momentary increases in the pulse-rate that were very difficult to rule out. On the other hand, the average data for the periods, whether of 15 minutes or 2 hours, tend to smooth out these temporary irregularities. It should be recognized, however, that the final observations, which are the resultant of many single observations, are of an entirely different character from the chance records of a nurse in her routine visits about a hospital ward, or of the physician in his office to whom the patient comes after having undergone more or less exertion and with almost invariably an agitated state of mind.

Strictly speaking, our results when obtained as above described are not based upon the pulse-rate at all, but are rather a register of the heart-rate. One of the reasons why the pulse-rate as the register of the metabolism has been looked upon with disapproval by some writers is undoubtedly due to the discrepancy between the pulse-rate and the heart-rate. Far more opportunities for error occur in the counting of the pulse-rate than in the counting of the heart-rate. Since, in this publication, it is the heart-rate and not the pulse-rate which furnishes the material for discussion, it might be desirable to introduce into the nomenclature the term heart-rate instead of pulse-rate, were it not for the fact that the latter has been used in previous publications for records obtained in the same way and also by other writers, and a change of terms at this time might lead to confusion.

\section{Summary of Previous Data upon Pulse-rate in Diabetes.}

Save for the discussion in the second monograph on metabolism in diabetes, ${ }^{a}$ the literature is almost barren of reference to the pulse-rate in diabetes. In that publication it is shown that whereas the average minimum and maximum pulse-rates of the 25 normal male and female subjects used for comparison were 54 and 74 beats, respectively, the corresponding figures for the 22 male and female diabetics were 65 and 81 beats, respectively. Average pulse-rates have more recently been calculated for the subjects included in the comparison. Without taking account of the sex, the average pulse-rate of the normals was 63 and of the diabetics 73. It will be seen, therefore, that for the normal individuals the minimum and maximum pulse-rates and also the average pulse-rate were markedly lower than those of the diabetics studied between 1908 and 1912.

It is furthermore pointed out in the earlier publication that the normal individuals led a much more active life, had a much greater muscular tone, and were more restless during the experiments than the diabetics. "This makes the difference in pulse-rate all the more striking, since one would ordinarily expect a somewhat higher value with the more active and restless normal subjects than with the weak, sick diabetics, disinclined to any extraneous muscular motion." On the other hand, the observation is made that "no regularity" is found "in either the minimum or maximum pulse-rates when individual

\footnotetext{
a Benedict and Joslin, Carnegie Inst. Wash. Pub. No. 176, 1912, p. 85.
} 
diabetics are compared with normal individuals, since some of the diabetic subjects show a minimum pulse-rate considerably lower than the average minimum pulse-rate of the normal subjects; and similarly, the normal individuals in some instances show a pulse-rate considerably higher than the average maximum pulse-rates of the diabetics. On the whole, however, a distinct tendency toward an increased pulse-rate in diabetes is here clearly shown." It is also stated that this "increase is fully in conformity with the increased metabolism previously noted ${ }^{a}$ and further substantiated by the evidence set forth in this report." "It is not at all impossible that the degree of acidosis and the degree of metabolism may be at least approximately estimated in diabetes by a careful examination of the pulse-rate." "We commend to the attention of the physician the importance of the pulse-rate in diabetes and particularly the value of changes in the pulse-rate in the same patient during the progress of the disease."

Since the above sentences were written, the changes in treatment which diabetic patients have undergone have been very great. (See p. 24.) Indeed, if a series of experiments had been designed to test the value of the pulse-rate as an expression of the metabolism, they could not have been better suited to the purpose. As already noted, this change in treatment began in June, 1914. It will be remembered that the chief difference in the conditions surrounding the patients before and after this date lay in the quantity of food consumed. This was notably less in the second period. It is also true that in this latter period the acidosis was less marked. It is evident, therefore, that the pulse-rates of the cases in our series must be divided and discussed in two groups. As a matter of fact, the outcome of this study was so decisive that it led to the adoption of this plan of procedure for the analysis of all the data.

\section{Pulse-Rate of Diabetic Patients Treated Before and Since June, 1914.}

In expressing the diabetic pulse-rate in the present publication, somewhat different methods have been adopted from those previously employed. First, averages of the values obtained during the course of observations of the metabolism have been used in place of the maximum and minimum values. Second, the importance of age has been taken into account and the average pulserates are grouped by decades ${ }^{b}$ according to the ages of the diabetics. Third, the policy has been followed here, and for the most part throughout this publication, of studying the data on the basis of experimental days rather than by grouping the results for the individual cases. This has been rendered necessary because a single case has so many phases. Thus, during the whole period of observation of a patient, there may be changes in age, weight, and even occasionally in height, and almost certainly in degree of severity and acidosis. In fact, the design has been to assemble data en masse, save under exceptional circumstances which plainly demand consideration of the patients as individuals. (See p. 40.)

The normal data which have been utilized for comparison were obtained from tables $\mathrm{C}$ and $\mathrm{D}$ in the biometric analysis of Harris and Benedict. ${ }^{c}$ These

\footnotetext{
a Benedict and Joslin, Carnegie Inst. Wash. Pub. No. 136, 1910, p. 193.

$b$ The youngest case was 14 years old.

${ }^{c}$ Harris and Benedict, Carnegie Inst. Wash. Pub. No. 279, 1919, pp. 40-47.
} 
tables supplied a series of observations upon the average pulse from which selections could be made according to age, each average value representing one or more experiments conducted upon these normals by the Nutrition Laboratory under conditions similar to those in the diabetic series. Because of the uniform conditions, the normal data here employed are of greater value than those used in a similar comparison in the previous monograph on metabolism in diabetes. ${ }^{a}$

For a comparison of the pulse-rate in diabetes with the normal pulse-rate, the average pulse-rate of the 31 diabetics between 11 and 60 years of age who were studied in the post-absorptive condition prior to June, 1914, i. e., before the change to treatment by undernutrition, may be compared with the average pulse-rate for 204 of the normal subjects analyzed by Harris and Benedict, for whom pulse records were obtained and whose range in age was the same as that of the diabetics. Such a comparison shows a marked difference between the two series, the average pulse-rate of the 31 diabetic men and women being 73 , in contrast with the average pulse-rate of 64 for the 204 normal men and women. he average pulse-rate of the 22 diabetics who were discussed in the preceding monograph was also 73 beats per minute. (See p. 30.)

If we compare the pulse-rate of the diabetics treated since June, 1914, with values for 210 subjects from the same normal series, but extended for the wider age limits, an entirely different picture is presented. Thus, the average diabetic pulse value, which is based upon 69 cases between the ages of 11 and 70 years, was but 1 beat higher than the normal value, or 65 as compared with 64 . This shows, therefore, that the average pulse-rate of diabetic subjects decreased markedly in the period subsequent to June, 1914, as compared to the period before that date.

Even a brief consideration of these general averages shows that fundamental alterations in the character of the disease or in its treatment must have caused a marked change in the pulse-rate. What more simple measure of the effect of change in treatment can be imagined than the demonstration that the average pulse-rate of the diabetics studied after June, 1914, fell from 9 beats above normal (or 14 per cent) to 1 beat above normal (less than 2 per cent)?

\section{Relation between Loss in Weight and Pulse-rate.}

In an earlier section (see p. 13) it was shown that the losses in weight of the diabetic subjects were very material. These losses ranged between 3 and 61 per cent of their maximum weight, and averaged 25 per cent. It is, therefore, of the greatest importance to find whether such alterations in body-mass affect the pulse-rate. For this purpose, a study of the pulse-rates before and after loss in weight should be made not only for the diabetics but also for normal individuals under similar conditions.

\section{EFFECT OF LOSS IN WEIGHT ON PULSE-RATE OF NORMAL INDIVIDUALS.}

The pulse-rates accompanying considerable losses of body-weight in a series of experiments ${ }^{b}$ carried out by this Laboratory upon 24 healthy young men in the International Young Men's Christian Association College at Spring-

a Benedict and Joslin,Carnegie Inst. Wash. Pub. No. 176, 1912, p. 86.

benedict, Miles, Roth, and Smith, Carnegie Inst. Wash. Pub. No. 280, 1919. 
field, Massachusetts, are available for comparison with the pulse-rates of diabetics. A group of these young men underwent a loss of approximately 10 per cent of the body-weight within a period of four months. During this time a considerable number of these subjects showed pulse-rates of 35 beats or below, and one subject gave positive evidence of a rate of 29 beats on at least one day. Rarely, if ever, have such low values for the pulse-rate been recorded with normal men. Incidentally it may be remarked that there were likewise reductions in the blood-pressure. In table 12, which is taken in part from the report of this research, ${ }^{a}$ the pulse-rates are given for a group of 11 of these men when they were upon a normal diet and also when they had lost on the average 9 per cent of their weight as the result of a reduced diet. It will be observed that the figures in the table are based upon weekly averages of pulse-rate and not upon minimum pulse-rates. The decrease in bodyweight between the two periods is also given for each subject.

TABLE 12.-Comparison of pulse-rates of normal men on ordinary diet with subsequent pulserates on reduced diet, after considerable loss in body-weight. Weekly averages.

[Subjects in lying position, without food.]

\begin{tabular}{|c|c|c|c|c|c|}
\hline \multirow{2}{*}{ Subject. } & \multicolumn{3}{|c|}{ Pulse-rate. ${ }^{1}$} & \multicolumn{2}{|c|}{$\begin{array}{l}\text { Decrease in } \\
\text { body-weight. }\end{array}$} \\
\hline & $\begin{array}{l}\text { Normal diet } \\
\text { Sept. } 27 \text { to } \\
\text { Oct. } 4,1917 .\end{array}$ & $\begin{array}{l}\text { Reduced diet } \\
\text { Nov. } 17 \text { to } \\
25,1917 .\end{array}$ & $\begin{array}{l}\text { Decrease in } \\
\text { pulse-rate. }\end{array}$ & Total. & Per cent. \\
\hline Bro ...................... & 57 & 52 & 5 & kg. & 9 \\
\hline Can $\ldots \ldots \ldots \ldots \ldots \ldots$ & 57 & 43 & 14 & $\begin{array}{l}5.0 \\
9.5\end{array}$ & 12 \\
\hline 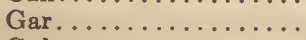 & 49 & 40 & 9 & 7.5 & 11 \\
\hline Gul $\ldots \ldots \ldots \ldots \ldots$ & 59 & 43 & 16 & 6.2 & 9 \\
\hline Mon .............. & 61 & 51 & 10 & 7.3 & 11 \\
\hline Mоу............... & 57 & 36 & 21 & 5.6 & 9 \\
\hline Рea . . . . & 51 & 35 & 16 & 7.5 & 11 \\
\hline Pec............ & 51 & 34 & 17 & 4.1 & 6 \\
\hline Spe.............. & 56 & 44 & 12 & 7.1 & 11 \\
\hline 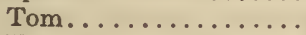 & 68 & 47 & 21 & 3.6 & 6 \\
\hline Vea............... & 50 & 34 & 16 & 5.5 & 8 \\
\hline Average. . . . . . . . . & 56 & 42 & 14 & 6.3 & 9 \\
\hline
\end{tabular}

${ }^{1}$ See Benedict, Miles, Roth, and Smith, Carnegie Inst. Wash. Pub. No. 280, 1919, table 81, p. 388 .

${ }^{2}$ Data obtained from original records, and represent the difference between the body-weights without clothing on Sept. 30,1917 , and the averages of the weights on Nov. 18, 20, 23, and $25,1917$.

These results show an average decrease in pulse-rate of 14 beats, or 25 per cent. All of the men registered a fall in rate, but this was by no means uniform, for with one subject the fall was but 5 beats and with two others it was 21 beats. It should be remembered that these individuals lost on the average but 9 per cent of their initial weight, whereas the 113 diabetics under observation had an average loss in body-weight from maximum of 25 per cent. From

\footnotetext{
a Benedict, Miles, Roth, and Smith, loc. cit., p. 388, table 81.
} 
these data acquired with normal subjects it would therefore appear that in view of the marked loss in weight of the diabetics, the accompanying decrease in the pulse-rate should be very considerable. Before considering the relationship between the loss of weight with diabetics and their pulse-rate, however, various factors should be mentioned which may have an influence upon this relationship.

\section{FACTORS INFLUENCING RELATION BETWEEN PULSE-RATE AND LOSS IN WEIGHT.}

At the present moment it is prudent to state that the changes in pulse-rate observed with the normal subjects studied at Springfield accompanied the 9 per cent loss in weight rather than were dependent upon it. This is necessary, because while these normal individuals were losing weight, they were also losing large amounts of body nitrogen, since 10 of the 11 men lost, on the average, 175 grams of body nitrogen ${ }^{a}$ between October 4, the initial day of the reduced diet, and January 27, inclusive. It is yet to be determined whether the changes in pulse-rate and also in metabolism which were observed were due to the loss in weight which had already taken place, to the loss in body nitrogen, or to the continued underfeeding. This same method of reasoning would apply to changes in the pulse-rates of diabetics, since with these patients loss in nitrogen is the rule rather than the exception.

The change in age which the diabetics underwent during the period of observation might theoretically be considered of importance as influencing the pulse-rate. As a matter of fact, however, these changes in age did not amount to more than 5 years, and the effect of so short a period would be almost negligible with individuals as old as those here considered, the youngest being 14 years old.

A second factor of obviously greater importance is the growing weakness due to the progress of the disease which accompanied the loss in weight with the diabetics. This, however, is not so simple a factor as would appear at first thought, because this weakness is manifestly of at least two types. The first type of weakness develops rather rapidly in the diabetic who has been living upon a stimulating protein-fat diet as he is about to pass into coma preceding death. This is associated with and perhaps dependent upon acidosis. Then there is a second type of weakness due to inanition.

For the former type of weakness there are few comparable data upon the pulse-rate with normal individuals, and strangely enough, the same may be said of the latter, though its acknowledgment is a matter of reproach to the medical profession. However, inanition seldom occurs in uncomplicated form. In the inanition of tuberculosis and sometimes in pernicious anemia, fever is present. The inanition of cardiac and renal disease is caused by organic disease of the heart itself and thus invalidates pulse records. Complications are less frequent in cancer, yet what data exist upon the pulse-rate in the successive months of cancer? Here is a field for research.

Finally, it should be borne in mind that the losses in weight above described with normal individuals took place during a few weeks, whereas the losses

\footnotetext{
p. 351 .

a See Benedict, Miles, Roth, and Smith, Carnegie Inst. Wash. Pub. No. 280, 1919, table 71,
} 
in weight with the diabetic patients usually occurred during a few years. It is possible that the greater loss in weight of the diabetic patients might be counterbalanced to some extent by the greater length of time during which it occurred.

\section{EFFECT OF LOSS IN WEIGHT ON PULSE-RATE OF DIABETICS, AND COMPARISON WITH NORMALS.}

That diabetics whose body-weight had suffered so great a loss from their maximum body-weight should have a pulse-rate as high or even higher than normal, must be of significance. In the Springfield series of experiments in which the pulse-rate averaged rather low, even with normal diet, the subjects were normal, healthy men who maintained their muscular vigor, as was proved by physical tests, despite the loss of weight. The loss in weight of the diabetics, on the other hand, can be considered to have been accomplished by a greater loss of muscle as well as of fat. This was a fait accompli and in the period before June, 1914, they were actually being overfed and showed an increased pulse-rate; in the period after June, 1914, they were underfed and the pulse-rate was far lower.

Both before and after June, 1914, the diabetic subjects were markedly under weight. Before that date the loss in weight from their maximum was, on an average, 21 per cent for $30^{\circ}$ of the 31 diabetics for whom pulse-rates were recorded, yet in spite of this loss the average pulse-rate was 73 beats, or 31 beats (74 per cent) greater than the average pulse-rate of 42 beats found with the group of normal men on reduced diet after a loss in weight of approximately half as much, or 9 per cent. (See table 12.) This brings out strikingly the increased pulserate of the diabetics before June, 1914. Subsequent to June, 1914, the loss in weight from maximum of $68^{\circ}$ diabetic patients averaged 27 per cent. Notwithstanding that this loss in weight was even greater than that of the normals, the average pulse-rate of this group of diabetics was reduced only 11 per cent from that of the group studied before June, 1914, i. e., to 65 beats. Even then it was 55 per cent above that of the undernourished normals, whose average pulse-rate was 42 beats. It is thus seen that both groups of diabetics, with a much greater loss in weight than the 9 per cent loss of the undernourished normals, had (1) higher pulse-rates than the latter, and (2) that the highest pulse-rates were obtained with the diabetics studied before June, 1914.

A partial explanation of the abnormal pulse-rates with the early group of diabetics is simple. The lowered pulse-rate of the Y. M. C. A. College students was due not so much to the loss of weight per se, as to the lowered food intake at the time of observation. The diabetics even before June, 1914, were thin enough to have had pulse-rates similar to those of the thin, underfed normals, but the earlier diabetics were being overfed, not to mention another factor which was more predominant then than later, namely, acidosis. The general level of the pulse-rate would be raised by the overfeeding, irrespective of any other cause.

The explanation of the great difference in pulse-rate ( 23 beats) between the two groups of undernourished individuals is not, however, so simple, and this

a Records of maximum weight were lacking for two of the diabetics whose pulse-rate was recorded; hence but 30 and 68 patients, respectively, are included in this comparison. 
variation deserves further study. While it is true that the average pulserate of the Y. M. C. A. College students immediately preceding their period of undernutrition was but 56 beats in contrast to the average of 64 beats found for the 204 normals of the Harris and Benedict series (see p. 32), yet this initial difference would account for only a part of the variation between the undernourished normals and undernourished diabetics, both of whom had lost weight. Since the loss in weight of the later group of diabetics was greater than that of the normal subjects, and their intake of food was relatively lower, it is evident that the higher pulse-rate of the diabetics was due to the disease, and that the loss in weight was of lesser effect.

\section{Effect of Sex upon Pulse-Rate.}

Thus far in the discussion little attention has been directed to the possible influence of sex upon the pulse-rate, either of normals or of diabetics. To determine the influence of this factor, the pulse-rates for the male and female normal and diabetic subjects in the post-absorptive state are given separately

TABLE 13.-Pulse-rate of male and female diabetics before and after June, 1914, compared with pulse-rate of normal men and women. Without food.

\begin{tabular}{|c|c|c|c|c|c|c|}
\hline \multirow{3}{*}{$\begin{array}{l}\text { Age in } \\
\text { years. }\end{array}$} & \multicolumn{3}{|c|}{ Males. } & \multicolumn{3}{|c|}{ Females. } \\
\hline & \multirow[b]{2}{*}{$\begin{array}{c}\text { Normals } \\
\text { (121 men). }\end{array}$} & \multicolumn{2}{|c|}{ Diabetics. } & \multirow[b]{2}{*}{$\begin{array}{c}\text { Normals }{ }^{2} \\
\text { (89 women). }\end{array}$} & \multicolumn{2}{|c|}{ Diabetics. } \\
\hline & & $\begin{array}{c}\text { Before } \\
\text { June, } 1914 . \\
\text { (25 cases). }\end{array}$ & $\begin{array}{c}\text { After } \\
\text { June, 1914. } \\
\text { (36 cases). }\end{array}$ & & $\begin{array}{c}\text { Before } \\
\text { June, } 1914 . \\
\text { (6 cases). }\end{array}$ & $\begin{array}{c}\text { After } \\
\text { June, } 1914 . \\
\text { (33 cases). }\end{array}$ \\
\hline 11 to 20 & 63 & 69 & 74 & 70 & 80 & 75 \\
\hline 2130 & 61 & 80 & 61 & 69 & 80 & ${ }^{3} 67$ \\
\hline 3140 & 59 & 69 & ${ }^{4} 66$ & 67 & 77 & 64 \\
\hline 50 & 61 & 71 & 62 & 66 & $\ldots \ldots \ldots$ & 66 \\
\hline 60 & 46 & 63 & 58 & 68 & $\ldots \ldots \ldots \ldots$ & 67 \\
\hline 6170 & 64 & ........ & 59 & 71 & $\ldots \ldots \ldots$ & 66 \\
\hline Average. . & 61 & 71 & 63 & 69 & 78 & 67 \\
\hline
\end{tabular}

${ }_{1}$ Cases 786 and 792 , owing to changes in age, were each included in two decades. Case 998 does not appear in this grouping, as he was outside of the age limits, i. e., 72 years old.

2 See Harris and Benedict, Carnegie Inst. Wash. Pub. No. 279, 1919, tables C and D, pp. 40 to 47 .

Pulse-rate of 101 in last post-absorptive observation with Case No. 1070 omitted because subject was on verge of coma.

4 Average pulse-rate of 98 for Case No. 1412 omitted because subject was on verge of coma

in table 13. In this table it will be observed that the values show a slight tendency for the pulse-rates of the normal individuals and a greater tendency for the pulse-rates of the diabetics to decrease as the age increases. This holds for both sexes.

The average pulse-rate for the normal males was 61 and for the diabetics, prior to June, 1914,71 beats. The increase in the diabetic pulse-rate above the normal for this period was therefore somewhat greater for the males than 
for the combined male and female values. (See p. 32.) Following June, 1914, the average diabetic rate for males decreased, but to no greater extent than for the combined male and female group. The male diabetic pulse-rate in this period was actually but 2 beats above the normal pulse-rate for males.

Examination of the pulse-rates of the normal and diabetic females in the same table shows the normal female pulse-rate for the second, third, and fourth decades ( 70 subjects) to have been, on the average, 69 beats, while that for the diabetic females before June, 1914, was considerably higher, namely, 78 beats. The average pulse-rate for the normal women for the six decades considered in the comparison with diabetics following June, 1914, was likewise 69 beats, and that for the diabetic females was 67 beats. The pulse-rate of the diabetic females, therefore, prior to June, 1914, was considerably above normal, but after that date slightly below, in contrast to the male pulse-rate after June, 1914, which still remained above normal. This is not a mere accident. The average maximum body-weights of the male diabetics for whom pulse-rates were taken before and after June, 1914, were 68 and $74 \mathrm{~kg}$., respectively, and the percentage loss from maximum weight to the time when the pulse-rates were taken was 21 per cent and 25 per cent for the corresponding periods. On the other hand, the average maximum body-weights of the female diabetics were 56 and $66 \mathrm{~kg}$., respectively, while the losses from maximum body-weight were 22 and 30 per cent. The pulse-rates of the female diabetic cases reflected these proportionately larger losses from maximum weight by a greater fall than was apparent in the pulse-rates of the males. If loss of weight was the only criterion to be considered in this connection, this would afford good evidence of the value of the pulse-rate in the interpretation of clinical data.

The higher pulse-rate prior to June, 1914, and the essentially normal pulserate after June, 1914, noted for the combined male and female diabetics hold for each sex when they are separately compared with their respective normal counterparts. The female diabetic pulse-rate, like the female normal pulserate, is higher than that of the male pulse-rate under practically all conditions.

\section{Relation between Food and Pulse-rate.}

The large number of experiments upon diabetic patients before and after they were given food affords material for the study of the relation of food to the pulse-rate in this disease. Fortunately it will be possible to present similar data for normal individuals which were obtained in a study made in the Nutrition Laboratory of the effect upon the metabolism of the ingestion of food. ${ }^{a}$ In the report of these studies, although the pulse-rates are recorded, the effect of food upon the pulse-rate is not discussed. Consequently, it seems especially desirable to summarize the effect of food upon the pulserate of normal individuals as shown in the studies of Benedict and Carpenter before considering the effect of food upon the pulse-rate of diabetics. Only the results obtained by these investigators in experiments with the respiration apparatus are used in this summary of normal data, as the basal pulse-rates are not given for all of the calorimeter experiments, and such as are given were not usually determined on the same day as those in the food experiments.

\footnotetext{
a Benedict and Carpenter, Carnegie Inst. Wash. Pub. No. 261, 1918.
} 
RELATION BETWEEN FOOD AND PULSE-RATE WITH NORMAL INDIVIDUALS.

The respiration experiments upon normal individuals made in the study referred to and of interest in this connection are those which were designed to determine the effect of mastication, drinking-water, coffee, and beef tea, and of taking various sugars (dextrose, levulose, sucrose, and lactose). Some of these were continued for considerable periods of time, but in the following discussion only such results as were obtained in periods comparable with the experiments with diabetics were considered, i. e., approximately from 1 to 3 hours. This applies particularly to the experiments with the various sugars.

The act of chewing caused a rise in the pulse-rate in 6 of the 7 experiments. The least rise in pulse-rate was 3 beats, and the greatest rise 25 beats. The average increase in the 7 experiments was 8 beats, or 13 per cent. The increase over the basal metabolism which, with one exception, was determined on the same day, averaged 17 per cent. It is important to point out that the act of chewing was not intermittent, as is customary in a meal, but extended throughout the entire period of observation.

The mere drinking of water either left the pulse-rate practically constant or raised it on the average not more than 4 beats in any one experiment. The average increase in pulse-rate in 6 experiments was 1 beat. The authors record no significant increment in the metabolism.

The influence of the drinking of coffee upon the pulse-rate was not great. In 6 experiments in which the period of observation used for comparison ranged between 91 and 230 minutes, there was one with a fall in the average pulse-rate of 4 beats, but the average increase for the group of experiments was 1.5 beats or 3 per cent. The metabolism showed at the same time an average increase of 8 per cent, with a minimum of 2 per cent and a maximum of 13 per cent. (See p. 201 for a discussion of the influence of coffee upon the metabolism.)

Beef tea increased the pulse-rate during the first three hours in five out of six experiments; in the remaining experiment the average pulse-rate did not change. The average increase for this length of time was 4 beats. If the entire period of observation is included, amounting in four instances to 6 hours or over, the increase was still 4 beats, or about 7 per cent. The metabolism is reported as having increased in these same experiments 8 per cent for the entire period of observation.

Dextrose was given in amounts of 100 or 75 grams in 14 experiments. The pulse-rate rose in all but two experiments, and of these two there was no change in one and a fall of 2 beats in the other. The average increase was 4 beats, or 7 per cent. The average maximum increase in metabolism was 14 per cent.

Levulose was given in 9 experiments, 100 grams in seven of the experiments and 75 grams in two experiments. The average increase in pulse-rate was 2 beats, or 3 per cent. The average peak effect of the pulse-rate was 5 beats, or 8 per cent, and the greatest increment was 16 per cent. The average maximum increase in the metabolism, including both the 75-gram and 100-gram experiments, was 15 per cent.

In a series of 15 experiments with 100 or 75 grams of sucrose, the average increase in pulse-rate was 4 beats. In four of the experiments the average pulse fell during the period of observation considered. The average increase 
amounted to 6 per cent and the greatest increase to 19 beats, or 29 per cent. The average maximum metabolism for the 100 -gram experiments was 24 per cent above the basal, the greatest maximum being 31 per cent above. The increase in metabolism for the 75-gram experiments was somewhat less, particularly as to the peak effect.

In 5 experiments with lactose the average increase in pulse-rate was less than 1 beat or between 1 and 2 per cent. The maximum increase was 10 beats, or 20 per cent. The average maximum increase in metabolism was 14 per cent, and the greatest increase 23 per cent.

\section{RELATION BETWEEN FOOD AND PULSE-RATE WITH DIABETICS.}

Pulse-rates obtained in experiments with 55 diabetics are available to show the differences between the pulse-rate for the post-absorptive state and that found after food. These pulse-rates, which represent 252 experiments without food and 158 experiments with food, are summarized in table 14. To make the comparison more valuable, only those patients are included in the table who were studied both when they were in the post-absorptive condition and also after they had taken food. The observations for the individual patients with and without food were not always made on the same day, however.

The data are grouped according to age in decades. It will be seen that the pulse-rate was increased by food in each decade, varying on the average from 3 to 8 beats. The average pulse-rate for the 55 subjects between the ages of 11 and 60 years was 66 beats when they were in the post-absorptive state and 71 beats after food, giving an average increase in pulse-rate due to food of 5 beats, or an increase of 8 per cent. This average does not take into account the number of experiments with each patient, but is a case average.

TABLE 14.-Pulse-rate of diabetics in post-absorptive state, compared with pulse-rate of same individuals after food.

\begin{tabular}{|c|c|c|c|c|}
\hline $\begin{array}{c}\text { Age } \\
\text { (years). }\end{array}$ & $\begin{array}{l}\text { No. of } \\
\text { subjects. }\end{array}$ & $\begin{array}{l}\text { Post- } \\
\text { absorptive. }\end{array}$ & $\begin{array}{l}\text { After } \\
\text { food. }\end{array}$ & $\begin{array}{l}\text { Increase } \\
\text { after food. }\end{array}$ \\
\hline $\begin{array}{lr}11 & \text { to } 20 \\
21 & 30 \\
31 & 40 \\
41 & 50 \\
51 & 60\end{array}$ & $\begin{array}{r}9 \\
21 \\
13 \\
7 \\
5\end{array}$ & $\begin{array}{l}71 \\
64 \\
67 \\
66 \\
57\end{array}$ & $\begin{array}{l}78 \\
69 \\
70 \\
74 \\
64\end{array}$ & $\begin{array}{l}7 \\
5 \\
3 \\
8 \\
7\end{array}$ \\
\hline Average. & 55 & 66 & 71 & 5 \\
\hline
\end{tabular}

If we obtain the grand averages for the pulse-rates with and without food by weighting the averages for each case according to the number of experiments from which it was obtained, we find that the average figure for the pulserate for the experiments included in table 14 with 55 subjects was practically the same as those which took no account of the number of observations with each patient, being 65 beats without food and 71 beats with food. The increase due to the ingestion of food was, however, a little higher, i. e., 6 beats or 9 per cent.

With 19 diabetic subjects between 11 and 60 years of age, whose metabolism was studied both when they were in the post-absorptive state and after a 
regular meal (breakfast or dinner), the average pulse-rate without food was found to be 64 and that after the breakfast or dinner was 69 beats. The average rise after the meal with these subjects was thus 5 beats, or an increase of 8 per cent.

Efrect of Levulose upon Pulse-rate of Diabetics.

The effect upon the pulse-rate of the ingestion of levulose was studied in 33 of the metabolism experiments, with the coöperation of 21 diabetics. The average pulse-rate obtained with the patients in the post-absorptive state was 64 beats, while after food it was 66 beats-an increase of 3 per cent. One might be inclined to assert that levulose failed to raise the pulse-rate of diabetics because of some peculiarity in the diabetic metabolism for this form of sugar, were it not for the fact that in the series of 9 levulose experiments with normal subjects recorded on page 38 , the average increase was likewise but 2 beats, or 3 per cent.

COMPARISON OF EFFECT OF FOOD ON PULSE-RATE OF NORMALS AND DIABETICS.

These observations with both normals and diabetics show the reaction of the body to food as indicated by the pulse-rate to be comparatively slight, seldom exceeding 5 beats, and less marked than that observed with variations in body-weight. A certain positive reaction is, however, almost invariably registered and a full meal appears to produce a greater reaction than a small quantity of food. So far as conclusions are justified from these two series of food experiments, which are acknowledged to be not exactly comparable in type, the pulse-rate of diabetic individuals shows as great a reaction to food as does the pulse-rate of normal individuals. The general trend of the observations suggests the desirability of further study of this question.

\section{Variations in Pulse-rate with Certain Individuals.}

Considerable variations in the pulse-rates of individual diabetics have been observed, both in the post-absorptive and food experiments. When the pulse data for the individual cases are compared for the 55 patients with whom observations were made while they were in the post-absorptive condition and also after the taking of food, we find variations between the maximum and minimum pulse-rate will range from 0 , when there was usually but a single experiment with the patient, to 33 beats as a result of two or more experiments. When the data are studied more closely, it is found that but 11 subjects out of the 43 who underwent multiple experiments in the post-absorptive state had a variation of more than 15 beats between the different tests.

To these 55 cases, 45 other cases can be added who were studied in the postabsorptive state, but not after food. Among the 112 experiments with these additional 45 cases there were 5 instances in which the variation in pulse-rate between the different experiments amounted to more than 15 beats. In other words, with 100 cases in the post-absorptive condition, there were but 16 with a variation of more than 15 beats in different experiments of similar type.

Of the 55 subjects whose pulse-rate was obtained both with and without food, there were 37 whose pulse was observed in more than one experiment 
after food. Of these, 10 showed a variation in pulse-rate of more than 15 beats. Oddly enough, the cases who present a variation of 15 or more beats in the post-absorptive state are, as a rule, not the ones who show so large a variation after food.

From the above studies upon the variations in the diabetic pulse-rate in certain individuals both with and without food, it is evident that wide variations in the pulse-rate for the same case were the exception.

\section{Relation of Severity of Diabetes to Pulse-rate.}

If the pulse-rate in diabetes is characteristic of the disease, one would anticipate a variation with the degree of severity. For the purpose of studying this question, the pulse-rates for 108 cases observed in the post-absorptive state have been assembled and grouped in table 15 according to the degree of severity, namely, mild, moderate, and severe. Inspection shows that the

TABLE 15.-Pulse-rates in diabetes of various degrees of severity. (Patients without food.)

\begin{tabular}{|c|c|c|c|c|c|c|c|c|}
\hline \multirow[b]{2}{*}{$\begin{array}{l}\text { Age in } \\
\text { years. }\end{array}$} & \multirow[b]{2}{*}{$\begin{array}{c}\text { Mild } \\
\text { diabetes } \\
\text { (12 cases). }\end{array}$} & \multirow[b]{2}{*}{$\begin{array}{c}\text { Moderate } \\
\text { diabetes } \\
\text { (33 cases). }\end{array}$} & \multirow[b]{2}{*}{$\begin{array}{c}\text { Severe } \\
\text { diabetes } \\
\text { (63 cases). }\end{array}$} & \multicolumn{2}{|c|}{ Before June, 1914.1 } & \multicolumn{3}{|c|}{ After June, 1914.} \\
\hline & & & & $\begin{array}{c}\text { Moderate } \\
\text { diabetes } \\
\text { (9 cases). }\end{array}$ & $\begin{array}{c}\text { Severe } \\
\text { diabetes } \\
\text { (23 cases). }\end{array}$ & $\begin{array}{c}\text { Mild } \\
\text { diabetes } \\
(10 \text { cases }) .\end{array}$ & $\begin{array}{c}\text { Moderate } \\
\text { diabetes } \\
\text { ( } 24 \text { cases). }\end{array}$ & $\begin{array}{c}\text { Severe } \\
\text { diabetes } \\
\text { (40 cases). }\end{array}$ \\
\hline 11 to 20 & & 86 & 69 & 99 & 67 & & 79 & 73 \\
\hline $21 \quad 30$ & 68 & 67 & 68 & 77 & 78 & 68 & 63 & 65 \\
\hline $31 \quad 40$ & 83 & 71 & 68 & 73 & 73 & 83 & 70 & 65 \\
\hline 4150 & 58 & 68 & 67 & 70 & 73 & 58 & 67 & 61 \\
\hline 51 & 69 & 62 & 62 & 158 & $\ldots \ldots \ldots$ & 73 & 63 & 62 \\
\hline 61 & & 59 & 66 & $\ldots$ & . . . . . . & $\ldots$ & 59 & 66 \\
\hline Average. & 68 & 69 & 68 & 75 & 73 & 68 & 266 & 65 \\
\hline
\end{tabular}

1 The one group of mild cases (51 to 60 years) before June, 1914, included but two patients with an average pulse-rate of 66 beats.

${ }^{2}$ Case No. 998 (72 years old), with moderate diabetes, had an average pulse-rate of 58 beats after June, 1914.

average pulse-rates are constant for the three groups of varying degrees of severity. Even when the averages for the decades are individually examined, no relation to severity is to be noted. But when the data are grouped according to the two periods of over and undernutrition before and after June, 1914, respectively, as is done in the last five columns of table 15, an entirely different picture is disclosed. The two mild cases in the early period (before June, 1914) had a pulse-rate of 66 beats (see footnote 1 ), the nine moderate cases a pulse-rate of 75 , and the 23 severe cases a pulse-rate of 73 , that is, the average pulse-rate was higher with the two severer groups of cases. On the other hand, during the period of undernutrition after June, 1914, the 40 severe cases give an average pulse-rate of 65 as compared with 68 for the 10 mild cases. Increasing severity raised the pulse-rate before June, 1914, but lowered it after June, 1914. (See p. 75.) The force of severity can not act in two opposite directions. Obviously the changes in pulse-rate above noted are either not due to severity per se or the effect of severity was overcome by stronger influences, such as acidosis, and difference in the quantity and character of food administered. 
After the administration of food the pulse-rate of the diabetics rose in large degree independently of the degree of severity of the patient. Thus, table 16 shows that the average pulse-rate for the mild cases after food was 66 beats, for the moderate cases 71 beats, and for the severe cases 71 beats, representing an increase of 3 beats for the mild cases, but of 5 beats for both moderate and severe cases. In this series food is shown to have fully as much, if not more, effect upon the pulse-rate with cases of moderate and severe diabetes as with cases of mild diabetes.

TABLE 16.-Comparison of pulse-rates with and without food, in diabetes of varying severity. (Age limits, 14 to 59 years.)

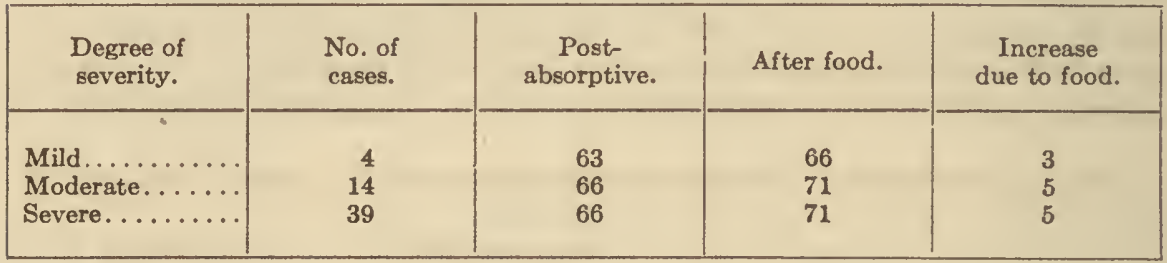

TABLE 17.-Pulse-rate of diabetics in post-absorptive observations without and with severe acidosis.

\begin{tabular}{|c|c|c|c|c|c|c|c|c|}
\hline \multirow{2}{*}{$\begin{array}{l}\text { Age in } \\
\text { years. }\end{array}$} & \multicolumn{4}{|c|}{ Pulse-rate with no acidosis. ${ }^{1}$} & \multicolumn{4}{|c|}{$\begin{array}{l}\text { Pulse-rate with severe acidosis } \\
\qquad(t+t) .1\end{array}$} \\
\hline & $\begin{array}{l}\text { No. of } \\
\text { cases. }\end{array}$ & Min. & Max. & Average. & $\begin{array}{l}\text { No. of } \\
\text { cases. }\end{array}$ & Min. & Max. & Average. \\
\hline $\begin{array}{lr}11 & \text { to } 20 \\
21 & 30 \\
31 & 40 \\
41 & 50 \\
51 & 60\end{array}$ & $\begin{array}{r}3 \\
16 \\
12 \\
8 \\
6\end{array}$ & $\begin{array}{l}56 \\
45 \\
49 \\
53 \\
55\end{array}$ & $\begin{array}{l}83 \\
87 \\
89 \\
77 \\
89\end{array}$ & $\begin{array}{l}65 \\
60 \\
63 \\
65 \\
66\end{array}$ & $\begin{array}{l}5 \\
7 \\
7 \\
4 \\
1\end{array}$ & $\begin{array}{l}56 \\
53 \\
55 \\
66 \\
68\end{array}$ & $\begin{array}{r}95 \\
101 \\
98 \\
90 \\
68\end{array}$ & $\begin{array}{l}71 \\
70 \\
77 \\
76 \\
68\end{array}$ \\
\hline $\begin{array}{l}\text { Average. . } \\
\text { Average. }\end{array}$ & & $\begin{array}{r}252 \\
4(62)\end{array}$ & $\begin{array}{r}285 \\
{ }^{8}(65)\end{array}$ & $\begin{array}{c}263 \\
2 \\
(63)\end{array}$ & $\cdots \cdots \cdots$ & $\begin{array}{l}260 \\
(71)\end{array}$ & $\begin{array}{c}290 \\
5(78)\end{array}$ & $\begin{array}{c}373 \\
3(73)\end{array}$ \\
\hline
\end{tabular}

1 Each observation used in the preparation of this table is an average of all pulse-rates recorded in an experiment. The minimum and maximum in the respective decades each represents an individual day and not single pulse counts. The averages are likewise computed from the values for experimental days.

Average of the five values shown in the above decades.

Average of daily values for all patients.

Average of all minima.

Average of all maxima.

\section{Relation of Acidosis to Pulse-rate.}

The influence of acidosis upon the pulse-rate is well shown in table 17 . Here are compared the values for 45 cases without acidosis and 24 cases with severe acidosis. The average pulse-rate in the former group is 63 beats and for the latter 73 beats. The average minimum and maximum rates, namely, 52 and 85 beats for the non-acidosis group, and 60 and 90 beats for those with acidosis, correspond. The averages for the individual decades are in line with the general averages. 
Excellent examples of increases in pulse-rate associated with rising acidosis are also to be found in the publications of Allen and Du Bois, ${ }^{a}$ and Gephart, Aub, Du Bois, and Lusk. ${ }^{b}$

Finally, all the values obtained with the patients when without food have been assembled in table 18 , and classified on the basis of age, according to the degree of acidosis at the time of the experiment. Here again, but on a larger and more complicated scale, the influence of acidosis is to be seen. The general tendency of the pulse-rate is obviously upward, though the values for mild and moderate acidosis are practically the same. If the methods now in common use for determining the extent of the acidosis had been employed in the early cases of this series, it is possible that the influence of acidosis upon the pulse-rate would be shown still more clearly. There is a hint of this when the individual protocols are examined. The profound effect of acidosis upon the diabetic is indicated by this change in pulse-rate and calls attention to the therapeutic necessity of overcoming or, better, preventing acidosis. Indeed, the query sometimes arises as to whether the recent improvement in the treatment of diabetes is not really due to the prevention of acidosis rather than to an improvement in the treatment of the disease itself.

TABLE 18.-Effect of varying degrees of acidosis upon pulse-rate of diabetics without and with food.

\begin{tabular}{|c|c|c|c|c|c|c|c|c|}
\hline \multirow{2}{*}{$\begin{array}{c}\text { Age } \\
\text { in years. }\end{array}$} & \multicolumn{4}{|c|}{$\begin{array}{l}\text { Average pulse-rate, without } \\
\text { food, with acidosis. }\end{array}$} & \multicolumn{4}{|c|}{$\begin{array}{l}\text { Average pulse-rate, with food, } \\
\text { with acidosis. }\end{array}$} \\
\hline & 0 & + & $+t$ & $+t+$ & 0 & + & ++ & $+t+$ \\
\hline 11 to 20 & 65 & 80 & 62 & 71 & 68 & 76 & 75 & 80 \\
\hline 2130 & 60 & 67 & 65 & 70 & 69 & 65 & 69 & 82 \\
\hline $31 \quad 40$ & 63 & 63 & 68 & 77 & 66 & 73 & 66 & 82 \\
\hline $41 \quad 50$ & 65 & 66 & 69 & 76 & 70 & 62 & 79 & 87 \\
\hline 51 & 66 & 60 & 62 & 68 & 63 & 66 & 61 & $\cdots$ \\
\hline 61 & & 59 & 66 & ...... & 63 & $\ldots \ldots \ldots$ & ........ & 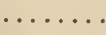 \\
\hline 71 & 58 & ..... & $\ldots \ldots$ & ....... & $\ldots \ldots \ldots$ & $\ldots \ldots$ & $\ldots \ldots \ldots$ & $\cdots$ \\
\hline Average. . & 63 & 67 & 65 & 73 & 67 & 68 & 70 & 81 \\
\hline
\end{tabular}

When food was given to diabetic patients, the effect of acidosis already observed in the post-absorptive state not only persisted but was even accentuated. (See table 18.) It would seem to be undesirable to feed diabetic patients in a state of acidosis or at least to give them food of the character that these patients received, because of the injurious influence it exerted upon the acidosis as disclosed by the rise in the pulse-rate.

Since with increasing acidosis there is an increase in the pulse-rate of diabetic patients, regardless of whether they are in a post-absorptive condition or fed, the question arises as to whether the increment in the pulse-rate due to food with diabetic patients who are acid-free is like or different from that when they are in a state of severe acidosis. Search of our data reveals experiments with 28 patients who were studied when acid-free after the adminis-

- Allen and Du Bois, Arch. Intern. Med., 1916, 17, p. 1010.

- Gephart, Aub, Du Bois, and Lusk, Arch. Intern. Med., 1917, 19, p. 908. 
tration of various kinds of food, and experiments with 17 patients who were similarly tested but were in a state of severe acidosis. The increase after food without acidosis ranged from 2 to 18 per cent, with a decrease after the ingestion of oatmeal, and oatmeal and fat. With severe acidosis the increase in the pulse-rate ranged from 2 to 12 per cent, with a decrease after dextrose and bread. Examination of the individual percentages, especially those for mixed diet, oatmeal and fat, and protein and fat, with which a direct comparison can be made for the two acidosis conditions, indicates a tendency for the food to produce a somewhat greater reaction with the diabetic burdened with acid poisoning than with the diabetic free from acidosis. This might be explained on the ground that food given to a patient burdened with acidosis increased the acidosis and the pulse-rate as well, whereas those patients who were free from acidosis failed to develop it as a result of the food and there was simply an increase in pulse-rate due to the food. On the other hand, tissues stimulated to activity by acidosis might be expected to react less to a superimposed stimulus.

It is recognized that the data above cited are meager and do not warrant broad inferences. The evidence of clinical experience clearly shows that the diabetic individual, while suffering from the effects of acidosis, excretes as sugar a larger percentage of the food consumed than the one free from acidosis. It would therefore appear that the action of food upon the pulse-rate of the diabetic patient is to some extent independent of its complete assimilation. Later, the data will be examined to note whether a study of the metabolism of the diabetics confirms this deduction. (See p. 217.)

There were a considerable number of experiments in which a pure carbohydrate, notably levulose, was given to diabetics both when they were acid-free and with severe acidosis. These show that levulose increased the pulse-rate in both states, but the influence is more marked when the patient is in a state of severe acidosis.

\section{Relation of Blood Sugar and Blood Fat to Pulse-rate.}

Since the ingestion of food is followed by an increase in pulse-rate, the question arises as to whether any relationship exists between the pulse-rate and increasing amounts of blood sugar and blood fat.

The available data bearing upon the relation between the pulse-rate and blood sugar were therefore accumulated and studied, and it was found that in general an increasing percentage of blood sugar was accompanied by a rising pulse-rate. Other reasons for the higher pulse-rate, however, were present. An increasing percentage of blood sugar frequently implies greater severity and a higher degree of acidosis, and since these factors stand in some relation to the pulse-rate, one must be slow before assuming that the progressive increase observed in the pulse-rate may be entirely due to the increasing percentage of blood sugar.

A similar attempt was made to establish a relationship between the pulserate and the blood fat, but the data available for the pulse-rate when the blood fat was in excess of 1.25 per cent were so meager that definite conclusions are not justified. 


\section{METABOLISM OF DIABETICS WITHOUT FOOD.}

In the two former publications from the Nutrition Laboratory, the data reported showed an increase in the metabolism of the patients whose diabetes was severe. This increase varied within considerable limits according to the basis of comparison. Other cases more recently under observation have shown a subnormal metabolism. It is therefore appropriate, first of all, to discuss the standards which shall be accepted as normal and, having adopted a standard, to compare with it the results obtained in the investigation of the metabolism of all the diabetics under observation by this Laboratory.

\section{Normal Standards.}

Normal individuals are so unlike one another that it is impossible to conceive of a fixed type, from which so comprehensive an expression of their vitality as is their metabolism will not swerve. A priori, therefore, in the endeavor to create a normal standard of human metabolism, it should be conceded that success would be attained if this measure of the metabolism should prove to be a zone with considerable latitude rather than a line. How wide this normal zone should be is a matter for speculation, but there are few investigators in metabolism who would venture to narrow the zone to less than 10 degrees, in other words, to 5 per cent below or above a given base-line. It is consequently gratifying, and speaks well for the accuracy of the present methods employed in the determination of the metabolism of man, that the Harris and Benedict and the Du Bois standards for normals, the two standards commonly employed, come within this really rather narrow zone. It is of advantage rather than otherwise that, in the formation of these standards, the question should be approached from somewhat different points of view, and this has been the case in the Harris and Benedict and the Du Bois methods.

The Harris and Benedict material is drawn from a large number of healthy individuals, 136 men and 103 women, such as would be accepted as good risks by any insurance company. The metabolism of these individuals was directly determined. From subsequent correlations the independent influences of age, sex, height, and weight were found and prediction formulas, involving these four factors, were derived. By means of these formulas, standard multiple-prediction tables were prepared for predicting the normal basal metabolism for both males and females between the ages of 21 and 70 years. ${ }^{a}$ So inclusive were the original groups of individuals that subsequent tests of numerous other normals have thus far (August, 1922) made revision of the original prediction tables unnecessary.

The standard for men advocated by Du Bois and his associates is based upon practically the same material as that used by Harris and Benedict, with a somewhat greater degree of restriction. It was made up as follows: 72 men were chosen from the large series of the Nutrition Laboratory, already mentioned, and 7 subjects added whose metabolism had been studied at the Cornell laboratory. ${ }^{b}$ To these 79 individuals other subjects also studied by Du Bois were subsequently added, ${ }^{c}$ these being 6 men between 77 and 83 years of

G Harris and Benedict, Carnegie Inst. Wash. Pub. No. 279, 1919, pp. 253-266.

- Gephart and Du Bois, Arch. Intern. Med., 1915, 15, p. 835.

- Aub and Du Bois, Arch. Intern. Med., 1917, 19, p. 823. 
age, and 8 boys 12 and 13 years of age. ${ }^{a} \quad$ From these subjects Du Bois derived a measure of the normal metabolism by means of his formula for determining body-surface, the best hitherto devised for this purpose, and to this applied corrections for sex and for age.

When the two standards are compared, it is shown that a metabolism of about -5 per cent according to the Du Bois standard corresponds with the Harris and Benedict base-line. More recently Dreyer ${ }^{b}$ has introduced another standard. Means and Woodwell, ${ }^{c}$ in a comparison of these three standards, conclude:

"In abnormal subjects, patients with hypothyroidism or hyperthyroidism, for example, it was found that the deviations by the three methods were essentially parallel, though on an average the Harris-Benedict deviation tended to be about 6 per cent higher and the Dreyer about 7 per cent higher than the Du Bois."

They point out that these differences can be practically abolished by a slight reduction in the Du Bois standard.

An examination of the average pulse-rates of the subjects constituting the basis for the Harris and Benedict and the Du Bois standards shows them to be almost identical. Thus, the average pulse-rate of the $121 \mathrm{Harris}$ and Benedict subjects was 61 beats; that for the Harris and Benedict subjects used by $\mathrm{Du}$ Bois was also 61 beats. The average pulse-rate for the $7 \mathrm{Du}$ Bois subjects was 63 beats, and of his 6 old men subjects was 62 beats. The average pulse-rate of the 8 boy subjects was higher, being 83 beats. Hitherto this similarity has not been commented upon.

Since the Harris and Benedict and the Du Bois normal standards are founded in large part upon the same material, their agreement is, as would be expected, remarkably close, but it would be a mistake to assume that the present standards are satisfactory. The diabetic patients whose metabolism is about to be considered weighed on the average 14 per cent below the normal weight for their age and height when the metabolism was first estimated and 18 per cent below when last estimated. Obviously it would be far more satisfactory to compare their metabolism with a group of normal, healthy individuals whose weight was similarly reduced than with those individuals whose weight was approximately normal. There is need for continued study of the metabolism of underweights. K. Blunt ${ }^{d}$ has recently found that the metabolism of 19 college women who were underweight averaged almost normal, although their food consumption was low.

Unless otherwise stated, and without further designation, the Harris and Benedict standards will be employed throughout this monograph, and more particularly in this chapter, as a basis for the comparison of the metabolism of diabetic subjects. The writer confesses that he feels much more at home and is more in sympathy with the plan upon which the Harris and Benedict tables were created, but even if he were not, he would deem it a privilege as well as a duty to use them because of proximity to the Laboratory in which they were devised.

a Du Bois, Arch. Intern. Med., 1916, 17, p. 887. Six of these boys were Boy Scouts

${ }^{b}$ Dreyer, Lancet, 1920, p. 289.

c Means and Woodwell, Arch. Intern. Med., 1921, 27, p. 608.

Blunt and Bauer, Journ. Home Economics, 1922, p. 232. 
The case is exactly analogous to the writer's use of the Folin test for blood sugar instead of the Stanley R. Benedict-Lewis test. Both tests are excellent, but more will be gained for medicine as a whole if, instead of all chemists following the same path, those in this vicinity will employ the Folin methods and explain to Professor Folin their successes and difficulties in using them, and a like course be adopted with the Benedict-Lewis test by the chemists near the Cornell University Medical School laboratory.

To indicate the method of predicting the basal metabolism according to the Harris and Benedict standard, we may use for an example a man 21 years old, 169 centimeters in height, and weighing $63.9 \mathrm{~kg}$. The formula ${ }^{a}$ employed for men is:

$$
h=66.473+13.752 w+5.003 s-6.755 a
$$

in which $h$ represents the heat-production per 24 hours, $w$ the nude bodyweight in kilograms, $s$ the height without shoes in centimeters, and $a$ the age in years. The calculation for a man of this age, height, and weight would therefore be as follows:

$$
h=66.473+(13.752 \times 63.9)+(5.003 \times 169)-(6.755 \times 21)=1,649 \text { calories. }
$$

Similar computations may be made for women by means of the formula: $:^{b}$

$$
h=655.096+9.563 w+1.850 s-4.676 a
$$

Results may be more quickly obtained by using the standard multiple-prediction tables ${ }^{c}$ for men and women between the ages of 21 and 70 years, inclusive, which have been derived from the Harris and Benedict formula.

While for boys weighing $10 \mathrm{~kg}$. or more ${ }^{d}$ and for men over 70 years the original Harris and Benedict formula will apply, it was necessary to employ other data for the female diabetics between the ages of 16 and 18 years, and such have been found in those recently secured by this Laboratory from a study of Girl Scouts. ${ }^{\circ}$ The metabolism of the six diabetic girls compared with the Girl Scouts gives so many opportunities for discussion and interpretation that this part of the material is considered separately and the figures do not, as a rule, enter into the general averages. (See p. 90.)

\section{Computation of Basal Metabolism.}

For the computation of the basal metabolism, the respiratory quotients were calculated from the data for the carbon dioxide exhaled and the oxygen absorbed, and the total metabolism was then computed from the oxygen values by employing the table of Zuntz and Schumburg $f$ to find the caloric value of a liter of oxygen corresponding to the various quotients. As a matter of fact, the table referred to gives values for the non-protein quotient,

a Harris and Benedict, Carnegie Inst. Wash. Pub. No. 279, 1919, pp. 190 and 227.

${ }^{b}$ Harris and Benedict, ibid.

- Harris and Benedict, Carnegie Inst. Wash. Pub. No. 279, 1919, pp. 253-266; also, Carpenter, Carnegie Inst. Wash. Pub. No. 303, 1921, tables 24 to 27, pp. 110-121.

${ }^{d}$ Benedict, Proc. Nat. Acad. Sci., 1920, 6, p. 9.

- Benedict and Hendry, Boston Med. and Surg. Journ., 1921, 184, pp. 217, 257, 282, 297, and 329. (See table XIII, p. 331.) For data for the 18-year-old girls, see Benedict, Boston Med. and Surg. Journ., 1923, 188, p. 127.

Zuntz and Schumburg, Physiologie des Marsches, Berlin, 1901, p. 361. See, also, Williarns, Riche, and Lusk, Journ. Biol. Chem., 1912, 12, p. 357. 
but in the calculations recorded in this book the actual quotient and not the non-protein quotient has been employed. The following examples show that such disregard of the nitrogen excretion is justifiable.

Case No. 561 excreted 10.2 grams of nitrogen on the day corresponding to the experiment. The basal metabolism computed without regard to the nitrogen correction amounted to 1,555 calories. With the use of the nitrogen correction, the total heat was 1,540 calories. The nitrogen excretion on this day was a customary figure, but if by chance it had been twice as great, namely, 20.4 grams, the computed total metabolism would have been 1,528 calories. Thus, even allowing 100 per cent error in the nitrogen value, the change in calories from those calculated in this book would have been but 27 , or less than 2 per cent.

Case No. 1011 excreted 9.5 grams of nitrogen on the day of the experiment. The metabolism computed without regard to nitrogen correction was 835 calories and with nitrogen correction 819 calories. If the nitrogen excreted had been twice as great, namely, 19 grams, the total heat-output would have been 801 calories.

\section{Varying Metabolism in Diabetes.}

Even a cursory glance at the protocols in Appendix I reveals the wide divergence in the character of the post-absorptive metabolism of the diabetic cases studied at the Nutrition Laboratory. Accepting the Harris and Benedict scale without further comment, it will be found that Case No. 1412 averaged 31 per cent above the standard metabolism for an individual of the same age, weight, height, and sex, and Case No. 1085 averaged 35 per cent below the

TABLE 19.-Extreme variations from normal standard in the daily basal metabolism of 10 diabetics.

\begin{tabular}{|c|c|c|c|}
\hline Case No. & $\begin{array}{l}\text { Range in metabolism } \\
\text { expressed as variations } \\
\text { from standard. }\end{array}$ & Difference. & Remarks. \\
\hline $\begin{array}{r}220 \\
246 \\
317 \\
765 \\
767 \\
786 \\
821 \\
1008 \\
1160 \\
1181\end{array}$ & $\begin{array}{ll}p . c t . & p . c t . \\
+32 & +4 \\
+28 & +5 \\
+31 & +5 \\
-1 & -27 \\
+6 & -17 \\
+12 & -24 \\
-7 & -30 \\
+13 & -18 \\
+8 & -17 \\
-1 & -24\end{array}$ & $\begin{array}{l}\text { p. } c t \text {. } \\
28 \\
23 \\
26 \\
26 \\
23 \\
36 \\
23 \\
31 \\
25 \\
23\end{array}$ & \multirow[t]{2}{*}{$\begin{array}{l}\text { Normal metabolism was com- } \\
\text { puted from the Harris and Benedict } \\
\text { prediction tables for individuals of } \\
\text { like sex, age, weight, and height. } \\
\text { (Harris and Benedict, Carnegie } \\
\text { Inst. Wash. Pub. No. 279, 1919.) }\end{array}$} \\
\hline Average. . & $\ldots \ldots \ldots$ & 26 & \\
\hline
\end{tabular}

standard. Nor are these illustrations very exceptional, because 23 per cent of the total number of observations, representing 27 per cent of the patients for whom the Harris and Benedict standard was used in the post-absorptive state, varied more than 20 per cent above or below the center of the normal zone of metabolism. 
The variation in metabolism is not only considerable between different diabetics, but it is also considerable with the individual diabetic. This is shown in table 19, in which a group of 10 cases exhibit extreme excursions in metabolism, with an average difference between the two extremes of 26 per cent. The greatest variation occurred with Case No. 786, and amounted to 36 per cent. In this case, as in the remaining cases, the change in variation of metabolism from standard was downwards as the years advanced from the first experiment in 1908.

In view of the above, it should ever be borne in mind in the consideration of the metabolism of diabetic patients between the years 1908 and 1917 that, although one is dealing with the same disease throughout, it is protean in form. This may be due to the fact that the methods of treatment to which it has been subjected have been so radically diverse in type. In considering the variations in the metabolism of the whole group of diabetics studied, therefore, it is desirable to take into consideration the fundamental change in treatment which took place about June, 1914. (See p. 24.) It should also be stated that variations in the metabolism, such as those with Cases Nos. 220, 246, and 317 in table 19, are due in part to the use of the chair calorimeter in the early part of the research.

\section{Metabolism of Diabetic Patients Before and After June, 1914.}

If the post-absorptive metabolism of all diabetics (exclusive of the girl patients) is compared with the normal standard, it will be found that before the change in treatment in June, 1914, to fasting and a reduced diet,

TABLE 20.-Variation in basal metabolism of diabetics from the normal standard before and after inauguration of treatment by undernutrition in June, 1914.

\begin{tabular}{|c|c|c|c|c|c|c|c|}
\hline \multirow{2}{*}{$\begin{array}{l}\text { Time of } \\
\text { obscrvation. }\end{array}$} & \multirow{2}{*}{$\begin{array}{l}\text { No. of } \\
\text { cases. }\end{array}$} & \multicolumn{2}{|c|}{$\begin{array}{l}\text { No. of experimental } \\
\text { days with metabolism }\end{array}$} & \multirow{2}{*}{$\begin{array}{c}\text { Average } \\
\text { variation } \\
\text { from } \\
\text { standard.1 }\end{array}$} & \multicolumn{2}{|c|}{$\begin{array}{l}\text { No. of cases with } \\
\text { average metabolism- }\end{array}$} & \multirow{2}{*}{$\begin{array}{c}\text { Average } \\
\text { variation } \\
\text { from } \\
\text { standard. }\end{array}$} \\
\hline & & $\begin{array}{l}\text { Above } \\
\text { standard. }\end{array}$ & $\begin{array}{l}\text { Below } \\
\text { standard. }\end{array}$ & & $\begin{array}{l}\text { Above } \\
\text { standard. }\end{array}$ & $\begin{array}{l}\text { Below } \\
\text { standard. }\end{array}$ & \\
\hline $\begin{array}{l}\text { Before June, } 1914 . \\
\text { After June, } 1914 \ldots\end{array}$ & $\begin{array}{l}229 \\
276\end{array}$ & $\begin{array}{r}107 \\
50\end{array}$ & $\begin{array}{r}12 \\
225\end{array}$ & $\begin{array}{l}\text { p. } c^{t} \\
+12 \\
-11\end{array}$ & $\begin{array}{l}27 \\
19\end{array}$ & $\begin{array}{r}2 \\
57\end{array}$ & $\begin{array}{l}\text { p. } c t . \\
+13 \\
-7\end{array}$ \\
\hline
\end{tabular}

1 With regard to sign.

2 Eight of the whole group of 113 cases are not included in these averages. They are as follows: five of the girl diabetics who were too young during the whole period of observation for comparison with the Harris and Benedict standard; Case No. 1412, who was on the verge of coma; and two patients, Nos. 320 and 757 , with whom only observations after food were made.

the metabolism was above the standard on 107 experimental days and below it on 12 experimental days, with an average variation for the 119 experimental days of 12 per cent above normal (see table 20). This percentage approximates the 15 to 20 per cent increase in diabetic metabolism reported from this Laboratory when the number of cases compared was somewhat smaller and confined to the severe type and the number of normals for controls was far less. ${ }^{a}$ In the series made after June, 1914, the metabolism was

\footnotetext{
a See Benedict and Joslin, Carnegie Inst. Wash. Pub. No. 176, 1912, p. 121; also, ibid., Carnegie Inst. Wash. Pub. No. 136, 1910, p. 193.
} 
below standard on 225 experimental days and above on 50 experimental days, with an average variation for the whole number of 275 experimental days of 11 per cent below normal. Oddly enough, the two average variations for the observations before and after June, 1914, are so nearly equal in distance from the normal standard that the average metabolism on all days before and after June, 1914, is 0 , with regard to sign.

If, instead of using the experiments regardless of the individuality of the diabetics, the results for the different cases are compared, as is likewise done in table 20, the general trend of the metabolism before and after June, 1914, is seen to be like that observed in the other comparison. Before June, 1914, 27 cases showed a metabolism above and only two cases below the normal standard, while after that date, the metabolism with 19 cases was above and with 57 cases lower than standard. The average variation by cases is essentially the same before June, 1914, as that found by averaging the variations for the experimental days in the observations, namely, plus 13 per cent, but the percentage below normal after that date is minus 7 per cent instead of the minus 11 per cent obtained in the average for the experimental days.

If no further data were supplied, the conclusion would be well founded that the metabolism in diabetes varies little from the normal, only departing from it in exceptional cases and under exceptional conditions. The problem awaiting decision is whether this is or is not the case, and, should the accumulated evidence favor the former idea, to explain either by the complications of the disease or the conditions under which the patients lived, the striking abnormalities in metabolism which have been encountered.

\section{Effect on Metabolism of Using Different Types of Apparatus, Including Changes in Position.}

The chair calorimeter was employed in 32 of the 456 post-absorptive experiments. It has been shown in this laboratory ${ }^{a}$ that the metabolism of individuals sitting in a chair is about 8 per cent greater than that of individuals in the lying position, the latter being the position of the subjects with the other apparatus used in the research. The number of the observations with the chair calorimeter (32) is, however, small in comparison with the number of the experiments in the whole research, and they have accordingly been utilized for this report, regardless of the higher results which they supplied. As a matter of fact, in five instances both positions were employed in observations on the same day, so that the average metabolism for those days represents values obtained with two types of apparatus, namely, the chair calorimeter, and the respiration apparatus.

Post-absorptive experiments with the chair calorimeter were made with Nos. $177,201,210,220,226,246,289,295,317$, and 373 . There is nothing noteworthy about the experiments with any of these cases, save those with Nos. 220, 246, and 317. In one observation with Case No. 317, the metabolism was unusually high, with a variation above standard of 31 per cent. This was the first experiment made with Case No. 317, however, and the value is undoubtedly too high to be representative of his ordinary metabolism. With Case No. 246 a number of observations were made with the chair calor-

\footnotetext{
a Emmes and Riche, Am. Journ. Physiol., 1911, 27, p. 406.
} 
imeter and the respiration apparatus and opportunity is thus afforded for comparison. In four instances the metabolism in the chair calorimeter test was invariably higher than that found with the respiration apparatus, but a general survey of the metabolism values suggests no need for exclusion of any of them. With Case No. 220, the variation in the metabolism from normal was considerable, and undoubtedly allowance must be made for the increase due to the apparatus. Granted, however, that the metabolism was increased 8 per cent by the difference in apparatus, a high value for the metabolism of Case No. 220 still holds, even if corrected for the change in position, as well as the relative change in the metabolism upon different dates.

Since most of the observations prior to June, 1914, when the patients were upon a liberal diet, were made with the chair and bed calorimeters and the respiration apparatus, and the majority of the observations after June, 1914, were made with the clinical respiration chamber, it might be thought that there was some connection between the types of apparatus used and the high and low average metabolism found in these two periods. That this is not the case is shown by high values for the metabolism having been found with Cases Nos. 983, 1008, and 1412, who were studied with the clinical respiration chamber. One of these three patients, Case No. 1412, was on the verge of coma at the time of the metabolism test. In other words, when a high metabolism existed, it was disclosed in the experiments, irrespective of the type of apparatus used. Observations with the bed calorimeter also gave high values for the metabolism, as may be seen in the data for Cases Nos. 235, 295,310 , and 344 . High values were frequently obtained with the Benedict respiration apparatus, in the experiments before June, 1914, when metabolism above standard was the general rule, but low values were also obtained with it, as illustrated by Cases Nos. 511 and 707 before June, 1914, and 765, 786, 810 , and 1069 after June, 1914. The lowest values obtained with the chair calorimeter were $+5,+3$ and +9 per cent, these percentages being found with Cases Nos. 177, 317, and 373.

The above facts are recorded because when the patients were lying down they obviously had a better opportunity to rest; in the clinical respiration chamber, particularly, they frequently fell asleep, but this was not the rule. To make sure that no unusual change in activity took place in any of the observations, the data and the accompanying memoranda obtained in all the periods of each experiment, were critically examined anew in 1921 from this standpoint, and those experiments in which the activity appeared to have a material influence upon the results were excluded.

\section{High and Low Metabolism in Diabetes.}

The wide divergence which may be found in the metabolism of diabetics is strikingly shown in table 21, which presents the 6 cases with the highest and the 7 cases with the lowest metabolism in the entire series, as indicated by the percentage variation from standard. The values recorded in the table represent the metabolism for a single day, being the largest variation from standard for each patient. Each figure is, however, substantiated by other high or low values for the same individual. With all of these cases, the diabetes was severe. 
For the cases with high metabolism the percentage variation ranged between +26 per cent and +33 per cent. ${ }^{a}$ Perhaps the best idea of the gravity of the conditions under which the subjects were living is obtained from the duration of life following the recorded observations. Case No. 1412 succumbed to the disease within three days. (See p. 158.) Comparison of the date of the observation as given in table 21 with the date of death in table 3 (p. 8), will show that Cases Nos. 549, 210, and 246 lived from one to six months after these data were obtained, while Case No. 220 lived nearly a year and a half. Case No. 983 is still alive in 1922. Comment upon the latter exceptional case has been made elsewhere. (See p. 155.) It is sufficient to state here that this patient was markedly obese, being 43 per cent above

TABLE 21.-Highest and lowest post-absorptive metabolism of diabetics as expressed by tariation from standard. (All cases severe).

\begin{tabular}{|c|c|c|c|c|c|c|c|c|c|c|c|c|}
\hline \multirow{3}{*}{$\begin{array}{l}\text { Case } \\
\text { No. }\end{array}$} & \multirow{3}{*}{ Date. } & \multirow{3}{*}{ 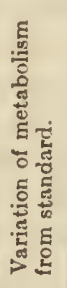 } & \multirow{3}{*}{ 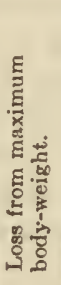 } & \multirow{3}{*}{ 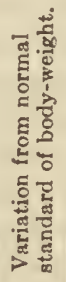 } & \multirow{3}{*}{$\begin{array}{l}\text { Aci- } \\
\text { dosis. }\end{array}$} & \multirow{3}{*}{$\begin{array}{l}\text { Sugar } \\
\text { in } \\
\text { blood. }\end{array}$} & \multicolumn{3}{|c|}{$\begin{array}{l}\text { Urinary nitrogen per } \\
\text { kilogram of body-weight } \\
\text { per } 24 \text { hours. }\end{array}$} & \multirow{3}{*}{ 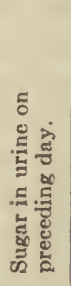 } & \multirow{3}{*}{ 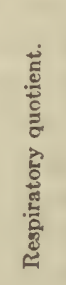 } & \multirow{3}{*}{ 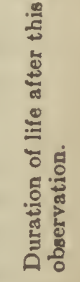 } \\
\hline & & & & & & & \multicolumn{2}{|c|}{$\begin{array}{l}\text { For days preced- } \\
\text { ing experiment. }\end{array}$} & \multirow{2}{*}{$\begin{array}{c}\text { On } \\
\text { experi- } \\
\text { mental } \\
\text { day. }\end{array}$} & & & \\
\hline & & & & & & & $\begin{array}{l}\text { No. of } \\
\text { days. }\end{array}$ & $\begin{array}{l}\text { Nitro- } \\
\text { gen. }\end{array}$ & & & & \\
\hline 210 & $\begin{array}{l}\text { Hiohest metabolism. } \\
\text { Aug. } 2-3, \quad 1910 \ldots .\end{array}$ & $\begin{array}{l}\text { p. ct. } \\
+2 t\end{array}$ & $\begin{array}{l}\text { p. ct. } \\
24\end{array}$ & $\begin{array}{l}\text { p. ct. } \\
-27\end{array}$ & + & p.ct. & 7 & $\begin{array}{l}g m . \\
0.325\end{array}$ & $\begin{array}{l}a m . \\
0.315\end{array}$ & $\underset{268}{g m .}$ & 0.71 & $\begin{array}{l}\text { years. } \\
0.3\end{array}$ \\
\hline 220 & Mar. $13-14,1909 . \ldots$. & +32 & 24 & -25 & $+t+$ & & & & 0.010 & & .69 & 1.4 \\
\hline 246 & June $8-9,1909$. . & +28 & 15 & +1 & $+t$ & & 1 & .210 & $\cdots$ & 104 & .67 & .5 \\
\hline 549 & Nov. $5-6,1912$. & +30 & 18 & -14 & +++ & & 2 & 1.370 & & 185 & 69 & 1 \\
\hline 983 & Feb. $2-3,1916 \ldots$ & +28 & & +43 & $+t+$ & 0.30 & 1 & .145 & .125 & 72 & .73 & Living. \\
\hline 1412 & $\begin{array}{l}\text { Oct. } 18-19,1917 \ldots \ldots \\
\text { Oct. } 19-20,1917, \ldots \ldots\end{array}$ & +33\{ & $\begin{array}{l}22 \\
22\end{array}$ & $\begin{array}{l}-23 \\
-23\end{array}$ & $\begin{array}{l}++t \\
++t\end{array}$ & .37 & ... & $\ldots \ldots \ldots$ & .380 & $\begin{array}{l}170 \\
167\end{array}$ & $\begin{array}{l}.72 \\
.76\end{array}$ & 3 days. \\
\hline 765 & Feb. $\quad 9-10,1916 \ldots$. & -27 & 23 & -31 & $+t$ & .23 & 7 & .180 & .110 & 14 & .76 & .8 \\
\hline 821 & $\begin{array}{l}\text { Apr. 3-4, } 1916 \ldots \\
\text { Apr. } 10-11,1916 \ldots\end{array}$ & -30\{ & $\begin{array}{l}25 \\
26\end{array}$ & $\begin{array}{l}-17 \\
-19\end{array}$ & + & $\ldots \ldots$ & $\begin{array}{l}7 \\
7\end{array}$ & .260 & .225 & $\begin{array}{r}0 \\
+\end{array}$ & .81 & 5 \\
\hline 1011 & Nov. $23-24,1917 .$. & -37 & 49 & -49 & 0 & .29 & 7 & .285 & .260 & 42 & .94 & .8 \\
\hline 1085 & Oct. $11-12,1916 \ldots$ & -40\{ & 50 & -43 & 0 & & & & & 0 & .81 & 1 \\
\hline & Oct. 31-Nov. 1, 1916.. & -40 & 54 & -46 & ++ & .35 & 7 & .275 & .165 & 15 & .81 & .1 \\
\hline 1196 & Dec, $15-16,1916 \ldots$ & -27\{ & $\begin{array}{l}29 \\
34\end{array}$ & $\begin{array}{l}-22 \\
-27\end{array}$ & ++ & .15 & $\begin{array}{l}6 \\
3\end{array}$ & .255 & .115 & $\begin{array}{r}35 \\
0\end{array}$ & .80 & 1.0 \\
\hline 1233 & $\begin{array}{l}\text { Jan. } \quad 6-7,1917 \ldots \\
\text { Feb. } 19-20,1917 \ldots\end{array}$ & $-33^{\prime}$ & $\begin{array}{l}34 \\
30\end{array}$ & $\begin{array}{l}-27 \\
-23\end{array}$ & $\begin{array}{l}0 \\
0\end{array}$ & 13 & 1 & $\begin{array}{r}2.415 \\
.280\end{array}$ & .380 & 0 & .80 & 1.3 \\
\hline 1378 & Nov. $13-14,1917 \ldots \ldots$ & -29 & 51 & -46 & 0 & .24 & & & & & .88 & 2.4 \\
\hline
\end{tabular}

${ }^{1}$ Average of determinations on Nov. 2-3 and Nov. 4-5, 1912

2 Average of determinations on Dec. 31, 1916-Jan. 1, 1917, and Jan. 4-5 and Jan. 5-6, 1917.

normal weight. The high metabolism and accompanying acidosis would appear to be due to a sudden restriction of the carbohydrate in the diet for the week preceding entrance to the hospital, the amount given for the four days before the test being but $80,55,50$, and 50 grams; for these same days the caloric intake amounted to $545,414,321$, and 240 calories. Previous to this time the patient had been living upon a liberal diet. This case is particularly instructive, because it shows that a temporary marked increase in metabolism with acidosis is not necessarily of bad prognostic import. On account of the obesity of this patient, which makes her an exceptional subject, her values will not be included in the general averages in discussing this series of data showing high and low metabolism.

a For variations in metabolism above the normal standard atter food, see p. 259. 
In contrast to the cases with high metabolism are seven patients with an exceptionally low metabolism, these averaging 32 per cent below standard. Despite this extraordinary decrease in metabolism, the life of these-patients was evidently not in so great jeopardy as those with high metabolism. Of these patients with low metabolism, one succumbed within a month, but the others lived longer, although varying only between 6 months and 2 years and 5 months from the date of the observation here recorded. Evidently, therefore, a diabetic patient whose metabolism is far below normal is, on the whole, in a safer condition than the diabetic patient whose metabolism is exceptionally high, though either extreme in metabolism is dangerous.

The respiratory quotients are strikingly different. With the omission of Case No. 983, the 5 remaining patients with the highest metabolism had an average quotient of 0.70 , while with the 7 patients with the low metabolism the average quotient was 0.84 . The significance of this wide variation in the respiratory quotient is discussed on page 167.

The average loss in weight from maximum of the 5 patients with the high metabolism, for whom maximum weights were recorded, was 21 per cent, which is not far from the average variation from the normal weight standard for the same patients. The losses in weight of the 7 patients with low metabolism were decidedly greater than those above mentioned. Thus, the average loss in weight below maximum was 37 per cent, and the average variation in weight from the normal standard was -34 per cent. The low metabolism was evidently connected with an exceptional loss of body-weight. However, other factors than the mere loss of weight must be considered in this connection.

Of greater importance than the loss in weight is the degree of acidosis. With one exception those with the high metabolism had an extreme degree of acidosis, but of the 7 cases with the low metabolism, 3 showed no acidosis, while with the other 4 cases acidosis was either absent in part of the tests, or not more than moderate in degree in others. In estimating the acidosis for these later cases the rating of acidosis erred on the side of being too high rather than too low.

A considerable number of determinations were made of the urinary nitrogen, either for the day of the observation, or within one week. The average urinary nitrogen per kilogram of body-weight of the cases with high metabolism (again omitting Case No. 983) for the days preceding the observation and also for the day of the test was 0.320 gram, and the average urinary nitrogen for these days of the patients with lowest metabolism was 0.255 gram per kilogram of body-weight. It will be observed that the highest value for urinary nitrogen per kilogram of body-weight was encountered with Case No. 1196 , whose metabolism was -27 per cent. The significance of a high urinary nitrogen is twofold. With an extremely high and an extremely low metabolism, this is discussed elsewhere. (See p. 120.) A high urinary nitrogen implies the disintegration of much protein, usually superabundant in the diet, and this leads to a high metabolism under ordinary conditions, as is universally recognized. On the other hand, a high urinary nitrogen due to disintegration of body protein and loss of body nitrogen is an entirely different situation, because it represents the last resort of the body to preserve existence and occurs when the metabolism is at its lowest ebb. 
The difference in treatment of the two groups of cases is shown plainly by the quantity of sugar in the urine for 24 hours preceding the period of observation. With the omission of Case No. 983, this varied from 104 to 268 grams with the patients having a high metabolism and from no sugar to 42 grams with the cases having a low metabolism, thus affording evidence that the early cases were fed more liberally than the later cases.

The two estimations of the blood sugar with the cases having a high metabolism were 0.30 and 0.37 per cent, respectively, but for six of the cases who had a low metabolism the estimations were between 0.13 and 0.29 per cent. With the remaining case the percentage of blood sugar was 0.35 per cent. Scanty as these data are, they likewise indirectly illustrate the undernutrition of the second period.

\section{Changes in Metabolism During Intervals of More than One Year.}

The post-absorptive metabolism of sixteen of the patients was observed at periods separated by intervals of 1 to 4.9 years and tests of the metabolism following food with six of the patients were made with intervals of 1.1 to 3.2 years. The results are presented in table 22 for both the post-absorptive metabolism and the metabolism after food.

Examining first the post-absorptive values for the five cases whose diabetes was severe throughout the period of study, we may note that these patients decreased in body-weight during intervals of 1 to 1.8 years, this decrease amounting to an average of 17 per cent. Corresponding to this loss in weight, there was a lowering of metabolism from an average variation of +10 per cent from standard to a variation of -2 per cent, or an average decrease of 12 per cent, but the actual decrease in metabolism ( 223 calories per 24 hours) was greater, i. e., 16 per cent, and like that found for the weight. The average fall in the pulse-rate during the same period was 11 beats. The respiratory quotient was variable, increasing in some cases and in others decreasing. The degree of acidosis remained nearly constant.

For the 7 subjects of the post-absorptive experiments whose diabetes changed from moderate to severe in type, the interval between the first and last observations was greater than with the severe cases, ranging from 1.0 to 4.9 years, but the average loss in weight was somewhat smaller (10 per cent); with this group the metabolism fell in five cases, with a rise in but one. For the six cases in which a direct comparison can be made, the average decrease in the variation of the metabolism from standard was 9 per cent, and of actual metabolism of 16 per cent. Thus loss of weight was of more effect upon the metabolism than increasing severity, which an increasing duration of life with a diabetic so often implies. With the case who showed a rising metabolism (No. 210), the acidosis changed in degree from 0 to +++ ; with the remaining six cases the acidosis disappeared in one instance and with the other patients either remained the same or increased slightly. The pulserate followed the metabolism closely, and increased with Case No. 210, whose metabolism also increased, but diminished with all the other cases (4) with whom estimations are available.

The respiratory quotient fell from 0.76 to 0.71 with Case No. 210 , thus corresponding to the great increase in acidosis. It also fell (from 0.78 to 0.71) with Case No. 1070 when the acidosis increased. Notwithstanding a 
TABLE 22.-Change in metabolism of diabetics having experimental observations during intervals of more than one year.

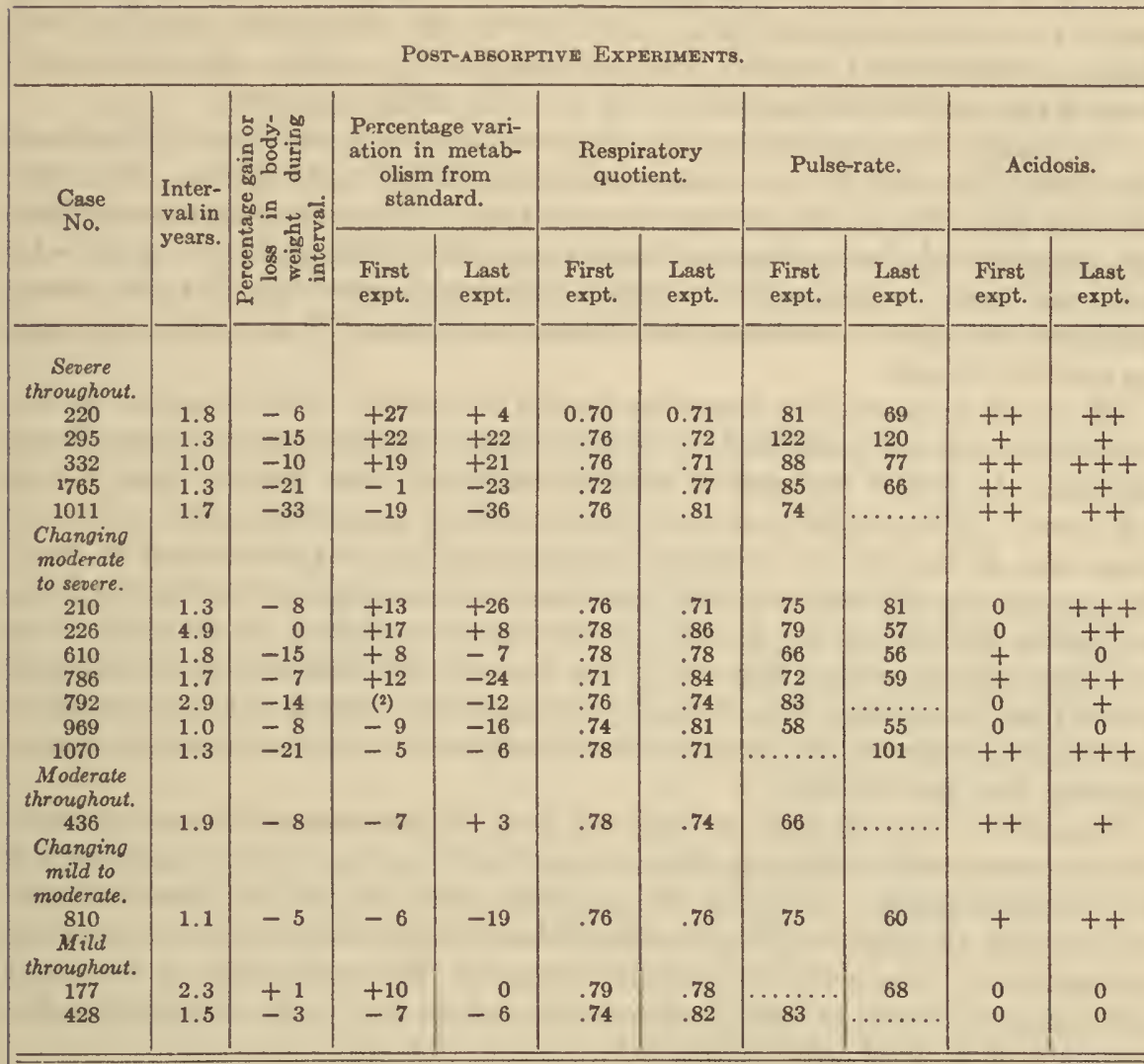

EXPERIMENTS WITH FOOD.

\begin{tabular}{|c|c|c|c|c|c|c|c|c|c|c|}
\hline \multirow{2}{*}{$\begin{array}{l}\text { Case } \\
\text { No. }\end{array}$} & \multirow{2}{*}{$\begin{array}{c}\text { Inter- } \\
\text { val in } \\
\text { years. }\end{array}$} & \multirow{2}{*}{ 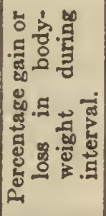 } & \multicolumn{2}{|c|}{$\begin{array}{c}\text { Calories } \\
\text { in diet } \\
\text { preceding } \\
\text { experiment. }\end{array}$} & \multicolumn{2}{|c|}{$\begin{array}{l}\text { Percentage in- } \\
\text { cresse in heat- } \\
\text { production } \\
\text { over basal. }\end{array}$} & \multicolumn{2}{|c|}{$\begin{array}{l}\text { Increase in } \\
\text { respiratory } \\
\text { quotient } \\
\text { over basal. }\end{array}$} & \multicolumn{2}{|c|}{ Acidosis. } \\
\hline & & & $\begin{array}{l}\text { First } \\
\text { expt. }\end{array}$ & $\begin{array}{l}\text { Last } \\
\text { expt. }\end{array}$ & $\begin{array}{l}\text { First } \\
\text { expt. }\end{array}$ & $\begin{array}{l}\text { Last } \\
\text { expt. }\end{array}$ & $\begin{array}{l}\text { First } \\
\text { expt. }\end{array}$ & $\begin{array}{l}\text { Last } \\
\text { expt. }\end{array}$ & $\begin{array}{l}\text { First } \\
\text { expt. }\end{array}$ & $\begin{array}{l}\text { Last } \\
\text { expt. }\end{array}$ \\
\hline $\begin{array}{c}\text { Severe } \\
\text { throughout. }\end{array}$ & & & & & & & & & & \\
\hline 332 & 1.1 & -8 & 140 & 385 & 2 & 14 & -0.02 & -0.03 & & $+t+$ \\
\hline 765 & 1.3 & $\begin{array}{l}-16 \\
-31\end{array}$ & 835 & $\begin{array}{l}355 \\
185\end{array}$ & $\begin{array}{l}27 \\
16\end{array}$ & $\begin{array}{r}7 \\
15\end{array}$ & $\begin{array}{r}.02 \\
-\quad 01\end{array}$ & -.02 & $\stackrel{+}{++}$ & $\begin{array}{c}+t \\
+t\end{array}$ \\
\hline $\begin{array}{l}\text { Changino } \\
\text { moderate } \\
\text { to severe. }\end{array}$ & 1.7 & & & & 16 & & & & & \\
\hline 226 & 3.2 & -3 & 660 & 685 & 19 & 13 & .02 & -.01 & + & $+t$ \\
\hline 610 & 1.4 & -10 & 220 & 220 & 16 & 28 & .02 & -.04 & 0 & + \\
\hline 786 & 1.6 & -8 & 795 & 280 & 21 & 11 & .05 & -.04 & + & ++ \\
\hline
\end{tabular}

1 Case No. 765 was considered as moderate in severity in November, 1914, but when next observed in January, 1916, was again severe.

2 Variation in metabolism in the first experiment with Case No. 792 at 18 years was computed as +61 per cent by comparison with the group of Girl Scouts. 
slight increase in acidosis, the respiratory quotient rose with Case No. 786 from 0.71 to 0.84 , but the metabolism fell from 12 per cent above standard to 24 per cent below standard. This rise in the respiratory quotient was likewise found with Case No. 969, accompanied by a fall in the metabolism from 9 per cent below standard to 16 per cent below standard.

The single case with whom the diabetes remained moderate throughout the study (No. 436) did not change noticeably in her metabolism. With the one case (No. 810) whose diabetes increased in severity from mild to moderate, the variation of the metabolism from standard decreased from -6 to -19 per cent, with a simultaneous change in the pulse-rate from 75 to 60 beats. With the two cases remaining mild throughout, Nos. 177 and 428, there was no notable change.

Of the six patients who were also studied after food, three remained severe in type throughout periods of 1.1 to 1.7 years, and three others changed from moderate to severe diabetes in a study extending over periods from 1.4 to 3.2 years. It is evident from the meager results presented in the table that there was no loss in the response of the metabolism to the stimulus of food. In general, any difference in the percentage increase due to food between the beginning and end of the period of study can be explained by the differences in caloric intake, except that with Case No. 610 the ingestion of 220 calories in the form of levulose did not produce so great an increase in the metabolism as that obtained with the same number of calories from a diet of carbohydrate, protein, fat, and alcohol.

From the foregoing data we may see that the post-absorptive metabolism of the severe cases decreased after an interval of a year or more along with a loss of body-weight. With but one exception, namely, that of a case developing acidosis, this rule held for the cases who changed from moderate to severe in character. There was no notable change in the metabolism of the cases remaining moderate or mild in character, and no loss in the response of the metabolism to food was observed.

\section{Relation of Age to Metabolism of Diabetics.}

The influence of age upon the metabolism of the diabetic patient is readily shown by an examination of the data for our diabetic clientele. These cases are grouped into seven decades, i. e., from the ages of 11 to 20 years to 71 to 80 years, inclusive. The results are given in table 23 with the usual division for change of treatment in June, 1914.

A feature of table 23 is the metabolism in the two decades 51 to 70 years. All the results available indicate that both prior and subsequent to June, 1914, in these decades, the metabolism varied only 1 per cent from the Harris and Benedict standard. In this connection it may be observed that the number of normals studied in these decades is far too small. The fact that the data for 51 to 60 years and for 61 to 70 years indicate an approximately normal metabolism corresponds to the generally accepted idea of the mildness of the disease at this epoch. Of the 18 cases, 5 were mild and 5 were moderate. It would appear that the diabetes at this period of life should, theoretically at least, be easily controlled because of the frequent occurrence of obesity at these ages, which may be considered an etiological factor. 
Greeley, ${ }^{a}$ from his experience at Hodgson's clinic several years ago, emphasized the connection between the decreasing severity of the diabetes with the simultaneous decrease in normal metabolism which advance in age brings. That one patient in our series in the decade 71 to 80 years had a metabolism 12 per cent above normal is not sufficient evidence to discredit this statement. The high metabolism of this subject simply indicates what may occur. As a matter of fact, this patient (Case No. 998) was clinically younger than his age, and was, when examined, a vigorous man of 72 years with ruddy cheeks, good arteries, a pulse-rate of 60 , and a blood-pressure of $120 \mathrm{~mm}$. $\mathrm{Hg}$ systolic and $80 \mathrm{~mm}$. Hg diastolic, despite his diabetes of 7 years' duration. He gave a history of jaundice and of his mother having probably succumbed to diabetes at 68 years.

TABLE 23.-The relation of age to the total metabolism of diabetics in experiments without food.

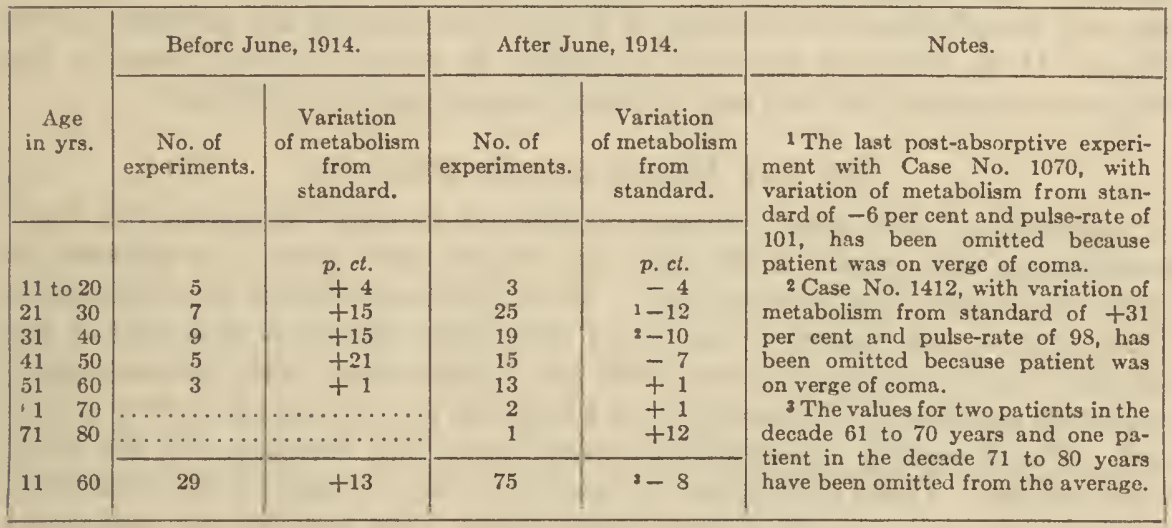

Both prior to and after June, 1914, the metabolism in the second decade (11 to 20 years) varied but little on the average from normal, being 4 per cent above and 4 per cent below normal in the respective periods. These are significant figures when considered in relation to each other, because they show for this decade the same tendency of rise and fall in metabolism for the two periods as the entire series. On the other hand, the data are so nearly within normal limits that they confirm the impression already furnished by table 20 that the diabetic metabolism is essentially normal. The disease in youth is so apt to be severe and has universally been considered to be so severe that it is also important and encouraging that the metabolism should prove to be so nearly normal for these boys. In the Shattuck lecture for $1922,{ }^{b}$ it is proved that eight children contracting diabetes in the first decade of life have lived more than five years with the disease. However, before concluding too much from this series of 8 cases, the results supplied by six young females not here included but to be discussed separately later (see p. 90) should be given due weight, particularly as the standard of comparison in that group is different. As compared with the Girl Scouts, the metabolism averaged +33 per cent before and +27 per cent after June, 1914, and with the Harris and

- Greeley, Boston Med. and Surg. Journ., 1916, 175, p. 753.

b Joslin, Boston Med. and Surg. Journ., 1923, 118, p. 127. 
Benedict standard extended ${ }^{a}$ for this purpose, +7 per cent and -19 per cent, respectively. The values by the Du Bois standard were -1 per cent and -21 per cent. In this comparison Case No. 773, though studied in October, 1914, has been grouped with cases before June, 1914. (See page 95.)

The three decades between 21 and 50 years present uniform metabolism, namely, an average increase above normal of 17 per cent before June, 1914, and an average decrease below normal of 10 per cent after that date. Since it is only for these three decades that the question of an abnormal metabolism in diabetes can be raised, it is significant that these are the decades which have supplied the majority of the subjects for this study of diabetic metabolism, and also the decades in which we have the most data for normals. It may be that these peculiarities in the metabolism can be explained by the fact that in these decades, with an average metabolism either notably above or below the normal standard, the patients were treated most strictly and showed the effects of overfeeding or lower diet, whereas the patients in the decade 11 to 20 years were less amenable to treatment and those in the decades subsequent to 50 years did not require rigorous treatment.

\section{Sex and Metabolism in Diabetes.}

Although sex does affect normal metabolism, in that females have a lower metabolism than males of the same age, height, and weight, in diabetes no particular effect of sex is to be noted. Prior to June, 1914, the average metabolism of the male diabetics was 12 per cent above standard, and that of the females 13 per cent above. (See table 24.) After June, 1914, the percentage variation was exactly the same for the two sexes, i. e., 11 per cent below standard. The foregoing comparison is based upon the averages for the daily observations. If the comparison is based upon the average for the individual patients, the percentage variations before June, 1914, are alike for males and females, being +13 per cent; after June, 1914, the two sexes are likewise exactly in agreement, namely, a variation of -7 per cent.

When only the severe cases subsequent to June, 1914, are considered, it is found that the average metabolism of the 23 males in this group was 12 per cent below standard, if based upon the daily observations, and 8 per cent if based upon the averages for individuals. The average metabolism of the 18 female severe cases was 15 per cent below when the results for the experimental days are averaged, and 11 per cent below when averages for individuals are used. Even in severe diabetes, therefore, sex exercises little or no influence upon metabolism. The slightly lower metabolism of the females may be explained by their diet possibly having been reduced more and for a longer time than that of the males, but the urinary nitrogen gives little support to this view. Thus, the average nitrogen excretion of the males for 329 days was 0.180 gram per kilogram of body-weight, or for 22 patients 0.185 gram per kilogram of body-weight, while for 233 days with the females, it was 0.175 gram per kilogram of body-weight, and for 18 patients it was 0.165 gram per kilogram of body-weight. Blunt and Bauer ${ }^{b}$ found that the metabolism of

${ }^{a}$ It should be stated that Harris and Benedict did not intend that their formula for women should be applied to girls, although subsequently it was found that their formula for men was applicable to boys.

b Blunt and Bauer, Journ. Home Economics, 1922, 14, p. 226. 
19 underweight college women averaged almost normal, but their food consumption was low. Eleven of them ate less than 500 calories above their basal metabolism and two only 137 and 210 calories above.

TABLE 24. -The relation of sex to the total metabolism of diabetics.

\begin{tabular}{|c|c|c|c|c|c|c|c|c|}
\hline \multirow{4}{*}{$\begin{array}{c}\text { Age } \\
\text { (years). }\end{array}$} & \multicolumn{8}{|c|}{ Averages of Experimental Days. } \\
\hline & \multicolumn{4}{|c|}{ Before June, 1914.} & \multicolumn{4}{|c|}{ After June, 1914.} \\
\hline & \multicolumn{2}{|r|}{ Male. } & \multicolumn{2}{|c|}{ Female. } & \multicolumn{2}{|c|}{ Male. } & \multicolumn{2}{|c|}{ Female. } \\
\hline & $\begin{array}{l}\text { No. in } \\
\text { aver- } \\
\text { age. }\end{array}$ & $\begin{array}{l}\text { Percentage } \\
\text { variation of } \\
\text { metabolism } \\
\text { from } \\
\text { standard. }\end{array}$ & $\begin{array}{l}\text { No. in } \\
\text { aver- } \\
\text { age. }\end{array}$ & $\begin{array}{l}\text { Percentage } \\
\text { variation of } \\
\text { metabolism } \\
\text { from } \\
\text { standard. }\end{array}$ & $\begin{array}{c}\text { No. in } \\
\text { aver- } \\
\text { age. }\end{array}$ & $\begin{array}{l}\text { Percentage } \\
\text { variation of } \\
\text { metabolism } \\
\text { from } \\
\text { standard. }\end{array}$ & $\begin{array}{l}\text { No. in } \\
\text { aver- } \\
\text { age. }\end{array}$ & $\begin{array}{l}\text { Percentage } \\
\text { variation of } \\
\text { metabolism } \\
\text { from } \\
\text { standard. }\end{array}$ \\
\hline 11 to 20 & 23 & +3 & .. & $\ldots \ldots \ldots \ldots$ & 4 & -1 & 1 & -21 \\
\hline 2130 & 39 & +14 & 1 & +13 & 78 & -14 & 56 & $2-15$ \\
\hline $31 \quad 40$ & 15 & +15 & 14 & +13 & 45 & -10 & 23 & -13 \\
\hline $41 \quad 50$ & 20 & +20 & $\ldots \ldots$ & $\ldots \ldots \ldots \ldots$ & 13 & -10 & 15 & -11 \\
\hline $51 \quad 60$ & 7 & +4 & $\ldots$ & $\ldots \ldots \ldots \ldots$ & 8 & -3 & 27 & 0 \\
\hline $61 \quad 70$ & $\ldots \ldots$ & $\ldots \ldots \ldots \ldots$ & $\ldots \ldots$ & $\ldots \ldots \ldots \ldots$ & 1 & -5 & 2 & +7 \\
\hline 7180 & $\ldots \ldots$ & $\ldots \ldots \ldots \ldots$ & $\ldots \ldots$ & $\ldots \ldots \ldots \ldots$ & 2 & +12 & $\ldots \ldots$ & $\ldots \ldots \ldots \ldots$ \\
\hline $\begin{array}{c}\text { Avg. all } \\
\text { days.... }\end{array}$ & 104 & +12 & 15 & +13 & 151 & -11 & 124 & -11 \\
\hline & \multicolumn{8}{|c|}{ Averages for Cases. } \\
\hline 11 to 20 & 5 & +4 & & & 2 & +5 & 1 & -21 \\
\hline 2130 & 6 & +16 & 1 & +13 & 16 & -12 & 9 & $2-12$ \\
\hline $31 \quad 40$ & 6 & +17 & 3 & +13 & 10 & $8-10$ & 9 & -10 \\
\hline 4150 & 5 & +19 & $\ldots \ldots$ & $\ldots \ldots \ldots$ & 6 & -5 & 9 & -8 \\
\hline $51 \quad 60$ & 3 & +1 & $\ldots \ldots$ & $\ldots \ldots \ldots$ & 4 & +2 & 9 & +1 \\
\hline 6170 & $\ldots$ & $\ldots \ldots \ldots$ & $\ldots \ldots$ & $\ldots \ldots \ldots$ & 1 & -5 & 1 & +7 \\
\hline $71 \quad 80$ & & & & $\ldots \ldots \ldots \ldots$ & 1 & +12 & $\ldots \ldots$ & $\ldots \ldots \ldots$ \\
\hline $\begin{array}{l}\text { Avg. all } \\
\text { cases... }\end{array}$ & 25 & +13 & 4 & +13 & 40 & -7 & 38 & -7 \\
\hline
\end{tabular}

1 With regard to signs.

2 Last post-absorptive experiment with Case No. 1070 has been omitted, because subject was on verge of coma. (See footnote 1, table 23.)

${ }^{3}$ Case No. 1412 omitted. (See footnote 2, table 23.)

\section{Pulse-rate as a Measure of Basal Metabolism in Diabetes.}

It is important for the clinician to know whether the metabolism of his diabetic patient can be estimated by the examination of the pulse-rate provided this is secured in a manner analogous to that adopted in this series of experiments. Considerable evidence is available indicating that such estimations can be made, provided the same precautions are adopted in securing the pulse-rate as are employed in the determination of the basal 
metabolism. It is partly because these rules have not been observed in the past, but more especially because of the generally lax measures employed in the routine clinical collection of data upon the pulse-rate by nurses and doctors that the value of this factor as a measure of the metabolism has been disregarded.

\section{RELATION BETWEEN PULSE-RATE AND METABOLISM OF DIFFERENT} INDIVIDUALS.

The relationship between the pulse-rate and the metabolism has been frequently commented upon in the publications of this Laboratory, ${ }^{a}$ this correlation at times approaching a percentage relationship. In practically all of these publications, however, emphasis has been laid upon the fact that this relation exists between values for the same individual, and not between those for different individuals. Thus, if Subject A has a pulse-rate one day of 60 beats and on another day of 70 beats, there is every probability that the metabolism will be higher on the second day. On the other hand, it is by no means certain that if Subject $A$ has a pulse-rate of 60 beats and Subject $B$ of 70 beats, that the metabolism of Subject $B$ will be higher than that of Subject A.

In an analysis of the gaseous metabolism of normal individuals, Harris and Benedict ${ }^{b}$ worked out the correlation between the pulse-rate and the total metabolism, metabolism per kilogram of body-weight, and metabolism per square meter of body-surface. In the several series of men and women studied by these authors, it was found that there was a positive correlation between pulse-rate and heat per square meter of body-surface, although of fairly low order, save in a series of 22 women with whom it was as high as 0.5283 when the body-surface was obtained by the Du Bois method.c The correlation for 121 men was 0.2837 and for 90 women 0.4020 . It is thus clear that there is some distinct correlation between pulse-rate and metabolism, but it does not seem to be of sufficiently high order to be of any great help in diagnostic purposes.

A closer analysis of the material presents phases that are worth considering. In two tables compiled by Harris and Benedict, ${ }^{d}$ the average pulse-rates, together with the heat-production per square meter of body-surface (Du Bois) are given for 121 men and 90 women. The extreme pulse-rates recorded for men in their table C, i. e., those between 43 and 52 beats per minute and between 70 and 82 beats per minute, together with the corresponding heatproduction, have been gathered together for comparison in table 25 .

From table 25 it is evident that of 12 observations of pulse-rate between 43 and 52 , there were two in which the heat-production per square meter of body-surface was under 800 calories and but four over 900 calories, whereas for the 13 cases with the pulse-rate between 70 and 82, there was no instance

a Cf., among others, Benedict and Cathcart, Carnegie Inst. Wash. Pub. No. 187, 1913, p. 153; Benedict and Talbot, Carnegie Inst. Wash. Pub. No. 201, 1914, p. 141; Benedict and Murschhauser, Carnegie Inst. Wash. Pub. No. 231, 1915, p. 85; Benedict, Miles, Roth, and Smith, Carnegie Inst. Wash. Pub. No. 280, 1919, p. 383.

${ }^{6}$ Harris and Benedict, Carnegie Inst. Wash. Pub. No. 279, 1919, pp. 80 and 81, particularly table 22 , column headed "Pulse-rate and heat per square meter by Du Bois height-weight chart."

"For those unfamiliar with terms of correlation, it may be said that a complete correlation would be 1 , and a total lack of correlation would be 0 .

${ }^{d}$ Harris and Benedict, Carnegie Inst. Wash. Pub. No. 279, 1919, pp. 40-47, tables C and D. 
in which the heat-production was under 800 calories and all but three were over 900 calories. Since the computation of the heat-production per unit of surface area is supposed to equalize all individuals, it can be seen that here there is clear evidence that when the pulse-rate is low there is a tendency for the metabolism to be low, and when the pulse-rate is high, there is a distinct tendency for the metabolism expressed on the basis of surface area to be high.

TABLE 25.-Comparison of the lower and higher pulse-rates of normal men with their heat-production per square meter of body-surface. ${ }^{1}$

\begin{tabular}{|c|c|c|c|c|c|}
\hline $\begin{array}{c}\text { Subject } \\
\text { No. }\end{array}$ & $\begin{array}{l}\text { Pulse- } \\
\text { rate. }\end{array}$ & $\begin{array}{l}\text { Heat-produc- } \\
\text { tion per sq. } \\
\text { meter of body- } \\
\text { surface pcr } \\
24 \text { hours. }\end{array}$ & $\begin{array}{c}\text { Subject } \\
\text { No. }\end{array}$ & $\begin{array}{l}\text { Pulse- } \\
\text { rate. }\end{array}$ & $\begin{array}{l}\text { Heat-produc- } \\
\text { tion per sq. } \\
\text { meter of body- } \\
\text { surface per } \\
24 \text { hours.2 }\end{array}$ \\
\hline $\begin{array}{r}22 \\
70 \\
135 \\
40 \\
\mathbf{4 3} \\
51 \\
67 \\
\mathbf{4 5} \\
78 \\
136 \\
\mathbf{5 3} \\
\mathbf{9 3}\end{array}$ & $\begin{array}{l}43 \\
47 \\
48 \\
49 \\
50 \\
50 \\
50 \\
51 \\
51 \\
51 \\
52 \\
52\end{array}$ & $\begin{array}{c}\text { calories. } \\
788 \\
779 \\
940 \\
857 \\
880 \\
805 \\
1,011 \\
889 \\
906 \\
832 \\
866 \\
947\end{array}$ & $\begin{array}{r}18 \\
27 \\
58 \\
7 \\
117 \\
72 \\
134 \\
57 \\
94 \\
85 \\
8 \\
91 \\
107\end{array}$ & $\begin{array}{l}70 \\
70 \\
70 \\
71 \\
71 \\
72 \\
72 \\
73 \\
73 \\
75 \\
78 \\
79 \\
82\end{array}$ & $\begin{array}{r}\text { calories. } \\
857 \\
955 \\
1,003 \\
1,053 \\
838 \\
985 \\
826 \\
922 \\
964 \\
1,019 \\
1,009 \\
1,067 \\
914\end{array}$ \\
\hline
\end{tabular}

1 See Harris and Benedict, Carnegie Inst. Wash. Pub. No. 279 , 1919, table C, pp. 40-43.

2 The body-surface was obtained by means of the Du Bois height-weight chart.

Unfortunately, at this time it is practically impossible to establish a normal pulse-rate table for individuals of different ages, weights, and heights. The records obtained in the Nutrition Laboratory, although seemingly very extensive (and over a decade has been occupied in collecting them) are still too unsatisfactory for such an attempt. Probably the elimination of psychical stimuli will be necessary before such a table can be compiled. This means that the pulse-rates obtained in the early morning hours during complete muscular repose, without food in the stomach, in sleep, are essential. Pulse-rates in sleep should be easily obtainable and would serve as a valuable control, though it is possible that after all they might prove to be less uniform $^{a}$ than would be anticipated. Thus far but a small proportion of our data will satisfactorily meet all of the above-mentioned tests. We believe, however, that the evidence is sufficiently clear to warrant more importance being attached to the relationship between the pulse-rate and the metabolism in general and to justify the statement that not only are the pulse-rate and the metabolism closely related with the same individual, but also that the extremes of pulse-rate are usually associated with extremes in metabolism in different persons. To these statements a qualification must be added because of sex. While the metabolism of males is higher than that of females, the

\footnotetext{
- Carpenter, Am. Journ. Physiol., 1922, 59, Proc. Am. Physiol. Soc., p. 440.
} 
pulse-rate of females is higher than that of males. As yet no explanation is afforded and, for the present, it must be considered simply as the sex factor. ${ }^{a}$

In considering the selection of subjects to be used in establishing a normal standard for comparison with the metabolism of diabetic patients, it was noted that the Harris and Benedict standard for men was based upon a group of 136 individuals and that the $\mathrm{Du}$ Bois standard was based upon 72 men selected from the Harris and Benedict group, with the addition of 7 men whose metabolism was investigated with the Russell Sage calorimeter. For the sake of discussion, accepting as correct the more inclusive grouping of the men represented by the Harris and Benedict standard, we find that the metabolism of the restricted group used for the Du Bois standard shows an increase of about 5 per cent over the Harris and Benedict standard. Pulserates for all of the men in either group are not available, but they are available for 121 of the 136 men in the Harris and Benedict group, the average pulse-rate being 61 beats. The average pulse-rate for 71 of the 72 men in the Harris and Benedict group which were used by Du Bois is likewise 61 beats. The pulse-rates for 5 of the 7 male subjects studied by Du Bois are available, but are incomplete. Using these records, such as they are, we find that the average pulse-rate for these 5 men is 63 beats. It is thus seen that the average pulse-rates of the men in the Harris and Benedict and the $\mathrm{Du}$ Bois series are practically alike.

Since the pulse-rates of the two groups are essentially the same, it is difficult to understand why the metabolism of the two groups, no matter by what standard compared, should not have the same normal base-line. Is it partly, perhaps, that the age effect is more intimately woven into the Harris and Benedict than into the Du Bois standard?

\section{METABOLISM AND PULSE-RATE IN DISEASE.}

In various diseases, particularly in hyperthyroidism, a definite relationship has been observed between the basal metabolism and the pulse-rate. Peabody, Wearn, and Tompkins ${ }^{b}$ studied the irritable hearts of soldiers. They found the metabolism of these soldiers to be normal, but observed that their tachycardia subsided when they lay down, the inference being that when the pulse-rate was taken under the same conditions as when the metabolism was observed, it was normal, and thus an index of normal metabolism. Means and $\mathrm{Aub}^{c}$ comment upon the slight relationship between the heart-rate and metabolism in different individuals in exophthalmic goiter, but with the same individual they considered the resting pulse-rate to be a tolerably good index of the patient's metabolism.

Sturgis and Tompkins, ${ }^{d}$ in a study of the resting pulse-rate and basal metabolism in hyperthyroidism, show that there is a fairly constant relationship between the two in a high percentage of instances. In 496 basal metabolism determinations on 154 patients with hyperthyroidism, there was a basal metabolism of 15 per cent or more above standard in 426 of the observations, which was associated in all but 16 per cent with a tachycardia of 90 or more

\footnotetext{
a See discussion of relationship between sex and pulse-rate on p. 36.

$\checkmark$ Peabody, Wearn, and Tompkins, Medical Clinics of No. Am., 1918, 2, p. 507.

' Means and Aub, Arch. Intern. Med., 1919, 24, p. 645.

${ }^{d}$ Sturgis and Tompkins, Arch. Intern. Med., 1920, 26, p. 467.
} 
to the minute. In 70 instances when the metabolism fell to normal, a simultaneous fall in pulse-rate to below 90 beats was found in 78 per cent of the observations. With 52 patients on whom a number of metabolism determinations were made, the pulse-rate gave an accurate picture of the course of the disease, as compared to the basal metabolism, with 85 per cent of the cases.

Sturgis and Tompkins extended their studies to include a series of 106 hospital patients with various diagnoses and normal basal metabolism. Of these only five had a heart-rate of 90 or more to the minute. Their final comment is as follows:

"There is in general an interrelationship between the pulse-rate and metabolism when a group of individuals are considered; that is, an extreme degree of tachycardia suggests a greatly increased metabolism while a slight tachycardia usually indicates a slight or moderate increase. The fact that a pulse-rate at complete rest below 90 per minute is seldom and below 80 per minute is rarely associated with an increase in metabolism is of practical importance in the recognition of the large group of nervous patients who have symptoms similar to those occurring in hyperthyroidism."

$\operatorname{Read}^{a}$ finds that a combination of the pulse-rate with the pulse-pressure gives a better measure of the circulatory system's response to variations in metabolic rate than either one alone.

Pulge-rate and Metabolism in Diabetes.

In any attempt to compare the values found for the pulse-rate and the metabolism in this series of observations on diabetes, the average pulse-rate for the entire period should really be used, and the comparison will become 100 per cent fair only when the average rate is known for the entire experiment. It is quite conceivable, however, that the pulse-rate for a given moment may be an even more exact index of the metabolism for the same moment than an observed value would be which would represent the average metabolism for a period of 30 or 60 minutes including that moment.

The relationship between the pulse-rate and the post-absorptive metabolism in this series of experiments with diabetics is brought out for the two periods of treatment in table 26. In the clinic one so commonly thinks of the patient's intake of food as "calories per kilogram of body-weight," that these data have been tabulated to compare the pulse-rate with the heat-output per kilogram of body-weight. Comparison is also made with the variation of the metabolism from standard. With the exception of the group with the highest pulse-rate, the values represent from 13 to 97 experimental days. The last group of values were drawn from 4 and 3 experimental days before and after June, 1914, respectively.

Inspection of the figures in table 26 shows that, both before and after June, 1914, the pulse-rate registers with considerable accuracy the changes in metabolism, the latter steadily rising as the pulse-rate increases. When, however, the values for the metabolism in the two periods are compared, we find that with the same range in pulse-rate the metabolism varies materially under the two methods of treatment. With the heat-output estimated per kilogram of body-weight, these differences are even as large as 23 per cent,

a Read, Journ. Am. Med. Assoc., 1922, 78, v. 1887. 
while the variation from normal standard with a pulse-rate of 61 to 70 beats is +13 per cent before June, 1914, and -10 per cent after that date. Accordingly, similar conditions of living are requisite for an interpretation of the pulse-rate. Granted these similar conditions, the value of the pulse-rate in estimating the comparative change in metabolism of diabetic patients is almost as great as the measurement of the metabolism itself.

TABLE 26.-Relation between pulse-rate and post-absorptive metabolism in daily observations with diabetics.

\begin{tabular}{|c|c|c|c|c|}
\hline \multirow[b]{2}{*}{$\begin{array}{l}\text { Range in } \\
\text { pulse-rate. }\end{array}$} & \multicolumn{2}{|c|}{ Before June, 1914.} & \multicolumn{2}{|c|}{ After June, 1914.} \\
\hline & $\begin{array}{l}\text { Heat-output } \\
\text { per kg. of } \\
\text { body-weight } \\
\text { per } 24 \text { hrs. }\end{array}$ & $\begin{array}{l}\text { Variation in } \\
\text { metabolism } \\
\text { from } \\
\text { standard. }\end{array}$ & $\begin{array}{l}\text { Heat-output } \\
\text { per kg. of } \\
\text { body-weight } \\
\text { per } 24 \text { hrs. }\end{array}$ & $\begin{array}{l}\text { Variation in } \\
\text { metabolism } \\
\text { from } \\
\text { standard. }\end{array}$ \\
\hline 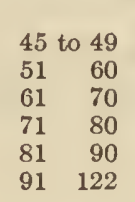 & \begin{tabular}{c}
\multicolumn{2}{c}{ calories. } \\
$\ldots \ldots$ \\
30 \\
30 \\
31 \\
32 \\
37
\end{tabular} & $\begin{array}{c}p . c t . \\
\ldots \ldots \\
+2 \\
+13 \\
+13 \\
+22 \\
+25\end{array}$ & $\begin{array}{l}\text { calories. } \\
22 \\
23 \\
24 \\
26 \\
26 \\
33\end{array}$ & $\begin{array}{l}\text { p. ct. } \\
-16 \\
-14 \\
-10 \\
-5 \\
-1 \\
+18\end{array}$ \\
\hline
\end{tabular}

2 Range of pulse-rate in this group after June, 1914, was 98 to 101.

A further study of the relationship between the pulse-rate and the metabolism of these diabetics in the post-absorptive condition is made for the different age groups in table 27 by comparing the pulse-rate with the energy output per kilogram of body-weight. From this table it will be seen that in each of the age groups the average pulse-rates steadily increased with the increase in metabolism. Nevertheless, the fallibility of the pulse-rate as a guide to the metabolism is also shown in the table by the value of 120 beats for a single case in the last right-hand column. The general average for all ages shows that below 30 calories per kilogram of body-weight, the average pulse-rate rose approximately 1 beat for each increase of 1 calorie in the metabolism, but above that point the rise in the pulse-rate was more rapid, i. e., about 1.5 beats per calorie increase. Correspondence between the pulse-rate and the post-absorptive metabolism is therefore established in dealing with this large number of approximately 390 experiments in which the pulse-rate was observed.

An examination of the pulse-rate for the different decades gives opportunity for a more delicate test of the reliability of this factor as an index of the metabolism, since on this basis comparison is possible for 25 instead of 5 groups. Examination of these groups shows that in only three of the 25 does the pulse-rate fail to rise as metabolism increases. One of these failures depends upon the data of but two patients and the two remaining inconsistencies are in the decade for 11 to 20 years.

It should be borne in mind that with all the above methods of reasoning, the experimental data based upon the respiratory metabolism are considered perfect, but it is questionable whether such a claim is justifiable. Errors 
arise in the estimation of the metabolism by the respiratory method all too frequently, and it is a question as to whether we do not ascribe more significance to such data than they deserve. The elaborate equipment required for the test on the one hand and the simple method in the other may influence our judgment.

Attention will be called to evidence of relationship between the pulse-rate and the metabolism as this becomes apparent in the discussion of other factors and their relation to the metabolism. (See pp. 83 and 191.)

TABLE 27.-Relation of metabolism to pulse-rate for different age groups.

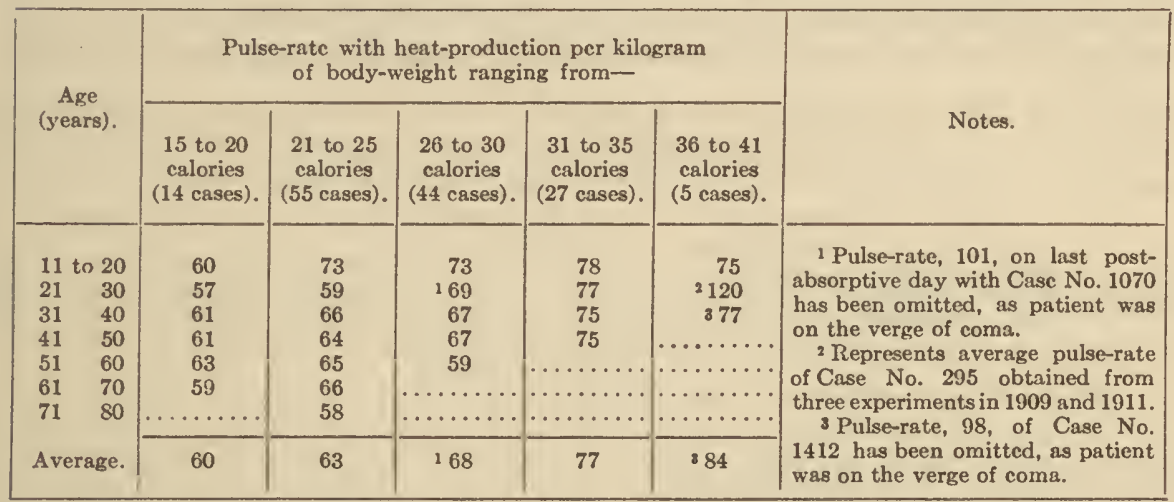

\section{Variations in Body-weight and Their Relation to Calculations of the Metabolism During Observation.}

The weights of the patients were taken before each observation of the metabolism and computed to naked weights. When the actual weight of the clothing was unknown, usually $2.5 \mathrm{~kg}$. were allowed for the clothes of women and $4.5 \mathrm{~kg}$. for the clothes of men.

During a series of observations with a single individual, the variations in weight were considerable. Not infrequently these were due in large measure to the increase or decrease of water in the body which was often demonstrated by the presence of edema. As a result, conclusions based upon the metabolism of diabetics are especially liable to considerable error. This is evident from the data for certain diabetics given below.

\section{EDEMA AND CALCULATIONS OF METABOLISM.}

Case No. 764, a man 29 years of age, weighed 66 kilograms on September 22, 1914, and 70.4 kilograms on September 25, 1914. During the first four days of this period the acidosis was moderate and in the remaining days mild. In the first period the volume of urine was 2,500 to 3,000 c. c. and in the latter, 1,000 to $1,500 \mathrm{c}$. c. The marked variations in the carbohydrate in the diet and the carbohydrate balance go far toward explaining the changes in weight. Presumably there was little or no gain in actual body-tissue during the four days cited, yet if these body-weights are used to find the standard metabolism, the predicted metabolism for September 22 would be 1,669 calories and for September 25, 1,730 calories, or an increase of 61 calories. 
The metabolism actually found on September 22 was 1,672 calories; on September 25 it was 1,598 calories, or a decrease of 74 calories. (See table 28). The corresponding variations from the standard metabolism for the two days would thus be 0 and -8 per cent, respectively. On September 21 the body-weight of this man was $65.1 \mathrm{~kg}$., which was typical of his bodyweight on September 15 to 20 , inclusive, the five days immediately preceding the sudden gain in weight. If the body-weight of Case No. 764 on September 21 be considered as his true body-weight on September 22 and 25, and used in computing the predicted metabolism for those days, it would be found that the determined metabolism would vary from standard +1 per cent on September 22 and -4 per cent on September 25, instead of 0 and -8 per cent when the actual, though misleading, weights for the day were used.

TABLE 28.-Variation in body-weight and metabolism of Case No. 764 within a period of 10 days.

[Male; age 29 years; height $178 \mathrm{~cm}$; severity moderate.]

\begin{tabular}{|c|c|c|c|c|c|c|c|c|c|c|}
\hline \multirow{2}{*}{ Date (1914). } & \multirow{2}{*}{$\begin{array}{l}\text { Body- } \\
\text { weight } \\
\text { naked. }\end{array}$} & \multirow{2}{*}{$\begin{array}{l}\text { Respi- } \\
\text { ratory } \\
\text { quotient. }\end{array}$} & \multicolumn{2}{|c|}{$\begin{array}{l}\text { Heat-output } \\
\text { per } 24 \text { hours. }\end{array}$} & \multicolumn{2}{|c|}{$\begin{array}{c}\text { Variation from } \\
\text { standard (H. and B.). }\end{array}$} & \multirow{2}{*}{$\begin{array}{c}\text { Average } \\
\text { pulse- } \\
\text { rate. }\end{array}$} & \multirow{2}{*}{$\begin{array}{l}\text { Urinary } \\
\text { nitrogen } \\
\text { per } 24 \\
\text { hours. }\end{array}$} & \multirow{2}{*}{$\begin{array}{l}\text { Carbo- } \\
\text { hydrate } \\
\text { in } \\
\text { diet. }\end{array}$} & \multirow{2}{*}{$\begin{array}{l}\text { Carbo- } \\
\text { hydrate } \\
\text { balance. }\end{array}$} \\
\hline & & & $\begin{array}{l}\text { Deter- } \\
\text { mined. }\end{array}$ & $\begin{array}{c}\text { Pre- } \\
\text { dicted. }\end{array}$ & $\begin{array}{c}\text { By use of } \\
\text { weight for } \\
\text { the day. }\end{array}$ & $\begin{array}{l}\text { By use of } \\
\text { weight for } \\
\text { Sept. } 21 \text {. }\end{array}$ & & & & \\
\hline Sept. 15-16 & $\begin{array}{l}k g . \\
64.5\end{array}$ & 10.68 & $\begin{array}{l}\text { cal. } \\
11,775\end{array}$ & $\begin{array}{c}\text { cal. } \\
1,648\end{array}$ & $\begin{array}{l}\text { p. } \text { ct. } \\
+8\end{array}$ & $\begin{array}{c}\text { p. ct. } \\
\ldots \ldots \ldots\end{array}$ & 72 & $\begin{array}{l}g m . \\
8.8\end{array}$ & $\begin{array}{l}g m . \\
125\end{array}$ & $\begin{array}{l}\text { gm. } \\
+\quad 15\end{array}$ \\
\hline Sept. 16-17 & 64.9 & $\ldots . . .$. & $\ldots \ldots \ldots$ & $\ldots \ldots \ldots$ & $\ldots \ldots$ & $\ldots \ldots \ldots$ & $\ldots .$. & $\ldots \ldots$ & 115 & +15 \\
\hline Sept. $17-18$ & 65.3 & $\ldots \ldots \ldots$ & & $\ldots \ldots \ldots$ & $\ldots$ & $\ldots \ldots$ & $\cdots$ & 9.1 & 100 & \\
\hline Sept. 18-19 & 64.9 & 1.80 & 11,735 & 1,654 & +5 & & 65 & 10.2 & 95 & +20 \\
\hline Sept. $21-22$ & 65.1 & 1.84 & 11,690 & 1,657 & +2 & +2 & 63 & 27.1 & 810 & -10 \\
\hline Sept. 22-23 & 66.0 & 1.72 & 11,672 & 1,669 & 0 & +1 & 60 & 5.2 & 1165 & +110 \\
\hline Sept. 23-24 & 69.0 & .73 & 1,650 & 1,710 & -4 & 0 & 54 & 4.2 & 1165 & +110 \\
\hline Sept. $24-25$ & 69.3 & .78 & 1,678 & 1,714 & -2 & +1 & 54 & 4.2 & $\$ 10$ & -5 \\
\hline Sept. $25-26$ & 70.4 & .77 & 1,598 & 1,730 & -8 & -4 & 52 & 4.1 & 75 & +55 \\
\hline
\end{tabular}

1 Measured in single 15-minute periods.

2 The urinary nitrogen determined for the preceding 24 hours was 8.2 grams.

${ }^{3}$ Vegetable day. 4 Oatmeal day.

The remarkable change in weight in this case can be explained by the interpolation of two oatmeal days, preceded by a vegetable day, and by the absence of control of salt in the diet. The influence of sodium bicarbonate can be disregarded, as 12 grams daily were administered from September 11 to 25 , inclusive.

The pulse-rate of Case No. 764 probably shows the trend of metabolism with far more accuracy than do the variations of the determined metabolism from the normal standard. From table 28 it will be seen that the pulse-rate decreased consistently from 72 on September 15 to 52 on September 25. The general trend of the determined heat-output corresponds closely with the course of the pulse-rate, but when the daily weights are used in computing the standard metabolism the variations from standard on September 15 and 25 are found to differ algebraically 16 per cent. On the other hand, when the daily weight is used in computing the standard metabolism of September 15 and the body-weight on September 21 is assumed to be the correct bodyweight for September 25 and used for computing the standard metabolism for that day, the variations from standard differ but 12 per cent. 
Another illustration follows of a considerable change in weight, which in this case was apparently due to the retention of sodium chloride. Case No. 1012 , a girl of 16 years, weighed $26.3 \mathrm{~kg}$. on September $22,1917,33.2 \mathrm{~kg}$. on October 2, on which date salt was excluded from the diet, and upon October 25 her weight had again fallen to $26.3 \mathrm{~kg}$., at which point it remained, save for a variation of less than $1 \mathrm{~kg}$., for the next two months. Undoubtedly, however, even this weight was abnormally high because of a certain amount of edema. The transitory gain in weight in early October was obviously due to edema. This gain represented an increase in weight of 26 per cent. Using the daily weight in calculating the metabolism for such a period is therefore unwise, but if these actual body-weights are employed for the period from October 9 to December 1 , the variation in the metabolism from standard would range between +7 and +31 per cent. (See table 29.) If the weight of September 22 (26.3 kg.) is accepted as the correct weight for the whole period, the metabolism, oddly enough, would vary in just the reverse manner, i. e., from +31 to +7 per cent.

TABLE 29.-Variations from standard metabolism of Case No.

1012, using different body-weights as basis for calculations. •

\begin{tabular}{|c|c|c|c|c|c|c|}
\hline \multirow{3}{*}{$\begin{array}{c}\text { Date } \\
\text { (1917). }\end{array}$} & \multirow{3}{*}{$\begin{array}{l}\text { Body- } \\
\text { weight, } \\
\text { naked. }\end{array}$} & \multicolumn{4}{|c|}{ Variations of metabolism from standard. ${ }^{1}$} & \multirow{3}{*}{$\begin{array}{l}\text { Pulse- } \\
\text { rate. }\end{array}$} \\
\hline & & \multirow{2}{*}{$\begin{array}{l}\text { Using } \\
\text { body- } \\
\text { weight } \\
\text { for day. }\end{array}$} & \multirow{2}{*}{$\begin{array}{l}\text { Using } \\
\text { body- } \\
\text { weight of } \\
\text { Sept. } 22 \\
\text { (26.3 kg.) }\end{array}$} & \multicolumn{2}{|c|}{$\begin{array}{l}\text { Using calculated } \\
\text { body-weights for } \\
\text { Oct. } 9 .\end{array}$} & \\
\hline & & & & $24.6 \mathrm{~kg}$. & $25.5 \mathrm{~kg}$. & \\
\hline \multirow{3}{*}{$\begin{array}{l}\text { Oct. } \\
\\
1 \\
2\end{array}$} & $k g$. & p. ct. & p. ct. & p. ct. & p. ct. & \\
\hline & $\begin{array}{l}32.2 \\
29.8\end{array}$ & $\begin{array}{l}+7 \\
+13\end{array}$ & $\begin{array}{l}+31 \\
+28\end{array}$ & $\begin{array}{l}+40 \\
+37\end{array}$ & $\begin{array}{l}+35 \\
+32\end{array}$ & $\begin{array}{l}62 \\
64\end{array}$ \\
\hline & 27.0 & $\begin{array}{l}1 \\
+22\end{array}$ & +25 & $\begin{array}{r}+33 \\
\end{array}$ & $\begin{array}{r}+29 \\
\end{array}$ & 64 \\
\hline 29 & 25.7 & +31 & +28 & $\begin{array}{l}+37 \\
\end{array}$ & $\begin{array}{l}+32 \\
\end{array}$ & 69 \\
\hline \multirow{3}{*}{ Nov. 8} & 25.7 & +18 & +15 & +23 & $\begin{array}{r}+19 \\
\end{array}$ & \\
\hline & 26.1 & +21 & +20 & +28 & +24 & 69 \\
\hline & 26.2 & +8 & +7 & +15 & +11 & 56 \\
\hline Dec. 1 & 25.7 & +15 & +13 & +21 & +16 & 65 \\
\hline
\end{tabular}

1 The Girl Scout group was used for comparison with this patient, as Case No. 1012 was but 16 years old.

The assumption that the true weight on October 9 was even as great as that upon September 22 is, however, not explainable by the diet. Between September 22 and October 9 her diet contained 5,410 calories and of this quantity the equivalent of 464 calories appeared as sugar in the urine, leaving a net intake of 4,946 calories. As the basal metabolism at the end of this period was 778 calories per 24 hours, we may conclude that this is representative of her daily basal metabolism for the preceding 17 days, so that the total metabolism for basal needs during this period would be 13,226 calories. Deducting from this total her net intake of 4,946 calories in the food ingested during the same period, we have a balance of 8,280 calories, representing 63 per cent of her metabolism for each 24 hours which was provided by her own 
body-tissue. In reality, considerably more calories were supplied from body material, because throughout much of the day the patient was obviously using more energy than was required for basal needs, but no estimate is here made for this additional requirement. Indeed, Freda (Case No. 1012) was unusually active for a patient with undernutrition. Even when the basal requirement alone is considered, however, it is difficult to determine the equivalent in body-weight of the 63 per cent of the basal metabolism $(8,280$ calories) supplied from body material, but the calculation is here attempted.

\section{CALORIC VALUE OF A KILOGRAM OF BODY-WEIGHT AND HYPOTHETICAL ESTIMATIONS CONNECTED THEREWITH.}

L., the Nutrition Laboratory subject, ${ }^{a}$ in the course of a 31-day fast, lost $13.2 \mathrm{~kg}$., or an average of 0.70 per cent of his original body-weight each day. Each kilogram lost represents a metabolism of 3,258 calories, if the estimated total metabolism of each day of L.'s fast is used for the computation. ${ }^{b}$ If the first four days of the fast are excluded, when the loss was somewhat rapid, and the remaining 27 days, when the loss was more gradual, are employed for the calculation, each kilogram of body material lost would represent 3,766 calories, and the average loss of body-weight each day based upon the weight of the morning of the fifth day would be 0.62 per cent.

Using the figure 0.62 per cent for the daily loss of Case No. 1012 , in 17 days she would have lost 10.5 per cent of her body-weight, provided she had been wholly without food. Only 63 per cent of her basal metabolism, however, came from body-tissue, and consequently the theoretical percentage loss in weight during this period was 63 per cent of 10.5, or 6.6 per cent of her original body-weight of $26.3 \mathrm{~kg}$. on September 22 . This would be $1.7 \mathrm{~kg}$. and therefore a more exact figure to use for body-weight in estimating her metabolism on October 9 perhaps would be 26.3 minus 1.7, or $24.6 \mathrm{~kg}$. Accordingly, this calculated body-weight for October 9 is also used for computing her metabolism from October 9 to December 1, and the results recorded in table 29.

By employing this new figure for body-weight, namely, $24.6 \mathrm{~kg}$., it appears that the metabolism on October 9, 1917, varied +40 per cent from standard as compared with +7 per cent if the actual weight is taken, and +31 per cent if we use the weight on September 22, when the edema had presumably not appeared. Here, therefore, is a difference of 33 per cent in computing the variation from standard metabolism for one day, according to whether the recorded weight of the patient is taken or the calculated true weight independent of edema. What effect edema has upon the metabolism is unknown, but its influence certainly could not produce a variation of 33 per cent.

Still another method of computing the probable weight of this subject on October 9 is found in the observations upon Squad A of the Y. M. C. A. College students in Springfield. Eleven men of this squad lost on the average 9 per cent of their initial body-weight between September 30 and approximately November 21, 1917, while on a reduced diet. Theoretically the rate of loss in body-weight of these subjects seems applicable to the data of Case

a Benedict, Carnegie Inst. Wash. Pub. No. 203, 1915, p. 80.

b Benedict, loc. cit., p. 403. 
No. 1012, who was undergoing treatment by undernutrition. Since the loss of the Springfield students was 9 per cent during the course of 52 days, it can be assumed that the loss of Case No. 1012 during the 17 days between September 22 and October 9 would be 2.9 per cent of her weight $(26.3 \mathrm{~kg}$.) on September 22 , or $0.8 \mathrm{~kg}$. Computed on this basis her weight on October 9 would therefore be $25.5 \mathrm{~kg}$. If this weight is used as the correct weight from October 9 to December 1, instead of $26.3 \mathrm{~kg}$. (the weight on September 22) the variation in metabolism from the Girl Scout standard becomes, on October 9 and December $1,+35$ and +16 per cent, respectively.

The above calculations indicate how necessary it is to base conclusions as to the metabolism of diabetics upon a large series of observations and preferably not upon one case but upon several cases, and especially not upon those derived from one experiment with a single case - a principle which this Laboratory has long held to be fundamental. But there is another lesson which is likewise important, namely, that in any metabolism experiment the aim should be to keep all factors constant save the one variable which leads to the investigation. Here oatmeal and vegetable days and the ingestion of varying quantities of salt led to confusion. Unfortunately, far too often in clinical work, as in this series of experiments, the desiderative cited can not be attained.

\section{EFFECT OF SUDDEN CHANGE IN BODY-WEIGHT ON CALCULATION OF} METABOLISM.

When the loss in weight of normal individuals is gradual, the sequence of changes in metabolism is not only consistent, but remains slight on successive days. This was exemplified in the falling trend in metabolism which occurred with a series of normal cases, studied under the auspices of the Nutrition Laboratory while they were undergoing a moderate reduction in weight during a period of three months, ${ }^{a}$ and also in the case of the subject L., previously cited, who never failed to lose daily in the 31 days of his fast. (See table 59, page 128.)

Of the diabetics studied at the Nutrition Laboratory, 15 cases showed marked losses or gains in weight within a period of nine days or less. To study the effect upon the metabolism of these sudden changes, the losses and gains of these diabetics are presented in two series in table 30 , the first series showing ten instances of sudden gains in weight, and the second a like number of sudden losses. The data include the number of days intervening between the first and last records of the period, the percentage gain or loss in weight, the basal metabolism upon both days, the comparison of the metabolism on the first day with the standard metabolism, also a comparison of the metabolism on the last day with the standard metabolism as computed (1) by using the actual weight for the day and (2) by using the body-weight on the first day.

With the first series of ten cases, there was, during an average period of six days, an average change in weight from $50.8 \mathrm{~kg}$. to $54.3 \mathrm{~kg}$., or 7 per cent. The averages for the heat produced per 24 hours on the two days at the beginning and end of this period are almost identical, i. e., 1,249 and 1,242 calories, respectively. If the actual weights recorded at the beginning and end of the periods of change are used for the calculation of the standard metabolism,

\footnotetext{
- Benedict, Miles, Roth, and Smith, Carnegie Inst. Wash. Pub. No.280, 1919, p. 688, fig. 124.
} 
it will be seen that the average variation from standard for the first day in the comparison was -10 per cent, and for the last day was -14 per cent. When the weights of the first day are used for the calculation of the standard metabolism on the last day, the variation is found to be -11 per cent. The difference between the average variations for these two days is not very striking, but if one looks at the series in detail, it will be found that far greater variations have occurred which were obliterated in averaging. Thus, com-

TABLE 30-Marked changes in body-weight of diabetics during 1 to 9 days, with variations of metabolism from normal standard.

\begin{tabular}{|c|c|c|c|c|c|c|c|c|c|c|c|c|}
\hline \multirow{3}{*}{$\begin{array}{l}\text { Case } \\
\text { No. }\end{array}$} & \multirow[b]{3}{*}{ Age. } & \multirow[b]{3}{*}{ Height. } & \multicolumn{2}{|c|}{ Period of change in weight. } & \multicolumn{2}{|c|}{$\begin{array}{c}\text { Body-weight } \\
\text { naked. }\end{array}$} & \multirow{3}{*}{ 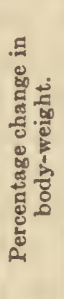 } & \multicolumn{2}{|c|}{$\begin{array}{l}\text { Heat produced } \\
\text { per } 24 \text { hours. }\end{array}$} & \multirow{2}{*}{\multicolumn{3}{|c|}{$\begin{array}{c}\begin{array}{c}\text { Variation from } \\
\text { normal standard. }\end{array} \\
\text { Last day. }\end{array}$}} \\
\hline & & & & & & & & & & & & \\
\hline & & & Dates. & $\begin{array}{l}\text { Dura- } \\
\text { tion. }\end{array}$ & $\begin{array}{l}\text { First } \\
\text { day. }\end{array}$ & $\begin{array}{l}\text { Last } \\
\text { day. }\end{array}$ & & $\begin{array}{l}\text { First } \\
\text { day. }\end{array}$ & $\begin{array}{l}\text { Last } \\
\text { day. }\end{array}$ & $\begin{array}{l}\text { First } \\
\text { day. }\end{array}$ & 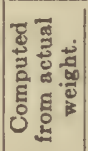 & 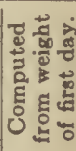 \\
\hline $\begin{array}{r}\text { Gains: } \\
319 \\
610 \\
764 \\
786 \\
821 \\
966 \\
1005 \\
1025 \\
1160 \\
1233\end{array}$ & \begin{tabular}{|c|} 
yrs. \\
31 \\
56 \\
29 \\
41 \\
25 \\
39 \\
35 \\
22 \\
26 \\
27
\end{tabular} & $\begin{array}{l}\mathrm{cm} . \\
173 \\
166 \\
178 \\
178 \\
168 \\
181 \\
152 \\
154 \\
180 \\
170\end{array}$ & $\begin{array}{lr}\text { Oct. } \quad \text { 1-Oct. } 5,1909 \\
\text { Apr. 5-Apr. 12, } 1917 \\
\text { Sept. 22-Sept. 25, } 1914 \\
\text { June 13-June 20, } 1916 \\
\text { Mar. 7-Mar. 13, } 1916 \\
\text { Jan. 8-Jan. 17, } 1916 \\
\text { Mar. 6-Mar. 11, } 1916 \\
\text { Apr. 17-Apr. 22, } 1916 \\
\text { Nov. 9-Nov. 14, } 1916 \\
\text { Feb. 26-Mar. 5, } 1917\end{array}$ & $\begin{array}{c}\text { days. } \\
4 \\
7 \\
3 \\
7 \\
6 \\
9 \\
5 \\
5 \\
5 \\
7\end{array}$ & $\begin{array}{l}\text { kg. } \\
48 .(1 \\
50.4 \\
66.0 \\
49.6 \\
54.1 \\
52.1 \\
33.6 \\
40.8 \\
65.5 \\
48.3\end{array}$ & $\begin{array}{c}k g . \\
50.0 \\
52.6 \\
70.4 \\
54.8 \\
56.6 \\
58.6 \\
36.0 \\
43.3 \\
69.1 \\
51.3\end{array}$ & $\begin{array}{l}+4 \\
+4 \\
+7 \\
+10 \\
+5 \\
+12 \\
+7 \\
+6 \\
+5 \\
+6\end{array}$ & $\begin{array}{r}\text { cal. } \\
1,440 \\
1,109 \\
1,686 \\
1,300 \\
1,123 \\
1,483 \\
936 \\
994 \\
1,406 \\
1,013\end{array}$ & $\begin{array}{r}\text { cal. } \\
1,411 \\
1,152 \\
1,590 \\
1,109 \\
1,138 \\
1,325 \\
989 \\
917 \\
1,771 \\
1,022\end{array}$ & $\begin{array}{l}p . c t . \\
+4 \\
-6 \\
+1 \\
-5 \\
-24 \\
+4 \\
-14 \\
-19 \\
-17 \\
-28\end{array}$ & $\begin{array}{r}p . c t . \\
0 \\
-4 \\
-8 \\
-23 \\
-25 \\
-12 \\
-11 \\
-27 \\
+2 \\
-29\end{array}$ & $\begin{array}{l}\text { p. ct. } \\
+2 \\
-3 \\
-5 \\
-19 \\
-23 \\
-7 \\
-10 \\
-25 \\
+5 \\
-27\end{array}$ \\
\hline Avg ... & 33 & 170 & $\ldots \ldots \ldots \ldots \ldots \ldots$ & 6 & 50.8 & 54.3 & +7 & 1,249 & 1,242 & -10 & -14 & -11 \\
\hline $\begin{array}{r}\text { Losses: } \\
610 \\
765 \\
786 \\
806 \\
821 \\
1011 \\
1049 \\
1085 \\
1160 \\
1233\end{array}$ & $\begin{array}{l}57 \\
23 \\
39 \\
39 \\
25 \\
29 \\
28 \\
35 \\
26 \\
27\end{array}$ & $\begin{array}{l}166 \\
170 \\
178 \\
176 \\
168 \\
161 \\
167 \\
165 \\
180 \\
170\end{array}$ & $\begin{array}{l}\text { Oct. 3-Oct. } 4,1917 \\
\text { Feb. 9-Feb. } 18,1916 \\
\text { Nov. 20-Nov. 23, } 1914 \\
\text { Dec. 19-Dec. 21, } 1914 \\
\text { Mar. 1-Mar. 7, } 1916 \\
\text { Nov. 23-Nov. } 30,1917 \\
\text { May 19-May 27, } 1916 \\
\text { Oct. 11-Oct. 19, } 1916 \\
\text { Nov. 4-Nov. 7, } 1916 \\
\text { Mar. 19-Mar. 26, } 1917\end{array}$ & $\begin{array}{l}1 \\
9 \\
3 \\
2 \\
6 \\
7 \\
8 \\
8 \\
3 \\
7\end{array}$ & $\begin{array}{l}49.2 \\
41.8 \\
56.8 \\
64.8 \\
56.7 \\
27.6 \\
44.0 \\
34.2 \\
68.6 \\
50.1\end{array}$ & $\begin{array}{l}47.1 \\
38.0 \\
54.0 \\
61.9 \\
54.1 \\
26.0 \\
41.3 \\
30.4 \\
66.2 \\
47.2\end{array}$ & $\begin{array}{l}-4 \\
-9 \\
-5 \\
-4 \\
-5 \\
-6 \\
-6 \\
-11 \\
-3 \\
-6\end{array}$ & $\begin{array}{r}1,037 \\
917 \\
1,309 \\
1,775 \\
1,166 \\
680 \\
1,058 \\
679 \\
1,541 \\
1,088\end{array}$ & $\begin{array}{r}1,066 \\
950 \\
1,210 \\
1,613 \\
1,123 \\
686 \\
1,056 \\
707 \\
1,483 \\
1,013\end{array}$ & $\begin{array}{l}-11 \\
-27 \\
-11 \\
+13 \\
-23 \\
-37 \\
-20 \\
-40 \\
-11 \\
-24\end{array}$ & $\begin{array}{l}-7 \\
-23 \\
-16 \\
+5 \\
-24 \\
-36 \\
-18 \\
-35 \\
-13 \\
-27\end{array}$ & $\begin{array}{l}-9 \\
-25 \\
-18 \\
+2 \\
-26 \\
-37 \\
-20 \\
-37 \\
-15 \\
-29\end{array}$ \\
\hline Avg... & 33 & 170 & & 5 & 49.4 & 46.6 & -6 & 1,125 & 1,091 & -19 & -19 & -21 \\
\hline
\end{tabular}

paring the values obtained by using the daily records of the body-weight, we find that Case No. 786 showed an algebraic variation of 18 per cent between the two days, Case No. 966 of 16 per cent, and Case No. 1160 of 19 per cent.

The second series gives 10 instances of losses in weight in an average period of five days from $49.4 \mathrm{~kg}$. to $46.6 \mathrm{~kg}$., or a loss of 6 per cent. The average amounts for the heat produced per 24 hours for the first and last days varied but slightly, namely, from 1,125 to 1,091 calories. Using the actual weights on the first and last days of the period of change, the average variations from the standard metabolism were -19 per cent for both days; but if the weight 
of the first day is used as a basis of the calculation for the last day, the average metabolism on that day would vary -21 per cent from the standard. Unlike the first series discussed, i. e., those showing gains in weight, it may be seen that this approach to uniformity in the averages is reflected by the individual cases, although algebraic differences as great as 8 per cent occurred. It will be noted that Case No. 786 appears in table 30 under both gains and losses in weight. With a gain in weight the loss in the metabolism from beginning to end of the period was 18 per cent on the basis of the normal standard, but when body-weight was lost, the decrease in the metabolism on the same basis was but 5 per cent, the former figure undoubtedly being too high and the latter too low.

With 9 of the patients showing sudden gains in weight, there were complete records of the pulse-rate at the beginning and end of the period of observation. These individuals presented an average fall from 60 to 55 beats per minute. At the same time the variation from standard decreased in the majority of instances.

With six of the 10 cases showing sudden losses of weight, the average pulse-rate was 61 beats for both days. This was analogous to the behaviour of the metabolism.

Acidosis decreased or remained constant with all of the patients who gained weight, but when the patients lost weight, acidosis remained constant in 6 instances, decreased in 2 instances, and increased in 2 instances. Gain in weight in association with edema has long been known as a favorable sign in the presence of severe acidosis.

For the patients gaining in weight the average of the combined nitrogen excretions on the preceding and experimental days was 6.8 grams per 24 hours on the first day and 7.5 grams for the last observation. For the cases losing weight the average of the nitrogen excretions on the preceding and experimental days was 8.3 grams for the first day and 6.7 grams for the last day. Thus, these figures, so far as they can be considered indicative of the diet, show a partial reason for gain or loss in weight.

The average carbohydrate balance for the patients with sudden gains in weight was +35 grams on the first day and +20 grams on the last day. For the patients with sudden loss in weight the carbohydrate balances were +40 grams and +25 grams, respectively, for the first and last days. Such small alterations in the carbohydrate balance are therefore not of account so far as weight is concerned, even though they continue for several days.

The respiratory quotient usually remained remarkably constant, despite the gains or losses in weight, the average changing only from 0.77 to 0.78 for the patients gaining weight, and from 0.80 to 0.79 for those losing weight.

From the above considerations it is safe to conclude that changes in weight of 2 or $3 \mathrm{~kg}$., even within as short periods of time as 6 days, are not of great influence upon the metabolism and can usually be disregarded. On the other hand, it is evident that the metabolism of individuals in groups of 10 each may disclose differences amounting to an average of 4 per cent on different days, and with individuals the differences may amount to 19 per cent. With these two groups of cases the changes in the metabolism were reflected in the pulse-rates. 


\section{Relation of Loss in Body-weight to Metabolism in Diabetes.}

As has already been shown in table 3 and on page 13, the loss in bodyweight of the diabetic patients from their maximum was considerable, most of this loss occurring before these individuals came under observation. As an indication of the effect which this loss of weight may have had upon the metabolism of the diabetics, information regarding the effect of similar marked losses in weight upon the metabolism of normal individuals would have significance. This might be expected to differ according to whether the loss in weight was rapid and in progress or, as in the case of the diabetics, slow, frequently extending over periods of years and months rather than of weeks.

In the section on pulse-rate and in the estimation of the caloric value of a kilogram of body-weight, reference has already been made to a group of young men (Y. M. C. A. students) studied by the Nutrition Laboratory, whose reduction in weight on a low diet during the course of four months amounted to approximately 10 per cent. ${ }^{a}$ Their total metabolism at the end of the period of study showed an average fall of 19 per cent, with an average loss in body-weight of 10.5 per cent. $^{b}$

Inasmuch as data are lacking for a series of normal individuals with losses in weight as considerable as those found with the diabetics, the computed standard metabolism of a group of diabetics at the time of their maximum weight has been compared in table 31 with the metabolism actually observed after marked losses in weight. The results obtained have then been compared with the changes in metabolism computed for a group of normal individuals with an assumed loss in weight equal to that of the group of diabetics.

For this purpose, 20 male and female diabetics have been selected because of extreme loss of body-weight from the series of patients observed by the Nutrition Laboratory, and their metabolism has been computed for the period of their reported maximum weights (see table 3, p. 8) by using the Harris and Benedict formula and their ages and body-weights at that time. The average maximum weight of all these patients was $73 \mathrm{~kg}$., the average age 34 years, and the average predicted metabolism 1,599 calories. These same individuals, at the period of minimum weight, on an average of five years later, showed an average loss in weight of 35 per cent from the maximum. Their observed metabolism averaged 1,241 calories, or a fall of but 22 per cent; that is, for each 1 per cent loss in weight there was a loss of 0.63 per cent in the metabolism.

This percentage loss in metabolism is in contrast to the group of Y. M. C. A. students just referred to, who lost but 10.5 per cent of their body-weight with a fall in metabolism of 19 per cent, or for 1 per cent loss in weight, there was a percentage loss in the metabolism of 1.8 per cent. One might conclude that this difference was due in part to the fact that the diabetics at maximum weight were more above normal weight than the students. This is, in part, true. The maximum weights of the twenty diabetics included in this particular comparison ranged from 88 per cent above to 16 per cent below normal standard, and the average was 18 per cent above normal, while the

\footnotetext{
a See pp. 33 and 68. See, also, Benedict, Miles, Roth, and Smith, Carnegie Inst. Wash. Pub. No. 280, 1919.

${ }^{b}$ Benedict, Miles, Roth, and Smith, $i b i d .$, pp. 513 and 228.
} 
initial weights of the eleven Y. M. C. A. students here cited varied from 16 per cent above to 12 per cent below the normal standard, the average being 5 per cent above standard. It is much more probable that the difference may be explained by the rapid loss in weight of the normals and the quick adaptability of the healthy body to the smaller caloric intake by a great curtailment of metabolism.

TABLE 31.-Comparison of basal metabolism of 20 diabetics at maximum and minimum bodyweights with that of similar normal individuals with like variation of body-weight.

\begin{tabular}{|c|c|c|c|c|c|c|c|c|c|c|c|c|c|c|}
\hline \multicolumn{8}{|c|}{ Diabetics. } & \multicolumn{7}{|c|}{ Normals. 1} \\
\hline \multirow[b]{2}{*}{$\begin{array}{l}\text { Case } \\
\text { No. } \\
\text { and } \\
\text { sex. }\end{array}$} & \multirow[b]{2}{*}{ 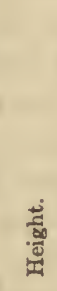 } & \multicolumn{3}{|c|}{$\begin{array}{c}\text { Period of } \\
\text { maximum weight. }\end{array}$} & \multicolumn{3}{|c|}{$\begin{array}{l}\text { Period of } \\
\text { minimum weight. }\end{array}$} & \multirow[b]{2}{*}{$\begin{array}{l}\text { Subject } \\
\text { No. } \\
\text { and } \\
\text { sex. }\end{array}$} & \multirow[b]{2}{*}{ 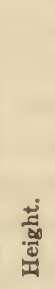 } & \multicolumn{3}{|c|}{$\begin{array}{l}\text { Normal } \\
\text { weight. }\end{array}$} & \multicolumn{2}{|c|}{$\begin{array}{c}\text { Reduced } \\
\text { weight. }\end{array}$} \\
\hline & & 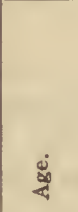 & 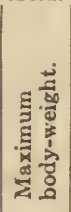 & 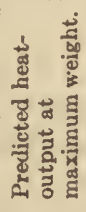 & $\Phi_{4}^{\infty}$ & 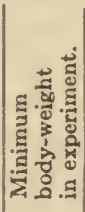 & 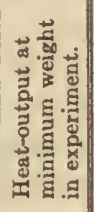 & & & \&ें & 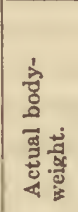 & 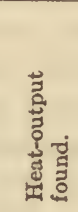 & 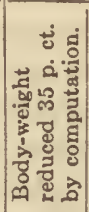 & 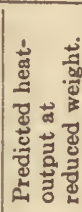 \\
\hline Males: & $\mathrm{cm}$. & years. & $k q$. & cal. & years. & $k o$. & cal. & Males: & $\mathrm{cm}$. & years. & $k g$. & cal. & $\mathrm{kg}$. & cal. \\
\hline 184 & 164 & 44 & 76 & 1.635 & 52 & 61.1 & 1,440 & 57 & 171 & 40 & 60.6 & 1,576 & 39.5 & 1,195 \\
\hline 201 & 176 & 22 & 81 & 1.912 & 23 & 58.2 & 1,872 & 56 & 165 & 23 & 60.8 & 1,460 & 39.4 & 1,278 \\
\hline 220 & 171 & 40 & 68 & 1,587 & 50 & 46.1 & 1,267 & 88 & 165 & 35 & 48.5 & 1,292 & 31.5 & 1,089 \\
\hline 246 & 166 & 29 & 74 & 1,719 & 30 & 54.9 & 1,670 & 38 & 169 & 23 & 73.7 & 1,526 & 47.9 & 1,415 \\
\hline 295 & 176 & 15 & 57 & 1,630 & 25 & 40.0 & 1,627 & 69 & 175 & 20 & 58.0 & 1,615 & 37.7 & 1,324 \\
\hline 549 & 164 & 38 & 65 & 1,524 & 40 & 50.9 & 1,526 & 47 & 173 & 22 & 65.1 & 1,543 & 42.4 & 1,367 \\
\hline 764 & 178 & 26 & 117 & 2,390 & 29 & 66.0 & 1,686 & 7 & 198 & 19 & 108.9 & 2,559 & 70.8 & 1,902 \\
\hline 1029 & 172 & 32 & 74 & 1,728 & 37 & 51.0 & 1,123 & 35 & 181 & 20 & 74.5 & 1,879 & 48.4 & 1,502 \\
\hline 1069 & 164 & 20 & 57 & 1,536 & 25 & 33.7 & 1.050 & 72 & 167 & 20 & 57.2 & 1,616 & 37.2 & 1.278 \\
\hline 1233 & 170 & 26 & 69 & 1.690 & 27 & 47.2 & 1,013 & 95 & 178 & 24 & 69.7 & 1,980 & 45.3 & 1,417 \\
\hline Females: & & & & & & & & Females: & & & & & & \\
\hline 263 & 162 & 32 & 83 & 1,599 & 41 & 60.9 & 1,310 & 3 & 161 & 21 & 88.3 & 1,591 & 57.4 & 1,403 \\
\hline 610 & 166 & 37 & 120 & 1,937 & 57 & 47.1 & 1,066 & 1 & 165 & 44 & 93.6 & 1,765 & 60.8 & 1,336 \\
\hline 765 & 170 & 21 & 54 & 1,388 & 23 & 38.0 & 950 & 33 & 168 & 25 & 52.4 & 1,321 & 34.1 & 1,175 \\
\hline 924 & 158 & 44 & 59 & 1,306 & 48 & 42.3 & 1,166 & 14 & 159 & 38 & 59.5 & 1,187 & 38.8 & 1,142 \\
\hline 979 & 163 & 33 & 88 & 1,644 & 50 & 57.1 & 1,259 & 2 & 164 & 21 & 90.2 & 1,756 & 58.6 & 1,421 \\
\hline 996 & 149 & 63 & 73 & 1,334 & 64 & 44.7 & 1,181 & 103 & 164 & 62 & 46.6 & 1,119 & 30.3 & 958 \\
\hline 1011 & 161 & 25 & 54 & 1,353 & 29 & 26.0 & 686 & 30 & 160 & 26 & 53.8 & 1,215 & 35.0 & 1,164 \\
\hline 1041 & 160 & 58 & 73 & 1,378 & 59 & 50.8 & 1.249 & 4 & 157 & 42 & 80.1 & 1,606 & 52.1 & 1,247 \\
\hline 1066 & 157 & 33 & 45 & 1,221 & 42 & 31.2 & 965 & 58 & 159 & 25 & 45.0 & 1., 393 & 29.3 & 1,112 \\
\hline 1085 & 165 & 32 & 68 & 1,461 & 35 & 30.4 & 707 & 5 & 170 & 39 & 67.2 & 1,521 & 43.6 & 1,204 \\
\hline Av. M. and F. & 166 & 34 & 73 & 1,599 & 39 & 46.9 & 1,241 & ....... & 168 & 29 & 67.7 & 1,576 & 44.0 & 1,296 \\
\hline
\end{tabular}

${ }_{1}^{1}$ Selected from tables C and D, Harris and Benedict, Carnegie Inst. Wash. Pub. No. 279, 1919, pp. 40-47.

The twenty normals in table 31 , selected from the Harris and Benedict series, closely approximated the twenty diabetics at their maximum weights. The average weight of these twenty normals was $67.7 \mathrm{~kg}$., or 8 per cent above normal, the average age 29 years, and the average basal metabolism as determined was 1,576 calories. The weights of the normal individuals were then individually reduced 35 per cent to conform to the average loss of the diabetic series and their metabolism predicted for these calculated weights. This predicted metabolism was found to be, on the average, 1,296 calories, which represents a loss of 18 per cent. This figure is not far from the loss found for the diabetics with similar losses in weight, as well as that found for the 
Y. M. C. A. normals who lost but 10.5 per cent in weight, in contrast to the 35 per cent loss in weight of the diabetics and the computed 35 per cent loss of the normals. From table 31 it would appear, therefore, that either diabetics or normals, losing equal weights, would lose an equal per cent in metabolism. On the other hand, when the actual values of the metabolism obtained with the Y. M. C. A. students at the two weightlevels are compared with each other, and these losses compared with those found with the diabeties and normals on the predicted basis, an equivalent loss in metabolism is noted for the Y. M. C. A. students with less than one-third the loss in body-weight. Rapidity of loss in weight as above stated is one explanation and another is that with the students the loss of weight was still in progress, but with the diabetics it was completed.

The relation between metabolism and body-weight is brought out in another table which will be described in detail under the discussion of urinary nitrogen, metabolism, and body-weight. (See table 56, p. 121.) This table gives the computed percentage variation of these weights from normal (appearing usually as a minus quantity in the averages), and relates them to the metabolism as expressed by variation from standard. The values in the table are grouped into the two periods before and after June, 1914.

Prior to June, 1914, no relation is apparent between the variation of the metabolism from standard and the percentage variation of the body-weight from standard. After June, 1914, there is likewise no direct correspondence between the variation from standard metabolism and the variations from standard weights until the metabolism is less than 10 to 5 per cent above standard. Above this level there were but 12 experiments, variously distributed, and below it 216 experiments, which may in part account for the fact that below this point there is a very intimate connection. Thus, when the metabolism was 10 to 5 per cent above standard, the average variation of the weights of the patients from normal was -2 per cent. When the metabolism was 35 to 40 per cent below standard, the average variation from standard weight was the most subnormal in the series, namely, -48 per cent. Between the extremes mentioned, the table registers almost uniform alterations.

Table 56 shows, therefore, that after June, 1914, body-weight is related to metabolism as referred to the normal standard, but it also suggests a reason for this relationship, namely, that it is the percentage fall in bodyweight below standard which produces the fall in metabolism. The peculiar relationship of the urinary nitrogen to these factors will be treated later. (See p. 120.)

\section{Relation of Severity of Diabetes to Metabolism.}

The influence of the severity of the disease upon the metabolism of diabetic patients was noted in each of the preceding publications, but the paucity of data relating to mild cases prevented positive conclusions, although the opinion was expressed that the metabolism increased with the intensity of the disease. The distinction between severity and acidosis was not adequately appreciated in the earlier publications, but in the classification of the severity of cases in the present monograph (see p. 20), acidosis is con- 
sidered as only one of several factors and receives less emphasis than in the preceding reports. Consequently, the inferences to be drawn from data about to be presented relative to severity, and later to acidosis, should prove somewhat more reliable, though the difficulties in çlassification are still very considerable.

The relation of the degree of severity of the diabetes to the post-absorptive metabolism at the time when the various observations were made upon the patients is shown in table 32 . As heretofore, the experiments are classified according to whether they took place prior or subsequent to June, 1914. Before June, 1914, the mild cases showed a normal metabolism in the daily observations, the moderate cases a metabolism 14 per cent above normal,

TABLE 32.-Relation of severity of diabetes to basal metabolism before and after June, 1914. ${ }^{1}$

\begin{tabular}{|c|c|c|c|c|c|c|}
\hline \multirow{2}{*}{$\begin{array}{l}\text { Percentage } \\
\text { variation } \\
\text { from } \\
\text { standard } \\
\text { metabolism. }\end{array}$} & \multicolumn{3}{|c|}{$\begin{array}{l}\text { Daily observations } \\
\text { before June, } 1914 .\end{array}$} & \multicolumn{3}{|c|}{$\begin{array}{l}\text { Daily observations } \\
\text { after June, } 1914 .\end{array}$} \\
\hline & $\begin{array}{c}\text { Mild } \\
\text { diabetes } \\
\text { (6 days). }\end{array}$ & $\begin{array}{l}\text { Moderate } \\
\text { diabetes } \\
\text { (20 days). }\end{array}$ & $\begin{array}{c}\text { Severe } \\
\text { diabetes } \\
\text { (93 days). }\end{array}$ & $\begin{array}{c}\text { Mild } \\
\text { diabetes } \\
\text { (22 days). }\end{array}$ & $\begin{array}{c}\text { Moderate } \\
\text { diabetes } \\
\text { (72 days). }\end{array}$ & $\begin{array}{c}\text { Severe } \\
\text { diabetes } \\
\text { (185 days) }\end{array}$ \\
\hline 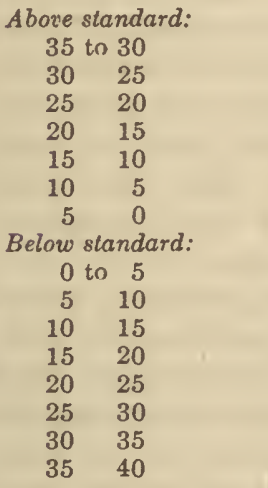 & 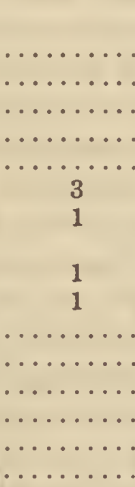 & 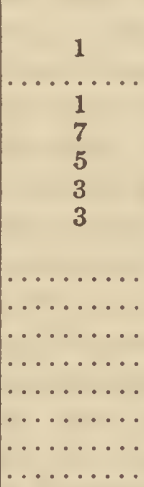 & 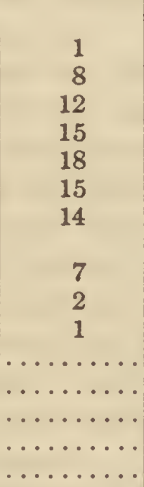 & 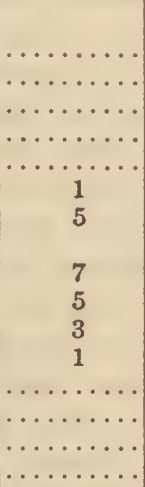 & 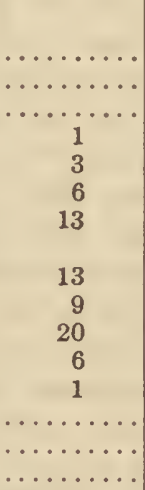 & $\begin{array}{r}2 \\
2 \\
\ldots \ldots \\
1 \\
6 \\
1 \\
12 \\
\\
25 \\
19 \\
22 \\
33 \\
34 \\
18 \\
6 \\
4\end{array}$ \\
\hline $\begin{array}{l}\text { Average all experi- } \\
\text { ments (p. ct.) }\end{array}$ & +4 & +14 & +12 & -4 & -5 & -13 \\
\hline
\end{tabular}

1 This table is based upon 106 cases, of whom 1 to 19 were in the several severity groups, and from 2 to 38 in the several metabolism groups.

and the severe cases a slightly less variation $(+12$ per cent). After June, 1914 , the metabolism in most of the daily observations with mild cases, and with moderate cases as well, was lower than standard, but the average in each group was still within the normal zone. The daily observations with the severe cases averaged 13 per cent below standard. In general, prior to June, 1914, the severer types of diabetes gave a higher metabolism than the mild, while subsequent to that date, on the contrary, the severest type of the disease exhibited a lower metabolism than the mild and moderate forms.

That the increasing severity of diabetes in and of itself will at one time raise the metabolism and at another lower it is inconceivable; for, as was 
brought out in discussing the relationship between the pulse-rate and severity (see p. 41), the force of severity can not act in opposite directions. It is, therefore, reasonable to conclude that one or more extraneous influences must have been present before and after June, 1914, to have brought this about. Inasmuch as the mild cases show the least and the severe cases the most variation in the metabolism, presumably the extraneous factors influenced the mild cases far less than they did the severe cases. In solving the problem, therefore, one would expect to get the greatest help from a study of cases of the severe type. Of such extraneous factors, four require commentdrugs, exercise, diet, and acidosis.

With the exception of sodium bicarbonate, drugs were never given to either group of patients. Even sodium bicarbonate was not used with these diabetics after September, 1915. So far as is known, there is no evidence that sodium bicarbonate exerts the slightest influence upon the metabolism in health. However, this would not exclude the possibility of such action in disease, especially in a disease like diabetes, because of the changed relations in the diabetic's acid-base equilibrium following the administration of an alkali. Subsequent discussion of the evidence bearing upon this question indicates that even in diabetes, the metabolism is not influenced by this alkali. (See p. 152.)

Exercise played no rôle, because the experiments were basal and exercise was not a part of the routine. Furthermore, there were no essential differences in the amount of exercise at other times of the day before and after June, 1914; in fact, in the later period, when the metabolism was lower, the exercise was fully as great, because the patients were urged more to take it. It is true that, on the whole, the mild and moderate cases took more exercise than the severe, but the conditions under which the experiments were conducted would tend to rule out any effect from exercise.

The change in the character of the diet is of far more importance in determining the cause of the change in the metabolism of these patients after June, 1914. The severe cases underwent strenuous overfeeding before June, 1914, and strenuous underfeeding after June, 1914, and the quantitative changes in the diet appear adequate to account for this phenomenon of changing metabolism. If this explanation is accepted, the metabolism of the mild and moderate cases is easily understood, inasmuch as the mild cases were subjected to less vigorous changes in diet, and yet these were distinct enough to produce a slight lowering of the metabolism in the observations after June, 1914. The moderate cases were likewise overfed prior to June, 1914, and the effect of this raised their metabolism to the level of the severe cases; after June, 1914, the moderate cases were underfed, but it would appear that the resultant benefit of underfeeding was so prompt that extreme underfeeding was unnecessary and their metabolism remained nearly normal. So far as the moderate cases of diabetes are concerned, therefore, this table may be considered as a support to the method of treatment of diabetes by undernutrition. The evidence is clear upon the effect of overfeeding and underfeeding the severe case. Each method of treatment was carried too far, but the underfed are living longer, largely due to their immunity from acidosis. The influence which may have been exerted by acidosis will be considered in the following section. (See p. 77.) 
By noting the number of experimental days under each degree of severity in table 32 , it will be seen that it was no chance coincidence that the mild cases presented a nearly normal metabolism, and that the metabolism of the moderate cases was above standard prior to June, 1914, and after that date was for the most part below standard, because the experiments were sufficiently numerous to support a general average. With the severe cases prior to June, 1914, there were but 10 days on which the metabolism was subnormal to 83 with an increased metabolism, whereas after that date, the relationship was 161 to 24 days.

The distribution in table 32 of the experimental days according to the percentage variations above and below standard for the different degrees of severity shows graphically the tendency to higher metabolism, as one passes from the mild and moderate types to the severe type of diabetes before June, 1914, and a corresponding change to a lower metabolism under similar conditions after June, 1914. There are but 23 experimental days with patients of the severe type which present such extremes in metabolism as more than 25 per cent above or more than 30 per cent below the standard, and 2 experimental days with moderate cases with an increase in metabolism above 20 per cent.

\section{Relation of Acidosis to Metabolism of Diabetics.}

Of the intrinsic causes which might affect the metabolism of the diabetic, none would appear to be more potent than acidosis, for acidosis is a complication of diabetes rather than a symptom. It may occur in all types of the disease and can easily be made extreme in a mild case, just as it can with a healthy individual. During the years that these experiments were in progress, acidosis was undoubtedly responsible for two-thirds of all the deaths from diabetes in the community and possibly for three-fourths of these deaths. Of the cases studied at the Nutrition Laboratory before June, 1914, 86 per cent of those who died later succumbed to coma, and of those studied from that date to the end of the research, December 5, 1917, 72 per cent of the deaths were due to coma. (See table 9, p. 23.)

TABLE 33.-Relation of acidosis to the metabolism as shown in approximately 400 daily observations upon 106 diabetics.

\begin{tabular}{|c|c|c|c|c|}
\hline 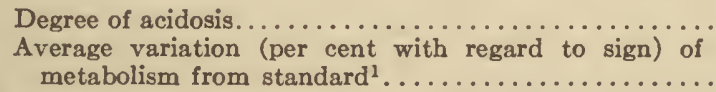 & $\begin{array}{r}0 \\
-9\end{array}$ & $\begin{array}{l}+ \\
-5\end{array}$ & $\begin{array}{l}++ \\
-5\end{array}$ & $\begin{array}{r}++ \\
+10\end{array}$ \\
\hline
\end{tabular}

1 The number of experimental days for the different degrees of acidosis were, in order, as follows: $110,83,145$, and 60 .

What effect has acidosis upon the metabolism of a diabetic? Is it responsible for the wide swing of the metabolic pendulum previously discussed? The data accumulated here are particularly appropriate for a study of these problems and should supply answers, for it is doubtful if ever again as many patients with severe acidosis will be available for study for such long periods as these have been, so largely have modern methods of treatment eliminated this complication. 
The relation of the acidosis to the total metabolism is exhibited in table 33 , in which the results of 398 daily observations upon 106 cases of diabetes are recorded. It indicates that with the development and increase of acidosis there is a general rise in the metabolism. Since this table has the limitations of all tables which combine the two epochs of overfeeding and underfeeding, the data should be further grouped according to whether they were secured before or after June, 1914. This is done in table 34, which is constructed to illustrate the transition from metabolism above standard to metabolism below standard which was found in the various experiments with different grades of acidosis before and after June, 1914.

TABLE 34.-Relation of acidosis to the basal metabolism of diabetic patients before and after June, 1914.

\begin{tabular}{|c|c|c|c|c|c|c|c|c|}
\hline \multirow{3}{*}{$\begin{array}{l}\text { Percentage } \\
\text { variations }{ }^{1} \\
\text { from } \\
\text { standard } \\
\text { metabolism. }\end{array}$} & \multicolumn{4}{|c|}{ Before June, 1914.} & \multicolumn{4}{|c|}{ After June, 1914.} \\
\hline & \multicolumn{4}{|c|}{ Variation $^{1}$ with acidosis. } & \multicolumn{4}{|c|}{ Variation ${ }^{1}$ with acidosis. } \\
\hline & $+t+$ & ++ & + & 0 & $+t+$ & $+t$ & + & 0 \\
\hline $\begin{array}{c}\text { Above standard: } \\
35 \text { to } 30\end{array}$ & $\begin{array}{l}\text { p. } c t . \\
+32\end{array}$ & p. ct. & p. ct. & p. ct. & $\begin{array}{l}\text { p. } c t . \\
+33\end{array}$ & p. ct. & p. ct. & p. ct. \\
\hline 25 & +29 & +27 & & & +28 & $\cdots$ & $\cdots$ & $\cdots$ \\
\hline 25 & +22 & +22 & +22 & +23 & & & & \\
\hline 20 & +18 & +18 & +16 & +17 & & +19 & +16 & \\
\hline 10 & +14 & +13 & +13 & +13 & & +12 & +12 & +12 \\
\hline 10 & +8 & +9 & +10 & +9 & $\because$ & +8 & +8 & +10 \\
\hline & +4 & +3 & +3 & +5 & +1 & + & +2 & +3 \\
\hline \multirow{2}{*}{ Below standard: } & & & & & & & & \\
\hline & -2 & -2 & -1 & -3 & & -2 & -3 & -3 \\
\hline $\begin{array}{l}10 \\
15\end{array}$ & ...... & -7 & ...... & -9 & -6 & -8 & -8 & -8 \\
\hline $\begin{array}{l}15 \\
20\end{array}$ & … & -12 & $\ldots$ & $\ldots$ & -13 & -14 & -12 & -13 \\
\hline $\begin{array}{l}20 \\
25\end{array}$ & $\cdots$ & ....... & ..... & ... & -18 & -18 & -18 & -18 \\
\hline 30 & & & & & -23 & $\begin{array}{l}-28 \\
-28\end{array}$ & -29 & -28 \\
\hline 35 & & & & & ....... & -32 & - & -33 \\
\hline $35 \quad 40$ & $\cdots$ & . & $\ldots \ldots$. & ...... & $\ldots \ldots \ldots$ & -38 & 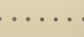 & -39 \\
\hline \multirow{2}{*}{$\begin{array}{l}\text { Av. }{ }^{1} \text { for all daily } \\
\text { observations } \\
\text { No. of experi- } \\
\text { mental days }\end{array}$} & +13 & +12 & +14 & +10 & +2 & -12 & -8 & -13 \\
\hline & 48 & 43 & 10 & 18 & 12 & 102 & 73 & 92 \\
\hline & & & & & & & & \\
\hline
\end{tabular}

1 With regard to sign.

Prior to June, 1914, acidosis was of frequent occurrence. Of the 119 experimental days included in table 34 for this period, there were but 18 on which no acidosis was found, or 15 per cent, and if we include also those with mild acidosis, there were but 28 days, or 24 per cent. After June, 1914, the patients were entirely without acidosis on 92 days, and including the days with mild acidosis raises this number to 165 , or 59 per cent of the 279 experimental days; on only 12 experimental days was the acidosis severe.

In the earlier period there was a tendency for the metabolism of the diabetic with acidosis to be higher than that of the diabetic without severe acidosis. 
Since June, 1914, acidosis has had less opportunity to exert an influence upon the metabolism. If acidosis stimulates the metabolism, it would be expected that the highest average metabolism encountered in cases of diabetes would occur when the highest acidosis was most frequent, i. e., in the period prior to June, 1914, especially as the additional stimulus of overfeeding was present. It would likewise be expected that the lowest metabolism would be found when acidosis was absent in the period after June, 1914, and the effects of undernutrition were also prominent. That this is the case is brought out in table 34, not only graphically from the general tendency of the figures, but actually, as may be seen by an examination of the average variations from standard metabolism recorded at the bottom of the table for each degree of acidosis before and after June, 1914.

\section{VARIATIONS IN SAME INDIVIDUAL OF ACIDOSIS AND METABOLISM.}

The relation between acidosis and metabolism would admit of more exact analysis if the metabolism of the same individual during different stages of acidosis could be determined. By this means the error introduced by the difficulty in classifying the acidosis would be lessened, because it is manifestly easier to decide upon the relative degree of acidosis for the same individual at two different periods than to compare the degree of acidosis in one patient with that of another.

For this reason, table 35 has been prepared. It consists of observations upon 12 patients studied before June, 1914, and 24 patients studied since June, 1914, whose metabolism was observed during at least two stages of acidosis in each instance. The table confirms the facts brought out in both tables 33 and 34. Prior to June, 1914, the average metabolism without acidosis was 8 per cent above standard, and with slight and moderate acidosis 14 per cent above standard; with severe acidosis it was 15 per cent above standard. After June, 1914, during the period of undernutrition, the group with no acidosis showed the lowest metabolism (17 per cent below standard) and the group with the most severe acidosis the highest metabolism (5 per cent below standard). Although there are various exceptions to the rule, this general tendency holds for the individual data.

In a comparison of metabolism and acidosis, Allen and Du Bois ${ }^{a}$ furnish data on cases previously reported from this Laboratory. ${ }^{b}$ Computations by these authors indicate that the metabolism of eight of these patients was 10 to 15 per cent above the normal standard of Du Bois. Of the eight cases, five had slight or no acidosis. Conversely, six cases showed severe or very severe acidosis with a normal or decreased metabolism. These authors are correct in thus estimating the acidosis. If one examines the protocols, however, it will be found that: (1) the data for the classification of acidosis preceding 1912 were less accurate and less abundant than they are to-day; (2) sodium bicarbonate was used in some cases and not in others, and though the alkali presumably had no effect upon the metabolism (see p. 152), it did lead to confusion in the interpretation of the tests then employed to determine acidosis (the ferric-chloride test for diacetic acid) and in the tests for ammonia; (3) the patients were not only upon heavy diets which varied in amount,

a Allen and Du Bois, Arch. Intern. Med., 1916, 17, p. 1010.

${ }^{b}$ Benedict and Joslin, Carnegie Inst. Wash. Pub. No. 176, 1912. 
but oatmeal, vegetable, and potato days were frequently interpolated; (4) finally, of the cases mentioned, Case B (No. 283) with severe acidosis and normal metabolism and taking 24 grams of sodium bicarbonate, was in an extremely weak condition, and thus resembled a patient treated by undernutrition, while Case Q (No. 371), with apparently severe acidosis, was tested while he was taking sodium bicarbonate, and a liberal amount of carbohydrate,

TABLE 35.-Relation of total metabolism and pulse-rate to varying degrees of acidosis in diabetes before and after June, 1914. (Subjects without food.)

\begin{tabular}{|c|c|c|c|c|c|c|c|c|}
\hline \multirow[b]{2}{*}{$\begin{array}{c}\text { Case } \\
\text { No. }\end{array}$} & \multicolumn{2}{|c|}{0} & \multicolumn{2}{|c|}{+} & \multicolumn{2}{|c|}{++} & \multicolumn{2}{|c|}{$+t+$} \\
\hline & $\begin{array}{l}\text { Average } \\
\text { variation } \\
\text { from } \\
\text { standard. }\end{array}$ & $\begin{array}{l}\text { Average } \\
\text { pulse- } \\
\text { rate. }\end{array}$ & $\begin{array}{l}\text { Average } \\
\text { variation } \\
\text { from } \\
\text { standard. }\end{array}$ & $\begin{array}{c}\text { Average } \\
\text { pulse- } \\
\text { rate. }\end{array}$ & $\begin{array}{c}\text { Average } \\
\text { variation } \\
\text { from } \\
\text { standard. }\end{array}$ & $\begin{array}{c}\text { Average } \\
\text { pulse- } \\
\text { rate. }\end{array}$ & $\begin{array}{c}\text { Average } \\
\text { variation } \\
\text { from } \\
\text { standard. }\end{array}$ & $\begin{array}{c}\text { Average } \\
\text { pulse- } \\
\text { rate. }\end{array}$ \\
\hline $\begin{array}{c}\text { Before June,1914: } \\
210 \\
220 \\
226 \\
246 \\
281 \\
289 \\
295 \\
310 \\
317 \\
319 \\
332 \\
371\end{array}$ & 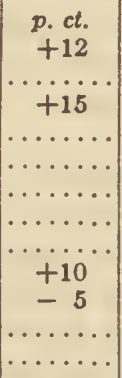 & 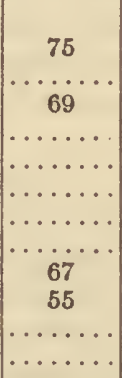 & $\begin{array}{c}\text { p.ct. } \\
\ldots \ldots \\
\ldots \ldots \\
+10 \\
\cdots \ldots \\
+16 \\
+22 \\
+22 \\
+31 \\
0 \\
\ldots \ldots \\
-1\end{array}$ & $\begin{array}{c}\cdots \cdots \\
\cdots \\
68 \\
\cdots \cdots \\
\cdots \ldots \\
66 \\
121 \\
84 \\
68 \\
55 \\
\ldots \ldots \\
65\end{array}$ & $\begin{array}{c}p . c t . \\
+20 \\
+9 \\
+18 \\
+6 \\
+14 \\
+26 \\
+14 \\
\ldots \ldots \\
+4 \\
+10 \\
\ldots \ldots\end{array}$ & $\begin{array}{r}75 \\
59 \\
68 \\
60 \\
79 \\
118 \\
80 \\
\ldots \ldots \\
55 \\
88 \\
\ldots \ldots\end{array}$ & $\begin{array}{c}\text { p. ct. } \\
+24 \\
+24 \\
\ldots \ldots \\
+11 \\
+5 \\
\ldots \ldots \ldots \\
\cdots \cdots \cdots \\
\cdots \cdots \\
\cdots \cdots \\
+21 \\
+5\end{array}$ & $\begin{array}{r}78 \\
86 \\
\ldots \ldots \\
64 \\
65 \\
\cdots \cdots \\
\cdots \cdots \\
\cdots \cdots \\
\cdots \cdots \\
\cdots \\
84 \\
79\end{array}$ \\
\hline Average. & +8 & 67 & +14 & 75 & +14 & 76 & +15 & 76 \\
\hline $\begin{array}{c}\text { After June, 1914: } \\
436 \\
610 \\
740 \\
746 \\
755 \\
765 \\
767 \\
786 \\
810 \\
821 \\
966 \\
983 \\
1005 \\
1011 \\
1025 \\
1026 \\
1049 \\
1070 \\
1085 \\
1160 \\
1181 \\
1196 \\
1233 \\
1307\end{array}$ & $\begin{array}{c}\cdots \\
\ldots \\
\cdots \cdots \\
\cdots \cdots \\
-18 \\
\cdots \cdots \\
-4 \\
-15 \\
-9 \\
-24 \\
-10 \\
\cdots \cdots \\
\cdots \cdots \\
\cdots \\
-19 \\
-13 \\
-20 \\
\cdots \cdots \\
-34 \\
-11 \\
-24 \\
-25 \\
-28 \\
-11\end{array}$ & \begin{tabular}{|c}
$\cdots$ \\
58 \\
$\cdots$ \\
$\cdots$ \\
$\ldots 8$ \\
58 \\
$\cdots \ldots$ \\
52 \\
61 \\
81 \\
50 \\
66 \\
$\cdots \cdots$ \\
$\cdots \cdots$ \\
$\cdots \cdots$ \\
60 \\
52 \\
51 \\
$\cdots \cdots \cdots$ \\
51 \\
53 \\
50 \\
57 \\
67 \\
87
\end{tabular} & $\begin{array}{c}+10 \\
+5 \\
\ldots \ldots \\
+5 \\
-22 \\
+19 \\
-8 \\
-6 \\
-27 \\
-12 \\
\ldots \ldots \\
-17 \\
\ldots \ldots \\
-27 \\
\ldots 8 \\
\ldots \ldots \\
\ldots \ldots \\
\ldots \ldots \\
\ldots 19 \\
\ldots \ldots \\
\ldots 18\end{array}$ & \begin{tabular}{|c} 
\\
$\quad 66$ \\
61 \\
$\ldots 3$ \\
83 \\
55 \\
70 \\
61 \\
60 \\
75 \\
53 \\
58 \\
$\ldots \ldots$ \\
52 \\
$\ldots \ldots$ \\
45 \\
68 \\
$\ldots \ldots \ldots$ \\
$\ldots \ldots \ldots$ \\
$\ldots \ldots \ldots$ \\
58 \\
49 \\
$\ldots \ldots \ldots$ \\
$\ldots \ldots \ldots$ \\
56
\end{tabular} & $\begin{array}{c}-7 \\
\ldots .1 \\
+1 \\
\ldots \ldots \\
-16 \\
\ldots \ldots \\
-17 \\
-17 \\
-15 \\
-1 \\
+19 \\
-19 \\
-26 \\
-14 \\
-15 \\
-12 \\
-18 \\
-35 \\
-5 \\
-10 \\
-23 \\
-30 \\
\ldots \ldots\end{array}$ & $\begin{array}{c}66 \\
\ldots \ldots \\
62 \\
78 \\
\ldots \ldots \\
69 \\
\ldots \ldots \\
61 \\
60 \\
56 \\
69 \\
66 \\
51 \\
67 \\
56 \\
55 \\
59 \\
59 \\
55 \\
60 \\
56 \\
59 \\
58 \\
\ldots \ldots\end{array}$ & 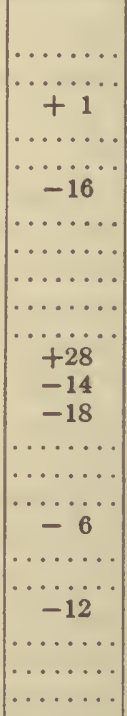 & 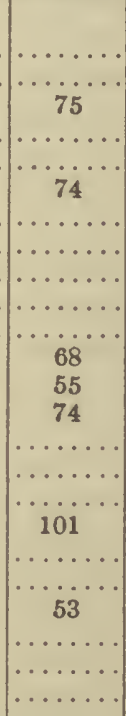 \\
\hline Average. & -17 & 60 & -10 & 62 & -14 & 61 & -5 & 71 \\
\hline
\end{tabular}


protein, and fat, and again immediately after a vegetable day with lower protein (6 eggs) and high fat, and two oatmeal days during which considerable quantities of butter and cream were also eaten. Similar notes could be added for Cases P (No. 441) and N (No. 281).

To the fair query as to why the conditions of the experiments were not simplified, the reply is that prior to 1912 , the treatment of acidosis and coma was less well understood and it was difficult to predict the immediate future of the patient. Furthermore, the endeavor throughout this investigation has been first of all to safeguard the patient, and next to observe the course of the disease, rather than to experiment upon it. It is easy to see now how these investigations could have been simplified without detriment to the patient. There is no doubt that so far as possible standard diets for prolonged periods of time should be employed preceding observations upon the metabolism when such diets are consistent with good therapeutics.

In table 36 , which is to some extent a replica of table 35 , though with a somewhat larger series of cases, not only the variation in the post-absorptive metabolism from standard and the pulse-rate for the varying degrees of acidosis are given, but also the metabolism expressed as calories per kilogram of body-weight. The data are grouped both according to sex and chronologically as to whether the observations were made before or after June, 1914. These averages differ from the figures presented in table 35 in that several girl diabetics have been added for whom the Girl Scout values were used in obtain-

TABLE 36. - Relation of post-absorptive metabolism and pulse-rate to varying degrees of acidosis in diabetes before and after June, 1914.

\begin{tabular}{|c|c|c|c|c|c|c|c|c|c|c|c|c|}
\hline \multirow[b]{2}{*}{ Case No. } & \multicolumn{3}{|c|}{0} & \multicolumn{3}{|c|}{+} & \multicolumn{3}{|c|}{++} & \multicolumn{3}{|c|}{+++} \\
\hline & 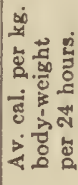 & 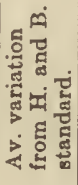 & 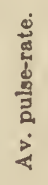 & 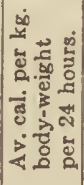 & 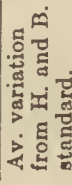 & 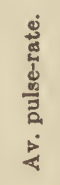 & 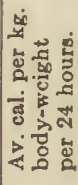 & 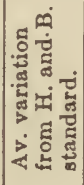 & 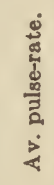 & 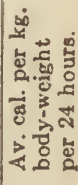 & 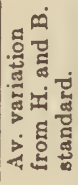 & 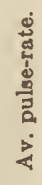 \\
\hline $\begin{array}{l}\text { Before June, } 1914 \\
\text { Men- }\end{array}$ & & & & & p. ct. & & & p.ci. & & & & \\
\hline $\begin{array}{l}210 \\
220\end{array}$ & 28 & +12 & 75 & & & & 30 & 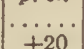 & 75 & 31 & $\begin{array}{r}+24 \\
+24\end{array}$ & $\begin{array}{l}78 \\
86\end{array}$ \\
\hline 226 & 31 & +15 & 69 & 29 & +10 & 108 & 29 & $\begin{array}{l}+20 \\
+9\end{array}$ & 59 & & & \\
\hline 246 & & & & & & & 30 & +18 & 68 & 29 & +11 & 64 \\
\hline 281 & & & & & & & 39 & +6 & 60 & 38 & +5 & 65 \\
\hline 289 & & & & 33 & +16 & 66 & 32 & +14 & 79 & & & 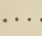 \\
\hline 295 & 07 & & & 39 & +22 & 121 & 38 & +26 & 118 & & & \\
\hline $\begin{array}{l}317 \\
319\end{array}$ & $\begin{array}{l}27 \\
27\end{array}$ & $\begin{array}{r}+10 \\
-5\end{array}$ & 67 & 33 & +31 & 68 & 30 & 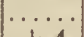 & 55 & $\cdots$ & $\ldots$ & $\ldots$ \\
\hline 371 & & & & $\begin{array}{l}28 \\
29\end{array}$ & -1 & $\begin{array}{l}53 \\
65\end{array}$ & 30 & +4 & 55 & 31 & +5 & 79 \\
\hline Average & 28 & +8 & 67 & 32 & +13 & 74 & 33 & +14 & 73 & 32 & +14 & 74 \\
\hline $\begin{array}{c}\text { Women- } \\
310 \\
332\end{array}$ & & & & 30 & +22 & $\begin{array}{l}84 \\
\ldots . .\end{array}$ & $\begin{array}{l}27 \\
34\end{array}$ & $\begin{array}{l}+12 \\
+19\end{array}$ & $\begin{array}{l}80 \\
88\end{array}$ & 36 & +21 & 84 \\
\hline Average & & & & 30 & +22 & 84 & 31 & +16 & 84 & 36 & +21 & 84 \\
\hline $\begin{array}{l}\text { Average, men } \\
\text { and women }\end{array}$ & 28 & +8 & 67 & 32 & +14 & 75 & 32 & +14 & 76 & 33 & +15 & 70 \\
\hline
\end{tabular}


TABLE 36.-Relation of post-absorptive metabolism and pulse-rate to varying degrees of acidosis in diabetes before and after June, 1914-Continued.

\begin{tabular}{|c|c|c|c|c|c|c|c|c|c|c|c|c|}
\hline \multirow[b]{2}{*}{ Case No. } & \multicolumn{3}{|c|}{0} & \multicolumn{3}{|c|}{+} & \multicolumn{3}{|c|}{$+t$} & \multicolumn{3}{|c|}{$+t+$} \\
\hline & 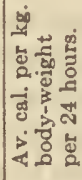 & 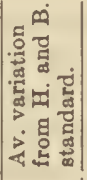 & 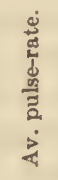 & 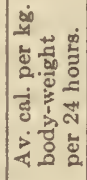 & 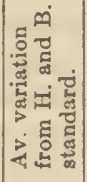 & 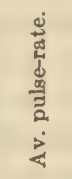 & 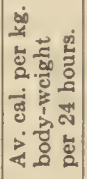 & 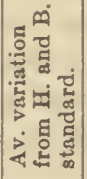 & 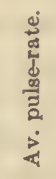 & 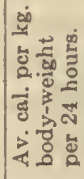 & 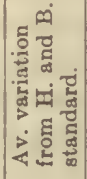 & 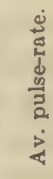 \\
\hline After June, 1914 & & p. ct. & & & p. ct. & & & p. ct. & & & p. ct. & \\
\hline $\begin{array}{l}632 \\
740\end{array}$ & & $\ldots \ldots$ & & 25 & $\begin{array}{l}-4 \\
\ldots \ldots\end{array}$ & & $\begin{array}{l}26 \\
26\end{array}$ & $\begin{array}{l}-1 \\
-11\end{array}$ & 62 & 29 & +1 & 75 \\
\hline 746 & & & & 28 & +5 & 83 & 27 & +1 & 78 & $\ldots$ & $\ldots \ldots$ & $\ldots$ \\
\hline 755 & 24 & -18 & 58 & 22 & -22 & 55 & & & & & & \\
\hline 786 & 22 & -15 & 61 & 28 & -8 & 60 & 22 & -17 & 61 & & .... & $\ldots$ \\
\hline 810 & 27 & -9 & 81 & 28 & -6 & 75 & 25 & -17 & 60 & & $\ldots \ldots$ & $\ldots$ \\
\hline 821 & 21 & -24 & 50 & 21 & -27 & 53 & 23 & -15 & 56 & & $\ldots \ldots$ & $\ldots$ \\
\hline 966 & 24 & -10 & 66 & 23 & -12 & 58 & 27 & -1 & 69 & & . & .. \\
\hline 1008 & & & & 21 & -14 & & 23 & -4 & 56 & & & $\ldots$ \\
\hline 1026 & 20 & -8 & 52 & 19 & -8 & 68 & 18 & -15 & 55 & & ... & $\ldots$ \\
\hline 1049 & 25 & -19 & 51 & & & & 27 & -11 & 59 & & & 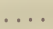 \\
\hline 1160 & 23 & -11 & 53 & 25 & -2 & 58 & 24 & -5 & 60 & & & \\
\hline 1181 & 21 & -24 & 50 & 23 & -19 & 49 & 25 & -10 & 56 & 25 & -12 & 53 \\
\hline 1196 & 21 & -25 & 57 & 20 & -25 & $\ldots \ldots$ & 21 & -23 & 59 & & ..... & .. \\
\hline 1233 & 21 & -28 & 67 & $\ldots$. & $\ldots \ldots$ & $\ldots \ldots$ & 21 & -30 & 58 & & . & $\ldots$ \\
\hline Average & 23 & -17 & 59 & 24 & -12 & 62 & 24 & -11 & 61 & 27 & -6 & 64 \\
\hline Women- & & & & & & & & & & & & \\
\hline 436 & & & & 24 & +6 & 86 & 21 & -7 & 66 & & & \\
\hline 610 & 22 & -6 & 58 & 24 & +5 & 61 & & & & & & \\
\hline 765 & & & & 24 & -19 & 70 & 25 & -16 & 69 & 27 & -16 & 74 \\
\hline 767 & 22 & -4 & 52 & 22 & +1 & 61 & ... & ...... & $\ldots .$. & .... & $\ldots . .$. & $\ldots$ \\
\hline 792 & 30 & (1) & 83 & 30 & $1-14$ & 77 & & & & & & \\
\hline 983 & & & . & & & & 20 & +16 & 66 & 22 & +28 & 68 \\
\hline 1005 & & & & 26 & -15 & 52 & 25 & -19 & 51 & 28 & -14 & 55 \\
\hline 1011 & 25 & -37 & .. & & & & 27 & -25 & 87 & 27 & -25 & 74 \\
\hline 1012 & 25 & (1) & 61 & 27 & (1) & 69 & 27 & (1) & 65 & $\ldots \ldots$ & $\ldots \ldots$ & .... \\
\hline 1025 & 25 & -19 & 60 & 21 & -27 & 45 & 26 & -14 & 56 & & & \\
\hline 1058 & $\ldots$ & $\ldots \ldots$ & $\ldots$ & 19 & -16 & $\ldots$ & 20 & -12 & & & & \\
\hline 1070 & $\ldots$ & & $\ldots \ldots$ & 20 & -23 & & 22 & -12 & 59 & 26 & -6 & 101 \\
\hline 1085 & 22 & -36 & 51 & & & 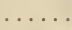 & 23 & -35 & 55 & ... & $\ldots \ldots$ & $\ldots$ \\
\hline 1147 & 24 & +10 & 89 & 22 & +1 & & & & ...... & $\ldots$ & $\ldots \ldots$ & $\ldots$ \\
\hline 1307 & 26 & -11 & 87 & 24 & -18 & 56 & 24 & -16 & $\ldots \ldots$ & & & $\ldots$ \\
\hline 1378 & 25 & -25 & $\cdots$ & $\ldots \ldots$ & ...... & $\ldots$. & 22 & -27 & $\cdots$ & $\cdots$ & $\cdots \cdots$ & $\cdots$ \\
\hline Average & 25 & -16 & 68 & 24 & -11 & 64 & 24 & -15 & 62 & 26 & -7 & 74 \\
\hline $\begin{array}{l}\text { Average, men } \\
\text { and women }\end{array}$ & 24 & -17 & 62 & 24 & -11 & 63 & 24 & -13 & 61 & 26 & -6 & 71 \\
\hline
\end{tabular}

1 For variations in metabolism from the Harris and Benedict standard and the Girl Scout values not stated here for Case No. 792, and variations from the Girl Scout values for Case No. 1012; see Appendix I.

ing the variation of metabolism from normal standard. (See p. 90.) The percentage variations for these patients are not, however, included in the table. Furthermore, the three averages for the individual patients for each degree of acidosis represent all the results obtained for the three respective factors and do not necessarily include the same number of daily observations; consequently in a few cases the averages are not strictly comparable with each other as they are in table 35 . Like the preceding table, however, the results represent data collected during two or more stages of acidosis for the individual patients. 
When acidosis was absent in the group of 12 patients studied before June, 1914 , the metabolism was, on the average, 28 calories per kilogram of bodyweight, with a variation from standard of +8 per cent, and a pulse-rate of 67 beats. With severe acidosis $(+++)$, the average metabolism for the whole group was 33 calories per kilogram of body-weight, the variation from standard +15 per cent, and the pulse-rate 76 beats. The averages shown in the table indicate that without acidosis the metabolism was lower than when acidosis, even mild in degree, was present. This has already been shown to be the case in earlier tables. (See p. 79.) The metabolism for all degrees of acidosis was more or less constant, or increased slightly with the acidosis, both on the basis of calories per kilogram and of variation from standard. The average pulse-rate also shows a general tendency to rise with the varying degrees of acidosis. With the individuals in the group there is some variance, as with Cases Nos. 226, 246, and 310.

A considerably larger number of cases comprise the group of diabetics studied after June, 1914, and included in table 36 . Here again it will be seen that the metabolism was lowest when the patients were free from acidosis, the calories per kilogram of body-weight being 23 for the men, 25 for the women, and averaging 24 for the whole group, while the average variation from standard for the group was -17 per cent. With severe acidosis $(++t)$ the calories per kilogram of body-weight for the men and women were 27 and 26 , respectively, with an average of 26 for the group, and the average variation from standard for the group was -6 per cent.

\section{ACIDOSIS, PULSE-RATE, AND METABOLISM.}

Both tables 35 and 36 contain data for the pulse-rates recorded for these patients and thus serve not only to show the relation of the pulse-rate to acidosis, but afford an excellent opportunity for comparing the pulse-rate with the metabolism in small groups of experiments. In table 35 it will be seen first that before June, 1914, the pulse-rate rose in the sequence of 67,75 , 76 , and 76 for the conditions of no acidosis, mild, moderate, and severe acidosis. After June, 1914, the change was similar, i. e., $60,62,61$, and 71 , though these averages reflect the lower metabolic level of that period. It is thus seen that the pulse-rate rises with increasing acidosis. Second, the correspondence between the average pulse-rate and the average metabolism for the data both before and after June, 1914, is practically perfect. The data for the pulse-rate before and after June, 1914, in table 36 likewise reflect clearly the tendency brought out by the metabolism figures to increase when acidosis is present.

\section{ACIDOSIS, SEVERITY OF THE DIABETES, AND METABOLISM.}

The relationship of the acidosis to the metabolism may be studied in still another way by grouping the data according to the severity of the diabetes and observing the effect of the acidosis within these groups. This is done in table 37. Among the cases of diabetes classed as of mild severity, there was no instance in any experiment in which the acidosis was severe. There were 22 experiments without acidosis, 4 with slight acidosis present, and 2 with moderate acidosis. An analysis of these data gives no evidence that the acidosis had a direct effect upon the metabolism, particularly if the obser- 
vations with the mild cases are classified according to their occurrence before or after June, 1914.

Among the cases with moderately severe diabetes prior to June, 1914, there was likewise no severe acidosis. With this group experiments were made on 10 days with cases without acidosis, on 5 days with cases exhibiting slight acidosis, and on 5 days with those with moderate acidosis. The metabolism in all groups was essentially the same, being increased above normal by 14 per cent, 16 per cent, and 13 per cent, respectively. Following June, 1914, severe acidosis did not appear with the moderate cases on any of the 72 experimental days. Moderate acidosis, however, was present on 13 days, with an average metabolism of -11 per cent, mild acidosis on 32 days, with an average metabolism of -1 per cent, and no acidosis on 27 days, with an average metabolism of -7 per cent. The differences in the metabolism for these various degrees of acidosis show no distinct trend and the extreme variation is but 10 per cent.

$\mathrm{T}_{\mathrm{ABLE}}$ 37.-Relation of acidosis and severity of diabetes to post-absorptive metabolism in experiments with diabetics.

\begin{tabular}{|c|c|c|c|c|c|c|}
\hline \multirow[b]{2}{*}{ Acidosis. } & \multicolumn{2}{|c|}{ Mild diabetes. } & \multicolumn{2}{|c|}{ Moderate diabetes. } & \multicolumn{2}{|c|}{ Severe diabetes. } \\
\hline & $\begin{array}{l}\text { No. of } \\
\text { days. }\end{array}$ & $\begin{array}{l}\text { Variation of } \\
\text { metabolism } \\
\text { from normal } \\
\text { standard. }\end{array}$ & $\begin{array}{l}\text { No. of } \\
\text { days. }\end{array}$ & $\begin{array}{l}\text { Variation of } \\
\text { metabolism } \\
\text { from normal } \\
\text { standard. }\end{array}$ & $\begin{array}{l}\text { No. of } \\
\text { days. }\end{array}$ & $\begin{array}{l}\text { Variation of } \\
\text { metabolism } \\
\text { from normal } \\
\text { standard. }\end{array}$ \\
\hline $\begin{array}{c}\text { Before June, 1914: } \\
0 \\
+ \\
++ \\
+++\end{array}$ & $\begin{array}{r}6 \\
\ldots \ldots\end{array}$ & $\begin{array}{r}\text { p. } c t . \\
+4 \\
\text { …... }\end{array}$ & $\begin{array}{r}10 \\
5 \\
5\end{array}$ & $\begin{array}{l}\text { p. ct. } \\
+14 \\
+16 \\
+13 \\
+\ldots\end{array}$ & $\begin{array}{r}2 \\
5 \\
38 \\
48\end{array}$ & $\begin{array}{l}\text { p. ct. } \\
+9 \\
+12 \\
+12 \\
+13\end{array}$ \\
\hline $\begin{array}{c}\text { After June, 1914: } \\
0 \\
+ \\
++ \\
+++\end{array}$ & $\begin{array}{r}16 \\
4 \\
2\end{array}$ & $\begin{array}{l}-4 \\
-5 \\
-4 \\
\cdots\end{array}$ & $\begin{array}{l}27 \\
32 \\
13\end{array}$ & $\begin{array}{l}-7 \\
-1 \\
-11 \\
\ldots\end{array}$ & $\begin{array}{l}49 \\
37 \\
87 \\
12\end{array}$ & $\begin{array}{l}-19 \\
-14 \\
-12 \\
+2\end{array}$ \\
\hline
\end{tabular}

With 22 cases of severe diabetes in various stages of acidosis, experiments were made on 93 days prior to June, 1914 . On only 9 of these days was the metabolism below normal. On 2 days with cases without acidosis the average metabolism was 9 per cent above standard, on 5 days with slight acidosis the metabolism was 12 per cent above standard, on 38 days with moderate acidosis 12 per cent above, and on 48 days with severe acidosis 13 per cent above standard.

After June, 1914, experiments were made on 185 days with 41 cases of severe diabetes. The lowest average metabolism was found on 49 days with diabetics having no acidosis, namely, 19 per cent below standard. On 37 days with mild acidosis present, the metabolism was 14 per cent below. The experiments on 87 days with moderate acidosis indicated a metabolism 12 per cent below standard. On the 12 days with severe acidosis the metabolism was 2 per cent above standard. 
In conclusion, therefore, it can be said that an examination of the influence of acidosis upon the metabolism of diabetics of different degrees of severity supports the view that acidosis raises the metabolism of severe cases. Upon mild and moderate cases the determination of the effect of acidosis is less satisfactory because in no instance did severe acidosis occur with these groups.

\section{ACIDOSIS AND METABOLISM OF INDIVIDUAL DIABETICS.}

Certain cases are worthy of special discussion because of the opportunity they present for a comparison of acidosis and metabolism. The experimental data of Case No. 983 show clearly such association in a fat diabetic. This patient stated that she had eaten little for a week preceding January 29. How true this is one can not say, but the presence of acidosis, despite 6.3 per cent of sugar in the urine, leads one to infer that presumably the relations for the carbohydrate, protein, and fat in the diet at least may have been altered. The effect of the caloric content of the daily diet upon the acidosis and metabolism is brought out by the data in table 38 . From these records it is seen that the post-absorptive metabolism of this woman decreased from 28 per cent to 12 per cent above normal, the urinary nitrogen per 24 hours for the experimental day fell from 13.0 grams to 5.3 grams, and the sugar in the urine disappeared. The decrease in the excretion of nitrogen, sugar, and ammonia and the fall in the metabolism coincided with the marked reduction in the total diet, namely, a change from a diet so abundant as to allow 6.3 per cent of sugar on January 29,1916 , to a diet so low that it averaged but 76 calories a day for the six days preceding the last metabolism test. On the other hand, the decrease in the metabolism of protein between February 1 and 7 , which, as computed from the urinary nitrogen, amounted to but 46 grams $(13.0-5.3=7.7 \times 6)$ for a woman weighing 90 kilograms, appears insufficient to explain the change in metabolism. Despite the fact that the patient was fat, that she was upon a very low diet, and was ultimately given a total fast, the acidosis decreased. This behavior is absolutely different from that of the non-diabetic fat woman reported by Folin and Denis ${ }^{a}$ when fasted for two 4-day and one 5-day periods, whose acidosis continually advanced in each period from day to day, though the total acidosis decreased in successive periods. The diabetic (Case No. 983) lost much of her acidosis upon fasting, whereas the normal non-diabetic individual, though obese, acquired it.

The explanation of this difference is found by computing the actual values of carbohydrate, protein, and fat burned at the beginning and end of the period. This has been done in the usual way with the use of the non-protein quotient and by adding 20 per cent to the heat-output per 24 hours as computed from the basal metabolism. On February 2-3 the carbohydrate in the diet was 50 grams, but the carbohydrate actually burned by the patient was 7 grams, whereas on February 8-9 the carbohydrate ingested was 5 grams, but the carbohydrate burned by the patient was 38 grams. To be sure, such calculations of the quantity of carbohydrate burned are purely theoretical because the metabolism was estimated for only about 2 hours out of each 24 hours; second, because no account is taken of food carbohydrate; and third,

\footnotetext{
- Folin and Denis, Journ. Biol. Chem., 1915, 21, p. 183.
} 
because of the practically constant respiratory quotient upon the three days for which this computation has been made. The difference in carbohydrate estimated as burned despite the constant respiratory quotient is explained by the effect of the change in urinary nitrogen upon the computation of the non-protein quotient. However, disregarding the many errors which may be present, it is still worth while to study the falling acidosis in this fat diabetic patient during fasting, particularly because the normal fat patient acquired an acidosis during fasting.

TABLE 38.-The metabolism of a diabetic (Case No. 989, female) with high acidosis.

[Age, 55 yrs.; height, $160 \mathrm{~cm}$.; average body-weight, naked, $90.4 \mathrm{~kg}$.; diabetes, severe. All experiments post-absorptive.]

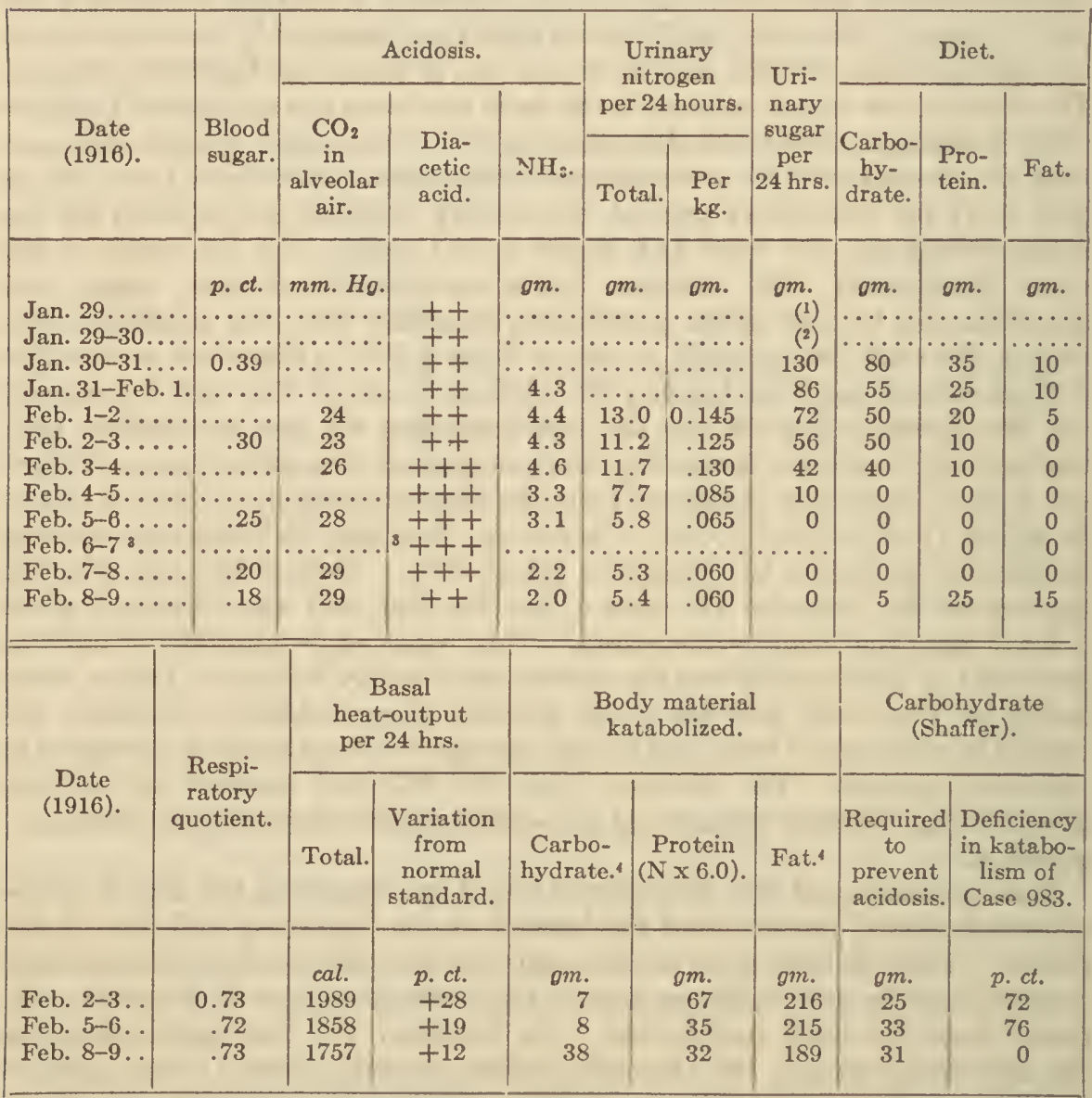

16.3 per cent of sugar was determined in specimen of urine on Jan. 29 preceding the night urine of Jan. 29-30, 1916.

2 Sugar in urine for 12 hours on night of Jan. 29-30, 1916, was 123 grams.

Not a 24-hour specimen.

4 Calories computed as derived from carbohydrate have been divided by factor 4.23; those from fat by factor 9.54. In this computation of materials katabolized the heat-output per 24 hours has been increased by 20 per cent to bring the metabolism to the basis of hospital activity. 
Using Shaffer's formula (see p. 139) the theoretical quantity of carbohydrate sufficient to prevent acidosis upon the first day would have been 25 grams. As the patient actually burned 7 grams, the deficiency of carbohydrate was 72 per cent, corresponding to the severe acidosis which she showed on that day. On the last day the theoretical quantity of carbohydrate sufficient to prevent acidosis would be 31 grams. On this day 38 grams were actually burned, which would be as much as required. Corresponding to this improvement in the oxidation of carbohydrate, the acidosis decreased but was still present and is explainable, as Shaffer has stated, on the ground that each ketogenic molecule does not meet its anti-ketogenic molecule in the body. Hence, to avoid acidosis, he suggests that twice the theoretical carbohydrate should be administered instead of the exact theoretical amount.

TABLE 39.-Decreasing acidosis coincident with falling metabolism and continued undernutrition. (Case No. 1181, male.)

[Age, 25 yrs.; height, $175 \mathrm{~cm}$.; average body-weight, $54.6 \mathrm{~kg}$;; diabetes, severe. All experiments post-absorptive.]

\begin{tabular}{|c|c|c|c|c|c|c|c|c|c|c|c|c|}
\hline \multirow[b]{2}{*}{ Date. } & \multicolumn{3}{|c|}{ Acidosis. } & \multirow{2}{*}{ 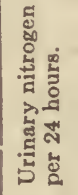 } & \multirow{2}{*}{ 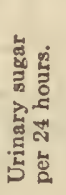 } & \multicolumn{4}{|c|}{ Diet. } & \multirow[b]{2}{*}{ 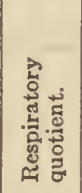 } & \multirow{2}{*}{ 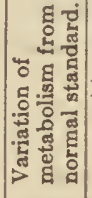 } & \multirow[b]{2}{*}{$\begin{array}{l}\text { Pulse- } \\
\text { rate. }\end{array}$} \\
\hline & $\begin{array}{c}\mathrm{CO}_{2} \\
\text { in } \\
\text { alveolar } \\
\text { air. }\end{array}$ & $\begin{array}{l}\text { Dir- } \\
\text { cetic } \\
\text { acid. }\end{array}$ & $\mathrm{NH}_{3}$. & & & $\begin{array}{c}\text { Carbo- } \\
\text { hydrate. }\end{array}$ & $\begin{array}{l}\text { Pro- } \\
\text { tein. }\end{array}$ & Fat. & $\begin{array}{l}\text { Cal- } \\
\text { ories. }\end{array}$ & & & \\
\hline 1916 & $m m . H_{g}$. & & om. & $g m$. & om. & $g m$. & $g m$ & $\mathrm{om}$ & & & p. ct. & \\
\hline Nov. $9-10$ & 129 & $+t+$ & 2.7 & 10.4 & 25 & 0 & 0 & 0 & 0 & 0.74 & -1 & 60 \\
\hline Nov. $10-11$ & 33 & $t+t$ & 2.7 & 9.3 & 17 & 0 & 0 & 0 & 0 & .74 & -4 & 58 \\
\hline Nov. $11-12$ & 24 & ++ & 2.7 & 11.7 & 17 & 15 & 20 & 10 & 230 & .71 & -12 & 53 \\
\hline Nov. $12-13$ & 30 & + & $\ldots \ldots$ & 15.2 & 16 & 10 & 50 & 10 & 330 & $\ldots \ldots$ & $\ldots .$. & $\ldots \ldots$ \\
\hline Nov. 13-14 & 34 & + & $\ldots \ldots$ & 12.3 & 11 & 0 & 0 & 0 & 0 & .74 & -9 & 55 \\
\hline Nov. $14-15$ & 32 & + & $\ldots \ldots$ & 9.1 & 5 & 0 & 0 & 0 & 0 & .75 & -16 & 54 \\
\hline Nov. $15-16$ & 30 & + & $\ldots \ldots$ & 7.8 & 0 & 0 & 0 & 0 & 0 & .75 & -20 & 53 \\
\hline Nov. $16-17$ & 36 & + & $\ldots \ldots$ & 8.6 & Tr. & 0 & 10 & 0 & 40 & .70 & -19 & 49 \\
\hline Nov. $17-18$ & 34 & 0 & $\ldots \ldots$ & $\ldots \ldots$ & 0 & 0 & 25 & 0 & 100 & $\ldots \ldots$ & ...... & $\ldots \ldots$ \\
\hline Nov. $18-19$ & $\ldots \ldots$ & 0 & $\ldots \ldots$ & $\ldots \ldots$ & Tr. & 0 & 60 & 5 & 285 & $\ldots \ldots$ & $\ldots \ldots$ & $\ldots \ldots$ \\
\hline Nov. $19-20$ & $\ldots \ldots \ldots$ & 0 & & & Tr. & 0 & 0 & 0 & 0 & $\ldots \ldots$ & $\ldots \ldots$ & $\ldots \ldots$ \\
\hline Nov. $20-21$ & 34 & 0 & $\ldots \ldots$ & & 0 & 5 & 45 & 35 & 515 & $\ldots \ldots$ & $\ldots \ldots$ & $\ldots \ldots$ \\
\hline Nov. 21-22 & $\ldots \ldots$ & 0 & $\ldots \ldots$ & ... & 0 & 10 & 45 & 35 & 535 & $\ldots \ldots$ & $\ldots \ldots$ & $\ldots \ldots$ \\
\hline Nov. $22-23$ & & 0 & $\ldots .$. & $\ldots . .$. & 0 & 15 & 50 & 35 & 575 & $\ldots \ldots$ & $\ldots \ldots$ & $\ldots \ldots$ \\
\hline Nov. 23-24 & & 0 & $\ldots .$. & 6.8 & 4 & 100 & 0 & 0 & 400 & .80 & -24 & 51 \\
\hline Nov. $24-25$ & & 0 & ..... & 11.6 & 0 & 10 & 60 & 10 & 370 & .75 & -24 & 49 \\
\hline
\end{tabular}

1 Determined on preceding day.

Case No. 1026, a fat man with a mild type of diabetes, was also treated upon a low diet quite similar to that given to the fat woman, Case No. 983. In contrast he at no time showed more than a slight to moderate acidosis. His metabolism changed from -8 to -15 per cent in 7 days. This is again in contrast to Case No. 983 who, with marked acidosis, presented a metabolism of +28 per cent and 6 days later with far less acidosis a metabolism of +12 per cent. With the decrease in acidosis the metabolism fell twice as rapidly with Case No. 983 as with Case No. 1026 who had no acidosis. The difference in the metabolism of these two cases is not to be explained by the diet, for Case No. 983 during the first 6 days of treatment received 3.2 (0.3 net) calories per kilogram of body-weight per 24 hours, and Case No. 1026, during 
TABLE 40.-The metabolism of a diabetic (Case No. 765 , female) to whom levulose was administered.

[Age, 23 yrs.; height, $170 \mathrm{~cm}$.; diabetes, severe at this period.]

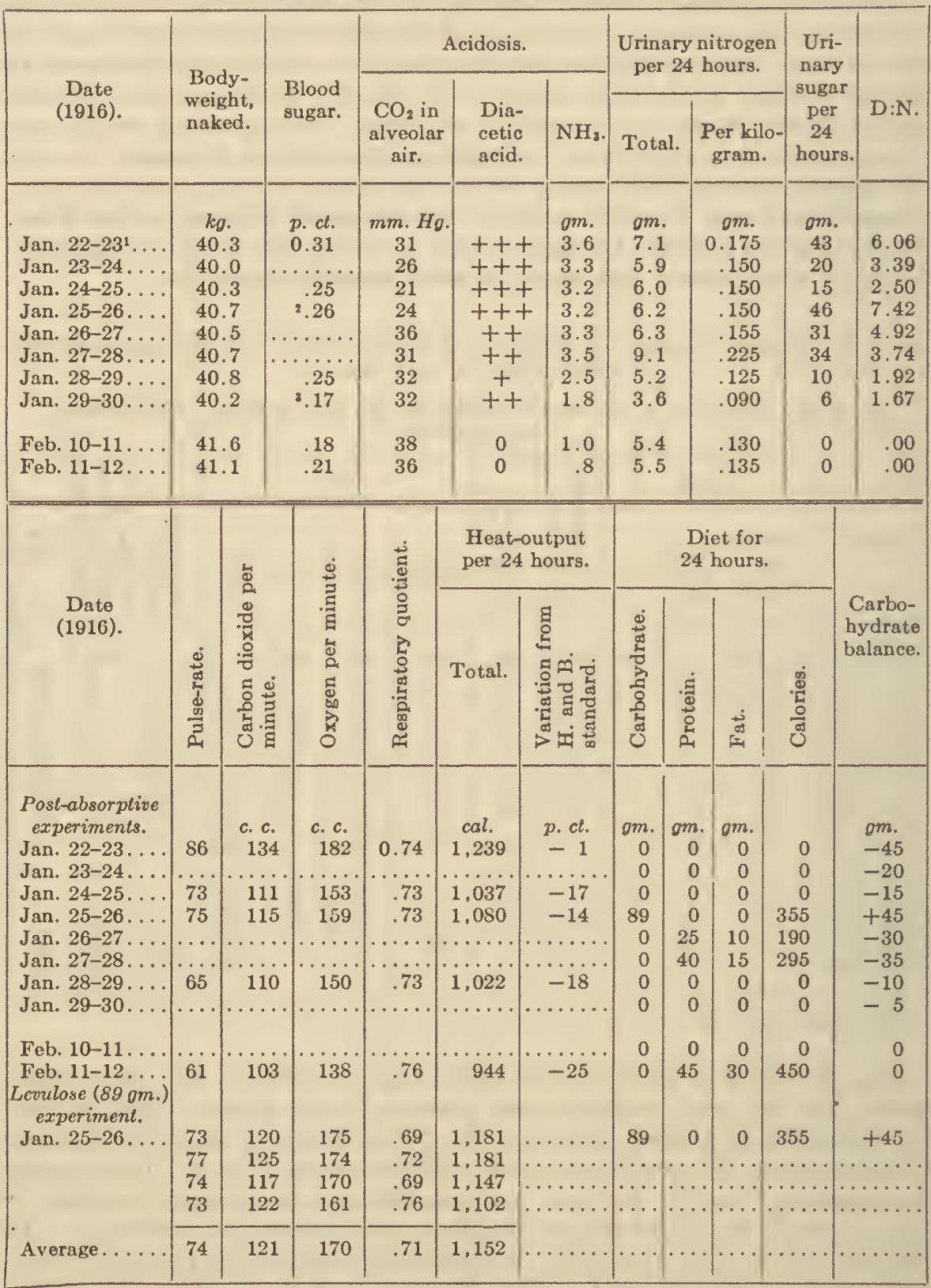

1 Detcrminations for urine of last 12 hours of Jan. 21-22, 1916, were as follows: Diacetic acid, $+++; \mathrm{NH}_{3}, 1.3$ grams; $\beta$-oxybutyric acid, 5.0 grams; nitrogen, 3.2 grams; sugar, 67 grams; dextrose-nitrogen ratio, 20.94. In the following 24 hours of Jan. 22-23, 1916, the determination of $\beta$-oxybutyric acid was 19.2 grams.

2 Blood sugar at $6 \mathrm{p} . \mathrm{m} ., 31 / 4$ hours after the taking of levulose, was 0.24 per cent.

Determined on morning of following day. 
the first 10 days of treatment, received 3.8 (3.6 net) calories per kilogram of body-weight per 24 hours.

With Case No. 1181 there was a gradual and consistent decrease in the metabolism as compared with the standard from -1 per cent to -24 per cent, as determined in post-absorptive experiments on 9 days in the course of a period of 16 days. (See table 39.) The body-weight and urinary nitrogen remained essentially constant during these 16 days. The energy in the diet on successive days ranged from 40 to 575 calories, with 6 fasting days in all. In this instance it is plain that the decrease in metabolism occurred during a period of continual undernutrition. The acidosis gradually decreased and eventually disappeared.

With Case No. 765 the metabolism decreased between January 22 and February 12 from -1 per cent below standard to -25 per cent below standard (see table 40), and coincidentally the acidosis which was originally high disappeared. The urinary nitrogen for the first three days varied between 0.175 and 0.150 gram per kilogram of body-weight, and for the last two days between 0.130 and 0.135 gram per kilogram of body-weight. The fall in metabolism and the disappearance of acidosis are independent of marked changes in the urinary nitrogen. (See, also, Case No. 436, page 143.)

TABLE 41.-Variations in basal metabolism compared with variations in acidosis, nitrogen excreted, and fat and calories in the diet.

[Summarized from experiments of Wilder, Boothby, and Beeler.]

\begin{tabular}{|c|c|c|c|c|c|c|c|c|}
\hline \multirow{3}{*}{$\begin{array}{l}\text { Percentage } \\
\text { variation } \\
\text { of metabo- } \\
\text { lism from } \\
\text { Du Bois } \\
\text { standard. }\end{array}$} & \multicolumn{5}{|c|}{ Acidosis. } & \multirow{3}{*}{$\begin{array}{l}\text { Urinary } \\
\text { nitrogen } \\
\text { of pre- } \\
\text { ceding } \\
\text { day. }\end{array}$} & \multirow{3}{*}{$\begin{array}{l}\text { Fat } \\
\text { in diet } \\
\text { of pre- } \\
\text { ceding } \\
\text { day. }\end{array}$} & \multirow{3}{*}{$\begin{array}{c}\text { Total } \\
\text { calories } \\
\text { in diet of } \\
\text { preceding } \\
\text { day. }\end{array}$} \\
\hline & \multicolumn{2}{|c|}{ Blood. } & \multicolumn{3}{|c|}{ Urine (preceding day). } & & & \\
\hline & $\begin{array}{l}\text { Carbon } \\
\text { dioxide. }\end{array}$ & $\begin{array}{c}\text { Acetone } \\
\text { bodies } \\
\text { (as ace- } \\
\text { tone). }\end{array}$ & $\mathrm{NH}_{3}$. & $\frac{\mathrm{NH}_{3}-\mathrm{N}}{\text { Total } \mathrm{N}}$ & $\begin{array}{c}\text { Acetone } \\
\text { bodies } \\
\text { (as ace- } \\
\text { tone). }\end{array}$ & & & \\
\hline $\begin{array}{ll}-1 \text { to } & -10 \\
-11 & -20 \\
-21 & -30\end{array}$ & $\begin{array}{c}\text { vol. p. } c t . \\
38 \\
49 \\
52\end{array}$ & $\begin{array}{c}g m . \\
0.057 \\
.028 \\
.020\end{array}$ & $\begin{array}{r}g m . \\
1.58 \\
1.19 \\
.50\end{array}$ & $\begin{array}{c}p . c t . \\
10 \\
13 \\
7\end{array}$ & $\begin{array}{l}g m . \\
8.1 \\
4.2 \\
2.0\end{array}$ & $\begin{array}{r}g m . \\
13.7 \\
9.4 \\
7.0\end{array}$ & $\begin{array}{r}g m \\
127 \\
104 \\
95\end{array}$ & $\begin{array}{l}1,587 \\
1,225 \\
1,074\end{array}$ \\
\hline
\end{tabular}

Table 41 is a recomputation of an exhaustive study of the metabolism of a case of diabetes by Wilder, Boothby, and Beeler. ${ }^{a}$ It shows that the metabolism is definitely related to the degree of acidosis, for when the metabolism is highest the acidosis is highest and when the metabolism is lowest the acidosis is least. Three other factors are introduced in table 41 which singly or together may be of importance in this supposed relation. These are the nitrogen excreted and the fat and total calories ingested. It will be seen that with each factor the metabolism varied as with the acidosis. Shall one ascribe the entire cause of the variation to the nitrogen, or in part to the acidosis which the fat and excessive diet caused? From evidence already submitted and to be submitted, the latter alternative appears as the more reasonable

-Wilder, Boothby, and Beeler, Journ. Biol. Chem., 1922, 51, p. 311. 
explanation. It is not for a moment denied that protein increased the metabolism of this individual, but that 40 grams of protein raised the metabolism of this patient to so great an extent appears improbable. Furthermore, is it justifiable to ascribe the entire rise to the protein and disregard the fat with its capacity for forming acid bodies?

TABLE 42.-Diet for an individual weighing 70 kilograms as computed from the diet of a diabetic.

\begin{tabular}{|c|c|c|c|c|c|c|c|c|c|c|}
\hline \multirow{2}{*}{ Period. } & \multirow{2}{*}{$\begin{array}{l}\text { Dura- } \\
\text { tion. }\end{array}$} & \multirow{2}{*}{$\begin{array}{c}\text { Average } \\
\text { body- } \\
\text { weight. }\end{array}$} & \multicolumn{4}{|c|}{ Diet given diabetic. } & \multicolumn{4}{|c|}{$\begin{array}{c}\text { Computed equivalent } \\
\text { for individual of } 70 \mathrm{~kg} \text {. }\end{array}$} \\
\hline & & & $\begin{array}{l}\text { Carbo- } \\
\text { hydrate. }\end{array}$ & $\begin{array}{l}\text { Pro- } \\
\text { tein. }\end{array}$ & Fat. & $\begin{array}{l}\text { Cal- } \\
\text { ories. }\end{array}$ & $\begin{array}{l}\text { Carbo- } \\
\text { hydrate. }\end{array}$ & $\begin{array}{l}\text { Pro- } \\
\text { tein. }\end{array}$ & Fat. & $\begin{array}{l}\text { Cal- } \\
\text { ories. }\end{array}$ \\
\hline & days & $\mathrm{kg}$. & $g m$. & $g m$. & $g m$. & & $g m$. & $g m$. & $g m$. & \\
\hline I & 18 & 33 & 20 & 49 & 86 & 1,077 & 43 & 105 & 184 & 2,320 \\
\hline II & 3 & ${ }^{1} 33$ & 7 & 16 & 28 & 356 & 14 & 35 & 60 & 757 \\
\hline III & 5 & 33 & 1 & 47 & 88 & 1,016 & 1 & 99 & 186 & 2,142 \\
\hline IV & 4 & 32 & 2 & 94 & 99 & 1,315 & 4 & 207 & 217 & 2,886 \\
\hline V & 5 & 32 & 3 & 104 & 138 & 1,721 & 7 & 228 & 304 & 3,788 \\
\hline VI & 10 & 32 & 15 & 13 & 85 & 909 & 33 & 28 & 189 & 2,007 \\
\hline VII & 4 & 31 & 15 & 31 & 109 & 1,201 & 33 & 69 & 245 & 2,695 \\
\hline VIII & 8 & 31 & 43 & 27 & 151 & 1,692 & 97 & 61 & 346 & 3,871 \\
\hline IX & 3 & 30 & 11 & 13 & 13 & 222 & 25 & 31 & 31 & 513 \\
\hline$X$ & 4 & 31 & 4 & 105 & 126 & 1,621 & 9 & 234 & 282 & 3,625 \\
\hline XI & 10 & 31 & 14 & 19 & 91 & 983 & 32 & 43 & 205 & 2,213 \\
\hline
\end{tabular}

1 Interpolated.

In the practical treatment of diabetes it favors a better orientation of the condition under which the patient is living to carry in mind the conception of a diabetic "twin" and to consider how the treatment proposed would affect that supposedly healthy individual. For this reason the diets employed in the observations of Wilder, Boothby, and Beeler have been translated into equivalents for a normal individual of $70 \mathrm{~kg}$. of body-weight. These are shown in table 42. From an examination of period $V$ it is seen that the calories in the diet for one day of this theoretical "twin" would contain 3,788 calories or 54 calories per kilogram of body-weight. In simple foods the components of the diet could be represented approximately by half a small orange, 38 eggs, and 3 ounces of butter. The considerable quantities of food which the supposedly normal individual at one time would be obliged to eat and the marked variations in the same from period to period during six weeks of confinement to a hospital with enforced muscular inactivity, raise the question as to how much significance can be attached to the changes in the metabolism for the different periods. A study of a healthy nurse (see p. 131) who lived upon a diabetic regime, then frequently prescribed for diabetic patients, had a profound effect upon the writer's ideas regarding the treatment of diabetes and the case just cited is also suggestive.

\section{Metabolism of Young Female Diabetics without Food.}

Six cases in the series of diabetic patients studied in this research were females between 16 and 18 years of age, and accordingly they do not fall within the age limits of the Harris and Benedict prediction tables. Their 
metabolism must be computed upon other bases, as the Harris and Benedict formula for women does not apply to girls of this age. (See p. 47.) For this reason, recent observations in the Nutrition Laboratory upon Girl Scouts are employed for comparison. ${ }^{\circ}$ These data were accumulated by determining the metabolism of 95 girls, 12 to 17 years old, who were studied in 9 groups, usually of 12 girls each, for a period of approximately $71 / 2$ hours at night. The normal value for 18 -year-old girls was obtained from a study with an additional group of 12 Girl Scouts of this age. ${ }^{b}$ For most of the time, these normal girls were asleep, so that the metabolism should be considered as a low basal; it is hardly safe to hazard an estimate as to how much too low, but the maximum difference could not be over 25 per cent.

The values for the basal metabolism of the Girl Scouts were obtained approximately 8 hours after a meal with a caloric content of about 500 calories. The possible rise in metabolism due to this food may have offset in part the fall in metabolism due to sleep. Yet one can not overlook the possibility that during some of the periods spent by the diabetic girls in the respiration chamber they may also have been asleep.

Since, however, the Girl Scout values are the only available data regarding the basal metabolism of girls of this age, they are introduced here as a tentative standard, or basis of comparison, to help in the interpretation of results obtained with the diabetic girls.

The following conclusions are cited from the published results of this study of Girl Scouts:

The average 24-hour basal heat-production of groups of girls from 12 to 17 years of age was found to be 1,250 calories per individual, irrespective of age.

The heat-production per kilogram of body-weight per 24 hours decreased regularly with increasing age from 29.9 calories at 12 years 2 months, to 21.7 calories at 17 years.

The metabolism of groups of young girls can be predicted from the general curve indicating the heat-production per kilogram of body-weight referred to age to within an average error of \pm 3.1 per cent.

The actual prediction figures used were 22.6 calories per kilogram of bodyweight per 24 hours for 16-year old girls, 21.2 calories for 17 -year old girls, and 21.9 calories for 18-year old girls. Even this large series of data does not give a wholly satisfactory standard with which to compare results with the diabetics, because two of the six diabetic girls (Cases Nos. 194 and 1213) were above the range of normal height for their age and one (Case No. 333) was above weight for her height and age. Thus three of the six cases were abnormal in their physical characteristics. The difficulties presented in the interpretation of the data must be plainly recognized and are emphasized if one computes the figures for the metabolism actually found on the basis of per kilogram of body-weight and per square meter of body-surface, and also compares them with the figures obtained with the Girl Scouts, with the

a Benedict and Hendry, Boston Med. and Surg. Journ., 1921, 184, pp. 217, 257, 282, 297, and 329 . The standard factors given (see their table 13) and used in this monograph have since been slightly changed. (Benedict, Boston Med. and Surg. Journ., 1923, 188, p. 127, table 5.)

${ }^{b}$ The data for the 18-year-old Girl Scouts had not been published when used in these computations. They have since appeared, with a slight change in the normal value. See Benedict, Boston Med. and Surg. Journ., 1923, 188, p. 127, table 5. 


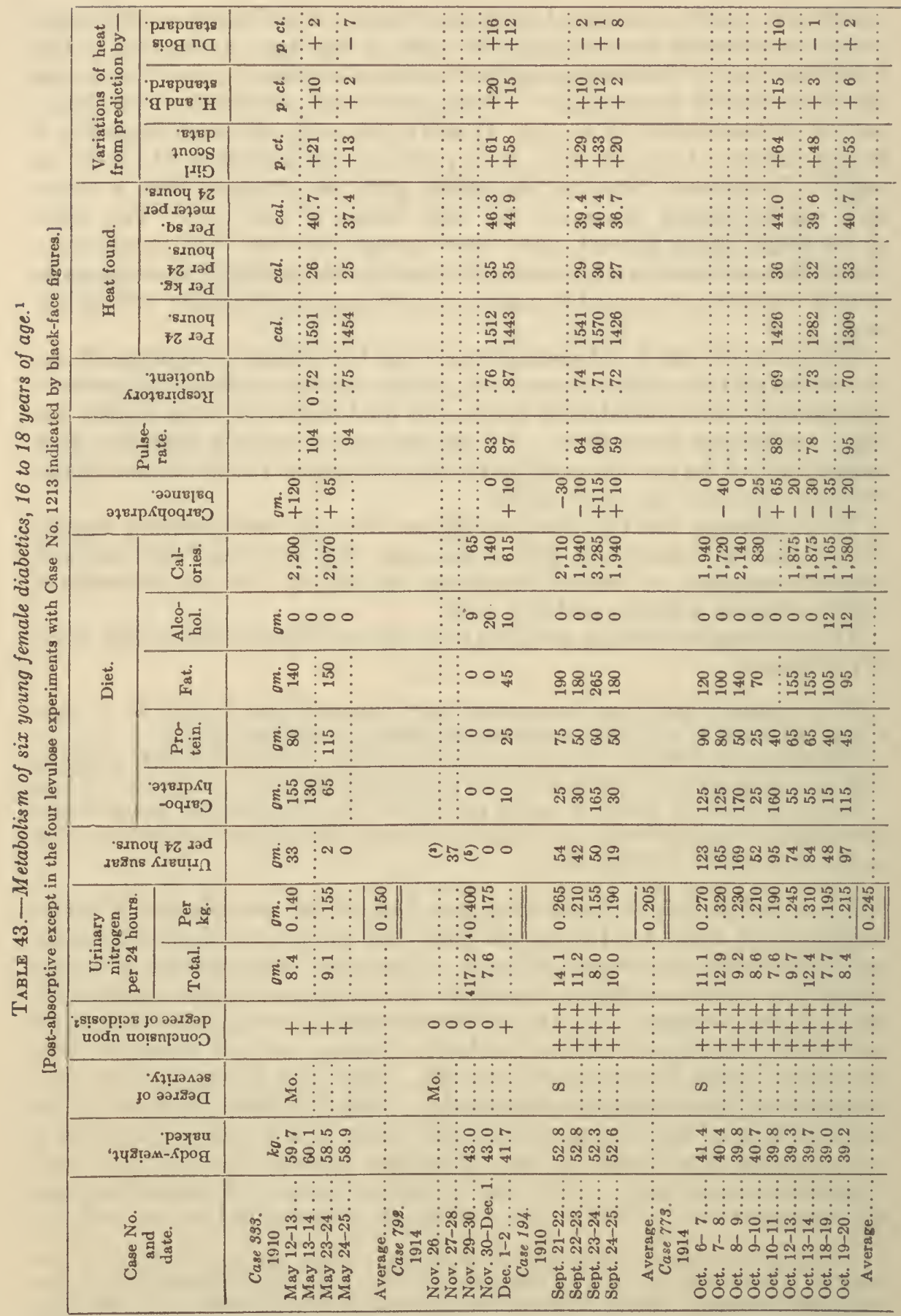




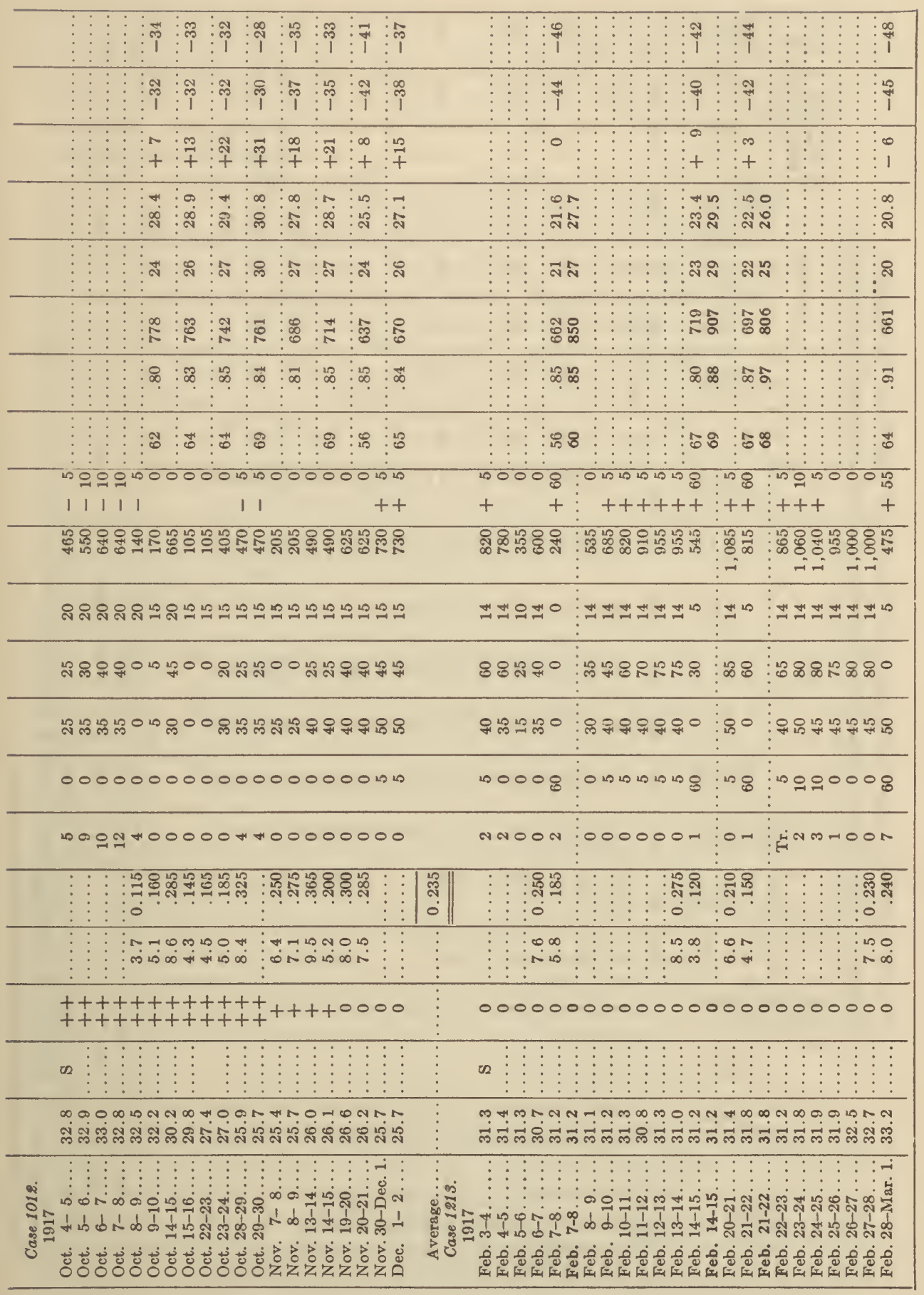




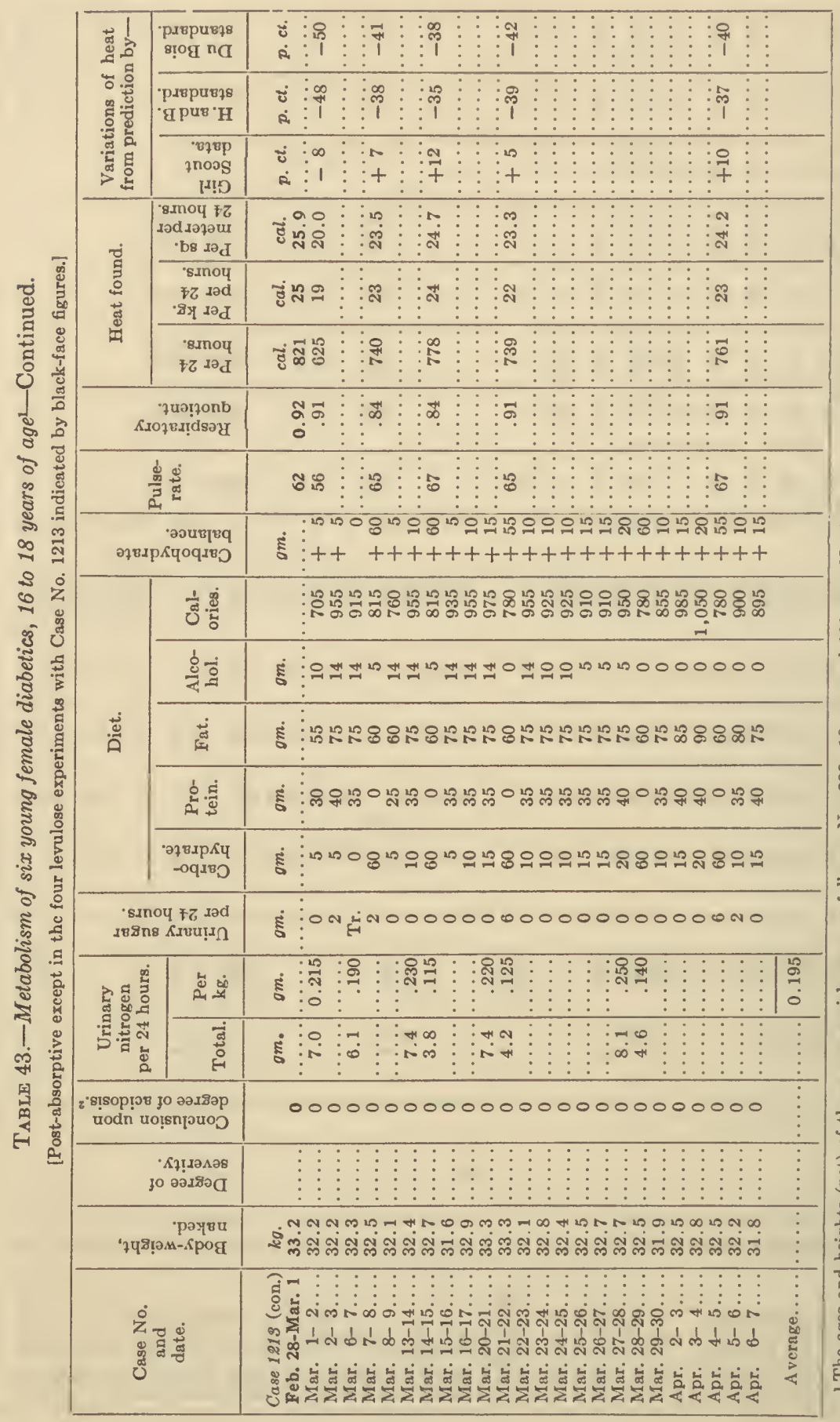


Harris and Benedict standard extended for the purpose (though this standard was never intended for such comparison), and with the Du Bois standard. Such comparative data are presented in table 43 , not so much because of their value from the diabetic standpoint as for their value as a contribution to the question of standards for comparison of the metabolism of individuals of this age, sex, and height.

\section{VARIATIONS IN METABOLISM OF DIABETIC GIRLS, WITH INFLUENCING} FACTORS.

As measured by the Girl Scout values, the lowest metabolism found was -8 per cent, and the highest +64 per cent, an algebraical difference of 72 per cent. Although the heights of these six subjects ranged between 141 and 173 centimeters, a variation of 23 per cent, it is obvious that the body-weights, which varied 137 per cent, or between 25.4 and $60.1 \mathrm{~kg}$., must have been of paramount influence. Yet age, height, and weight are insufficient to account for such radical changes in the metabolism, and a search must be made for other factors. Of these there are four factors which the study of the diabetic material previously presented show to be of significance: (1) the severity of the disease, (2) the caloric intake prior to the date of observation, (3) the degree of acidosis, and (4) the degree of emaciation. Since all these factors did not remain constant in any one case for the entire period of observation, the difficulties of comparison are increased.

Analyzing the material in this way, it will be found that four of these cases of diabetes were severe in type and two moderate. Two of the four severe cases also exhibited severe acidosis, one showed moderate, mild, and no acidosis at different periods, and the remaining case was entirely free from acidosis throughout the period of observation. Of the two severe cases with severe acidosis, one (Case No. 194) was studied in 1910 and the second (Case No. 773) was studied in October, 1914, just as treatment by undernutrition was beginning to be introduced. Since both cases received liberal quantities of food, i. e., about 40 calories per kilogram of body-weight per 24 hours, they may be classed as undergoing treatment similar to that of the great majority of cases prior to June, 1914. The other two severe cases (Nos. 1012 and 1213), with little or no acidosis, were under observation in 1917 and thus are typical of the diabetics who were given the later method of treatment by undernutrition. The two moderate cases of diabetes were studied in 1910 and 1914, the first receiving the liberal diet of early treatment and the other the restricted diet inaugurated in June, 1914. The metabolism of the severe cases may first be discussed, considering (1) the influence of the caloric content of the diet, and (2) the effect of acidosis.

INFLUENCE OF LIBERAL DIET UPON METABOLISM OF SEVERE CASES.

Cases Nos. 194 and 773, the two severe cases who were observed before the change in treatment to undernutrition began, and with whom the acidosis was high, had an average metabolism of 1,512 and 1,339 calories per 24 hours, respectively. On the basis of per kilogram of body-weight per 24 hours, the metabolism of the two girls is in close agreement, averaging respectively 29 and 34 calories per kilogram of body-weight. So, too, by body-surface the agreement is close, namely 38.8 calories and 41.4 calories, respectively, per square meter per hour. When compared with the Girl Scout values, however, 
there is considerable variation, though with both cases there is a marked increase in metabolism over that of the normal group. Case No. 194 presents an average increase above the Girl Scout figures of 27 per cent, and Case No. 773 of 55 per cent. In fact, the latter case on this basis had nearly the highest. metabolism found for any diabetic patient by any method used in this monograph. With the Harris and Benedict and the Du Bois standards, the average metabolism was only slightly above normal in each instance. Thus, the average metabolism by the Harris and Benedict methods for Case No. 194 was +8 per cent and by the Du Bois method -3 per cent. The average metabolism for Case No. 773 by the Harris and Benedict method was +8 per cent and by the Du Bois method +4 per cent. Which of the five standards shall one accept as correct? The standards based on body-weight and body-surface and the Girl Scout values agree in showing an increased metabolism. This was found with other cases studied at this same epoch, and it would appear that this was the case with these two diabetic girls. It is, however, probable that the percentage increases obtained by the use of the Girl Scout figures are so very high in part because the Girl Scouts for the greater part of the time were asleep and the diabetic girls, on the other hand, were for most of the time awake. It would indeed appear natural for the sleeping and resting metabolism of young people to vary proportionately far more than the sleeping and resting metabolism of adults, for young individuals sleep more soundly and, when awake, are more active than adults.

Conservatism in decisions as to the reason for the increased metabolism of these young girls is indicated by the investigations of Blunt, Nelson, and Oleson. ${ }^{a}$ In two groups of underweight children they have shown that the metabolism was higher than to be expected when compared with the Benedict and Talbot standard. ${ }^{b}$ In the first group of 13 children in every instance the metabolism was above the standard and in one case 39 per cent above.

\section{INFLUENCE OF RESTRICTED DIET UPON METABOLISM OF SEVERE CASES.}

Cases Nos. 1012 and 1213, the two severe cases who were treated by the later method in 1917 and who showed little or no acidosis, had an average total basal metabolism of 719 calories and 709 calories, respectively. The diet of these two patients was on a far lower scale than the two severe cases earlier treated and just cited. Case No. 1012 received an average of 16 calories per kilogram on the 20 days appearing in the table between October 4 and December 1, 1917, inclusive, and Case No. 1213 received on the average 26 calories per kilogram on the 45 days recorded in table 43 for February 3 to April 6, 1917, inclusive.

The average metabolism of Case No. 1012 per kilogram of body-weight was 26 calories and of Case No. 1213 was 22 calories in experiments without food. A greater difference between these two patients is indicated when the metabolism is estimated by body-surface. Thus the average calories per square meter of body-surface of Case No. 1012 were 28.3 and of Case No. 1213 were 22.7 in experiments without food. When the Girl Scout figures are used for computing the variation of the metabolism from normal, an average of +17 per cent is found for Case No. 1012 and a much lower average of +4

\footnotetext{
a Blunt, Nelson, and Oleson, Journ. Biol. Chem., 1921, 49, p. 247.

$\checkmark$ Benedict and Talbot, Carnegie Inst. Wash. Pub. No. 302, 1921.
} 
per cent for Case No. 1213. On the other hand, when comparison is made with the Harris and Benedict and the Du Bois standards, it is found that the metabolism is subnormal, and relatively much lower than was estimated by the Girl Scout values. Thus, the average variation by the Harris and Benedict standard for Case No. 1012 was -35 per cent and the average variation by the Du Bois standard was -34 per cent. With Case No. 1213 the average variation was -41 per cent when compared with the Harris and Benedict standard and -43 per cent with the Du Bois standard. Such wide differences in the results secured by using different normal standards for comparison with the metabolism of diabetic girls between 16 and 18 years of age show what an opportunity awaits the investigator for further research. The wide difference in the metabolism of the two earlier cases, Nos. 194 and 773, as compared with the later cases, Nos. 1012 and 1213, is perhaps the most important conclusion to be drawn, because it illustrates the radical alteration in the diabetic treatment and the different conditions under which the diabetics were living when treated by the earlier and later methods.

INFLUENCE OF ACIDOSIS UPON METABOLISM OF SEVERE CASES.

The two severe cases first discussed (Nos. 194 and 773) showed severe acidosis, whereas Case No. 1012 showed moderate, mild, and no acidosis, and Case No. 1213 no acidosis whatsoever. The influence of acidosis is plainly seen by a study of the metabolism per kilogram of body-weight for these four cases, though at the same time one must recognize the simultaneous alteration in the diet. The two severe cases with severe acidosis (Nos. 194 and 773) had the highest metabolism; Case No. 1012 with varying degrees of acidosis was next in order, and the lowest metabolism of the four was found for Case No. 1213 with no acidosis, despite the fact that the caloric intake per kilogram of body-weight was higher than that of Case No. 1012.

The influence of acidosis can be studied directly with Case No. 1012, because this young girl was observed at various stages of acidosis. Perhaps one reason why the effect does not appear more marked in this instance may be attributed to the loss of 22 per cent of body-weight by the patient during the period of observation here given, combined with the fact that she received nearly twice as many calories per kilogram of body-weight in the period without acidosis as in the period with it. That acidosis should still make its influence felt despite these handicaps is notable. When in the stage of moderate acidosis she had an average metabolism of 27 calories per kilogram of body-weight or -32 per cent with the Harris and Benedict standard. When in the stage of slight acidosis, the metabolism was 27 calories per kilogram, or -36 per cent by the Harris and Benedict standard, and with no acidosis 25 calories per kilogram or -40 per cent by the Harris and Benedict standard.

From this study of the four girls with severe diabetes, it is evident that a high caloric intake was directly associated with an increase in metabolism. and that the greater the acidosis, the greater was the increase in metabolism,

METABOLISM OF MODERATELY SEVERE CASES.

The two moderately severe cases, Nos. 333 and 792, agree in showing either very slight acidosis or none at all. Case No. 333 was receiving a diet of about 35 calories per kilogram of body-weight, but Case No. 792 was upon a restricted 
diet, which averaged about 7 calories per kilogram of body-weight for the three days November 29 to December 1, inclusive. Notwithstanding these great variations in caloric intake the total metabolism was essentially the same with each girl, the average metabolism for Case No. 333 for two days being 1,523 calories and for Case No. 792 for two days being 1,478 calories. Upon the body-weight basis the metabolism of Case No. 333 averaged 26 calories and of Case No. 792, 35 calories per kilogram of body-weight per 24 hours. A similar variation is shown when the metabolism is estimated on the body-surface basis. The average metabolism of Case No. 333 was 39.1 calories and of Case No. 792 was 45.6 calories per square meter per hour. By the Girl Scout figures the metabolism of Case No. 333 averaged 17 per cent above normal and that of Case No. 792 was 60 per cent above, the latter being the highest average variation from normal metabolism with any diabetic in this monograph by any standard. The Harris and Benedict and the Du Bois standards gave relatively lower increases in the metabolism over normal, but the relation of the two to one another was preserved. Thus, the average metabolism of Case No. 333 by the Harris and Benedict standard was +6 per cent and by the Du Bois standard -3 per cent. That of Case No. 792 by the Harris and Benedict standard was +18 per cent and by the Du Bois standard +14 per cent.

The outstanding peculiarity of the metabolism of these two moderately severe cases is the relatively high metabolism of Case No. 792. This patient was classed as a moderate diabetic, was nearly free from acidosis, and yet presents the highest average metabolism of any of the 6 cases, notwithstanding that the caloric intake was but 7 calories per kilogram of body-weight. The protocols, however, explain the reason for the high metabolism. This patient first came under observation on November 26, 1914. At that time she showed 5 per cent of sugar in the urine and on November 28, 3.4 per cent. The specific gravities of the urine were, respectively, 1.035 and 1.036. Fortunately the nitrogen was determined in an 11/ $/ 2$-hour specimen of urine for November 29-30, as the patient entered the hospital on November 29. This amounted to 8.26 grams or, calculated on a 24 -hour basis and per kilogram of body-weight, 0.4 gram. This would be equivalent to an excretion of 28 grams nitrogen (175 grams protein) per 24 hours for an adult of $70 \mathrm{~kg}$. It is evident, therefore, that this patient, although on a very much reduced ration from November 29 to December 2 , had in the immediate past lived upon an excessively high-protein diet. Sudden restrictions of the diet are not reflected immediately by a lowering of the metabolism. This has been repeatedly observed with normal individuals during fasting, such as L. at this Laboratory, and Miss L., who was given the dietetic treatment of a diabetic. (See p. 131.) Accordingly the metabolism of Case No. 792 was really high because of excessive food in the immediate past, and bears no especial relation to severity or acidosis.

\section{COMPARISON OF STANDARDS.}

All the standards for estimating the metabolism of these six diabetic cases are unsatisfactory. By the Girl Scout figures it is high. The metabolism of Case No. 792 by this method is 61 per cent and 58 per cent on two successive days. This is said despite the increased metabolism noted in under- 
nourished children by Blunt, Nelson, and Oleson, ${ }^{a}$ but whether it is 15,20 , or at the most, 25 per cent too high, no one can tell. The Du Bois and Harris and Benedict standards on the other hand give low values. They agree in the case of one girl diabetic in registering the metabolism at -50 and -48 per cent respectively. Lusk ${ }^{b}$ states that -37 per cent, obtained with one diabetic patient at the Russell Sage Laboratory, is the lowest recorded in the literature. There is but one below this figure in our series of adult diabetics, namely, Case No. 1085, 35 years of age, whose metabolism, when calculated by both the $\mathrm{Du}$ Bois and Harris and Benedict standards, was -40 per cent, both on October 11 and October $31,1916 .^{\circ}$

On the basis of per kilogram of body-weight and per square meter of bodysurface, the average metabolism of the moderate cases (Nos. 333 and 792) per kilogram of body-weight was 31 calories, and per square meter of bodysurface 42.4 calories. The average metabolism of the early severe cases (Nos. 194 and 773) was essentially the same, being 32 calories per kilogram of body-weight, 40.1 calories per square meter of body-surface, but the average metabolism of the late severe cases (Nos. 1012 and 1213) on the lower diets was only 24 calories per kilogram of body-weight, 25.5 calories per square meter body-surface. It is hard to believe that these girls, while upon a lowered caloric intake (one proof of which is the loss of 28 per cent from maximum weight in about $11 / 2$ years), did have a metabolism above normal. The values obtained with these six young diabetics, therefore, show the need in all metabolic investigations, first, of the same experimental conditions, second, of comparing an individual with disease with an individual who is healthy as well as of like age, height, and weight, and third, living under the influence of a similar caloric intake for weeks rather than days.

\section{RELATION BETWEEN PULSE-RATE AND METABOLISM OF DIABETIC GIRLS.}

The pulse-rates of these young female diabetics were remarkably constant for the individual cases, even though the observations with some of the patients were continued over considerable periods of time. A comparison of the data grouped according to the time of observation (before or after June, 1914) is made in table 44 , in which the metabolism is also included.

The two cases studied before June, 1914, (Nos. 194 and 333) had widely varying average pulse-rates of 61 and 99 beats, respectively. On the other hand, the basal metabolism of these two cases, as represented by the heatoutput per kilogram of body-weight, was essentially the same, the average of three experiments with Case No. 194 being 29 calories, and that for the two experiments with Case No. 333, 26 calories per kilogram of body-weight. Furthermore, when their metabolism is compared with the Girl Scout values (which may here be used for relative reference, case to case, and date to date,

a Blunt, Nelson, and Oleson, Journ. Biol. Chem., 1921, 49, p. 247.

${ }^{b}$ Gephart, Aub, Du Bois and Lusk, Arch. Intern. Med., 1917, 19, p. 908.

c Since this was written, another case has been found with a still lower metabolism. This patient was Case No. 866, whose diabetes had a duration of $83 / 4$ years, and whose body-weight was 50 per cent below normal. On October 14 and 16, 1922, his basal metabolism was 854 and 749 calories, respectively, or 33 to 43 per cent below the Harris and Benedict standard. These percentages were well supported by values obtained in the subsequent three weeks. Ten weeks later, after treatment with insulin (iletin, Lilly) and increase in the amount of food ingested, the metabolism was still 26 per cent below the normal level. See Joslin, Journ. Metabolic Research, 1922, 2, Nos. 5 and 6. 
as well as perhaps any basis of comparison with the relativity inherent), the former had an average metabolism of +27 per cent, and the latter an average metabolism of only +17 per cent. It will be seen, therefore, that the variation in metabolism of Cases Nos. 194 and 333, as registered by these two methods, is distinctly opposed to that indicated by the pulse-rate.

TABLE 44.-Relation of pulse-rate of girl diabetics to heat-output per kilogram of body-weight and variation of metabolism from Girl Scout values.

\begin{tabular}{|c|c|c|c|c|c|}
\hline $\begin{array}{l}\text { Range in } \\
\text { pulse-rate. }\end{array}$ & $\begin{array}{l}\text { Case } \\
\text { No. }\end{array}$ & $\begin{array}{c}\text { Date of } \\
\text { observation. }\end{array}$ & $\begin{array}{l}\text { Pulse- } \\
\text { rate. }\end{array}$ & $\begin{array}{l}\text { Calories } \\
\text { per kg. } \\
\text { of body- } \\
\text { weight. }\end{array}$ & $\begin{array}{l}\text { Percentage varia - } \\
\text { tion of metabolism } \\
\text { from Girl Scout } \\
\text { values. }\end{array}$ \\
\hline \multirow{3}{*}{$\begin{array}{l}\text { Before June, 1914: } \\
51 \text { to } 60\end{array}$} & \multirow{3}{*}{194} & & & & \multirow{6}{*}{$\begin{array}{l}+33 \\
+20\end{array}$} \\
\hline & & Sept. $23-24,1910 \ldots \ldots$ & 60 & 30 & \\
\hline & & Sept. $24-25,1910 \ldots \ldots$ & 59 & 27 & \\
\hline 61 & 194 & Sept. $22-23,1910 \ldots \ldots$ & 64 & 29 & \\
\hline 104 & 333 & May $13-14,1910 \ldots \ldots$ & 104 & 26 & \\
\hline & & May $24-25,1910 \ldots \ldots$ & 94 & 25 & \\
\hline \multirow{3}{*}{$\begin{array}{l}\text { After June, } 1914: \\
51 \text { to } 60\end{array}$} & \multirow[b]{2}{*}{1213} & & & & \\
\hline & & $\begin{array}{l}\text { Feb. } 7-8,1917 \ldots \ldots \\
\text { Mar. } 1-2,1917 \ldots \ldots\end{array}$ & $\begin{array}{l}56 \\
56\end{array}$ & $\begin{array}{l}21 \\
19\end{array}$ & $\begin{array}{r}0 \\
-8\end{array}$ \\
\hline & 1012 & Nov. $20-21,1917, \ldots$. & 56 & 24 & +8 \\
\hline \multirow[t]{13}{*}{$61 \quad 70$} & \multirow[t]{6}{*}{1012} & Oct. $\quad 9-10,1917, \ldots \ldots$ & 62 & 24 & +7 \\
\hline & & Oct. $15-16,1917, \ldots \ldots$ & 64 & 26 & +13 \\
\hline & & Oct. $23-24,1917, \ldots \ldots$ & 64 & 27 & +22 \\
\hline & & Oct. $29-30,1917, \ldots \ldots$ & 69 & 30 & +31 \\
\hline & & Nov. $14-15,1917, \ldots \ldots$ & 69 & 27 & +21 \\
\hline & & Dec. $1-2,1917 \ldots \ldots$ & 65 & 26 & +15 \\
\hline & \multirow[t]{7}{*}{1213} & Feb. $14-15,1917, \ldots \ldots$ & 67 & 23 & +9 \\
\hline & & Feb. $21-22,1917 \ldots \ldots$ & 67 & 22 & +3 \\
\hline & & Feb. 28-Mar. 1, $1917 \ldots$ & 64 & 20 & -6 \\
\hline & & Mar. 7-8, $1917 \ldots \ldots$ & 65 & 23 & +7 \\
\hline & & Mar. $14-15,1917 \ldots \ldots$ & 67 & 24 & +12 \\
\hline & & Mar. $21-22,1917, \ldots \ldots$ & 65 & 22 & +5 \\
\hline & & Apr. $4-5,1917 \ldots \ldots$ & 67 & 23 & +10 \\
\hline 80 & 773 & Oct. $13-14,1914 \ldots \ldots$ & 78 & 32 & +48 \\
\hline 90 & 773 & Oct. $10-11,1914 \ldots \ldots$ & 88 & 36 & +64 \\
\hline & 792 & Nov. 30 -Dec. $1,1914 \ldots$ & 83 & 35 & +61 \\
\hline & & Dec. $1-2,1914 \ldots \ldots$ & 87 & 35 & +58 \\
\hline $91 \quad 100$ & 773 & Oct. $19-20,1914, \ldots \ldots$ & 95 & 33 & +53 \\
\hline
\end{tabular}

After June, 1914, observations with four patients are available for study. These cases conform for the most part to the general rule found with the larger series of diabetics, in that the pulse-rate follows more or less closely the course of the metabolism. In fact, if one compares the pulse-rate of these four young diabetics with either their heat-output per kilogram of bodyweight or the variation in the metabolism from that of the Girl Scouts, there is hardly an exception to the general rule that the pulse-rate varies with the metabolism.

COMPARISON OF METABOLISM AND URINARY NITROGEN OF DIABETIC GIRLS.

The urinary nitrogen of the two moderate cases came within normal limits, averaging 0.150 and 0.175 gram per kilogram of body-weight per 24 hours. The two early severe cases (Nos. 194 and 773) showed 0.205 and 0.245 gram, respectively, per kilogram of body-weight, or an average of 0.225 gram. 
Their metabolism on the Girl Scout basis was increased on the average 41 per cent. In contrast to these cases are the two late severe cases (Nos. 1012 and 1213), who differed from the former, as has already been said, by a lower diet, a greater loss of weight, and much less acidosis. These cases, Nos. 1012 and 1213, respectively, showed an excretion of urinary nitrogen of 0.235 and 0.195 gram per kilogram of body-weight, or an average of 0.215 gram, essentially the same as that of the early cases, yet by the Girl Scout figures the average metabolism of these two cases was 11 per cent, in contrast to that of the early severe cases, which was 41 per cent. This contrast may be noted regardless of the method of comparison employed for the metabolism. The independence of metabolism and urinary nitrogen is thus here beautifully shown. In the special section upon urinary nitrogen the explanation for the varying metabolism with the same values for urinary nitrogen will be given. (See p. 122.)

\section{RESPIRATORY QUOTIENTS OF DIABETIC GIRLS.}

The varying respiratory quotients for these six girl diabetics are significant. It will be observed that the three cases first studied (No. 333, a moderate case, and Nos. 194 and 773, two of the severe cases) had low quotients, their averages being $0.71,0.72$, and 0.74 , respectively. The fourth girl, No. 792, a moderate case, who was studied in November and December, 1914, showed somewhat higher quotients, with an average of 0.82 . The fifth girl in the group, No. 1012, a severe case, was observed late in 1917 and the rise in quotient was still more marked, the average quotient for the eight experiments being 0.83 . Case No. 1213 , the remaining severe case, who was studied in the early part of 1917 , had still higher quotients, these averaging 0.87 . This case was the only one whose rise in quotient was not strictly in chronological sequence. Evidently factors were at work to raise the quotients with these cases, and as time passed the effect of these factors became more pronounced.

The change in diet which took place between 1910 and 1917 in part accounts for the rising quotient. The three early cases were receiving excessive quantities of fat, amounting to not far from 3 to 4 grams per kilogram of bodyweight, in contrast to the last three cases, who seldom exceeded 1 to 1.5 grams of fat per kilogram of body-weight. Evidently the fat rather than the carbohydrate was of influence upon the quotient in the former instance. Although the early cases received far more carbohydrate than the later, they utilized comparatively little of it and so in reality the later cases burned more, which raised their quotients. The protein was lower with the last three cases, but the differences in protein by no means approach the great differences pointed out in the amounts of fat administered per kilogram of body-weight. Fat, therefore, must be looked upon as one of the essential elements in producing the low quotients with the three cases earlier studied.

Acidosis was far more marked in the earlier period of liberal feeding than in the later period of restricted diet. This would be expected from the excessive quantity of fat in the diet of the patients before June, 1914, and even with Case No. 773 in October and November of that year. The effect of the formation of $\beta$-oxybutyric acid upon the respiratory quotient will later be pointed out (see p. 205), and there is no doubt but that the large quantities of acid formed contributed to keep the quotient below that of fat. Carbohy- 
drate was evidently burned to a considerable degree by Case No. 1213 and decidedly more than by any of the earlier cases who showed lower respiratory quotients. But the quantity of carbohydrate burned appears too small in amount to account for the height of the quotient.

Finally, it may be noted from table 43 that with this small series of young diabetics, as with the large series of patients, the respiratory quotient rose as the metabolism fell.

\section{COMPARISON OF RESPIRATORY QUOTIENTS AND URINARY NITROGEN OF} DIABETIC GIRLS.

Too often it is overlooked that the quantity of food metabolized is the important factor in determining the respiratory quotient rather than the quantity of food given. Already this has been commented upon in relation to the varying amounts of carbohydrate and fat administered to these six subjects. Both the quantity of protein in the diet and the quantity of protein metabolized, as shown by the excretion of nitrogen in the urine when studied on the basis of per kilogram of body-weight, varied considerably. It is true that with Case No. 194 the nitrogen per kilogram of body-weight averaged 0.205 gram, and that a similar average was observed with Case No. 773, i. e., $0.245 \mathrm{gram}$. These figures, however, can only partly be explained by the quantities of protein ingested, for Case No. 194 in the four days included in the table received 1.1 grams protein per kilogram of body-weight per day, and Case No. 7731.4 grams per kilogram of body-weight per day, which were by no means excessive quantities. On the other hand, Case No. 1012, receiving 0.9 gram of protein per kilogram of body-weight per day on the days for which the urinary nitrogen is recorded in the table, excreted per kilogram of body-weight 0.235 gram urinary nitrogen per day, which indicates a greater katabolism of protein than intake. In the period October 8 to 16 , when the total intake of protein was 35 grams, the average nitrogen excretion was 0.175 gram per kilogram of body-weight. Between October 22 and November 21, when the protein intake was from 25 to 40 grams a day, save for one day of fasting, the nitrogen excretion was 0.260 gram per kilogram of body-weight. It will also be observed that the respiratory quotients of this patient increased as the urinary nitrogen increased. The increase in urinary nitrogen is partially to be explained by the diet having contained considerably more protein at the same time, partially by the greater metabolism of body protein and perhaps, too, by the extreme stage of inanition which with the adults was found associated with high respiratory quotients.

Case No. 1213 received fairly constant quantities of protein on the days when it was included in the diet, but there were 8 days when no protein was eaten. The excretion of urinary nitrogen fluctuated according to the nature of the diet, but on the average was high. If we compare the urinary nitrogen excretion with the protein intake for the 16 days on which both values are known, it will be seen that the total nitrogen excretion for these 16 days amounted to a total of 111 grams (101.1 grams and 10.0 grams allowance for fecal nitrogen) and the protein intake to a total of 395 grams ( 63 grams nitrogen). There was, therefore, a minus nitrogen balance of 48 grams for these 16 days, i. e., about 0.095 gram per kilogram of body-weight per day. This may have been one factor in the production of the high respiratory quotient, though it could hardly have been a large one. 
BODY-WEIGHT OF DIABETIC GIRLS.

The body-weights of five of the diabetic girls were fairly constant throughout the period of observation. The remaining patient, Case No. 1012, lost $7.1 \mathrm{~kg}$. between October 4 and December 1, inclusive, or 22 per cent, and $6.5 \mathrm{~kg}$., or 20 per cent, between October 9 (the day of the first determination of the metabolism) and December 1. This loss in weight of 20 per cent was accompanied by a fall of 14 per cent in the total metabolism, and by the increased downward variation of the metabolism from the different standards. Here there was as rapid a loss of weight as with the Y. M. C. A. students; indeed, the percentage was twice as large, and yet the fall in metabolism was less.

The data regarding the body-weights of these young female diabetics, including the average weights during the time of observation and the percentage variations from their maximum weights and from the normal weights for their ages and heights, are recorded in table 45. The average metabolism per kilogram of body-weight and the average respiratory quotients are also included for comparison; likewise the duration of the diabetes from the date of onset to death. (See table 3, p. 8.) With Case No. 1012 the average bodyweight is given for the period from October 28 to December 1 only, because during that period the body-weight was nearly constant and the previous weights represented edema.

TABLE 45.-Average body-weight of young female diabetics.

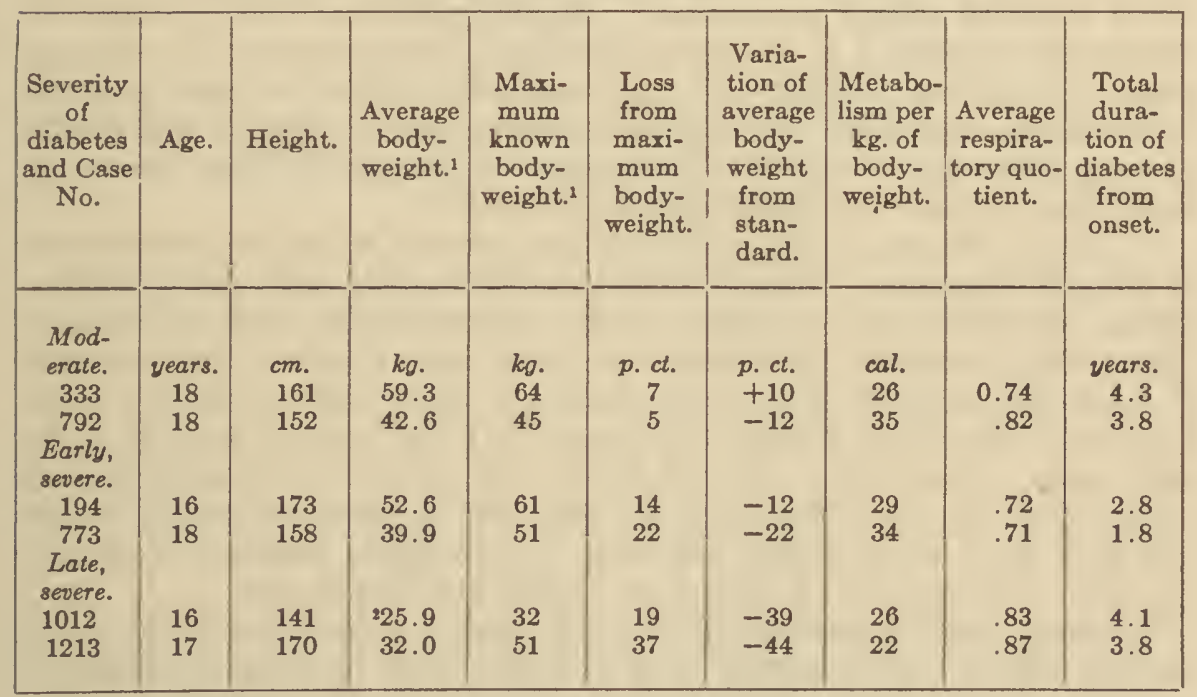

1 Without clothes.

2 With Case No. 1012, the average weight from October 28 to December 1, 1917, is used.

From table 45 it will be seen that with the two moderately severe cases the losses in body-weight from their greatest known weights were trifling, averaging but 6 per cent. With the two early severe cases the average loss in weight from maximum was 18 per cent, and with the two later severe cases 28 per cent. If one examines the variation in weight below the normal standard of 
the four severe cases, it will be found to have increased chronologically from 12 and 22 per cent for the early cases to 39 and 44 per cent for the late cases. At the same time, this is an index of the change in character of dietetic treatment during successive years.

In this connection the total duration of the disease from onset in the entire group of six cases should be considered. The duration in the two cases of moderate severity, Nos. 333 and 792 , was 4.3 years and 3.8 years, respectively, or an average of 4.1 years. The total duration of the early severe cases, Nos. 194 and 773, was distinctly less, 2.8 years and 1.8 years, respectively, or an average of 2.3 years. On the other hand, the total duration of the two cases treated in 1917 was distinctly greater, the duration for Case No. 1012 being 4.1 years and for Case No. 1213, 3.8 years, or an average for the two of 4.0 years, which is approximately the same as that of the two moderate cases who lost the least weight. As far as this table shows, therefore, undernutrition was far less harmful than overnutrition. The increase in duration of life of the later severe cases expresses the prolongation of life which appears to have been brought about by underfeeding in contrast to overfeeding. The greater the loss of weight sustained by a diabetic, the longer is often the duralion of life; the smaller the loss, the shorter is the life, paradoxical as it may seem.

It may be observed here, though it is in anticipation of a more general discussion in the section on the respiratory quotient, that the high respiratory quotient with the severe cases in table 45 occurred when the loss in weight below standard weight was greatest. In the relation of loss of weight to respiratory quotient it is the actual emaciation which counts. If one compares the observed weight with the standard weights for these patients, it will be seen that Case No. 1012 with a respiratory quotient of 0.83 was 39 per cent below normal standard in contrast to Case No. 773, who was 22 per cent below and gave a respiratory quotient of 0.71 .

A study of the metabolism of the six girl diabetics mirrors the metabolism of the adult diabetics. Before 1914, the metabolism was high, after 1914, low. Before 1914 the patients showed marked acidosis, after 1914, no acidosis. The average variation in weight from the normal standard was moderate ( -8 per cent) for the early cases, but marked ( -32 per cent) for the later cases. Case No. 773, though studied in October, 1914, has been included with the early cases. (See p. 95.) As with adults, low quotients contrast with high quotients for the two periods, and the cases with the greatest losses in weight and with the lowered metabolism show a remarkable excretion of urinary nitrogen. The girls who lost the most weight lived the longest.

While the above facts are easily stated in relative terms, when one attempts to discuss the metabolism in terms of standards based on normal individuals, the subject becomes complex and it is plain that more normal data are required by which to measure these girls' metabolism in terms which will carry confidence. By the Girl Scout values the metabolism is extraordinarily high, even reaching +60 per cent, and by the $\mathrm{Du}$ Bois and the Harris and Benedict standards, though these are not strictly applicable to individuals so young, the results are extraordinarily low, even -50 per cent. The need is for a standard based upon observations of normal girls awake, and an auxiliary series for girls abnormal alone in height and weight. 


\section{Relation of Various Constituents of Blood and Urine to Metabolism in Diabetes.}

Not only are both sugar and fat frequently found in excess in the blood of diabetics, but in this disease these products often accumulate without sharing so intimately in the metabolism as with normal individuals. Unfortunately, determinations of the blood sugar, blood fat, and non-protein nitrogen were far less frequently made at the period when these experiments took place than is customary to-day; in fact, blood tests were seldom made prior to June, 1914, but sufficient material has been obtained between that date and 1917 to demand its study.

\section{RELATION BETWEEN METABOLISM AND PERCENTAGE OF SUGAR IN THE BLOOD.}

All of the samples for the blood-sugar tests were secured before breakfast, unless otherwise recorded.

The percentages obtained for the blood sugar, when compared with the metabolism; indicate no general relationship between the two, the values for blood sugar not only varying widely with a constant metabolism, but similar percentages occurring with widely varying metabolism. The average variations of the metabolism from standard likewise show no consistent course

TABLE 46.-Relation between blood sugar, severity, acidosis, and variations of metabolism from standard in post-absorptive experiments with diabetics. (After June, 1914.)

\begin{tabular}{|c|c|c|c|c|c|c|c|c|}
\hline \multirow{2}{*}{$\begin{array}{l}\text { Percentage of } \\
\text { blood sugar. }\end{array}$} & \multirow{2}{*}{$\begin{array}{c}\text { No. } \\
\text { of ex- } \\
\text { peri- } \\
\text { mental } \\
\text { days. }\end{array}$} & \multicolumn{3}{|c|}{$\begin{array}{c}\text { Average variation } \\
\text { of metabolism from } \\
\text { standard with severity - }\end{array}$} & \multicolumn{4}{|c|}{$\begin{array}{c}\text { Average variation } \\
\text { of metabolism from } \\
\text { standard with acidosis- }\end{array}$} \\
\hline & & Mild. & Moderate. & Severe. & 0 & + & $+t$ & $+t+$ \\
\hline 0.05 to 0.11 & 8 & p. ct. & $\begin{array}{l}\text { p. ct. } \\
-5\end{array}$ & $\begin{array}{l}\text { p. ct. } \\
-21\end{array}$ & $\begin{array}{l}\text { p. ct. } \\
-7\end{array}$ & $\begin{array}{l}\text { p. ct. } \\
-2\end{array}$ & $\begin{array}{l}\text { p. ct. } \\
\text {...... }\end{array}$ & $\begin{array}{l}\text { p.ct. } \\
\text {...... }\end{array}$ \\
\hline $\begin{array}{ll}.12 & .20\end{array}$ & 95 & -6 & -8 & -15 & -12 & -11 & -11 & \\
\hline & 89 & -7 & -4 & -14 & -15 & -7 & -13 & -7 \\
\hline .40 & 25 & -6 & +12 & -11 & -11 & -5 & -14 & +3 \\
\hline .43 & 2 & & & +5 & & 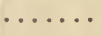 & +5 & \\
\hline $\begin{array}{l}\text { Av. of all ex- } \\
\text { perimental days }\end{array}$ & & -5 & -6 & -14 & -13 & -9 & -12 & \\
\hline No. of days . & 219 & 21 & 52 & 146 & 78 & 53 & 79 & 9 \\
\hline
\end{tabular}

with increasing amounts of blood sugar. Indeed, if the metabolism in and of itself had an effect upon the blood sugar, one would expect to see a more constant and greater change take place in it than occurs in hyperthyroidism. Since, however, a certain relation was observed between the blood sugar and the pulse-rate (see p. 44), an attempt was made to study further the relationships between the blood sugar and the metabolism by grouping the data in table 46 according to the severity of the diabetes. Except in the one observation with a moderate case when the variation from standard was +12 per cent, both the mild and moderate cases had a fairly constant metabolism, but the percentage of blood sugar varied widely. On the other hand, the 
severe cases give a different picture, inasmuch as the metabolism rose as the blood sugar increased. The data are sufficiently numerous to warrant some significance being attached to this mutual change, though the extreme values are both based upon only two experiments. The lowest percentages of blood sugar (0.05 to 0.11$)$ are associated with the unusually low metabolism of 21 per cent below standard and the highest (0.41 to 0.43 ), with the average metabolism of 5 per cent above standard. (Case No. 1085 on November 10 with a blood sugar of less than 0.10 per cent had a post-absorptive metabolism of -40 per cent on October 31.) This definite relation for the severe cases of diabetes between the increasing percentage of blood sugar and increasing metabolism has further interest, in view of the reverse relationship found between the blood sugar and the respiratory quotient, which will be subsequently discussed. (See p. 194.)

Still another effort was made to discover some correspondence between the blood sugar and the metabolism by also grouping the cases in table 46 according to the degree of acidosis. For the diabetic patients entirely free from acidosis and for those with slight acidosis, there is but meager evidence of a relation between the percentage of blood sugar and the metabolism, as the latter altered but little, regardless of whether the percentage of blood sugar was low or high. More decisive evidence is obtained from the nine experiments with patients having a high degree of acidosis, because the percentages of blood sugar are on the whole distinctly larger than with the lower grades of acidosis or with no acidosis. The relationship, however, is less clear than that for the blood sugar, metabolism, and the severity of the diabetes.

From these comparisons it is seen that, in general, the connection between the blood sugar and metabolism is far from intimate. There is, however, a distinct relation between the average percentages of sugar in the blood and the metabolism if the data are grouped according to the severity of the diabetes, although the relationship is paradoxical in that the more nearly normal the blood sugar is, the more subnormal is the metabolism and often the more severe the diabetes. A low blood sugar in diabetes, like a low metabolism may be an expression of inanition. Acidosis, on the other hand, fails to exert any essential influence upon the relation between the blood sugar and the metabolism.

\section{FAT IN THE BLOOD OF DIABETICS.}

In the course of these studies with diabetics, a series of observations was made upon the fat in the blood. The fat estimated was in the form of total fat, as described by Bloor. ${ }^{a}$ The amount obtained by analysis represents about 95 per cent of the total fat in the blood. All of the analyses were made subsequent to June, 1914, and invariably upon blood samples taken when the patient was in the post-absorptive state. It will be recalled that the total quantity of fat in the blood normally approximates 0.70 per cent. The total fatty acids represent the predominant form in which fat appears in the blood, and normally vary in the whole blood between 0.29 and 0.42 per cent. The lecithin is next in amount and varies normally between 0.28 and 0.33 per cent. Cholesterol is least abundant and varies between 0.19 and 0.25 per cent.

a Bloor, Journ. Biol. Chem., 1914, 17, p. 377. See, also, ibid., 1921, 49, p. 201, and Physiol. Reviews, 1922, 2, p. 92. 


\section{Relation of Blood Fat and Severity of Diabetes.}

A study of table 47 brings out the fact that the percentage of total fat rises with the increasing severity of the disease. Thus, the average percentage of fat found in 10 observations on mild cases was 0.79 . In 27 observations upon cases of moderate severity, the percentage of blood fat was 0.93 , and in 90 observations upon severe cases of diabetes was 1.48. These general relations are also found to exist if the data are studied in detail according to the grouping of individual tests by the increasing percentages of blood fat. With the mild cases the blood fat did not exceed in any test 1.03 per cent, and 90 observations with the severe cases gave only 12 instances in which the blood fat was below 0.76 per cent.

TABLE 47.-Relation of fat in the blood to severity and acidosis in experiments with diabetics. ${ }^{1}$

\begin{tabular}{|c|c|c|c|c|c|c|c|c|}
\hline \multirow[b]{2}{*}{ Condition. } & \multicolumn{7}{|c|}{ Days with blood-fat determinations of- } & \multirow{2}{*}{$\begin{array}{l}\text { Average } \\
\text { blood } \\
\text { fat. }\end{array}$} \\
\hline & $\begin{array}{l}0.59 \\
\text { to } \\
0.75 \\
\text { p. ct. }\end{array}$ & $\begin{array}{l}0.76 \\
\text { to } \\
1.00 \\
\text { p. ct. }\end{array}$ & $\begin{array}{l}1.01 \\
\text { to } \\
1.25 \\
\text { p. ct. }\end{array}$ & $\begin{array}{l}1.26 \\
\text { to } \\
1.50 \\
\text { p. ct. }\end{array}$ & $\begin{array}{l}1.51 \\
\text { to } \\
1.75 \\
\text { p. ct. }\end{array}$ & $\begin{array}{l}1.76 \\
\text { to } \\
2.00 \\
\text { p. ct. }\end{array}$ & $\mid \begin{array}{c}2.01+ \\
\text { p. ct. }\end{array}$ & \\
\hline 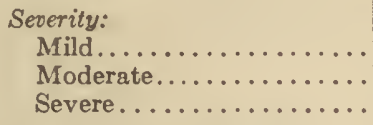 & $\begin{array}{r}4 \\
10 \\
12\end{array}$ & $\begin{array}{r}5 \\
11 \\
26\end{array}$ & $\begin{array}{r}1 \\
3 \\
24\end{array}$ & ${ }_{i 1} \ldots$ & $\ddot{1}$ & $\begin{array}{l}\cdots \\
2\end{array}$ & $\begin{array}{c}\cdots \cdots \\
\cdots \\
11\end{array}$ & $\begin{array}{l}\text { p. } c t . \\
0.79 \\
.93 \\
1.48\end{array}$ \\
\hline Total experimental days.... & 26 & 42 & 28 & 11 & 5 & 4 & 11 & 1.31 \\
\hline $\begin{array}{c}\text { Acidosis: } \\
0 \\
+ \\
++ \\
+++\end{array}$ & $\begin{array}{l}3 \\
3 \\
9 \\
1\end{array}$ & $\begin{array}{c}6 \\
7 \\
10 \\
\cdots \cdots\end{array}$ & $\begin{array}{l}7 \\
2 \\
5 \\
4\end{array}$ & $\begin{array}{c}7 \\
\cdots \\
1 \\
\cdots\end{array}$ & \begin{tabular}{l}
\multicolumn{2}{c}{3} \\
$\cdots \cdots$ \\
$\cdots \cdots$ \\
$\cdots \cdots$
\end{tabular} & $\begin{array}{c}2 \\
\cdots \\
1 \\
\cdots\end{array}$ & $\begin{array}{c}\cdots \cdots \\
\cdots \\
\cdots \\
\cdots\end{array}$ & $\begin{array}{l}1.19 \\
0.87 \\
1.91 \\
1.02\end{array}$ \\
\hline Total experimental days..... & 16 & 23 & 18 & 8 & 3 & 3 & 8 & 1.44 \\
\hline
\end{tabular}

1 Estimation of acidosis within two days before or after the date of the blood-fat determinations.

Relation Between Blood Fat and Acidosis.

One would naturally anticipate that the relation between blood fat and acidosis would be very close, because of the predominant formation of acid bodies from fat. The facts in table 47 , however, speak otherwise. Thus, the highest average value for blood fat, namely, 1.91 per cent, was found for the cases with moderate acidosis, while for the five cases with severe acidosis the average was distinctly less, being 1.02 per cent, and the cases with no acidosis had a higher percentage of fat than either those with + or +++ acidosis. Furthermore, a study of the distribution of the values for moderate acidosis makes it evident that of itself acidosis was not a controlling factor in this series.

\section{Relation Between Blood Fat and Metabolism.}

A comparison has also been made of the blood fat and the metabolism. In this comparison the data for the blood fat were obtained within seven days of the observation of the metabolism and not in all instances on the morning 
before the experiment or even upon the adjacent days. This variation in time seems partly justifiable, because changes in blood fat take place much more slowly than changes in blood sugar.

The series of observations in table 48 indicate a definite relation between blood fat and metabolism, the metabolism decreasing as the percentage of blood fat increased. The patients with the lowest blood fat had an average metabolism of -5 per cent, but when the blood fat was highest, i. e., over 2 per cent, the average metabolism was -25 per cent. The association of high blood fat with severity of the disease and with low pulse-rate has already been pointed out. It is possible that this association of a low metabolism with high blood fat simply results from a common cause and is not in direct connection.

TABLE 48.-The relation between blood fat and percentage variation in metabolism from standard in post-absorptive experiments with diabetics. (After June, 1914.)

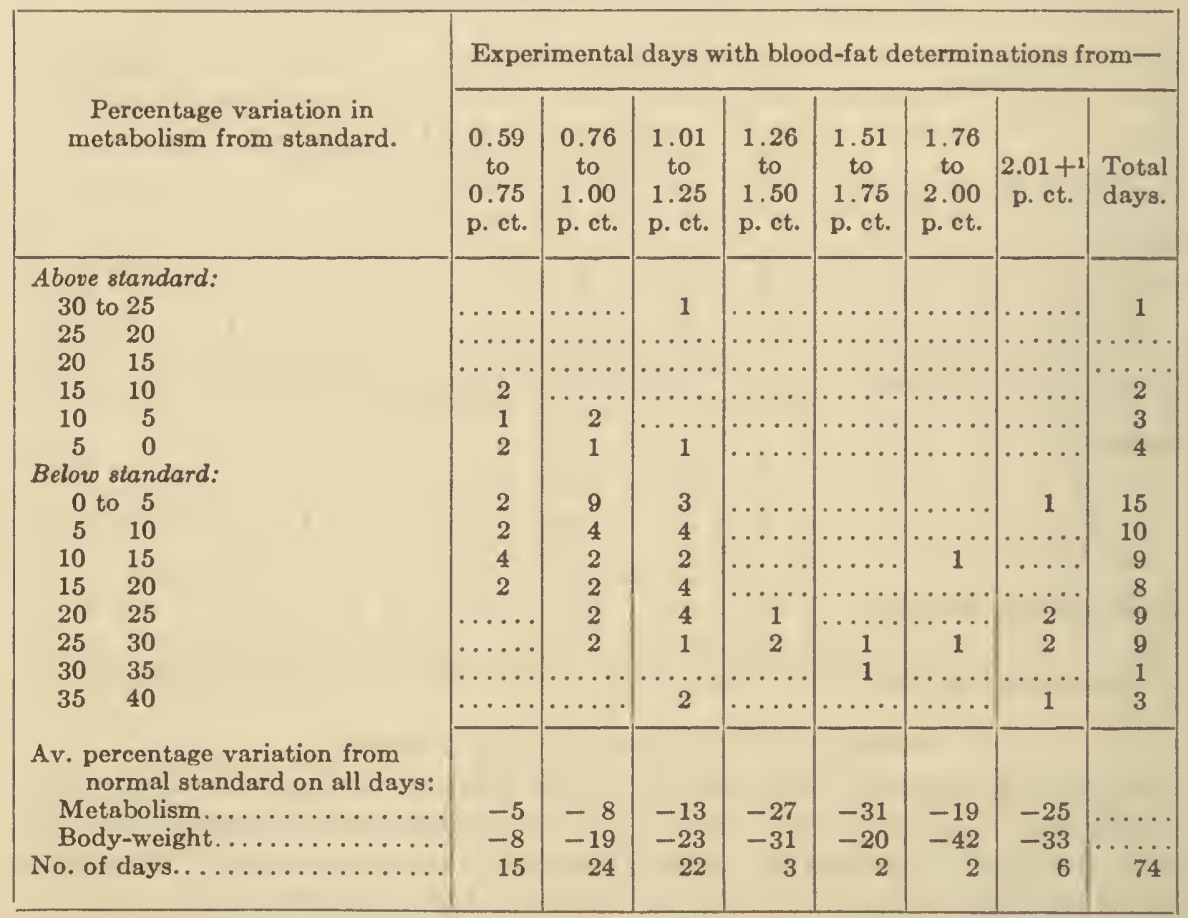

1 The following patients made up this group: Case No. 786, blood fat 8.90 p. ct., variation of metabolism from standard -5 p. ct.; Case No. 786, blood fat 2.28 and 4.44 p. ct., variations from standard -24 and -23 p. ct., respectively; Case No. 1085, blood fat 2.94 p. ct., variation from standard -30 p. ct.; Case No. 1233 , blood fat 3.67 p. ct., variation from standard -28 p. ct.; Case No. 1085 , blood fat 2.74 p. ct., variation from standard -40 p. ct.

One factor exerting an influence upon both the metabolism and the blood fat is body-weight. In a previous discussion of body-weight and metabolism, it was pointed out that the cases with the lowest metabolism were those who were the most below standard body-weight. (See p. 74.) The patients whose blood-fat values averaged nearest normal had a body-weight 8 per cent below standard, and as the blood fat increased in quantity, there was a 
steady loss in body substance. Here, therefore, are three factors which are found in relation-increase in blood fat, a low metabolism, and a loss of body-weight. It is suggestive that with increase in blood fat, the respiratory quotient rises. However, with evidence based upon so few analyses of the fat in the blood, one hesitates to speculate upon the significance of the data recorded.

Table 49 gives a series of blood-fat values which were obtained from 11 analyses for six patients when the blood fat was above 1.50 per cent. All of these cases were severe, except the moderate case No. 1265. None of the values were associated with extreme acidosis, and, except in one instance, even moderate acidosis did not appear until the percentage of blood fat amounted to about 2.25 per cent. The blood sugar obtained within 24 hours of the observation ranged from 0.13 to 0.35 per cent, the higher values usually appearing with the higher blood fats. The body-weight was invariably below the normal standard, the variation amounting to as much as 48 per cent in one case, and never less than 18 per cent. With two exceptions, the metabolism of these individuals was likewise very low. Incidentally this table shows that as the blood fat rose there was a tendency for the respiratory quotient to fall and for acidosis to develop.

TABLE 49.-Relation of high percentages of blood fat of diabetics to variation in body-weight from standard, and to metabolism in post-absorptive experiments.

\begin{tabular}{|c|c|c|c|c|c|c|}
\hline $\begin{array}{l}\text { Case } \\
\text { No. }\end{array}$ & $\begin{array}{l}\text { Date of blood-fat } \\
\text { determination. }\end{array}$ & $\begin{array}{l}\text { Blood } \\
\text { fat. }\end{array}$ & $\begin{array}{l}\text { Variation of body- } \\
\text { weight from } \\
\text { normal standard. }\end{array}$ & $\begin{array}{l}\text { Variation of } \\
\text { metabolism } \\
\text { from standard. }\end{array}$ & $\begin{array}{l}\text { Respi- } \\
\text { ratory } \\
\text { quotient. }\end{array}$ & $\begin{array}{l}\text { Aci- } \\
\text { dosis. }\end{array}$ \\
\hline $\begin{array}{r}1213 \\
1233 \\
\\
1011 \\
1265 \\
786 \\
1085 \\
\\
1233 \\
786\end{array}$ & $\begin{array}{l}\text { Mar. } 14,1917 \ldots \ldots \\
\text { Feb. } 19,1917 \ldots \ldots \\
\text { Mar. } 5,1917 \ldots \ldots \\
\text { Oct. } 8,1917 \ldots \ldots \\
\text { Nov. } 20-21,1917 . \\
\text { June } 28,1916 \ldots \ldots \\
\text { Oct. } 31,1916 \ldots \ldots \\
\text { Oct. } 30,1916 \ldots \ldots \\
\text { Jan. } 30,1917 \ldots \ldots \\
\text { June } 22,1916 \ldots \ldots \\
\text { June } 14,1916 \ldots \ldots\end{array}$ & $\begin{array}{l}p . c t . \\
1.52 \\
1.51 \\
1.52 \\
1.76 \\
1.81 \\
2.28 \\
2.74 \\
2.94 \\
3.62 \\
4.44 \\
8.90\end{array}$ & $\begin{array}{c}p . c t . \\
-43 \\
-22 \\
-18 \\
-48 \\
-36 \\
-30 \\
-46 \\
-46 \\
-20 \\
-25 \\
-32\end{array}$ & $\begin{array}{r}p . c t . \\
\left({ }^{1}\right) \\
-33 \\
-29 \\
-26 \\
-11 \\
-24 \\
-40 \\
-30 \\
-28 \\
-23 \\
-5\end{array}$ & $\begin{array}{r}0.84 \\
.86 \\
.85 \\
.85 \\
.84 \\
.84 \\
.81 \\
.70 \\
.74 \\
.78 \\
.78\end{array}$ & $\begin{array}{l}0 \\
0 \\
0 \\
++ \\
0 \\
++ \\
++ \\
++ \\
++ \\
++ \\
++\end{array}$ \\
\hline
\end{tabular}

1 In the experiment used for comparison with blood-fat determination the variation in metabolism was +12 p. ct. by comparison with the Girl Scout values.

\section{RELATION BETWEEN METABOLISM AND NON-PROTEIN NITROGEN IN THE BLOOD.}

Values for the non-protein nitrogen in the blood are available in connection with metabolism experiments in but 17 instances and therefore merit only brief notice. In four experiments with four cases the non-protein nitrogen in the blood was very low, in seven experiments with five cases the nonprotein nitrogen was within normal limits, and in six experiments with three cases it was above normal. With two of these cases other evidence favored a very slight renal insufficiency far out of proportion to the high non-protein nitrogen; with the third the high non-protein nitrogen might have been con- 
nected with pregnancy. These values are recorded in table 50 and associated with them are details regarding the body-weight, the urinary nitrogen, the blood sugar, the metabolism, and respiratory quotient.

The non-protein nitrogen in this small series gradually rose as the bodyweights successively fell below the normal standard for the cases represented in these three groups, but the table is rendered obscure by the fact that Case No. 1182 weighed above rather than below standard. A high non-protein nitrogen was, however, most common with the diabetics whose weights were most below the normal standard for their age, height, and sex, i. e., with individuals who had lost very materially in weight.

TABLE 50.-Relation of non-protein nitrogen in blood to post-absorptive metabolism in experiments with diabetics.

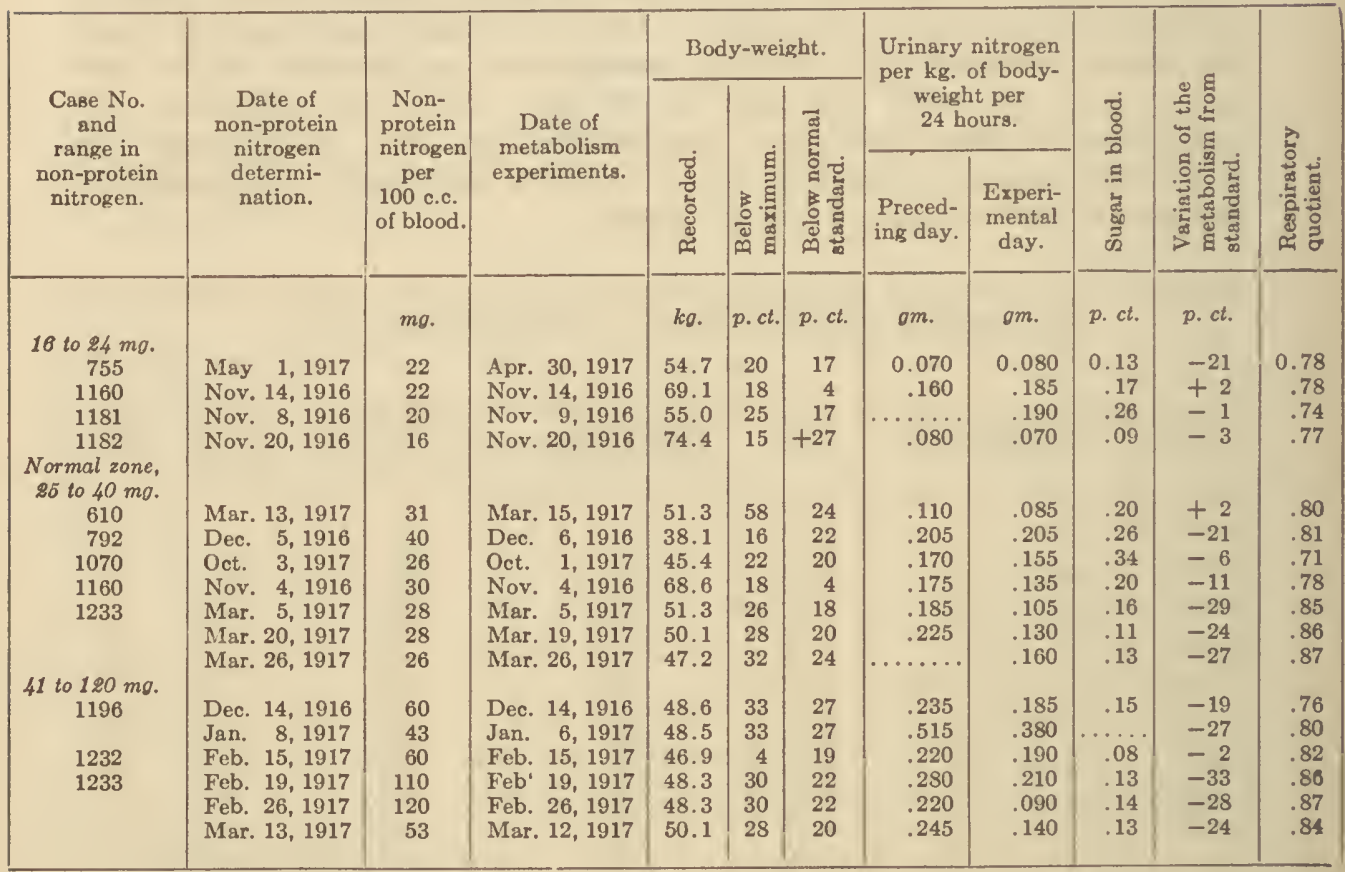

The non-protein nitrogen varied with considerable regularity with the urinary nitrogen for the preceding day, indicating that the high non-protein nitrogen values were not due to lack of power on the part of the kidneys to remove nitrogen from the blood.

The table suggests no connection between the percentage of sugar in the blood and the non-protein nitrogen, save for the three cases with high values for non-protein nitrogen. This group of patients showed nearly normal blood-sugar values, the average being 0.13 per cent. 'Thus, two of the patients with the greatest reduction in weight below standard, the highest excretion of urinary nitrogen per kilogram of body-weight, and the lowest blood sugar agree in having high percentages of non-protein nitrogen in the blood. 
The metabolism varied inversely with the non-protein nitrogen. The average variation of the metabolism from standard for the group with low non-protein nitrogen was -6 per cent, for the group with normal non-protein nitrogen it was -17 per cent, and for the group with the highest non-protein nitrogen the average variation was -22 per cent.

The respiratory quotient, on the other hand, directly followed the course of the non-protein nitrogen. With the lowest values, it averaged 0.77 , with the normal values, 0.81 , and with the group of the highest non-protein nitrogen values, the average was 0.83 .

While not wishing to attach undue importance to this limited series of cases, the facts herewith brought out regarding the non-protein nitrogen and its various relations suggest that the high values obtained were due to an unusual activity in protein metabolism, with retention not attributable to diseased kidneys. The evidence is consistent with one explanation of the high respiratory quotients observed with some of the patients and to be described in the section discussing the respiratory quotients. (See p. 184.) According to this theory, such quotients were due to the katabolism of the protein molecule, the oxidation of the carbohydrate portion, and the retention of the non-carbohydrate portion, the latter condition presumably being connected with the need of the body for new protein synthesis.

\section{RELATION BETWEEN METABOLISM AND URINARY SUGAR.}

In this study with diabetics the observations of the metabolism usually began about two hours after the collection of the urine for the preceding 24 hours had been completed. By a comparison of the values obtained it has been found that a certain relation exists between the metabolism of the diabetic and the quantity of sugar excreted in the urine of the preceding day. This relationship is clearly seen from the data recorded in table 51. Thus, when the sugar in the urine amounted to 101 grams or more, the average metabolism of the patient in the post-absorptive state before June, 1914, was 17 per cent above standard; after June, 1914, it was 11 per cent above standard. When sugar was absent from the urine, the metabolism prior to June, 1914, was but 8 per cent above standard, but after June, 1914, the average metabolism, as determined in 147 experiments, was -12 per cent. Freedom of the urine from sugar was associated with a lowering of the metabolism both before and after June, 1914.

The highest maximum variation in the metabolism of +33 per cent was observed after June, 1914, with a patient showing approximately 170 grams of sugar in the urine for the preceding 24 hours; the lowest minimum metabolism of -40 per cent also occurred after June, 1914, with a patient with but 15 grams of sugar in the urine.

Between the extremes of sugar-free urine and a content of over 100 grams of sugar, the transitions from low to high metabolism are not uniform. It appears to make comparatively little difference, so far as the metabolism is concerned, whether the urine is sugar-free or contains even as much as 50 grams of sugar. Amounts above this latter quantity, however, are related to the metabolism, because both before and after June, 1914, when the sugar in the urine was between 51 and 100 grams, the metabolism rose somewhat. It can be stated, therefore, that the metabolism of a patient voiding over 
100 grams of sugar is almost invariably increased. Evidently exceptions to this rule exist, because after June, 1914, there was one case in this group whose metabolism reached a minimum of 23 per cent below standard.

Table 51 indicates again the danger of extremes in metabolism. High metabolism results when the urine is allowed to contain much sugar, and a dangerously low metabolism may occur when the patient is sugar-free.

TABLE 51.-Relation between urinary sugar and metabolism of diabetics before and after June, 1914.

\begin{tabular}{|c|c|c|c|c|c|c|}
\hline \multirow{2}{*}{ Metabolism. } & \multicolumn{6}{|c|}{$\begin{array}{l}\text { Variations of metabolism from standard for grams of } \\
\text { urinary sugar in preceding } 24 \text { hours ranging from- }\end{array}$} \\
\hline & 0 & 1 to 5 & 6 to 25 & 26 to 50 & 51 to 100 & ${ }^{1} 101+$ \\
\hline $\begin{array}{r}\text { Before June, 1914: } \\
\text { Maximum... } \\
\text { Minimum... }\end{array}$ & $\begin{array}{l}\text { p. ct. } \\
+18 \\
-9\end{array}$ & $\begin{array}{l}\text { p. } c t \\
+17 \\
+8\end{array}$ & $\begin{array}{l}\text { p. } c t \\
+24 \\
-8\end{array}$ & $\begin{array}{l}\text { p. } c t \\
+15 \\
-6\end{array}$ & $\begin{array}{l}\text { p. } c t \\
+27 \\
-2\end{array}$ & $\begin{array}{l}\text { p. } c t \\
+31 \\
+2\end{array}$ \\
\hline $\begin{array}{r}\text { Average... } \\
\text { No. of days...... }\end{array}$ & $+\begin{array}{r}8 \\
5\end{array}$ & $\begin{array}{r}+13 \\
3\end{array}$ & $+\begin{array}{r}4 \\
13\end{array}$ & $\begin{array}{r}8 \\
9\end{array}$ & $\begin{array}{r}+11 \\
32\end{array}$ & $\begin{array}{r}+17 \\
38\end{array}$ \\
\hline $\begin{array}{r}\text { After June, 1914: } \\
\text { Maximum... } \\
\text { Minimum... }\end{array}$ & $\begin{array}{l}+12 \\
-36\end{array}$ & $\begin{array}{l}+5 \\
-35\end{array}$ & $\begin{array}{l}+19 \\
-40\end{array}$ & $\begin{array}{l}+13 \\
-37\end{array}$ & $\begin{array}{l}+28 \\
-31\end{array}$ & $\begin{array}{l}+33 \\
-23\end{array}$ \\
\hline $\begin{array}{r}\text { Average... } \\
\text { No. of days..... }\end{array}$ & $\begin{array}{r}-12 \\
147\end{array}$ & $\begin{array}{r}-11 \\
28\end{array}$ & $\begin{array}{r}-12 \\
42\end{array}$ & $\begin{array}{r}-11 \\
10\end{array}$ & $\begin{array}{r}-6 \\
18\end{array}$ & +11 \\
\hline
\end{tabular}

1 Range of sugar values in this group was 102 to 452 grams before June, 1914, and 102 to 170 grams after June, 1914.

\section{Nitrogen Excretion in the URINe.}

The nitrogen excretion in the urine was extensively studied in this series of experiments, analyses being available for the 24-hour excretion on 319 of the experimental days on which the 456 post-absorptive experiments were made and on 155 of the experimental days on which the 205 food experiments were made. In addition to these data, determinations are on record representing the nitrogen excretion on 1,107 days in periods other than the experimental days. Frequently one determination represents an aliquot of the nitrogen in the urines combined for several days. ${ }^{a}$

Many of the nitrogen values obtained were for the day immediately preceding the experiment. These data are really better for studies upon the relationship between the urinary nitrogen and the post-absorptive metabolism than data for the experimental day itself, because they represent the dietary conditions in the 24 hours immediately preceding the observation of the metabolism, whereas the nitrogen for the day of the test represents the few hours of the actual experimental period in the earlier part of the day and the large remainder of the 24 hours during which changes in diet (usually restrictions) may have been made.

\footnotetext{
${ }^{a}$ Food and fasting experiments frequently occurred on the same day, which accounts for the apparent discrepancy between the total number given here of experimental days on which nitrogen determinations were made and the number stated on page 113 .
} 
Before June, 1914, the nitrogen excretion, based upon 37 cases, is known for 458 days, and subsequent to June, 1914, for 75 cases for 1,050 days. The data, therefore, are so extensive that they give a clear picture of the diabetic nitrogenous metabolism both before and after June, 1914. The diabetic patients varied so much in weight that the nitrogen excretion will be discussed, for comparative purposes, as grams per kilogram of body-weight per 24 hours.

Prior to June, 1914, the diabetic patient excreted on the average 0.265 gram of urinary nitrogen per kilogram of body-weight. After June, 1914, the excretion averaged about one-third less, or 0.185 gram per kilogram of body-weight. This latter quantity, computed as protein, would amount to a little over 1 gram of protein per kilogram of body-weight. This is generally considered as an ample allowance of protein for a normal individual, though it is possible to exist with even a third less. ${ }^{a}$ Perhaps the fact that the nitrogen excretion was not further reduced after June, 1914, is due not so much to the character and the amount of the food ingested as to the undernourishment of the patients during this period, which obliged them to draw upon body protein for energy. If more calories are supplied, either in carbohydrate or fat, the quantity of nitrogen metabolized and, in consequence, excreted may be decreased. Until the recent work of Marsh, Newburg, and Holly, ${ }^{b}$ it has generally been believed that unless a considerable proportion (10 per cent) of the total calories is supplied in the form of carbohydrate, the protein metabolism is not greatly decreased. These writers, however, have shown that nitrogen balance can be maintained when the carbohydrate is but 3.8 per cent of the total caloric intake, the remainder of the diet being made up of 0.68 gram of protein per kilogram of body-weight and of fat sufficient to bring the total energy of the diet up to 33 calories per kilogram of body-weight. It is surely very important for diabetic patients to be kept in nitrogen equilibrium save for temporary periods, if by analogy protein loss is regained with as great difficulty as loss in weight.

Strange figures are often encountered for the urinary nitrogen with diabetic patients. It is desirable to call attention to such instances because the nitrogen excretion is more and more employed in planning the treatment of a patient.c Thus, Case No. 1673, once a patient at the New England Deaconness Hospital, and later cared for elsewhere, according to A. A. Hornor presented the anomaly of a minus nitrogen balance amounting to 8.7 grams daily for a period of 6 days. When, however, the nitrogen was quantitated in the broths and bouillon cubes which the boy received, the explanation was found, because this amounted to 8 grams, and thus offset the nitrogen loss. This same boy also voided between 19 and 24 grams of sodium chloride daily, and the source of this large excretion was likewise found in the broths and bouillon cubes. The protocols of our cases, particularly those with low nitrogen values, have been examined for possible errors of this sort. At the time of these examinations broth was little used; it was made especially weak, and it is estimated that these cases received less than 0.1 gram nitrogen in this form per day and frequently none whatsoever. Some of the patients received 0.3 gram nitrogen in the form of coffee jelly. Possible errors on

a Sherman, Journ. Biol. Chem., 1920, 41, p. 97.

${ }^{b}$ Marsh, Newburg, and Holly, Arch. Intern. Med., 1922, 29, p. 97.

' Shaffer, Journ. Biol. Chem., 1922, 50, p. 26. 
account of bran biscuits seldom arose. There is still another factor: many of these patients were of light weight; consequently an error of 6 grams protein would be equivalent to twice that in a man of medium weight.

\section{INDIVIDUAL VARIATIONS IN EXCRETION OF URINARY NITROGEN.}

Individual variations in the nitrogen excretion were considerable both before and after June, 1914. Prior to June, 1914, the lowest excretion of urinary nitrogen per kilogram of body-weight per 24 hours was 0.080 gram (Case No. 707) and the highest excretion was 0.835 gram (Case No. 550), representing a total excretion for the 24 hours of 4.1 grams and 48.3 grams, respectively, when calculated according to the patients' weights, or 4.8 grams and 50.1 grams when calculated for an individual with a body-weight of $60 \mathrm{~kg}$.

The nitrogen excretion for Case No. 550 was not only the highest value obtained before June, 1914, but was the highest value noted for the entire series of patients. This patient was an Italian, the only one of the 113 cases not finally traced, who just before commencement of treatment voided in 24 hours 7,000 c. c. of urine containing 48.3 grams of nitrogen. This illustrates the large quantity of protein food which an untreated diabetic consumes.

After June, 1914, the lowest excretion of nitrogen per kilogram of bodyweight was that of Case No. 1207, amounting to 0.050 gram, and the highest was 0.515 gram for Case No. 1011. It is of particular interest that the latter case showed upon another occasion a nitrogen excretion of 0.055 gram per kilogram of body-weight.

A discussion of individual cases will be of advantage, because of the different reasons which may be adduced to account for the low and high urinary nitrogen values.

\section{Low Nitrogen Excretion.}

The very low excretion of urinary nitrogen of Case No. 707, mentioned above, i. e., 0.080 gram per kilogram of body-weight, took place in May, 1914 , just a month before the date taken as a dividing-line for the beginning of treatment by undernutrition. The amounts of nitrogen excreted by this individual for several days at this period are given in table 52, which clearly demonstrates the reasons for these low nitrogen values. It will be observed that the patient was receiving a diet containing a large number of calories, which were chiefly obtained from fat. Except for three days (May 15-16, 18-19, and 20-21), one of which was an "oatmeal day," the amounts of protein and carbohydrate in the diet were low. For example, on May 16-17 the diet consisted of three eggs and $180 \mathrm{c}$. c. of olive oil. The diet on the two days following also contained an excessive amount of fat, with a relatively small amount of protein. May 19-20 was a fast day in preparation for the "oatmeal day" to follow. The data for this case, therefore, represent a transition period of treatment. They are presented here to illustrate that with a large caloric intake, even though the amount of carbolyydrate is extremely small, the nitrogen excretion can be depressed to a very low degree, in this instance to 4.1 grams, or 0.080 gram per kilogram of body-weight.

After June, 1914, the low values for urinary nitrogen were due to two causes. First, they were associated with obese patients who had been 
placed upon a very low diet or even fasted, and second, they were obtained with diabetic patients in a stage of extreme inanition, often combined with a diet actually low in calories or whose net caloric value was low for the patient in question, because unassimilated. Thus Case No. 1026, whose weight was 98 kilograms, or 59 per cent above normal, voided 0.055 gram nitrogen per kilogram of body-weight upon April 24-25, 1916, having taken but 6 calories per kilogram of body-weight per 24 hours for the preceding 16 days. Case No. 983 was another obese woman, weighing $91 \mathrm{~kg}$., or 44 per cent above normal. Following an average caloric intake per day of 1 calorie per kilogram of body-weight for five days, she excreted upon a fasting day 0.060 gram nitrogen per kilogram of body-weight. Case No. 1207, a woman with a body-weight of $88 \mathrm{~kg}$., or 43 per cent above normal, excreted upon a fasting day 0.050 gram nitrogen per kilogram of body-weight. These three individuals, excreting a low quantity of nitrogen, may be placed in comparison with Case No. 707, just cited, who also had a low nitrogen excretion. The three fat women protected their body protein by their endogenous fat, while the latter (the thin boy) protected it by the excessive quantity of fat which he ingested.

TABLE 52.-Unusually low excretion of urinary nitrogen upon a high-fat low-protein and lowcarbohydrate diet.

[Case No. 707. Male; age, 17 years; height, 176 centimeters.]

\begin{tabular}{|c|c|c|c|c|c|c|c|c|c|c|c|c|}
\hline \multirow{3}{*}{ Date. } & \multirow{3}{*}{$\begin{array}{l}\text { Body- } \\
\text { weight, } \\
\text { naked. }\end{array}$} & \multicolumn{6}{|c|}{ Urine per 24 hours. } & \multicolumn{4}{|c|}{ Diet. } & \multirow{3}{*}{ 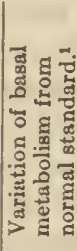 } \\
\hline & & \multirow{2}{*}{$\begin{array}{l}\text { Vol- } \\
\text { ume. }\end{array}$} & \multirow{2}{*}{$\begin{array}{l}\text { Dia- } \\
\text { cetic } \\
\text { acid. }\end{array}$} & \multirow{2}{*}{$\mathrm{NH}_{3}$. } & \multicolumn{2}{|c|}{ Nitrogen. } & \multirow[b]{2}{*}{ Sugar. } & \multirow[b]{2}{*}{ C. } & \multirow[b]{2}{*}{ P. } & \multirow[b]{2}{*}{ F. } & \multirow{2}{*}{$\begin{array}{l}\text { Cal- } \\
\text { ories. }\end{array}$} & \\
\hline & & & & & Total. & $\begin{array}{l}\text { Per kg. } \\
\text { of body- } \\
\text { weight. }\end{array}$ & & & & & & \\
\hline $\begin{array}{l}1914 \\
\text { May } 15-16\end{array}$ & $k g$. & c. c. & & $g m$. & $\mathrm{gm}$. & $\mathrm{gm}$ & $g m$. & $\mathrm{gm}$. & $\mathrm{gm}$. & $g m$. & & p. ct. \\
\hline $\begin{array}{l}\text { May } 15-16 \\
\text { May } 16-17\end{array}$ & 51.8 & 900 & ++ & & 5.9 & 0.115 & 18 & 50 & 30 & 185 & 1,985 & \\
\hline $\begin{array}{l}\text { May } 16-17 \\
\text { May } 17-18\end{array}$ & 51.7 & 570 & +++ & & 4.1 & .080 & 5 & 0 & 20 & 200 & 1,880 & $-\varepsilon$ \\
\hline $\begin{array}{l}\text { May } 17-18 \\
\text { May } 18-19\end{array}$ & 51.7 & 570 & $++t$ & 2.7 & 4.8 & .095 & Tr. & 15 & 20 & 115 & 1,175 & -4 \\
\hline May $18-19$ & 51.7 & 900 & +++ & 3.1 & 7.5 & .14 & 7 & 35 & 45 & 145 & 1,625 & 0 \\
\hline May $19-20$ & 52.2 & 900 & +++ & 3.8 & 7.8 & .150 & 7 & 0 & 0 & 0 & & +1 \\
\hline May 20-21 & 51.6 & 720 & ++ & 2.2 & 6.7 & .130 & 29 & 115 & 40 & 105 & 1,565 & \\
\hline May 21-22 & 52.5 & 540 & $\ldots \ldots$ & 3.1 & 5.5 & .105 & & 35 & 20 & 100 & 1,120 & -6 \\
\hline May 22-23 & 52.8 & & & & & & & & & & & -12 \\
\hline
\end{tabular}

1 Respiratory quotient (0.73) was determined only on May 22-23, 1914.

Examples of a low urinary excretion of nitrogen due to inanition may also be cited. Case No. 1011, on March 26-27, 1916, excreted 0.055 gram of nitrogen per kilogram of body-weight. At that time her weight was 30 per cent below normal. In the preceding ten days she had received a total of 750 calories, or approximately 2 calories daily per kilogram of body-weight. This in itself would appear to be a sufficient example of the extremes to which treatment by undernutrition was carried in the early days of its use, were not other still more striking evidences at hand based upon analyses of the urinary nitrogen of this patient and of that of Case No. 1085, which will later be mentioned. 


\section{Higi Nitrogen Excretion.}

A high excretion of urinary nitrogen may simply reflect the diet, as has already been noted in the instance of Case No. 550, or may reflect exactly the opposite condition, namely, the extreme state of inanition reached just before death in which a so-called prelethal rise of nitrogen takes place. This prelethal rise was found with Case No. 1011, the patient just described as having an extremely low value for urinary nitrogen in the spring of 1916 . On September 26, 1917, her weight had fallen to $26.4 \mathrm{~kg}$, , or 52 per cent below normal, in contrast to $38.8 \mathrm{~kg}$., or 30 per cent below normal, on March 26, 1916. Her diet had been low in the period preceding this observation in September, 1917. During the ensuing days at the hospital, it varied from day to day, but on November 27-28, 1917, the day on which the highest nitrogen excretion of 0.515 gram per kilogram of body-weight was observed, it consisted of carbohydrate 10 grams, protein 40 grams, fat 27 grams, and alcohol 23 grams, the body-weight being $26.3 \mathrm{~kg}$. The high nitrogen excretion on this day was not exceptional for this patient. Thus, upon 11 days in the two weeks before the day cited, the average nitrogen excretion was 0.305 gram per kilogram of body-weight. Her basal metabolism between November 6 and November 30 decreased from 878 to 686 calories per 24 hours and the calories in her diet varied between 1213 and 210 .

Criticism may rightly be raised that Case No. 1011 did not exhibit a true prelethal nitrogen, as she did not die until October of the following year, 1918. This is readily explained. The patients who died of inanition, and they were fortunately few in number, by no means proceeded to death in a mathematical fashion, but irregularly. High feeding was interspersed with low feeding. This patient was undoubtedly near her end when this high value was obtained, but she left the hospital, broke her diet, ate liberally, and it would appear thereby prolonged her life for upwards of one year, though eventually she succumbed to diabetic coma as a result of excessive food. In 1918 it was Scylla or Charybdis, but it is not so to-day.

The question arises as to what is meant by prelethal rise in nitrogen. How long before death can it occur, at what stage of undernutrition is one allowed to use the phrase? Loewy, according to Lusk, ${ }^{a}$ was approaching that stage when his weight reached 22 per cent below standard.

Case No. 1085 represents still more clearly a prelethal high nitrogen. This patient, on October 18-19, 1916, excreted 0.510 gram of nitrogen per kilogram of body-weight. During three weeks following this observation, the average nitrogen excretion was 0.295 gram, being 0.340 gram per kilogram of bodyweight per day in the four days from November 3 to November 7 . On November 10 the blood sugar had fallen to less than 0.10 per cent. This was the first case of inanition with low blood sugar which had come to the writer's attention, and the need of carbohydrate feeding was not recognized. The patient, realizing her desperate condition, desired to go home and left the hospital. Five days later, she succumbed to inanition. Attention is directed to the sudden fall in weight of this patient from $34.2 \mathrm{~kg}$. to $30.4 \mathrm{~kg}$. in the course of eight days, October 11 to October 19, at the end of which period the high nitrogen value was obtained. This loss in weight was apparently

\footnotetext{
${ }^{a}$ Lusk, Physiol. Reviews, 1921, 1, p. 523.
} 
only in part due to the removal of edema and was accompanied by an extreme loss of strength. The relationship between high excretion of urinary nitrogen, reduction in weight, extremely low metabolism, and high respiratory quotient will be considered in detail in a later chapter. (See p. 178.)

RELATION OF EXCRETION OF URINARY NITROGEN IN PERIODS OF OVERNUTRITION AND UNDERNUTRITION TO SEVERITY OF DIABETES.

The relation of the urinary nitrogen to the severity of the diabetes before and after June, 1914, is shown in table 53. This table is divided into two parts, giving the average nitrogen excretion per kilogram of body-weight per 24 hours of the diabetic subjects both for the day preceding the determination of their metabolism and for the 24 hours of the experimental day. The average nitrogen values for the two periods before and after June, 1914, are based upon 83 and 84 observations, respectively, before June, 1914, and upon 221 and 303 observations, respectively, subsequent to June, 1914. All the values are classified according to the degree of severity.

TABLE 53.-Relation of urinary nitrogen to severity of diabetes before and after June, 1914.

\begin{tabular}{|c|c|c|c|c|}
\hline \multirow{3}{*}{ Severity. } & \multicolumn{4}{|c|}{ Nitrogen excretion per kilogram of body-weight per 24 hours. } \\
\hline & \multicolumn{2}{|c|}{ Before June, 1914.} & \multicolumn{2}{|c|}{ After June, 1914.} \\
\hline & $\begin{array}{c}\text { Preceding } \\
\text { day. }\end{array}$ & $\begin{array}{l}\text { Experimental } \\
\text { day. }\end{array}$ & $\begin{array}{l}\text { Preceding } \\
\text { day. }\end{array}$ & $\begin{array}{c}\text { Experimental } \\
\text { day. }\end{array}$ \\
\hline $\begin{array}{l}\text { Mild .............. } \\
\text { Moderate.......... } \\
\text { Severe......... }\end{array}$ & $\begin{array}{r}g m . \\
0.190 \\
.270 \\
.280\end{array}$ & $\begin{array}{c}g m . \\
\ldots \ldots \ldots \ldots \\
0.260 \\
.235\end{array}$ & $\begin{array}{r}g m . \\
0.150 \\
.150 \\
.205\end{array}$ & $\begin{array}{r}g m . \\
0.150 \\
.135 \\
.175\end{array}$ \\
\hline Average...... & .275 & .240 & .190 & .165 \\
\hline
\end{tabular}

Before June, 1914, the average daily excretion of nitrogen per kilogram of body-weight per 24 hours was 0.275 gram for the day preceding the experiment and 0.240 gram for the experimental day. The corresponding values for the larger group of diabetic subjects after June, 1914, are 0.190 and 0.165 gram, respectively. The average value after June, 1914, for the preceding and experimental days would therefore be $0.175 \mathrm{gram}$, or approximately the nitrogen excretion of a healthy individual. The difference of 13 per cent in both periods between the nitrogen values for the preceding day and the day of the experiment is easily understood, since on the day of the experiment the patients frequently missed a meal.

The relative excess of nitrogen in the urine prior to June, 1914, goes a long way towards explaining the increased metabolism found for the patients in that period, and is probably the best confirmatory evidence at hand that these patients were overfed. It is not meant to imply that the increased metabolism was due alone to the excessive amount of protein consumed, but rather that the excessive nitrogen was an index of an excessive protein and, by inference, excessive caloric intake. Following June, 1914, undernutrition

- This patient on October 31 was 46 per cent below standard weight and the metabolism was -40 per cent. 
was the practice, and these nitrogen values are very likely high in comparison with the intake, because the body-tissues of the subjects were more frequently called upon to supply calories, and these were often obtained at the expense of body protein as well as of body fat. The fact that metabolism is lowered on an undernutrition diet served to keep these patients as well as they were.

If one examines table 53 from the point of view of the severity of the disease, it will be found that the mild cases invariably showed a lower nitrogen excretion than the severe cases. The evidence for the moderate cases is not wholly consistent. Before June, 1914, on the preceding day it was greater than the excretion of the mild cases, but after June, 1914, it was exactly the same on the preceding day for these two grades of severity, while on the experimental day the average for the moderate cases was less than that of the mild cases.

The conclusion may be drawn from this table, therefore, from the values for both periods, that the excretion of nitrogen increased with the severity of the disease. It is not yet proved, however, that the severity of the diabetes was due to the high nitrogen excretion, in that it represented a high protein intake, but the suggestion is strong that the severe cases both before and after June, 1914, were undergoing an unusually active protein katabolism. Before June, 1914, a high protein intake must be admitted, but after June, 1914, the protein given was not above the normal quantity taken in health and usually it was far less, and yet the cases of greatest severity in this period showed the very high nitrogen excretion to be explained only by the katabolism of body protein. Manifestly it would be of the greatest importance if it could be proved that patients would be safer if they were fed either 10, 20, or even 30 per cent less than the customary 1 or 1.5 grams of protein per kilogram daily, or 10,20 , or 30 per cent more than this amount. This is not readily demonstrated, because these special diets should be continued for years; in fact, essentially during the remainder of the life of the patient.

\section{RELATION OF EXCRETION OF URINARY NITROGEN TO ACIDOSIS.}

The relation of the urinary nitrogen to acidosis before and after June, 1914, is displayed in table 54. The values in the table are for the experimental days alone, as in this monograph the acidosis is recorded only for these days. It will be observed that for the 85 days prior to June, 1914, when acidosis was present in 95 per cent of the observations, the average nitrogen excretion per kilogram of body-weight was 0.240 gram and for the 304 days after June, 1914, when acidosis was present on but 70 per cent of the days, it averaged 0.165 gram.

If the nitrogen excretion and the acidosis are compared more closely, values appear which require explanation. It will be seen that both before and after June, 1914, the higher values for the nitrogen excretion were present when the acidosis was absent or extreme in degree. This may partially be explained by the fact that patients without acidosis in the earlier period received considerable carbohydrate which they were able to oxidize, at least to some extent, and in the latter period, while receiving but little food, the patients drew upon body protein for calories and also, as has elsewhere been shown, that the patients with severe acidosis, both before and after June, 1914, were being supplied more liberally with food than those without acidosis. 
There are, however, several exceptions to this general tendency. The conclusion would appear to be justified that no clear relation exists between the nitrogen excretion and acidosis.

TABLE 54.-Relation of urinary nitrogen to acidosis before and after June, 1914.

\begin{tabular}{|c|c|c|c|c|}
\hline \multirow[b]{2}{*}{ Acidosis. } & \multicolumn{2}{|c|}{ Before June, 1914.} & \multicolumn{2}{|c|}{ After June, 1914.} \\
\hline & $\begin{array}{l}\text { No. of experi- } \\
\text { mental days. }\end{array}$ & $\begin{array}{l}\text { Nitrogen } \\
\text { per kg. of } \\
\text { body-weight } \\
\text { per } 24 \text { hrs. }\end{array}$ & $\begin{array}{l}\text { No. of experi- } \\
\text { mental days. }\end{array}$ & $\begin{array}{l}\text { Nitrogen } \\
\text { per kg. of } \\
\text { body-weight } \\
\text { per } 24 \text { hrs. }\end{array}$ \\
\hline $\begin{array}{c}0 \\
+ \\
+t \\
+t+\end{array}$ & $\begin{array}{r}4 \\
8 \\
29 \\
44\end{array}$ & $\begin{array}{c}g m . \\
0.285 \\
.240 \\
.220 \\
.250\end{array}$ & $\begin{array}{r}94 \\
80 \\
108 \\
22\end{array}$ & $\begin{array}{r}g m . \\
0.170 \\
.155 \\
.165 \\
.205\end{array}$ \\
\hline Average........ & 85 & .240 & 304 & .165 \\
\hline
\end{tabular}

\section{RELATION BETWEEN ACIDOSIS, URINARY NITROGEN, AND BODY-WEIGHT}

To discover whether any relationship existed with individual diabetics for the degree of acidosis, the excretion of urinary nitrogen, and the body-weight, data for a series of cases who showed varying degrees of acidosis at different times have been grouped in table 55. These cases have been divided as usual, according to the period of observation before or after June, 1914; the percentage variations in weight from standard which occurred with the various degrees of acidosis are also given.

TABLE 55.-Relation of nitrogen in urine of diabetics to varying degrees of acidosis.

[Cases with two or more degrees of acidosis.]

\begin{tabular}{|c|c|c|c|c|c|c|}
\hline \multirow[b]{2}{*}{ Acidosis. } & \multicolumn{3}{|c|}{ Before June, 1914.} & \multicolumn{3}{|c|}{ After June, 1914.} \\
\hline & $\begin{array}{l}\text { No. of } \\
\text { cases. }\end{array}$ & $\begin{array}{l}\text { Urinary } \\
\text { nitrogen } \\
\text { per kg. of } \\
\text { body-weight } \\
\text { per } 24 \text { hrs. }\end{array}$ & $\begin{array}{l}\text { Variation } \\
\text { in body- } \\
\text { weight from } \\
\text { normal } \\
\text { standard. }\end{array}$ & $\begin{array}{l}\text { No. of } \\
\text { cases. }\end{array}$ & $\begin{array}{l}\text { Urinary } \\
\text { nitrogen } \\
\text { per kg. of } \\
\text { body-weight } \\
\text { per } 24 \mathrm{hrs} .\end{array}$ & $\begin{array}{l}\text { Variation } \\
\text { in body- } \\
\text { weight from } \\
\text { normal } \\
\text { standard. }\end{array}$ \\
\hline $\begin{array}{c}0 \\
+ \\
++ \\
++\end{array}$ & $\begin{array}{l}2 \\
5 \\
6 \\
2\end{array}$ & $\begin{array}{r}g m . \\
0.285 \\
.260 \\
.220 \\
.250\end{array}$ & $\begin{array}{l}\text { p. ct. } \\
-7 \\
-15 \\
-17 \\
-14\end{array}$ & $\begin{array}{r}22 \\
23 \\
25 \\
7\end{array}$ & $\begin{array}{r}g m . \\
0.185 \\
.150 \\
.150 \\
.175\end{array}$ & $\begin{array}{l}\text { p. } c t . \\
-21 \\
-17 \\
-17 \\
-16\end{array}$ \\
\hline
\end{tabular}

Prior to June, 1914, when the patients were overfed, acidosis was present when the standard weight varied from -14 to -17 per cent, and acidosis was absent when the loss of weight was but 7 per cent, i. e., the cases without acidosis in that period had suffered little from the diabetes. The variations 
in the nitrogen excretion per kilogram of body-weight for the various acidosis groups were negligible.

After June, 1914, the patients with acidosis had an average underweight similar to that before June, 1914, namely, -17 per cent, while those without acidosis varied from normal -21 per cent, suggesting that these patients to become free from acidosis had been subjected to more strenuous undernutrition. With the patients subsequent to June, 1914, the highest nitrogen excretion was usually found when the acidosis was absent and the loss of weight was greatest, indicating that these cases depended on body protein. One must be cautious in drawing conclusions regarding patients without acidosis for the two periods, because of the small number of cases (two) before June, 1914. The statements made above, however, appear to be well founded.

RELATION OF EXCRETION OF URINARY NITROGEN TO BASAL METABOLISM.

The relation of the urinary nitrogen to the basal metabolism of the diabetics under observation both before and after June, 1914, is shown in table 56. The average nitrogen excretion of 21 diabetics, as indicated by 68 determinations prior to June, 1914, was 0.240 gram per kilogram of body-weight per 24 hours, and for 69 diabetics, representing 228 days of observation after June, 1914, 0.150 gram per kilogram of body-weight per 24 hours. Oddly enough, this latter figure corresponds rather closely with the average excretion of the subject L., during his 31 days of fast at the Nutrition Laboratory, which was 0.170 gram per kilogram of body-weight per 24 hours, and with that of a healthy young woman, later described, undergoing the routine treatment of a severe case of diabetes during 20 days, which was 0.140 gram per kilogram of body-weight per 24 hours. (See p. 131.)

Prior to June, 1914, the nitrogen excretion followed the course of the metabolism, both above and below standard. Thus, when the metabolism was 35 to 30 per cent above the basal standard, the nitrogen excretion was 0.380 gram per kilogram of body-weight, and when the metabolism was 5 to 10 per cent below standard the nitrogen excretion was 0.095 gram per kilogram of body-weight. No essential deviation from this decrease in urinary nitrogen is found for any of the grades of metabolism recorded.

After June, 1914, a radical change is noted in the relation between the basal metabolism and the urinary nitrogen. As before noted, the urinary nitrogen excretion in this period was far less than before June, 1914. During this period, also, the basal metabolism was above standard on a much smaller proportional number of days, and the relation between the metabolism and the urinary nitrogen for these few observations was by no means so close as in the earlier period. This is readily understood by an examination of the protocols of the four cases whose metabolism was above 15 per cent.

The single case with the highest metabolism after June, 1914, who also showed the highest nitrogen excretion, was Case No. 1412. His body-weight was but 23 per cent below standard. He developed coma subsequent to great excesses of diet immediately before admission to the hospital. The high metabolism and the high urinary nitrogen were the result of excessive feeding at the acme of acidosis in a patient who needlessly sacrificed himself. The patient with a metabolism 30 to 25 per cent above standard was a fat woman, Case No. 983, who entered the hospital five days before, with 6.3 
per cent of sugar in the urine and whose diet was radically restricted, so that for the 24 hours preceding the test she received but carbohydrate 50 grams, protein 19 grams, and fat 5 grams. This patient therefore also shows very well the independence of protein metabolism and acidosis, as well as the avoidance of high endogenous protein metabolism when there is a liberal supply of fat tissue. For some additional data regarding this patient, see page 158.

One of the two observations in which the metabolism was 20 to 15 per cent above standard was made with Case No. 983 , which was carried out a few days later than the one cited above, when the acidosis was still extreme and the nitrogen elimination 0.065 per kilogram of body-weight. The other observation was with Case No. 800, the day after admission to the hospital, when the patient was sugar-free and with slight acidosis, although one month previously the urine contained 6 per cent of sugar.

TABLE 56.-Relation of urinary nitrogen to basal metabolism of diabetics before and after June, 1914 .

\begin{tabular}{|c|c|c|c|c|c|c|c|c|}
\hline \multirow{2}{*}{$\begin{array}{l}\text { Percentage } \\
\text { variation in } \\
\text { metabolism } \\
\text { from } \\
\text { standard. }\end{array}$} & \multicolumn{4}{|c|}{ Before June, 1914.} & \multicolumn{4}{|c|}{ After June, 1914.} \\
\hline & 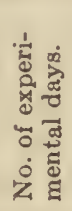 & 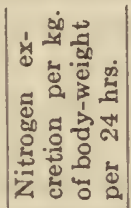 & 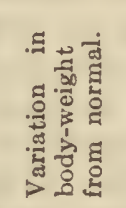 & 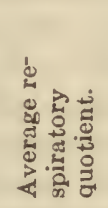 & 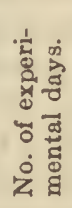 & 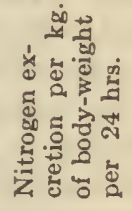 & 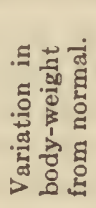 & 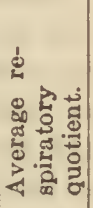 \\
\hline $\begin{array}{c}\text { Above standard. } \\
35 \text { to } 30\end{array}$ & 1 & $\begin{array}{l}o m . \\
0.380\end{array}$ & p. ct. & 0.73 & 1 & $\begin{array}{r}g m . \\
0.380\end{array}$ & $\begin{array}{l}\text { p. ct. } \\
-23\end{array}$ & \\
\hline $30 \quad 25$ & 3 & .290 & -27 & .71 & 1 & .125 & +43 & $\begin{array}{r}0.72 \\
.73\end{array}$ \\
\hline 25 & 10 & .255 & -26 & .73 & & & & \\
\hline 20 & 12 & .250 & -18 & .72 & 2 & .105 & +18 & .75 \\
\hline 10 & $\begin{array}{l}11 \\
13\end{array}$ & $\begin{array}{l}.245 \\
.240\end{array}$ & $\begin{array}{l}-20 \\
-16\end{array}$ & $\begin{array}{l}.73 \\
.74\end{array}$ & $\begin{array}{l}8 \\
4\end{array}$ & $\begin{array}{l}.150 \\
.165\end{array}$ & $\begin{array}{l}-y \\
-2\end{array}$ & .74 \\
\hline $\begin{array}{rl}10 & 5 \\
5 & 0\end{array}$ & 12 & .245 & -20 & .74 & 23 & .145 & $-1 \overline{1}$ & .77 \\
\hline $\begin{array}{c}\text { Below slandard. } \\
0 \text { to } 5\end{array}$ & 4 & 135 & -1 & 76 & 38 & 145 & -14 & 75 \\
\hline $\begin{array}{ll}5 & 0 \\
5 & 10\end{array}$ & $\begin{array}{l}4 \\
2\end{array}$ & .095 & -16 & & 27 & .14 & -17 & .77 \\
\hline $10 \quad 15$ & 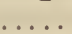 & $\ldots \ldots \ldots$ & $\ldots \ldots$ & $\ldots$. & 38 & .130 & -14 & .78 \\
\hline 20 & & & & & 31 & .14 & -23 & .77 \\
\hline 25 & & & & & 29 & .14 & -23 & .79 \\
\hline 30 & & & . & ... & 18 & .18 & -31 & .80 \\
\hline 35 & .. & & $\ldots$. & & 6 & .20 & -39 & .82 \\
\hline 40 & . & 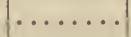 & ......... & $\ldots \ldots \ldots$ & 2 & .215 & -48 & .88 \\
\hline Average. & 168 & .240 & -20 & .73 & ${ }^{2} 228$ & .150 & -18 & .77 \\
\hline
\end{tabular}

1 The metabolism was above standard on 62 days, below standard on 6 days.

2 The metabolism was above standard on 39 days, below standard on 189 days.

The cases after June, 1914, having a metabolism below standard are so numerous that the data for the excretion of urinary nitrogen on these subnormal days (189 of a total 228 days) deserve special attention. When the metabolism was within 10 per cent of the normal standard, the nitrogen excretion was constant, but after the metabolism had decreased to 10 to 15 per cent 
below standard, the nitrogen excretion was 0.130 gram and thereafter gradually rose instead of decreasing until, with a metabolism of 35 to 40 per cent below normal, the highest average value for the nitrogen excretion with subnormal metabolism was obtained, namely, 0.215 gram.

From the above it will be seen that the tendencies indicated by these data for basal metabolism and the excretion of urinary nitrogen are contradictory. Prior to June, 1914, the excretion of urinary nitrogen follows the decrease in the metabolism, but after June, 1914, for the most part, we find the reverse to be true in that when the metabolism falls the nitrogen excretion rises. $A$ consideration of these relations between urinary nitrogen and metabolism certainly tends to the conclusion that the nitrogen metabolism in and of itself does not alone control the metabolism of the diabetic.

Lusk, ${ }^{a}$ in his discussion of this subject, writes:

"It is evident that in this emaciated individual the metabolism would have been lower in the first instance had he not been diabetic. The high-protein metabolism would sufficiently account for the increased total heat-production in this patient, although in some other instances of increased metabolism in diabetes, this factor does not apparently always suffice to explain the increase."

Prior to June, 1914, the high nitrogen excretion would seem to indicate the large quantity of protein food which the patients consumed, this being an index also of the total quantity of food in the diet. After June, 1914, the occurrence of the highest excretion of nitrogen with those patients having the lowest metabolism, with the single exception of Case No. 1412, must be explained in an entirely different manner. It has already been shown that these patients were all free from acidosis, but on the other hand their diabetes was of the severest type, and in general, for this reason, they received at that special period the least food. Accordingly, the tissues of these diabetics must have been taxed severely to provide not only calories but protein. Furthermore, as has been pointed out in various ways, the body fat of these patients was largely exhausted, and so to supply calories it was all the more necessary for body protein to be drawn upon.

Evidence of the extreme degree of inanition which these patients with subnormal metabolism had reached is also supplied by table 56 , for the data show that in the period of undernutrition after June, 1914, the body-weight was likewise subnormal and followed the course of the decreasing metabolism. Thus, when the average metabolism of 31 patients was 15 to 20 per cent below standard, the average weight was 23 per cent below normal, and when the lowest metabolism was reached, namely, 35 to 40 per cent below standard, the weight was -48 per cent. The high nitrogen excretion of these extremely emaciated diabetics with the lowest metabolism indicates a prelethal rise of urinary nitrogen which has long been known from animal experimentation.

The independence of the nitrogen excretion and the metabolism is well shown by two cases of extreme inanition, Cases Nos. 1011 and 1085. With Case No. 1011 the nitrogen excretion was almost the lowest in the series, i. e., 0.080 gram, with the metabolism 19 per cent below standard, while at another time it was 0.445 gram, or nearly at the highest mark, with the metabolism 18 per cent below standard. With Case No. 1085, the nitrogen excretion was

\footnotetext{
"Lusk, "The Science of Nutrition," 3d edition, 1917, p. 477.
} 
TABLE 57.-Cases with nitrogen and metabolism determined on successive experimental days (three days and more).

\begin{tabular}{|c|c|c|c|c|c|c|}
\hline \multirow[b]{2}{*}{$\begin{array}{l}\text { Case } \\
\text { No. }\end{array}$} & \multirow{2}{*}{\multicolumn{2}{|c|}{ Date. }} & \multirow[b]{2}{*}{$\begin{array}{l}\text { Body- } \\
\text { weight, } \\
\text { naked. }\end{array}$} & \multicolumn{2}{|c|}{ Nitrogen. } & \multirow[b]{2}{*}{$\begin{array}{l}\text { Variation in } \\
\text { metabolism } \\
\text { from stand- } \\
\text { ard. }\end{array}$} \\
\hline & & & & $\begin{array}{l}\text { Per } 24 \\
\text { hours. }\end{array}$ & $\begin{array}{l}\text { Per kg. of } \\
\text { body-weight } \\
\text { per } 24 \text { hours. }\end{array}$ & \\
\hline \multirow{4}{*}{226} & & & ko. & $g m$. & $\mathrm{gm}$. & p. ct. \\
\hline & 1913 , & Dec. $4-5$ & 63.7 & 15.5 & 0.245 & +11 \\
\hline & & Dec. $5-6$ & 64.4 & 11.4 & .175 & +8 \\
\hline & & Dec. $\quad 6-7$ & 64.4 & 11.2 & .175 & +8 \\
\hline \multirow[t]{6}{*}{246} & 1909 & Oct. $25-26$ & 54.9 & 16.3 & .295 & +17 \\
\hline & & Oct. $26-27$ & 54.9 & 13.3 & .240 & +10 \\
\hline & & Oct. $27-28$ & 54.9 & 19.6 & .355 & +15 \\
\hline & & Oct. $28-29$ & 56.1 & 19.4 & .345 & +15 \\
\hline & & Oct. $29-30$ & 56.1 & 14.7 & .260 & +8 \\
\hline & & Oct. $30-31$ & 56.1 & 16.3 & .290 & +7 \\
\hline \multirow[t]{4}{*}{561} & 1913 & Feb. $7-8$ & 44.1 & 17.5 & .395 & +17 \\
\hline & & Feb. $\quad 8-9$ & 44.6 & 10.2 & .230 & +18 \\
\hline & & Feb. $\quad 9-10$ & 45.1 & 7.0 & .155 & +11 \\
\hline & & Feb. 10-11 & 44.7 & 8.7 & .195 & +14 \\
\hline \multirow[t]{5}{*}{591} & 1913 & Apr. $10-11$ & 47.2 & 13.1 & .280 & +15 \\
\hline & & Apr. $11-12$ & 47.1 & 12.5 & .265 & +9 \\
\hline & & Apr. $12-13$ & 47.6 & 9.6 & .200 & +15 \\
\hline & & Apr. $13-14$ & 47.2 & 6.8 & .145 & +10 \\
\hline & & Apr. $14-15$ & 47.2 & 6.7 & .140 & +15 \\
\hline \multirow[t]{6}{*}{707} & 1914 & May $16-17$ & 51.7 & 4.1 & .080 & -8 \\
\hline & & May 17-18 & 51.7 & 4.8 & .095 & -4 \\
\hline & & May 18-19 & 51.7 & 7.5 & .145 & 0 \\
\hline & & May $19-20$ & 52.2 & 4.2 & .080 & +1 \\
\hline & & May $20-21$ & 51.6 & 6.7 & .130 & -3 \\
\hline & & May 21-22 & 52.5 & 5.5 & .105 & -6 \\
\hline \multirow[t]{5}{*}{740} & 1915 & Apr. $15-16$ & 52.9 & 16.5 & .310 & +1 \\
\hline & & Apr. $16-17$ & 52.2 & 16.2 & .310 & -2 \\
\hline & & Apr. $17-18$ & 51.7 & 9.6 & .185 & -1 \\
\hline & & Apr. $18-19$ & 52.1 & 8.1 & .155 & -8 \\
\hline & & Apr. $19-20$ & 51.7 & 6.7 & .130 & -6 \\
\hline \multirow[t]{3}{*}{746} & 1914 . & Oct. $8-9$ & 55.8 & 6.5 & .115 & +4 \\
\hline & & Oct. $\quad 9-10$ & 57.0 & 5.9 & .105 & +1 \\
\hline & & Oct. $10-11$ & 57.3 & 6.9 & .120 & -2 \\
\hline \multirow[t]{4}{*}{764} & 1914 & Sept. 22-23 & 66.0 & 5.2 & .080 & +1 \\
\hline & & Sept. 23-24 & 69.0 & 4.2 & .060 & -3 \\
\hline & & Sept. $24-25$ & 69.3 & 4.2 & .060 & -3 \\
\hline & & Sept. $25-26$ & 70.4 & 4.1 & .060 & -8 \\
\hline \multirow[t]{3}{*}{821} & 1916 , & Feb. $14-15$ & 55.0 & 7.3 & .130 & -7 \\
\hline & & Feb. $15-16$ & 55.0 & 7.0 & .130 & -8 \\
\hline & & Feb. $16-17$ & 55.5 & 6.6 & .120 & -15 \\
\hline \multirow[t]{3}{*}{1160} & 1916 & Nov. $7-8$ & 66.2 & 6.4 & .095 & -13 \\
\hline & & Nov. $8-9$ & 65.4 & 5.6 & .085 & -17 \\
\hline & & Nov. $9-10$ & 65.5 & 8.1 & .125 & -17 \\
\hline \multirow[t]{7}{*}{1181} & 1916 & Nov. $9-10$ & 55.0 & 10.4 & .190 & -1 \\
\hline & & Nov. $10-11$ & 54.2 & 9.3 & 170 & -4 \\
\hline & & Nov. $11-12$ & 54.0 & 11.7 & .215 & -12 \\
\hline & & Nov. $13-14$ & 54.4 & 12.3 & .225 & -9 \\
\hline & & Nov. $14-15$ & 54.6 & 9.1 & .165 & -16 \\
\hline & & Nov. $15-16$ & 54.7 & 7.8 & .145 & -20 \\
\hline & & Nov. $16-17$ & 55.0 & 8.6 & .155 & -19 \\
\hline \multirow[t]{3}{*}{1196} & 1916 & Dec. $14-15$ & 48.6 & 9.1 & .185 & -19 \\
\hline & & Dec. $15-16$ & 51.9 & 6.0 & .115 & -27 \\
\hline & & Dec. $16-17$ & 51.9 & 6.6 & .125 & -22 \\
\hline
\end{tabular}


0.510 gram, with the metabolism 35 per cent below standard, and later it was 0.190 gram, with the metabolism 40 per cent below standard. Furthermore, when the nitrogen excretion was extremely low as a result of the oxidation of large quantities of fat, either exogenous (see Case No. 707 in table 52) or endogenous (see Cases Nos. 983, 1026, and 1207), the metabolism with different individuals varied to a great degree and to a considerable degree with the same individual.

In table 57 the urinary excretion of nitrogen and the metabolism as determined on three or more successive experimental days are given for 12 individuals. The table shows well how greatly the urinary nitrogen may vary from day to day, but if one studies the data in detail, it will be found that there is no close relation between the metabolism and the nitrogen excretion. In comparison with the great variations of nitrogen with a single individual, the variations in metabolism, as indicated by the percentage variations from the Harris and Benedict standard, are remarkably slight, being from 3 to 19 per cent in any individual series, with an average of 8 per cent. These variations are far less than Blunt and Dye ${ }^{a}$ found with normal women from day to dayvariations which, representing the percentage of the maximum metabolism per 24 hours above the minimum, ranged from 7.4 to 28.8 per cent, or an average of 13.2 per cent. The observations of Blunt and Dye were not, however, made on successive days, as were those in table 57. If the variations in the daily metabolism are computed for the 12 patients included in table 57 by the method used by Blunt and Dye, the range in variation is 2.0 to 249 . per cent, or an average of 8.4 per cent.

In the following chapter upon the respiratory quotient, the relation between the excretion of urinary nitrogen and the metabolism will be considered again in the light of additional information which the quotient supplies.

The relation of urinary nitrogen, as an index of protein katabolism to the metabolism has been extensively discussed by Bernstein and Falta. ${ }^{b}$ They, as well as Wilder, Boothby and Beeler, ${ }^{c}$ believe the protein katabolism an all-controlling factor in regulating the metabolism of the diabetic. The data of the latter admit of various interpretations, and to the writer the evidence does not seem to warrant this assumption. In the preceding section upon acidosis (see p. 89), an attempt was made to correlate the data in a manner which will help in the elucidation of the problem.

\section{Heat-production per Kilogram of Body-Weight as Index of Caloric NeEds of Diabetics.}

Since for years it has been customary to express the metabolism of an individual in calories per kilogram of body-weight, and most physicians still treat their diabetic patients on this basis, the data for the metabolism per kilogram of body-weight of this series of diabetic patients when they were at rest have been grouped in table 58. These values are based entirely on cases which are comparable to the Harris and Benedict standard, and do not include the girl diabetics who were compared with the figures supplied by the experiments with Girl Scouts. (See p. 90.)

\footnotetext{
a Blunt and Dye, Jour'n. Biol. Chem., 1921, 47, p. 69.

- Bernstein and Falta, Deutsch. Arch. f. klin. Med., 1916, 121, p. 95.

- Wilder, Boothby, and Beeler, Journ. Biol. Chem., 1922, 51, p. 311.
} 
It will be observed that table 58 gives the averages for both the number of patients and the number of experimental days, there being six groups, according to the increasing number of calories metabolized. For each of these six groups both the range and the average number of calories for the group are given. Thus, 18 patients, representing 33 experimental days, were included in the first group, with an average basal metabolism ranging from 15 to 20 calories per 24 hours, and an average heat-production of 19 calories per kilogram of body-weight per 24 hours. The second group was the largest and included 61 subjects, representing 175 experimental days. The range was from 21 to 25 calories, with an average of 23 calories per kilogram of bodyweight per 24 hours.

TABLE 58.-Post-absorptive metabolism of diabetics arranged according to calories per kilogram of body-weight.

\begin{tabular}{|c|c|c|c|c|c|c|}
\hline \multirow{2}{*}{$\begin{array}{l}\text { Heat-pro- } \\
\text { duction per } \\
\mathrm{kg} \text {. body- } \\
\text { weight per } \\
24 \text { hours. }\end{array}$} & \multirow{2}{*}{$\begin{array}{l}\text { Av. heat- } \\
\text { production } \\
\text { per } \mathrm{kg} \text {. } \\
\text { body- } \\
\text { weight per } \\
24 \text { hours. }\end{array}$} & \multirow{2}{*}{$\begin{array}{l}\text { No. of } \\
\text { experi- } \\
\text { mental } \\
\text { days. }\end{array}$} & \multirow{2}{*}{$\begin{array}{l}\text { No. of } \\
\text { cases. }\end{array}$} & \multicolumn{2}{|c|}{$\begin{array}{l}\text { Av. deviation } \\
\text { of metabolism } \\
\text { from standard. } 2\end{array}$} & \multirow{3}{*}{$\begin{array}{l}\text { Notes. } \\
\text { 1 Average heat-production on } \\
\text { basis of both experimental } \\
\text { days and cases, except that } \\
\text { for cases with an output of } \\
36 \text { to } 40 \text { calories, the average } \\
\text { is } 37 \text { calories. The average } \\
\text { heat-production per kilogram } \\
\text { of body-weight per } 24 \text { hours for } \\
\text { all days and all cases is } 26 \\
\text { calories. } \\
\text { 3 With regard to sign. } \\
\text { 'Includes only those patients } \\
\text { compared with the Harris and } \\
\text { Benedict standard, excluding } \\
\text { the girl diabetics. }\end{array}$} \\
\hline & & & & $\begin{array}{l}\text { By } \\
\text { experi- } \\
\text { mental } \\
\text { days.8 }\end{array}$ & $\begin{array}{c}\text { By } \\
\text { cases. }\end{array}$ & \\
\hline $\begin{array}{lr}\text { calories. } \\
15 & \text { to } 20 \\
21 & 25 \\
26 & 30 \\
31 & 35 \\
36 & 40\end{array}$ & $\begin{array}{c}\text { calories. } \\
19 \\
23 \\
28 \\
32 \\
138 \\
41\end{array}$ & $\begin{array}{r}33 \\
175 \\
122 \\
51 \\
16 \\
1\end{array}$ & $\begin{array}{r}18 \\
61 \\
45 \\
25 \\
5 \\
1\end{array}$ & $\begin{array}{r}\text { p. ct. } \\
-16 \\
-11 \\
0 \\
+15 \\
+14 \\
+22\end{array}$ & $\begin{array}{l}\text { p. ct. } \\
-13 \\
-9 \\
+1 \\
+14 \\
+18 \\
+22\end{array}$ & \\
\hline
\end{tabular}

With the third group, which was nearly as large as the second and represented 45 patients or 122 experimental days, the basal metabolism ranged between 26 and 30 calories, with an average of 28 calories. The next group was nearly as small as the first, with 25 patients and 51 experimental days, a range in basal metabolism from 31 to 35 calories, and an average of 32 calories. With 5 cases, representing 16 experimental days, there was a range of 36 to 40 calories, and an average of 38 calories per kilogram of body-weight per 24 hours on the basis of experimental days and of 37 calories on the basis of cases. But one patient (Case No. 295) exceeded 40 calories, his post-absorptive metabolism being 41 calories per kilogram of body-weight on February 23, 1911, with a total metabolism 22 per cent above standard. This was the highest metabolism per kilogram of body-weight recorded in this series for any experimental day. ${ }^{1}$ The lowest value on this basis was obtained with Case No. 1207 on January 3 and on January 4, 1917, of 15 calories per kilogram of body-weight, with a total metabolism 15 per cent below standard. ${ }^{\circ}$

- The highest total post-absorptive metabolism observed was with Case No. 1412, with a variation from standard of +39 per cent on October 18 and October 19, 1917. (See table 21, p. 52.) The heat-output per kilogram of body-weight on both these days was 38 calories. The patient was at this time on the verge of coma, and the figure has accordingly been excluded from the average values in this monograph. (See footnote 2 , table $20, \mathrm{p}$. 49.) The lowest total postabsorptive metabolism observed was with Case No. 1085, which was 40 per cent below standard on October 11 and October 31, 1916, but the heat-output per kilogram of body-weight on these dates was 20 and 21 calories, respectively. 
The data in table 58 are of clinical importance, inasmuch as with this large group of diabetics, examined in periods of treatment of both overnutrition and undernutrition, but one-sixth of the observations indicated a need for more than 30 calories per kilogram of body-weight to maintain the basal metabolism. It is equally of clinical importance to observe that in one out of every 12 experiments there was a basal metabolism of 20 calories or less per kilogram of body-weight. By the present hospital method of beginning the treatment of diabetic cases with undernutrition, the energy intake per kilogram of body-weight for days and weeks is often below 20 calories. Such procedures are temporarily justifiable if a gain in tolerance for carbohydrate or for a larger amount of food is ach eved, but it is almost as bad practice for a physician to keep his patient sugar-free by requiring him to live permanently upon a diet below the caloric needs as it is, through carelessness, to allow the presence of glycosuria and thus bring the net caloric intake below the necessary minimum. The treatment of the diabetic should be planned for a period of years rather than of months.

The average deviation of the metabolism per kilogram of body-weight from the normal standard for each of the six groups is also recorded in table 58, as based both on the experimental days and on the number of patients. From these figures we find that in over one-half of the experiments the diabetics had a basal metabolism of 10 or more per cent below normal. This is the most important lesson to be derived from these data. The metabolism would have been still lower had it not been for the cases treated prior to June, 1914.

In this connection it should be remembered that the normal individuals studied by this Laboratory who were subjected to a loss in body-weight of approximately 10 per cent, presented a reduction in metabolism per kilogram of 15 to 20 per cent. ${ }^{a}$ Subsequent to this loss of weight, the diet necessary for maintenance represented a reduction of nearly 40 per cent from that in the pre-experimental period. The evidence afforded by the studies upon diabetic patients, however, does not show that they could subsist upon a correspondingly lowered ration, despite a loss in weight even greater than that of the normal subjects referred to. Indeed, if comparison is justifiable between these two groups, it is plain that although the metabolism of the diabetic was, as a rule, subnormal, it was actually increased relatively in comparison to that of other undernourished individuals, a conclusion also reached by Lusk in his discussion of the metabolism of Cyril $\mathrm{K}^{{ }^{b}}$

It is safe to say that any diabetic patient who receives less than 20 calories per kilogram of body-weight is almost certainly drawing upon his own tissues for energy, even if he keeps perfectly still in bed, and furthermore, that this is likely to be the case even if he receives as much as 26 calories per kilogram of body-weight. If any activity at all is attempted, about 20 per cent more calories are necessary. Such activity would be represented by hospital life, including sitting up, reading, and an occasional slow walk.

a Benedict, Miles, Roth, and Smith, Carnegie Inst. Wash. Pub. No. 280, 1919, p. 525.

- Lusk, The Science of Nutrition, 3d ed., Philadelphia, 1917, p. 477. 


\section{Fasting and Undernutrition in Health.}

Undernutrition plays such an important part in the treatment of diabetes to-day that its significance, both with a healthy individual and with a diabetic patient, should be kept clearly and constantly in view. As a basis for a true understanding of the effects of undernutrition upon diabetic patients, it is therefore desirable to study first the results of observations with individuals during prolonged fasting or undernutrition, when living under conditions similar to those of the diabetic patients.

\section{METABOLISM OF A HEALTHY INDIVIDUAL DURING A PROLONGED FAST.}

No data are better fitted for studying the metabolism during a long fast than those obtained with the subject L., with whom observations were made at this Laboratory during a fast of 31 days in the year 1912. ${ }^{\circ}$ These are recorded in table 59, which gives the body-weight, the heat-production per 24 hours as computed from observations of the gaseous exchange on the morning following each day, the predicted heat-production as computed by the Harris and Benedict formula, and the percentage variation of the metabolism from this normal standard. The values cited represent not only the data for each day of the fast, but the post-absorptive metabolism following each of the four food days immediately preceding the fast.

It is a curious coincidence that the range in metabolism of this individual, as determined before the beginning of his fast and again at the end of the fasting period, closely approximates that of the diabetic patients before June, 1914, when they were in a state of overnutrition, and after June, 1914, when they were in a state of undernutrition. The post-absorptive metabolism observed in the morning following each of the four days of food immediately preceding L.'s fasting period, was slightly above the normal standard, averaging +5 per cent, or 26 calories per kilogram of body-weight per 24 hours. His weight at this time was 11 per cent below normal. It will be recalled that prior to June, 1914, the metabolism of the diabetic patients other than the girl diabetics, as shown by case averages, was 13 per cent above standard or 31 calories per kilogram of body-weight per 24 hours. The average weight of these cases when first observed in an experiment was 16 per cent below normal.

On the morning following the thirty-first day of L.'s fast, his metabolism was 14 per cent below the predicted metabolism for his height and weight at that time, or 24 calories per kilogram of body-weight per 24 hours. The metabolism of the diabetic cases after June, 1914, exclusive of the girl diabetics, and based on case averages, was likewise below standard (7 per cent) or 24 calories per kilogram of body-weight. At the time these data were accumulated, the average body-weight of the patients was 13 per cent below normal.

In the averages above cited, a comparison is drawn between the metabolism of a healthy man at the conclusion of a prolonged fast and that of diabetic patients, and also the comparison of the metabolism of a healthy man before and at the end of his fast compared with the standard for normal individuals in normal nutrition at both periods. This, however, tells but part of the

a Benedict, Carnegio Inst. Wash. Pub. No. 203, 1915. 
story. The actual metabolism of $\mathrm{L}$. at the end of his fasting period should be compared with that immediately preceding the beginning of the period. If this is done, it will be observed that his basal metabolism decreased during the 31 days of fasting from 1,526 to 1,118 calories per 24 hours or 27 per cent. The loss in weight of $\mathrm{L}$. during his period of fast was $13.2 \mathrm{~kg}$., his original weight being $60.6 \mathrm{~kg}$. and his final weight $47.4 \mathrm{~kg}$. Comparing this loss in body-weight of 22 per cent with the decrease in metabolism of 27 per cent, it is evident that L.'s decrease in metabolism proceeded more rapidly

TABLE 59.-Metabolism of subject $L$. during a $\$ 1$-day fast as computed from results in morning respiration experiments.

Male; age, 40 years; height, $171 \mathrm{~cm}$. All observations were on the morning following each designated day.

\begin{tabular}{|c|c|c|c|c|c|}
\hline \multirow[b]{2}{*}{ Day. } & \multirow[b]{2}{*}{$\begin{array}{l}\text { Body- } \\
\text { weight, } \\
\text { naked. }\end{array}$} & \multirow[b]{2}{*}{$\begin{array}{l}\text { Pulse- } \\
\text { rate. }\end{array}$} & \multicolumn{3}{|c|}{ Heat-production per 24 hours. } \\
\hline & & & $\begin{array}{l}\text { Computed } 1 \\
\text { from gaseous } \\
\text { metabolism. }\end{array}$ & $\begin{array}{l}\text { Standard pre- } \\
\text { dicted by H. } \\
\text { and B. for- } \\
\text { mula. }\end{array}$ & $\begin{array}{l}\text { Variation } \\
\text { from } \\
\text { standard. }\end{array}$ \\
\hline Post-absor ptive, & & & & & \\
\hline after food: & $k o$. & & cal. & cal. & p. ct. \\
\hline 1st......... & 60.1 & 72 & 1.577 & 1,478 & +7 \\
\hline $2 \mathrm{~d} \ldots \ldots \ldots$ & 60.5 & 73 & 1,541 & 1,483 & +4 \\
\hline $3 \mathrm{~d} \ldots \ldots \ldots$ & 61.0 & 72 & 1,572 & 1,490 & +6 \\
\hline 4th......... & 60.6 & 73 & 1,526 & 1,485 & +3 \\
\hline Fast: & & & & & \\
\hline Ist... & 59.6 & 74 & 1,615 & 1,471 & +10 \\
\hline $2 d \ldots$ & 58.7 & 73 & 1.558 & 1,459 & +7 \\
\hline $3 d \ldots \ldots \ldots$ & 57.8 & 70 & 1.524 & 1,446 & +5 \\
\hline 4th... & 57.0 & 68 & 1,433 & 1,435 & \\
\hline Sth... & 56.4 & 67 & 1,394 & 1,427 & -2 \\
\hline 6 th........ & 55.9 & 64 & 1,349 & 1,420 & -5 \\
\hline 7 th. ........ & 55.5 & 64 & 1,380 & 1,415 & -2 \\
\hline 8 th........ & 55.1 & 65 & 1.378 & 1,409 & -2 \\
\hline gth.... & 54.6 & 63 & 1,289 & 1,402 & -8 \\
\hline 10 th...$\ldots \ldots$ & 54.1 & 63 & 1.277 & 1.395 & -8 \\
\hline 11 th.... & 53.9 & 61 & 1.262 & 1,393 & -8 \\
\hline 12 th... & 53.6 & 61 & 1,262 & 1,389 & $-\theta$ \\
\hline 13th........ & 53.5 & 59 & 1,291 & 1,387 & -7 \\
\hline 14 th.... & 53.2 & 58 & 1,222 & 1,383 & -12 \\
\hline 15th....... & 52.8 & 57 & 1,202 & 1,378 & -13 \\
\hline 16 th........ & 52.3 & 58 & 1,228 & 1,371 & -11 \\
\hline 17 th...$\ldots \ldots$ & 51.8 & 57 & 1.226 & 1,364 & -10 \\
\hline 18th.... & 51.5 & 56 & 1,159 & 1,360 & -15 \\
\hline 10th.... & 51.1 & 57 & 1,183 & 1,354 & -13 \\
\hline 20 th........ & 50.9 & 58 & 1,157 & 1,351 & -14 \\
\hline 21 st.... & 50.5 & 59 & 1,162 & 1.346 & -14 \\
\hline $22 \mathrm{~d} . . . .$. & 50.1 & 59 & 1,142 & 1,340 & -15 \\
\hline $23 \mathrm{~d} \ldots \ldots \ldots$ & 50.0 & 58 & 1,116 & 1,339 & -17 \\
\hline 24 th...... & 49.6 & 59 & 1.128 & 1,334 & -16 \\
\hline 25 th.... & 49.3 & 60 & 1,128 & 1,328 & -15 \\
\hline 26 th........ & 49.0 & 61 & 1,133 & 1,325 & -14 \\
\hline 27 th....... & 48.7 & 62 & 1,164 & 1,321 & -12 \\
\hline 28 th....... & 48.5 & 81 & 1,118 & 1,318 & -15 \\
\hline 29 th....... & 48.1 & 63 & 1,142 & 1,313 & -13 \\
\hline 30 th... & 47.7 & 59 & 1,109 & 1,307 & -15 \\
\hline 3lst.... & 47.4 & 60 & 1.118 & 1,303 & -14 \\
\hline
\end{tabular}

1 Benedict, Carnegie Inst. Wash. Pub. No. 203, 1915, p. 398.

than his loss in weight. If one should select two individuals from the prediction tables corresponding to the weights of $\mathrm{L}$. at the beginning and end of the fast, the metabolism of the lighter would be 12 per cent less. Thus, to the fast must be attributed the 15 per cent greater decrease in L.'s metabo-

a Benedict, Carnegie Inst. Wash. Pub. No. 203, 1915, p. 73. 
lism. This illustrates the importance of not only considering the metabolism of a given individual on a given day, but also of considering what the diet has been in the preceding period. Thus, Magnus-Levy's case ${ }^{a}$ was 29 per cent under standard weight in November, 1896, at which time the metabolism was -32 per cent (Harris and Benedict standard). Between January and March, 1897 , the variation of average body-weight from normal had risen to -7 per cent and the metabolism to +11 per cent, but during this period tubercle bacilli were found in the sputum. When symptoms had subsided by March to May, 1897, the weight had again risen, and reached -1 per cent below standard, and the metabolism was +3 per cent.

During L.'s fast of 31 days, the loss of body nitrogen was very considerable, being 277 grams for the entire period, or 8.95 grams per day. ${ }^{b}$ During the first four days of the fast, when the body-weight for 24 hours averaged $58.3 \mathrm{~kg}$., the nitrogen in the urine averaged 9.68 grams or 0.165 gram per kilogram of body-weight. Upon the thirty-first day of the fast, when the average daily body-weight had fallen to $47.4 \mathrm{~kg}$, the total nitrogen in the urine was 6.94 grams, or 0.146 gram per kilogram of body-weight. The losses of nitrogen from day to day were variable, but there was a general tendency to a decrease after the first four days. The highest quantity of nitrogen excreted in any 24-hour period was 11.87 grams upon the fourth day, and the lowest quantity of nitrogen in the urine was 6.94 grams upon the thirty-first day. The lowest amounts excreted per kilogram of body-weight were 0.118 gram on the first day, 0.142 gram on the second day, and 0.146 gram on the twenty-third and thirty-first days.

Karl Thomas ${ }^{c}$ records his nitrogen excretion during a fasting period when his body-weight was $75 \mathrm{~kg}$. as 6.85 grams and 7.47 grams per 24 hours. It may be assumed, therefore, that an individual of approximately 60 to $70 \mathrm{~kg}$. will excrete about 7 to 8 grams of nitrogen when he fasts for 24 hours.

If one accepts the current view that 3 per cent of the body-weight is due to nitrogen, the body of L., with an initial weight of $60.6 \mathrm{~kg}$., would contain 1,818 grams of nitrogen. As he lost 277 grams of nitrogen during the fasting period, this loss amounted to 15 per cent of the original amount of nitrogen in the body. This decrease in body nitrogen of 15 per cent was distinctly less than the decrease in the body-weight, which was 22 per cent, and considerably less than the decrease in the basal metabolism of 27 per cent. The tissue lost by this subject amounted to $13.2 \mathrm{~kg}$. and each kilogram of body tissue thus lost contained 2.1 per cent of nitrogen, which is a third less than the 3 per cent of nitrogen per kilogram of body-weight which body tissue has been assumed to contain. The body therefore conserved its nitrogen. On the other hand, it is plain that the percentage of nitrogen being katabolized per kilogram of body-weight at the beginning of the fast was more than that being katabolized at the end of the fast. It is not justifiable, however, to assert that the lowering in metabolism was a result of diminished nitrogenous katabolism exclusively and not due to the total loss in weight represented by carbohydrate, protein, and fat. The point was evidently not reached by this individual when there was insufficient body fat to supply the metabolic needs, requiring in con-

agnus-Levy, Zeitschr. f. klin. Med., 1906, 6o, p. 177.

' Benedict, Carnegie Inst. Wash. Pub. No. 203, 1915, p. 251.

- Thomas, Arch. f. Physiol., 1910, Supp., p. 248. 
sequence that an excessive amount of protein be drawn upon to make up the deficiency. In contrast to this normal individual who fasted 31 days and maintained a proper proportionate excretion of nitrogen at the end of the period are certain of the diabetic patients whose proportionate nitrogen excretion after prolonged undernutrition was much greater.

The number of calories represented by each kilogram of body-weight lost by L. may be determined, since his metabolism was observed at intervals during the day, and his activities were somewhat definitely estimated, thus giving the material for computing with a fair degree of accuracy his total metabolism for each 24 hours. The total metabolism for the 31 days when computed in this way amounted to 43,010 calories, ${ }^{\circ}$ or 1,387 calories per day. This would be equivalent to 3,258 calories for each kilogram of body-weight lost. Knowing the loss in body nitrogen for the period, the total metabolism for the 24 hours can be apportioned to the carbohydrate, protein, and fat oxidized daily by using the proper factors involved in the method. In these computations no allowance is made for the loss of nitrogen in feces, as the bowels did not move during the fasting period. It is, of course, incorrect to assume that no feces were formed during these 31 days and that no nitrogen was thus lost to the body, for the feces, though subsequently proved to be small in amount, simply accumulated in the intestinal tract, but for these somewhat gross computations the nitrogen lost in this way may be disregarded.

The computations of the body material lost show that, on the basis of per kilogram of body-weight lost, the average amount of carbohydrate oxidized during the 31 days was 15 grams per kilogram, ${ }^{b}$ of protein 126 grams, and of fat 277 grams. The remaining 582 grams of each kilogram of body-weight lost must therefore be attributed to a loss of water and to a slight extent of salts. The changes in body-weight due to an alteration in water balance are often very great. With this particular individual the changes were very considerable, but as they chanced to be in both directions, the excess of water lost was essentially made up by water retained, so that for the entire 31 days the water balance was almost constant. Although this was the case in this particular instance, it must not be assumed that the water-content of a kilogram of body-material at the end of a fast is exactly the same as at the beginning of a fast. As a matter of fact, with prolonged fasting, water tends to accumulate in the body, and the fact that with this man it did not accumulate to any considerable degree was somewhat due to design.

The calories lost by $\mathbf{L}$. for each kilogram decrease in body-weight probably represent with a fair degree of accuracy the calories lost by a diabetic subject with the loss of each kilogram of body-weight. It is unessential for our purpose whether the difference is plus or minus 5,10 , or 15 per cent, since the fact to bear in mind is this, that the loss of a kilogram of body-weight means a loss of about 3,000 calories. All clinicians are in practical agreement to-day that overnutrition must be avoided in diabetes. It is seldom that more than 5 or 10 per cent of extra food can be taken by a diabetic patient without injury to his carbohydrate tolerance. This being true, it is evident that a

\footnotetext{
a Benedict, Carnegie Inst. Wash. Pub. No. 203, 1915, p. 403, table 61, column M.

b The oxidation of carbohydrate, however, occurred wholly in the first 13 days of the fast.
} 
loss of a kilogram in body-weight, or the equivalent of 3,000 calories, by an individual whose ordinary metabolism is 1,500 calories, would require about 20 days for replacement, providing he could take an excess of 10 per cent of calories per day, and 40 days if he could bear but 5 per cent excess. Is it therefore strange that a loss of a kilogram of body-weight by a diabetic patient is seldom regained?

\section{METABOLISM OF A HEALTHY YOUNG WOMAN UNDERGOING THE ROUTINE UNDERNUTRITION TREATMENT OF A DIABETIC.}

Whereas thousands of diabetic patients are placed upon a diet which radically departs from the normal, it is almost unique for a healthy individual to undergo the same régime. On this account it was decided in 1916 to observe the effect upon a normal individual of methods then commonly employed in the treatment of diabetes, namely, fasting, followed by a progressively increasing diet.

Miss L., a healthy nurse, long familiar with diabetic patients, volunteered to undergo such a test. Her age was 25 years, body-weight without clothing $57.2 \mathrm{~kg}$., and height $170 \mathrm{~cm}$. The observations began June 5, 1916, and were concluded June 24, 1916, covering a period of 20 days. During this time there were 18 observations of the metabolism. A supplementary determination of the metabolism was also made on June 26, 1916, and various data were obtained for June 25, 1916. After an interval of 6 years and 5 months, the post-absorptive metabolism of Miss $\mathrm{L}$. was again determined. The results are given on page 140 .

For the first four days of the period of study, Miss L. fasted save for small quantities of weak bouillon. Thereafter the carbohydrate in the diet was steadily increased from 10 grams on the fifth day to 155 and 200 grams on the nineteenth and twentieth days. The protein, which was 5 grams on the fifth day, amounted to 90 grams on the nineteenth day, and 75 grams on the twentieth day. The fat, which was begun on the ninth day with 20 grams, reached 145 and 140 grams on the nineteenth and twentieth days. The ultimate diet reached represented an intake of 2,360 calories, or 44 calories per kilogram of body-weight.

During the period of observation the subject remained in the New England Deaconess Hospital. The apparatus used for the tests of the metabolism was the clinical respiration chamber. The metabolism was first determined with the subject in the post-absorptive state on June 5, 1916, at which time fasting began, and thereafter daily observations were made to June 24, inclusive, with but two exceptions (June 11 and 18). As previously stated, a supplementary test was made on June 26 . The results are given in table 60 . In addition to the tests of the metabolism, the body-weight and pulse-rate were recorded, determinations made of the carbon dioxide in the alveolar air, the urine examined for diacetic acid, ammonia, nitrogen, and sugar, and determinations made of the carbon dioxide and sugar in the blood. A complete record of the diet was also made. Catamenia appeared on June 7 and continued until June 12, inclusive. 
TABLE $60-$ Metabolism of healthy woman under treatment of diabetic patient. [Age, 25 yrs.; height, $170 \mathrm{~cm}$. All experiments were post-absorptive.]

\begin{tabular}{|c|c|c|c|c|c|c|c|c|c|}
\hline \multirow{4}{*}{$\begin{array}{c}\text { No. } \\
\text { of day. }\end{array}$} & \multirow{4}{*}{ Date. } & \multirow{4}{*}{$\begin{array}{c}\text { Body- } \\
\text { weight } \\
\text { naked. }\end{array}$} & \multirow{4}{*}{$\begin{array}{l}\text { Blood } \\
\text { sugar. }\end{array}$} & \multirow{4}{*}{$\begin{array}{l}\text { Volume } \\
\text { of urine. }\end{array}$} & \multicolumn{5}{|c|}{ Acidosis. } \\
\hline & & & & & \multirow{3}{*}{$\begin{array}{l}\mathrm{CO}_{2} \text { in } \\
\text { blood. }\end{array}$} & \multirow{3}{*}{$\begin{array}{c}\mathrm{CO}_{2} \text { in } \\
\text { alveolar } \\
\text { air. }\end{array}$} & \multirow{3}{*}{$\begin{array}{l}\text { Diacetic } \\
\text { acid. }\end{array}$} & \multicolumn{2}{|c|}{ Ammonia. } \\
\hline & & & & & & & & & $\mathrm{NH}_{8}-\mathrm{N}$ \\
\hline & & & & & & & & Total. & $\overline{\text { Total N }}$ \\
\hline & 1916. & ko. & p. ct. & c. $c$. & $\mathrm{mm} . \mathrm{Ho}_{\mathrm{O}}$ & $m m \cdot H_{0}$ & & $o m$. & p. $c$. \\
\hline 1 & June $5-6$. & 57.2 & 0.12 & 600 & 42 & 41 & 0 & $\ldots$. & $\ldots \ldots$ \\
\hline 2 & June $6-7$. & 56.8 & .11 & 700 & $\ldots \ldots$ & $\ldots \ldots$ & 0 & $\ldots \ldots$ & $\ldots$ \\
\hline 3 & June $7-8$. & 55.8 & .10 & 650 & $\ldots \ldots \ldots$ & 41 & ++ & 1.2 & 11 \\
\hline 4 & June $8-9$. & 55.0 & .10 & 980 & $\ldots \ldots$ & 36 & $+t+$ & 1.8 & 17 \\
\hline $\bar{b}$ & June $9-10$ & 54.0 & .09 & 1,100 & 25 & 29 & $+t+$ & 2.7 & 25 \\
\hline 6 & June $10-11$ & 53.1 & .11 & 800 & $\ldots \ldots$ & 31 & ++ & 2.8 & 30 \\
\hline 7 & June $11-12$. & $\ldots \ldots$ & $\ldots \ldots$ & 650 & $\ldots \ldots$ & 32 & $+t$ & 2.5 & 31 \\
\hline 8 & June 12-13. & 53.1 & .08 & 700 & $\ldots \ldots \ldots$ & 34 & ++ & 2.5 & 31 \\
\hline 9 & June $13-14$. & 53.5 . & $\ldots \ldots$ & 900 & $\ldots \ldots$ & 36 & $+t$ & 2.1 & 29 \\
\hline 10 & June $14-15$. & 53.2 & .09 & ${ }^{1} 600+$ & 36 & 38 & $+t$ & $2.0+$ & 25 \\
\hline 11 & June $15-16$ & 53.1 . & $\ldots \ldots$ & 600 & $\ldots \ldots$ & 40 & $+t+$ & 1.7 & 20 \\
\hline 12 & June $16-17 \ldots$ & 53.2 & .09 & 600 & . & 43 & $+t+$ & 1.4 & 18 \\
\hline 13 & June $17-18 \ldots$ & 53.8 . & $\ldots \ldots$ & 1,150 & $\ldots \ldots$ & 41 & + & 1.4 & 15 \\
\hline 14 & June 18-19. . & $\ldots \ldots$ & $\ldots \ldots$ & 910 & $\ldots \ldots$ & 41 & + & 1.4 & 12 \\
\hline 15 & June 19-20. . & 54.0 & .09 & 1,300 & 41 & 41 & Sl. + & 1.1 & 11 \\
\hline 16 & June $20-21 .$. & 54.2 & $\ldots \ldots$ & 1,600 & $\ldots \ldots \ldots$ & 40 & 0 & .9 & 9 \\
\hline 17 & June 21-22. . & 53.6 & .09 & 1,300 & $\ldots \ldots \ldots$ & 39 & 0 & $\ldots \ldots$ & $\ldots \ldots$ \\
\hline 18 & June $22-23$. . & 53.5 . & $\ldots \ldots$ & 1,800 & 44 & 43 & 0 & $\ldots \ldots$ & $\ldots \ldots$ \\
\hline 19 & June $23-24$. & 53.2 & .11 & 1,000 & $\ldots \ldots \ldots$ & 39 & 0 & $\ldots \ldots$ & $\cdots$ \\
\hline \multirow[t]{3}{*}{20} & June $24-25$. & 53.1 & 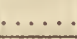 & 850 & $\ldots$ & 43 & 0 & $\ldots \ldots$ & . \\
\hline & June 25-26. . & & & 620 & & 44 & 0 & & \\
\hline & & 53.6 & .13 & & & & & $\therefore$ & $\because$ \\
\hline \multirow{3}{*}{$\begin{array}{c}\text { No. } \\
\text { of day. }\end{array}$} & \multirow{3}{*}{ Date. } & \multicolumn{3}{|c|}{$\begin{array}{l}\text { Urinary nitrogen } \\
\text { per } 24 \text { hours. }\end{array}$} & \multicolumn{4}{|c|}{ Diet. } & \multirow{3}{*}{$\begin{array}{l}\text { Pulse- } \\
\text { rate. }\end{array}$} \\
\hline & & \multirow[b]{2}{*}{ Total. } & & Per kilo- & & & & & \\
\hline & & & & gram. & hydrate. & Protein. & Fat. & Calories. & \\
\hline & 1916. & $\mathrm{om}$. & & $o m$. & $g m$. & $g m$. & gm. & & \\
\hline 1 & June $5-6$. & 4.9 & & 0.085 & 0 & 0 & 0 & 0 & \\
\hline 2 & June $6-7 \ldots$ & 7.7 & & .135 & 0 & 0 & 0 & 0 & \\
\hline 3 & June $7-8$. & 8.8 & & .155 & 0 & 0 & 0 & 0 & \\
\hline 4 & June $8-9$. & 9.4 & & .170 & 0 & 0 & 0 & 0 & 62 \\
\hline 5 & June $9-10 \ldots$ & 8.9 & & .165 & 10 & 5 & 0 & 60 & 78 \\
\hline 6 & June $10-11 \ldots$ & 7.7 & & .145 & 20 & 10 & 0 & 120 & 76 \\
\hline 7 & June $11-12$. & 6.5 & & .120 & 30 & 15 & 0 & 180 & \\
\hline 8 & June $12-13$. & 6.9 & & .130 & 40 & 20 & 0 & 240 & 68 \\
\hline 9 & June $13-14 .$. & 6.0 & & .110 & 40 & 35 & 20 & 480 & 65 \\
\hline 10 & June $14-15$. & $6.6-$ & & $.120+$ & 50 & 50 & 30 & 670 & 60 \\
\hline 11 & June $15-16$. & 7.2 & & .135 & 55 & 60 & 45 & 865 & $\ldots \ldots$ \\
\hline 12 & June 16-17.. & 6.5 & & .120 & 55 & 75 & 70 & 1,150 & $\ldots \ldots$ \\
\hline 13 & June $17-18$. . & 8.0 & & .150 & 55 & 60 & 60 & 1,000 & 63 \\
\hline 14 & June $18-19$. & 9.7 & & .180 & 55 & 75 & 85 & 1,285 & $\ldots \ldots$ \\
\hline 15 & June $19-20$ & 7.7 & & .145 & 55 & 70 & 105 & 1,445 & $\ldots \ldots$ \\
\hline 16 & June $20-21$. & 7.9 & & .145 & 55 & 75 & 115 & 1,555 & $\ldots$ \\
\hline 17 & June $21-22$. & 9.2 & & .170 & 55 & 85 & 120 & 1,640 & 57 \\
\hline 18 & June 22-23. & 11.2 & & .210 & 60 & 75 & 130 & 1,710 & \\
\hline 19 & June 23-24. . & 7.5 & & .140 & 155 & 90 & 145 & 2,285 & 59 \\
\hline \multirow[t]{2}{*}{20} & June $24-25$. & 6.2 & & .115 & 200 & 75 & 140 & 2,360 & 61 \\
\hline & June 25-26. . & 5.3 & & .100 & & & & & \\
\hline
\end{tabular}

1 Does not represent the complete volume of urine for this day.

'Urine was tested for sugar each day and no sugar was found. This column represents, therofore, the carbohydrate utilized, i. e., the carbohydrate balance. 
$\mathrm{T}_{\mathrm{ABLE}} 60-$ Metabolism of healthy woman under treatment of diabetic patient-Continued.

\begin{tabular}{|c|c|c|c|c|c|c|c|c|c|}
\hline \multirow[b]{2}{*}{$\begin{array}{l}\text { No. } \\
\text { of day. }\end{array}$} & \multirow[b]{2}{*}{ Date, } & \multirow{2}{*}{$\begin{array}{c}\text { Car- } \\
\text { bon } \\
\text { di- } \\
\text { oxide } \\
\text { per } \\
\text { min- } \\
\text { ute. }\end{array}$} & \multirow{2}{*}{$\begin{array}{l}\text { Oxy- } \\
\text { gen } \\
\text { per } \\
\text { min- } \\
\text { ute. }\end{array}$} & \multirow{2}{*}{$\begin{array}{c}\text { Respi- } \\
\text { ratory } \\
\text { quo- } \\
\text { tient. }\end{array}$} & \multicolumn{3}{|c|}{ Heat-output per 24 hours. $^{3}$} & \multirow{2}{*}{$\begin{array}{c}\text { Heat } \\
\text { per 24 } \\
\text { hrs. in- } \\
\text { creased } \\
\text { by } 24 \\
\text { p. ct. }\end{array}$} & \multirow{2}{*}{$\begin{array}{l}\text { Non-pro- } \\
\text { tein respi- } \\
\text { ratory quo- } \\
\text { tient in } \\
\text { post-ab- } \\
\text { sorptive ex- } \\
\text { periment. }\end{array}$} \\
\hline & & & & & Total. & $\begin{array}{c}\text { Per kilo- } \\
\text { gram. }\end{array}$ & $\begin{array}{l}\text { Varia- } \\
\text { tion from } \\
\text { H. and B. } \\
\text { standard. }\end{array}$ & & \\
\hline & 1916. & c. $c$. & c. $c$. & & cal. & cal. & p. $c l$. & cal. & \\
\hline 1 & June $5-6$. & 149 & 180 & 0.83 & 1,254 & 22 & -10 & 1,505 & 0.83 \\
\hline 2 & June $6-7$. & 159 & 202 & .79 & 1,393 & 25 & 0 & 1,672 & .79 \\
\hline 3 & June $7-8$. & 152 & 193 & .79 & 1,331 & 24 & -4 & 1,597 & .78 \\
\hline 4 & June $8-9 .$. & 138 & 179 & .77 & 1,228 & 22 & -11 & 1,474 & .76 \\
\hline 5 & June $9-10$. & 138 & 184 & .75 & 1,256 & 23 & -8 & 1,507 & .74 \\
\hline 6 & June $10-11$. & 141 & 180 & .78 & 1,238 & 23 & -8 & 1,486 & .78 \\
\hline 7 & June 11-12.. & $\cdots \cdots$ & & $\ldots$ & & & & & $\cdots$ \\
\hline 8 & June 12-13. . & 141 & 189 & .75 & 1,290 & 24 & -5 & 1,548 & .73 \\
\hline$\theta$ & June 13-14. . & 152 & 177 & .86 & 1,243 & 23 & -9 & 1,492 & .87 \\
\hline 10 & June 14-15. . & 144 & 185 & .78 & 1,272 & 24 & -7 & 1,526 & .77 \\
\hline 11 & June $15-16 .$. & 132 & 173 & .76 & 1,184 & 22 & -13 & 1,421 & .75 \\
\hline 12 & June $16-17$. & 148 & 179 & .80 & 1,237 & 23 & -9 & 1,484 & .84 \\
\hline 13 & June 17-18. . & 142 & 187 & .76 & 1,280 & 24 & -6 & 1,536 & .75 \\
\hline 14 & June $18-19$. & $\ldots$ & $\ldots \ldots$ & ...... & $\ldots \ldots$ & $\cdots$ & $\cdots \cdots$ & $\ldots \ldots$ & $\cdots$ \\
\hline 15 & June 19-20.. & 130 & 158 & .82 & 1,098 & 20 & -20 & 1,318 & .83 \\
\hline 16 & June $20-21 .$. & 142 & 186 & .76 & 1,273 & 24 & -7 & 1,528 & .76 \\
\hline 17 & June 21-22. & 138 & 175 & .79 & 1,207 & 23 & -12 & 1,448 & .79 \\
\hline 18 & June 22-23. & 140 & 178 & .79 & 1,228 & 23 & -10 & 1,474 & .78 \\
\hline 19 & June 23-24. & 151 & 199 & .76 & 1,362 & 26 & 0 & 1,634 & .75 \\
\hline \multirow[t]{2}{*}{20} & June 24-25. & 147 & 175 & .81 & 1,213 & 23 & -11 & 1,456 & .85 \\
\hline & June 26-27.. & 144 & 182 & .79 & 1,255 & 23 & -8 & & \\
\hline & \multirow[b]{2}{*}{ Date, } & \multicolumn{8}{|c|}{ Materials katabolized per 24 hours. } \\
\hline of day. & & \multicolumn{2}{|c|}{$\begin{array}{l}\text { Protein } \\
(\mathrm{N} \times 6.0)\end{array}$} & \multicolumn{2}{|c|}{$\begin{array}{l}\text { Carbohydrate } \\
\text { by method I. }\end{array}$} & $\begin{array}{l}\text { Fat by } \\
\text { method I. }\end{array}$ & \multicolumn{2}{|c|}{ - $\left|\begin{array}{c}\text { Carbohydrate } \\
\text { by method II. }\end{array}\right|$} & $\begin{array}{l}\text { Fat by } \\
\text { method II.5 }\end{array}$ \\
\hline & 1916 & \multirow{2}{*}{\multicolumn{2}{|c|}{$\begin{array}{l}g m . \\
29.4\end{array}$}} & \multirow{2}{*}{\multicolumn{2}{|c|}{$\begin{array}{c}g m . \\
137\end{array}$}} & $g m$. & \multicolumn{2}{|c|}{$\begin{array}{c}g m . \\
137\end{array}$} & $g m$. \\
\hline 1 & June $5-6 \ldots$ & & & & & 83 & \multirow{2}{*}{\multicolumn{2}{|c|}{$\begin{array}{r}137 \\
99\end{array}$}} & 83 \\
\hline 2 & June $6-7 \ldots$ & \multicolumn{2}{|c|}{46.2} & \multicolumn{2}{|c|}{99} & 110 & & & 110 \\
\hline 3 & June $7-8 \ldots$ & \multicolumn{2}{|c|}{52.8} & 81 & & 107 & 81 & 1 & 107 \\
\hline 4 & June $8-9$. & 56 & .4 & 53 & & 105 & 63 & 3 & 105 \\
\hline 5 & June $9-10 \ldots$ & 53 & .4 & 35 & & 118 & 10 & 0 & 128 \\
\hline 6 & June $10-11 \ldots$ & 46 & & 76 & & 101 & 20 & 0 & 126 \\
\hline 7 & June 11-12. & 39 & & & & & & & \\
\hline 8 & June $12-13$. & 41 & & 27 & & 131 & 40 & 0 & 126 \\
\hline$\theta$ & June 13-14. . & 36 & & 170 & & 62 & 40 & 0 & 123 \\
\hline 10 & June $14-15$. & 39 & & 70 & & 111 & 50 & 0 & 120 \\
\hline 11 & June $15-16 \ldots$ & 43 & & 44 & & 110 & 55 & 5 & 105 \\
\hline 12 & June $16-17 \ldots$ & 39 & & 141 & & 75 & 55 & 5 & 114 \\
\hline 13 & June $17-18 \ldots$ & 48 & & 47 & & 118 & 55 & 5 & 115 \\
\hline 14 & June $18-19$. & 58 & & 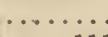 & & $\cdots$ & & & $\cdots$ \\
\hline 15 & June $19-20$. & 46 & & 111 & & 68 & 55 & 5 & 93 \\
\hline 16 & June $20-21 \ldots$ & 47 & & 57 & & 113 & 55 & 5 & 115 \\
\hline 17 & June 21-22. . & 55 & & 81 & & 90 & 55 & 5 & 103 \\
\hline 18 & June 22-23. & 67 & & 70 & & 92 & 60 & 0 & 98 \\
\hline 18 & June 23-24. . & 45 & & 51 & & 128 & 155 & & 84 \\
\hline 20 & June $24-25 \ldots$ & 37 & & 150 & & 69 & 200 & & 50 \\
\hline
\end{tabular}

3 The experiments were made for the most part between the hours $9 \mathrm{a} . \mathrm{m}$. and 12 noon.

- An increase of 20 per cent over basal metabolism for the 24 hours is assumed as the effect of food and exercise.

- Method I uses the non-protein respirstory quotient obtained in the morning respiration experiment of the day. In method II the non-protein respiratory quotient obtained in the morning experiment is used for the first four days. For the other days it is assumed that the carbohydrate burned is represented by the carbohydrates in the food for the day and that the remainder of the estimated heat-production was from protein and fat. 
Changes in Body-weyght.

Inspection of table 60 shows that the body-weight of the subject decreased $4.1 \mathrm{~kg}$., namely, from $57.2 \mathrm{~kg}$. on June 5 to $53.1 \mathrm{~kg}$. on June 10 . It is notable that the body-weight was the same on the sixth and the twentieth days of the experiment, although on the days between there were fluctuations upward of 0.1 to $1.1 \mathrm{~kg}$. The body-weight recorded the morning of each day on which the metabolism was determined showed an average loss of 216 grams per day for the 19 days covered by the records of body-weight, or 0.38 per cent of the original body-weight. As the diet contained on the average 16 calories per kilogram of body-weight per day during the 20 days of observation, it is easy to understand why the loss of weight was only half as great as that of L., the fasting subject of the Nutrition Laboratory, whose average daily loss during a fast of 31 days was 0.7 per cent of his weight at the beginning of this period. Similar losses in weight should therefore be expected with diabetic patients. In fact, such are the rule and, indeed, they are often exceeded during a similar period of time.

The gain in weight frequently observed with diabetics at the inauguration of treatment was not found with Miss L. during the first four days when she fasted. Later slight gains in weight were observed. With diabetics these gains in weight are really artificial and often to be explained by retention of salt, though Wilder and Beeler ${ }^{a}$ have recently observed gain in weight from edema as a result of extreme undernutrition without disturbance of the salt metabolism. The question therefore again arises whether, in calculating body metabolism during an investigation continuing but two or three weeks, the weight of the subject at the beginning should be taken as the basis for the metabolic studies throughout, or whether the weight for each day of the experiment should be employed. In some instances, like those cited in table 30 , page 70 , the weight of the diabetics increased abnormally, while in others the decrease in weight appears to have been considerable. The practice uniformly followed at this Laboratory has been to use the daily weight in calculating the metabolism. There is a question, however, as to whether this is a correct procedure under all conditions.

With Miss L., for example, the rapid loss of $4.1 \mathrm{~kg}$. in 5 days accompanied a heat-output of 6,462 calories due to the basal metabolism alone. (See table 60.) With the addition of 20 per cent to bring the metabolism for the five days to the basis of hospital activity this figure becomes 7,755 calories. If the intake on the fifth day of 60 calories is deducted, the net loss would be 7,695 calories, or 1,877 calories for each kilogram of body-weight lost. In the following 15 days, assuming as best we may that the basal heat for June 11 and June 18 was equal to the average of the heat-output computed in each instance for the preceding and following days, the total basal heat-output was 18,578 calories. On the basis of hospital activity this figure becomes 22,294 calories and with a total energy intake in the same period of 16,985 calories, there is a net loss of 5,309 calories with a fluctuation in weight of not more than $1.1 \mathrm{~kg}$. For the entire period of 20 days from June 5 to June

- Wilder and Beeler, Am. Journ. Physiol., 1921, 55, p. 287. 
24 inclusive, the net loss of energy, computed by this method from the basal metabolism, was 13,003 calories, or 3,171 calories for each kilogram of bodyweight lost. It will be remembered that $\mathrm{L}$. lost the equivalent of 3,258 calories for each kilogram of reduction in body-weight in a long fast.

If one pursues the effect of these changes in weight further, it will be observed that the heat-output per kilogram of body-weight was 22 calories at the beginning of the experiment and 23 calories on the last day, an increase of 5 per cent in the metabolism. When compared with the normal standard, there was a fall from 10 per cent below standard at the beginning of the experiment to 11 per cent below at the end, or a decrease of 1 per cent. If the same weight for the beginning and end of the experiment is employed, it will be found that the metabolism decreased per kilogram of body-weight to 21 calories, and was 13 per cent below standard at the end of the experiment. These figures would appear to represent more exactly the true metabolism.

\section{Pulse-Rate.}

The data for the pulse-rate are unfortunately lacking for the first three days, and also for seven other days. Upon the fourth day of fasting the pulse-rate was 62 , but it quickly rose on the first and second days of feeding to 78 and 76 , respectively. It then fell in a few days to 60 , and remained at about this level until the end of the period of observation. The falling pulse-rate is corroborative evidence of reduction in metabolism.

\section{VOLUME OF URINE.}

The volume of urine during the fasting period of four days averaged 733 c. c. It rose to $1,100 \mathrm{c}$. c. when food was begun, but immediately fell to subnormal, the average daily excretion for the second week (June 12 to 18) being 780 c. c. In the concluding 6 days of the experiment (June 19 to 24), the urine was about normal, with an average excretion of 1,308 c. c. Even the small quantity of urine during the four fasting days was insufficient to prevent the loss of body-fluid which is shown by the loss of body-weight. This marked fall in body-weight, as well as the decrease in the excretion of urine, lead to the therapeutic suggestion that this loss of weight can be avoided by the free administration of liquids. Diabetic patients almost invariably protect themselves against such a loss in the course of treatment, but this is not the case at the beginning of treatment, a time at which the advantages of drinking freely should be brought to their attention.

Recently Case No. 1500, whose weight was $50 \mathrm{~kg}$., height without shoes 167 centimeters, and age 47 years and 9 months, lost $4.5 \mathrm{~kg}$. in 17 days. At first his rapid loss of weight appeared astonishing, but further calculations show that although it was partly owing to loss of fat, it was largely due to a loss of water. During this period his diet contained 17,291 calories, but the carbohydrate excreted in the urine amounted to 68 calories. The net intake was thus 17,223 calories, with a daily intake of about 1,000 calories, or 20 calories per kilogram of body-weight. His basal metabolism, according to 
the Harris and Benedict standard, was 1,265 calories, and if one adds a requirement of 20 per cent for activity, his metabolic needs were approximately 1,500 calories daily. Therefore, for the 17 -day period he lacked 8,500 calories, and this was represented by the loss in body-weight of $4.5 \mathrm{~kg}$. According to statements previously made (see p. 135), the fasting subject L. lost per kilogram of reduction in body-weight approximately 3,258 calories, and Miss L. approximately 3,171 calories, whereas Case No. 1500 lost about 1,890 calories for each kilogram of body-weight lost. Evidently the diabetic excreted more water in this period than either the fasting subject $L$. or the nurse Miss L.

\section{Excretion of Urinary Nitrogen.}

The urinary nitrogen of Miss L. steadily increased, as is usual in fasting, during the four fasting days, rising from 4.9 to 9.4 grams per day, or from 0.085 gram per kilogram of body-weight to 0.170 gram per kilogram of body-weight. As soon as even a small quantity of carbohydrate and protein food was given, the urinary nitrogen decreased to approximately 6 or $7 \mathrm{grams}$, at which point it remained until the protein increased to about 1 gram per kilogram of body-weight. Thereafter, as the amount of protein in the diet was added to, the amount of urinary nitrogen also increased, especially on June 21 and 22 , when the total diet was more liberal. Notwithstanding the greater output of urinary nitrogen during the last ten days of the experiment, the excretion did not increase so rapidly as the intake and there was evidently a nitrogen retention to compensate for the loss at the beginning of the experimental period. Again it is evident, as has elsewhere been noted, that great drafts upon body protein are made by fasting and a low diet, and that as soon as the body is able to replace the nitrogen lost, it makes every endeavor to do so. With a diabetic it is more difficult to replace protein lost, and one should consequently more zealously conserve it.

The dietary régime during this experiment with a normal subject corresponded closely to the routine which a diabetic patient underwent at this period, i. e., after June, 1914. The first four days were fasting days; the subsequent ten or twelve days represented a period of comparatively low diet, and not until the seventeenth day (June 21-22) did the energy in the food ingested amount to 30 calories per kilogram of body-weight. During the last two days the energy of the diet averaged 44 calories per kilogram of body-weight, an amount of food seldom exceeded in prescriptions for adult diabetic patients.

During the twenty days covered by the whole observation, the total protein in the diet was 875 grams, representing 140 grams of nitrogen. The total urinary nitrogen for this period of twenty days was 154 grams, showing a net nitrogen loss through the urine of 14 grams. If the loss of nitrogen in feces and by the skin is included, the loss would be nearer 30 to 40 grams. Each kilogram of body-weight lost by Miss L. during the 20 days of observation was thus represented by a net loss of 3 grams of urinary nitrogen, or about 18 grams of protein. This is very different from the results obtained with the fasting subject $L_{\text {. }}$, who excreted in the urine the nitrogen equivalent of 126 
grams of protein for each kilogram of body-weight lost during his 31-day fast. Even if one estimates the total loss of nitrogen to be as high as 40 grams, it would represent a loss of but 50 to 60 grams of protein per kilogram of body-weight lost, instead of 180 grams of protein which a kilogram of body-tissue is estimated to contain. The small loss of protein in Miss L.'s case would indicate that the loss in weight was largely water.

A more exact comparison of the effect of Miss L.'s diet and that of actual fasting is obtained by using only the nitrogen excretion for the first 20 days of L.'s fast." During these days L.'s loss of urinary nitrogen was 192 grams, or 0.175 gram per kilogram of body-weight per day, in contrast to the output of urinary nitrogen by Miss L. of 154 grams, or 0.140 gram per kilogram of body-weight per day. It is also worthy of note that the diabetic patients prior to June, 1914, excreted on the average 0.265 gram of urinary nitrogen per kilogram of body-weight per day, and after June, 1914, the excretion was 0.185 gram of body-weight per day. The latter amount is not far from the urinary excretion of Miss L. It will be remembered that before June, 1914, the diabetic patients ate very freely, but after June, 1914, very moderately or even too little food. The above comparison brings out the fact that this young woman upon a diet similar to that of the diabetic patient after June, 1914, behaved essentially the same as the diabetic.

Upon the nineteenth and twentieth days of the experiment Miss L. was given 2,285 and 2,360 calories, representing 43 and 44 calories per kilogram of body-weight. Upon this diet she failed to gain weight, but there was marked retention of body nitrogen, the excretion for the two days being but 7.5 and 6.2 grams, respectively. It will be observed that the average metabolism upon these two days was actually less than the average metabolism for the first four days when the patient was fasting. In other words, fasting does not immediately lower the metabolism, nor does an excess of food, following a period of restricted diet, raise it. The organism does not at first decrease metabolism with sufficient rapidity to save body tissue. Conversely, feeding does not immediately raise the metabolism, for the surplus food is utilized to replace body tissue lost.

\section{BLOod Stgar.}

At the beginning of the experiment the blood sugar was 0.12 per cent, a rather high value for a normal subject before breakfast. This decreased as the days progressed. After 4 days of fasting and 4 days of feeding, during which the diet had advanced to but 40 grams of carbohydrate, and to $240 \mathrm{cal}-$ ories in a day, it reached its lowest level at 0.08 per cent. On the nineteenth day, when the diet had been increased to 155 grams of carbohydrate and 2,285 calories ( 43 calories per kilogram of body-weight), it rose to 0.11 per cent.

The lowest blood sugar, namely, 0.08 per cent, deserves attention. Presumably this decrease in blood sugar is to be expected with a fasting or undernourished normal individual, but the data upon such cases in the literature are as yet scarce and insufficient. A few cases of death from diabetes, asso-

- Benedict, Carnegio Inst. Wash. Pub. No. 203, 1915, p. 251. 
ciated with low blood sugar, have been recorded. Two cases of this character (Nos. 1085 and 1831) have occurred under the writer's observation. In the latter case the blood-sugar value was 0.04 per cent. A dangerous lowering of the blood sugar may be expected occasionally with undernutrition when this method is carried to the extreme, and the possibility should be borne in mind. In my larger series of cases there was one recovery in a patient (Case No. 2079) whose blood sugar fell to 0.05 per cent, after carbohydrate was given freely. ${ }^{\circ}$

\section{Acidosis.}

The acidosis was studied by means of the usual methods. Two days of fasting sufficed to produce a positive reaction for diacetic acid and an ammonia excretion of 1.2 grams, but the carbon dioxide in the alveolar air remained unchanged. All tests appeared or were more marked following the third day of fasting, and if the subject had been a diabetic, she would have been said to exhibit mild acidosis. This became great enough during the fifth to eighth days to be classified as moderately severe. The ammonia-nitrogennitrogen ratio amounted to 31 per cent and the $\mathrm{CO}_{2}$ in the blood fell to $25 \mathrm{~mm}$. expressed in terms of millimeters tension $\mathrm{Hg}$ pressure. This moderate acidosis persisted and even continued when the patient was given 55 grams of carbohydrate, though from this point onward with an increase of calories chiefly in the form of fat, and to some extent in protein, the acidosis became milder in character and eventually entirely disappeared, but this did not occur until the sixteenth day, when the total calories in the diet amounted to 1,555 , or 29 calories per kilogram of body-weight. Since the acidosis decreased when the fat was increased, although the carbohydrates and protein remained practically the same, it is very plain that the acidosis was not solely dependent upon the constituents of the diet or their relation to each other, but rather on the total number of calories administered. Oxidation of body fat and body protein also play an important rôle, as has been emphasized by Newburgh and Marsh, ${ }^{b}$ and Woodyatt, ${ }^{c}$ and still more recently by Shaffer. ${ }^{d}$ It is not the food given, but the material oxidized, either endogenous or exogenous which counts.

This question of acidosis should therefore be examined from the relation of the carbohydrate in the diet to the total metabolism. The average daily basal metabolism for this subject, as indicated by the 18 observations, was 1,255 calories. If one adds 20 per cent to represent the effect of food ingested and the calories required for muscular activity, the total metabolism per day rises to 1,500 calories. The acidosis began to decrease when the carbohydrate

- Joslin, Med. Clinics of No. America, 1921, 4, p. 1723.

b Newburgh and Marsh, Arch. Intern. Med., 1920, 26, p. 657; also Arch. Intern. Med., 1921, 27, D. 699 .

Woodyatt, Arch. Intern. Med., 1921, 28, p. 125.

Shaffer, Journ. Biol. Chem., 1921, 49, p. 143. 
in the diet reached 30 grams, or 120 calories, and as soon as the energy from the carbohydrate in the diet amounted to 220 calories, or 15 per cent of the total metabolism, the acidosis was slight. On the eleventh day, when the carbohydrate was 55 grams, the fat in the diet was but 45 grams, but in reality the actual amount of fat oxidized was 107 grams. This is evident if one deducts from the total metabolism of the day, which would be 1,420 calories as estimated by the method outlined above, the energy intake from 55 grams carbohydrate and 60 grams protein of 220 and 240 calories, respectively, and divide the remainder by 9 .

This figure for the actual amount of fat oxidized (107 grams) is somewhat below that obtained by Woodyatt's formula for the quantity of fat which could be oxidized by this amount of carbohydrate, i. e.,

$$
F=2 C+\frac{P}{2} \text { or } F=2 \times 55+\frac{60}{2}=140 \text { grams. }
$$

Utilizing Shaffer's formula to determine the amount of carbohydrate required to protect from acidosis, the computation is as follows:

Minimal carbohydrate to prevent acidosis $=$

$$
\frac{\text { Calories of total metabolism - urinary } \mathrm{N} \times 100}{50} \text { or } \frac{1420-720}{50}=14 \text { grams. }
$$

But Shaffer rightly points out that as this 14 grams must be oxidized continuously throughout the day to prevent individual molecules of $\beta$-oxybutyric acid from being unburned, it is far safer and, indeed, necessary to give twice the minimal amount, which in this case would be 28 grams. It is observable that the actual turning-point in the acidosis began, as registered by the change in ammonia, when the carbohydrate reached 30 grams. The two formulæ may therefore be applied to the seventh day, which was the turning-point in the acidosis. By Woodyatt's formula, the calculation would be:

$$
F=2 \times 30+\frac{15}{2}, \text { or fat }=68 \text { grams, }
$$

and as the fat actually oxidized was 145 grams, acidosis must still exist. Applying Shaffer's formula:

$$
C=\frac{1,500-650}{50}=17 \text { grams. }
$$

Multiplying this figure by 2, we find there is likewise reason for the acidosis. Bearing in mind Shaffer's conception of the necessity for continuous oxidation of carbohydrate to offset acidosis, we can readily understand why the acidosis gradually decreased. At periods in the day following meals, sufficient carbohydrate was available to prevent acidosis, whereas at other periods in the 24 hours it was lacking. 


\section{Basal Metabolism.}

The basal metabolism was remarkably constant throughout the period of observation, varying only between 1,098 calories (for the fifteenth day) and 1,393 calories (for the second day), and from 20 to 26 calories per kilogram of body-weight. If one relates the total metabolism to the normal standard, the variations range from -13 per cent to 0 per cent, except for one variation on the fifteenth day (June 19) of -20 per cent. These variations in the course of a long series must be expected, according to Blunt and Dye. ${ }^{a}$ If the original body-weight of the patient is used for the calculations on all subsequent days, it will be found that the metabolism varied from the normal standard by -1 and -22 per cent. The striking feature of the metabolism is that upon all but two of the eighteen days on which it was determined, it was subnormal. If the average is taken for the entire period, it was 8 per cent below the normal standard. These observations, therefore, show that a normal individual who lived upon a diet for twenty days similar to the routine diet advised for diabetics had a metabolism which was 8 per cent subnormal. As the diabetics frequently have a smaller diet, and in addition, for a portion of the period while under treatment, they lose calories in the form of sugar, it is readily understood why their metabolism should be somewhat more subnormal than that of Miss L.

Table 60 is furthermore striking in that it shows how constant the metabolism remains, irrespective of temporary changes in food. Thus, upon the four days of fast at the beginning of the experiment, the basal metabolism averaged 1,302 calories, upon four days in the middle of the experiment (June 14 to 18) it averaged 1,243 calories, and upon the last four days, the average was 1,253 calories. Similar evidence is furnished by the observations upon diabetics.

The metabolism of this nurse was again determined after an interval of 6 years and 5 months (on November 22, 1922). The values obtained were: Body-weight, $55.6 \mathrm{~kg}$. ; height, $169 \mathrm{~cm}$.; age, 31 years; carbon-dioxide production, 135 c. c. per minute; oxygen consumption, 179 c. c. per minute; respiratory quotient, 0.76 ; heat-production per 24 hours, 1,225 calories; variation of metabolism from standard, -10 per cent.

\section{Respiratory QUOTIENT.}

As a result of the four days of fasting, the respiratory quotient fell steadily from 0.83 to 0.75 . It is hard to understand why it rose on June 10-11 to 0.78 , for this rise can not be attributed to the 10 grams of carbohydrate and 5 grams of protein which were given in the diet of June 9-10. Perhaps little significance should be attached to it, because such variations are also noted in daily observations upon healthy individuals. At any rate, upon the morning of June $12-13$, the respiratory quotient was again 0.75 as might be expected, since on June 11 the carbohydrate in the diet was 30 grams and the protein 15 grams. From this point onward, however, the respiratory quotient was higher. The average respiratory quotient for the ten days during which the subject was taking but 40 to 55 grams of carbohydrate daily was 0.79 , which differs but slightly from the average respiratory quotient of 0.81 for 68 female subjects whose post-absorptive metabolism was observed when

- Blunt and Dye, Journ. Biol. Chem., 1921, 47, p. 69. 
they were on a full diet. This relatively high respiratory quotient upon a diet with low carbohydrate and low calories is somewhat analogous to the high respiratory quotient observed with the extremely undernourished diabetics.

\section{Materials Katabolized.}

The non-protein respiratory quotient was computed for the first 6 days according to the method described in the report of the research with the fasting subject L. $^{b}$ Obviously it is inaccurate thus to estimate the materials katabolized for the entire day, because the experiments in this case were in the morning and they approximated only 2 hours in duration. A suggestive picture of the kind of katabolism which was taking place may be gained, however, and although the defects are realized, it is presented.

The loss of carbohydrate for the first 4 days of fasting was marked, amounting to 370 grams, an amount similar though larger than that usually observed by others in fasting experiments. Even though the actual figures might be somewhat less, if based on longer calorimetric periods, it presents vividly the enormous drain upon the glycogen reserves of the body which fasting entails. The fasting subject L. at this Laboratory lost 153.7 grams glycogen in the same space of time and two other normal subjects studied during fasting by Benedict ${ }^{c}$ have katabolized during five observations amounts between 118.6 and 258.7 grams in 4 days. Even in the following 2 days the katabolism of carbohydrate averaged over 50 grams per day.

The protein katabolized gradually increased from 29.4 grams on the first day to 56.4 grams on the fourth. This may be compared with L.'s values which were 42.6 and 71.2 grams on the first and fourth days, respectively. His weight on these days averaged but 2 kilograms more than that of our subject.

The quantity of fat metabolized varied between 83 grams for the first day and 105 grams on the fourth, rising to 110 grams on one of the intervening days. These values are but slightly below L.'s, which were $135,142,130$, and 136 grams.

\section{Summary of Regults with Healthy Woman Under Diabetic Regime.}

In June, 1916, a healthy young woman underwent for 20 days the treatment then in vogue to render the urine of a diabetic patient sugar-free and to build up tolerance for carbohydrate, together with an adequate supply of calories. During this period the subject lost $4.1 \mathrm{~kg}$. of body-weight. The post-absorptive blood sugar decreased from 0.12 per cent at the beginning of the experiment to 0.08 per cent on the eighth day. During the preceding seven days the subject had taken a total amount of food containing carbohydrate 60 grams, protein 30 grams, and fat none. Thereafter the blood sugar gradually rose until upon the second morning after the conclusion of the experiment, when the patient was on full diet, it had reached 0.13 per cent, essentially the same as at the beginning of the experiment.

Acidosis developed, which did not begin to subside until the subject had taken 30 grams of carbohydrate, representing 15 per cent of the total basal metabolism plus 20 per cent additional for effect of food and exercise. The

- Benedict and Emmes, Journ. Biol. Chem., 1915, 20, p. 253.

- Benedict, Carnegie Inst. Wash. Pub. No. 203, 1915, p. 401.

- Benedict, Carnegie Inst. Wash. Pub. No. 77, 1907, p. 464, table 228. 
acidosis did not entirely disappear until the carbohydrate, with gradually increasing protein and fat, had risen to 55 grams and had been continued for five days.

The volume of urine markedly decreased upon the first fasting day, but thereafter gradually increased, though still remaining at a low level until the subject was taking approximately 30 calories per kilogram of body-weight, when it reached approximately 1,500 c. c. daily.

The urinary nitrogen for the first day of fasting was 0.085 gram per kilogram of body-weight, but thereafter steadily rose until at the end of the fourth day of fasting it was 0.170 gram per kilogram. Thereafter it dropped to between 6 and 7 grams daily, an average of 0.125 gram per kilogram of body-weight, and increased but slightly when additional food was given, an obvious nitrogen retention taking place. Each kilogram of body-weight lost contained less nitrogen and more water than body tissues.

For the first four days of the experiment the subject was without food, and thereafter the carbohydrate was gradually increased to 50 and 55 grams, at which point it remained for 8 days until the protein had been brought up to 75 to 85 grams and the fat to 120 grams, giving the patient 30 calories per kilogram of body-weight.

The pulse-rate showed an increase near the beginning of the study with a fairly steady decrease thereafter to the end of the experiment. With the four successive fasting days the respiratory quotient steadily decreased from 0.83 to 0.75 , but subsequently rose gradually with the taking of food to 0.79 .

The total calories lost by the subject during the four days of fasting, ${ }^{a}$ computed from the basal metabolism, plus an allowance of 20 per cent for activity, amounted to 7,695 calories, or 1,924 calories per day, and for the following 15 days a net loss of 5,309 calories. From June 5 to June 24 inclusive, each kilogram of body-weight lost was represented by 3,171 calories. An even greater loss of calories must, therefore, be expected with a diabetic patient on the same diet, because of the additional losses which such a patient would undergo by the excretion of sugar in the urine and possibly greater acidosis.

The metabolism of this subject was as high during the first four days of fasting as during the fourteenth to eighteenth days, when she was receiving an adequate supply of food. The body, therefore, does not react to fasting with a sudden reduction of metabolism, and following prolonged undernutrition it conserves body tissue by not increasing its basal metabolism, even when there is a liberal food intake.

Effect of Extraneous Factors upon Metabolism in Diabetes. INFLUENCE OF CATAMENIA, THE MENOPAUSE, AND OVARIOTOMY UPON THE METABOLISM OF DIABETIC PATIENTS.

Opportunity was afforded to note the influence of catamenia, the menopause, and ovariotomy upon the metabolism of the diabetic patients. Such data as are available regarding the patients compared with the Harris and Benedict standard are given in table 61 . With the 15 patients with whom catamenia persisted, the metabolism reached no extremes, save for Case No. 332, with whom it was 21 per cent above normal, and for Case No. 765, with whom

\footnotetext{
a On the fifth day but 60 calories were ingested.
} 
it was 17 per cent below normal. In general, the metabolism of these patients showed essentially the same variation as that for the entire group of cases.

TABLE 61.-Influence of catamenia, the menopause, and ovariotomy upon the metabolism of diabetic patients.

\begin{tabular}{|c|c|c|c|c|c|c|c|}
\hline \multicolumn{2}{|c|}{ Catamenia persisting. } & \multicolumn{2}{|c|}{ Catamenia ceased. } & \multicolumn{2}{|c|}{ Menopause. } & \multicolumn{2}{|c|}{ Ovariotomy. } \\
\hline Case No. & $\begin{array}{c}\text { Average } \\
\text { variation } \\
\text { from } \\
\text { standard } \\
\text { (15 cases). }\end{array}$ & Case No. & $\begin{array}{c}\text { Average } \\
\text { variation } \\
\text { from } \\
\text { standard } \\
\text { (10 cases). }\end{array}$ & Case No. & $\begin{array}{l}\text { Average } \\
\text { variation } \\
\text { from } \\
\text { standard } \\
\text { (9 cases). }\end{array}$ & Case No. & $\begin{array}{l}\text { Average } \\
\text { variation } \\
\text { from } \\
\text { standard } \\
\text { (1 case). }\end{array}$ \\
\hline & p. ct. & & p. ct. & & p. ct. & & p. ct. \\
\hline $\begin{array}{l}263 \\
310\end{array}$ & $\begin{array}{l}-3 \\
+14\end{array}$ & $\begin{array}{l}283 \\
436\end{array}$ & $\begin{array}{l}+3 \\
+3\end{array}$ & $\begin{array}{l}558 \\
970\end{array}$ & $\begin{array}{l}-1 \\
+8\end{array}$ & $\begin{array}{c}810 \\
\ldots \ldots\end{array}$ & -4 \\
\hline 332 & +21 & 979 & -1 & 983 & +20 & $\cdots \cdots \cdots$ & $\cdots \cdots \cdots$ \\
\hline 552 & +13 & 1005 & -15 & 996 & +7 & $\ldots \ldots \ldots$ & $\ldots \ldots \ldots$ \\
\hline 765 & -17 & 1007 & +1 & 1041 & +8 & $\ldots \ldots \ldots$ & $\ldots \ldots \ldots \ldots$ \\
\hline 767 & -2 & 1011 & -26 & 1214 & +2 & $\ldots \ldots \ldots$ & $\ldots \ldots \ldots$ \\
\hline 792 & -16 & 1025 & -18 & 1265 & -11 & $\ldots \ldots \ldots$ & $\ldots \ldots \ldots$ \\
\hline 924 & +3 & 1066 & -10 & 1303 & -11 & $\ldots \ldots \ldots$ & $\ldots \ldots \ldots$ \\
\hline 1070 & -15 & 1085 & -35 & 1414 & -8 & $\ldots \ldots \ldots$ & $\ldots \ldots \ldots \ldots$ \\
\hline 1159 & -2 & 1307 & -15 & $\ldots \ldots$ & $\ldots \ldots$ & $\ldots \ldots \ldots$ & $\ldots \ldots \ldots$ \\
\hline 1182 & -3 & $\ldots \ldots \ldots$ & $\ldots \ldots \ldots \ldots$ & $\ldots \ldots$ & $\ldots \ldots \ldots$ & $\ldots \ldots$. & $\ldots \ldots \ldots$ \\
\hline 1207 & -14 & $\ldots \ldots \ldots$ & $\ldots \ldots \ldots \ldots$ & $\ldots \ldots$ & $\ldots \ldots \ldots$ & $\ldots \ldots \ldots$ & $\ldots \ldots \ldots$ \\
\hline 1215 & -14 & $\ldots \ldots \ldots$ & $\ldots \ldots \ldots$ & $\ldots \ldots$ & $\ldots \ldots \ldots$ & $\ldots \ldots \ldots$ & $\ldots \ldots \ldots$ \\
\hline 1226 & -15 & $\ldots \ldots \ldots$ & $\ldots \ldots \ldots$ & $\ldots . . .$. & $\ldots \ldots \ldots$ & 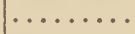 & $\ldots \ldots \ldots$ \\
\hline 1232 & -2 & $\ldots \ldots \ldots$ & $\ldots \ldots \ldots \ldots$ & $\ldots \ldots \ldots$ & $\cdots \ldots \ldots$ & $\ldots \ldots \ldots$ & $\ldots \ldots \ldots \ldots$ \\
\hline Av. & -3 & & -11 & ......... & +2 & $\ldots$ & -4 \\
\hline
\end{tabular}

When catamenia ceased, as it was known to have done with 10 of the patients, the metabolism was distinctly lower for cases both before and after June, 1914, the average being 11 per cent below standard. This is quite as one would expect, because it is known that with the loss of weight and vitality which occurs in undernutrition catamenia will cease. Nine cases were examined after the menopause. The average metabolism of these 9 cases was 2 per cent above standard. With one exception (Case No. 983) the range in metabolism was from 8 per cent above to 11 per cent below standard, and thus not very different from the general average of all cases, though upon a slightly lower basis.

Ovariotomy was without influence upon the metabolism, the one individual with whom it had taken place having a metabolism of 4 per cent below normal.

\section{DIABETES DURING PREGNANCY.}

Opportunity was afforded for studying three cases of diabetes during the course of pregnancy. The details regarding each case are as follows:

Observations with Case No. 436.

Case No. 436 came under observation in August, 1911. The patient developed diabetes in May, 1909, at the age of 20 years and 3 months, when 8 per cent of sugar was found in the urine. The family history, which showed 
a marked diabetic heredity, together with various other details concerning the patient, will be found in a previous publication. ${ }^{a}$ The physical examination was negative. From the first visit until the present time (February, 1923) the patient has continued in good health. During the thirteen years since the onset of diabetes, the urine has usually contained sugar, though frequently just before visits to the office the patient would restrict carbohydrates more sharply and, in consequence, sugar would disappear and evidence of acidosis develop.

The first observation of the metabolism was made on December 7, 1914, about 8 months before pregnancy occurred. (See Appendix I, p. 292.) In the 24 hours preceding the experiment, the urine contained 4 grams of sugar, the diacetic acid was +++ , the ammonia was 2.0 grams in 24 hours, and the nitrogen 6.3 grams ( 0.10 gram per kilogram of body-weight), but on the day of the experiment the nitrogen was 7.4 grams (0.12 gram per kilogram of body-weight). The patient was considered to have a moderate acidosis, but on this occasion, as on several others, this was probably of recent origin, brought on by a sudden restriction of carbohydrate in the diet. The exact composition of the diet is unknown. The metabolism on December 7, 1914, with the patient in a post-absorptive condition, was 7 per cent below standard, or 21 calories per kilogram of body-weight, with a respiratory quotient of 0.78 .

The second observation was made on January 13, 1916, when the patient was 5 months pregnant. The diet at this time contained approximately 60 grams of carbohydrate, 79 grams of protein, and 143 grams of fat, with 1,843 calories, equivalent to 30 calories per kilogram of body-weight. The patient had been practically sugar-free for some time and the tolerance for carbohydrate was distinctly greater than before pregnancy took place. The urine in the preceding 24 hours contained 2 grams of sugar, 1.2 grams of ammonia, and 10.9 grams of nitrogen ( 0.17 gram per kilogram of body-weight). The acidosis was considered to be slight. The metabolism at this second observation was 5 per cent above standard, or 24 calories per kilogram of body-weight, with a respiratory quotient of 0.82 .

The third observation was made on March 21, 1916, when the patient was 7 months pregnant. At that time the diet contained 50 grams or more of carbohydrate, but the quantities of protein and fat are problematical, although undoubtedly as great as in January, 1916. The urine contained no sugar and no diacetic acid. The carbon-dioxide tension in the alveolar air was not determined on this day, but upon March 14 it was $36 \mathrm{~mm}$. and on March 28 it was $29 \mathrm{~mm}$. The metabolism was 10 per cent above standard, or 24 calories per kilogram of body-weight, with a respiratory quotient of 0.84 .

Confinement took place on April 30, 1916. It was anticipated that a Cesarean section would be the safest means of delivery, but labor proceeded so rapidly and so painlessly that delivery was effected in the course of a few minutes, with low forceps.

The fourth observation of the metabolism was on November 7, 1916, six months after confinement. The exact composition of the diet for the preceding day is unknown. The percentage of sugar in the urine was probably not far from 1 per cent, the ammonia amounted to $1.9 \mathrm{grams}$, and the nitrogen

\footnotetext{
" Joslin, "Treatment of Diabetes Mellitus," Philadelphia, 1917, 2d ed., p. 455.
} 
upon the day following the observation was 9.9 grams (0.16 gram per kilogram of body-weight). The metabolism was 3 per cent above standard, or 24 calories per kilogram of body-weight, with a respiratory quotient of $0.74 .^{\circ}$

It will be noted that the metabolism for the four observations, extending over the period from December 7, 1914, to November 7, 1916, varied between 7 per cent below standard before pregnancy to 5 and 10 per cent above standard during pregnancy, and fell to 3 per cent above standard 6 months after confinement.

The behavior of the respiratory quotient for the four periods is significant. In the first period, upon December 7, 1914, this was found to be 0.78 . At the second observation, January 13,1916 , it rose to 0.82 . It will be recalled that the tolerance of the patient had been improving. At the third observation, March 21, 1916, it rose again to 0.84 , corresponding to the still greater improvement in tolerance. Finally, six months after confinement, in November, 1916, the tolerance for carbohydrate had decreased and the condition of the patient was not so good. In line with these clinical facts is the respiratory quotient, which fell to 0.74 .

Observations with Case No. 1070.

The patient was born July 15, 1889. The diabetes began in May, 1916, when the patient was 26 years 10 months old and 6 months pregnant. She came under observation June 19, 1916, and died October 11, 1917, in coma. The physical examination at the first visit was negative except for the pregnancy. The urine contained 5 per cent of sugar and the acidosis was severe, but with appropriate treatment, the patient was made sugar-free and acid-free readily. ${ }^{b}$ The course of the case is shown in table 62 .

During the first period of observation (A), the diabetes was of moderate severity. But one test of the metabolism was made in this period, which was upon June 29, 1916, with the patient in a post-absorptive condition. On this day the urine was sugar-free and the acidosis moderate; the metabolism was found to be 5 per cent below standard, or 23 calories per kilogram of body-weight. The respiratory quotient was 0.78 . For this date the acidosis was considered to be of moderate degree, although on June 23 the carbondioxide tension of the alveolar air was as low as $19 \mathrm{~mm}$. and the carbon dioxide in the blood reckoned on the same basis amounted to $21 \mathrm{~mm}$.

In the interpretation of the basal metabolism upon June 29, it should be borne in mind that for the seven days preceding the estimation of the metabolism, owing to the restrictions of diet to render the patient sugar-free and acid-free, the total calories ingested in the food amounted to but 2,140, or an average of 306 calories daily, the equivalent of 5 calories per kilogram of body-weight. If one should subtract from the total calories ingested the calories lost as sugar in the urine during the same period, namely, approximately 900 calories, the available calories would be still less. As a matter of fact, even this figure should be reduced to allow for the calories lost by the excretion of acetone bodies. During a similar period of 7 days the normal subject, Miss L., with a total amount of 360 calories in the diet (51 calories per

\footnotetext{
- In a later observation of this patient (October 26, 1922) the metabolism was 12 per cent below standard, or 21 calories per kilogram of body-weight, with a respiratory quotient of 0.79 . The sugar in a 24-hour specimen of urine was 2.8 per cent, and the nitrogen 9.2 grams.

b Joslin, "Treatment of Diabetes Mellitus," Philadelphia, 1917, 2d ed., p. 457.
} 


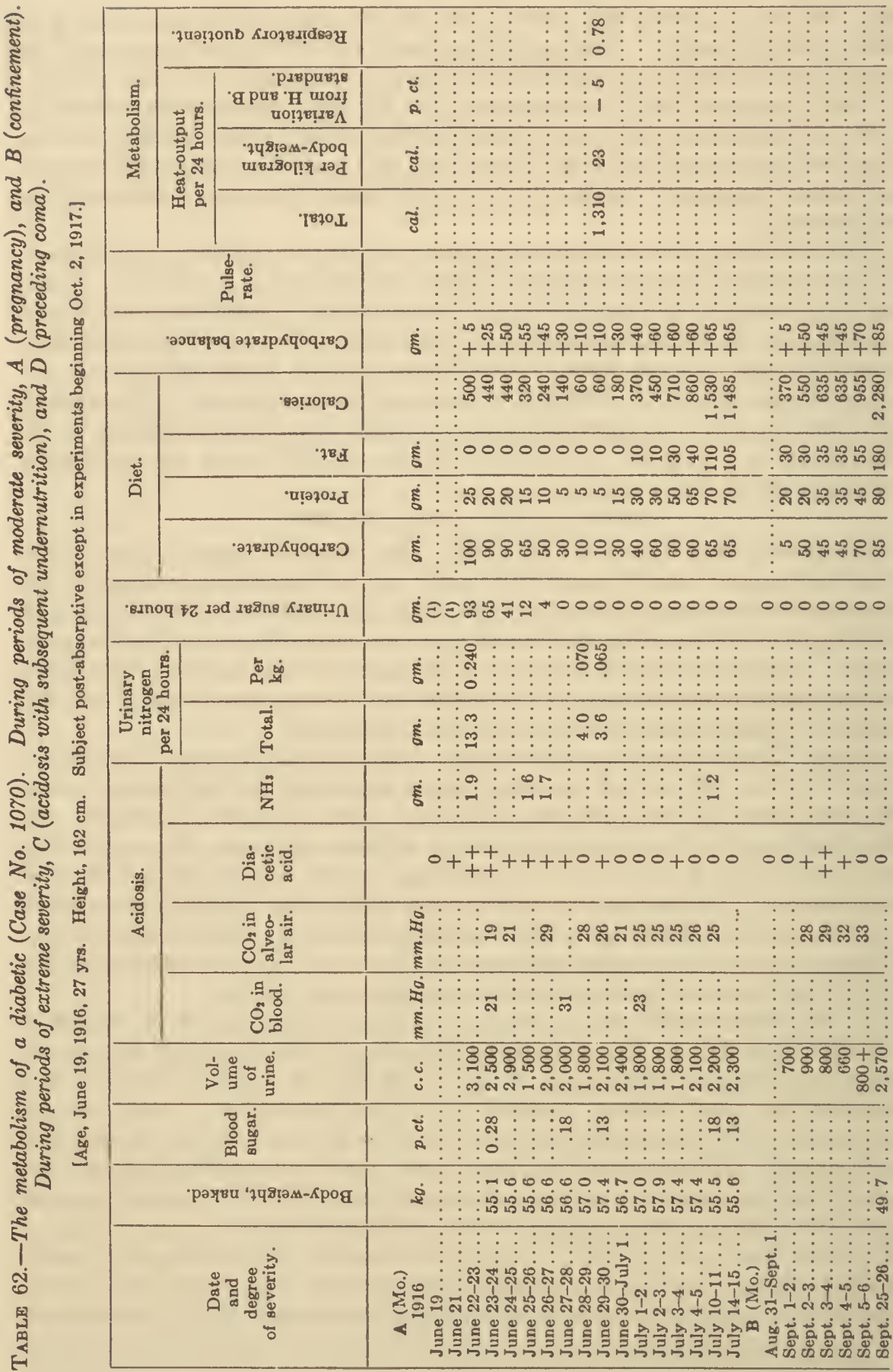




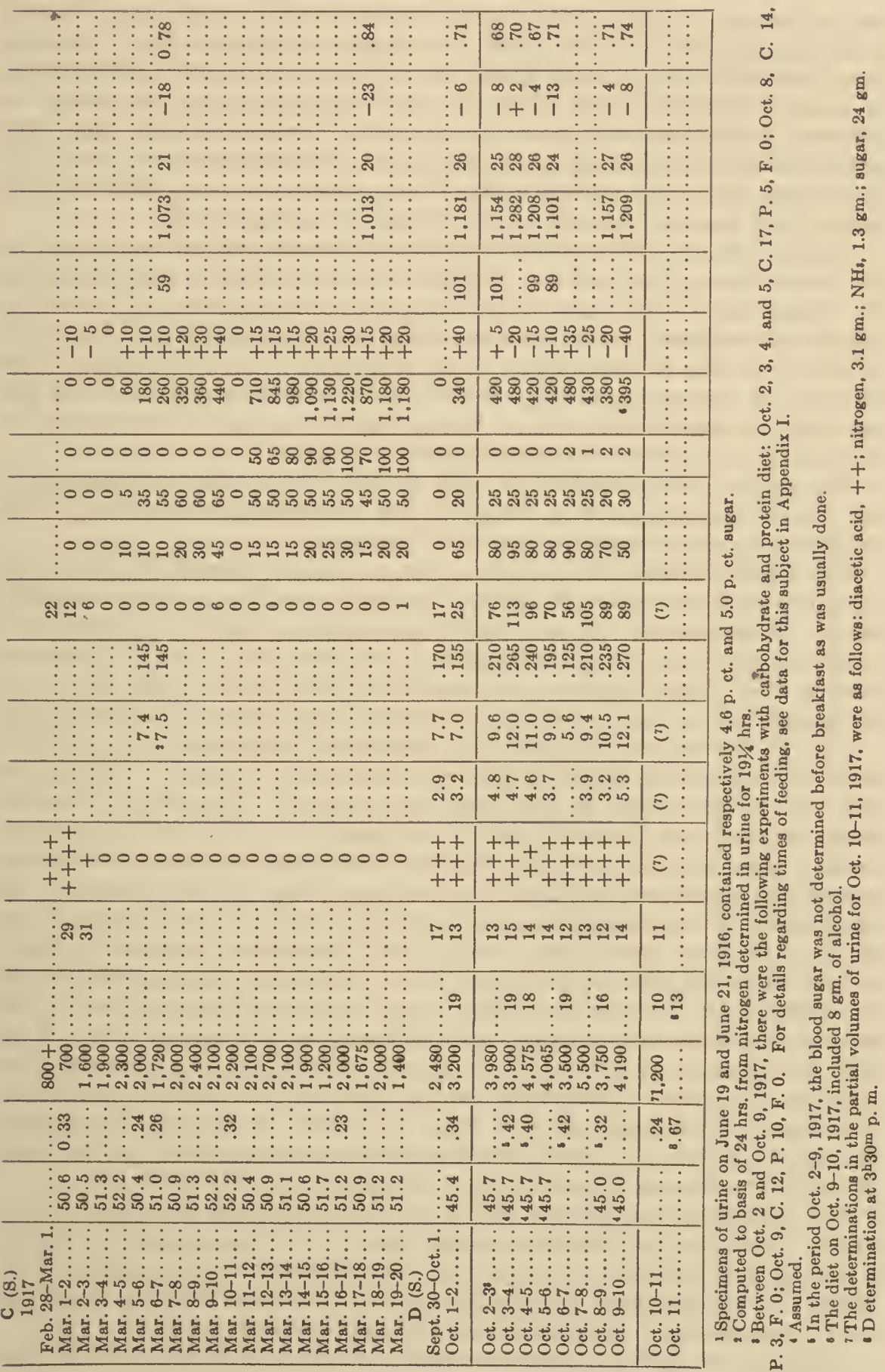


day or less than 1 calorie per kilogram of body-weight per 24 hours) showed a fasting metabolism of 24 calories per kilogram of body-weight. Between June 22 and 29, Case No. 1070 gained about $2 \mathrm{~kg}$., doubtless through retention of water. Evidently every effort was made on the part of the patient to conserve body-tissue as is shown by the fall of urinary nitrogen from 13.3 grams per 24 hours (0.2 gram per kilogram of body-weight) on June 22-23 to 4 grams (0.07 gram per kilogram of body-weight) on June 28-29, and 3.6 grams (0.07 gram per kilogram of body-weight) on June 29-30.

Table 62 shows discrepancies between the diacetic acid as determined by the ferric-chloride test and the acidosis as shown by the carbon dioxide in the alveolar air. These latter values, however, were controlled by the carbon dioxide in the blood. It is noteworthy that when the diacetic acid amounted to only ++ , the carbon dioxide in the alveolar air was 19 and that of the blood 21 , in terms of $\mathrm{mm}$. Hg. In fact, the ammonia for the preceding day was only 1.9 grams in 24 hours, thus corresponding more closely with the diacetic acid than with the carbon dioxide in the blood.

The patient was discharged on July 15,1916 , with a diet containing carbohydrate, 65 grams; protein, 70 grams; fat, 105 grams; and calories, 1,481; the blood sugar was almost normal ( 0.13 per cent).

The patient entered the hospital a second time on August 31, 1916, and remained until September 26,1916 . The diabetes still remained moderately severe. Confinement was uneventful, occurring on Aug. 31 by means of a Cesarean section under local anesthesia, performed by Dr. J. C. Hubbard. Section B of Table 62 shows the condition of the patient while she was in the hospital during this period; no observations were made of the metabolism.

The third entrance of the patient to the hospital (see section C of table 62) occurred on February 28, 1917, because of recurrence of sugar. The diabetes had now become severe in type, and this persisted. The patient remained in the hospital until March 21, 1917. As upon the first admission, she rapidly became sugar-free and acid-free, but the blood sugar was not so easily controlled and amounted to 0.23 per cent within 5 days of her discharge. An observation of the metabolism was made upon March 6, 1917, when it was found to be 18 per cent below standard, or 21 calories per kilogram of bodyweight with a respiratory quotient of 0.78 . The total energy in the diet for the 5 days preceding the observation upon the metabolism amounted to 240 calories, or no more than 1 calorie per kilogram of body-weight per day. Even this low figure must be reduced by nearly one-half because of excretion of sugar in the urine. The metabolism of this patient should be contrasted with that of individuals after a period of 5 days of fasting. The fasting subject, L., following 5 days of fasting showed a metabolism of -5 per cent; Miss L. after 4 days of fasting showed a metabolism of -8 per cent.

How prolonged was the undernutrition of this patient is plain from further study. Even for the 7 days preceding March 17-18 the calories in the diet averaged only 855 daily, or 17 calories per kilogram of body-weight per 24 hours. The metabolism was observed on this date and found to be 23 per cent below standard, or 20 calories per kilogram of body-weight.

The behavior of the respiratory quotient is also noteworthy. At the first observation in this period (March 6, 1917), it was 0.78, the same as on June 29-30, 1916. As previously stated, the patient continued to live upon a low 
diet for a prolonged period, and at the end of this time (upon March 17-18, 1917), the respiratory quotient had risen to 0.84. Acidosis was absent.

The fourth admission to the hospital and final period of observation of this patient (see section D, table 62) began on September 30 and extended to her death in coma on October 11, 1917. At this period the patient was in the severest state of diabetes and the acidosis was intense. The treatment consisted of the free administration of fluids and a diet without fat but containing 50 to 95 grams of carbohydrate daily and a small quantity of protein. During 9 days of this period (October 1 to 10) a study of the protocols shows that the patient took 3,765 calories, or 418 calories daily, amounting to 9 calories per kilogram of body-weight per day. If one subtracts the calories represented by the sugar in the urine from October 1 to 10 , namely, 2,876, there remains but 889 calories for the 9 days or 2 calories per kilogram of body-weight per 24 hours. This minimal figure is actually too high, because no allowance has been made for calories lost as acetone bodies. The metabolism at this time, therefore, really represents the metabolism during a 10-day fast. As the patient took a little food during the day, the metabolism was not actually a fasting metabolism, but practically must be considered as nearly its equivalent. The metabolism of this patient has therefore been obtained under conditions preceding death in coma which are quite the reverse of those described with Case No. 1412 (p. 158). Case No. 1070 was practically fasting while Case No. 1412 had been overeating.

The metabolism of this patient upon June 29, 1916, while pregnant, was 5 per cent below standard (see section A); a year later (March 6 and 17, 1917) it was 18 and 23 per cent below standard, respectively (see section C). Upon her return to the hospital for the last period, her metabolism on October 1,1917 (10 days before her death in coma), rose to 6 per cent below the standard, despite the extreme undernutrition. From this point onward until death, it varied unessentially from 13 below to 2 per cent above standard, the last observation being -8 per cent, two days before the patient's death. (See table 62, p. 147.) What is more significant, however, is the series of low quotients, varying from 0.67 to 0.74 , between October 1 and 9 , inclusive, which are indicative of a high fat metabolism. In contrast to these low quotients is the quotient 0.84 previously obtained on March $17-18,1917$. Conditions were essentially the same in these two periods so far as underfeeding was concerned, but in the former instance acidosis was absent and in the latter acidosis was present. The patient weighed 10 per cent less in the later period, yet it is evident that the body still contained enough fat to lead to acidosis as a result of the lowering of the ability to oxidize carbohydrate. It should be recalled that the patient during this last stay in the hospital received food, but the net amount was but 2 calories per kilogram of body-weight and grossly was but 9 calories per kilogram of body-weight. In comparison with the earlier data and taking into consideration the prolonged low diet and the great variation from standard weight amounting to -20 per cent and a nitrogen excretion of 0.220 gram per kilogram of body-weight, it is clear that the metabolism was relatively increased just before death, although by normal standards it was near the normal zone. The only factor which appears responsible for the increase in the metabolism at this time is the presence of acidosis. 
The rise in the respiratory quotient to 0.74 on the last day of observation is similar to that noted with Case No. 1412 under like conditions, i. e., before death in coma.

These figures should be considered in relation to other individuals undergoing a fast. Thus, the subject $L .^{a}$ at the end of a fast of 31 days had a metabolism 14 per cent below standard, a weight 29 per cent below normal, and a nitrogen excretion of 0.146 gram per kilogram of body-weight. The healthy nurse, Miss L., who fasted for a period of 4 days and then took food containing but 4 calories per kilogram of body-weight for the next 5 days, and whose body-weight was 14 per cent below standard and nitrogen excretion 0.120 gram per kilogram, of body-weight, had a metabolism of -7 per cent at the end of this period of 9 days.

The low nitrogen excretion of Case No. 1070, despite the low caloric intake and the high acidosis, is notable. The acidosis was severe, as shown by tests for diacetic acid, ammonia, and carbon dioxide in the blood and breath.

The last hours of this patient were atypical. Notwithstanding the low values for carbon dioxide in the alveolar air just preceding death, the respiration of this patient was not such as to attract attention, and was not that characteristic of Kussmaul's coma. As the respiration was hardly perceptible and not labored and the carbon-dioxide values were so low, Miss Barker, from Dr. Francis W. Peabody's laboratory in the Peter Bent Brigham Hospital, kindly controlled our analyses of the blood and alveolar air by the Van Slyke and Fridericia methods by making duplicate analyses of the blood with another Van Slyke apparatus and of the alveolar air with a Plesch apparatus. The results in the two laboratories agreed closely, those obtained by us for the carbon dioxide in the blood and the alveolar air on October 8 being 16 and $12 \mathrm{~mm}$., and those obtained by Miss Barker 19 and $15 \mathrm{~mm}$., respectively. With the few other patients treated by undernutrition and later coming under observation with coma, the writer has also observed the absence of stormy respiration, such as was formerly seen with patients living upon large diets. It is possible that the difference in respiration may be attributed simply to the weakened condition of the patient in one instance and the sudden appearance of coma while in stronger physical condition in the other.

Obrervations with Case No. 1232.

Diabetes was discovered with this patient in January, 1917, when she was 30 years of age and two months pregnant. She came under observation in February, 1917. The excretion of sugar had been at no time considerable, amounting originally to 0.6 per cent. The acidosis was slight, with + diacetic acid. The physical examination was negative. A mere trace of sugar and a + diacetic-acid reaction were present upon entrance to the New England Deaconess Hospital on February 2, 1917. The diet was quickly raised from carbohydrate 25 grams, protein 40 grams, and fat 0 grams, to carbohydrate 49 grams, protein 78 grams, and fat 121 grams. The patient remained practically sugar-free throughout her stay in the hospital. On July 8 she returned for confinement, and delivery on July 10 was effected without incident by Cesarean section with local anesthesia.

- Benedict, Carnegie Inst. Wash. Pub. No. 203, 1915. See, also, page 127 of this monograph. 
On February 15, 1917, an observation was made of the metabolism, which was found to be 2 per cent below the normal standard, or 26 calories per kilogram of body-weight per 24 hours, with a respiratory quotient of 0.82 . At this time the non-protein nitrogen was $60 \mathrm{mg}$. per $100 \mathrm{c}$. c. of blood, and on July 9, 1917, at the time of confinement, it was $105 \mathrm{mg}$. However, the patient showed no evidence of renal disturbance and in February, 1922, had a blood-pressure of $115 \mathrm{~mm}$. systolic and $75 \mathrm{~mm}$. diastolic.

\section{Conclusions Regarding Metabolism in Diabetes with Pregnancy.}

The metabolism of these three diabetic patients during pregnancy presents no abnormalities, either as compared with normal women in similar condition or with one patient as compared with herself at an earlier period when not pregnant and yet diabetic. Prior to pregnancy, the metabolism was 7 per cent below standard with Case No. 436; when the patient was five months pregnant, the metabolism rose to 5 per cent above standard, and at the seventh month it reached 10 per cent above standard. Five months after confinement the metabolism fell to 3 per cent above standard. With Case No. 1070 the metabolism was 5 per cent below standard in the seventh month of pregnancy, but this determination followed a restriction of diet to less than 5 calories per kilogram of body-weight for 7 days. The later observations in this case bore no relation to the pregnancy. The third case (No. 1232) during the third month of pregnancy showed a metabolism 2 per cent below standard. If one allows for the restrictions of diet to which these patients were submitted, it is justifiable to conclude that their metabolism may be considered to conform to the conclusions of Carpenter and Murlin, ${ }^{\circ}$ namely, that the metabolism of pregnant women is slightly more (about 4 per cent) than that of women in complete sexual rest.

\section{ENLARGED THYROID GLAND.}

Among all the diabetic patients, there was but one, Case No. 841, who showed an enlargement of the right and, to a lesser extent, of the left lobe of the thyroid gland. This, however, exerted little if any influence upon the metabolism, as his pulse-rate averaged 62 and 64 beats per minute in the two experiments without food, and the metabolism was 8 and 4 per cent, respectively, above standard.

\section{JAUNDICE.}

One patient, Case No 767, had an attack of temporary jaundice during the period of observation. Coincidently with the onset of the jaundice the pulse-rate fell and the metabolism rose-an unusual phenomenon and one suggesting the desirability of investigation of other patients with jaundice.

On September 28, 1912, prior to the jaundice, the pulse-rate was 59 beats per minute, and the metabolism 3 per cent below standard. Seven days later the metabolism was -1 per cent and the pulse-rate 78 . The rise in the pulse-rate was possibly due to excitement, as the patient was about to go home. Upon October 15 she returned to the hospital and jaundice developed upon October 24. The average pulse-rate for the experiment on this day was 45 beats, and the metabolism 6 per cent above standard. On October 29,

\footnotetext{
a Carpenter and Murlin, Arch. Intern. Med., 1911, 7, p. 184; Murlin and Bailey, Journ. Am. Med. Assoc., 1912, 59, p. 1522; and ibid., Arch. Intern. Med., 1913, 12, p. 288.
} 
when the patient was still jaundiced but improving, the pulse-rate was still 45 , and the metabolism 3 per cent above normal. On October 31 , when the urine had been free from bile for 24 hours, the pulse was 47 and the variation in the metabolism +4 per cent.

\section{INFLUENCE OF SODIUM BICARBONATE UPON THE METABOLISM.}

Patients with acidosis almost universally received sodium bicarbonate from the beginning of this investigation up to 1915 . The clinical results obtained with the administration of sodium bicarbonate were so unsatisfactory that it was gradually given up, and, in fact, alkali has not been included in the treatment of acidosis since September, 1915. The abandonment of sodium bicarbonate is by no means wholly responsible for the better results obtained in the treatment of such cases, but it is satisfactory to report that of 525 successive cases of diabetes treated by the writer in hospitals since

TABLE 63.-Post-absorptive metabolism of diabetics in experiments with patients taking soda and patients without soda.

\begin{tabular}{|c|c|c|c|c|c|c|c|c|c|}
\hline \multirow[b]{2}{*}{ Acidosis. } & \multicolumn{5}{|c|}{ With soda. } & \multicolumn{4}{|c|}{ Without soda. } \\
\hline & $\begin{array}{c}\text { No. } \\
\text { of } \\
\text { cases. }\end{array}$ & $\begin{array}{l}\text { No. of } \\
\text { experi- } \\
\text { mental } \\
\text { days. }\end{array}$ & $\begin{array}{l}\text { Range } \\
\text { in } \\
\text { amounts } \\
\text { of soda. }\end{array}$ & $\begin{array}{c}\text { Average } \\
\text { variation } \\
\text { of metabo- } \\
\text { lism from } \\
\text { normal } \\
\text { standard. }\end{array}$ & $\begin{array}{l}\text { Aver- } \\
\text { age } \\
\text { respi- } \\
\text { ratory } \\
\text { quo- } \\
\text { tient. }\end{array}$ & $\begin{array}{c}\text { No. } \\
\text { of } \\
\text { cases. }\end{array}$ & $\begin{array}{l}\text { No. of } \\
\text { experi- } \\
\text { mental } \\
\text { days. }\end{array}$ & $\begin{array}{c}\text { Average } \\
\text { variation } \\
\text { of metabo- } \\
\text { lism from } \\
\text { normal } \\
\text { standard. }\end{array}$ & $\begin{array}{l}\text { Aver- } \\
\text { age } \\
\text { respi- } \\
\text { ratory } \\
\text { quo- } \\
\text { tient. }\end{array}$ \\
\hline $\begin{array}{c}0 \\
+ \\
++ \\
+++\end{array}$ & $\begin{array}{l}2 \\
9 \\
4 \\
8\end{array}$ & $\begin{array}{r}3 \\
12 \\
7 \\
25\end{array}$ & \begin{tabular}{rr}
\multicolumn{2}{c}{ gm. } \\
4 to & 8 \\
2 & 38 \\
12 & 45 \\
12 & 60
\end{tabular} & $\begin{array}{l}\text { p. ct. } \\
+1 \\
+3 \\
+7 \\
+13\end{array}$ & $\begin{array}{r}0.85 \\
1.76 \\
.73 \\
.71\end{array}$ & $\begin{array}{l}9 \\
8 \\
5 \\
3\end{array}$ & $\begin{array}{r}22 \\
18 \\
21 \\
9\end{array}$ & $\begin{array}{r}p . c t . \\
+7 \\
0 \\
+9 \\
+14\end{array}$ & $\begin{array}{r}0.78 \\
.75 \\
8.74 \\
.70\end{array}$ \\
\hline Average & $\cdot$ & & 260 & +9 & .73 & .. & $\ldots \ldots$ & +7 & .75 \\
\hline
\end{tabular}

1 Average of respiratory quotients for 8 days.

Average of respiratory quotients for 15 days.

April 1, 1919, there have been but 11 deaths. Of these 11 deaths there were but four uncomplicated cases of diabetic coma, the remaining seven being due to pregnancy, influenzal pneumonia, and coma in one instance, to gangrene and coma in a second, to an operation for cancer of the gall bladder in a man of 66 years in a third instance, and to inanition in four cases. At the present writing 15 cases of diabetes have recovered from threatening coma when the degree of acidosis of these patients, as measured in terms of carbondioxide tension in the alveolar air or in the blood, varied between 11 and $18 \mathrm{~mm} \cdot{ }^{\circ}$

Opportunity is afforded for a study of the relation of sodium bicarbonate to the metabolism in a considerable number of instances. For this purpose the data for the individual patients have been arranged in table 63 in four groups, according to the absence of acidosis or its degree if present, each

\footnotetext{
- The data relative to two of these 15 cases were given me by Dr. H. Rawle Geyelin.
} 
group being again divided into comparable groups of those treated or untreated with sodium bicarbonate. All of the data in table 63 were obtained prior to June, 1914, and therefore under like conditions as to dietetic treatment.

Examination of the group of patients with severe acidosis $(+++)$ brings out the fact that the average variation of the metabolism from standard in 25 observations with 8 cases was +13 per cent for those cases who received an average of 23 grams of sodium bicarbonate daily, with a range in daily administration of from 12 to 60 grams. The average variation found in 9 observations upon 3 cases with equal acidosis, who did not receive sodium bicarbonate, was +14 per cent. For the 4 patients with 7 observations in the stage of moderate acidosis $(++)$ who received sodium bicarbonate, the variation in the metabolism was +7 per cent, and for 5 patients representing 21 observations with a like degree of acidosis who did not receive an alkali, the average variation was +9 per cent. For 9 patients representing 12 observations in the stage of slight acidosis $(+)$, the variation in the metabolism was +3 per cent, while for 8 patients representing 18 observations with a similar degree of acidosis who were not given sodium bicarbonate, the average metabolism did not vary from standard. For 2 cases representing 3 observations without acidosis, who received on the average 5 grams of sodium bicarbonate daily (a trifling amount), the variation of the metabolism from standard was +1 per cent, while for 9 comparable cases treated without alkalis, representing 22 observations, the average variation was +7 per cent. It is, therefore, plain that the use of sodium bicarbonate has no effect upon the metabolism of diabetic patients.

\section{EFFECT OF OVERWEIGHT ON METABOLISM OF DIABETICS AND NORMAL INDIVIDUALS.}

Three of the diabetic patients were much overweight at the time of their examination, and it has appeared worth while to compare their metabolism with that of non-diabetics who were similarly overweight. The metabolism of such a series of non-diabetic overweight individuals has been reported by Means, ${ }^{a}$ and five of his cases have been selected for comparison with the three diabetics in table 64 . The non-diabetics varied in weight from 44 to 106 per cent above standard, while the body-weight of the three diabetic cases varied between 42 and 62 per cent above standard.

Except in the case of two experiments with one of the normal subjects (Mrs. McK.), the diet for the day preceding the observation of the metabolism was low. This difference in diet with Mrs. McK. apparently had no great influence, for a comparison of the metabolism on these two days with that for the same subject on four other days, following a diet only one-half as large, shows a negligible difference in the variation from the standard metabolism.

The low quantity of nitrogen excreted in the urine per kilogram of bodyweight is notable both for three observations with one of the non-diabetics (Mrs. McK.) and for the three diabetics. The values for the nitrogen excretion on the day preceding the experiment are essentially the same for both groups, though the lowest value of 0.043 gram per kilogram of body-weight was obtained with a healthy individual and the highest value, 0.145 gram, was with one of the diabetics. There were, however, but three instances in

- Means, Journ. Med. Research, 1915, 32, p. 121. 
which the urinary nitrogen was more than 0.085 gram per kilogram of bodyweight. How low this is will be better realized if we recognize the fact that this would represent for an individual weighing 70 kilograms only 5.95

TABLE 64.-Comparison of post-absorptive metabolism of non-diabetic and diabetic obese subjects.

\begin{tabular}{|c|c|c|c|c|c|c|c|c|c|}
\hline \multirow{2}{*}{$\begin{array}{c}\text { Subject and } \\
\text { sex. }\end{array}$} & \multirow{2}{*}{ Date. } & \multirow{2}{*}{$\begin{array}{c}\text { Calories } \\
\text { per kg. } \\
\text { of body- } \\
\text { weight } \\
\text { in diet } \\
\text { of pre- } \\
\text { ceding } \\
24 \\
\text { hours. }\end{array}$} & \multirow{2}{*}{$\begin{array}{l}\text { Per- } \\
\text { cent- } \\
\text { age of } \\
\text { weight } \\
\text { above } \\
\text { normal } \\
\text { stand- } \\
\text { ard. }\end{array}$} & \multicolumn{2}{|c|}{$\begin{array}{l}\text { Urinary nitro- } \\
\text { gen per kg. of } \\
\text { body-weight } \\
\text { per } 24 \text { hours. }\end{array}$} & \multirow{2}{*}{$\begin{array}{c}\mathrm{NH} \text {. } \\
\text { per } \\
24 \\
\text { hrs. }\end{array}$} & \multirow{2}{*}{$\begin{array}{l}\text { Pulse- } \\
\text { rate. }\end{array}$} & \multirow{2}{*}{$\begin{array}{l}\text { Variation } \\
\text { in metabo- } \\
\text { lism from } \\
\text { normal } \\
\text { stand- } \\
\text { ard (H. } \\
\text { and B.). }\end{array}$} & \multirow{2}{*}{$\begin{array}{l}\text { Res- } \\
\text { pira- } \\
\text { tory } \\
\text { quo- } \\
\text { tient. }\end{array}$} \\
\hline & & & & $\begin{array}{l}\text { Pre- } \\
\text { ceding } \\
\text { day. }\end{array}$ & $\begin{array}{c}\text { Experi- } \\
\text { mental } \\
\text { day. }\end{array}$ & & & & \\
\hline $\begin{array}{c}\text { Non-diabetics. } \\
\text { Mrs. McI.... }\end{array}$ & ${\underset{1915}{\operatorname{Jan} .}}^{1916} 7$ & . & 106 & gm. & gm. & $g m$. & 65 & $\begin{array}{l}\text { p. ct. } \\
+4\end{array}$ & 0.68 \\
\hline Mrs. Sha..... & $\begin{array}{l}\text { Nov. } 4 \\
\text { Nov. } 14 \\
\text { Nov. } 26 \\
\text { Dec. } 17 \\
1914\end{array}$ & $\begin{array}{l}\cdots \cdots \\
\cdots \cdots \\
\cdots \cdots \\
\cdots \cdots\end{array}$ & $\begin{array}{r}106 \\
96 \\
94 \\
86\end{array}$ & $\begin{array}{l}\ldots \ldots \\
\cdots \ldots \\
\cdots \cdots \\
\cdots \cdots\end{array}$ & $\mid \begin{array}{l}\ldots \ldots \\
\cdots \ldots \\
\cdots \cdots \\
\cdots \cdots \\
\cdots\end{array}$ & $\begin{array}{l}\cdots \cdots \\
\cdots \cdots \\
\cdots \cdots \\
\cdots \cdots\end{array}$ & $\begin{array}{l}68 \\
68 \\
68 \\
66\end{array}$ & $\begin{array}{l}+1 \\
-7 \\
-4 \\
-5\end{array}$ & $\begin{array}{l}.65 \\
.76 \\
.77 \\
.67\end{array}$ \\
\hline Mrs. Mc K. . . & $\begin{array}{l}\text { Feb. } 24 \\
\text { Feb. } 25 \\
\text { Mar. } 9 \\
\text { Mar. } 10 \\
\text { Mar. } 19 \\
\text { Mar. } 20 \\
1915\end{array}$ & $\begin{array}{r}29 \\
23 \\
11 \\
11 \\
8 \\
12\end{array}$ & $\begin{array}{c}91 \\
\ldots \ldots \\
84 \\
\ldots \ldots \\
77 \\
\ldots \ldots\end{array}$ & $\begin{array}{c}0.092 \\
\ldots \ldots \\
.048 \\
\ldots . \ldots \\
.043 \\
\ldots \ldots\end{array}$ & $\begin{array}{r}0.053 \\
.061 \\
.038 \\
.030 \\
.047 \\
.055\end{array}$ & $\begin{array}{r}\cdots . .50 \\
\because .49 \\
.38 \\
.61 \\
.61\end{array}$ & $\begin{array}{l}80.5 \\
82.0 \\
74.5 \\
72.5 \\
78.5 \\
80.0\end{array}$ & $\begin{array}{l}-8 \\
-7 \\
-7 \\
-13 \\
-12 \\
-12\end{array}$ & $\begin{array}{l}.71 \\
.69 \\
.76 \\
.75 \\
.79 \\
.76\end{array}$ \\
\hline $\begin{array}{l}\text { Mr. Z. . . . . } \\
\text { Mr. P. A. M... }\end{array}$ & $\begin{array}{l}\text { Dec. } 1 \\
\text { Oct. } 13\end{array}$ & . & $\begin{array}{l}53 \\
44\end{array}$ & $\ldots \ldots$ & $\begin{array}{l}\ldots \ldots \\
\ldots \ldots\end{array}$ & $\ldots \ldots$ & $\left(\begin{array}{l}\cdots \cdots \\
\cdots \cdots \\
\ldots\end{array}\right.$ & $\begin{array}{l}-2 \\
+6\end{array}$ & $\begin{array}{l}.98 \\
.80\end{array}$ \\
\hline Diabetics. & & & & & & & & & \\
\hline 983 (F.). & Feb. 2 & 4 & 43 & .145 & .125 & 4.3 & 68 & +28 & .73 \\
\hline & Feb. 5 & 0 & 43 & .085 & .065 & 3.1 & 66 & +19 & .72 \\
\hline & Feb. 8 & 0 & 45 & .060 & .060 & 2.0 & & +12 & .73 \\
\hline 1026 (M.)... & Apr. 11 & 2 & 62 & .080 & .065 & 1.4 & 68 & -8 & .75 \\
\hline & Apr. 18 & 8 & 61 & .085 & .060 & $\cdots \cdots$ & 55 & -15 & .79 \\
\hline & Apr. 24 & 14 & 57 & .075 & .055 & $\ldots \ldots$ & 52 & -13 & .80 \\
\hline & $\operatorname{May}_{1917} 3$ & 8 & 54 & .120 & .135 & $\ldots \ldots$ & $\ldots \ldots$ & -3 & .77 \\
\hline 1207 (F.)... & Jan. 3 & 3 & 43 & $\ldots \ldots$ & .065 & .5 & 64 & -15 & .76 \\
\hline & Jan. 4 & 3 & 42 & $\ldots \ldots$ & .100 & .5 & 62 & -15 & .76 \\
\hline & Jan. 8 & 7 & 43 & .085 & .050 & .5 & $\ldots \ldots$ & -12 & .77 \\
\hline
\end{tabular}

1 See Means, Journ. Med. Research, 1915, 27, p. 121. Variation of metabolism from standard calculated on $\mathrm{H}$. and $\mathrm{B}$. basis for comparative purposes.

$2 \mathrm{Had}$ been on thyroid extract for previous 5 days. Started at 1.5 grains per day and increased to 7.5 grains per day.

3 No food for 48 hours. Had been on ovarian extract (Armour) for previous 5 days. Started at 2 grains; worked up to 10 grains per day.

- Reported by the author as ammonia-nitrogen; recomputed here as $\mathrm{NH}_{3}$ for comparison.

grams of urinary nitrogen per 24 hours. For the day of the experiment the values were distinctly lower, falling in the case of Mrs. McK. to 0.030 gram per kilogram of body-weight, and as low as 0.050 gram with one of the diabetics. Such low nitrogen values are rarely encountered with individuals of normal weight. 
The pulse-rates of two of the non-diabetic individuals averaged 67 beats, but that of the third (Mrs. McK.) averaged 78 beats. With the diabetics the pulse-rate was decidedly lower, in no instance being above 68 beats, and in two experiments with Case No. 1026, 52 and 55 beats, respectively.

Corresponding to the pulse-rate, the metabolism of both non-diabetics and diabetics was almost universally a little below standard. The one exception was the diabetic No. 983; the metabolism of this patient will be discussed later. With the five non-diabetics and the other two diabetics, the metabolism at no time exceeded +6 per cent, and there were but three instances when the metabolism was above the normal standard. With the non-diabetic individuals, the metabolism fell as low as -13 per cent, and with the diabetics to -15 per cent. In other words, both the non-diabetics and the diabetics, all living on quantities of food presumably low just before the experiment, showed a subnormal metabolism.

The one exception among these five non-diabetics and three diabetics (Case No. 983) is especially striking, as the variations from standard metabolism on three occasioas were $+28,+19$, and +12 per cent, respectively. Not only are these high figures significant, but the gradual decrease in percentages in the three successive observations within a week also has significance. The reason for this increased metabolism and its gradual decrease is found in the presence of a considerable acidosis. Thus, when the metabolism was +28 per cent, there was a high excretion of ammonia, amounting in the 24 hours to 4.3 grams; with a metabolism of +19 per cent, it was 3.1 grams; and three days later, with a metabolism of +12 per cent, it was 2.0 grams. This instance of increased metabolism in contrast to the slightly subnormal metabolism of the other diabetics and the overweight non-diabetics can well be explained by the acidosis.

The low respiratory quotients of Case No. 983 are also significant, as they averaged but 0.73 , giving further evidence of the acidosis. The respiratory quotients of the two other diabetics and of the non-diabetics ranged between 0.75 and 0.80 in the majority of instances. With one of the non-diabetics (Mrs. McK.) two respiratory quotients on successive days of 0.71 and 0.69 were obtained. One would expect the presence of acidosis with this patient, but the excretion of ammonia, which is recorded as 0.50 gram, does not bear out this supposition. One other non-diabetic, Mrs. McI., had a respiratory quotient of 0.68 , but as this was the only observation with this subject, it does not permit discussion.

The data in table 64 therefore show that obese individuals on a low diet excrete extremely small quantities of nitrogen per kilogram of body-weight, accompanied by a low metabolism. The exceptional diabetic whose metabolism was high was the only one of the group who was known to have acidosis. One of the purposes in the preparation of this table was to discover whether obese individuals would tend to show low respiratory quotients in contrast to the extremely thin diabetic individuals who have been distinguished by high respiratory quotients. We find from this table, however, that with the single exception of Case No. 983, and a few exceptions among the nondiabetics, the respiratory quotients of both the non-diabetic and diabetic obese individuals were not particularly low. 
Mftabolism of Diabetic Patients within a Month and a Half of Death.

Of the 88 fatal cases in the entire series of 113 diabetics included in this study, two (Cases Nos. 1070 and 1412) died while they were in the hospital within ten and three days, respectively, of the last observation of their metabolism. Eight other cases died after they had left the hospital within an average period of 22 days from the last determination of their metabolism. table 65 gives the data obtained in the last few observations of the metabolism of these 10 diabetics, and also for their excretion of urinary nitrogen on the experimental days and, so far as possible, for subsequent days.

The early dates of the metabolism experiments indicate how much more fatal the disease was before June, 1914, with the treatment by overfeeding, than after that date, when the treatment was by underfeeding. Before June, 1914, 32 cases were under observation but since June, 1914, 81 cases have been studied. It will be seen, therefore, that there were relatively more deaths to the total number of cases studied in the earlier period than later. This is a striking commentary upon the improvement in treatment.

The intervals between the last observation and death ranged between 3 and 42 days. The cause of death in 9 of the 10 cases was coma. Of the 6 cases who died within 15 days, 5 died in coma, 2 of these being the cases who died in the hospital; inanition caused the death of the sixth case. The small number of deaths in this series after June, 1914, was due to the infrequency of coma. Thus, although nearly three times as many cases were studied after June, 1914, than before, less than one-third of the deaths were from this cause.

The data for the urinary nitrogen on the basis of per kilogram of bodyweight are included in table 65 for both the day preceding the experiment and the experimental day; values are also given for subsequent days. In other places it has been pointed out that preceding death, whether in coma or from inanition, the urinary nitrogen tends to be high. (See p. 116.) The data of this table present confirmatory evidence of this. As elsewhere explained, the high nitrogen excretion preceding June, 1914, may have been in large measure due to the excessive protein intake, but after June, 1914, is best attributed to extreme.inanition, which was in some cases so extreme that the high values for the urinary nitrogen may be considered to be the pre-lethal high nitrogens described in experiments upon fasting animals.

The average excretion of urinary nitrogen per kilogram of body-weight for the days preceding the observations was 0.295 gram and for the days of the observations themselves 0.260 gram; 12 values for urinary nitrogen were obtained subsequent to the last test of the metabolism; 3 of these were 0.195 gram or under, 3 were 0.210 gram, and 6 were 0.235 gram or over per kilogram of body-weight. Case No. 441, 10 days before death, had an excretion of 0.380 gram, Case No. 1070, 2 days before death, had an excretion of 0.270 gram, and Case No. 1085 an aliquot excretion for 4 successive days ending 12 days before death of 0.340 gram per kilogram of body-weight, while Case No. 1412, 4 days before death, gave an excretion of 0.380 gram per kilogram of body-weight.

The metabolism was above standard in the majority of cases. Case No. 1412 in the last observation before death had the highest metabolism of all the cases, or 33 per cent above standard. This was the patient who developed 
coma and died a few days after entering the hospital. The other extreme of metabolism was -40 per cent, which occurred with Case No. 1085, who died

TABLE 65.-Post-absorptive metabolism of diabetics preceding death.

\begin{tabular}{|c|c|c|c|c|c|c|c|}
\hline \multirow{2}{*}{$\begin{array}{l}\text { Case No. and } \\
\text { cause of death. }\end{array}$} & \multirow{2}{*}{$\begin{array}{l}\text { Date of ob- } \\
\text { servation. }\end{array}$} & \multirow{2}{*}{$\begin{array}{l}\text { Interval } \\
\text { between } \\
\text { last exper- } \\
\text { imental } \\
\text { observa- } \\
\text { tions and } \\
\text { death. }\end{array}$} & \multirow{2}{*}{$\begin{array}{l}\text { Variation } \\
\text { in metab- } \\
\text { olism from } \\
\text { standard. }\end{array}$} & \multirow{2}{*}{$\begin{array}{c}\text { Respir- } \\
\text { atory } \\
\text { quo- } \\
\text { tient. }\end{array}$} & \multicolumn{3}{|c|}{$\begin{array}{l}\text { Urinary nitrogen per } \\
\text { kg. of body-weight } \\
\text { per } 24 \mathrm{hrs} \text {. }\end{array}$} \\
\hline & & & & & $\begin{array}{l}\text { Pre- } \\
\text { ceding } \\
\text { day. }\end{array}$ & $\begin{array}{l}\text { Experi- } \\
\text { mental } \\
\text { day. }\end{array}$ & $\begin{array}{l}\text { Subse- } \\
\text { quent } \\
\text { days. }\end{array}$ \\
\hline & & days. & p.ct. & & $a m$. & $\mathrm{om}$. & om. \\
\hline \multirow{9}{*}{$\begin{array}{l}220(\operatorname{com} a) \ldots \ldots \\
246(\operatorname{com} a) \ldots . .\end{array}$} & 1910, Aug. 10 & 14 & +4 & 0.71 & 0.120 & & $\ldots \ldots$ \\
\hline & 1909, Oct. 25 & 44 & +17 & .69 & .390 & 0.295 & $\ldots \ldots$ \\
\hline & Oct. 26 & 43 & +10 & .71 & $\ldots \ldots$ & .240 & \\
\hline & Oct. 27 & 42 & +15 & .71 & $\ldots \ldots$ & .355 & \\
\hline & Oct. 28 & 41 & +15 & .66 & $\ldots \ldots$ & .345 & \\
\hline & Oct. 29 & 40 & +8 & .68 & $\ldots \ldots$ & .260 & . \\
\hline & Oct. 30 & 39 & +7 & .71 & $\ldots \ldots$ & .290 & \\
\hline & Oct. 31 & 38 & +7 & .69 & $\ldots \ldots$ & $\ldots \ldots$ & \\
\hline & Nov. 7 & 31 & . & $\ldots$ & $\ldots$ & $\ldots \ldots$ & 0.185 \\
\hline \multirow{3}{*}{$\begin{array}{l}283(\operatorname{coma}) \ldots \ldots \\
310(\operatorname{coma}) \ldots \ldots\end{array}$} & 1910, Mar. 2 & 42 & +7 & .74 & .195 & $\ldots$ & $\ldots \ldots$ \\
\hline & Mar. 5 & 60 & +16 & .76 & .275 & $\ldots$ & $\ldots \ldots$ \\
\hline & Apr. 22 & 12 & +14 & .76 & .235 & . & $\ldots$ \\
\hline \multirow[t]{3}{*}{381 (coma)..... } & 1911, Feb. 14 & 19 & +18 & .71 & .260 & .225 & $\ldots \ldots$ \\
\hline & Feb. 16 & 17 & +11 & .75 & .225 & .185 & ......... \\
\hline & Feb. 17 & 16 & $\ldots \ldots \ldots$ & $\ldots$ & $\ldots \ldots$ & $\ldots \ldots$ & .210 \\
\hline \multirow[t]{6}{*}{441 (coms) } & Sept. 25 & 41 & +5 & .70 & .320 & .350 & $\ldots \ldots$ \\
\hline & Sept. 29 & 37 & +3 & .70 & .275 & .135 & $\ldots \ldots$ \\
\hline & Oct. 9 & 27 & +6 & .68 & .280 & .205 & $\ldots \ldots$ \\
\hline & Oct. 16 & 20 & +8 & .71 & .455 & .420 & $\ldots \ldots$ \\
\hline & Oct. 25 & 11 & +2 & .71 & .390 & .460 & $\ldots \ldots$ \\
\hline & Oct. 26 & 10 & $\ldots \ldots \ldots$ & $\ldots \ldots \ldots$ & $\ldots \ldots$ & $\ldots \ldots$ & .380 \\
\hline \multirow[t]{3}{*}{549 (coma)...... } & 1912, Nov. 5 & 32 & +30 & .69 & .320 & $\ldots \ldots$ & $\ldots \ldots$ \\
\hline & Nov. 12 & 25 & +16 & .69 & .155 & .175 & $\ldots \ldots$ \\
\hline & Nov. 13 & 24 & +20 & .70 & $\ldots \ldots$ & .140 & $\ldots \ldots$ \\
\hline \multirow[t]{8}{*}{$1070(\operatorname{com} n) . .}$. & 1917, Oct. 1 & 10 & -6 & .71 & .170 & .155 & $\cdots \cdots$ \\
\hline & $\begin{array}{ll}\text { Oct. } & 2 \\
\text { Oct. } & 3\end{array}$ & $\begin{array}{l}9 \\
8\end{array}$ & $\ldots \ldots \ldots$ & $\cdots \cdots \cdots$ & $\ldots \ldots$ & $\cdots \cdots \cdots$ & $\begin{array}{l}.210 \\
.265\end{array}$ \\
\hline & Oct. 4 & 7 & $\mid \begin{array}{l}\cdots \\
\cdots \ldots \ldots \cdots\end{array}$ & …… & an & $\mid \cdots \cdots \cdots$ & .240 \\
\hline & Oct. 5 & 6 & $\ldots \ldots \ldots$ & $\ldots \ldots$ & $\ldots \ldots$ & $\ldots \ldots$ & .195 \\
\hline & Oct. 6 & 5 & $\ldots \ldots \ldots$ & $\ldots \ldots \ldots$ & $\ldots \ldots$ & $\ldots \ldots \ldots$ & .125 \\
\hline & Oct. 7 & 4 & $\ldots \ldots \ldots$ & $\ldots \ldots \ldots$ & $\ldots \ldots$ & $\ldots \ldots$ & .210 \\
\hline & Oct. 8 & 3 & $\ldots \ldots \ldots$ & $\ldots \ldots \ldots$ & $\ldots \ldots$ & $\ldots \ldots$ & .235 \\
\hline & Oct. 9 & 2 & $\ldots \ldots \ldots$ & $\ldots \ldots \ldots$ & $\ldots \ldots$ & $\ldots \ldots$ & .270 \\
\hline \multirow[t]{6}{*}{1085 (inanition).. } & 1916, Oct. 11 & 35 & -40 & .81 & $\ldots \ldots$ & $\ldots \ldots$ & $\ldots \ldots$ \\
\hline & Oct. 19 & 27 & -35 & .81 & .510 & .290 & $\ldots \ldots$ \\
\hline & Oct. 23 & 23 & -32 & .79 & .470 & .185 & $\ldots \ldots$ \\
\hline & Oct. 30 & 16 & -30 & .70 & .290 & .190 & $\ldots \ldots$ \\
\hline & Oct. 31 & 15 & -40 & .81 & $\ldots \ldots$ & .165 & $\ldots \ldots$ \\
\hline & Nov. 3-7 & 12 & $\ldots \ldots$ & $\ldots \ldots \ldots$ & $\ldots \ldots$ & $\ldots \ldots$ & ${ }^{1} .340$ \\
\hline \multirow[t]{3}{*}{$1412(\operatorname{com} R) . .}$. & 1917. Oct. 17 & 5 & +28 & .71 & $\ldots \ldots$ & $\ldots \ldots$ & $\ldots \ldots$ \\
\hline & Oct. 18 & 4 & +33 & .72 & $\ldots \ldots$ & .380 & $\ldots \ldots$ \\
\hline & Oct. 19 & 3 & +33 & .76 & & $\ldots \ldots$ & $\ldots \ldots$ \\
\hline
\end{tabular}

1 Average per day in composite for 4 days.

of inanition a few days after returning home. The second patient who died in the hospital (Case No. 1070) showed a post-absorptive metabolism of -6 per cent 10 days before death, and a metabolism of -8 per cent about 
two hours after eating a small amount of food two days before her death, but elsewhere (p. 150) it has been recorded that the coma was atypical in this case. A partial explanation of the comparatively low metabolism, during coma, which was, however, higher than the metabolism previously found with Case No. 1070, is the low diet upon which she had lived for the preceding 10 days. (See p. 149.) For the other 7 cases, all of whom were studied before June, 1914, the metabolism averaged 9 per cent above standard at the last observation, which was a trifle lower than the average for all the 32 cases studied prior to June, 1914.

The average respiratory quotients obtained for the 9 patients who died of coma varied within this short interval before death between 0.69 and 0.76 , with an average for the whole group of 0.72 . A low respiratory quotient in diabetes is a precursor of death from coma. The respiratory quotient of the patient who died with inanition varied between 0.79 and 0.81 , save for a single intermediate observation of 0.70 .

\section{METABOLISM OF DIABETICS ON VERGE OF COMA PRECEDING DEATH.}

Case No. 1412 developed diabetes in January, 1914, at the age of 27 years and 11 months, and came under observation October 16, 1917. At that time he had cast aside all dietetic precautions and acknowledged eating ice cream, sweet cakes, corn muffins, and rolls just before admission to the hospital. This excess carbohydrate accounted for the excretion of 4,200 c. c. of urine in the first 13 hours following his coming to the hospital, the excretion of 210 grams of sugar, and signs of severe acidosis. On account of the acidosis, fat was withdrawn from the diet and protein somewhat restricted, but carbohydrates were allowed freely. Despite these precautions, the acidosis advanced, and although liquids were given freely, the bowels emptied, body heat conserved, and circulatory stimulants administered, the patient succumbed to coma on October 22,1917 . The details are given in table 66 .

The metabolism of this patient represents that of a patient with severe diabetes and severe acidosis on the verge of coma, whose diet preceding the first observation had been unrestricted. In this latter respect the case is unlike that of Case No. 1070, who was under observation for ten days preceding death in coma with a diet greatly curtailed. (See table 62, p. 146, in which are summarized the data from June 19, 1916, to October 11, 1917.)

Case No. 1412 is particularly suitable for a discussion of the metabolism, because the weight remained constant for the three successive days upon which the observations were made. It will be noter that the pulse-rate was high (98 beats). This corresponded to the high metabolism of a variation from standard of +28 per cent for the first and +33 per cent for the second and third days, or 36 and 38 calories, respectively, per kilogram of body-weight per 24 hours. The respiratory quotient was 0.71 and 0.72 on the first two days, corresponding to a metabolism derived exclusively from fat, and on the third day 0.76 . This rise in respiratory quotient is commonly observed in diabetic cases of severe type when subjected to undernutrition, but I do not remember to have seen recorded a change like this in a patient of this type. It is, of course, a question whether inferences should be drawn from this one observation.

The urinary nitrogen was 17.6 grams or 0.38 gram per kilogram of body- 
weight on the second day following admission, when the metabolism was +33 per cent. This may be compared with the urinary nitrogen of Case No. 1070 two days before death in coma, which was 12.1 grams or 0.27 gram per kilogram of body-weight, with a metabolism on this day of 8 per cent below standard. ${ }^{\circ}$ Unfortunately complete figures for the urinary nitrogen of Case No. 1412 are lacking for the third day (when the respiratory quotient was 0.76 ), but the high values upon the preceding and following days, and the fact that the nitrogen in the $1,100 \mathrm{c}$. c. of urine representing a part of the 24hour quantity for the third day amounted to 6.8 grams, suggest that the protein katabolism was most active.

TABLE 66.-The metabolism of a case of severe diabetes (Case No. 1412, male) on the verge of coma.

[Age, $32 \mathrm{yrs}$; height, $165 \mathrm{~cm}$.]

\begin{tabular}{|c|c|c|c|c|c|c|c|c|c|c|}
\hline \multirow{2}{*}{$\begin{array}{l}\text { Date } \\
\text { (1917.) }\end{array}$} & \multirow{2}{*}{$\begin{array}{l}\text { Body- } \\
\text { weight, } \\
\text { naked. }\end{array}$} & \multirow{2}{*}{$\begin{array}{l}\text { Blood } \\
\text { sugar. }\end{array}$} & \multirow{2}{*}{$\begin{array}{l}\text { Volume } \\
\text { of } \\
\text { urine. }\end{array}$} & \multicolumn{5}{|c|}{ Acidosis. } & \multicolumn{2}{|c|}{$\begin{array}{c}\text { Urinary } \\
\text { nitrogen } \\
\text { per } 24 \text { hours. }\end{array}$} \\
\hline & & & & \multicolumn{2}{|c|}{$\begin{array}{c}\mathrm{CO}_{2} \\
\text { in } \\
\text { blood. }\end{array}$} & $\begin{array}{l}\mathrm{CO}_{2} \text { in } \\
\text { alveolar } \\
\text { air. }\end{array}$ & $\begin{array}{l}\text { Dia- } \\
\text { cetic } \\
\text { acid. }\end{array}$ & $\mathrm{NH}_{2}$. & Total & $\begin{array}{r}\text { Per } \\
\text { kilo- } \\
\text { I }\end{array}$ \\
\hline \multirow{4}{*}{$\begin{array}{l}\text { Oct. } 16-17 \ldots \\
\text { Oct. } 17-18 \ldots \\
\text { Oct. } 18-19 \ldots \\
\text { Oct. } 19-20 \ldots \\
\text { Oct. } 20-21, \ldots\end{array}$} & & $\begin{array}{c}\text { p.ct. } \\
\ldots \ldots \ldots\end{array}$ & \multirow{4}{*}{$\begin{array}{c}\text { c.c. } \\
4,200 \\
3,130 \\
3,400 \\
21,100+ \\
2,200\end{array}$} & \multicolumn{2}{|c|}{$m m . H g}$. & \multirow{4}{*}{$\begin{array}{c}m m . H o . \\
25 \\
23 \\
25 \\
24 \\
17\end{array}$} & \multirow{2}{*}{++} & $\underset{(1)}{g m .}$ & $\underset{(1)}{g m .}$ & om. \\
\hline & 46.3 & 0.37 & & & & & & & & \\
\hline & 46.2 & & & & & & \multirow{2}{*}{$\begin{array}{c}t+t \\
t++ \\
+++t \\
t .+t+\end{array}$} & 4.3 & \multirow{2}{*}{$\begin{array}{r}17.6 \\
6.8+\end{array}$} & 0.380 \\
\hline & 46.3 & . & & & & & & $1.7+$ & & $+\ldots \ldots$ \\
\hline \multirow[b]{2}{*}{$\begin{array}{c}\text { Date } \\
\text { (1917). }\end{array}$} & \multirow{2}{*}{\begin{tabular}{c|} 
Uri- \\
nary \\
sugar \\
for \\
24 \\
hrs.
\end{tabular}} & \multicolumn{4}{|c|}{ Diet. } & \multirow[b]{2}{*}{$\begin{array}{l}\text { Carbo- } \\
\text { hydrate } \\
\text { balance. }\end{array}$} & \multirow[b]{2}{*}{$\begin{array}{l}\text { Pulse- } \\
\text { rate. }\end{array}$} & \multicolumn{3}{|c|}{ Metabolism. } \\
\hline & & $\begin{array}{c}\text { Carbo- } \\
\text { hydrate. }\end{array}$ & $\begin{array}{l}\text { Pro- } \\
\text { tein. }\end{array}$ & Fat. & $\begin{array}{l}\text { Cal- } \\
\text { ories. }\end{array}$ & & & \multicolumn{2}{|c|}{$\begin{array}{l}\text { Variation } \\
\text { from } \\
\text { H. and B. } \\
\text { standard. }\end{array}$} & $\begin{array}{l}\text { Respi- } \\
\text { ratory } \\
\text { quo- } \\
\text { tient. }\end{array}$ \\
\hline Oct. $16-17$. & $\underset{(1)}{o m .}$ & om. & $g m$. & om. & & $o m$. & & p. $c t$ & & \\
\hline Oct. $17-18$. & 170 & 210 & 65 & 0 & 1100 & +40 & 98 & +2 & & 0.71 \\
\hline Oct. $18-19$. & 167 & 175 & 60 & 0 & 940 & +10 & 98 & +3 & & .72 \\
\hline Oct. $19-20$ & $51+$ & 125 & 35 & 0 & 640 & $\ldots$ & & +3 & & .76 \\
\hline Oct. $20-21^{\circ}$. & 73 & 70 & 5 & 0 & 300 & -5 & $\ldots$. & & & \\
\hline
\end{tabular}

1 Volume for 13 hours only. Determinations made were: nitrogen, $12.2 \mathrm{gm} . ;$ NH $3,2.9$ gm.; sugar, $210 \mathrm{gm}$. Nitrogen computed to basis of 24 hours was $22.5 \mathrm{gm}$.

2 Volume incomplete.

Patient died October 22, 1917.

Still another case whose metabolism was obtained under similar conditions of imminent coma was Case No. 220, who was under observation at the Laboratory at intervals from November 4, 1908, to August 24, 1910. Acido-

- The metabolism for this day is not included in"table 65, as it does not represent a strictly post-absorptive metabolism, since the observation followed the ingestion of a small amount of lood. (See table 62.) 
sis continued to be of moderate degree, and he succumbed to coma on August 24,1910 . His case, however, differed in three respects from both of those hitherto considered. First, his diet was liberal and not excessive like that of Case No. 1412, nor was it almost equivalent to a fast like that of Case No. 1070 ; second, signs of probable tuberculosis were found in one lung on August 5, 1910, and confirmed on August 8, 1910; third, the acidosis was moderate rather than severe in degree.

A study of the protocols for August $10^{\circ}$ shows that the metabolism, in contrast to preceding observations in which it had ranged from 14 to 32 per cent above standard, was on August 10, 1910, but 4 per cent above. The lowered vitality of the patient (due in part to the disease) and the less severe acidosis are factors which may account for the comparatively slight increase in metabolism over normal. The respiratory quotient, however, still remained low, namely, 0.71. It is possible that an acidosis less intense than that which was found with the two preceding cases was sufficient to cause the death of this weakened patient. This can not be said upon the authority of quantitative experimental evidence, but only upon qualitative evidences of acidosis. The pulse-rate was 69 , which was the lowest value, save two others obtained for this subject. These were upon November 18, 1908, when the pulse-rate was 67 and the metabolism 17 per cent above standard, and on December 16, 1908, when the pulse-rate was 65 and the metabolism 24 per cent above standard, two additional examples illustrating lack of correspondence of pulserate and metabolism.

From the foregoing it will be seen that three patients, Cases Nos. 1070, 1412 , and 220 , upon the verge of death from diabetic coma, present a varying metabolism of -8 per cent, +33 per cent, and +4 per cent, respectively. These figures represent great differences in metabolism, but, under the conditions existing in each instance, they are all high. The rate of -8 per cent for Case No. 1070 represents an increase of 20 to 30 per cent above the metabolism which the preceding undernutrition would usually produce, the +33 per cent was the metabolism of a patient with severe acidosis and on the verge of coma as the result of unrestricted diet preceding the three days of experimental observations, and the +4 per cent for Case No. 220, the worn out, debilitated diabetic of 12 years' duration with complicating tuberculosis, may likewise be considered a high figure. With all three patients, the respiratory quotient was low, even below the respiratory quotient of fat, but with two there was a slight rise in the respiratory quotient shortly before death. The last observations of urinary nitrogen obtained with these three patients were $0.270,0.380$, and 0.120 gram per kilogram per 24 hours, respectively.

\section{Factors of Influence in the Prognosis of Diabetes.}

The series of diabetic patients studied at the Nutrition Laboratory afford an unusual opportunity for estimations of the value of certain factors in prognosis. The investigations themselves covered a period of nine years, ending in 1917, and data regarding the cases remaining alive at the end of the study have been secured up to June, 1922. Of the 113 cases included in the research, 112 have been traced.

\footnotetext{
- See Appendix I, p. 283.
} 
The data for the average metabolism, expressed as variations from the normal standard, are summarized in table 67 for the living and fatal cases. ${ }^{\circ}$ It will be observed that the average metabolism of the cases who are still living was practically normal, but that the metabolism of the fatal cases was distinctly abnormal, the metabolism being 13 per cent above standard prior to June, 1914, and 9 per cent below after June, 1914. Extreme variations in metabolism are therefore especially dangerous for diabetics.

TABLE 67.-Summary of average variations from standard in the metabolism of living and fatal cases of diabetes.

\begin{tabular}{|c|c|c|c|c|}
\hline \multirow{2}{*}{ Group. } & \multirow{2}{*}{$\begin{array}{l}\text { No. of } \\
\text { cases. }\end{array}$} & \multicolumn{2}{|c|}{$\begin{array}{l}\text { Variation of metabolism } \\
\text { from normal standard. }\end{array}$} & \multirow{3}{*}{$\begin{array}{l}\text { Notes. } \\
1 \text { One living case was not included because } \\
\text { the metabolism was observed only in food } \\
\text { experiments. } \\
\text { 2 Five of the fatal cases were girl diabetics } \\
\text { for whom comparison of the metabolism was } \\
\text { made with the Girl Scout values and so } \\
\text { excluded from the averages. One case was } \\
\text { not included because the metabolism was } \\
\text { observed only in food experiment. One } \\
\text { case, undoubtedly fatal, could not be traced. }\end{array}$} \\
\hline & & $\begin{array}{c}\text { Before } \\
\text { June, } 1914 .\end{array}$ & $\begin{array}{c}\text { After } \\
\text { June, } 1914 .\end{array}$ & \\
\hline $\begin{array}{l}\text { Living. } \\
\text { Fatal. . }\end{array}$ & $\begin{array}{l}123 \\
282\end{array}$ & $\begin{array}{l}\text { p. ct. } \\
+5 \\
+13\end{array}$ & $\begin{array}{r}\text { p. } c t \text {. } \\
-1 \\
-9\end{array}$ & \\
\hline
\end{tabular}

Table 68 gives the duration of life after the last experimental observation for the various diabetic patients, also the pulse-rate, arranged according to the maximum variation from standard metabolism. As elsewhere, the data are divided for the two epochs preceding and following June, 1914.

According to table 68 for the cases whose metabolism was above standard before June, 1914, the duration of life subsequent in each case to the last observation averaged 1.2 years, and after June, 1914, nearly half again as long, i. e., 1.7 years. The duration of life of the two cases with subnormal metabolism before June, 1914, was 0.3 year, and for the 45 cases with subnormal metabolism after June, 1914, it was 1.2 years. But if one compares the larger groups, namely, the 23 diabetics before June, 1914, whose metabolism was above normal and the 45 diabetics after June, 1914, whose metabolism was below normal, it will be seen that the duration of life of each group was the same. Extreme measures resulted in equally bad results.

If we examine the protocols upon which the table is based, we find that table 68 is misleading as to the subsequent duration of life of diabetics before June, 1914, in that the duration of the two cases in the group with a metabolism 35 to 30 per cent above standard averaged 4.5 years, whereas, as a matter of fact, one of these patients (Case No. 220) lived but 0.1 year, dying of coma and tuberculosis, while Case No. 317 lived 8.8 years and died of influenzal pneumonia. The patient with a similarly high metabolism after June, 1914, (Case No. 1412) was on the verge of coma when the observations were made. The single case also after June, 1914, with a metabolism above standard between 25 and 20 per cent, was Case No. 800, a moderately severe case with temporary acidosis at the time of the test. He afterwards lived on

\footnotetext{
- Both Cases Nos. 1070 and 1412, though observed when on the verge of coma, are included in this table, but the girl diabetics, one patient with whom no post-absorptive experiment was made and the untraced patient, were excluded.
} 
a restricted diet and died of coma 6.2 years later, in March, 1921. This observation is significant, because it shows that an extremely high metabolism of brief duration is not necessarily of serious prognostic import.

TABLE 68.-Duration of life after last experimental observation, and pulse-rate ${ }^{1}$ observed at maximum variation of the metabolism from standard.

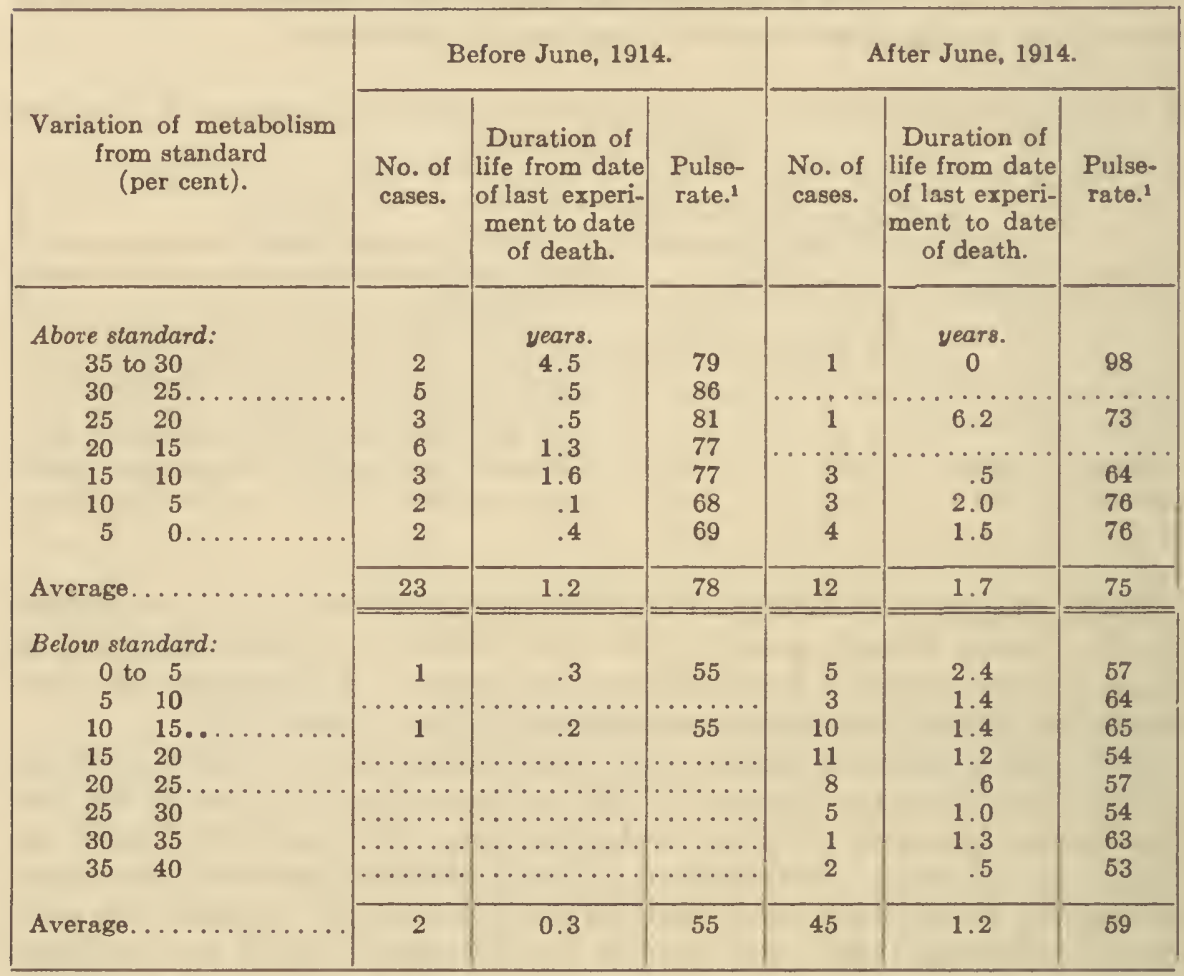

1 The pulse-rate here given is averaged from the observations on days showing the maximum variation from the standard metabolism for the respective cases.

The course of the pulse-rate as recorded in table 68 corresponds in general to that of the metabolism. The higher the pulse, the higher was the metabolism, and with but few exceptions the prognosis became more unfavorable as the metabolism and pulse-rate increased. This is particularly evident in the period of increased metabolism before June, 1914. After June, 1914, the data are less striking, though, in general, the lower the metabolism fell, the lower fell the pulse, and the shorter became the expectation of life. Incidentally the table brings out very well the fact that both before and after June, 1914, when the metabolism was high the average pulse-rates were high and similar (78 and 75 beats) and likewise when the metabolism was low, the pulse-rates were likewise low and similar ( 55 and 59 beats).

\section{SEVERITY OF DIABETES AND DURATION OF LIFE.}

The influence of the severity of the disease upon the expectation of life was marked with these diabetics. The data, based upon the 88 cases who died before June, 1921, are as follows. There were four mild cases; these lived for 2.8 
years after the last observation. (See table 69.) In this classification of mild cases some patients were included who, though showing considerable quantities of sugar at the time of observation, were readily made sugar-free. There

TABLE 69.-Duration of life of fatal cases after last experimental observation arranged according to severity of diabetes.

\begin{tabular}{|c|c|c|c|}
\hline Severity. 1 & $\begin{array}{l}\text { No. } \\
\text { of } \\
\text { cases. }\end{array}$ & $\begin{array}{l}\text { Duration of } \\
\text { life after last } \\
\text { experimental } \\
\text { observation. }\end{array}$ & Note. \\
\hline 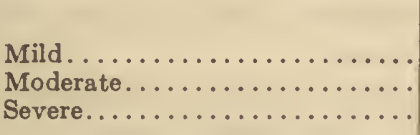 & $\begin{array}{r}4 \\
29 \\
55\end{array}$ & $\begin{array}{c}\text { years. } \\
2.8 \\
1.8 \\
.9\end{array}$ & \multirow{2}{*}{$\begin{array}{l}1 \text { For Cases Nos. } 210,226,310, \\
610,786,792,969 \text { and } 1070 \text { (Mo. } \\
\text { and S.); } 810 \text { (Mi. and Mo.) and } \\
765 \text { (S., Mo., and S.), the initial } \\
\text { severity determined the group in } \\
\text { which the subject was averaged. }\end{array}$} \\
\hline Average of all fatal cases.... & $\ldots$ & 1.3 & \\
\hline
\end{tabular}

were 29 cases of moderate severity, and these lived for an average period of 1.8 years after the last observation, while the average duration of the 55 severe cases was but 0.9 year. These facts bring out most clearly the almost hopeless condition into which the treatment of diabetes had fallen when these investigations began, and in the years immediately following. The data for these cases regarding the total duration of life after the onset of diabetes may be found in table 3, p. 8 .

\section{ACIDOSIS AND DURATION OF LIFE.}

The relation of degree of acidosis to the duration of life of fatal cases of diabetes subsequent to observation has been analyzed, and the results are given in table 70. These figures are based upon the duration of life calculated from the first day on which the highest acidosis was found to the actual date of death. The patients free from acidosis or with slight acidosis lived

TABLE 70.-Relation of severity of acidosis of fatal cases of diabetes to duration of life subsequent to first observation with highest acidosis.

\begin{tabular}{|c|c|c|c|}
\hline \multirow{2}{*}{ Acidosis. } & \multirow{2}{*}{$\begin{array}{l}\text { No. of } \\
\text { cases. }\end{array}$} & \multicolumn{2}{|c|}{$\begin{array}{l}\text { Duration of life following } \\
\text { most severe acidosis. }\end{array}$} \\
\hline & & Average. & Range. \\
\hline $\begin{array}{c}0 \\
+ \\
++ \\
++t\end{array}$ & $\begin{array}{l}13 \\
19 \\
33 \\
23\end{array}$ & $\begin{array}{c}\text { years. } \\
2.2 \\
2.2 \\
1.2 \\
.7\end{array}$ & \begin{tabular}{rr}
\multicolumn{2}{l}{ years. } \\
0.7 to & 4.0 \\
.3 & 8.8 \\
.1 & 3.7 \\
.1 & 2.5
\end{tabular} \\
\hline
\end{tabular}

on the average 2.2 years. Those with moderate acidosis succumbed within 1.2 years, and those with severe acidosis survived but 0.7 year. If calculated from the last day, the period is shortened by only 0.2 year for the cases with mild and severe acidosis. A maximum acidosis is therefore more serious than a maximum severity. The range in duration of life was considerable, 
but of these fatal cases none with the most severe type of acidosis lived over 2.5 years. On the other hand, one must remember that Case No. 983, the fat woman, is still alive (July 20, 1922), although she experienced severe acidosis. It was, however, of a temporary character, being innocently induced by a sudden restriction of carbohydrate in 1914. Experience with this case taught a lesson never to be forgotten.

\section{DURATION OF LIFE AND BODY-WEIGHT.}

The influence of the original maximum body-weight upon the duration of life of these diabetics is marked and is shown in table 71. In general, the overweight cases lived longest, but there are exceptions. The two cases most obese lived on an average 4.9 years ( 6.8 and 3.0 years).

With the two cases 50 to 41 per cent above standard weight, the duration was 12.5 years. The 12 cases with a weight 40 to 21 per cent above standard had an average duration of 4 years. It is significant that 25 cases with only a slight excess of weight, namely, 20 to 6 per cent, showed an average duration of 5.4 years, and that also those within 5 per cent more or less of normal weight lived a similar period of 4.7 years. This demonstrates that the diabetic of average weight is by no means handicapped. The maximum weight of 22 of the cases before the onset of diabetes was reported to be from 6 to 20 per cent below standard. These individuals have the shortest duration of all, namely, an average of 3.2 years. This conforms to the general impression that when diabetes develops in an underweight individual, it is apt to be severe. In such cases an inherent diabetic tendency is at work in the body which does not require overnutrition to bring it to light.

TABLE 71.-Relation between duration of diabetes of fatal cases and percentage variation of maximum body-weight from standard weight.

\begin{tabular}{|c|c|c|}
\hline $\begin{array}{l}\text { Percentage variation of } \\
\text { maximum weight from } \\
\text { standard weight. }\end{array}$ & $\begin{array}{l}\text { No. } \\
\text { of } \\
\text { cases. }\end{array}$ & $\begin{array}{l}\text { Duration } \\
\text { of } \\
\text { diabetes. }\end{array}$ \\
\hline 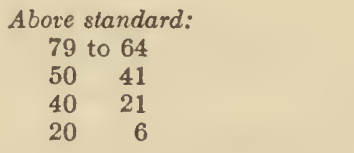 & $\begin{array}{r}2 \\
2 \\
12 \\
25\end{array}$ & $\begin{array}{r}\text { years } \\
4.9 \\
12.5 \\
4.0 \\
5.4\end{array}$ \\
\hline Average of all cases... & . & 5.3 \\
\hline $\begin{array}{l}\text { +5 to }-5 \\
\text { Below standard: } \\
6 \text { to } 20\end{array}$ & $\begin{array}{l}24 \\
22\end{array}$ & $\begin{array}{l}4.7 \\
3.2\end{array}$ \\
\hline
\end{tabular}

Diabetic patients, whether overweight or underweight, are liable to death from coma at any time, but only diabetic patients who are markedly underweight are liable to death from inanition. No diabetic patient need fear death from undernutrition, until his loss of weight has considerably exceeded 50 per cent. Consequently, first of all protect all diabetics from acidosis and then fight undernutrition. 


\section{RESPIRATORY QUOTIENT IN DIABETES.}

The respiratory quotients of the severe cases of diabetes studied at the Nutrition Laboratory between the years 1908 and 1911 averaged 0.73 , and those of the moderately severe cases averaged 0.77 in the calorimeter experiments and 0.73 in the experiments with the respiration apparatus. With the single mild case it was 0.77 and 0.75 , respectively. ${ }^{a}$ The influence of severity, acidosis, and other conditions upon the respiratory quotients of the 113 diabetics in the entire series of observations will be subsequently discussed, but attention is first invited to a comparison of the respiratory quotient and the metabolism.

\section{Relation between the Respiratory Quotient and the Metabolism of Diabetics.}

The metabolism, not only of diabetics but of normal individuals as well, has been considered as entirely unrelated to the respiratory quotient, the belief being general that the latter merely registered the quality and not the quantity of material burned. Inasmuch as great variations have been seen to take place in the metabolism of these 113 diabetics, it is especially worth while to investigate this supposed non-relationship between their metabolism and respiratory quotients. ${ }^{b}$ The data for such comparison have therefore been gathered together in tables 72 and 73 for the patients with whom the Harris and Benedict standard was used, but do not include the girl diabetics who were compared with the group of Girl Scouts.

It will be seen from table 72 that before June, 1914, the average respiratory quotient for 122 observations was 0.73 (the same as that already reported for the severe cases of diabetes studied between 1908 and 1911). After June, 1914, the average respiratory quotient was 0.77 for 292 observations. The average metabolism in these same observations was 13 per cent above standard prior to June, 1914, and 10 per cent below standard after June, 1914. The respiratory quotient in diabetes, therefore, appears to bear a definite relation to the metabolism in that it is low when the metabolism is high and higher when the metabolism is low. This is in striking contrast to the universally accepted idea that the respiratory quotient is independent of the metabolism. While it is true that a change in the quotient of but 0.01 to 0.04 in a single case or experiment may be of little significance, a change of 0.04 can not be disregarded when the data are based upon 414 experiments, all undertaken with the patients in the post-absorptive condition.

In table 72 the average quotients for the experiments are grouped for short ranges, together with the corresponding average percentage variations in the metabolism from standard. Prior to June, 1914, the lowest average quotient of the series $(0.68)$ was accompanied by the highest average metabolism of the series, namely, +17 per cent. With the higher respiratory quotients the metabolism fell to as low as +8 per cent, but with the highest average quotient it increased again to +12 per cent. After June, 1914, the metabolism steadily fell from a variation of -2 per cent to -16 per cent, as the

\footnotetext{
a Benedict and Joslin, Carnegie Inst. Wash. Pub. No. 176, 1912, p. 113, table 127.

b It has already been pointed out in one of the previous monographs on metabolism in diabetes (Benedict and Joslin, Carnegie Inst. Wash. Pub. No. 176, 1912, p. 126) "that apparently the lower the amount of carbohydrates in the diet, the higher the metabolism."
} 
average respiratory quotient rose from 0.68 to 0.81 . Thereafter it increased somewhat to -11 per cent for the highest quotients.

These figures demonstrate a relation between the metabolism of these diabetics and the respiratory quotient. This is still more apparent if the general trend of the figures in the table is observed, the only distinct breaks in the series, if they are considered in succession, being the relation of the metabolism observed before June, 1914, for the average respiratory quotient of 0.81 and the change in course after June, 1914, with the quotients above 0.81 .

TABLE 72.-Comparison of respiratory quotient with variation in metabolism from standard in experiments with diabetics without food, and with all degrees of severity.

\begin{tabular}{|c|c|c|c|c|c|c|}
\hline \multirow[b]{2}{*}{$\begin{array}{l}\text { Range in } \\
\text { respiratory } \\
\text { quotient. }\end{array}$} & \multicolumn{3}{|c|}{$\begin{array}{l}\text { Before June } 1914 \\
\text { (122 experiments). }\end{array}$} & \multicolumn{3}{|c|}{$\begin{array}{c}\text { After June } 1914 \\
\text { (292 experiments). }\end{array}$} \\
\hline & $\begin{array}{l}\text { No. } \\
\text { of experi- } \\
\text { ments. }\end{array}$ & $\begin{array}{l}\text { Average } \\
\text { respi- } \\
\text { tory } \\
\text { quotient. }\end{array}$ & $\begin{array}{l}\text { Average } \\
\text { variation } \\
\text { of metab- } \\
\text { lism from } \\
\text { standard. }\end{array}$ & $\begin{array}{l}\text { No. } \\
\text { of experi- } \\
\text { ments. }\end{array}$ & $\begin{array}{l}\text { Average } \\
\text { respi- } \\
\text { tory } \\
\text { quotient. }\end{array}$ & $\begin{array}{l}\text { Average } \\
\text { variation } \\
\text { of metab- } \\
\text { lism from } \\
\text { standard. }\end{array}$ \\
\hline 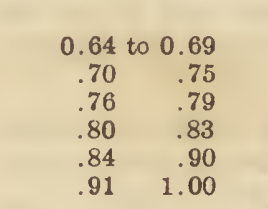 & $\begin{array}{r}16 \\
77 \\
22 \\
4 \\
3 \\
\ldots \ldots \ldots\end{array}$ & $\begin{array}{r}0.68 \\
.73 \\
.77 \\
.81 \\
.86 \\
\ldots \ldots \ldots\end{array}$ & $\begin{array}{c}\text { p. } c t . \\
+17 \\
+13 \\
+12 \\
+8 \\
+12 \\
\ldots \ldots \ldots\end{array}$ & $\begin{array}{r}9 \\
101 \\
83 \\
67 \\
29 \\
3\end{array}$ & $\begin{array}{r}0.68 \\
.73 \\
.77 \\
.81 \\
.85 \\
.93\end{array}$ & $\begin{array}{l}\text { p. } c t . \\
-2 \\
-5 \\
-11 \\
-16 \\
-15 \\
-11\end{array}$ \\
\hline Av., all experiments. & $\ldots \ldots \ldots$ & .73 & +13 & $\ldots \ldots \ldots \ldots$ & .77 & -10 \\
\hline
\end{tabular}

Table 72 includes all experiments with all grades of severity, but in table 73 the relation between the respiratory quotient and the metabolism is presented for severe cases alone. By this means possible fluctuations in the respiratory quotient, due to the ingestion of considerable quantities of carbohydrate by mild and moderate cases, are eliminated. The averages for the quotients before and after June, 1914, remain the same as in table 72 . Before June, 1914, there is still comparatively little change in the metabolism as the quotient rises, and the break in the general trend for the range between 0.80 and 0.83 is apparent but not so pronounced as in the values for all degrees of severity. The slight variation in the metabolism may be explained in part by the very few experiments in which the quotient was 0.80 or more. After June, 1914, the course of the metabolism is somewhat changed from that shown in table 72 , as the downward trend continues even with the higher quotients.

The metabolism and the respiratory quotient are further compared in table 74, which gives for all degrees of severity the number of experiments for each group of respiratory quotients as compared with progressively decreasing ranges in the variation of the metabolism from standard. An inspection of this table also brings out the fact that when the metabolism was high low respiratory quotients were observed, and when the metabolism was 
low the respiratory quotients were high. Thus, with the highest metabolism in table 74 , i. e., 35 to 30 per cent above standard before June, 1914, the average of three experiments gives a respiratory quotient of 0.70 , which is the lowest average quotient found in the observations according to this grouping. With the lowest metabolism, namely, 35 to 40 per cent below standard after June, 1914, the average respiratory quotient for four observations was 0.84 , the highest average given in the table. Between these two extremes a general tendency is seen for the quotient to rise as the metabolism falls.

TABLE 73.-Relation between respiratory quotient and variation in metabolism from standard in experiments without food with cases of severe diabetes.

\begin{tabular}{|c|c|c|c|c|c|c|}
\hline \multirow[b]{2}{*}{$\begin{array}{l}\text { Range in } \\
\text { respiratory } \\
\text { quotient. }\end{array}$} & \multicolumn{3}{|c|}{$\begin{array}{l}\text { Before June, } 1914 \\
\text { (94 experiments). }\end{array}$} & \multicolumn{3}{|c|}{$\begin{array}{c}\text { After June, } 1914 \\
\text { (199 experiments). }\end{array}$} \\
\hline & $\begin{array}{l}\text { No. of } \\
\text { experi- } \\
\text { ments. }\end{array}$ & $\begin{array}{l}\text { Average } \\
\text { respira- } \\
\text { tory } \\
\text { quotient. }\end{array}$ & $\begin{array}{l}\text { Average } \\
\text { variation } \\
\text { of metab- } \\
\text { olism from } \\
\text { standard. }\end{array}$ & $\begin{array}{l}\text { No. of } \\
\text { experi- } \\
\text { ments. }\end{array}$ & $\begin{array}{c}\text { Average } \\
\text { respira- } \\
\text { tory } \\
\text { quotient. }\end{array}$ & $\begin{array}{l}\text { Average } \\
\text { variation } \\
\text { of metab- } \\
\text { olism from } \\
\text { standard. }\end{array}$ \\
\hline 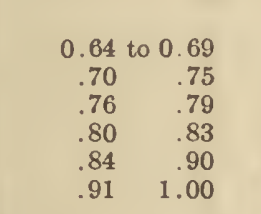 & $\begin{array}{r}16 \\
63 \\
11 \\
1 \\
3 \\
1\end{array}$ & $\begin{array}{r}0.68 \\
.72 \\
.76 \\
.80 \\
.86 \\
\cdots\end{array}$ & $\begin{array}{l}p . c t . \\
+17 \\
+13 \\
+12 \\
+10 \\
+12 \\
\ldots \ldots\end{array}$ & $\begin{array}{r}7 \\
75 \\
51 \\
47 \\
18 \\
1\end{array}$ & $\begin{array}{r}0.68 \\
.73 \\
.77 \\
.81 \\
.85 \\
.94\end{array}$ & $\begin{array}{l}\text { p. ct. } \\
-1 \\
-7 \\
-14 \\
-19 \\
-23 \\
-37\end{array}$ \\
\hline Av., all experiments & & .73 & +14 & & .77 & -13 \\
\hline
\end{tabular}

Clinical Importance of Relation between Respiratory Quotient and Metabolism.

The inferences to be drawn from these three tables as to the relationship between the respiratory quotient and the metabolism are of the utmost clinical importance. With the low carbohydrate diet of the diabetic a low respiratory quotient is to be expected and was found, as evidenced by the average quotient of 0.73 for the cases before June, 1914. This low quotient is in contrast to the average quotient of 0.83 found with 236 of the 239 normal individuals in the Harris and Benedict series. ${ }^{\circ}$ After June, 1914, the average quotient for the diabetics was higher than previous to that date, namely, 0.77 , which is still somewhat below the normal. In looking for a cause for the difference in the quotients in these two periods, we have not the usual recourse to variations in the amount of carbohydrate in the diet, because in both epochs this was low, certainly averaging less than a fourth of the normal quota, with a difference between the two periods of probably less than 25 grams. Moreover, after a post-absorptive period of 14 hours, the small amount of carbohydrate taken would have but little influence upon the

- Harris and Benedict, Carnegie Inst. Wash. Pub. No. 279, 1919, pp. 40 and 44, tables $\mathrm{C}$ and $\mathrm{D}$. The respiratory quotients are not printed in these tables, but have readily been calculated. 
quotient. (See p. 186.) Some other cause, therefore, than the usual oxidation of carbohydrate must be found for these varying quotients. It is not easy to explain them by the normal metabolism of protein and fat.

TABLE 74.-Relation between respiratory quotient and metabolism with diabetics before and after June, 1914.

\begin{tabular}{|c|c|c|c|c|c|c|c|c|}
\hline \multirow{2}{*}{$\begin{array}{l}\text { Percentage } \\
\text { variation of } \\
\text { metabolism } \\
\text { from standard. }\end{array}$} & \multicolumn{6}{|c|}{$\begin{array}{c}\text { No. of experiments with respiratory } \\
\text { quotients ranging from- }\end{array}$} & \multirow{2}{*}{$\begin{array}{l}\text { Total } \\
\text { experi- } \\
\text { ments. }\end{array}$} & \multirow{2}{*}{$\begin{array}{l}\text { Average } \\
\text { respira- } \\
\text { tory quo- } \\
\text { tients. }\end{array}$} \\
\hline & $\begin{array}{l}0.64 \\
\text { to } \\
0.69\end{array}$ & $\begin{array}{l}0.70 \\
\text { to } \\
0.75\end{array}$ & $\begin{array}{l}0.76 \\
\text { to } \\
0.79\end{array}$ & $\begin{array}{l}0.80 \\
\text { to } \\
0.83\end{array}$ & $\begin{array}{l}0.84 \\
\text { to } \\
0.90\end{array}$ & $\begin{array}{l}0.91 \\
\text { to } \\
1.00\end{array}$ & & \\
\hline 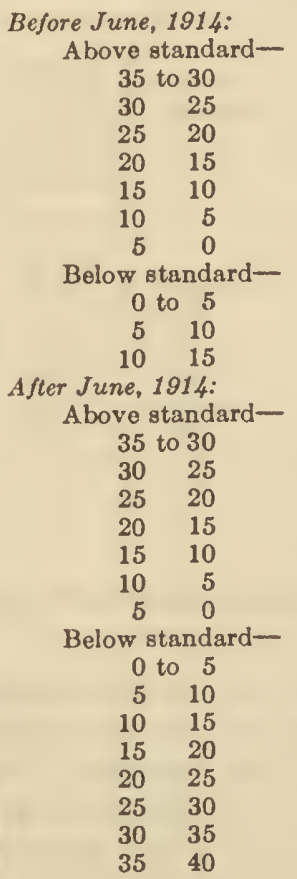 & 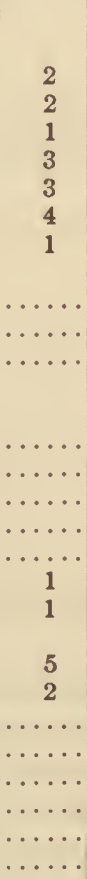 & $\begin{array}{r}1 \\
2 \\
1 \\
1 \\
7 \\
3 \\
18 \\
\\
20 \\
13 \\
12 \\
13 \\
6 \\
4 \\
\ldots . . \\
\ldots .\end{array}$ & $\begin{array}{c}\ldots \ldots \\
2 \\
4 \\
9 \\
2 \\
2 \\
\\
3 \\
\ldots \ldots \\
\ldots \ldots\end{array}$ & 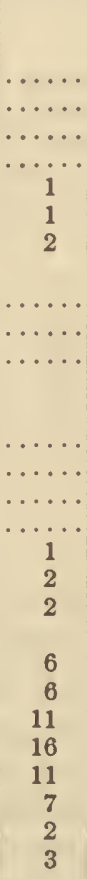 & $\begin{array}{c}\ldots \ldots \\
\cdots \ldots \\
\cdots \cdots \\
\cdots \cdots \\
\cdots \cdots \\
2 \\
2 \\
\\
4 \\
2 \\
4 \\
\ldots \\
7 \\
6 \\
2 \\
\ldots \ldots\end{array}$ & 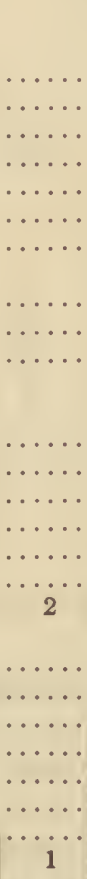 & $\begin{array}{r}2 \\
2 \\
1 \\
1 \\
10 \\
11 \\
30 \\
\\
\\
48 \\
34 \\
47 \\
40 \\
35 \\
21 \\
6 \\
4\end{array}$ & $\begin{array}{l}.74 \\
.72 \\
.74 \\
.72 \\
.75 \\
.77 \\
.77 \\
\\
.76 \\
.76 \\
.78 \\
.78 \\
.80 \\
.80 \\
.82 \\
.84\end{array}$ \\
\hline
\end{tabular}

Associated with this change in respiratory quotient between the two periods is an algebraical change in the metabolism of 23 per cent (from +13 to -10 per cent) with all cases and of 27 per cent (from +14 to -13 per cent) with the severe cases. A high metabolism with diabetic patients is found to be associated with a low respiratory quotient. As the respiratory quotient approaches that of normal individuals, the metabolism tends towards the normal level. When the metabolism attains a very low level, the respiratory quotient rises to a level abnormally high for a severe diabetic.

With the cases of severe diabetes, we find that both excessively low and excessively high respiratory quotients are usually associated with an abnormal metabolism, so that, although a high respiratory quotient is welcomed in 
such a disease as diabetes, because it suggests the ability of the patient to burn carbohydrate, one must not lose sight of the fact that it is obtained only through a metabolism of threateningly low degree. The causes of the low respiratory quotients and the accompanying high metabolism, and the high respiratory quotients and low metabolism must be eradicated for successful treatment of a case. The data here set forth show that an added significance can be attached to the respiratory quotient in diabetes.

Krogh and Lindhard ${ }^{a}$ in an article which unfortunately escaped the writer's attention until just before this book was completed, have formulated a theory of much importance. They state (the italics being the writer's):

"The proportion of carbohydrate to fat katabolized is a function of the relative available quantities of the two substances, and substantially the same during rest and during muscular work.

"Fat is formed from carbohydrate and stored up when the available supply of carbohydrate is in excess of the supply of fat. The formation becomes distinct at quotients above 0.90 . When the total quotient during rest has reached unity the katabolic quotient is only about 0.95 . The conversion of carbohydrate into fat takes place with a loss of energy and a consequent increase of a few per cent in the total standard metabolism at high quotients.

"Sugar (or substances allied to carbohydrates) is formed from fat (and protein) and stored up when the available supply of fat is in excess of the supply of carbohydrate. The formation becomes distinct at quotients below 0.80 . When the total quotient during rest has reached 0.71 the katabolic quotient is about 0.74 . The conversion of fat takes place with a loss of energy and a consequent increase in the standard metabolism at decreasing quotients.

"It is a consequence of this hypothesis that neither fats alone nor carbohydrates alone are suitable for the supply of the energy requirements of the body, but that the katabolic disintegration of either of these substances requires the presence and the sinultaneous katabolization of the other.

"While it has long been concluded from the acidosis and excretion of keto-substances in severe diabetes and during starvation that carbohydrates are necessary for the complete katabolization of fat and our results only lend support to this view, it is so far as we are aware, a new hypothesis that fats are likewise necessary for the katabolization of carbohydrate."

\section{Low and High Respiratory Quotients.}

The respiratory quotient represents the proportions of fat and carbohydrate burned at any given moment. It can not be expected to change unless there is a change in this proportion. In general, if carbohydrate is being burned, the quotient will remain high, but if carbohydrate is not being burned, the respiratory quotient will fall.

There are two sources of carbohydrate, the exogenous and the endogenous, and from each source carbohydrate may be obtained in three forms: First, from carbohydrate; second, from protein; and third, to a slight extent from fat. So far as the quotient is concerned, save in exceptional instances, one deals only with carbohydrate obtained from carbohydrate, as starch and sugar in the diet, or glycogen and sugar stored in the body. If the diet contains no starch and sugar, and if there is no storage of glycogen or sugar in the body, then the only methods by which the quotient can continue

\footnotetext{
a Krogh and Lindhard, Biochem. Journ., 1920, 14, p. 290.
} 
high or rise are (1) by the liberation and oxidation of carbohydrate derived from excessive katabolism of protein without simultaneous oxidation of the protein residue, or (2) what has hitherto been undemonstrated with the diabetic, by the formation of fat from carbohydrate. By the former method it is theoretically immaterial whether the protein so metabolized is supplied from without the body or from the body itself, but, so far as is known, the oxidation of protein from without the body has never raised the respiratory quotient above the characteristic protein quotient of 0.81 . On the other hand, some observations upon these diabetic patients appear to indicate that when an excessive amount of body protein is oxidized, as is evidently the case when the body has reached a stage of extreme inanition with almost complete exhaustion of its storage of fat, the quotient will then rise above the respiratory quotient of protein. (See Cases Nos. 1011, 1213, and 1378, in table 78 , p. 180.)

The possibility of a rise in the respiratory quotient in consequence of the conversion of carbohydrate into fat in diabetes will be discussed in considering the relation between blood fat and the respiratory quotient, but especially in connection with the discussion of high respiratory quotients after the administration of levulose. (See pp. 197 and 233.)

The factors which influence the respiratory quotient in diabetes are many. Not only are we dealing with the standard quotients for carbohydrate, protein, and fat, of $1.00,0.81$, and 0.707 , respectively, but with many other quotients. If the carbohydrate in protein is not burned, the quotient for protein reverts to $0.632,{ }^{a}$ but if the amino-acid molecules in protein, which are producers of fat, are not burned, a different quotient results. During periods of acidosis ammonia is formed and excreted. The nitrogen thus removed from the body does not require oxygen, and in consequence the quotient tends to rise to 0.88 if all the nitrogen of protein metabolism is eliminated as ammonia. ${ }^{b} \quad$ Nor does the metabolism of fat run smoothly with the diabetic. Imperfect oxidation may take place and $\beta$-oxybutyric acid, diacetic acid, and acetone be formed which have very different quotients from that of the molecule. The formation of these bodies from fat tends to lower the respiratory quotient, their oxidation to raise it. Magnus-Levyc calculated that from 100 grams of fat it is possible to form 36.2 grams of $\beta$-oxybutyric acid. If this should take place, the respiratory quotient for fat would be 0.669 , instead of 0.707 . In the light of all these variations taking place in the diabetic organism, one may expect strange quotients, even though their explanation at present is fraught with difficulties or impossible.

In the discussion of the high quotients, some evidence will be presented to show that in extremely severe cases of diabetes, with the patient in extreme degree of inanition, remarkably high quotients are obtained, particularly high after the administration of levulose, so that one is forced to consider the possibility of the transformation of carbohydrate into fat. Conversely, with equally severe cases of diabetes with low quotients forced upon them by excessive quantities of fat in the diet, must one not also consider the possibility of a transformation, to some degree at least, of fat into carbohydrate?

\footnotetext{
a Lusk, Arch. Intern. Med., 1915, 15, p. 939.

brafe, Zeitschr. f. physiol. Chem., 1910, 65, p. 48.

c Magnus-Levy, Ergeb. d. inn. Med., 1908, 1, p. 384.
} 
In all discussions of the respiratory quotient it is far too common to consider that the transfer of carbohydrate into fat only takes place when the quotient is above 1.00. Drs. Benedict and Carpenter have repeatedly called the writer's attention to "the possibility that this change may take place with respiratory quotients at a far lower level." Krogh a says that, when the respiratory quotient is above 0.90 , it is an indication that carbohydrate is being changed into fat, but when it is below 0.80 , the reverse action is probable. (See p. 169.)

\section{LOW RESPIRATORY QUOTIENTS IN DIABETES.}

A low respiratory quotient in diabetes is easily explained by the nature of the disease as well as by the diet. In diabetes there is failure to oxidize carbohydrate, and as a result the respiratory quotient, left dependent upon protein and fat, must fall. The fall is further accentuated if $\beta$-oxybutyric acid and its derivatives are formed, because these require oxygen. A low quotient is also brought about by a small proportion of carbohydrate and a preponderance of fat in the diet. This is true even with mild cases who retain the power to burn some carbohydrate.

In contradistinction to diabetics with low quotients and high metabolism, living upon diets low in carbohydrate and high in fat, as did the patients in this series prior to June, 1914, are the observations of Means, ${ }^{b}$ upon fat individuals during fasting. Case 1 of his series, during four days of fasting, gave respiratory quotients of $0.69,0.69,0.68$, and 0.74 , respectively, yet the metabolism was below standard rather than above, amounting to -2 per cent $^{c}$ for the four days, or between 15 and 16 calories per kilogram of bodyweight. In a second period of fasting, about 10 days later, the respiratory quotients were $0.75,0.75,0.72,0.71$, and 0.73 , respectively, but the metabolism was -8 per cent ${ }^{c}$ or between 14 and 16 calories per kilogram of bodyweight. After another six days, during a third period of fasting, the respiratory quotients were practically the same, being $0.76,0.74,0.72$, and 0.71 , respectively, with but little or no change in the metabolism, namely, -10 per cent ${ }^{c}$ or about 15 calories per kilogram of body-weight. It will be observed that there was a tendency between the first and the second periods of fasting for the respiratory quotient to rise, the average respiratory quotient for the first period being 0.70 , for the second period, 0.73 , and for the third period, 0.73. The change in quotient is, however, very slight. But it is significant that as the quotient rose with this normal obese individual, the metabolism fell and incidentally the acidosis lessened.

\section{Extremely Low Respiratory Quotients in the Literature.}

When Pflüger was told of the discovery of very low respiratory quotients, he is said by Magnus-Levyd to have remarked: "dass der niedrige R.-Q. nur eine Bildung von 'sauerstoffreichen' Korpern aus 'sauerstoffarmen' beweist, aber nichts über die Quelle der Ersteren aussagt." Coming from Pflüger, what a legacy to posterity of scientific restraint!

a Krogh and Lindhard, Biochem. Journ., 1920, 14, p. 290.

' Means, Journ. Med. Research, 1915, 27, p. 121.

- Harris and Benedict standard.

d Magnus-Levy, Zeitschr. f. klin. Med., 1905, 56, p. 83. 
Respiratory quotients below 0.69 have been looked upon with suspicion, and often considered the result of poor technique. Such quotients, however, have been obtained far too frequently in health and disease, and by too many authors, to be disregarded.

Benedict and Higgins ${ }^{a}$ obtained a quotient of 0.67 with a healthy man (H. L. H.) who omitted his evening meal on one day, lived on a carbohydratefree diet the next, and was tested the following morning.

Lehmann and Zuntz, in the study of a fasting individual, observed low quotients which during several days averaged $0.67 . .^{\circ}$

Leo, in 1891, with a very severe diabetic, who had lost 30 kilograms of body-weight, records a quotient of $0.67 .^{\circ}$

Magnus-Levy reports quotients in a series of studies upon a severe diabetic of $0.654,0.657$, and 0.651 . This patient excreted about 100 grams of sugar in the urine daily and the diet contained carbohydrate about 40 grams, protein 100 to 150 grams, and fat 200 to 300 grams.d Magnus-Levy, in the above article refers to the theoretically possible quotient of 0.653 for diabetics, but states that it can only be attained if sugar is formed from fat.

Leimdörfer ${ }^{e}$ obtained post-absorptive quotients of $0.644,0.645,0.641$, and 0.678 with four cases of severe diabetes, showing acidosis, who were living upon a strict non-carbohydrate diet. Following these periods of non-carbohydrate diet, these patients were placed upon a diet of vegetables with fat in the form of butter or bacon, and eggs or egg yolks, and some alcohol. This period was followed by three oatmeal days, during which oatmeal 250 grams and butter 250 grams, and also alcohol, were taken daily. As a result, the above patients showed quotients respectively of $0.655,0.655,0.723$, and 0.691 .

Bernstein and Faltas obtained an average quotient of 0.667 upon three successive days with a normal individual. Like Leimdörfer, during days in which oatmeal or wheat and butter were given, he found quotients of $0.657,0.653$, and on two different days 0.631 .

The Russell Sage Laboratory, in all of their publications, report but one low respiratory quotient with a diabetic.s With Cyril K., a quotient of 0.687 was obtained, the quotient in one of the periods being 0.656 . In the opinion of these investigators "quotients as low as 0.66 have not been reported in trustworthy experiments in the basal metabolism in diabetes," and again, Allen and Du Bois ${ }^{h}$ write: "Leimdörfer is the only recent author who reports such low quotients; and as they are so numerous in his experiments, while his cases of diabetes were obviously of no extraordinary severity, it is apparent that something in his methods tended to give low values."

In contrast to this one quotient below 0.69 from the Russell Sage Laboratory are 17 such quotients ranging as low as 0.65 recently reported by Wilder, Boothby, and Beeleri in the course of 44 experiments with a single case of

a Benedict and Higgins, Am. Journ. Physiol., 1912, 30, p. 217.

b Lehmann, Mueller, Munk, Senator, and Zuntz, Arch. f. path. Anat. u. Physiol. u. f. klin. Med., 1893, 131, Suppl., p. 50.

c Leo, Zeitschr. f. klin. Med., 1891, 19, Suppl., p. 101.

d Magnus-Levy, Zeitschr. f. klin. Med., 1905, 56, p. 83.

- Leimdörfer, Biochem. Zeitschr., 1912, 40, p. 326.

$f$ Bernstein and Falta, Deutsch. Arch. f. klin. Med., 1916-17, 121, p. 95.

- Gephart, Aub, Du Bois, and Lusk, Arch. Intern. Med., 1917, 19, p. 908.

A Allen and Du Bois, Arch. Intern. Med., 1916, 17, p. 1010.

i Wilder, Boothby, and Beeler, Journ. Biol. Chem., 1922, 51, p. 311. 
diabetes. The case was not exceptionally severe. This is shown by the absence of glycosuria for four successive days (May 15 to 18) with a diet containing approximately 1 gram of protein and 30 calories per kilogram of bodyweight, with carbohydrate amounting to 14.7 grams and again later for 7 days (June 4 to 10) upon a diet of two-thirds gram of protein and 33 calories per kilogram of body-weight. At the end of these periods $D: N$ ratios ceased to exist and the respiratory quotients were respectively 0.72 and 0.73 . By placing this patient upon diets containing 57 calories per kilogram (April 30 to May 4) and 51 calories per kilogram (May 30 to June 2), containing respectively 138 and 126 grams of fat, and 3 and 4 grams of carbohydrate, $\mathrm{D}: \mathrm{N}$ ratios of $3.65: 1.00$ were obtained, though not obtained when larger quantities of carbohydrate ( 43 grams), less protein, and larger quantities of fat (151 grams) were given. None of the low quotients were obtained when the patient had received upon the preceding day over 20 grams of carbohydrate, save with one exception. The protein and fat in the diet shortly preceding the tests were comparatively high. Thus, the fat with these quotients varied between 83 and 151 grams, save on May 30, which was but 3 days after an 8-day period of the ingestion of 151 grams of fat daily. At no time were quotients below 0.69 obtained when the energy in the diet was less than 30 calories per kilogram of body-weight upon the preceding day, save in three instances, when one or two days of lower diets or fasting intervened between periods of the administration of 51 to 57 calories per kilogram for 4 to 7 successive days.

\section{Extremely Low Respiratory QUotients in this Laboratory.}

Among the 113 patients studied at this Laboratory between 1908 and 1917, respiratory quotients of 0.69 or below were observed on 18 occasions with 9 patients in the post-absorptive state. The data for these observations are given in table 75. Thirteen of these occurred in the period before June, 1914, and five before May, 1915, thus showing their relation to the period of overfeeding. Save for the five exceptions above noted, such low quotients were absent with the 80 patients studied since June, 1914, when they were in the post-absorptive condition. The hall-marks of overnutrition in the early period are apparent with these patients. The metabolism was more than 5 per cent above standard in 13 of the observations recorded in table 75 , and on only one day was it as low as -10 per cent. Acidosis was severe in the majority of observations and absent in none. 'All but one of the cases were severe. The weight was below standard not more than 15 per cent in 7 instances and was more than 25 per cent below standard in only one observation, thus indicating that the patients had not been subjected to marked undernutrition, or by inference had lived upon a liberal diet, which is also indicated by the nitrogen being high in most instances when compared with the weight. The carbohydrate balance was, as a rule, markedly negative, the four major exceptions being explained by a temporarily high carbohydrate intake on the previous day.

The question of the previous diet, however, for the day, days, or months before the observations is of enough importance to record in detail. Case No. 246, from June to October, was upon a diet which contained 175 grams of fat. The lowest fat in the diet for Case No. 220 between October, 1908 and 
February, 1909, was 180 grams, and the highest 245 grams. Case No. 441 on the day before the experiment lived upon bacon, butter, cream, and 5 per cent vegetables. Case No. 549 received 200 grams fat on the day preceding the first experiment, though less upon the day preceding the experiment of the second day. Case No. 591 received 264 grams fat preceding April 13-14 and 90 grams preceding the second day. Case No. 740 took 70 grams fat, but the experiment was preceded by a fasting day. Case No. 773, weighing $40 \mathrm{~kg}$., was an exceptionally severe case, admitted to the hospital on October 5 ,

TABLE 75.-Low respiratory quotients (0.69 and below) in post-absorptive experiments with diabetics.

\begin{tabular}{|c|c|c|c|c|c|c|c|c|c|c|c|}
\hline \multirow{2}{*}{$\begin{array}{l}\text { Case } \\
\text { No. }\end{array}$} & \multirow{2}{*}{ Date. } & \multirow{2}{*}{$\begin{array}{l}\text { Re- } \\
\text { spira- } \\
\text { tory } \\
\text { quo- } \\
\text { tient. }\end{array}$} & \multicolumn{2}{|c|}{$\begin{array}{l}\text { Variation from } \\
\text { normal standard. }\end{array}$} & \multirow{2}{*}{$\begin{array}{l}\text { Se- } \\
\text { ver- } \\
\text { ity. }\end{array}$} & \multirow{2}{*}{$\begin{array}{l}\text { Aci- } \\
\text { dosis. }\end{array}$} & \multirow{2}{*}{$\begin{array}{c}\text { Urinary } \\
\text { nitrogen } \\
\text { in pre- } \\
\text { ceding } \\
24 \text { hrs. }\end{array}$} & \multirow{2}{*}{$\begin{array}{l}\text { Urinary } \\
\text { sugar } \\
\text { in pre- } \\
\text { ceding } \\
24 \text { brs. }\end{array}$} & \multicolumn{2}{|c|}{$\begin{array}{l}\text { Carbohydrate } \\
\text { in diet. }\end{array}$} & \multirow{2}{*}{$\begin{array}{c}\text { Carbo- } \\
\text { hydrate } \\
\text { balance on } \\
\text { day of ex- } \\
\text { periment. }\end{array}$} \\
\hline & & & $\begin{array}{c}\text { Metabo- } \\
\text { lism. }\end{array}$ & $\begin{array}{l}\text { Body- } \\
\text { weight. }\end{array}$ & & & & & $\begin{array}{l}\text { Pre- } \\
\text { ceding } \\
\text { day. }\end{array}$ & $\begin{array}{l}\text { Experi- } \\
\text { mental } \\
\text { day. }\end{array}$ & \\
\hline & & & p. ct. & p. ct. & & & om. & $\sigma m$. & $g m$. & om. & $g m$ \\
\hline 220 & Mar. 13-14, $1909 \ldots \ldots$ & 0.69 & $\begin{array}{l}+32 \\
+28\end{array}$ & -25 & S. & $+t+$ & $\cdots \cdots \cdots$ & $\cdots \cdots$ & $\cdots \cdots \cdots$ & $\cdots \cdots$ & $\ldots \ldots \ldots$ \\
\hline \multirow{6}{*}{246} & June $15-16,1909 \ldots \ldots$ & .08 & $\begin{array}{l}+28 \\
+22\end{array}$ & $\begin{array}{l}+1 \\
+1\end{array}$ & S. & & $\begin{array}{l}13.2 \\
21.8\end{array}$ & $\begin{array}{l}104 \\
122\end{array}$ & $\cdots \cdots \cdots$ & $\begin{array}{l}\ldots \ldots \\
\ldots \ldots\end{array}$ & $\ldots \ldots \ldots$ \\
\hline & June $25-26,1909 \ldots \ldots$ & .69 & +14 & +1 & S. & $+t$ & 22.3 & 123 & 1 & $\ldots$ & $\ldots .$. \\
\hline & Oct. $25-26,1909 \ldots \ldots$ & .69 & +17 & -10 & S. & $+t+$ & 21.5 & 89 & $\ldots$ & 15 & -55 \\
\hline & Oct. $28-29,1909 \ldots \ldots$ & .66 & +15 & -8 & S. & $+t+$ & 19.6 & 134 & 65 & 65 & -40 \\
\hline & Oct. $29-30,1909 \ldots \ldots$ & .68 & +8 & -8 & S. & $+t+$ & 19.4 & 107 & 65 & 125 & +25 \\
\hline & Oct. 31-Nov. 1, 1909 . & .69 & +7 & -8 & $\mathrm{~S}$. & $+t+$ & 16.3 & 93 & 65 & $\ldots \ldots$ & $\ldots$ \\
\hline 441 & Oct. $\quad 9-10,1911 \ldots \ldots$ & .68 & +6 & -31 & S. & $+t+$ & 11.1 & 54 & 15 & $\ldots$ & -50 \\
\hline \multirow[t]{2}{*}{549} & Nov. $5-6.1912 \ldots \ldots$ & .69 & +30 & -14 & S. & $+t+$ & 16.6 & 185 & 100 & 85 & -50 \\
\hline & Nov. $12-13,1912 \ldots \ldots$ & .69 & +16 & -17 & S. & $+t+$ & 7.9 & 92 & 10 & 165 & -10 \\
\hline \multirow[t]{2}{*}{591} & Apr. $14-15,1913 \ldots \ldots$ & .65 & +15 & -21 & S. & $t+t$ & 6.8 & 77 & 170 & 50 & +5 \\
\hline & Apr. $15-16,1913 \ldots \ldots$ & .69 & +10 & -20 & S. & $+t+$ & 6.7 & 48 & 50 & $\ldots \ldots$ & $\ldots \ldots$ \\
\hline 740 & Apr. $15-16,1915 \ldots \ldots$ & .69 & +1 & -13 & S. & $+t+$ & 14.6 & $\ldots \ldots$ & $\ldots \ldots$ & 15 & -25 \\
\hline 773 & Oct. $10-11,1914 \ldots \ldots$ & .69 & (1) & -22 & S. & $+t+$ & 8.6 & 52 & 25 & 160 & +65 \\
\hline \multirow[t]{2}{*}{786} & Nov. $9-10,1914 \ldots \ldots$ & .66 & -1 & -25 & Mo. & + & $\ldots \ldots$ & 0 & 0 & 0 & \\
\hline & Nov. $12-13,1914 \ldots \ldots$ & .68 & -10 & -25 & Mo. & + & 7.8 & 0 & 15 & 60 & +60 \\
\hline 806 & Dec. $22-23,1914 \ldots \ldots$ & .68 & -1 & -14 & S. & $+t$ & 8.4 & 0 & 10 & 70 & +65 \\
\hline
\end{tabular}

1 The variation from normal metabolism on this date for the girl diabetic, Case No. 773, as obtained by comparison with the Girl Scout values, was +64 p. ct.

and allowed a very liberal diet of protein and fat, though for the day immediately preceding the experiment the carbohydrate had been reduced to 15 grams and fat to 69 grams. Case No. 786 was given alcohol freely upon admission to the hospital, but was otherwise upon a low diet for the intervening five days preceding the experiment. This was the patient with whom Bloor found 13.1 per cent total lipoids in the blood plasma some months later, on June 15, 1916. Case No. 806 showed 7.8 per cent sugar in the urine 5 days before the experiment, but the diet was radically curtailed in the intervening days. These low quotients, therefore, would appear to be the result primarily of overfeeding diabetics who were severe in type, but had not yet lost much weight.

Respiratory quotients 0.70 or below were obtained in 37 observations after food, irrespective of the kind of food taken; in 24 of these, the quotient was 0.69 or below. The data are collected in table 76 . Even among the 37 experiments with the low quotients, there were 9 in which individual periods of 
the experiment showed quotients higher than 0.71 . Like the low quotients obtained with the patient in the post-absorptive state, all of these, save with one patient, occurred before January, 1915. The acidosis was severe or mod-

TABLE 76.-Low respiratory quotients (0.70 and below), following the ingestion of food in experiments with diabetics.

[All cases severe. Data indicated by asterisks (*) are averages from experimental periods which include respiratory quotients higher than 0.71.$]$

\begin{tabular}{|c|c|c|c|c|c|c|c|c|}
\hline \multirow{2}{*}{$\begin{array}{l}\text { Case } \\
\text { No. }\end{array}$} & \multirow{2}{*}{ Date. } & \multirow{2}{*}{$\begin{array}{l}\text { Body- } \\
\text { weight, } \\
\text { naked. }\end{array}$} & \multicolumn{2}{|c|}{$\begin{array}{l}\text { Respiratory } \\
\text { quotient. }\end{array}$} & \multicolumn{3}{|c|}{$\begin{array}{l}\text { Meal preceding } \\
\text { experiment. }\end{array}$} & \multirow{2}{*}{$\begin{array}{l}\text { Acido- } \\
\text { sis. }\end{array}$} \\
\hline & & & Basal. & $\begin{array}{l}\text { After } \\
\text { food. }\end{array}$ & C. & P. & F. & \\
\hline 194 & Sept. 23-24,1910..... & $\begin{array}{l}k g . \\
52.3\end{array}$ & 0.71 & 0.70 & $\begin{array}{l}g m . \\
40\end{array}$ & $g m$. & gm. & $+t+$ \\
\hline \multirow{2}{*}{246} & Aug. $9-10,1909 \ldots \ldots$ & 61.0 & .71 & $\begin{array}{l}.70 \\
.67\end{array}$ & $\begin{array}{l}40 \\
40\end{array}$ & $\begin{array}{l}16 \\
10\end{array}$ & $\begin{array}{r}66 \\
4\end{array}$ & $+十$ \\
\hline & Oct. $29-30,1909 \ldots \ldots$ & 56.1 & 2.68 & $.70 *$ & 60 & 15 & 6 & $++t$ \\
\hline \multirow[t]{3}{*}{332} & Mar. 31-Apr. 1, 1911.. & 39.9 & .71 & $.69 *$ & Levul & ose 100 & gms. & $+t+$ \\
\hline & June $2-3,1911 \ldots \ldots$ & 36.8 & .71 & $.69 *$ & 50 & 10 & 60 & $+t+$ \\
\hline & June $3-4,1911 \ldots \ldots$ & 35.8 & .71 & .68 & 0 & 40 & 25 & $+t$ \\
\hline \multirow[t]{2}{*}{344} & Aug. $15-16,1911 \ldots \ldots$ & 58.2 & $\ldots \ldots$ & .67 & Mixed & break & fast. & -+ \\
\hline & Sept. $15-16,1911 \ldots \ldots$ & 57.2 & $\ldots \ldots$ & .67 & 82 & 28 & 182 & + \\
\hline \multirow[t]{2}{*}{373} & Nov. $10-11,1908 . \ldots \ldots$ & 58.6 & .72 & $.70 *$ & 0 & 88 & 55 & \\
\hline & Nov. $17-18,1908 \ldots \ldots$ & 59.3 & .75 & .70 & 0 & 110 & 70 & \\
\hline 430 & Sept. 14-15,1914..... & 54.1 & .75 & .69 & 30 & 20 & 27 & \\
\hline \multirow[t]{7}{*}{441} & Sept. $29-30,1911 \ldots .$. & 39.7 & .70 & .70 & 57 & 17 & 94 & \\
\hline & Oct. $\quad 9-10,1911 \ldots \ldots$ & 40.0 & .68 & $.70 *$ & 32 & 9 & 50 & $+t+$ \\
\hline & & & & .67 & 15 & 5 & 15 & \\
\hline & & & & $.69 *$ & 83 & 24 & 123 & \\
\hline & Oct. $10-11,1911 \ldots \ldots$ & 38.7 & .68 & .68 & 5 & 49 & 43 & +++ \\
\hline & Oct. $16-17,1911 \ldots \ldots$ & 39.1 & .71 & .68 & 0 & 80 & 57 & -+ \\
\hline & Oct. $25-26,1911 \ldots \ldots$ & 39.1 & .71 & $.68 *$ & 5 & 80 & 67 & $+t+$ \\
\hline \multirow[t]{10}{*}{591} & Apr. $10-11,1913 \ldots \ldots$ & 47.2 & .74 & .70 & 40 & 50 & 110 & $+t$ \\
\hline & Apr. $12-13,1913 \ldots \ldots$ & 47.6 & .70 & .67 & 35 & 10 & 55 & $+t$ \\
\hline & & & & .65 & 35 & 10 & 55 & \\
\hline & & & & .67 & 35 & 10 & 55 & \\
\hline & & & & .58 & 35 & 10 & 55 & \\
\hline & Apr. 13-14,1913.. & 47.2 & .73 & .70 & 40 & 12 & 65 & $+t+$ \\
\hline & & & & .67 & 40 & 12 & 65 & \\
\hline & & & & .66 & 40 & 12 & 65 & \\
\hline & & & & .62 & 40 & 12 & 65 & \\
\hline & Apr. 14-15,1913..... & 47.2 & .65 & .62 & 50 & 35 & 50 & $++t$ \\
\hline 746 & Oct. $\quad 9-10,1914 \ldots \ldots$ & 57.0 & .73 & .70 & 40 & 10 & 22 & ++ \\
\hline \multirow[t]{2}{*}{773} & Oct. $8-9,1914 \ldots \ldots$ & 39.8 & .69 & .69 & 25 & 8 & 17 & $+t+$ \\
\hline & Oct. $19-20,1914 \ldots \ldots$ & 39.2 & .70 & .70 & 85 & 25 & 45 & +++ \\
\hline \multirow[t]{2}{*}{806} & Dec. $21-22,1914, \ldots \ldots$ & 61.9 & .71 & .70 & 10 & 10 & 10 & ++ \\
\hline & Dec. $22-23,1914, \ldots \ldots$ & 61.8 & .68 & .69 & 60 & 10 & 0 & ++ \\
\hline \multirow[t]{3}{*}{1070} & Oct. $2-3,1917 \ldots \ldots$ & 45.7 & .71 & $.68 *$ & 17 & 5 & 0 & +++ \\
\hline & Oct. $3-4,1917 \ldots \ldots$ & 45.7 & .71 & $.70 *$ & 17 & 5 & 0 & $+t+$ \\
\hline & Oct. $\quad 4-5,1917 \ldots \ldots$ & 45.7 & .71 & .67 & 17 & 5 & 0 & $t+t$ \\
\hline
\end{tabular}

1 The complete record of all food taken in connection with the experiments is recorded in the protocols. Table 123 also shows, for multiple feedings on the same day in the series with Cases Nos. 194, 441, and 591, the total food ingested for the day up to the time of each individual experiment.

${ }^{2}$ Not obtained on the same apparatus as that used for the food experiment on this day; hence the experiment does not appear as basal in other comparisons with food experiments. 
TABLE 77.-Post-absorptive metabolism in respiration experiments with diabetic patient, Case No. 707 (Male).

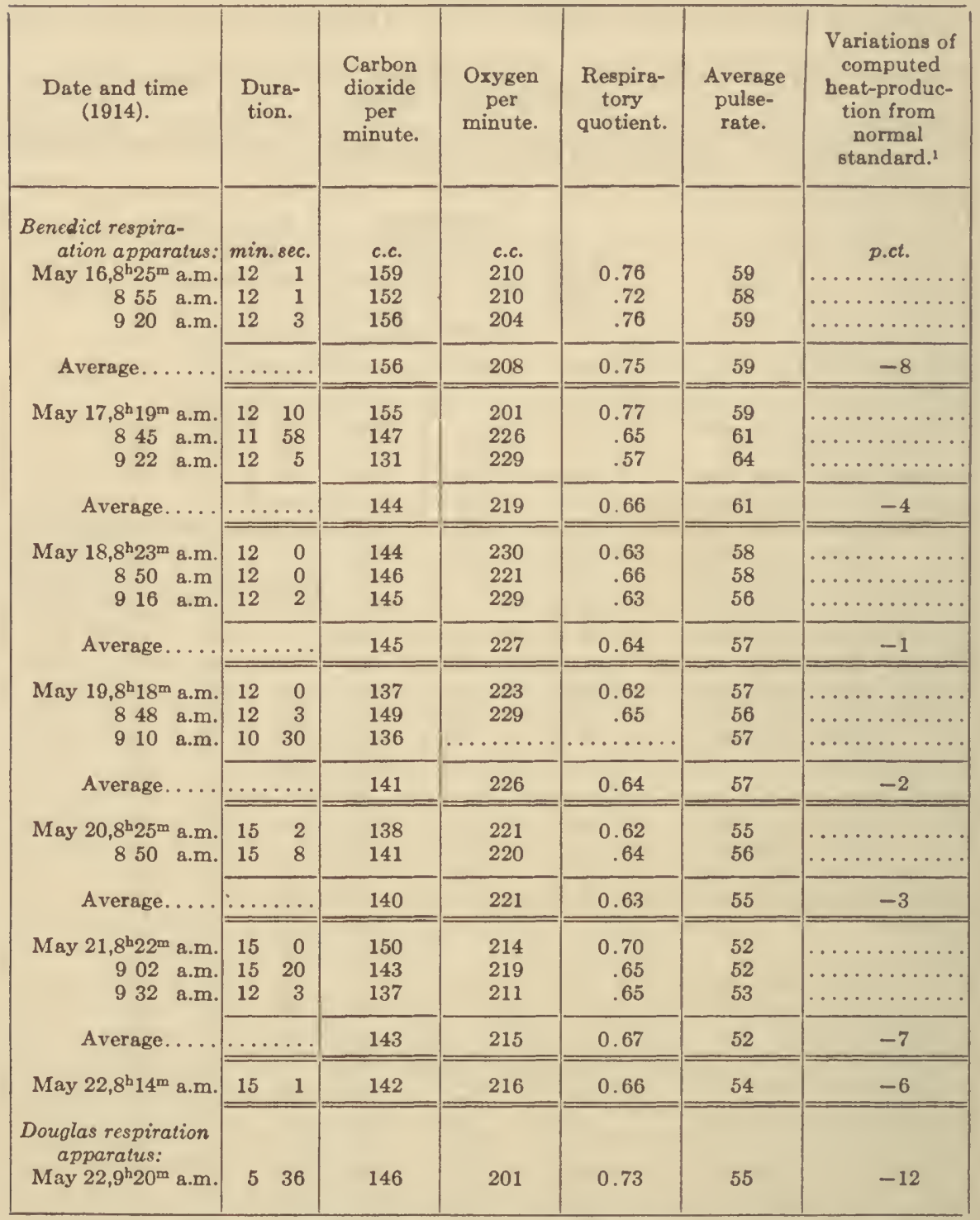

1 In the computation of heat-production from the gaseous exchange, the calorific value of oxygen for a respiratory quotient of 0.70 has been used for all lower quotients.

erate, except that in a single experiment with one case it was mild. All cases were severe in type. The meals which preceded the tests in this early period were often not so accurately recorded as is the custom to-day, yet they are sufficiently well known to show their distinctive quality, i. e., a predominance in fat with high caloric content. It is evident from table 76 that the low quotients obtained in this Laboratory, like those secured by other observers, 
have almost without exception been found with patients who have ingested many calories, much fat, and occasionally alcohol.

With one patient, Case No. 707, so many low quotients were obtained that they were originally rejected and do not appear in the protocols. These are given in detail in table 77, together with correlated data. There is doubt as to whether the quotients for the first two days of experimentation with this individual must be excluded, but there is no evidence at hand which justifies the exclusion of those obtained in the last five days, save one experiment with the Douglas bag which gave a quotient of 0.73 . When this latter apparatus was employed, the patient complained of difficulty in inhaling. The data for the carbon-dioxide output and the oxygen consumption are given both for the individual experimental periods and as daily averages. A comparison of the values for the carbon dioxide obtained with the respiration apparatus on May 18 to 22 with that found with the Douglas bag on May 22 gives confidence in the reliability of the records. The values found for the oxygen consumption with the respiration apparatus both by days and by periods are measurably consistent with one another. Their exclusion is not justified by a lower result with a single experiment with the Douglas bag which led the patient to complain of difficulty in its use, as recorded on the protocol.

In addition to errors arising in the technique of experimentation, one must also remember that marked changes in the respiratory quotient may take place when subjects fall asleep, and that these may even result in a lowering of the quotient amounting to from 0.05 to 0.07 . Carpenter ${ }^{a}$ observed that this was usually accompanied by similar, parallel changes in the pulse-rate. With Case No. 707, however, the pulse-rate gives no indication of his having fallen asleep. If drowsiness or sleep were a factor in his experiments, one would not have expected it to be present to exactly the same extent on each day and during each individual period. Furthermore, it can not be adduced against the experiment that the patient was very ill and therefore near coma, because with Case No. 1412, who was in the beginning stages of coma, quotients as low as this were not obtained. Indeed, as a matter of fact, patients in beginning diabetic coma are usually restless, rather than as the term implies, quiet.

Low quotients, and, to a certain extent, it can be said of dextrose-nitrogen ratios of $3.65: 1.00$, are forced quotients and forced ratios. They are not inherent in the ordinary metabolism of diabetes. The undisturbed diabetic has no such quotients. They are analogous to the condition produced by an overdose of digitalis in an individual with a moderately decompensated heart. When administered in moderate doses, digitalis, like fat and protein, does good, but in excessive doses auricular fibrillation results on the one hand, low quotients and dextrose-nitrogen ratios of $3.65: 1.00$ on the other, and the patients are brought to the verge of death. Low respiratory quotients, and dextrosenitrogen ratios of $3.65: 1.00$ are evidence of poor medical treatment. In the past these were frequently obtained through ignorance, but their occurrence to-day demands explanation. From the data recorded above it is hoped that it has been demonstrated that low quotients exist only by accident

- Carpenter, Am. Journ. Physiol., 1922, 59, Proc. Am. Physiol. Soc., p. 440. 
or design and that the diabetic will no longer be blamed for their occurrence. For long the writer has believed that it was cowardly to consider any case of diabetes hopeless, and in the explanation of these low quotients there is support for this opinion. ${ }^{a}$

\section{HIGH RESPIRATORY QUOTIENTS IN DIABETES.}

High respiratory quotients, when obtained with mild or moderate cases of diabetes, are readily explained by the combustion of carbohydrate in the diet and by the combustion of carbohydrate previously stored in the body. On the other hand, the explanation of high respiratory quotients found in observations with cases of severe diabetes is by no means simple, since carbohydrate as such is not available for combustion, either from the diet or from the body. Some evidence exists to show that the high respiratory quotients appear when the body is compelled to draw upon protein owing to a lack of available fat, and there is also some evidence which will be presented in the discussion of the experiments which followed the ingestion of levulose that there is a transformation of carbohydrate into fat which would also sufficiently explain this unlooked-for phenomenon. (See tables 98 and 105, pp. 218 and 234.) Examination of the case histories of the severe type of patients whose experiments gave these high quotients shows that they were most often obtained when the individuals were in extremis and without acidosis. This precludes the explanation of the high respiratory quotients on the theory of oxidation of acid bodies which have high quotients, because, though this explanation would hold for a few days when the patient was becoming free from acidosis, it would hardly explain the phenomenon for long periods when there is no evidence that acidosis exists.

The Russell Sage Laboratory not only obtained their lowest respiratory quotients with Cyril K., but also their highest respiratory quotients. This high quotient was in a period of convalescence and so is hardly to be classed with the other high quotients discussed in this section. On February 10 it reached 0.97 , on February $16,0.915$, and on March $9,0.860 .^{b}$

The explanation of the lack of higher quotients for the case reported by Wilder, Boothby, and Beeler ${ }^{c}$ is found in the fact that no observations of the gaseous metabolism were made after the two periods of fasting of two days each, or after the continuation of diets which had been demonstrated as most advantageous to the patient. Even before the end of these diet periods (May 5 to 14 and June 3 to 12) the records of the observers show a distinct rise in the quotient to 0.72 and 0.73 , respectively.

Respiratory quotients of 0.84 or over may be considered as unusual with severe cases of diabetes in the post-absorptive state. It has already been noted that, exclusive of the 6 girl diabeties, the average respiratory quotient

\footnotetext{
a Lusk (Science of Nutrition, Philadelphia, 3d ed., 1917, p. 479) writes: "Joslin has for a long time privately informed the writer that he would not place a patient upon a diet consisting of protein and fat alone on account of the deleterious effects which might be produced, and he has stated in personal conversation that fatal results might ensue if the diet were long continued. The experiment on C. K., as well as one unpublished experiment not here described, shows most clearly that Joslin is correct as regards the evil effect of even a moderately high protein intake upon the diabetic patient."

${ }^{6}$ Gephart, Aub, Du Bois, and Lusk, Arch. Intern. Med., 1917, 19, p. 908.

cWilder, Boothby, and Beeler, Journ. Biol. Chem., 1922, 51, p. 311.
} 
of the 29 cases studied in 122 observations before June, 1914, was 0.73 , and the average respiratory quotient of the 76 cases in 292 observations after June, 1914, was 0.77 . The same averages were found for the severe cases alone. (See tables 72 and 73.) The average post-absorptive respiratory quotient obtained in 441 experiments upon 110 of the 113 diabetics studied at this Laboratory between 1908 and 1917, including the girl diabetics, was likewise 0.77 .

Among these 441 observations there were 49 experiments in which the respiratory quotient was 0.84 or over. These are grouped in table 78 according to the standard used in computing the normal metabolism, and the degree of severity of the diabetes. Although 14 high quotients obtained with cases of moderate or mild diabetes are included in table 78, they need not be discussed here, for they can not be considered as extraordinary, inasmuch as the amount of carbohydrate in the diet was more nearly normal and the patients were able to oxidize much of it. Of the other high quotients, 22 were obtained with severe cases of diabetes for whom the Harris and Benedict standard was used and 13 with 2 severe cases among the girl diabetics for whom the Girl Scout values were employed for comparison.

Table 78 is arranged to show the date of the experiment, the average respiratory quotient and pulse-rate, the variation of the metabolism from standard, the body-weight (naked), the percentage loss from maximum weight at the time of observation, the percentage variation from the normal weight for the given sex, age, and height, the degree of acidosis if present, the nitrogen per kilogram of body-weight in the urine, the calories per kilogram in the diet for seven to ten days preceding the observation, the carbohydrate balance for the preceding day, and the date of death.

There was but one patient among the severe cases (Case No. 1011) with a respiratory quotient as high as 0.94 . The metabolism at the time of this observation was -37 per cent, and a study of the protocols in Appendix I shows that this value was well supported by other data obtained with this individual. She was at the time in a state of extreme inanition, with a bodyweight 49 per cent below normal, and was, moreover, free from acidosis. A feature possibly contributing to the explanation of this high quotient and low metabolism was her high nitrogen excretion at this time which, on the day preceding the observation, amounted to 0.285 gram of urinary nitrogen per kilogram of body-weight. Three and four days after the experiment the excretion per kilogram of body-weight was 0.410 and 0.515 gram, respectively, with the protein in the diet during the six days between November 22 and 27 varying from 0 to 51 grams per day, or, on the average, 1.1 grams per kilogram of body-weight. The average respiratory quotient for the first group of 10 severe cases in 22 observations was 0.86 , and for all of the severe cases in table 78, including the girl diabetics, it was likewise 0.86 . How unusual these quotients are is shown by noting the dates of the experimental observations, there being but three of these quotients which were obtained before June, 1914. In fact, these 35 high quotients with severe cases represent but a little over 10 per cent of the 316 average respiratory quotients obtained with the 67 severe cases for whom post-absorptive quotients were secured. The average of the quotients of this selected group of observations with severe 


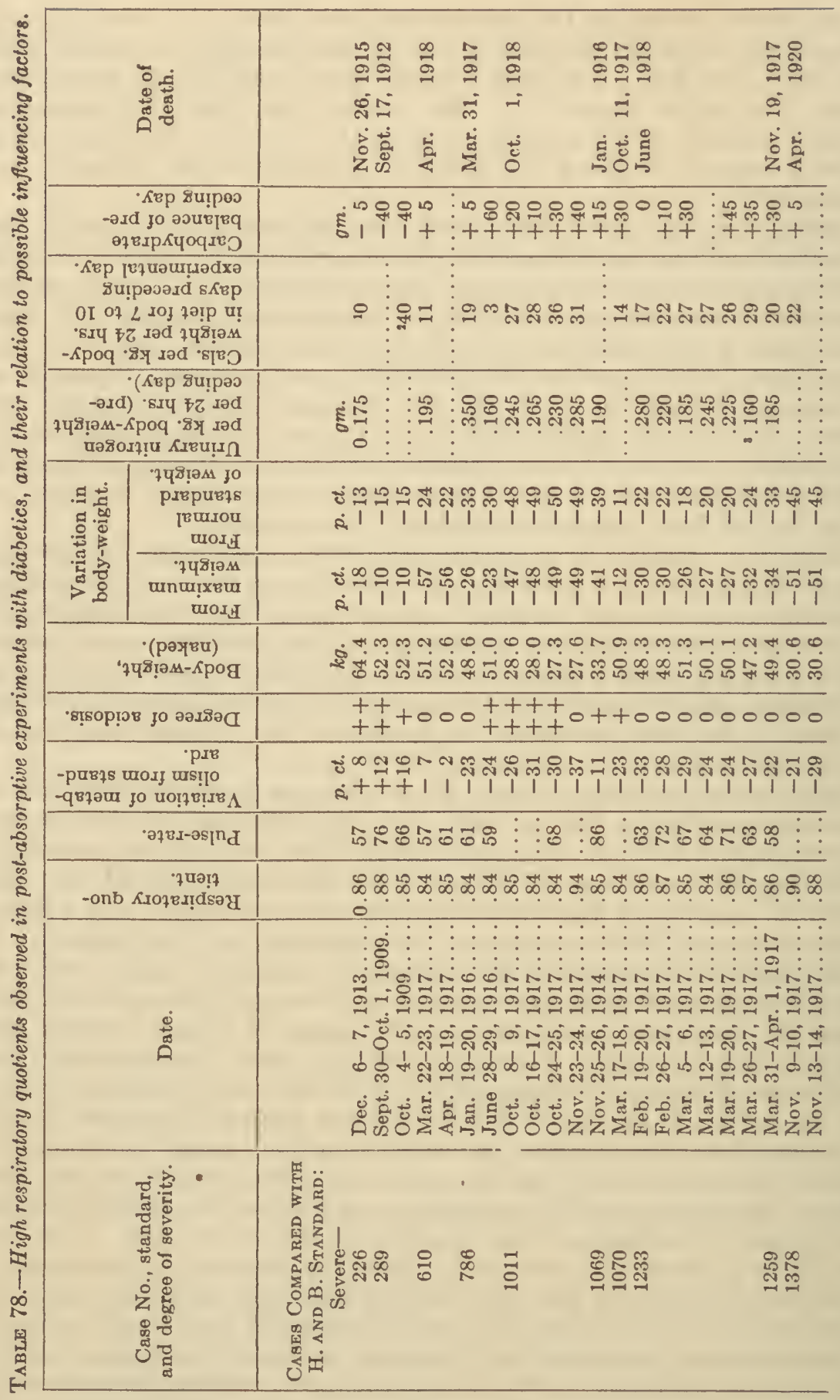




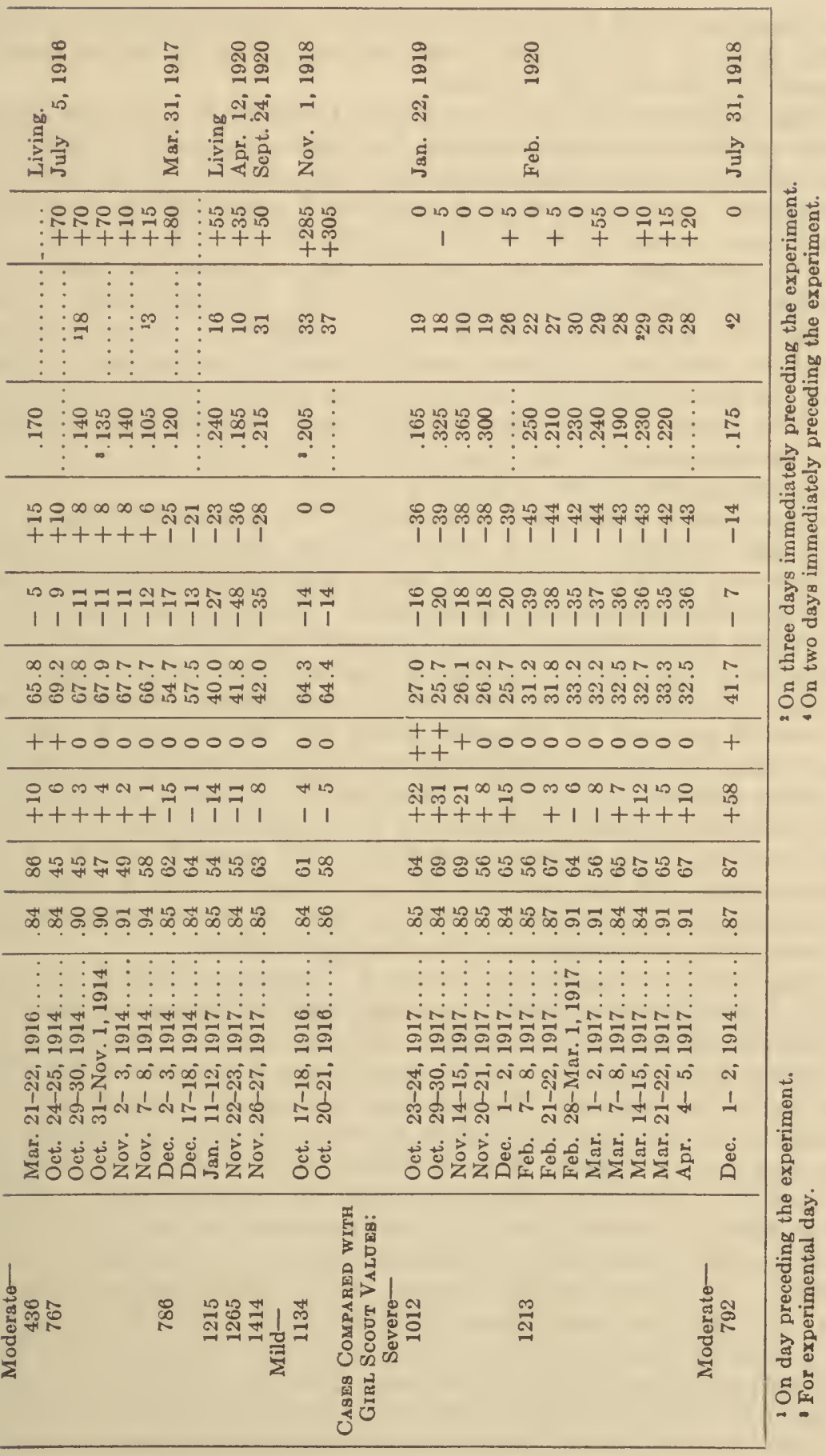


cases of diabetes is 0.86 , in contrast to 0.78 , the average quotient of all the moderate cases, or of 0.76 , the average quotient of all the severe cases in this research. (See table 80, p. 188.)

The high quotients in the three experiments before June, 1914, were accompanied by a metabolism above standard, but those obtained after June, 1914, for the remaining 19 experiments with the adult group of severe cases were accompanied in most instances by an extremely low metabolism, the average variation from standard in these 19 experiments being -24 per cent. The two girl diabetics, Cases Nos. 1012 and 1213, had an average respiratory quotient in the 13 experiments in this table of 0.87 . The metabolism as compared with that of the Girl Scouts averaged +9 per cent. Elsewhere attention has been called to the different results obtained by comparing the metabolism of the girl diabetics with the Harris and Benedict standard and with the $\mathrm{Du}$ Bois standard. With these two standards, the average variations for the 13 observations with Cases Nos. 1012 and 1213 would be -39 and -40 per cent, respectively. (See table 43, p. 92.)

A marked loss of weight also characterized the cases represented in this group of high quotients. This is evidenced by the percentage loss of weight from the known maximum weight for each individual, and also by the computed percentage below the normal standard. Whereas the average greatest loss of weight from maximum during the experimental period for all of the diabetics was 25 per cent, the average loss of weight from maximum of the severe cases in table 78, as shown by the experimental records for these dates, was 33 per cent for the adult group and 28 per cent for the girl diabetics, thus indicating the degree of emaciation, unusual even for diabetics, which these patients had reached. That this loss of weight actually represented emaciation is better evidenced by the percentage variation from the normal standard. The diabetics included in this research had an average minimum weight of 18 per cent below the normal standard, but the adult severe cases with high quotients in table 78 were 29 per cent below standard and the severe cases of the girl diabetics were 41 per cent below standard.

The body-weight of the fasting subject L., previously referred to at the end of 31 days of fasting was also 29 per cent below the normal standard, with a loss from initial weight of 22 per cent. His underweight, therefore, was as great as that of the diabetics. Yet L.'s respiratory quotients rose but a trifle toward the end of the fast. He differs in this respect from the diabetics, as he also does in not showing a marked increase in nitrogen metabolism during the final days of his fast. Was the remaining fat of this man more available for oxidation than that of the diabetics with similar losses in weight? Likewise, with the students studied in the undernutrition research in Springfield, ${ }^{b}$ there was no rise in the respiratory quotient as the undernutrition progressed. Their loss in weight, however, was on the average approximately 10 per cent. In this connection one might also refer to table 56, page 121 , in which it is shown that after June, 1914, progressive lowering of the bodyweight was accompanied by a progressive lowering of metabolism and a progressive rise of the respiratory quotient and excretion of urinary nitrogen. From table 53 (p. 117) it may be seen that the quantity of nitrogen in the urine

- Benedict, Carnegie Inst. Wash. Pub. No. 203, 1915, p. 69.

Benedict, Miles, Roth, and Smith, Carnegie Inst. Wash. Pub. No. 280, 1919. 
upon the day preceding the experiments and upon the experimental day as well was comparatively large. The average quantity of nitrogen in the urine for all the diabetics after June, 1914, for both days was 0.175 gram per kilogram of body-weight, but in this series of experiments with high quotients, the nitrogen in the urine was notably in excess, especially for the severe cases.

The urinary nitrogen per kilogram of body-weight of the adult severe cases excreted for the 24 hours preceding the observation of the metabolism varied between 0.160 and 0.350 gram, and averaged 0.225 gram. For 13 of the observations the excretion was 0.185 gram or above and 3 were below this level, thus indicating the high nitrogenous excretion, particularly for individuals upon a known low diet. These high nitrogen figures are significant, because the protein katabolized from exogenous sources was not sufficient to account for the nitrogen excreted. With the moderate and mild cases the condition was reversed, since but 4 of 10 observations showed an excretion of urinary nitrogen 0.185 gram or over per kilogram of body-weight.

With the girl diabetics whose metabolism was compared with that of the Girl Scouts, the nitrogen excretion was almost invariably high; in fact, there were but 3 , one of which was with a mild case, out of the 12 analyses in which the nitrogen excretion was below 0.210 gram per kilogram of body-weight; with 3 analyses it was 0.300 gram or above.

The difference in protein katabolized as represented by the excretion of 0.175 gram nitrogen per kilogram of body-weight, and 0.225 gram would represent an increase of but 18 grams of protein (10 grams of carbohydrate) for an individual of 60 kilograms. The oxidation of this amount of carbohydrate could not change a quotient of 0.77 to 0.86 .

Acidosis was absent in a majority of the experiments, but in 8 of the observations with the severe cases it was present to a moderate degree and in 4 to a slight degree. In fact, one would not expect the presence of severe acidosis with respiratory quotients as high as these, for as pointed out later, when the respiratory quotients reached 0.80 , severe acidosis almost invariably disappeared, and even mild and moderate acidosis persisted in only a few experiments beyond 0.83 . (See table 82.)

The energy in the diet preceding the observations was low. With only 3 of the 18 observations with adult severe cases for which the data regarding the preceding diet are available did the energy exceed 30 calories per kilogram of body-weight during a period of several days before the experimental day. With one of the girl diabetics (Case No. 1012) the energy in the diet was comparatively low and the nitrogen excretion high. With the other girl diabetic (Case No. 1213) reverse conditions may be noted, i. e., a nearly normal number of calories in the diet and a high but relatively lower nitrogen excretion. The loss of weight and the condition of these cases, however, is not so much to be attributed to the diet at this particular period as to the prolonged low diets or unselected diets during earlier stages of the disease.

The carbohydrate balances for the preceding day were positive, as a rule, but with the adult severe cases and the girl diabetics no instance occurred in which the positive balance exceeded 60 grams and it usually was but half this amount. These meager balances rule out the possibility of explaining the high quotients by the carbohydrate intake. 
As may be seen from the date of death in the last column, all of the twelve severe cases succumbed within three years of the time of observation and seven within 18 months. The seriousness of their condition when the tests were made is therefore evident.

Regrettably few observations were made of the non-protein nitrogen in the blood and they are therefore omitted from table 78, but the few values obtained indicate an excess.' As there was no reason for nitrogen retention, evidence favors the theory that excessive protein katabolism was going on, and that the nitrogenous portion of the molecule was being retained instead of excreted. It is, therefore, inconceivable that these high quotients should long continue if due to protein metabolism, because these would result in an excessive retention of non-protein nitrogen and an excessive destruction of body protein resulting in early death from toxemia and inanition. If death did not occur it would mean that the respiratory quotient had fallen and the patient was taking a diet with fat which in such severe diabetes would eventually end in death from coma. Clinically the above reasoning is borne out by the subsequent histories of these patients. Therefore, it should not be considered that a low quotient alone is of grave significance in diabetes, for an extremely high quotient may be equally hazardous for the patient. Again the rule holds that extremes are always dangerous.

TABLE 79.-Relation of extremely low metabolism in post-absorptive experiments with diabetics to influencing factors and the respiratory quotient. (All cases severe.)

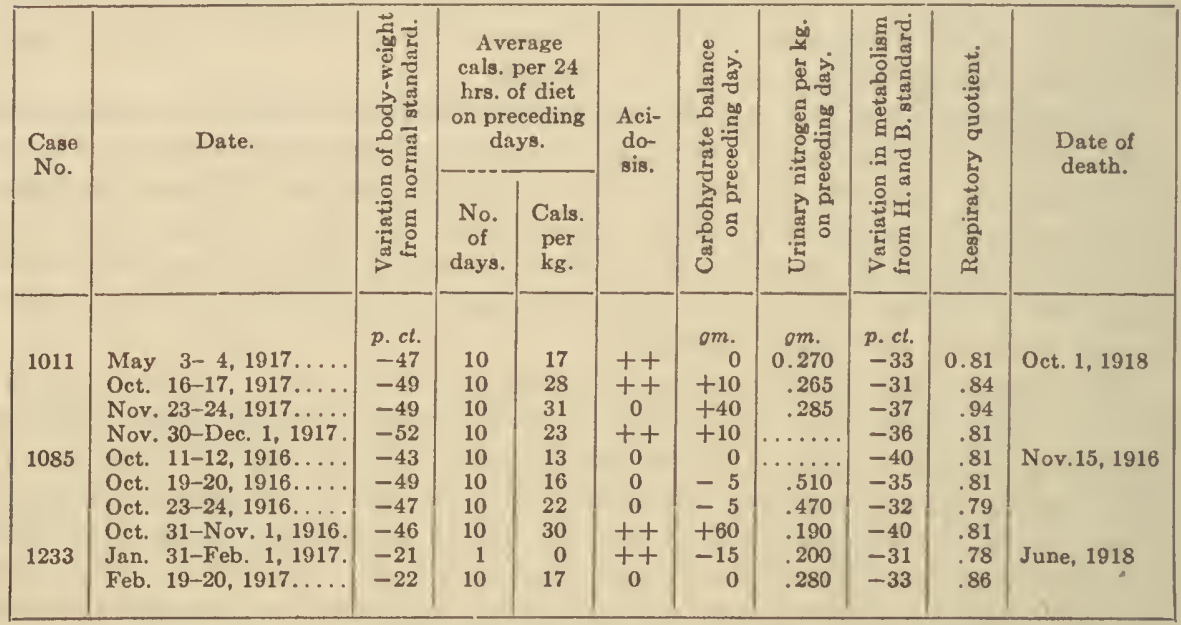

The likewise meager number of values obtained for blood fat show that an excessive quantity was present in the circulating blood. The meaning of this is not clear. It is true that unusual quantities of fat have been reported in the blood of fasting individuals, and perhaps these large amounts signify no more than this. On the other hand, the body fat is constantly being drawn upon for body needs. Under such circumstances the passage of fat from the tissues into the blood is constantly taking place and not intermittently as after a meal, and yet such high values for blood fat do not occur as were here found. This explanation is, therefore, hardly satisfactory. Neither 
is the evidence satisfactory that the sugar in the blood of these patients is being transformed into fat. The data, however, so far as they go, supply some support to this latter idea, for while the blood fat is high, the blood sugar for this type of case is comparatively low. There is just enough hint of these two possibilities, namely, the oxidation of the carbohydrate portion of the protein molecule with the retention of the nitrogenous portion and the conversion of carbohydrate into fat, to warrant seriously pursuing the study of other cases along these lines.

The subject of high quotients is considered in a somewhat different manner in table 79. Since the high respiratory quotients were so frequently found after the change in treatment to undernutrition, a group of post-absorptive observations upon three cases is given in which the metabolism had reached the unusually low level of 31 per cent or more below standard, together with the corresponding respiratory quotients, the acidosis, the daily caloric value of the diet for the ten days preceding the experiments, and the carbohydrate balance and the urinary nitrogen per kilogram of body-weight for the immediately preceding day.

These cases correspond to the series of patients with high quotients in table 78 already discussed in presenting extreme losses of weight, and the table further indicates that this loss of weight was probably brought about by a low caloric intake, for the energy in the daily diet for the 10 days preceding the experiments was on the average 20 calories per kilogram of bodyweight. The urinary nitrogen per kilogram of body-weight for the preceding day, as elsewhere pointed out, was unusually high, averaging 0.309 gram for the 3 cases in table 79, and for the adult severe cases in table 78 with the particularly high quotients, 0.225 gram.

Data regarding the non-protein nitrogen in the blood are lacking for many of the observations in table 79 , but it is significant that of six values obtained, one-half were far above the normal range of 20 to $40 \mathrm{mg}$. per $100 \mathrm{c}$. c. of blood. All of these high values, namely, $110,95,53$, and $120 \mathrm{mg}$., were obtained between February 19 and 26 with Case No. 1233, and one must therefore look to the protocols for this patient to determine whether there were any indications of diseased kidneys. The urine of this patient was, it is true, free from albumin, but the phenolphthalein excretion on eight occasions (February 21 to March 23) varied from a trace to 24 per cent in 2 hours. A 2-hour renal test on March 25 gave a range of specific gravities from 1010 to 1025 . On February 15 the non-protein nitrogen was $53 \mathrm{mg}$. per $100 \mathrm{c}$. c. and five observations between March 5 and 26 were between 26 and 28 milligrams per 100 c. c. This patient, therefore, had inefficient kidneys at the time the high non-protein nitrogen was obtained.

The carbohydrate balances for the 24 hours immediately preceding the observations are included in the table. In but three instances did they vary more than 10 grams from zero. Case No. 1011 showed a positive balance of +40 grams during a period in which she was taking a high carbohydrate and low fat diet. Case No. 1085 showed a positive carbohydrate balance of +60 grams on November 1,1916 , due to a levulose test on the preceding day. It is desirable here to point out that even if considerable carbohydrate is taken by a normal individual on a preceding evening the respiratory quotient the next morning will be less affected than is shown by these respiratory quotients. 
Benedict, Emmes, and Riche ${ }^{a}$ studied the influence of the preceding diet on the respiratory quotient after active digestion had ceased. They found that 7 healthy individuals after meals containing approximately $300 \mathrm{grams}$ of carbohydrate, and at times even 400 or 500 grams, which were taken the evening preceding the observation, showed an average respiratory quotient the following morning of 0.88 , with a range from 0.86 to 0.90 . With diets low in carbohydrates, the average respiratory quotient was 0.81 , with a range from 0.76 to 0.83 . The diabetics showed quotients above this latter average figure, notwithstanding the fact that their storage of glycogen was low if our conceptions of glycogen storage in diabetes have been correct. Furthermore, evidence is present in table 79 that the carbohydrate balance of the preceding day was not of significance in the case of the diabetics, because frequently as high quotients were obtained when the carbohydrate balances were extremely low or even minus as, for instance, when they amounted to 10 or even 60 grams.

The blood fat for these three cases was above normal. With Case No. 1011 it was 1.01 and 1.16 per cent on November 23 and November 30 ; with Case No. 1085 it was 2.94 and 2.74 per cent on October 30 and 31, respectively; with Case No. 1283 it was 3.62 and 1.51 per cent on January 30 and February 19. Inanition is known ${ }^{b}$ to be accompanied in the early stages by an increase in the percentage of fat in the blood. Bloor ${ }^{e}$ writes:

"In fasting it (the lipoid level) may or may not be disturbed, depending apparently on the nutritional condition of the subject, or rather perhaps on the availability of the stored fat, since it is apparently the case that fat may be more or less loosely stored, with the result that the stimulus of hunger may produce an excessive or merely adequate outflow depending on the nature of the storage. It is significant that the increases in blood lipoids in fasting take place only in the first days, and after that the lipoid content remains constant or slowly diminishes till the death of the animal."

Is the increase in the percentage of fat here simply an expression of that state?

The blood-sugar percentages varied between 0.13 per cent and 0.35 per cent. Case No. 1011 showed 0.13 per cent on May 3, 0.30 and 0.29 per cent on November 23 and 30, respectively, Case No. 1085, 0.26, 0.29, and 0.35 per cent on October 19,23, and 31, respectively, and Case No. 1233, 0.29 and 0.13 per cent on January 31 and February 19, respectively. In general, these percentages are higher than for the larger group of cases with low metabolism. They do not at all approximate the low percentages preceding death from inanition elsewhere mentioned. (See p. 116.)

A mild case of diabetes may have a high respiratory quotient without any loss of body-weight. A severe case of diabetes can have a high respiratory quotient only when the loss of weight is marked, but an extremely severe case of diabetes presents a high respiratory quotient only when the loss of weight is extraordinary, and even then the respiratory quotiont will not rise quite so high as that of the other groups. A high respiratory quotient in an extremely severe case of diabetes is only attained when the caloric intake is extremely low.

a Benedict, Emmes, and Riche, Am. Journ. Physiol., 1911, 27, p. 383.

b Schulz, Archiv. f. d. ges. Physiol., 1896, 65, p. 299.

' Bloor, Physiol. Reviews, 1922, 2, p. 92. 
Respiratory Quotients with Men of Same Height but of Varying WEIGHT.

To discover whether the amount of body fat influences the respiratory quotient, 19 normal individuals of similar height were selected and grouped according to body-weight, and their respiratory quotients compared. The average age, height, and weight of the 6 heaviest males were 30 years, $179 \mathrm{~cm}$., and $73 \mathrm{~kg}$.; respectively. The average respiratory quotient for the group was 0.83. The average age, height, and weight of the 6 males of the medium group were 29 years, $179 \mathrm{~cm}$., and $67.5 \mathrm{~kg}$., respectively. The average respiratory quotient was 0.86 . The average age, height, and weight of the 7 men in the group of thin men were 32 years, $179 \mathrm{~cm}$., and $58.9 \mathrm{~kg}$., respectively. The average respiratory quotient was 0.84 .

It is evident that a difference in the average weights amounting to as much as $14.1 \mathrm{~kg}$. (24 per cent of the average for the thin group) is without influence upon the respiratory quotient, inasmuch as the average quotient varied only between 0.83 and 0.86 , the higher value being for the medium group. The values for the metabolism of these groups as calculated on the basis of bodyweight, showed 24.7 calories per kilogram per 24 hours for the heavier subjects, 25.3 calories for the medium-weight men, and 25.7 calories for the thin individuals. The differences therefore are not of significance.

\section{Respiratory Quotient in Relation to the Different Types of Severity.}

In the second monograph on metabolism in diabetes ${ }^{a}$ published from this Laboratory, a respiratory quotient of 0.77 was reported for the mild and moderate cases when studied with the respiration calorimeter, and 0.75 and 0.73 , respectively, when the respiration apparatus was used. With the severe cases, the respiratory quotient averaged 0.73 with both apparatus. The difference in quotients with the difference in severity of the diabetes was easily explained, because the patients with severe diabetes, having lost their power to oxidize carbohydrate, were forced to live on fat and protein, and the preponderance of the former would produce a low quotient. To this end, also, the formation of $\beta$-oxybutyric acid contributed, because of its comparative richness in oxygen. The higher quotients obtained with cases of lighter severity were explained by the capacity of these individuals to oxidize more carbohydrate, which their diets undoubtedly contained.

The data in table 80 show the relation of severity of the diabetes to the respiratory quotient in experiments with the diabetics without food both before and after June, 1914. In the earlier period the diabetics of mild and moderate severity had an average respiratory quotient of 0.76 , while those of the severe type had a lower average quotient of 0.73 . On the other hand, with the diabetics after June, 1914, in the three groups of mild, moderate, and severe, the average quotient was the same for all degrees of severity, i. e., 0.78. These figures are significant, because they show the profound difference in the condition of the patients before and after June, 1914. While all three types of severity were observed in both epochs, yet after June, 1914, something took place which prevented the patients of a severe type from having a lower quotient than those of the milder types.

- Benedict and Joslin, Carnegie Inst. Wash. Pub. No. 176, 1912, p. 113. 
An explanation of the difference in the average respiratory quotient of 0.73 for all cases before and 0.78 for all cases after June, 1914, may be the character of the diet, or perhaps, we may better say, the character of the diet and its utilization. Prior to June, 1914, it is probable that not only was less carbohydrate given, but less carbohydrate was utilized than after June, 1914. Conversely, prior to June, 1914, a much greater quantity of fat was given which, like the carbohydrate, was not well utilized, a considerable quantity being excreted as $\beta$-oxybutyric acid. With Case No. 344, 25 to 50 grams or more of $\beta$-oxybutyric acid were excreted almost daily for weeks. ${ }^{a}$ The formation of this acid, therefore, would tend to lower the quotient more than even the fat alone. After June, 1914, the smaller quantity of fat consumed, the lesser quantity of $\beta$-oxybutyric acid formed, and the greater quantity of carbohydrate oxidized, would all tend to raise the quotient. The data in this table, therefore, may be interpreted as showing that it was not so much the severity of the case which influenced the quotient as the relative quantities of carbohydrate and fat ingested and also oxidized by the patients irrespective of severity.

TABLE 80.-The relation of severity to the respiratory quotient in experiments with diabetics without food.

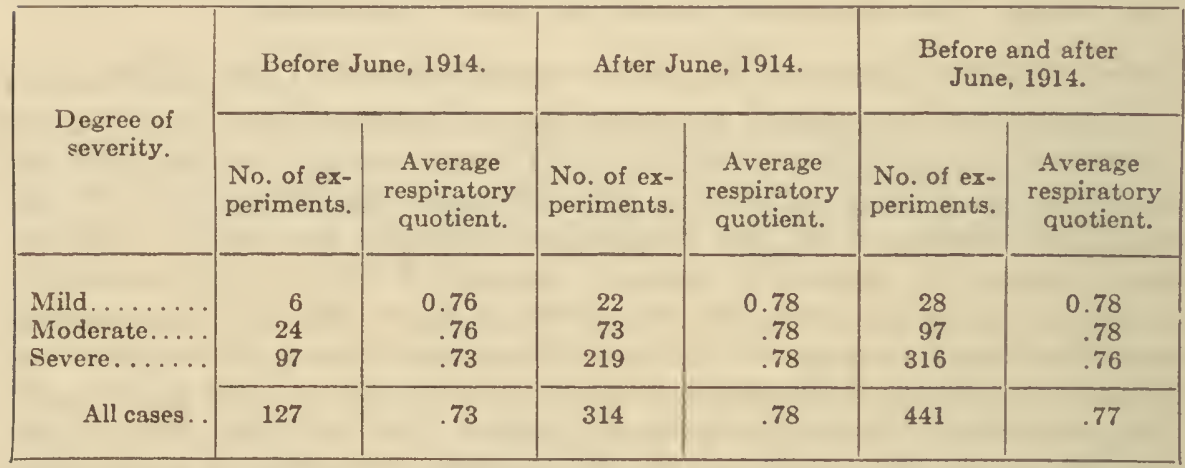

To bring out the differences in the respiratory quotients for mild, moderate, and severe cases of diabetes before and after June, 1914, the percentage frequency of each of the various degrees of severity for given groups of respiratory quotients has been calculated and is recorded in table 81 .

Prior to June, 1914, the quotients of the mild cases were grouped equally between 0.70 and 0.75 and between 0.76 and 0.79 . The grouping for the moderate cases was not unlike that for the mild cases, except for 13 per cent which occurred between 0.80 and 0.83 . With the severe cases, however, the quotients ranged lower, as only 15 per cent of the 97 quotients rose above 0.75 and 16 per cent were found between 0.64 and 0.69 .

The quotients obtained after June, 1914, are in striking contrast to those found before that date. With both mild and moderate cases, they ranged even higher than in the earlier period. With the mild cases, 36 per cent of the quotients were found between 0.80 and 0.90 , whereas before June, 1914,

- Benedict and Joslin, Carnegie Inst. Wash. Pub. No. 176, 1912, table 65, D. 57 ot seq. 
no quotients were found with these cases above 0.79 . With the moderate cases 33 per cent were found between 0.80 and 0.90 and 3 per cent were even as high as 0.91 to 0.94 . The quotients of the severe cases also ranged higher than before June, 1914, and their general distribution was not widely different from that of the mild and moderate cases. But 4 per cent of the quotients for the severe cases in this period were under 0.70 and 37 per cent were 0.80 or above.

TABLE 81.-Percentage distribution of respiratory quotients obtained with mild, moderate, and severe cases of diabetes in experiments without food.

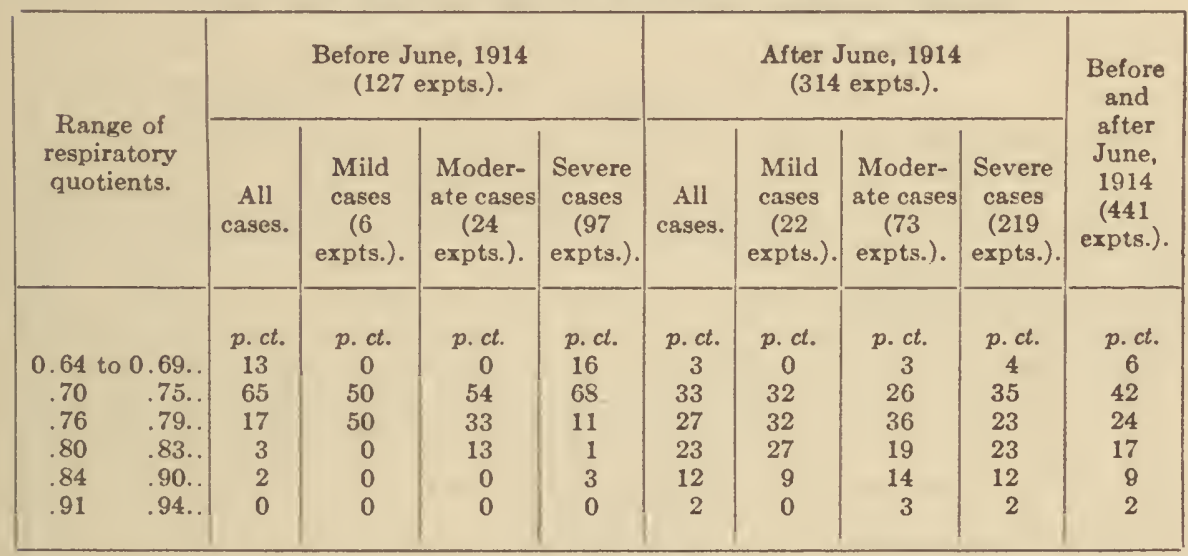

From the foregoing it will be seen that although patierits with different degrees of severity have somewhat different quotients, particularly before June, 1914, upon analysis it appears that it is not so much the severity of the cases as the conditions of exogenous or endogenous metabolism under which the patients were living that established the respiratory quotient.

\section{Respiratory Quotient in Relation to the Degree of Acidosis.}

It has been shown in the previous discussion that the principle appears to hold in diabetes that the lower the respiratory quotient is, the higher the metabolism will be, and vice versa. Furthermore, it appears that this reverse relationship was present in both periods of observation, i. e., before June, 1914, when the patients were overfed, and after June, 1914, when the patients were underfed. Support of this principle should be afforded by a study of the relation of acidosis to the respiratory quotient, because acidosis indicates primarily an abnormal fat metabolism and this is of such a nature that it tends to lower the quotient.

The relationship between the respiratory quotient and acidosis is very plainly shown in table 82 , in which the observations made with varying degrees of acidosis are grouped according to respiratory quotients ranging from 0.64 to 0.69 up to 0.91 to 0.94 , both before and after June, 1914. With patients free from acidosis (0), there were no records of respiratory quotients between 0.64 and 0.69 either before or after June, 1914, and patients with severe acidosis $(+++)$ supplied none of the respiratory quotients in the group 
from 0.84 to 0.90 . In general, the intermediate quotients of the table also bear out the observation that experiments upon patients free from acidosis gave high respiratory quotients, and that as the acidosis increased, the respiratory quotient decreased. It is thus seen that although the metabolism varied markedly in the two periods before and after June, 1914, and the respiratory quotients were notably higher after June, 1914, yet the relation between acidosis and the respiratory quotient holds for both epochs. Increasing acidosis was always accompanied by a falling respiratory quotient, regard-

TABLE 82.-Relationships between respiratory quotient, metabolism, and acidosis in postabsorptive experiments with diabetics before and after June, 1914.

\begin{tabular}{|c|c|c|c|c|c|c|c|c|}
\hline \multirow{2}{*}{$\begin{array}{l}\text { Respiratory quotient and } \\
\text { metabolism. }\end{array}$} & \multicolumn{4}{|c|}{$\begin{array}{l}\text { Before June, 1914, with } \\
\text { acidosis- }\end{array}$} & \multicolumn{4}{|c|}{$\begin{array}{l}\text { After June, 1914, with } \\
\text { acidosis- }\end{array}$} \\
\hline & 0 & + & ++ & +++ & 0 & + & ++ & +++ \\
\hline $\begin{array}{l}\text { No. of experiments with all } \\
\text { cases for respiratory quotients. } \\
0.64 \text { to } 0.69 \ldots \ldots \ldots \ldots \ldots\end{array}$ & & & 6 & 10 & & 2 & 5 & \\
\hline .70 & 8 & 9 & 31 & 34 & 10 & 25 & 57 & 11 \\
\hline .76 & 9 & 2 & 6 & 5 & 25 & 21 & 36 & 2 \\
\hline .80 & 2 & & 2 & & 36 & 20 & 14 & 1 \\
\hline .84 & & 1 & 2 & & 27 & 6 & 6 & \\
\hline .91 & & & & & 7 & & & \\
\hline $\begin{array}{l}\text { Average respiratory quotient. } \\
\text { All cases................. }\end{array}$ & 0.76 & 0.75 & 0.73 & 0.72 & 0.81 & 0.77 & 0.76 & 0.72 \\
\hline 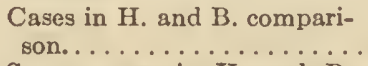 & .76 & .75 & .73 & .72 & .81 & .77 & .75 & .73 \\
\hline $\begin{array}{l}\text { Severe cases in } \mathrm{H} \text {. and } \mathrm{B} \text {. } \\
\text { comparison } \ldots \ldots \ldots \ldots \ldots \ldots\end{array}$ & .76 & . & .73 & 20 & .82 & . & . & 73 \\
\hline Cases in Girl Scout comparison & & .74 & & .72 & .86 & .84 & .83 & .71 \\
\hline $\begin{array}{l}\text { Percentage variation in metab- } \\
\text { olism from standard. }\end{array}$ & & & & & & & & \\
\hline 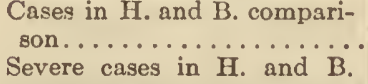 & + & +14 & +15 & + & -13 & -8 & -11 & +2 \\
\hline comparison............... & +9 & +12 & +15 & +12 & -19 & -14 & -11 & +2 \\
\hline Cases in Girl Scout comparisou & & +17 & & +27 & +10 & +32 & +18 & +55 \\
\hline
\end{tabular}

less of whether the observation was made before or after June, 1914, although in the later period the patients without acidosis or with a low acidosis tended to have higher respiratory quotients than before June, 1914. It is also significant that 49 observations upon patients with severe acidosis before June, 1914 , gave a respiratory quotient of 0.72 , and that this is exactly the average quotient of the 17 observations upon patients after June, 1914, with similar acidosis. The definite relation between acidosis and respiratory quotient is thus very clearly demonstrated. It may even be said that the definite dependence of acidosis upon the fat metabolism is thus demonstrated.

When one analyzes the same relations for the severe cases alone for the two periods, as found in the second section of table 82, the tendencies are still significant, in that after June, 1914, the average respiratory quotients, $0.82,0.78,0.75$, and 0.73 , for these cases ranged slightly higher, save those 
with moderate acidosis, than the corresponding quotients, $0.81,0.77,0.76$, and 0.72 , for all the diabetics for like degrees of acidosis. The quotients obtained with the diabetic girls also correspond to the other data here recorded.

For convenience the average metabolism as represented by variation from standard and corresponding to the various grades of acidosis of all the subjects is also recorded in the lower section of table 82. Here as elsewhere it is seen that the general tendency of the metabolism is to rise as the acidosis increases and the respiratory quotient falls, not only for all the patients in general, but in particular for the girl diabetics compared with the Girl Scout group.

\section{Respiratory Quotient in Relation to Pulse-rate of Diabetics.}

If the pulse-rate is to be depended upon as a valuable asset in the estimation of the metabolism of a patient, it should show very definite characteristics in relation to the respiratory quotient, particularly when severity and acidosis are involved. The general relation between the respiratory quotient and pulse-rate in all the post-absorptive experiments with diabetics is therefore brought out in table 83. The highest pulse-rate is found to accompany the lowest quotient, namely, with an average pulse-rate of 70 , the range in the respiratory quotient was 0.64 to 0.69 . The lowest average pulse-rate ( 60 beats) was found with the high quotients of 0.91 and over.

TABLE 83.-Relation between respiratory quotient and pulse-rate in diabetes. (Experiments without food.)

\begin{tabular}{|c|c|c|c|c|c|c|}
\hline \multirow{2}{*}{$\begin{array}{l}\text { Range of } \\
\text { respiratory } \\
\text { quotient. }\end{array}$} & \multicolumn{2}{|c|}{$\begin{array}{c}\text { Pulse-rate before } \\
\text { June, } 1914 .\end{array}$} & \multicolumn{2}{|c|}{$\begin{array}{c}\text { Pulse-rate after } \\
\text { June, } 1914 .\end{array}$} & \multicolumn{2}{|c|}{$\begin{array}{c}\text { Pulse-rate before and } \\
\text { after June, } 1914 .\end{array}$} \\
\hline & $\begin{array}{l}\text { No. of ex- } \\
\text { periments. }\end{array}$ & $\begin{array}{c}\text { Average } \\
\text { pulse- } \\
\text { rate. }\end{array}$ & $\begin{array}{l}\text { No. of ex- } \\
\text { periments. }\end{array}$ & $\begin{array}{l}\text { Average } \\
\text { pulse- } \\
\text { rate. }\end{array}$ & $\begin{array}{l}\text { No. of ex- } \\
\text { periments. }\end{array}$ & $\begin{array}{l}\text { Average } \\
\text { pulse- } \\
\text { rate. }\end{array}$ \\
\hline 0.64 to 0.69 & 16 & 70 & 10 & 70 & 26 & 70 \\
\hline $.70 \quad .75$ & 82 & 72 & 85 & 66 & 167 & 69 \\
\hline .76 & 21 & 76 & 63 & 62 & 84 & 66 \\
\hline .80 & 33 & 64 & 56 & 61 & 59 & 61 \\
\hline .84 & 3 & 66 & 34 & 63 & 37 & 64 \\
\hline .91 & & $\ldots$ & 6 & 60 & 6 & 60 \\
\hline
\end{tabular}

If one examines the right-hand column of table 83 which gives the average pulse-rate for the whole period of the research, it will be seen that as the respiratory quotients rise, the pulse-rates successively decrease. If the pulserate is considered for the periods before and after June, 1914, the same general tendency holds, but the change does not take place uniformly.

\section{Respiratory Quotient in Relation to the Glycosuria of Preceding 24 Hours.}

The relation between the respiratory quotient and the glycosuria during the 24 hours preceding the post-absorptive experiments may be observed from the results of the available 365 urinary analyses which are grouped in table 84. It is a striking fact that when the sugar in the urine amounted to 101 
grams or more, the lowest average respiratory quotient was found, this being true both before and after June, 1914. Furthermore, when the urine was approximately sugar-free in either period, the highest respiratory quotients were observed. The transition from high to low respiratory quotients for each period is gradual, and the sequence is seldom broken. When all the experiments are combined for the two periods, the changes are remarkably even.

TABLE 84.-Relation of amount of sugar in urine to respiratory quotient of diabetics in post-absorptive experiments.

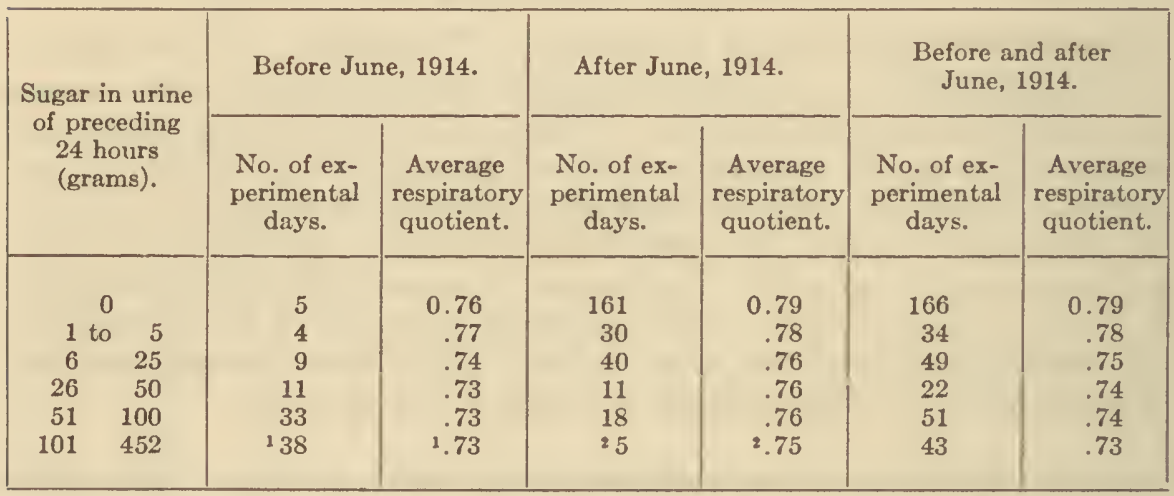

1 Range of sugar values in this group before June, 1914, was 102 to 452 grams.

2 Range of sugar values in this group after June, 1914, was 102 to 170 grams.

It is notable that amounts of sugar in the urine between 6 and 25 grams are distinctly associated with this lowering of the quotient. On the other hand, it appears to matter little, so far as change in quotient is concerned, whether the sugar in the urine is between 26 and 50 grams or 51 and 100 grams. Large quantities of sugar in the urine in these experiments imply that large quantities of fat are burned either completely or incompletely to the $\beta$-oxybutyric acid stage. Large quantities of sugar in the urine also imply that even if large quantities of carbohydrate are ingested, most of it fails of oxidation. It might be claimed that the 14-hour interval after food is so great that the effects of the oxidation of carbohydrate would have passed off by the time the experiment began, while that of the oxidation of fat would remain. That this is not the case is evident from the fact that in a group of 166 experiments in which no sugar was excreted, the respiratory quotient was as high as 0.76 and 0.79 .

If one examines the original data for the experiments in which the sugar in the urine exceeded 101 grams, it will be found that although the average respiratory quotient for the group was low, when the quantities of sugar were very high, the quotient might rise. Thus a patient with an excretion of 452 grams of sugar had a respiratory quotient of 0.77 . As a matter of fact, the average respiratory quotient in five observations before June, 1914, when the sugar excreted amounted to 200 grams or more, was 0.75 . A comparison of the sugar in the urine and the sugar forming material metabolized pre- 
cludes the inferences from these data alone that any of the sugar excreted is formed from fat.

To sum up, we may say that when the sugar in the urine amounted to 26 grams or more in the 24 hours, the respiratory quotient was approximately 0.73 ; when the urine was sugar-free, or nearly sugar-free, the average respiratory quotient was 0.76 to 0.79 ; but with quantities of urinary sugar of 200 grams or more, the respiratory quotient sometimes rose to 0.75 or above, indicating that a great excess of carbohydrate in the diet was accompanied by the oxidation of at least a portion of it.

\section{Relation between Respiratory Quotient and Carbohydrate Balance.}

The quantity of sugar excreted in the urine for the 24 hours preceding the post-absorptive experiment fails to give an exact idea of the quantity of carbohydrate ingested during the preceding 24 hours, or its utilization. Data are not available to show the actual amount of total carbohydrate burned, because the protein and fat ingested are unknown in so many instances, and there is always the uncertainty as to whether 58 per cent of the carbohydrate in the protein and 10 per cent in the fat may not have been unoxidized. The carbohydrate balance as used in this monograph refers to the relation between the carbohydrate in the diet and the sugar in the urine. Data of this limited character are available. As elsewhere indicated it is unfortunate that figures for the total glucose of the food are wanting.

TABLE 85.-Relation between carbohydrate balance and respiratory quotient of diabetics in post-absorptive experiments.

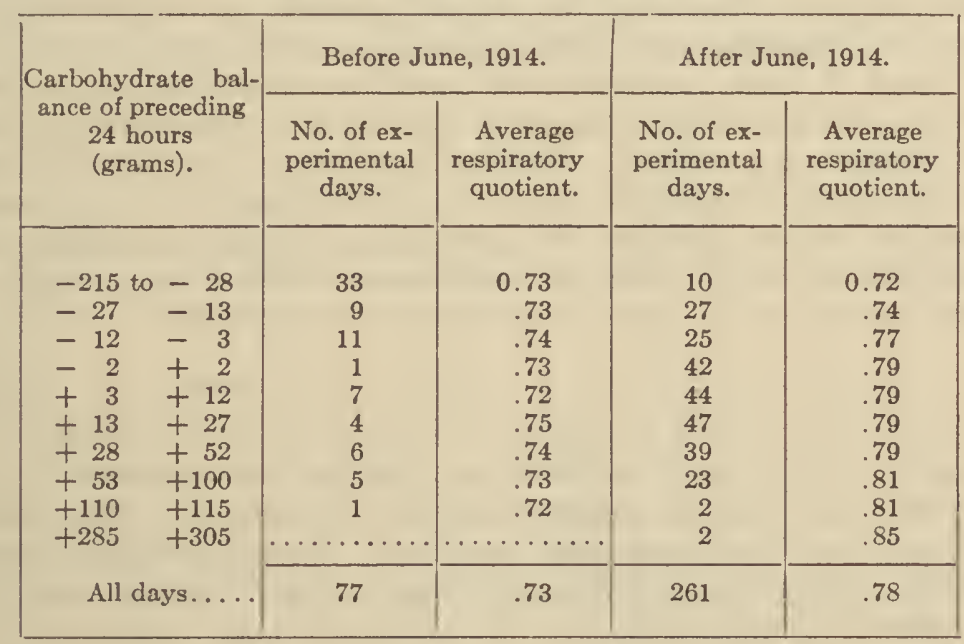

The carbohydrate balance is obviously one of the measures of severity, and likewise is closely linked with the presence or absence of acidosis; consequently one would expect to find the lowest respiratory quotient with the lowest carbohydrate balance. This proves to be the case, as may be seen from table 85 . Thus, when the carbohydrate balance ranged between -215 and -28 grams, the average respiratory quotient was approximately 0.72 both before and after June, 1914, but when the carbohydrate balance 
approached 0 , the behavior of the respiratory quotient varied according to whether the period was before or after June, 1914. Before June, 1914, it remained practically uninfluenced by the carbohydrate balance, whether positive or negative, large or small. After June, 1914, the relationship changed, the quotient gradually increasing as the negative carbohydrate balance disappeared and was replaced by a positive balance. As soon as a positive balance was attained, the rise in the quotient ceased, until the carbohydrate balance increased to +53 to +100 grams, when there was a further rise in the quotient to 0.81 and later to 0.85 .

Minus carbohydrate balances, therefore, are associated with lower quotients than are found with positive carbohydrate balances, but when the carbohydrate balance is about to become positive, the respiratory quotients promptly rise after June, 1914, to about 0.79 . The lack of rise in quotient with a positive carbohydrate balance prior to June, 1914, is explained by the fact that these positive carbohydrate balances were in the first place comparatively small, and probably quickly oxidized rather than stored as glycogen for future use. During the latter part of the post-absorptive interval of 14 hours, the metabolism would thus depend chiefly upon fat and, to a lesser extent, upon protein. After June, 1914, the patients, as a rule, oxidized rather more carbohydrate, not only from carbohydrate itself, but from the carbohydrate in the protein molecule, so that although their metabolism during the night depended in greatest degree upon fat, there was still available in the morning some carbohydrate from the protein which could be and was oxidized.

Those clinicians who ignole the present methods of rigid dieting in the treatment of their cases can derive but scant comfort from the statistics in tables 84 and 85 , since these show with gratifying regularity that the smaller the amount of sugar in the urine, even though the carbohydrate balance be low, the higher is the quotient. On the other hand, those who faithfully try to keep their patients sugar-free are here furnished support for this practice, for there are few who will gainsay the advantage of a high respiratory quotient for their patients, save in those few instances in which the rise is akin to the pre-lethal rise toward the close of a period of undernutrition.

\section{Relation of Constituents of the Blood and Respiratory Quotient.}

In the preceding section comparison was made of the metabolism with the constituents of the blood to determine whether any relationship existed between them. A similar comparison may be made with the respiratory quotient and the blood sugar and blood fat. The relationship between the non-protein nitrogen in the blood and the respiratory quotient has already been discussed. (See p. 111.)

\section{RESPIRATORY QUOTIENT IN RELATION TO BLOOD SUGAR.}

The percentage of sugar in the blood in 233 post-absorptive observations upon diabetics are compared with the respiratory quotients in table 86 , by giving the number of experiments in which the quotients and percentages of blood sugar designated were found. The total number of experiments and the average respiratory quotient for each range in blood sugar are also given. In discussing these data no account will be taken of the possibility of various 
kinds of sugar being differently combined or disposed of in the blood. The aim will be simply to bring out the relationship between the percentage of sugar and the respiratory quotient.

According to the figures in table 86, when the blood sugar was normal ( 0.05 to 0.11 per cent), the average respiratory quotient was 0.80 , a little below the average respiratory quotient of 236 of the 239 subjects upon which the Harris and Benedict standard is based, which was 0.83. ${ }^{\circ}$ With each successive rise in blood sugar the respiratory quotient fell, until when the blood sugar was between 0.41 to 0.43 per cent, the quotient averaged 0.71 . But it is important to point out that even when the blood sugar was between 0.21 and 0.30 per cent, the respiratory quotient still remained at 0.78 . These data therefore afford a comparison between the effects upon the respiratory quotient of sugar in the blood and the coincidental appearance of sugar in the urine. Simultaneously with the appearance of a few grams of sugar in the urine, the respiratory quotient is altered, but only a very marked increase in the blood sugar is accompanied by any change in the respiratory quotient. Clinicians can well take this to heart, and should be very slow in substituting estimations of sugar in the blood for those of sugar in the urine.

TABLE 86.-Relation between respiratory quotient in post-absorptive experiments and percentage of sugar in the blood of diabetics.

\begin{tabular}{|c|c|c|c|c|c|c|}
\hline \multirow{2}{*}{$\begin{array}{l}\text { Range in } \\
\text { respiratory } \\
\text { quotient. }\end{array}$} & \multicolumn{5}{|c|}{$\begin{array}{l}\text { No. of experiments with percentage of sugar in the blood ranging } \\
\text { from- }\end{array}$} & \multirow{2}{*}{$\begin{array}{l}\text { Total } \\
\text { experi } \\
\text { ments }\end{array}$} \\
\hline & 0.05 to 0.11 & 0.12 to 0.20 & 0.21 to 0.30 & 0.31 to 0.40 & 0.41 to 0.43 & \\
\hline 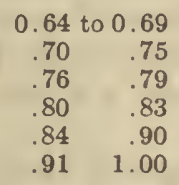 & $\begin{array}{l}0 \\
2 \\
2 \\
2 \\
2 \\
0\end{array}$ & $\begin{array}{r}2 \\
23 \\
31 \\
24 \\
13 \\
3\end{array}$ & $\begin{array}{r}1 \\
33 \\
31 \\
19 \\
14 \\
14 \\
3\end{array}$ & $\begin{array}{r}0 \\
17 \\
3 \\
4 \\
2 \\
0\end{array}$ & $\begin{array}{l}0 \\
2 \\
0 \\
0 \\
0 \\
0\end{array}$ & $\begin{array}{r}3 \\
77 \\
67 \\
49 \\
31 \\
6\end{array}$ \\
\hline $\begin{array}{c}\text { All experi- } \\
\text { ments..... } \\
\text { Average res- } \\
\text { piratory } \\
\text { quotients. }\end{array}$ & 0.80 & 0.79 & 0.78 & 0.76 & 0.71 & 233 \\
\hline
\end{tabular}

While it should be observed that the quotients corresponding to the highest and lowest blood-sugar values are based upon few observations, the steady fall in the respiratory quotient as the blood sugar rises would appear to be sufficiently positive proof that it is inconsistent to give carbohydrates to a severe case of diabetes with the hope of promoting the oxidation of carbohydrate.

It would be easy to give undue importance to the clear relation brought out in table 86 between blood sugar and the respiratory quotient. The blood sugar is an index of the severity of the disease, and with increasing

a Harris and Benedict, Carnegie Inst. Wash. Pub. No. 279, 1919, pp. 40 and 44, tables $\mathrm{C}$ and $\mathrm{D}$. The respiratory quotients are not printed in these tables, but have been calculated. 
severity there is usually an increase in the percentage of sugar in the blood. On the other hand, after prolonged inanition there may be a terminal stage in which the blood sugar falls and the respiratory quotient rises. It will, therefore, be desirable to confine the study of the percentage of blood sugar in its relation to the respiratory quotient to those observations upon severe cases of diabetes with whom the quotient was high for a diabetic, and also upon similar severe cases with whom the quotient was low for a diabetic. This comparison is made in table 87.

TABLE 87.-Relation between low and high respiratory quotients and percentage of sugar in the blood in post-absorptive experiments with cases of severe diabetes.

\begin{tabular}{|c|c|c|c|c|c|c|c|}
\hline \multirow{2}{*}{$\begin{array}{l}\text { Range in } \\
\text { respiratory } \\
\text { quotient. }\end{array}$} & \multicolumn{4}{|c|}{ Acidosis. } & \multirow{2}{*}{$\begin{array}{l}\text { No. of ex- } \\
\text { periments. }\end{array}$} & \multirow{2}{*}{$\begin{array}{l}\text { No. of } \\
\text { cases. }\end{array}$} & \multirow{2}{*}{$\begin{array}{l}\text { Avcrage } \\
\text { percentage } \\
\text { of sugar } \\
\text { in blood. }\end{array}$} \\
\hline & 0 & + & ++ & $+t+$ & & & \\
\hline 0.69 to 0.73 & & 4 & 22 & 6 & 32 & 19 & 0.27 \\
\hline $.80 \quad .83$ & 16 & 7 & 6 & 1 & 30 & 12 & .22 \\
\hline $.84 \quad .84$ & 13 & 1 & 4 & $\ldots \ldots$ & 18 & 7 & .20 \\
\hline
\end{tabular}

With these severe cases, when the respiratory quotient was low $(0.69$ to 0.73$)$, the blood sugar averaged 0.27 per cent. When the respiratory quotient was high ( 0.80 to 0.83 ), the percentage of blood sugar had fallen to 0.22 . When it was still higher, i. e., between 0.84 and 0.94 , the average percentage of blood sugar was even lower, or 0.20 per cent. Although certain exceptions to this general relationship can be found in each group in this table, the study of the blood sugar in severe cases of diabetes confirms the conclusions regarding all cases of diabetes in showing that a low respiratory quotient is accompanied by a high percentage of blood sugar and a high respiratory quotient by a significantly lower, though not normal, percentage of blood sugar.

The relation of the respiratory quotient and of high percentages of blood sugar ( 0.33 per cent and over) to the severity of the diabetes and the acidosis has been studied by collecting in table 88 the data for 14 patients having a percentage of sugar in the blood of 0.33 or over. The data have been arranged on three bases, in the three sections of the table from left to right, (1) percentage of blood sugar, (2) respiratory quotients, and (3) degree of acidosis.

All but one of the cases (No. 810; see footnote to table 88 ) having 0.33 per cent or over of sugar in the blood were of the severe type of diabetes, this case being mild in character. At the time the high blood sugar was noted with the mild case, it was only three months after the onset of the disease and almost at the beginning of his treatment, which followed a period of so liberal a diet that the sugar in the urine amounted to 6.6 per cent.

The first section of the table demonstrates that as the blood sugar increases there is a rather imperfect tendency for the respiratory quotients to fall. In the second section of the table, classified by respiratory quotients, it is seen that when the respiratory quotients rise, the tendency for the blood sugar to fall is a little more evident. When the values are classified according to degree of acidosis, as in the third section of the table, there is found to be 
no relation existing between acidosis and blood sugar, but there is the usual relation of a high quotient with no acidosis and low quotients with high acidosis.

These data, like those in table 86 , give no encouragement to the practice sometimes followed of administering carbohydrates to diabetics when the blood sugar is high.

TABLE 8S.-Relation of blood sugar, respiratory quotient, and acidosis in post-absorptive experiments with diabetics when sugar in blood is 0.33 per cent and over (severe cases ${ }^{1}$ ).

\begin{tabular}{|c|c|c|c|c|c|c|c|c|c|c|c|}
\hline $\begin{array}{c}\text { Case } \\
\text { No. }\end{array}$ & $\begin{array}{l}\text { Percent- } \\
\text { age of } \\
\text { sugar in } \\
\text { blood. }\end{array}$ & $\begin{array}{l}\text { Respi- } \\
\text { ratory } \\
\text { quo- } \\
\text { tient. }\end{array}$ & $\begin{array}{l}\text { Aci- } \\
\text { dosis. }\end{array}$ & $\begin{array}{l}\text { Case } \\
\text { No. }\end{array}$ & $\begin{array}{l}\text { Respi- } \\
\text { ratory } \\
\text { quo- } \\
\text { tient. }\end{array}$ & $\begin{array}{l}\text { Percent- } \\
\text { age of } \\
\text { sugar in } \\
\text { blood. }\end{array}$ & $\begin{array}{l}\text { Aci- } \\
\text { dosis. }\end{array}$ & $\begin{array}{l}\text { Case } \\
\text { No. }\end{array}$ & $\begin{array}{l}\text { Aci- } \\
\text { dosis. }\end{array}$ & $\begin{array}{l}\text { Percent- } \\
\text { age of } \\
\text { sugar in } \\
\text { blood. }\end{array}$ & $\begin{array}{l}\text { Respi- } \\
\text { ratory } \\
\text { quo- } \\
\text { tient. }\end{array}$ \\
\hline 740 & 0.33 & 0.71 & ++ & 740 & 0.70 & 0.43 & $+t$ & 610 & 0 & 0.37 & 0.81 \\
\hline 821 & & .75 & ++ & & .71 & .33 & $T T$ & 1160 & + & .40 & .74 \\
\hline & & .75 & ++ & 1070 & .71 & .34 & +++ & 740 & ++ & .43 & .70 \\
\hline 1005 & & .74 & +++ & 1412 & .71 & .37 & +++ & & ++ & .33 & .71 \\
\hline 1011 & & .84 & ++1 & 996 & .72 & .41 & ++ & 821 & ++ & .33 & .75 \\
\hline & & .83 & ++ & 1196 & .72 & .37 & ++ & & ++ & .33 & .75 \\
\hline 1159 & & .75 & ++ & 1008 & .73 & .35 & ++ & 996 & ++ & .41 & .72 \\
\hline 1070 & .34 & .71 & +++ & 1005 & .74 & .33 & +++ & 1008 & ++ & .35 & .73 \\
\hline 1008 & .35 & .73 & ++ & 1160 & .74 & .40 & + & 1011 & ++ & .33 & .84 \\
\hline 1085 & & .81 & ++ & 821 & .75 & .33 & ++ & & ++ & .33 & .83 \\
\hline 610 & 37 & .81 & & & .75 & .33 & ++ & 1085 & ++ & .35 & .81 \\
\hline 1196 & & .72 & ++ & 1159 & .75 & .33 & ++ & 1159 & ++ & .33 & .75 \\
\hline 1412 & & .71 & +++ & 610 & .81 & .37 & 0 & 1196 & ++ & .37 & .72 \\
\hline 1160 & .40 & .74 & + & 1085 & .81 & .35 & ++ & 1005 & +++ & .33 & .74 \\
\hline 996 & .41 & .72 & ++ & 1011 & .83 & .33 & ++ & 1070 & $++t$ & .34 & .71 \\
\hline 740 & .43 & .70 & ++ & ... & .84 & .33 & ++ & 1412 & $+t+$ & .37 & .71 \\
\hline
\end{tabular}

1 With a patient with mild disbetes (Case No. 810) there was observed: blood sugar, 0.33 per cent; respiratory quotient, 0.76 ; acidosis, +

\section{RELATION BETWEEN RESPIRATORY QUOTIENT AND BLOOD FAT.}

When carbohydrate is burned in the body, the respiratory quotient approaches 1.00 , but when fat is consumed it falls toward 0.71 . One would naturally expect, therefore, a tendency toward a high quotient with a high percentage of carbohydrate in the blood, and a low quotient with a high percentage of fat in the blood. It has already been found that, so far as carbohydrate is concerned, the reverse is true, for the higher the percentage of sugar in the blood the lower is the respiratory quotient. A study of table 89 will show that a like reversal is found in the relation between the quotient and the blood fat.

When the blood fat was essentially normal (between 0.59 and 0.75 per cent), the average respiratory quotient was 0.77 , but when the blood fat was between 1.26 and 2.00 per cent in ten analyses, the average respiratory quotients were $0.88,0.85$, and 0.85 in the three groups. An exception to the general trend is the average quotient for the six analyses when the fat in the blood was 2.01 per cent or over, for here the respiratory quotient falls again to 0.78 .

A more detailed study of the protocols upon which this table is based shows that the cases having more than 1.00 per cent of fat in the blood were practically all severe. A high percentage of fat in the blood is often accompanied by a high quotient. It must be stated, however, that severe cases do not necessarily have high respiratory quotients or high percentages of blood fat. 
An increased amount of fat in the blood accompanying a high quotient, therefore, implies that the fat is being transported rather than burned. The questions now arise for investigation whether the increased fat in the blood is due to the intake of fat in the food; whether it comes from the tissues; or whether it is being formed from carbohydrate, or even protein. Inconsistencies appear in the table which studies arranged with design should clear away. For example, Case No. 1085 had a respiratory quotient of 0.70 and 0.81 on two successive days, with blood fats of 2.94 and 2.74 per cent. After the conclusion of the experiment on the first of the two days, the patient received 75 grams of levulose, or 2.35 grams per kilogram of body-weight. This appeared to affect the respiratory quotient but not the blood fat, unless one assumes that the levulose was being transformed into fat, and a single experiment would not justify such an assumption. More probably it is to be explained by the slower response of fat than of sugar in the blood to food.

TABLE 89.-Relation of fat in the blood to respiratory quotient in post-absorptive experiments with diabetics.

[Experiments after June, 1914.]

\begin{tabular}{|c|c|c|}
\hline $\begin{array}{l}\text { Percentage of fat in } \\
\text { the blood. }\end{array}$ & $\begin{array}{l}\text { No. of experi- } \\
\text { ments. }\end{array}$ & $\begin{array}{l}\text { Average } \\
\text { respiratory } \\
\text { quotient. }\end{array}$ \\
\hline 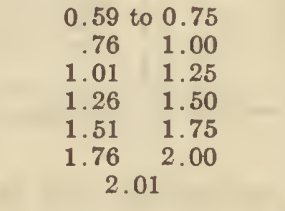 & $\begin{array}{r}16 \\
26 \\
23 \\
5 \\
3 \\
2 \\
6\end{array}$ & $\begin{array}{r}0.77 \\
.78 \\
.79 \\
.88 \\
.85 \\
.85 \\
.78\end{array}$ \\
\hline $\begin{array}{l}\text { All determinations of } \\
\text { blood fat........... }\end{array}$ & 81 & .79 \\
\hline
\end{tabular}

\section{EFFECT OF ADMINISTERING LEVULOSE AND OTHER FOODS TO DIABETICS.}

\section{General Factors Influencing Normal Metabolism.}

The knowledge acquired regarding metabolism is of such recent origin that the most fundamental facts relating to it are often overlooked. Among these is its extraordinarily labile character. When one considers the varying circumstances which occur in the waking hours of a man, it is inconceivable that the metabolism with any two individuals should be exactly alike. Even in sleep ${ }^{a}$ the metabolism varies with the individual. More influences tend to raise the metabolism under normal conditions than to depress it. The chief of these are exercise and food.

\section{INCREASE IN METABOLISM DUE TO EXERCISE.}

Although reclining in an easy chair may not appreciably increase the heatproduction of the human organism over that obtained with the body in a

- Benedict, Carnegie Inst. Wash. Pub. No. 203, 1915, p. 343. 
horizontal position, ${ }^{a}$ yet the simple maintenance of an upright position will raise the metabolism 10 per cent. ${ }^{b}$ This statement is likewise applicable to diabetics, as was shown in the two previous monographs on metabolism in diabetes. ${ }^{c}$ Walking raises the metabolic rate still more, the increase as demonstrated in this Laboratory ${ }^{d}$ varying for walking on a level from 100 per cent at approximately $11 / 2$ miles an hour to 800 per cent at approximately $51 / 2$ miles an hour. In grade walking, the increase may amount to as much as 1,200 to 1,300 per cent. Experiments also conducted in this Laboratory upon a professional bicycle rider have shown that under extreme conditions the increase due to muscular effort might amount to more than ten times the normal metabolism, or 1,000 per cent. The total metabolism of a normal individual engaged in a sedentary occupation may be estimated as 25 to 30 per cent above the basal level, and for the inactive diabetic at 20 per cent above his basal metabolism.

\section{INCREASE IN METABOLISM DUE TO INGESTION OF FOOD.}

The changes in the metabolism produced by food are not so sensational as those iust cited as a result of exercise. They are, however, very considerable, and furthermore, continue for a relatively longer period. This last consideration is one of no mean importance. Whereas following exercise the metabolism returns to essentially a normal level in a comparatively few minutes, hours are required before the normal is reached after food. For this reason the total caloric excess above the basal metabolism produced by a meal of 600 to 800 calories may be the equivalent of a climb up the Washington Monument (168 meters high, with a requirement of 80 calories), and the excess of calories following a light breakfast might suffice to carry the subject to the top of the monument on Bunker Hill. The effect of the ingestion of protein upon the metabolism may not cease for twelve or more hours, $s$ that of fat continues for a somewhat shorter period, while with a meal of carbohydrate food, the metabolism usually reaches its maximum within two hours, and then rapidly falls. $a$

Two dimensions, as it were, must therefore be considered in estimating the effect of food, namely, the average height which the metabolism reaches above the basal metabolism and the length of time during which the increase persists. From these data the total accrual of heat may be determined. The heat due to basal metabolism subtracted from the total heat obtained in the period of increment after the ingestion of food gives the total heat incre ment. If this total heat increment is compared with the caloric value of the meal, i. e., fuel value, the resulting percentage represents the cost of digestion.

a Soderstrom, Meyer, and Du Bois, Arch. Intern. Med., 1916, 17, p. 872; also, Emmes and Riche, Am. Journ. Physiol., 1911, 27, p. 406.

${ }^{b}$ Benedict and Murschhauser, Carnegie Inst. Wash. Pub. No. 231, 1915; Benedict and Carpenter, Carnegie Inst. Wash. Pub. No. 126, 1910.

' Benedict and Joslin, Carnegie Inst. Wash. Pub. No. 136, 1910, p. 217; ibid., Carnegie Inst. Wash. Pub. No. 176, 1912, p. 114.

${ }^{d}$ Benedict and Murschhauser, Carnegie Inst. Wash. Pub. No. 231, 1915; Smith, Carnegie Inst. Wash. Pub. No. 309, 1922.

- Benedict and Cathcart, Carnegie Inst. Wash. Pub. No. 187, 1913.

Benedict and Carpenter, Carnegie Inst. Wash. Pub. No. 261, 1918.

- The rate of decrease is to a considerable extent dependent upon the rate of absorption from the stomach. Even with a pure carbohydrate like glucose, this is most variable, as Fitz reported at the Am. Society for Clinical Investigation, May, 1922. 
The highest point which the metabolism reaches after the administration of food is known as the peak effect of that food, and this same term is sometimes applied to the change in respiratory quotient. For example, the total heatproduction measured in periods and estimated for the intervals between periods of a respiration experiment following the ingestion of 100 grams of levulose by a healthy subject ${ }^{a}$ was 379 calories, covering a period of about $51 / 2$ hours. The basal metabolism for this length of time was 343 calories and the difference between the two, or 36 calories, represents the total heat increment. The energy of the levulose was 379 calories. Dividing the total heat increment of 36 calories by the caloric value of the meal (379 calories), one obtains 9 per cent, which represents the cost of digestion of the meal. The metabolism reached its highest point, or 18 per cent above the basal metabolism, two hours after the ingestion of levulose, and this maximum increase therefore represents the peak effect of the meal. About one hour after the ingestion of the food the respiratory quotient attained a maximum of 1.03 , or the peak effect.

The results obtained in a study ${ }^{b}$ of the increase in the metabolism of healthy individuals following the ingestion of different classes of food materials are summarized in table 90. For our use the different classes of food materials have been more sharply defined than was the case in the original publication of the figures. Furthermore, in the preparation of the table, the results for all of the experiments in the series were averaged without regard to the apparatus used for the observations, instead of their being grouped according to whether the determinations were made with the calorimeter or with the respiration apparatus. A number of the experiments, especially those with protein foods, were not continued long enough to obtain the full period of increment. The figures may therefore be considered in some cases as below the actual percentage increases.

From these data it would appear that an ordinary-sized meal of carbohydrate food may increase the heat-production over basal on the average 10 per cent, with an average maximum increase of 16 per cent. As the result of a meal of protein, the heat-production was increased on the average 12 per cent, with an average maximum of 19 per cent, while after a meal of fat the average and maximum increases were 6 and 11 per cent, respectively. With the specific foods studied, the metabolism increased with starches from 1 to 11 per cent, with a range in average maximum from 6 to 19 per cent. With pure carbohydrates (sugars) the average increase was from 7 to 12 per cent, and the average maximum increase from 14 to 19 per cent. Beefsteak increased the metabolism on the average 14 per cent, with an average maximum of 21 per cent, while the average increment following the taking of cream was 6 per cent and the average maximum 11 per cent. Ordinary mixed meals raised the heat-production on the average 16 per cent, with an average maximum of 26 per cent; beefsteak and bread, or beefsteak and potato chips, gave an average increase of 10 per cent, with an average maximum of 16 and 17 per cent; with milk these increases were 9 and 14 per cent, respectively. If the amounts ingested are limited to an energy content of 1,000 calories, no great variation is found in these percentages.

\footnotetext{
- Benedict and Carpenter, Carnegie Inst. Wash. Pub. No. 261, 1918, p. 212, table 141.

b Benedict and Carpenter, Carnegie Inst. Wash. Pub. No. 261, 1918.
} 
The estimated cost of digestion for the pure carbohydrates (sugars) ranged from 5 to 7 per cent, for starches from 2 to 7 per cent, for protein foods 13 per cent, for fat 3 per cent, for milk 8 per cent, and for mixed meals 5 per cent.

TABLE 90.-Effects of food upon the metabolism in health.

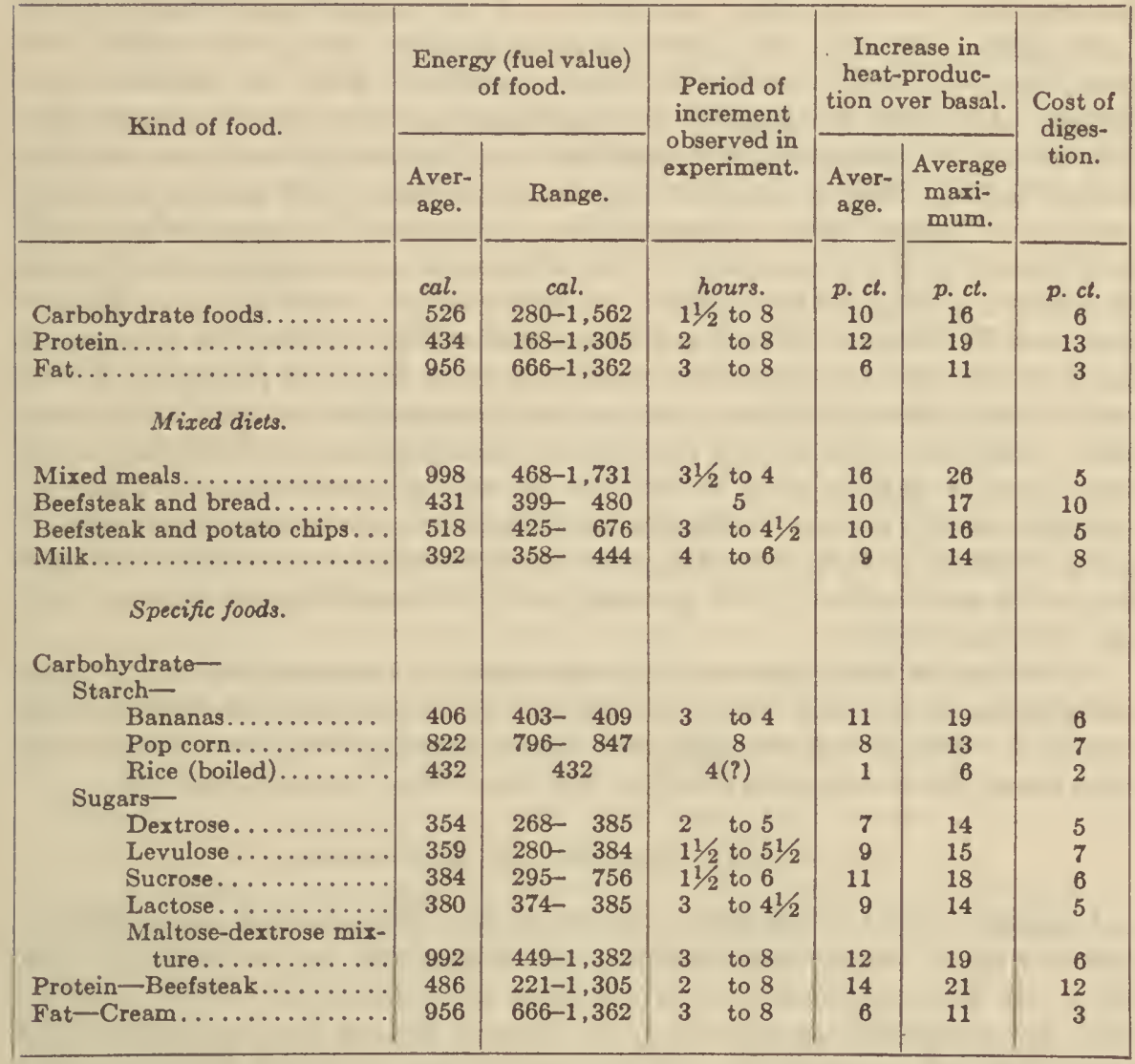

The mechanical act of eating is in itself an expense. Thus the drinking of more than 500 c. c. of cold water may affect the metabolism, which has been known to rise in consequence as much as 16 per cent, though the average increase in 11 observations was but 3 per cent. Chewing may cause a rise of 17 per cent. Beef tea and coffee increase the metabolism, coffee increasing it considerably.

\section{Effect of Coffee upon Metabolism.}

In the observations upon the post-absorptive metabolism of the diabetic subjects prior to November, 1914, and occasionally even up to December 4, 1917 (Case No. 1414), it was not uncommon for some of the patients to take 180 c. c. (a small cupful) of clear coffee about 7 a. m.; in other words, about an hour before the beginning of the rest period preliminary to the tests. At one time $e^{a}$ this caused us some apprehension as it was thought that the taking

a Jenedict and Carpenter, Carnegie Inst. Wash. Pub. No. 261, 1918, p. 158. 
of the coffee may have been in no small part responsible for the increase in the metabolism then noted with patients with severe diabetes. A further study of the literature upon the subject, however, shows this fear to have been groundless.

In the first place, a considerable interval, about $1 \frac{1}{2}$ to 2 hours, occurred between the time the coffee was taken and the actual measurement of the metabolism. Secondly, the increases in metabolism found after coffee have been observed with considerably larger quantities than our patients consumed. According to Benedict and Carpenter, ${ }^{6}$ a large cup of strong coffee (325 grams) will increase the metabolism on an average about 8 per cent for several hours. Such an amount of coffee as they gave (325 grams) probably contained 0.3 gram caffein, whereas 250 c. c. of unusually strong coffee is said to contain 0.25 gram of caffein. ${ }^{b}$ The coffee which our patients took was not of this strong type and the amount was nearer 180 c. c. than 250 c. c. Means, Aub, and Du Bois, ${ }^{\text {' with }} 0.53$ to 0.66 gram of caffein, observed in five experiments an increase in metabolism ranging from 11.3 to 31.6 per cent. Edsall and Means, ${ }^{d}$ after 0.324 gram caffein sodium salicylate, injected subcutaneously, observed a rise of 10.6 per cent in the metabolism in one patient and with another patient after 0.39 gram of caffein given subcutaneously an average rise of 3 per cent. Higgins and Means ${ }^{e}$ in one experiment after 0.32 gram of caffein sodium benzoate, given subcutaneously, observed an average rise in the metabolism of 13.8 per cent, and with another patient an average rise of 4.5 per cent.

In conclusion, the ingestion of a large cupful of strong coffee increases the metabolism about 8 per cent. In contrast to this, our patients took a small cupful of coffee of less strength, and experimental periods were usually not even begun for an hour and a half to two hours after this was ingested.

\section{FACTORS DECREASING THE METABOLISM.}

A decrease in the metabolism is known to take place normally as a result of undernutrition, and is considerable. A decrease also occurs during normal sleep. In the experiments upon a fasting man conducted by this Laboratory, the metabolism at the end of 31 days of fasting had been lowered to 14 per cent below standard.f The actual decrease in calories was from 1,526 to 1,118 , or 27 per cent. Subsequent observations by the Nutrition Laboratory upon two groups of students (Squad A and Squad B) in the Young Men's Christian Association College at Springfield,o who were subjected to a loss in body-weight of 10.5 per cent for Squad A and 6.5 per cent for Squad B in 18 weeks and 3 weeks, respectively, showed a decrease in metabolism of 19 per cent for both groups.

a Benedict and Carpenter, Carnegie Inst. Wash. Pub. No. 261, 1918, p. 158.

${ }^{b}$ von Noorden and Salomon, Handbuch der Ernährungslehre, Berlin, 1920, 1, p. 688.

'Means, Aub, and Du Bois, Arch. Intern. Med., 1917, 19, p. 832.

${ }^{d}$ Edsall and Means, Arch. Intern. Med., 1914, 14, p. 897.

- Higgins and Means, Journ. Pharm. and Exp. Therapeutics, 1915, 7, p. 1.

Benedict, Carnegie Inst. Wash. Pub. No. 203, 1915. The variation from standard was calculated from the basal metabolism data given in his table 58, p. 389, using for the standard the metabolism as computed by means of the Harris and Benedict formula for a man of like age, height, and weight. (See also, table 59, p. 128 of this monograph.)

Benedict, Miles, Roth, and Smith, Carnegie Inst. Wash. Pub. No. 280, 1919, p. 228. 
The metabolism of a neurasthenic man studied by Magnus-Levy ${ }^{a}$ was 33 per cent below standard, an actual fall of 44 per cent. His weight was 30 per cent below normal. Undernutrition with coincident loss of weight, therefore, is a very important factor in the lowering of the metabolism; this has already been considered. (See p. 127.)

\section{VARIATIONS IN METABOLISM DUE TO PATHOLOGICAL CONDITIONS.}

Under pathological conditions the most notable example of increased metabolism is in hyperthyroidism. ${ }^{b}$ Here the increase may reach 100 per cent and is frequently as great as 50 per cent. Fever may also cause an increase, as is shown by the report of Carpenter and Benedict ${ }^{c}$ on cases of probable mercurial poisoning, and by the studies, upon typhoid-fever patients conducted by Coleman and Du Bois. ${ }^{d}$ These latter investigators observed that at the height of the fever there was an average increase in the basal metabolism of about 40 per cent above the normal, but in some cases it rose to more than 50 per cent. In malaria, Barr and Du Bois found that the heatproduction increased 100 to 200 per cent during the chill; immediately after the chill it fell to within 20 to 38 per cent of the average basal level. McCann and Barrf found the basal metabolism of tuberculous patients may be normal or very sl'ghtly above that of normal men of the same size. In 10 cases the variation from average normal was from -3 to +15 per cent Du Boiso refers to experiments conducted at the Russell Sage Laboratory which show an increase in metabolism in erysipelas, arthritis, and the fever produced by intravenous injections of protein. Leukemia causes a marked rise in metabolism. This has been observed in lymphatic leukemia by Murphy, Means, and $\mathrm{Aub}^{h}$ and in myelogenous leukemia by Gunderson. ${ }^{i}$

The effect of drugs is not here considered, except that for special reasons the influence of caffein has already been discussed.

A lowering in metabolism occurs chiefly in myxedema, and at times the metabolism may fall to 33 per cent below normal. ${ }^{j}$ In chronic anemia, when it is profound, the metabolism may sometimes be reduced to 26 per cent below normal. ${ }^{k}$

$A u b,{ }^{l}$ in a recent paper upon the relation of the internal secretions to metabolism, has shown that following removal of the thyroid gland the metabolism is lowered. He points out the predominating influence of the thyroid and the adrenal glands upon the total metabolism, considers the mechanism of their action independent, and probably due to thyroxin and adrenalin, respectively.

a Magnus-Levy, Zeitschr. f. klin. Med., 1906, 60, p. 177.

' Du Bois, Arch. Intern. Med., 1916, 17, p. 915; Means and Aub, Arch. Intern. Med., 1919, 24, p. 645 .

C Carpenter and Benedict, Am. Journ. Physiol., 1909, 24, p. 203.

- Coleman and Du Bois, Arch. Intern. Med., 1915, 15, p. 887.

- Barr and Du Bois, Arch. Intern. Med., 1918, 21, p. 627.

$f$ MeC.ann and Barr, Arch. Intern. Med., 1920, 26, p. 663.

- Du Bois, Journ. Am. Med. Assoc., 1921, 77, p. 352.

${ }^{h}$ Murphy, Means, and Aub, Arch. Intern. Med., 1917, 19, p. 890.

i Gunderson, Boston Med. and Suro. Journ., 1921, 185, p. 785.

; Means and Aub, Arch. Intern. Med., 1919, 24, p. 404. See, also, Means and Burgess, Arch. Intern. Mf $\epsilon$., 1922, 30, p. 507.

k Tompkins, Brittingham, and Drinker, Arch. Intern. Med., 1919, 23, p. 441.

'Aub, Journ. Am. Med. Assoc., 1922, 79, p. 95. 


\section{EfFect of Food on Respiratory Quotient of Normal Individuals.}

A study of the effect of food upon the total metabolism is incomplete unless the influence which it exerts upon the respiratory quotient is also given. The respiratory quotient varies with the character of the material which is burned in the body, and is represented by the fraction $\frac{\mathrm{CO}_{2}}{\mathrm{O}_{2}}$. The average postabsorptive respiratory quotient of 236 of the 239 individuals upon whom the Harris and Benedict prediction tables are based was $0.83 .^{\circ}$ Presumably the diets of these subjects for the previous day were the usual average diet, namely, carbohydrate 400 to 300 grams, protein 100 to 75 grams, and fat 100 to 50 grams, which, when expressed in proportion of calories for each food material, would be carbohydrate 58 per cent, protein 14 per cent, fat 28 per cent. The ingestion of additional carbohydrate immediately before a test would raise this quotient, because the respiratory quotient of carbohydrate is 1.00. Whether the addition of more fat would tend to lower it, since the respiratory quotient of fat is $\mathbf{0 . 7 1}$, is yet to be proved for normals, but for diabetics it seems probable. An increase or decrease of the proportion of protein in the diet would make little change, since the characteristic quotient for protein is 0.81 .

The effect of a hearty evening meal, rich in carbohydrate as compared with one low in carbohydrate, upon the respiratory quotient the following morning was studied by Benedict, Emmes, and Riche. ${ }^{b}$ In a series of experiments with seven subjects, they found that with an excessive carbohydrate diet the average respiratory quotient was 0.88 , while with a low carbohydrate diet the respiratory quotient was 0.81 . It is seldom, however, that such great changes in the diet are encountered as were employed by these experimenters with their subjects.

On the other hand, there is no doubt that Bernstein and $\mathrm{Falta}^{e}$ were right in emphasizing the importance of standard diets before metabolism tests and in recommending that these be continued for several days. This criterion was fulfilled at the Russell Sage Laboratory in the observations with Cyril K. One of the chief values of the recent work of Wilder, Boothby, and Beelerd is that this procedure (i. e., observation over long consecutive periods) was carried out in their 44 tests made with Bessie B., a diabetic. The results of a part of these observations are given in table 91. Between May 19 and May 27 the patient was upon a constant diet of carbohydrate 43 grams, protein 27 grams, fat 151 grams, equivalent to 55 calories per kilogram of body-weight. The metabolism at the beginning of this period was -22 per cent as compared with the Du Bois standard, the carbon dioxide in the blood 59 and 49 volumes per cent, and the acidosis slight. In the middle of the period the average metabolism had risen to -12 per cent, with an increase in acidosis as shown by the carbon dioxide in the blood of 45 volumes per cent. At the conclusion of the period, the metabolism was -11 per cent and the acidosis again higher as the carbon dioxide in the blood was 41 volumes per cent. If the tests

\footnotetext{
- Harris and Benedict, Carnegie Inst. Wash. Pub. No. 279, 1919, pp. 40 to 47, inclusive. The quotients can be calculated from the data for carbon dioxide and oxygen.

${ }^{6}$ Benedict, Emmes, and Riche, Am. Journ. Physiol., 1911, 27, p. 383.

- Bernstein and Falta, Deutsch. Arch. f. klin. Med., 1916, 121, p. 95.

${ }^{d}$ Wilder, Boothby, and Beeler, Journ. Biol. Chem., 1922, 51, p. 311.
} 
after the first two days of dieting were considered alone, the influence of acidosis in raising the metabolism in this patient would have been overlooked. The respiratory quotient on May 18, preceding the high-diet period, was 0.72 and on May 27, at the end of this period, had fallen to 0.67 , though on two of the intermediate days (May 23 and 24) it rose, respectively, to 0.74 and 0.72.

TABLE 91.-The advantage of constant diets of several days' duration in metabolism experiments.

(Wilder, Boothby, and Beeler.)

\begin{tabular}{|c|c|c|c|c|c|c|c|c|c|}
\hline \multirow[b]{3}{*}{ Date. } & \multirow{2}{*}{\multicolumn{4}{|c|}{ Diet. }} & \multicolumn{4}{|c|}{ Acidosis. } & \multirow{3}{*}{$\begin{array}{l}\text { Varia- } \\
\text { tion of } \\
\text { metabo- } \\
\text { lism } \\
\text { from } \\
\text { Du Bois } \\
\text { stand- } \\
\text { ard. }\end{array}$} \\
\hline & & & & & \multicolumn{2}{|c|}{ Urine. } & \multicolumn{2}{|c|}{ Blood. } & \\
\hline & C. & P. & F. & $\begin{array}{l}\text { Cals. } \\
\text { per } \\
\text { kg. }\end{array}$ & $\begin{array}{l}\text { Acetone } \\
\text { bodies } \\
\text { as } \\
\text { acetone. }\end{array}$ & $\begin{array}{c}\text { Am- } \\
\text { monia- } \\
\text { nitro- } \\
\text { gen. }\end{array}$ & $\begin{array}{l}\text { Acetone } \\
\text { bodies } \\
\text { as } \\
\text { acetone. } \\
\text { per } 100 \\
\text { c. c. }\end{array}$ & $\begin{array}{l}\text { Carbon } \\
\text { dioxide. }\end{array}$ & \\
\hline $\begin{array}{r}\text { May } 10 \text { to } 14 \\
15 \text { to } 18 \\
19 \\
20 \\
21 \\
22 \\
23 \\
24 \\
25 \\
26 \\
27\end{array}$ & $\begin{array}{l}o m . \\
16 \\
15 \\
43 \\
43 \\
43 \\
43 \\
43 \\
43 \\
43 \\
43 \\
0\end{array}$ & $\begin{array}{l}g m . \\
10 \\
31 \\
27 \\
27 \\
27 \\
27 \\
27 \\
27 \\
27 \\
27 \\
0\end{array}$ & $\begin{array}{c}o m . \\
83 \\
109 \\
151 \\
151 \\
151 \\
151 \\
151 \\
151 \\
151 \\
151 \\
0\end{array}$ & $\begin{array}{c}28 \\
38 \\
\mathbf{5 5} \\
\mathbf{5 5} \\
\mathbf{5 5} \\
\ldots \ldots \\
\mathbf{5 5} \\
\mathbf{5 5} \\
\mathbf{5 5} \\
\mathbf{5 5} \\
\ldots \ldots\end{array}$ & $\begin{array}{l}\text { gm. } \\
2.0 \\
3.2 \\
5.3 \\
3.0 \\
2.4 \\
4.4 \\
3.5 \\
6.2 \\
6.5 \\
6.5 \\
(2)\end{array}$ & $\begin{array}{r}o m . \\
0.6 \\
.5 \\
.6 \\
.6 \\
.6 \\
.6 \\
.6 \\
.6 \\
.8 \\
1.1 \\
.7\end{array}$ & 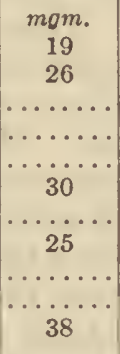 & $\begin{array}{c}\text { vol. } p . c t . \\
59 \\
49 \\
\ldots \ldots \\
\ldots \ldots \\
\ldots \ldots \ldots \\
50 \\
\ldots \ldots \\
45 \\
\ldots \ldots \\
\ldots \ldots \\
41\end{array}$ & $\begin{array}{r}\text { p. } c t . \\
-22 \\
1-20 \\
-22 \\
-20 \\
-17 \\
\ldots-10 \\
-12 \\
-14 \\
-13 \\
-11\end{array}$ \\
\hline
\end{tabular}

1 For computing this average, the basal metabolism ( -22 per cent) for May 19 is included because the value represents the result for the diet of this period.

2 The value given in the original text is 0.61 , a decrease of 91 per cent in 24 hours and a lower value than that obtained on any day between Mar. 31 and July 12 . It was therefore excluded from this table, but the authors assure me there is no reason to doubt its accuracy.

In the discussion of the series of observations upon food with diabetics, one must remember the many opportunities for unusual quotients which have previously been discussed. (See p. 169.) The respiratory quotient of an individual will rise when (1) an additional proportion of carbohydrate is burned in the metabolism; when (2) $\beta$-oxybutyric acid and its derivatives are burned, if the basal respiratory quotient is below 0.75 ; and (3) when the quotient is under 0.81 , it will rise when additional protein is oxidized. The respiratory quotient will also rise, even if the carbohydrate is not burned, provided (4) the carbohydrate is changed into fat, because in this process an excess of carbon dioxide is set free and the numerator of the respiratory quotient fraction $\frac{\mathrm{CO}_{2}}{\mathrm{O}_{2}}$ is thereby increased. The conversion of protein to fat (5) will accomplish the same result, though in much smaller degree. It is also conceivable that (6) a rise of the respiratory quotient above 0.81 would take place if the carbohydrate portion of the protein molecule was burned and the non-carbohydrate portion retained in the body. There are but two possibilities by which the respiratory quotient may rise above 1.00 ; these are by the conversion of carbohydrate into fat or of protein into fat. 
The respiratory quotient will fall when the percentage of carbohydrate in the diet which is oxidized decreases, and also when there is incomplete oxidation of fat. For further discussion of this question, see page 170 .

Great caution must therefore be exercised in interpreting the respiratory quotients obtained. An uncertain element is introduced into the computations of the respiratory quotient when the carbohydrate ingested is not oxidized immediately, but is stored as glycogen to be drawn upon later from time to time for oxidation. The mere storage of carbohydrate, however, would not affect the respiratory quotient. Fat may also be stored and not immediately burned. The storage capacity for protein is most uncertain.

The question of the storage of carbohydrate, fat, and protein in the body, particularly in the liver, greatly complicates the problem. According to figures obtained in studies with dogs, this organ, which contains one-half to one-fifth of the glycogen in the entire body, may vary in its content of glycogen from a negligible amount to 10 per cent, even upon a protein diet, and this percentage is as great as after feeding carbohydrate alone. The liver normally contains less than 6 per cent of fat; in starvation the quantity may amount to 10 per cent. When Pflüger ${ }^{a}$ fed a dog for 30 days on large quantities of fat only, at the end of this period the liver contained 45 per cent of fat and no glycogen. There appears to be an antagonism in the liver between glycogen and fat. MacLeod ${ }^{b}$ states regarding insulin that following its administration this antagonism did not appear to exist. The metabolism of protein is well known to be in large measure affected by the storage of fat in the body. When the fat in a fasting organism is abundant, protein metabolism is spared and the influence upon it of the ingestion of 100 to 300 grams of fat has been shown to be slight. This is, however, in the healthy animal, not in the diabetic. Contrariwise, when the store of fat is very, very greatly reduced in the body, protein is drawn upon to excess.

Finally, if carbohydrate and fat are both available for combustion, the percentage of carbohydrate burned is the greater. Even when the metabolism has been raised by the ingestion of fat, it will be still further raised by the ingestion of carbohydrate. Experiments should be conducted by clinicians, metabolists, pathologists, and chemists for the purpose of studying the relations in health and disease of carbohydrate and fat in the liver to the diet and the blood.

\section{EFFECT OF INGESTION OF CARBOHYDRATE UPON RESPIRATORY QUOTIENTS OF NORMAL INDIVIDUALS.}

Before taking up the consideration of the effect of carbohydrate upon diabetics, it will be advantageous to note the influence rather more specifically of carbohydrate upon normal individuals. For this purpose, table 92, based upon Benedict and Carpenter's results, ${ }^{\circ}$ has been compiled to show the effect of various sugars upon the respiratory quotient when given to healthy subjects. The amount of carbohydrate administered was 100 grams, or on the average 1.60 grams per kilogram of body-weight.

\footnotetext{
a Pflüger, Arch. f. d. ges. Physiol., 1907, 119, p. 123.

- MacLeod, Trans. Royal Soc. of Canada, 1922, 3d ser., 16, p. 1.

c Benedict and Carpenter, Carnegie Inst. Wash. Pub. No. 261, 1918, p. 246, table 183.
} 
Since the majority of the experiments with the diabetics began almost immediately after the ingestion of the food and continued for approximately 2 hours, the average respiratory quotients of these normal controls for the same length of time have been interpolated in the table. In the lowest line of the table is given the average maximum increase in the respiratory quotient for the series of experiments with each sugar. The increases in the respiratory quotient with levulose $(0.18)$ and sucrose $(0.21)$, in contradistinction to the increases for lactose (0.14) and dextrose (0.12) are noteworthy. It suggests

TABLE 92.-The effect of 100 grams of various sugars upon the respiratory quotient of normal individuals.

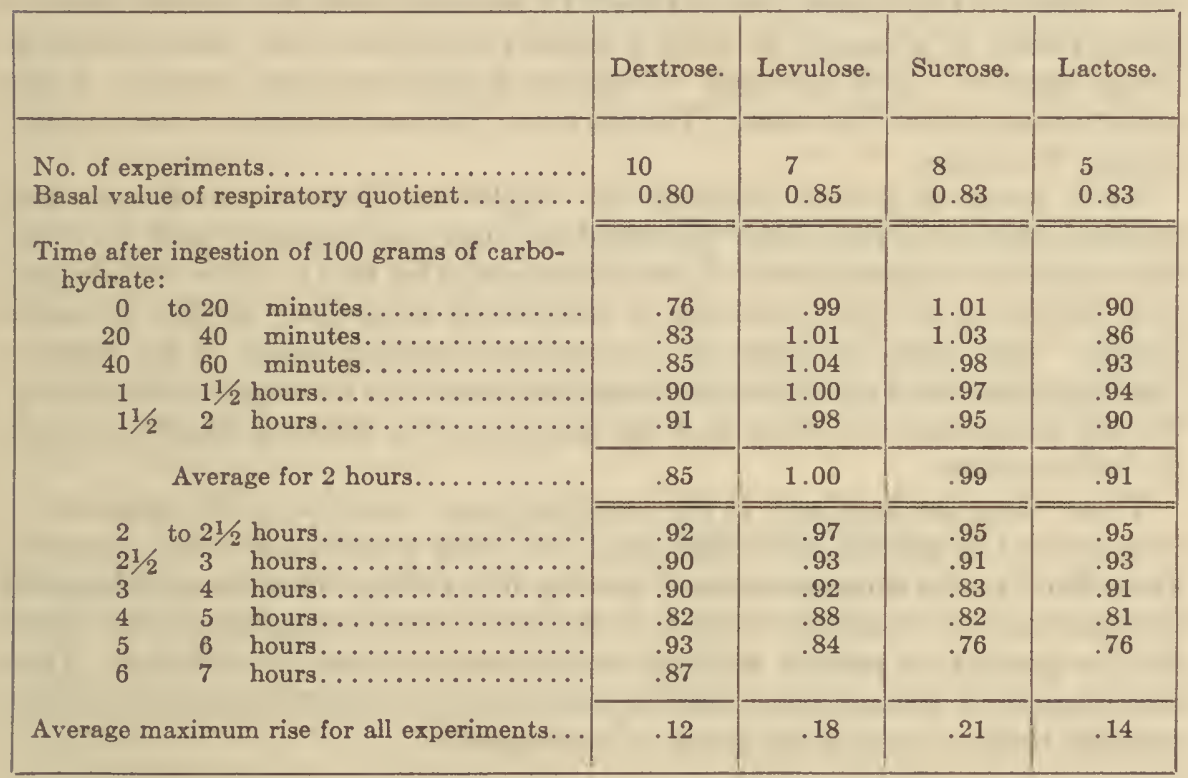

that levulose derived by inversion of the sucrose molecule may be partly responsible for the high quotient obtained with sucrose. The observations with both levulose and sucrose showed respiratory quotients above 1.00 and in each instance the quotient rose much higher than those obtained with dextrose and lactose. Almost invariably four hours elapsed before the quotient returned to the basal value and in some of these experiments it had not returned in six hours. Both Durig and Lusk ${ }^{b}$ have also noted the greater increase in metabolism after levulose than after glucose.

Benedict and Carpenter state:

"It is clear that there is a specific property of levulose that is markedly different from dextrose in its effect on the metabolism, both quantitatively and (as is now seen) qualitatively. To what extent this is determined by direct and rapid combustion, intermediary processes in transformation to glycogen or fat, or to the stimulating action of intermediary products may not at present be stated with surety." c

a Tögel, Brezina, and Durig, Biochem. Zietschr., 1913, 50, p. 296.

${ }^{6}$ Lusk, Journ. Biol. Chem., 1915, 20, p. 555.

' Benedict and Carpenter, Carnegie Inst. Wash. Pub. No. 261, 1918, p. 243. 
It has been pointed out that a rise in respiratory quotient may be due to the substitution of the combustion of carbohydrate for that of protein and fat, and second, to the formation of fat from carbohydrate as a result of excessive carbohydrate feeding. The rapid ingestion of 100 grams of carbohydrate makes immediately available 400 calories with which to offset a basal requirement of perhaps 70 calories per hour. The taking of this moderate quantity of carbohydrate would therefore logically suffice for the basal requirement during a period of five or six hours. In normal individuals, therefore, whether carbohydrate is oxidized or changed to fat, more carbon dioxide is being produced and the quotient should be raised for about five hours. If this does not take place, one is forced to conclude that the carbohydrate is being stored as glycogen or what is equally important, the carbohydrate is being excreted. The quantity of carbon dioxide may also increase if the total intake of food is raised. In this event the respiratory quotient would remain the same.

As a result of protein feeding, the respiratory quotient undergoes less violent alterations than after carbohydrate, but on the other hand the total metabolism is changed more. Carbohydrate and fat lead to a low metabolism but protein to a high metabolism, because of its greater specific dynamic action. The cause or causes of the specific dynamic action of the various food materials need not claim attention here, since this monograph is primarily for the presentation of facts and the theories to be deduced therefrom must be left to others.

From what has been said in the foregoing pages concerning the administration of food to normal individuals and the many possibilities which must be considered in the interpretation of results, it is evident that the problem will become far more intricate when it is desired to learn what takes place when food is given to a patient with so complicated a disease as diabetes. That investigator is oversanguine who expects to unravel more than a few of the tangled threads by any one series of experiments.

\section{Methods Employed in Studying Effect of Food upon Metabolism in Diabetes.}

\section{COMPARISON WITH BASAL METABOLISM.}

In the majority of the experiments about to be described, the basal metabolism was determined directly before the administration of food. Occasionally this was not done, particularly in the early experiments which were of long duration. For these cases dependence was placed upon the basal metabolism of the previous day, or upon that determined on a still earlier date. As a rule, it is evident from a glance at the protocols at the end of this volume (Appendix I) which experiment served as the control for the basal metabolism. A value obtained later than the food experiment was but rarely selected; occasionally the average results of several post-absorptive experiments were taken. In general, the same type of apparatus and the same length of period were employed in securing the basal metabolism and that after food. Reference to the protocols will show the type of each experiment and the food given. 
An endeavor was made to determine the metabolism as soon as possible after the food was administered. Occasionally the subjects took the food without leaving the respiration chamber and directly after the close of a determination of the basal metabolism, but even when this precaution was taken, probably an average interval of thirty minutes ensued before the preliminary period of the food experiment was over and the test of the metabolism after food actually began.

\section{CLINICAL DETAILS.}

Examinations of the urine were made for the 24 hours preceding practically all of the experiments upon the basal metabolism and the metabolism after food. The urinary examinations included estimations of the sugar and nitrogen and tests for acidosis. In an increasing number of experiments, as time progressed, analyses were made of the sugar and fat in the blood. Frequently, however, the blood-sugar values subsequent to food were obtained the following morning, a time which was not so desirable for the interpretation of results as if the determinations had been made directly at the conc'usion of the food periods. The reason for this was that these early analyses were performed more with a view to determine whether the giving of so much carbohydrate was without harm to the patient. A return of the blood sugar to its original value the morning after the experiment was considered as proof of the harmlessness of the test.

\section{QUALITY AND QUANTITY OF FOODS ADMINISTERED.}

A list of the food materials and the number of experiments with each have already been given in table 2, page 4 . The greatest number of observations were made after levulose had been ingested, a considerable number after the taking of oatmeal, and a few experiments after dextrose and sucrose. In all of these experiments the quantities of food eaten were accurately measured. There were also numerous observations following mixed meals of known character which the patients were taking in the regular course of treatment. In the tabulation and discussion of the data of the observations following the mixed meals, the composition of the diet has been given, an endeavor being made to group the results of similar experiments whenever possible. As a rule, the amount of carbohydrate in the mixed meals varied between 2 and 50 grams, the protein between 10 and 35 grams, and the fat between 10 and 50 grams. In the carbohydrate experiments, relatively larger quantities of carbohydrate were prescribed toward the end than at the beginning of the investigation. It should be remembered that the first of these experiments dates back to 1908, at which time the writer felt considerable hesitancy in giving carbohydrates to a diabetic.

Not all of the experiments which are listed in table 2 can be included in a discussion of the effect of food on the metabolism in diabetes, because of the conditions under which some of the observations were made. Satisfactory basal values were available for comparison with most of the food experiments, but occasionally the basal metabolism either was not observed or was obtained at a time too remote for comparison with the metabolism after food. The experiments with Case No. 1070 represented practically 
fasting conditions and therefore were not comparable with the other experiments of the carbohydrate and protein group. This patient was on the verge of coma and taking small quantities of food during the day. Other experiments could not be included in the discussion for equally good reasons. The experiments presented in the tables in the following pages have been grouped according to food materials in table 93 . The number given for the multiple experiments on oatmeal days represents series of feedings of oatmeal and fat.

TABLE 93.-Groups of experiments used in comparison of results obtained with diabetics after food.

\begin{tabular}{|c|c|c|c|}
\hline Food materials. & $\begin{array}{l}\text { No. of ex- } \\
\text { periments. }\end{array}$ & Food materials. & $\begin{array}{l}\text { No. of ex } \\
\text { periments. }\end{array}$ \\
\hline Levulose. & 51 & Protein (meat) and fat. & 12 \\
\hline Orange juice. . & 4 & Oatmeal.............. & 3 \\
\hline Dextrose..... & 1 & Oatmeal with fat. & 7 \\
\hline Sucrose... & 1 & Oatmeal day, single meal. & $\theta$ \\
\hline Dextrose and bread.... & 4 & Oatmeal day, multiple meals.. & 10 \\
\hline Levulose and fat..... & 8 & Mixed diet: & \\
\hline Orange and fat... & 3 & Breakfast or dinner (first meal) & 22 \\
\hline Olive oil...... & 1 & Dinner (breakfast eaten) ..... & 18 \\
\hline Protein.. & 4 & Two or three meals. & 5 \\
\hline \multirow[t]{2}{*}{ Protein and fat......... } & 10 & Carbohydrate and protein. & 7 \\
\hline & & To & 177 \\
\hline
\end{tabular}

\section{Character of Information Supplied by Experiments after Food.}

In no instance do these experiments provide data as to the total increment of heat produced or the cost of digestion. While the caloric value of the food given was known and the basal metabolism as well, the experiments were not of sufficient duration to allow the metabolism to return to its basal level. The experiments, however, do furnish information as to the following: first, concerning the effect of food upon the metabolism during periods of time analogous to those of the basal periods and in divided intervals, most often within two hours; second, they afford an opportunity to study the cumulative effect of several meals; and third, they present data concerning the respiratory quotient under these various conditions. As most of the food experiments comprised several periods, each with a duration between 15 and 60 minutes, the peak effect upon metabolism and respiratory quotients could be observed; fourth, the urinary examinations show the amounts of sugar and usually of nitrogen excreted for the 24 hours in which the food experiments occurred, and thus give information as to the quantities of these substances excreted in comparison with the intake.

Aside from the general information thus presented as to the effect of food on the diabetic patient, the great variety in the character of the food and in the type of the cases gives an opportunity for comparing the effects of these various foods and for noting differences which result from the varying degrees of severity and of acidosis that the patients presented and the quantities of sugar or fat in the blood. 


\section{Experiments Following Ingestion of Levulose.}

Minkowski ${ }^{a}$ discovered that levulose diminished the protein metabolism in a diabetic dog, but Mandel and Lusk, ${ }^{b}$ as well as von Noorden, ${ }^{c}$ were unable to confirm this with a diabetic man. On the other hand, Verzár ${ }^{d}$ demonstrated that levulose, when given to a depancreatized dog, raised the respiratory quotient for a considerable period after glucose had failed to do so, though eventually it too lost the power.

Tögel, Brezina, and Durige observed that levulose increased the metabolism to a greater degree than glucose, that the increase began earlier and in their opinion led more than glucose to the formation of fat. With a patient to whom they gave 30 grams of levulose in hourly doses the respiratory quotient was kept at 1.00 for a long time. They also observed that the respiratory quotient fell for the first few moments after carbohydrate was given. Külz was apparently the first clinician to advocate seriously the therapeutic use of levulose.

Lusko used the oxygen as well as the carbon dioxide in the study of the effect of 50 grams of various sugars (glucose, sucrose, and levulose) which he gave to a dog. He noted increases in metabolism in the order named of 30 per cent, 34 per cent, and 37 per cent, but only with levulose did any considerable increase persist throughout the fifth and subsequent hours. The respiratory quotients rose to $1.00,1.02$, and 1.02 , respectively. There was no increase in the metabolism and respiratory quotient with lactose and but little with galactose. Levulose ( 2.8 grams) appeared in the urine as such in the levulose experiment, and 0.25 gram appeared as sucrose after the sucrose experiment, but the urine was sugar-free following glucose. In the light of Folin and Berglund's ${ }^{h}$ recent studies upon blood sugar (see p. 240), the question arises whether the particular dog used in Lusk's investigation might not have had a low levulose threshold.

Bernstein and Falta ${ }^{i}$ gave 100 grams of levulose on three successive days to a diabetic patient. No rise in respiratory quotient is recorded, but from the test it would appear that the metabolism tests made were basal tests and upon the mornings after the levulose was given.

The most extensive investigations with levulose have been made by Johansson. In 1904 he, with Billström and Heijl,i gave 100 grams of dextrose, sucrose, and levulose to normal individuals and determined the rise in carbon dioxide expelled as compared with basal values for succeeding hours. They observed that glucose increased the carbon dioxide 7 per cent, sucrose 14 per cent, and levulose (93 grams), 15 per cent. When the effect of these sugars had passed off, the carbon-dioxide values fell below the basal value.

a Minkowski, Arch. f. exp. Path. u. Pharm., 1890, 26, p. 371, or 1893, 31, p. 85.

b Lusk, "Science of Nutrition," Philadelphia, 3d ed., 1917, p. 485.

e von Noorden, cited by Lusk, loc. cit., p. 486.

d Verzár, Biochem. Zeitschr., 1914, 66, p. 75.

'Tögel, Brezina, and Durig, Biochem. Zeitschr., 1913, 50, p. 296.

f Külz, "Diabetes Mellitus," Marburg, 1874, p. 130. For literature, see von Noorden, "Metabolism and Practical Medicine," Chicago, 1907, 3, p. 635.

- Lusk, Journ. Biol. Chem., 1915, 20, p. 555.

${ }^{h}$ Folin and Berglund, Journ. Biol. Chem., 1922, 51, p. 213.

$i$ Bernstein and Falta, Deutsch. Arch. f. klin. Med., 1916, 121, p. 95.

i Johansson, Billström, and Heijl, Skand. Arch. f. Physiol., 1904, 16, p. 263. 
The increase in carbon dioxide, they explain, might be due to increased metabolism or the conversion of carbohydrate into fat, but what percentage of the increase should be assigned to each factor, the experiments did not disclose. The rapidity of the ox dation as well as the rapidity of storage they ascribe to the concentration of the given materials in the blood and tissue fluids. With a lower concentration of blood sugar and a low glycogen content in the body, they surmised and proved that oxidation of carbohydrate would go on more slowly and storage more rapidly. They noted that the rapidity of oxidation of levulose was greater and the rapidity of storage as glycogen less than with glucose.

In a subsequent article, Johansson ${ }^{a}$ confirmed the results just cited. Incidentally he observed that the increase in carbon dioxide varied with the rapidity of absorption of the sugars from the gastro-intestinal tract, and interpreted the results of his experiments as showing that the increase in carbon dioxide varied with the amount of glycogen stored in the body at the beginning of the experiment. The increase of carbon dioxide after the administration of the various sugars began within the first 30 minutes and reached its maximum either in the first or second half-hour; the period of increase never exceeded six hours. Levulose increased the excretion of carbon dioxide twice as much as glucose. The reduction of glycogen storage reduced the increase of carbon dioxide excreted after glucose was given, but although the individual similarly tested with levulose had a greater reduction in glycogen storage, the reduction in the excretion of carbon dioxide was no greater. Johansson concluded either that levulose is less suited for the formation of glycogen or that glycogen formation from levulose does not go on in the same manner or with the same rapidity as that from glucose.

He performed several experiments with diabetic patients. In some instances the ingestion of sugar increased the carbon dioxide and in others did not, or increased it to a less extent than with normals. In one diabetic dextrose brought about an increase of 7 per cent in the carbon-dioxide elimination, whereas levulose increased the carbon-dioxide elimination 13 per cent. In other words, the same relation between glucose and levulose was obtained with this diabetic as with normals.

Loeffler ${ }^{b}$ gave 100 grams of levulose to a diabetic patient and at an interval of seven hours repeated the dose. He observed an increase in the metabolism, with an increase in the respiratory quotient, both of which were greater after the second feeding. The increases were not more marked than with glucose, but less of the levulose was excreted in the urine.

OBSERVATIONS WITH DIABETICS AFTER LEVULOSE IN PRESENT RESEARCH.

Fifty-one tests with levulose were carried out with diabetic patients by the Nutrition Laboratory between March 31, 1911, and June 25, 1917, only three of these being previous to January 11,1916 . In most of the observations the levulose was taken about noon, although in a few it was given in the morning (about $9 \mathrm{a} . \mathrm{m}$.), and in two it was administered about $2 \mathrm{p} . \mathrm{m}$. In two experiments with one patient, the levulose was given during the night.

\footnotetext{
a Johansson, Skand. f. Arch. Physiol., 1908, 21, p. 1.
}

b Loeffer, Zeitschr. f. klin. Med., 1919, 87, p. 309. 
At the time of taking the food, the patients were in the post-absorptive state in all instances, except that in one case 90 grams of oil had been taken earlier in the day. The total quantity of levulose ingested varied between 28 and 100 grams, and per kilogram of body-weight between 0.90 gram and 2.50 grams. In the tables which follow, further details will be presented, but the intimate data of each experiment can be found in the protocols in Appendix I.

TABLE 94.-Levulose ingested, sugar excreted in urine, and carbohydrate balances in experiments with mild, moderate, and severe cases of diabetes. (Levulose the only carbohydrate ingested during the day).

\begin{tabular}{|c|c|c|c|c|c|c|c|c|c|}
\hline \multirow{2}{*}{$\begin{array}{l}\text { Case } \\
\text { No. }\end{array}$} & \multicolumn{2}{|c|}{ Levulose. } & \multirow{2}{*}{$\begin{array}{l}\text { Urinary } \\
\text { sugar per } \\
24 \text { hrs. } \\
\text { of experi- } \\
\text { mental day. }\end{array}$} & \multirow{2}{*}{$\begin{array}{l}\text { Carbo- } \\
\text { hydrate } \\
\text { balance } \\
\text { of experi- } \\
\text { mental day. }\end{array}$} & \multirow{2}{*}{$\begin{array}{l}\text { Case } \\
\text { No. }\end{array}$} & \multicolumn{2}{|c|}{ Levulose. } & \multirow{2}{*}{$\begin{array}{l}\text { Urinary } \\
\text { sugar per } \\
24 \mathrm{hrs} \text {. } \\
\text { of experi- } \\
\text { mental day. }\end{array}$} & \multirow{2}{*}{$\begin{array}{l}\text { Carbo- } \\
\text { hydrate } \\
\text { balance } \\
\text { of experi- } \\
\text { mental day. }\end{array}$} \\
\hline & $\begin{array}{l}\text { To- } \\
\text { tal. }\end{array}$ & $\begin{array}{l}\text { Per } \\
\text { kg. }\end{array}$ & & & & $\begin{array}{l}\text { To- } \\
\text { tal. }\end{array}$ & $\begin{array}{l}\text { Per } \\
\text { kg. }\end{array}$ & & \\
\hline Mild: & $g m$. & $g m$. & $g m$. & $g m$. & \multirow{3}{*}{$\begin{array}{r}\text { Severe: } \\
1011\end{array}$} & $g m$. & $g m$ & $o m$. & $g m$. \\
\hline 1051 & 41 & 1.00 & 0 & +41 & & 60 & $\begin{array}{l}1.50 \\
1.60\end{array}$ & 29 & $\begin{array}{l}+21 \\
+31\end{array}$ \\
\hline \multirow{2}{*}{1059} & 60 & 1.00 & 0 & +60 & & 28 & .90 & 2 & +26 \\
\hline & 50 & 1.00 & 0 & $+50^{1}$ & 1049 & $\begin{array}{l}41 \\
82\end{array}$ & $\begin{array}{r}.95 \\
2.00\end{array}$ & $\begin{array}{c}0 \\
\mathrm{Tr} .\end{array}$ & $\begin{array}{l}+41 \\
+82\end{array}$ \\
\hline \multirow{3}{*}{ Average. } & & & & 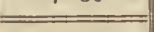 & \multirow[t]{3}{*}{1085} & 50 & 1.65 & 2 & +48 \\
\hline & & & & & & 50 & 1.60 & 5 & +45 \\
\hline & & & & & & 75 & 2.35 & 15 & +60 \\
\hline Moderate: & & & & & 1159 & 75 & 1.90 & 3 & +72 \\
\hline 610 & 55 & 1.05 & 0 & +55 & 1160 & 100 & 1.45 & 23 & +77 \\
\hline 1058 & 60 & 1.00 & 3 & $\begin{array}{l}+57 \\
\end{array}$ & & 100 & 1.45 & 9 & +91 \\
\hline 1066 & 32 & 1.00 & 0 & +32 & 1181 & 100 & 1.80 & 4 & +96 \\
\hline 1147 & 100 & 1.50 & Tr. & +100 & \multirow[t]{2}{*}{1196} & 100 & 2.05 & 35 & +65 \\
\hline \multirow[t]{2}{*}{1182} & 100 & 1.35 & 0 & +100 & & 100 & 1.95 & 26 & +74 \\
\hline & 69 & 1.20 & 1 & $+68^{1}$ & \multirow[t]{4}{*}{1213} & $\begin{array}{r}100 \\
60\end{array}$ & $\begin{array}{l}1.95 \\
1.90\end{array}$ & $\begin{array}{r}38 \\
2\end{array}$ & $\begin{array}{l}+62 \\
+58\end{array}$ \\
\hline \multirow{3}{*}{ Average. } & & & & & & 60 & 1.90 & 1 & +59 \\
\hline & & & & & & 60 & 1.90 & 1 & +59 \\
\hline & & & & & & 60 & 1.80 & 7 & +53 \\
\hline & & 1.00 & 0 & +52 & \multirow{3}{*}{1233} & 30 & 1.85 & 0 & +60 \\
\hline \multirow[t]{3}{*}{632} & 100 & 1.60 & 5 & +95 & & 75 & 1.55 & 0 & +75 \\
\hline & 100 & 1.60 & 7 & $\begin{array}{r}+93 \\
\end{array}$ & & 75 & 1.55 & 1 & +74 \\
\hline & 100 & 1.65 & 4 & +96 & 1259 & 75 & 1.50 & 4 & +71 \\
\hline \multirow[t]{4}{*}{755} & 50 & & 0 & +50 & \multirow[t]{3}{*}{1303} & 50 & 1.20 & 18 & +32 \\
\hline & 50 & .95 & 0 & $\begin{array}{l}+50 \\
\end{array}$ & & 50 & 1.20 & 6 & +44 \\
\hline & 50 & .95 & 0 & $\begin{array}{r}+50 \\
+50\end{array}$ & & 50 & 1.15 & 3 & +47 \\
\hline & 50 & 1.00 & 0 & +50 & \multirow[t]{3}{*}{1307} & 45 & 1.00 & 3 & +42 \\
\hline 765 & 89 & 2.20 & 46 & +43 & & 45 & 1.05 & 0 & +45 \\
\hline 821 & 100 & 1.90 & 8 & $\begin{array}{r}+92 \\
+\end{array}$ & & 50 & 1.20 & 7 & +43 \\
\hline 966 & 295 & ${ }^{21.85}$ & & $\because \ldots$ & Average. & 68 & 1.55 & 8 & $+60^{1}$ \\
\hline 1005 & 68 & 2.00 & 11 & +57 & Average. & 68 & 1.55 & 8 & +60 \\
\hline
\end{tabular}

1 The levulose utilized, as computed from the carbohydrate balance, was as follows: Mild casses, 100 p. ct.; moderate cases, 99 p. ct.; severe cases, 88 p. ct.

2 Omitted from average, as other data not available.

3 Experiment in the afternoon. In the morning, subject had 60 grams olive oil.

The levulose used in these observations actually contained 4.8 per cent of moisture, ${ }^{\circ}$ but the figures for levulose cited in this report do not take cognizance of this fact, first, because this was not originally known, and second, because disregarding it gave greater simplicity to the calculations. The caloric value of levulose is 3.73 calories per gram and of dextrose 3.74 calories per gram $^{b}$ in contrast to sucrose, which produces 3.96 calories per gram, but in

a Benedict and Carpenter, Carnegie Inst. Wash. Pub. No. 261, 1918, p. 204.

3 Emery and Benedict, Am. Journ. Physiol., 1911, 28, p. 301. 
these experiments it was considered sufficiently accurate to compute the caloric value of one gram of levulose by using the round figure of 4 calories per gram.

\section{UTILIZATION OF LEVULOSE BY DIABETICS.}

The quantities of levulose ingested were well utilized by the patients. This may be seen from table 94 , in which are included only those experiments made on days when no other food was given, so that the carbohydrate balances represent those for levulose only. In the two experiments with the mild cases, no sugar appeared in the urine after the administration of 1.00 gram of levulose per kilogram of body-weight. Almost equally good results were obtained with the five moderate cases who received, on the average, 1.20 grams of levulose per kilogram of body-weight. In three of the experiments the urine remained sugar-free for the corresponding 24 hours; in one but 3 grams were excreted and in the other a trace. In the severe group there were 41 experiments with 19 cases. The urines remained sugar-free for the $24-$ hour period in only 9 of these 41 experiments, although the excretion exceeded 10 grams in but 9 of the remaining 32 experments. The greatest quantity of urinary sugar occurred with Case No. 765, who excreted 46 grams. His intake of levulose was 89 grams, or 2.20 grams per kilogram of body-weight, which was larger per kilogram of body-weight than that given to any other patient, except in one experiment with Case No. 1085. The average quantity of levulose given in the various experiments with the severe cases was 1.55 grams per kilogram of body-weight, and 88 per cent of this carbohydrate was assimilated. It is thus seen that the levulose was nearly all utilized and, if not oxidized, must have been retained in the body in some form. ${ }^{\circ}$ The carbohydrate balance will be subsequently discussed in detail. (See p. 237.)

\section{EFFECT OF INGESTION OF LEVULOSE UPON METABOLISM.}

The administration of levulose to the diabetic patient increased the metabolism in 51 observations on the average by 17 per cent. An increase occurred in the metabolism in each experiment, the least increase being 5 per cent and the greatest increase 32 per cent. This rise in metabolism of the diabetic patients is remarkable, as it was slightly greater than the rise found in this Laboratory with normal subjects (see table 90) under similar conditions. Furthermore, it persisted at a higher level for a greater period of time than with the normal individuals.

Effect upon Metabolism of Variation in Amounts of Levolose.

In seeking for an explanation of the wide variation in the response of the diabetics to levulose, it will be found that it is in part due to the difference in the quantities of levulose given per kilogram of body-weight. The amounts of levulose administered were by no means insignificant, varying as previously stated, between 28 and 100 grams, and 0.90 and 2.50 grams per kilogram of body-weight. Since 75 grams of levulose in oxidation liberate approximately 300 calories, this amount taken by a patient like Case No. 1085 , whose bodyweight was $32.2 \mathrm{~kg}$., would represent if oxidized, about 40 per cent of the

- At the beginning of the investigation, all of the urines showing the presence of sugar were examined for levulose and its presence demonstrated. Later, the special tests for levulose were omitted. 
needs for the basal metabolism for 24 hours, which in this case was 778 calories. Moreover, this 40 per cent of the food requirement was actually taken in the course of one or two minutes of time.

The quantities of levulose given per kilogram of body-weight have been arranged in three groups in table 95. From these data it will be seen that the greater the quantity of levulose per kilogram of body-weight, the greater is the rise in the metabolism. With the lowest amount of levulose, namely, 0.90 to 1.25 grams per kilogram of body-weight, the average rise in metabolism was 14 per cent, but when 1.80 to 2.50 grams per kilogram of bodyweight were taken by the patient, the average rise in metabolism was 20 per cent.

TABLE 95.-Relation between amounts of levulose ingested and the heat-production in experiments with cases of diabetes of all degrees of severity.

\begin{tabular}{|c|c|c|c|c|c|c|c|}
\hline \multirow[b]{2}{*}{$\begin{array}{l}\text { Levulose in } \\
\text { grams per kg. } \\
\text { of body- } \\
\text { weight. }\end{array}$} & \multicolumn{5}{|c|}{ Percentage increase in heat-production. } & \multicolumn{2}{|c|}{ Average pulse-rate. ${ }^{1}$} \\
\hline & $\begin{array}{l}5 \text { to } 10 \\
\text { p. ct. ( } 7 \\
\text { expts.). }\end{array}$ & $\begin{array}{l}11 \text { to } 15 \\
\text { p. ct. (19 } \\
\text { expts.). }\end{array}$ & $\begin{array}{l}16 \text { to } 20 \\
\text { p. ct. ( } 11 \\
\text { expts.). }\end{array}$ & $\begin{array}{l}21 \text { to } 32 \\
\text { p. ct. (14 } \\
\text { expts.). }\end{array}$ & $\begin{array}{c}\text { Average } \\
\text { percentage } \\
\text { for all ex- } \\
\text { pcriments } \\
\text { (51 expts.). }\end{array}$ & $\begin{array}{c}\text { Basal } \\
(30 \text { expts. }) .\end{array}$ & $\begin{array}{c}\text { After } \\
\text { levulose } \\
\text { (30 expts.) }\end{array}$ \\
\hline $\begin{array}{ll}0.90 & \text { to } 1.25 \\
1.30 & 1.75 \\
1.80 & 2.50\end{array}$ & $\begin{array}{l}5 \\
8 \\
7\end{array}$ & $\begin{array}{l}14 \\
14 \\
13\end{array}$ & $\begin{array}{l}17 \\
18 \\
18\end{array}$ & $\begin{array}{l}22 \\
22 \\
26\end{array}$ & $\begin{array}{l}14 \\
15 \\
20\end{array}$ & $\begin{array}{l}63 \\
59 \\
65\end{array}$ & $\begin{array}{l}66 \\
60 \\
67\end{array}$ \\
\hline Average... & 6 & 14 & 18 & 25 & 17 & 63 & 65 \\
\hline
\end{tabular}

${ }^{1}$ Comparison of basal pulse-rates and pulse-rates after levulose, mostly on the same day, was obtained for but 30 of the total 51 experiments with levulose.

The number of experiments corresponding to each increase in metabolism is also inserted in this table. Inspection of these data confirms the general statement that the more levulose given, the greater is its effect. These results give assurance of the accuracy of the picture of the metabolism after levulose, because they demonstrate that the mere act of taking food was not the cause for the rise in metabolism, but that the actual quantity of the food determined in large part the amount of the rise. Table 95 also illustrates the importance of constantly bearing in mind the relation between the amount of levulose given per kilogram of body-weight and its effect upon the metabolism when one seeks for relations between the effect of levulose and the different types of severity and of degrees of acidosis in diabetic patients.

\section{Effect of Levolose in Diabetes of Different Degrees of Severity.}

From the data in table 95 for all of the diabetics, it was found that the average rise in metabolism following the ingestion of levulose was 17 per cent, and that this rise varied largely according to the quantity of levulose given per kilogram of body-weight. In table 96 the data are restricted to those obtained with severe cases of diabetes. These indicate a response to levulose which was directly proportional to the quantities given, the rise in metabolism varying from 14 per cent when 0.90 to 1.25 grams of levulose 
per kilogram of body-weight were taken to 21 per cent when the amounts varied between 1.80 and 2.50 grams. In particular it will be seen that with the smallest quantity the increase in the metabolism in 8 of the 13 experiments was between 11 and 15 per cent, but with the largest quantity of levulose, 9 out of 18 experiments showed an increase of metabolism varying between 21 and 32 per cent. Thus the severe cases reacted more energetically with a rise in metabolism to levulose than did the normals (see table 92), and this was the rule and not the exception, as the details of table 96 make clear.

TABLE 96.-Relation between amounts of levulose ingested and the heat-production in experiments with cases of severe diabetes.

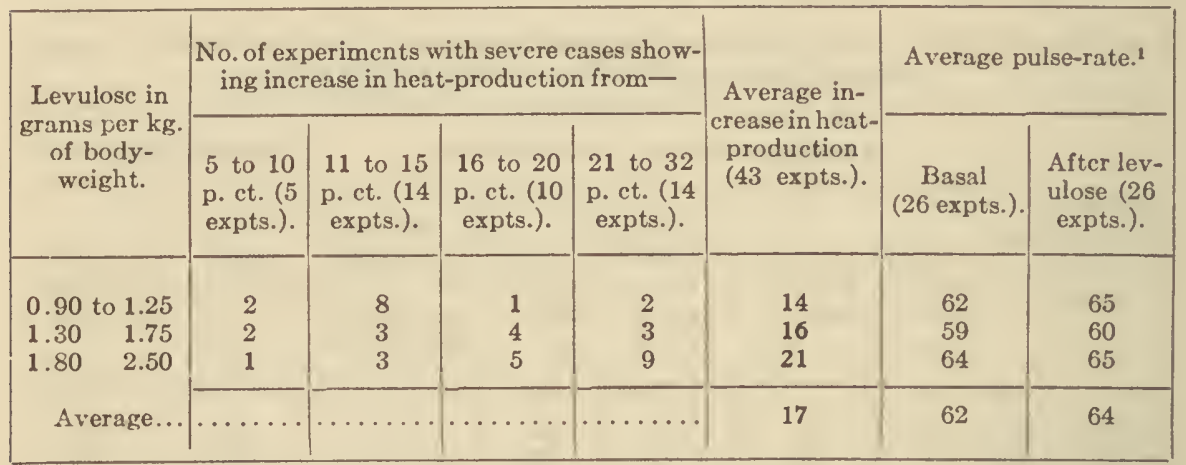

1 Comparison of basal pulse-ratcs and pulse-rates after levulose, mostly on the same day, was obtained for but 26 of the 43 levulose experiments with sevcre cases.

The results obtained in the two experiments upon patients considered at the time as having mild diabetes gave an average increase over the basal metabolism of 14 per cent. It will be seen from table 94 that the quantity of levulose administered in these experiments with mild cases was but 1 gram per kilogram of body-weight. For this small quantity of levulose ingested, the rise of 14 per cent noted in the metabolism is very considerable, because it approximates the average rise for all degrees of severity, particularly when the comparison is limited to those individuals who received less than 1.80 gram of levulose per kilogram of body-weight. (See table 95.) The quantity of levulose given in the six experiments with diabetes of moderate severity was in two experiments 1 gram, in a third 1.05 grams, and in the three others $1.35,1.50$, and 2.40 grams, respectively. The rise in metabolism with these cases averaged 12 per cent. Owing to the limited number of levulose tests with these diabetics of mild and moderate severity, one must be cautious in drawing conclusions. It is certainly surprising that the severe cases of diabetes react to levulose even more than the moderate or mild, just as it is that diabetics as a whole react with a higher metabolism than do normals. An explanation is not easily forthcoming. A priori, one would expect no increase in the metabolism whatever, if old conceptions of the slight utilization of carbohydrate in severe diabetes were correct. Confirmatory evidence must be brought, however, before it is justifiable to conclude that the levulose in these experiments with cases of severe diabetes was normally burned. 
Effect of Levulose on Metabolism with Varying Degrees of Acidosis.

Acidosis is not a factor in the effect which the administration of levulose produces upon the metabolism of diabetic patients. Fortunately, the quantities of levulose taken in each group of experiments exhibiting the different degrees of acidosis were approximately the same. The data will be found in table 97 , and give not only the increase in the heat-production, but also, for convenience, the effect of acidosis upon the respiratory quotient, but the latter will be discussed later. (See p. 240.)

TABLE 97.-Effect of acidosis upon the metabolism and respiratory quotient of diabetics after the administration of levulose.

\begin{tabular}{|c|c|c|c|c|c|c|c|c|}
\hline \multirow{3}{*}{$\begin{array}{l}\text { Degree of } \\
\text { acidosis. }\end{array}$} & \multirow{3}{*}{$\begin{array}{l}\text { Levu- } \\
\text { lose per } \\
\mathrm{kg} \text {. of } \\
\text { body- } \\
\text { weight. }\end{array}$} & \multirow{3}{*}{$\begin{array}{l}\text { No. of } \\
\text { experi- } \\
\text { ments. }\end{array}$} & \multirow{3}{*}{$\begin{array}{l}\text { Increase } \\
\text { in heat- } \\
\text { produc- } \\
\text { tion. }\end{array}$} & \multicolumn{5}{|c|}{ Respiratory quotient. } \\
\hline & & & & \multirow[b]{2}{*}{ Basal. } & \multirow{2}{*}{$\begin{array}{l}\text { After } \\
\text { levu- } \\
\text { lose. }\end{array}$} & \multicolumn{3}{|c|}{ Experiments showing- } \\
\hline & & & & & & Increase. & Decrease. & $\begin{array}{c}\text { No } \\
\text { change. }\end{array}$ \\
\hline $\begin{array}{c}0 \\
+ \\
++ \\
+++\end{array}$ & $\begin{array}{l}\text { gm. } \\
1.50 \\
1.45 \\
1.55 \\
1.95\end{array}$ & $\begin{array}{r}20 \\
13 \\
13 \\
5\end{array}$ & $\begin{array}{c}\text { p. } c t . \\
16 \\
15 \\
19 \\
17\end{array}$ & $\begin{array}{r}0.82 \\
.78 \\
.75 \\
.74\end{array}$ & $\begin{array}{r}0.86 \\
.80 \\
.78 \\
.73\end{array}$ & $\begin{array}{r}16 \\
9 \\
10 \\
0\end{array}$ & $\begin{array}{l}2 \\
3 \\
2 \\
4\end{array}$ & $\begin{array}{l}2 \\
1 \\
1 \\
1\end{array}$ \\
\hline Average. & 1.55 & 51 & 17 & .79 & .81 & & & $\ldots$ \\
\hline
\end{tabular}

The increments in the heat-production for the different grades of acidosis vary but 4 per cent; furthermore, the extremes (no acidosis and severe acidosis) agree in showing essentially the same increments. These experiments, therefore, lead to the conclusion that with diabetics the presence or absence of acidosis is without influence upon the stimulating effect of levulose upon the metabolism. Such an observation is surprising, because in the treatment of diabetics, those patients free from acidosis almost invariably appear to tolerate carbohydrate better than those with whom acidosis is present. It suggests that the acidosis itself does not exert as deleterious an influence upon the metabolism of carbohydrate, or at least of levulose, as has generally been thought, and that some other factor must be sought to explain the harmful effect of acidosis clinically.

\section{EFFECT OF INGESTION OF LEVULOSE UPON RESPIRATORY QUOTIENT.}

Effect of Levulose with Basal Quotients of Drfferent Levels.

When the basal metabolism was determined for the 28 diabetics to whom the levulose was later given in 51 experiments, the average respiratory quotient was found to vary between wide limits, i. e., from 0.70 to 0.91 , with an average of 0.79 . The effect of the administration of carbohydrate under such varying conditions, even in health, would be a matter of speculation, for it is possible that with a respiratory quotient of $0.70,1.5$ grams of carbohydrate per kilogram of body-weight would produce a rise different in amount from that found with a respiratory quotient of 0.91 . In the former case the individual is living almost exclusively upon the katabolism of fat and in the latter to a very large extent upon the katabolism of carbohydrate; 
in the one case the body is presumably depleted of carbohydrate and in the latter liberally supplied therewith.

In order, therefore, to secure information upon the effect of levulose when the respiratory quotient is at different levels, the basal and levulose quotients are compared in table 98 for the 44 days on which the patients were studied under both conditions. In this table the respiratory quotients are arranged in four groups: 0.70 to $0.73,0.74$ to $0.78,0.79$ to 0.83 , and 0.85 to 0.91 .

In passing it may be said that the urinary nitrogen per kilogram of bodyweight is recorded in table 98 for the diabetics. With the low and high groups of quotients, the nitrogen excretion per kilogram of body-weight is the same, thus eliminating protein metabolism as a factor.

The average quotient for the seven basal experiments in the first group was 0.72 , and the average amount of levulose given per kilogram of bodyweight, 2 grams. The rise in the quotient for the entire period after the ingestion of this quantity of levulose was 0.04 , but if the average maximum quotient is used (0.81), there was an average maximum increase of 0.09 . The average increase in heat-production with this quotient was 17 per cent.

TABLE 98.-Metabolism in levulose experiments following post-absorptive experiments, with respiratory quotients indicating the predominance of fat, protein, or glycogen katabolism.

[Basal and levulose experiments on same day in each case.]

Levulose Experiments with Diabetics

\begin{tabular}{|c|c|c|c|c|c|c|c|c|c|}
\hline \multirow[t]{2}{*}{ Case No. } & \multirow[t]{2}{*}{ Date. } & \multirow{2}{*}{$\begin{array}{l}\text { Average } \\
\text { respiratory } \\
\text { quotients } \\
\text { in basal } \\
\text { experi- } \\
\text { ments. }\end{array}$} & \multirow{2}{*}{$\begin{array}{c}\text { Jevu- } \\
\text { lose } \\
\text { per } \mathrm{kg} . \\
\text { of } \\
\text { body- } \\
\text { weight. }\end{array}$} & \multicolumn{2}{|c|}{$\begin{array}{l}\text { Respiratory } \\
\text { quotients } \\
\text { in levulose } \\
\text { experiments. }\end{array}$} & \multirow{2}{*}{$\begin{array}{l}\text { Elapsed } \\
\text { time from } \\
\text { taking of } \\
\text { levulose. }\end{array}$} & \multirow{2}{*}{$\begin{array}{l}\text { Increase } \\
\text { in heat- } \\
\text { produc- } \\
\text { tion over } \\
\text { basal. }\end{array}$} & \multirow{2}{*}{$\begin{array}{c}\text { Increase } \\
\text { of average } \\
\text { experi- } \\
\text { mental } \\
\text { respiratory } \\
\text { quotient } \\
\text { over basal. }\end{array}$} & \multirow{2}{*}{$\begin{array}{l}\text { Uri- } \\
\text { nary } \\
\text { nitro- } \\
\text { gen per } \\
\text { kg. of } \\
\text { body- } \\
\text { weight. }\end{array}$} \\
\hline & & & & Avg. & Max. & & & & \\
\hline $\begin{array}{r}1085 \\
1303 \\
332 \\
1196 \\
552 \\
765 \\
1160\end{array}$ & $\begin{array}{l}\text { Oct. } 30,1916 \\
\text { May } 28,1917 \\
\text { Mar. } 31,1911 \\
\text { Dec. } 16,1916 \\
\text { Dec. } 19,1912 \\
\text { Jan. } 25,1916 \\
\text { Oct. } 28,1916\end{array}$ & $\begin{array}{c}0.70 \text { to } 0.73 \\
0.70 \\
.70 \\
.71 \\
.72 \\
.73 \\
.73 \\
.73\end{array}$ & $\begin{array}{l}\text { om. } \\
2.35 \\
1.20 \\
2.50 \\
1.95 \\
2.40 \\
2.20 \\
1.45\end{array}$ & $\begin{array}{r}0.79 \\
.77 \\
.69 \\
.83 \\
.77 \\
.71 \\
.75\end{array}$ & $\begin{array}{r}0.84 \\
.80 \\
.73 \\
.93 \\
.80 \\
.76 \\
.80\end{array}$ & 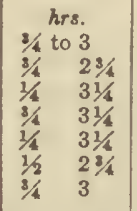 & $\begin{array}{c}\text { p. et. } \\
18 \\
15 \\
20 \\
22 \\
14 \\
7 \\
21\end{array}$ & $\begin{array}{r}0.09 \\
-.07 \\
-.02 \\
.11 \\
-.04 \\
-.02 \\
.02\end{array}$ & $\begin{array}{l}0 m . \\
0.190 \\
.130 \\
.240 \\
.125 \\
1.275 \\
.150 \\
.185\end{array}$ \\
\hline 1160 & Average. . & .72 & 2.00 & .76 & .81 & 10 & 17 & .04 & .170 \\
\hline $\begin{array}{r}1005 \\
632 \\
1051 \\
1147 \\
1303 \\
1058 \\
1196 \\
785 \\
1159 \\
1182 \\
1307 \\
755 \\
1160 \\
1307\end{array}$ & $\begin{array}{l}\text { Mar. } 6,1916 \\
\text { Mar. } 8,1916 \\
\text { May } 25,1916 \\
\text { Oct. 21,1916 } \\
\text { June 11,1917 } \\
\text { May } 23,1916 \\
\text { Dec. } 14,1916 \\
\text { Dec. } 15,1914 \\
\text { Oct. 27,1916 } \\
\text { Nov. 20,1916 } \\
\text { June } 7,1917 \\
\text { Apr. 30,1917 } \\
\text { Nov. 4,1916 } \\
\text { June 25,1917 }\end{array}$ & $\begin{array}{c}0.74 \text { to } 0.78 \\
0.74 \\
.75 \\
.75 \\
.75 \\
.75 \\
.76 \\
.76 \\
.77 \\
.77 \\
.77 \\
.77 \\
.78 \\
.78 \\
.78\end{array}$ & $\begin{array}{l}2.00 \\
1.60 \\
1.00 \\
1.50 \\
1.15 \\
1.00 \\
2.05 \\
1.95 \\
1.90 \\
1.35 \\
1.00 \\
.90 \\
1.45 \\
1.20\end{array}$ & $\begin{array}{l}.74 \\
.75 \\
.76 \\
.81 \\
.78 \\
.77 \\
.81 \\
.74 \\
.78 \\
.83 \\
.79 \\
.80 \\
.79 \\
.80\end{array}$ & $\begin{array}{l}.82 \\
.78 \\
.80 \\
.84 \\
.81 \\
.79 \\
.88 \\
.78 \\
.82 \\
.89 \\
.84 \\
.84 \\
.83 \\
.84\end{array}$ & \begin{tabular}{|ll}
1 & to 3 \\
$3 / 4$ & 3 \\
$1 / 2$ & $21 / 2$ \\
$3 / 4$ & $23 / 4$ \\
$3 / 4$ & $23 / 4$ \\
$3 / 2$ & $21 / 2$ \\
$3 / 4$ & $23 / 4$ \\
$3 / 4$ & 3 \\
$3 / 4$ & $31 / 4$ \\
1 & $21 / 2$ \\
$1 / 2$ & $21 / 2$ \\
$3 / 4$ & $23 / 4$ \\
$11 / 4$ & $31 / 2$ \\
$1 / 2$ & $23 / 4$
\end{tabular} & $\begin{array}{r}19 \\
13 \\
15 \\
14 \\
19 \\
15 \\
27 \\
11 \\
18 \\
8 \\
14 \\
11 \\
17 \\
14\end{array}$ & $\begin{array}{l}.00 \\
.00 \\
.01 \\
.06 \\
.03 \\
.01 \\
.05 \\
-.03 \\
.01 \\
.06 \\
.02 \\
.02 \\
.01 \\
.02\end{array}$ & $\begin{array}{l}.070 \\
.105 \\
.110 \\
1.100 \\
.085 \\
.080 \\
.185 \\
.155 \\
.110 \\
.070 \\
.105 \\
.080 \\
.135 \\
.150\end{array}$ \\
\hline & Average.... & .76 & 1.45 & .78 & .83 & $\cdots \cdots$ & 15 & .02 & .110 \\
\hline
\end{tabular}

On preceding day. Not included in the average. 
TABLE 98.-Metabolism in levulose experiments jollowing post-absorptive experiments, with respiratory quotients indicating the predominance of fat, protein, or glycogen katabolism-Continued.

Levulose Experments with Diabetics-Continued.

\begin{tabular}{|c|c|c|c|c|c|c|c|c|c|}
\hline \multirow[t]{2}{*}{ Case No. } & \multirow[t]{2}{*}{ Date. } & \multirow{2}{*}{$\begin{array}{l}\text { Average } \\
\text { respiratory } \\
\text { quotients } \\
\text { in basal } \\
\text { experi- } \\
\text { ments. }\end{array}$} & \multirow{2}{*}{$\begin{array}{c}\text { Levu- } \\
\text { lose } \\
\text { per kg. } \\
\text { of } \\
\text { body- } \\
\text { weight. }\end{array}$} & \multicolumn{2}{|c|}{$\begin{array}{l}\text { Respiratory } \\
\text { quotients } \\
\text { in levulose } \\
\text { experiments. }\end{array}$} & \multirow{2}{*}{$\begin{array}{l}\text { Elapsed } \\
\text { time from } \\
\text { taking of } \\
\text { levulose. }\end{array}$} & \multirow{2}{*}{$\begin{array}{c}\text { Inerease } \\
\text { in heat- } \\
\text { produc- } \\
\text { tion over } \\
\text { basal. }\end{array}$} & \multirow{2}{*}{$\begin{array}{c}\text { Inerease } \\
\text { of average } \\
\text { experi- } \\
\text { mental } \\
\text { respiratory } \\
\text { quotient } \\
\text { over basal. }\end{array}$} & \multirow{2}{*}{$\begin{array}{l}\text { Uri- } \\
\text { nary } \\
\text { nitro- } \\
\text { gen per } \\
\text { kg. of } \\
\text { body- } \\
\text { weight. }\end{array}$} \\
\hline & & & & Avg. & Max. & & & & \\
\hline $\begin{array}{r}610 \\
1085 \\
1303 \\
1307 \\
610 \\
1049 \\
1066 \\
1181 \\
1196 \\
1213 \\
755\end{array}$ & $\begin{array}{lr}\text { May } 15,1916 \\
\text { Oet. } 23,1916 \\
\text { June } 4,1917 \\
\text { June } 14,1917 \\
\text { Mar. } 15,1917 \\
\text { May } 19,1916 \\
\text { May } 26,1916 \\
\text { Nov. } 23,1916 \\
\text { Dec. } 15,1916 \\
\text { Feb. } 14,1917 \\
\text { May } 7,1917 \\
\text { May } 14,1917 \\
\text { May } 21,1917 \\
\text { May } 10,1917 \\
\text { Oet. } 19,1916 \\
\text { May } 27,1916 \\
\text { May } 31,1916\end{array}$ & $\begin{array}{c}0.79 \text { to } 0.83 \\
0.79 \\
.79 \\
.79 \\
.79 \\
.80 \\
.80 \\
.80 \\
.80 \\
.80 \\
.80 \\
.81 \\
.81 \\
.81 \\
.81 \\
.81 \\
.82 \\
.83\end{array}$ & $\begin{array}{r}0 m . \\
1.05 \\
1.60 \\
1.20 \\
1.05 \\
1.00 \\
.95 \\
1.00 \\
1.80 \\
1.95 \\
1.90 \\
.95 \\
.95 \\
1.00 \\
.90 \\
1.65 \\
2.00 \\
1.00\end{array}$ & $\begin{array}{l}0.81 \\
.80 \\
.79 \\
.82 \\
.78 \\
.80 \\
.88 \\
.81 \\
.78 \\
.88 \\
.83 \\
.85 \\
.86 \\
.84 \\
.86 \\
.88 \\
.82\end{array}$ & $\begin{array}{r}0.84 \\
.83 \\
.82 \\
.85 \\
.84 \\
.86 \\
.95 \\
.84 \\
.91 \\
1.02 \\
.88 \\
.90 \\
.92 \\
.89 \\
.90 \\
.94 \\
.87\end{array}$ & 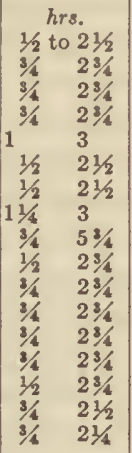 & $\begin{array}{c}p . c t . \\
16 \\
9 \\
23 \\
5 \\
14 \\
22 \\
6 \\
25 \\
24 \\
26 \\
14 \\
12 \\
5 \\
14 \\
6 \\
32 \\
13\end{array}$ & $\begin{array}{r}0.02 \\
.01 \\
.00 \\
.03 \\
-.02 \\
.00 \\
.08 \\
.01 \\
-.02 \\
.08 \\
.02 \\
.04 \\
.05 \\
.03 \\
.05 \\
.06 \\
-.01\end{array}$ & $\begin{array}{c}o m . \\
0.065 \\
.185 \\
.080 \\
.130 \\
.085 \\
.185 \\
.100 \\
.125 \\
.115 \\
.120 \\
.135 \\
.110 \\
\ldots . . \\
.100 \\
.290 \\
1.155 \\
.155\end{array}$ \\
\hline 1059 & Average.... & .80 & 1.30 & .83 & .89 & $\ldots \ldots \ldots$ & 16 & .03 & .130 \\
\hline $\begin{array}{l}1213 \\
1233 \\
1259 \\
1213 \\
1233 \\
1213\end{array}$ & $\begin{array}{l}\text { Feb. } 7,1917 \\
\text { Feb. } 19,1917 \\
\text { Mar. } 31,1917 \\
\text { Feb. } 21,1917 \\
\text { Feb. } 26,1917 \\
\text { Feb. } 28,1917\end{array}$ & $\begin{array}{c}0.85 \text { to } 0.91 \\
0.85 \\
.86 \\
.86 \\
.87 \\
.87 \\
.91\end{array}$ & $\begin{array}{l}1.90 \\
1.55 \\
1.50 \\
1.90 \\
1.55 \\
1.80\end{array}$ & $\begin{array}{l}.85 \\
.95 \\
.81 \\
.97 \\
.95 \\
.92\end{array}$ & $\begin{array}{r}.95 \\
1.00 \\
.87 \\
1.04 \\
1.08 \\
.96\end{array}$ & $\begin{array}{ll}3 / 4 & \text { to } 23 / 4 \\
1 & 3 \\
3 / 4 & 23 / 4 \\
3 / 2 & 23 / 4 \\
3 / 4 & 3 \\
3 / 4 & 23 / 4\end{array}$ & $\begin{array}{l}28 \\
14 \\
15 \\
16 \\
19 \\
24\end{array}$ & $\begin{array}{r}.00 \\
.09 \\
-.05 \\
.10 \\
.08 \\
.01\end{array}$ & $\begin{array}{l}.185 \\
.210 \\
.125 \\
.150 \\
.090 \\
.240\end{array}$ \\
\hline 1213 & Average.... & .87 & 1.70 & .91 & .99 & & 19 & .04 & .165 \\
\hline
\end{tabular}

Levulose Experiments with Normal Subjeçts.

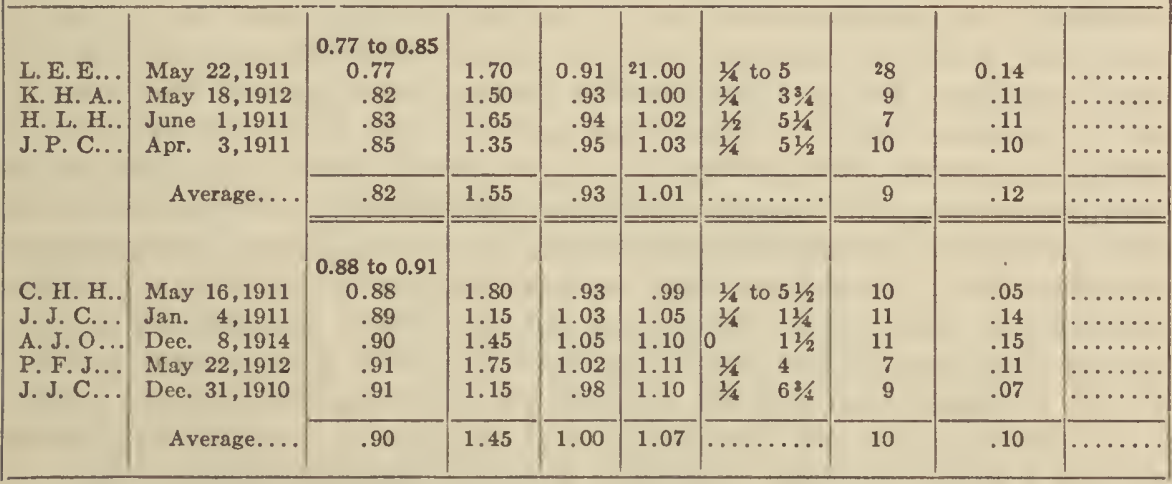

1 On preceding day. Not included in the average.

2 The period of increment in this experiment was shorter than the experimental period. The average respiratory quotient for the period of inerement only was 0.95 , an inerease of 0.18 over basal. 
In the second group of quotients, drawn from 14 experiments, the average basal quotient was 0.76 . The quantity of levulose given was somewhat less, being 1.45 grams per kilogram of body-weight. The average rise in the quotient was 0.02 , the average maximum rise 0.07 , and the increase in the heat-production 15 per cent.

For the third group, in which the quotients represent 17 experiments, the average quotient was 0.80 . In these experiments the quantity of levulose given was still further reduced, being on the average 1.30 grams per kilogram of body-weight. The average rise in quotient following this ingestion of carbohydrate was 0.03 , with an average maximum increase of 0.09 . The average increase in the heat-production was 16 per cent.

The average for the final group of these basal quotients was 0.87 , with an ingestion, on the average, of 1.70 grams of levulose per kilogram of bodyweight. The average rise in quotient was 0.04 , with an average maximum rise of 0.12 , while the average increase in the heat-production was 19 per cent.

For comparison the respiratory quotients of the eight normal subjects who took levulose in the study of carbohydrates previously referred to (see p. 206) are divided into two groups, namely, those with basal quotients averaging 0.82 , and those with quotients averaging 0.90 . The quantity of levulose per kilogram of body-weight given to each group was essentially the same. As a result it will be observed that the two groups reacted equally to the levulose, with practically the same rise in average respiratory quotient, i. e., 0.12 and 0.10 . Moreover, the average maximum effect with each group was almost identical. The rise in metabolism was the same for both groups.

This study of the effect of levulose at different levels of the respiratory quotient shows, therefore, that the increase after food is independent of whether the basal quotient is low or high, and that this statement holds not only for the average quotients of the entire periods, but also for the average maximum quotients. Finally, the increase in heat-production over basal after the ingestion of levulose is practically the same at all quotient levels, the greatest variation between the averages of the diabetic groups being but 4 per cent. The uniformity in rise of the respiratory quotient after levulose, quite independent of the low or high basal quotient, is contrary to what takes place with glucose. Loeffler ${ }^{a}$ found that single doses of 50 to 150 grams of glucose had no effect upon the gaseous metabolism of diabetics, and led to glycogen storage, but that when a second dose was given within six to seven hours it caused an increase in the carbon dioxide in proportion to the sugar consumed. This action of levulose is contrary, too, to what would be anticipated by investigations along another line. Staub's ${ }^{b}$ work on blood sugar indicated that a protein-fat diet, as shown by a low respiratory quotient, presented an unfavorable substratum for the action of carbohydrate, the storage of glycogen in the body being depleted. With a respiratory quotient of 0.70 , indicating a protein-fat diet, one would not expect so good a utilization of the levulose, provided it was first changed in the body to glucose, as with a higher quotient indicating a carbohydrate-protein-fat diet. Of course it is possible that in the present series of experiments the amount

\footnotetext{
a Loeffler, Zeitschr. f. klin. Med., 1919, 87, p. 309.
}

${ }^{b}$ Staub, Biochem. Zeitschr., 1921, 118, p. 93. 
of glucose formed from levulose was so great that it not only sufficiently filled the reservoirs, but afforded sufficient for oxidation, too; but if this were the case one would not expect a rise in the respiratory quotient with small quantities of levulose, and such did take place. One avoids all these difficulties if one assumes that the levulose is first transformed into fat, because in that event the quotient would rise to an equal degree independently of the basal respiratory quotient.

\section{Variations in Quotients in Different Periods of Basal Experiments.}

Not only were variations found in the respiratory quotients of the different basal experiments, but considerable variations were likewise noted in the different periods of individual experiments. It is again pointed out that although the clinical respiration chamber gives surprisingly uniform results for periods as short as 30 minutes, it is really not a form of apparatus designed for such brief intervals of time. There is also another factor which must be considered. In post-absorptive experiments when preliminary periods are short, one has no hesitation in discarding the first in a series of four periods, but when the metabolism is to be determined after food has been ingested, particularly carbohydrate food which has immediate effect, each minute saved is to be desired. One should therefore study the degree of uniformity of the respiratory quotient in the different periods of single observations of the basal metabolism so as not to be misled by the variations in the respiratory quotients in food experiments, particularly as it is necessary to know whether the so-called "peak" effect of food is worthy of attention or whether it should be disregarded. The following instance will serve as an illustration:

With Case No. 1303, respiratory quotients were obtained with the clinical chamber as follows in four successive periods of an observation of the basal metabolism: $0.69,0.69,0.73$ and 0.70 , with an average of 0.70 for the experiment. A week later, however, the basal respiratory quotients for the four periods of an experiment with the same patient were $0.85,0.71,0.89$, and 0.73 , with an average of 0.79 . At first sight, the quotients in the last experiment would appear to be erroneous, and if obtained with a respiration apparatus might rightly be excluded, whereas this would not be the case when obtained, as in this instance, with the respiration chamber. If averages are taken of the first two and the last two periods, they will be found to be 0.78 and 0.81 , respectively. The oxygen intake was the cause of the discrepancies in that it was not truly representative of the conditions existing at the end of each period, but compensation took place during the longer intervals.

A study of the respiratory quotients in the experiments which served as basal to the levulose experiments reveals that there was a variation of 0.01 to 0.05 in the different periods of 22 experiments, of 0.06 to 0.11 in 25 experiments, and of 0.14 to 0.18 in 4 experiments. The largest variation was obtained with but one patient, i. e., Case No. 1303 referred to above.

Variations in Quotients in Different Periods of Levolose Experinents.

A wider variation of the respiratory quotients in different periods of the experiments with levulose, or any carbohydrate for that matter, is to be expected, because the effect of carbohydrate upon the quotient is at first considerable and then gradually subsides. If capable of demonstration this 
would in itself serve as proof of the combustion of the levulose, provided that a consistent tendency in the variation in successive periods was also found. A slight average change in the respiratory quotient for single periods would mean little, because it has already been demonstrated that this takes place with the periods of the basal experiments. On account of the wide variations for the different periods of the basal metabolism experiments, it is plain that it would be unwise to lay great weight upon the comparison of a single levulose experiment, period for period, with the corresponding basal experiment. Furthermore, differences less than 0.02 in the average respiratory quotient for a single basal and a single levulose experiment should not be considered of sufficient significance for argument. It is manifest, however, that when a series of many basal and many levulose experiments is studied, a difference in the grand averages of even 0.02 would be worthy of note.

When the periods of the levulose experiments are examined, the differences between the respiratory quotients in the same experiment prove to be far greater than was found with those of the basal experiments. Thus, there was but one experiment in which the quotients varied from each other less than 0.05 ; there were but 4 experiments in which the variations in the different periods were limited to $0.05,31$ experiments with variations between 0.06 and $0.11,10$ experiments with variations between 0.12 and 0.18 , and 1 each with a variation between the quotients as great as $0.21,0.26$, and 0.29 , as well as two with a variation of 0.22 .

Comparison of Basal Respiratory Quotients of Diabetics with Respiratory QUOTIENTS AFTER INGESTION OF LRVULOSE.

The average respiratory quotient in the basal control experiments with the diabetics preceding the ingestion of levulose was 0.79 , and for the interval during which the metabolism was tested after the ingestion of levulose was 0.81 , a rise of but 0.02 . The lowest average respiratory quotient observed in an experiment following levulose was 0.69 and the highest 0.97 . In the levulose experiment with the minimum average quotient, the quotient in the first period was 0.63 . If this period should be discarded, the average quotient for the experiment would then be 0.71 , or if the values for the first two hours after levulose only are included, it would be 0.72 .

In 11 experiments there was not only no rise, but a fall in the average quotient. In four experiments this amounted to 0.01 , in five experiments, to 0.02 , and in one experiment each to 0.03 and 0.05 . In five experiments no change whatever in the average quotient was observed. In 35 experiments there were average increases in quotient ranging from 0.01 in seven to 0.11 in one experiment. As the rise in quotient grew greater between these extremes, the number of experiments in which these changes were observed gradually decreased.

Effect on Respiratory Qdotient of Varying Amounts of Levulose Per Kilogram of BODY-WEIGHT.

The slight increase in the respiratory quotient after levulose seems peculiar and an explanation should be sought. It will be remembered that there was a consistent rise in the metabolism with increasing quantities of levulose per kilogram of body-weight (see table 95, p. 215). This intimate relation 
is not found between the respiratory quotient and the amounts of levulose. While it is true that the greatest increases in the quotient occurred when the largest amounts of levulose were given, and also the lowest increases with the lowest quantities of levulose, yet various inconsistencies were found. For example, in the 35 experiments with increases in the respiratory quotient, the amounts ingested averaged 1.50 grams of levulose per kilogram of bodyweight, and in the experiments with no change in the quotient the levulose per kilogram of body-weight was practically the same, 1.55 grams. It is still more disconcerting to find that the patients in the 11 experiments with a fall in respiratory quotient received larger quantities of levulose, namely, 1.70 grams per kilogram of body-weight, than either the group with rising quotients, or the group with unchanged quotients.

A determination of the influence upon the respiratory quotient of variation in the quantities of levulose ingested has been further sought by a separation of the patients into three groups in table 99, according to the amount of levulose ingested. In this table only those quotients were used which were obtained within two hours of the ingestion of the levulose. The quantity of levulose ingested varied between 0.90 and 1.25 grams, 1.30 and 1.75 grams, and 1.80 and 2.50 grams per kilogram of body-weight. The number of experiments in each group is so large as to give reliability to the respective averages. The average basal respiratory quotient for all three groups was 0.79 ; the average respiratory quotients for the three groups of levulose experiments were $0.81,0.82$, and 0.83 , respectively, thus indicating but slight change, even when the amount of levulose per kilogram of body-weight was doubled. It is true that only a given number of calories can be oxidized by an individual in one hour, but nevertheless when large quantities of carbohydrate food are administered, a higher respiratory quotient has not infrequently been found with normals, rising even above unity, than when smaller quantities of carbohydrate have been given. Carpenter ${ }^{a}$ noted no definite change in the respiratory quotient in four experiments when 25 grams of levulose were given by rectum, but after 50 grams of levulose, there was an increase of 0.03 to 0.05 in two experiments after 1 to 2 hours, and in a third experiment an increase of 0.15 within 3 hours of the injection. Evidence, therefore, both for and against, is afforded for the theory of metabolism which is based on the number of food molecules in the blood. The practical uniform increase in respiratory quotient found with diabetics after the taking of varying quantities of levulose is akin to the recent work of various writers who have shown that even after small quantities of glucose the rise in blood sugar is the same as after larger quantities.

In the series of experiments with 8 normal men at the Laboratory, the increase in respiratory quotient 2 hours after 100 grams levulose were given to 7 of the number was 0.15 , and in two experiments with one individual after 75 grams levulose were taken, the result was the same, 0.14. Thus, neither with diabetics nor with a limited number of normals was the increase in respiratory quotient affected by varying amounts of levulose.

The 7 experiments with these normals, in which the amount of levulose ingested was 100 grams (1.60 grams per kilogram of body-weight), have

- Carpenter, Am. Journ. Physiol., 1922, 59, Proc. Am. Physiol. Soc., p. 440. 
been compared in table 100 with 14 experiments with diabetics to whom levulose was given in like amount, though on the basis of body-weight it was 1.80 grams per kilogram. In this comparison only those quotients are used which were obtained within approximately two and one-fourth hours after the ingestion of the levulose. These data show an average rise in the quotient with the diabetics from 0.76 to 0.81 , as compared to a rise in quotient with the series of normals from 0.85 to 1.00 . (See p. 226.)

TARLE 99.-Average respiratory quotients of diabetics in levulose and control experiments grouped according to varying amounts of levulose given.

[Respiratory quotients obtained in the first 2 hours after the taking of levulose.]

\begin{tabular}{|c|c|c|c|}
\hline Case No. & Date. & $\begin{array}{l}\text { Average respiratory } \\
\text { quotient, basal. }\end{array}$ & $\begin{array}{l}\text { Respiratory quotient } \\
\text { in first } 2 \text { hours } \\
\text { after levulose. }\end{array}$ \\
\hline \multirow{3}{*}{610} & & & $\cdot$ \\
\hline & May $15-16,1916 \ldots \ldots \ldots \ldots$ & 0.79 & 0.80 \\
\hline & Mar. $15-16,1917 \ldots \ldots \ldots \ldots$ & .80 & .79 \\
\hline \multirow[t]{4}{*}{755} & Apr. 30-May 1, 1917 ...... & .78 & .79 \\
\hline & May $7-8,1917 \ldots \ldots \ldots \ldots$ & .81 & .83 \\
\hline & May $14-15,1917 \ldots \ldots \ldots \ldots$ & .81 & .85 \\
\hline & May $21-22,1917, \ldots \ldots \ldots \ldots$ & .81 & .88 \\
\hline 1011 & May $10-11,1917 \ldots \ldots \ldots \ldots$ & .81 & .87 \\
\hline 1049 & May $19-20,1916 \ldots \ldots \ldots \ldots$ & .80 & .83 \\
\hline 1051 & May $25-26,1916 \ldots \ldots \ldots \ldots$ & .75 & .75 \\
\hline 1058 & May $23-24,1916 \ldots \ldots \ldots \ldots$ & .76 & .76 \\
\hline 1059 & May 31-June 1, 1916...... & .83 & .82 \\
\hline 1066 & May $26-27,1916 \ldots \ldots \ldots \ldots$ & .80 & .90 \\
\hline \multirow[t]{3}{*}{1303} & May $28-29,1917, \ldots \ldots \ldots \ldots$ & .70 & .78 \\
\hline & June $4-5,1917 \ldots \ldots \ldots \ldots$ & .79 & .79 \\
\hline & June $11-12,1917, \ldots \ldots \ldots \ldots$ & .75 & .78 \\
\hline \multirow[t]{4}{*}{1307} & June $7-8,1917 \ldots \ldots \ldots \ldots$ & .77 & .82 \\
\hline & June $14-15,1917 \ldots \ldots \ldots \ldots$ & .79 & .82 \\
\hline & June $25-26,1917 \ldots \ldots \ldots \ldots \ldots$ & .78 & .80 \\
\hline & Average. . . . . . . . . . . & .79 & .81 \\
\hline \multicolumn{4}{|c|}{1.30 to 1.75 grams levulose per kilogram. } \\
\hline \multirow[t]{3}{*}{632} & Mar. $8-9,1916 \ldots \ldots \ldots \ldots$ & 0.75 & 0.75 \\
\hline & Mar. $15-16,1916 \ldots \ldots \ldots \ldots$ & 1.75 & .80 \\
\hline & Mar. $22-23,1916 \ldots \ldots \ldots \ldots$ & 1.75 & .81 \\
\hline \multirow[t]{2}{*}{1011} & Mar. $30-31,1916 \ldots \ldots \ldots \ldots$ & 1.76 & .76 \\
\hline & Apr. $\quad 4-5,1916 \ldots \ldots \ldots \ldots$ & 1.76 & .74 \\
\hline \multirow[t]{2}{*}{1085} & Oct. $19-20,1916 \ldots \ldots \ldots \ldots$ & .81 & .84 \\
\hline & Oct. $23-24,1916 \ldots \ldots \ldots \ldots$ & .79 & .79 \\
\hline 1147 & Oct. $21-22,1916 \ldots \ldots \ldots \ldots \ldots$ & .75 & .80 \\
\hline \multirow[t]{2}{*}{1160} & Oct. $28-29,1916 \ldots \ldots \ldots \ldots$ & .73 & .76 \\
\hline & Nov. $4-5,1916 \ldots \ldots \ldots \ldots$ & .78 & .80 \\
\hline 1182 & Nov, $20-21,1916, \ldots \ldots \ldots \ldots$ & .77 & .83 \\
\hline \multirow[t]{2}{*}{1233} & Feb. $19-20,1917 \ldots \ldots \ldots \ldots$ & .86 & .96 \\
\hline & Feb. $26-27,1917 \ldots \ldots \ldots \ldots$ & .87 & 1.00 \\
\hline \multirow[t]{2}{*}{1259} & Mar. 31-Apr. 1, 1917....... & .86 & .83 \\
\hline & Average. & .79 & .82 \\
\hline
\end{tabular}

1 Not on same day. 
TABLE 99.-Average respiratory qustients of diabetics in levulose and control experiments grouped according to varying amounts of levulose given-Continued.

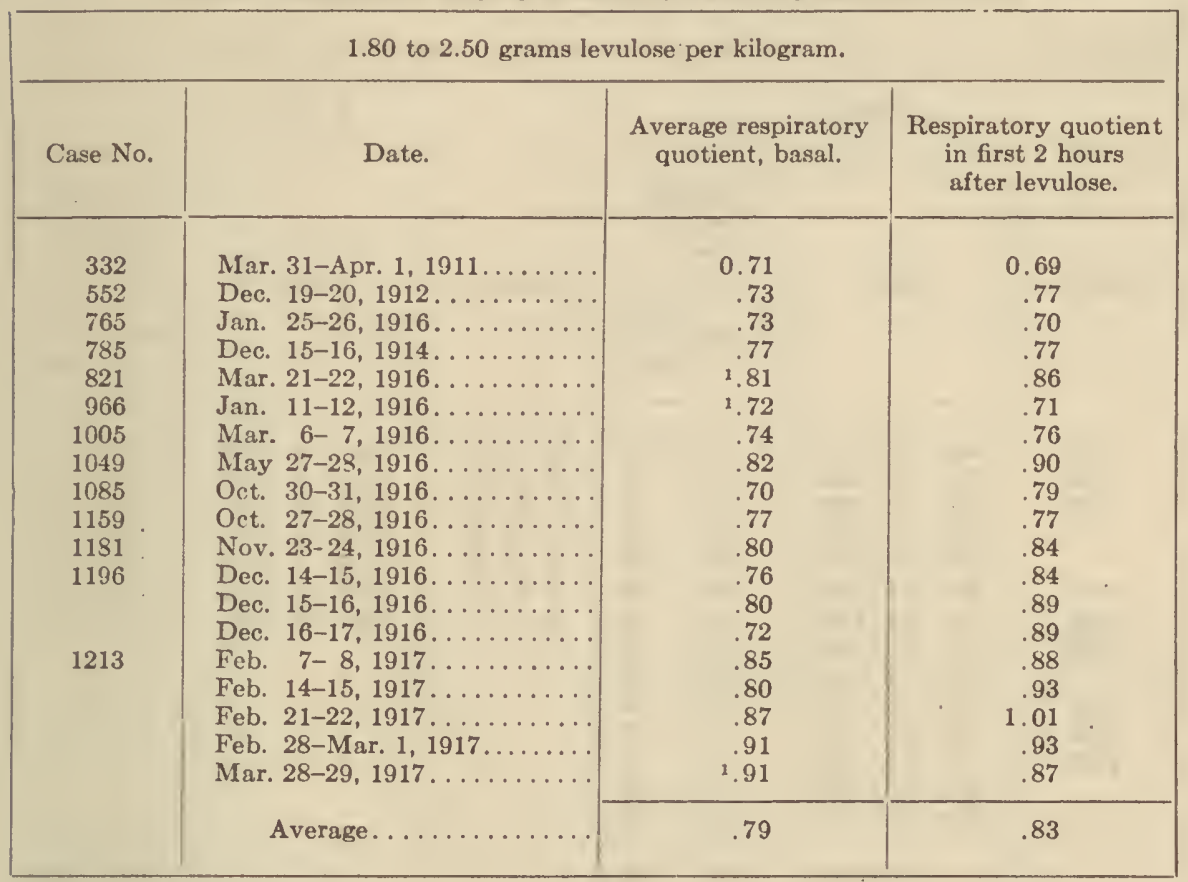

${ }^{1}$ Not on same day.

Effect of Levulose on the Respiratory Quotient in Successive Half-Hodr Periods.

Compared with its effect upon the respiratory quotient of normals, the effect of the administration of levulose to diabetics seems slight. From the analysis of the respiratory quotients thus far given there is little to suggest that the levulose is immediately burned. Such a conclusion, however, is not justified, because it is based upon the average respiratory quotient for the entire period of the experiment after the levulose was taken, as compared with the entire interval of the basal experiment with the same individuals. In view of what has already been noted regarding the rapid combustion of carbohydrate by normal individuals and the utilization of the levulose in these experiments (see p. 214), the suggestion arises that the slight increase in average quotient after levulose secured with diabetics, as compared with their basal respiratory quotient, might be explained on the ground that the rise in quotient after levulose occurred only in the early periods, and that this rise was effaced when a single early period was combined with several later periods. In the experiments with normals it was pointed out that the peak of oxidation occurred within 40 to 60 minutes after levulose was given. ${ }^{a}$ Unfortunately, our data will not show what took place for the first 30 or 35 minutes after the patients took levulose, as this time was occupied in closing the apparatus and for a preliminary period of adjustment. Subsequently, however, reliable records were obtained in 30 -minute periods and the average results for these periods are presented in tables 101 and 102.

a Benedict and Carpenter, Carnegie Inst. Wash. Pub. No. 261, 1918, p. 246. 
TABLE 100.-Comparison of respiratory quotients in experiments with diabetic and normal subjects after the ingestion of 100 gms. of levulose.

[Quotients averaged are those obtained within about $2 \frac{1}{6}$ hours after the ingestion of levulose.]

\begin{tabular}{|c|c|c|c|c|c|c|c|}
\hline \multicolumn{4}{|c|}{ Diabetics. } & \multicolumn{4}{|c|}{ Normals. } \\
\hline \multirow{2}{*}{ Case No. } & \multirow{2}{*}{ Date. } & \multicolumn{2}{|c|}{$\begin{array}{l}\text { Average } \\
\text { respiratory } \\
\text { quotient. }\end{array}$} & \multirow{2}{*}{ Subject. } & \multirow{2}{*}{ Date. } & \multicolumn{2}{|c|}{$\begin{array}{c}\text { Average } \\
\text { respiratory } \\
\text { quotient. }\end{array}$} \\
\hline & & Basal. & $\begin{array}{l}\text { After } \\
\text { levu- } \\
\text { lose. }\end{array}$ & & & Basal. & $\begin{array}{l}\text { After } \\
\text { levu- } \\
\text { lose. }\end{array}$ \\
\hline 332 & Mar. 31, 1911 & 0.71 & 0.70 & K. H. A. & May 18,1912 & 0.82 & 0.96 \\
\hline 552 & Dec. 19,1912 & .73 & .78 & J.P.C. & Apr. 3,1911 & .85 & 1.01 \\
\hline \multirow[t]{3}{*}{632} & Mar. 8, 1916 & .75 & .75 & L. E. E. & May 22,1911 & .77 & .96 \\
\hline & Mar. 15, 1916 & .75 & .80 & C. H. H. & May 16,1911 & .88 & .95 \\
\hline & Mar. 22, 1916 & .75 & .81 & H. L. H. & June 1,1911 & .83 & 1.00 \\
\hline 821 & Mar. 21, 1916 & .81 & .86 & P. F. J. & May 22,1912 & .91 & 1.05 \\
\hline 1147 & Oct. 21,1916 & .75 & .80 & A. J. 0 . & Dec. 8,1914 & .90 & 1.05 \\
\hline \multirow[t]{2}{*}{1160} & Oct. 28,1916 & .73 & .76 & & & & \\
\hline & Nov. 4,1916 & .78 & .80 & & & & \\
\hline 1181 & Nov. 23,1916 & .80 & .84 & & & & \\
\hline & Nov. 20,1916 & .77 & .83 & & & & \\
\hline \multirow[t]{4}{*}{1196} & Dec. 14,1916 & .76 & .84 & & & & \\
\hline & Dec. 15,1916 & .80 & .89 & & & & \\
\hline & Dec. 16,1916 & .72 & .89 & & & & \\
\hline & Average... & .76 & .81 & & & .85 & 1.00 \\
\hline
\end{tabular}

Fortunately, it was possible to secure basal experiments preceding 44 of the 51 levulose experiments. In table 102 basal and levulose tests were all upon the same day. In four instances in table 101 it was necessary to use basal values which were obtained in experiments made $1,5,7$, and 10 days, respectively, before the levulose experiment with which it was compared, and for still another experiment a quotient obtained 6 days afterwards. In two instances, averages were used of basal quotients determined 7 days before and after and 14 days before and after the food experiment. The uniformity in the quotients of the basal periods is well shown in table 101. In the periods designated as second, third, fourth, and fifth half-hours, i. e., in the first two hours of the observations, the respiratory quotients averaged precisely the same throughout, i. e., 0.79 . This average was based upon from 42 to 51 experiments for each half hour. The basal value for the sixth half-hour is drawn from only 5 experiments, with an average slightly less than the preceding averages, 0.76. Confidence in the technique of experimentation is established by such a series of results.

The levulose experiments began, on the average, about 35 minutes after the food was taken. The average quotient for the first period of the experiment (the second half-hour after the ingestion of the food) was 0.84 , and is drawn from 45 experiments. For each succeeding half-hour, even through the eighth half-hour, the average quotients fell steadily and for the most part uniformly, being 0.83 in the third, 0.81 in the fourth, and 0.79 in the 
fifth half-hour, all drawn from 47 to 51 experiments. In the sixth half-hour the quotient was 0.74 , as obtained in 7 experiments, and in the seventh half-hour, 0.72 , an average secured from 2 experiments. Individual quotients were obtained for Case No. 1196 in the eighth, ninth, and tenth half-hours after levulose, with values of $0.70,0.72$, and 0.69 , respectively.

This distinct rise over the basal quotient which was found after levulose and which persisted, though gradually declining, is the best proof that levulose was being oxidized, at least in the early periods. The uniformity in the quotients for the basal experiments leads one to expect in the levulose experiments no change in quotient from the second to the fifth half-hour, except such as may be due to the ingestion of the food. It will be observed

$\mathrm{T}_{\mathrm{ABLE}}$ 101.-The average respiratory quotients before and after ingestion of levulose arranged in successive periods of time.

\begin{tabular}{|c|c|c|c|c|c|c|c|c|c|}
\hline \multirow[b]{2}{*}{ Kind of experiments. } & \multicolumn{9}{|c|}{ Average respiratory quotient in- } \\
\hline & $\begin{array}{c}2 \mathrm{~d} \\
\text { half- } \\
\text { hour. }\end{array}$ & $\begin{array}{c}\text { 3d } \\
\text { half- } \\
\text { hour. }\end{array}$ & $\begin{array}{l}\text { 4th } \\
\text { half- } \\
\text { hour. }\end{array}$ & $\begin{array}{c}\text { 5th } \\
\text { half- } \\
\text { hour. }\end{array}$ & $\begin{array}{c}\text { 6th } \\
\text { half- } \\
\text { hour. }\end{array}$ & $\begin{array}{l}7 \text { th } \\
\text { half- } \\
\text { hour. }\end{array}$ & $\begin{array}{l}\text { 8th } \\
\text { half- } \\
\text { hour. }\end{array}$ & $\begin{array}{l}\text { 9th } \\
\text { half- } \\
\text { hour. }\end{array}$ & $\begin{array}{l}10 \text { th } \\
\text { half- } \\
\text { hour. }\end{array}$ \\
\hline Diabetics: & & & & & & & & & \\
\hline $\begin{array}{l}\text { Basal............ } \\
\text { After levuloses. }\end{array}$ & $\begin{array}{r}0.79 \\
8.84\end{array}$ & $\begin{array}{r}0.79 \\
83\end{array}$ & $\begin{array}{r}0.79 \\
81\end{array}$ & $\begin{array}{r}0.79 \\
79\end{array}$ & $\begin{array}{r}0.76 \\
.74\end{array}$ & $\begin{array}{r}0.76 \\
.72\end{array}$ & 70 & 0.72 & 0.69 \\
\hline $\begin{array}{l}\text { Percentage increase in } \\
\text { heat-production..... }\end{array}$ & ${ }^{3} 16$ & 16 & 18 & 18 & 16 & $\begin{array}{r}.72 \\
9\end{array}$ & $\begin{array}{r}0.60 \\
13\end{array}$ & 10 & 10 \\
\hline $\begin{array}{l}\text { Normals: } \\
\text { Basal experiment aver- }\end{array}$ & & & & & & & & & \\
\hline $\begin{array}{l}\text { ages }{ }^{8} \ldots \ldots \ldots \ldots \\
\text { After levulose }\end{array}$ & $\left|\begin{array}{r}0.88 \\
71.04\end{array}\right|$ & $\begin{array}{l}0.87 \\
1.00\end{array}$ & $\begin{array}{r}0.86 \\
.98\end{array}$ & $\begin{array}{r}0.85 \\
.97\end{array}$ & $\begin{array}{r}0.85 \\
.94\end{array}$ & $\begin{array}{r}0.82 \\
.86\end{array}$ & $\begin{array}{r}0.86 \\
.93\end{array}$ & $\begin{array}{r}0.85 \\
.90\end{array}$ & $\begin{array}{r}0.83 \\
.84\end{array}$ \\
\hline $\begin{array}{l}\text { Percentage increase in } \\
\text { heat-production..... }\end{array}$ & ${ }^{7} 12$ & 14 & 13 & 11 & 7 & $3-2$ & 5 & 3 & 1 \\
\hline
\end{tabular}

1 The first period in the levulose experiments was begun on the average about 35 minutea after the taking of levulose.

The amounts of levulose taken by the diabetic subjects included in this table varied from 0.90 to 2.50 grams per kilogram of body-weight.

Respiratory quotients were obtained in the first half-hour after levulose as follows: Case No. 332, 0.63; Case No. 552, 0.75, with increases in heat-production of 30 and 10 per cent, respectively.

- From Benedict and Carpenter, Carnegie Inst. Wash. Pub. No. 261, 1918.

- Basal quotients here used for the normals are experiment averages basal to the levulose experiments represented in each half hour.

- Levulose taken by normals included in this comparison varied from 1.15 to 1.80 grams per kilogram of body-weight.

7 In the first half-hour for normals the average respiratory quotient was 1.01 ; the average increase in heat-production 10 per cent. The average basal experiment respiratory quotient for the corresponding eight subjects was 0.87 .

8 Based upon one experiment.

that by the fifth half-hour the average respiratory quotient following levulose had decreased to 0.79 , this value corresponding exactly with the average quotient for the first two hours of the basal experiments made on the same day. It can therefore be said that the effect of levulose upon the respiratory quotient when administered to diabetic patients in the amounts stated continued up to the fifth half-hour after its administration. How high the quotient rises in the first half-hour is not known, but it is demonstrated that 
the maximum quotient in subsequent half-hour periods begins with the second half-hour.

This comparison in table 101 of the relative effect of the levulose in successive half-hour periods explains why the average quotient obtained for the entire periods of the levulose experiments was so little above the average for the entire periods of the basal experiments. Since the effect of levulose upon the respiratory quotient disappears at the end of two hours, in studying the effect of its ingestion one should limit comparisons to the values obtained during the first, second, third, and fourth half-hours. Looking at the table from this point of view, it will be seen that the rise in quotient in the second half-hour was 0.05 , in the third half-hour 0.04 , and in the fourth half-hour 0.02 .

TABLE 102.-The average respiratory quotients immediately before and after the ingestion of levulose in experiments continuing beyond the fifth half-hour.

\begin{tabular}{|c|r|r|r|r|r|r|r|r|r|}
\hline & \multicolumn{2}{|c|}{ Average respiratory quotients, basal, and for each half-hour } \\
after levulose.
\end{tabular}

1 The beginning of this second half-hour in levulose experiments was on the average about 35 minutes after the taking of levulose.

2 Basal quotients here used are experiment averages basal to the levulose experiments represented in each half hour. The number of basal and levulose experiments represented in the halfhours from $2 \mathrm{~d}$ to 7 th were respectively $4,6,8,8,7$, and 2. But one levulose experiment extended through the eighth, ninth, and tenth half-hours.

3 The amounts of levulose taken by the eight diabetics included in the table varied from 1.00 to 2.50 grams per kilogram of body-weight.

- Data with this case are included in the above averages.

5 Levulose ingested per kilogram on Dec. 15-16, 1916, was 1.95 grams.

For the sake of comparison, the lower half of this table contains a summary of levulose experiments upon normals prepared in similar manner. The normals differed from the diabetics in one striking particular. With them the increases in the respiratory quotient continued into the ninth half-hour instead of ending at the fourth half-hour as with the diabetics. So far as heatproduction was concerned, that of the diabetics was invariably higher, but the two groups agreed save in one experiment with a normal individual in which the heat-production reached the basal level in the seventh half-hour instead of persisting throughout the tenth half-hour as with the other normals and with all the diabetics. 
The effect of levulose in the later half-hours is further indicated by the data in table 102 , in which have been tabulated the results obtained in a few experiments which were more extended than usual. For comparison, basal values are also included in the table, these basal values representing quotients obtained with the same patients as those with whom the levulose quotients were secured. For these basal quotients, however, average values for the whole experimental period were used, as it was not always possible to obtain quotients determined in the half hours of the basal experiments which corresponded with those in the levulose experiments, especially in the eighth, ninth, and tenth half-hours. Such a comparison is permissible, as the basal quotient has been shown to change but little, on the average, during the course of the experiment. (See table 101.)

Analysis of the quotients after levulose shows for this smaller group of patients much the same picture as that for the entire group of 51 experiments in table 101. In the second half-hour the levulose quotient was 0.09 above basal, in the third half-hour 0.06 , and in the fourth half-hour 0.03 higher, but in the fifth half-hour it was 0.02 below basal. The course of these quotients apparently indicates that the increase due to levulose persists throughout the fourth half-hour, then the quotient falls below the basal level. Since the quotients in the fifth half-hour were obtained in 8 experiments, it would seem as if the evidence were trustworthy.

In the seventh half-hour the basal and levulose quotients of the diabetics in table 102 are identical (0.72), but these values represent but two experiments. The levulose quotients for the last three half-hours represent single determinations with but one individual (Case No. 1196), and therefore are more of general interest than of standard value.

Although both tables 101 and 102 are concerned chiefly with respiratory quotients, the increases in the heat-production after food are likewise recorded for comparison. It will be observed that these persisted not only for six half-hours, which is the customary length of duration of the increase in heatproduction with normals under similar conditions, but continued even until the tenth half-hour. Diabetic data do not suffice to show the prolonged duration of the action of levulose with a large group of cases, but as the marked increase was found to persist throughout the fifth half-hour in as many as 47 experiments, it is very evident that this is a general rule. In considering the action of levulose with diabetics, therefore, one must bear in mind its prolonged effect in raising the metabolism even for 5 hours.

In the lower portion of table 102 are given the results with the diabetic who was observed after the ingestion of levulose for a period of 10 half-hours on December 15-16, 1916 (Case No. 1196). The basal quotients for successive half-hours are used in this comparison instead of the average for the whole basal period, as was done in the upper part of the table, but the average heatproduction is still employed in computing the increase for the heat-production, as has been the rule throughout this monograph. The increase over basal in the respiratory quotient with this patient was 0.08 in the second half-hour, 0.04 in the third half-hour, and 0.14 in the fourth half-hour. From this point onward there are no data for the basal respiratory quotient.

The metabolism of Case No. 1196 after levulose rose 41 per cent in the second half-hour and 40 per cent in the third half-hour, in the subsequent 
three half-hours the increases were, respectively, 20,36 , and 25 per cent. Even to the tenth half-hour the metabolism was 10 per cent above the average basal metabolism for this day. An increase in heat-production of 41 per cent after the ingestion of carbohydrate is an anomaly in health and hitherto unreported in diabetes.

Levolose Experiments in which Respiratory Quotient Remained Unchanged OR FELL.

In five experiments after levulose was ingested, no change in the average respiratory quotient was observed and in 11 experiments an actual fall was recorded. This appeared so exceptional and was at such variance with the great mass of data that the experiments with these cases are given in detail

TABLE 103.-Average respiratory quotients after the ingestion of levulose in experiments which show no change, or an actual fall from basal quotient.

\begin{tabular}{|c|c|c|c|c|c|c|}
\hline \multirow{2}{*}{$\begin{array}{l}\text { Time in } \\
\text { half-hours. }\end{array}$} & \multicolumn{3}{|c|}{ No change in average quotient. ${ }^{2}$} & \multicolumn{3}{|c|}{ With fall in average quotient. ${ }^{2}$} \\
\hline & $\begin{array}{c}\text { Basal experi- } \\
\text { ment } \\
\text { averages. }\end{array}$ & $\begin{array}{c}\text { After } \\
\text { levulose. }\end{array}$ & $\begin{array}{l}\text { Increase in } \\
\text { heat-pro- } \\
\text { duction. }\end{array}$ & $\begin{array}{c}\text { Basal experi- } \\
\text { ment } \\
\text { averages. }\end{array}$ & $\begin{array}{c}\text { After } \\
\text { levulose. }\end{array}$ & $\begin{array}{l}\text { Increase in } \\
\text { heat-pro- } \\
\text { duction. }\end{array}$ \\
\hline $\begin{array}{l}2 d^{6} \\
3 d^{4} \\
4 \text { th } \\
5 \text { th } \\
6 \text { th } \\
7 \text { th } \\
8 \text { th } \\
9 \text { th } \\
10 \text { th }\end{array}$ & 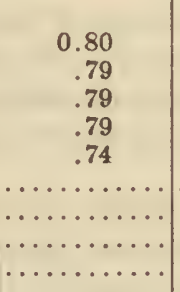 & 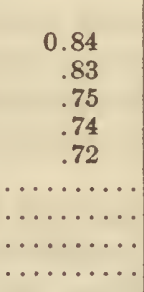 & 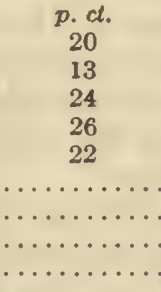 & $\begin{array}{r}0.80 \\
.79 \\
.79 \\
.78 \\
.77 \\
.71 \\
.80 \\
.80 \\
.80\end{array}$ & $\begin{array}{l}0.81 \\
.78 \\
.77 \\
.77 \\
.72 \\
.69 \\
.70 \\
.72 \\
.69\end{array}$ & $\begin{array}{l}\text { p. } c t . \\
16 \\
17 \\
19 \\
14 \\
18 \\
14 \\
13 \\
10 \\
10\end{array}$ \\
\hline
\end{tabular}

1 With all subjects showing no change in the average quotient, there was a rise in quotient in the first or the first two periods after levulose.

2 In six of the eleven experiments showing falls in the average quotient, there was a rise in quotient in one or both of the first two periods after levulose. In two of these six experiments there was a rise in either the third or fourth period; in four other experiments there was a rise in one or both of the third and fourth periods after levulose. In five of the experiments in this group, the basal value was obtained from one to ten days before the levulose experiment.

- Basal quotients here used are experiment averages basal to the levulose experiments represented in each half hour.

The amounts of levulose taken by the five subjects included in this average varied from 0.95 to 2.00 grams per kilogram of body-weight.

The amounts of levulose taken by the ten subjects included in this average varied from 1.00 to 2.50 grams per kilogram of body-weight.

- The beginning of this second half-hour, i. e., the first period after levulose, was on the average about 35 minutes after the taking of levulose.

in table 103. The value of comparisons of the period quotients immediately following the ingestion of the levulose as compared with comparisons of the average quotients for the observations has already been emphasized. This method of tabulation has therefore been followed here, and brings out the fact that in the first group, although the average for the entire period did not change, yet the respiratory quotient did rise in the second and third halfhours after levulose was taken. Thereafter the respiratory quotient fell to below the basal respiratory quotient in a manner analogous to that of blood 
sugar with normals. The average increase in the metabolism in this group of levulose experiments was higher than usual (21 per cent).

Considering the group of levulose experiments in which the average respiratory quotient actually fell, it may be seen that this fall is accounted for almost wholly by the marked fall below basal of the respiratory quotient after the fifth half-hour. Before that time the average respiratory quotients for the basal and levulose experiments were essentially constant. In this series of experiments the metabolism rose on the average 16 per cent. A rise in metabolism following the ingestion of levulose is therefore independent of a rise in respiratory quotient.

High Respiratory Quotients Obtained After Administration of Levelose.

In four experiments with two cases the respiratory quotient rose considerably above normal after the ingestion of levulose. The quotients obtained are given in table 104. Case No. 1213 received on February 14, 1917, 1.90 grams of levulose per kilogram of body-weight. The average basal respiratory quotient of this patient on this day was 0.80 , but after the levulose it rose to 0.94 , dropped in the third half-hour to 0.83 , rose again in the fourth half-hour to 1.02 , and in the fifth half-hour dropped to 0.73 . It might be thought that the considerable variations in the respiratory quotient counterbalanced one another, but this is not the case as is shown by a duplicate experiment on February 21, 1917, with the same individual after the ingestion of a like amount of levulose. On this day the average basal respiratory quotient was 0.87 . After the levulose, the quotient maintained a consistently higher level, the four values for the succeeding halfhours being $0.98,1.01,1.04$, and 0.86 , respectively. If one examines the respiratory quotients of these experiments in the protocols, it will be found that the carbon dioxide eliminated increased proportionately more than the oxygen absorbed.

So extraordinary did these high respiratory quotients appear for a case of severe diabetes after the ingestion of carbohydrate that one would have doubted their existence had they not been duplicated with this patient and also in two experiments with still another patient (Case No. 1233). With the second individual, who received 1.55 grams of levulose per kilogram of bodyweight, the quotient was maintained in both experiments at an exceptionally high level for a diabetic, and ranged in the second, third, and fourth half-hour periods from 0.93 to 1.08 . The peak increase in the experiment of February 19, which occurred in the second half-hour after the ingestion of the levulose, was 0.14 over the average basal quotient of 0.86 , while that in the experiment of February 26, which was found in the third half-hour period, was 0.21 over the average basal quotient of 0.87 , and 0.23 over the basal quotient for the corresponding period. In both experiments the levulose quotients decreased in the fifth half-hour, thus confirming the reliability of the other quotients.

Still another experiment with the first patient (Case No. 1213) is included in table 104, as it gives nearly analogous results, although the levulose ingested was in this case combined with fat. The amounts of the two food materials were the same, namely, 1.85 grams each of levulose and fat per kilogram of body-weight. Here, too, with an average basal respiratory quotient of 0.84 , the respiratory quotient rose after levulose to above 1.00 and, 
in fact, was maintained at a higher level throughout the four half-hour periods than in any of the other experiments. It was above basal even in the fifth half-hour.

TABLE 104.-Respiratory quotients arranged in successive periods of time for two subjects who showed unusually high quotients afier levulose.

\begin{tabular}{|c|c|c|c|c|}
\hline & $\begin{array}{l}\text { Second } \\
\text { half- } \\
\text { hour. }\end{array}$ & $\begin{array}{l}\text { Third } \\
\text { half- } \\
\text { hour. }\end{array}$ & $\begin{array}{c}\text { Fourth } \\
\text { half- } \\
\text { hour. }\end{array}$ & $\begin{array}{l}\text { Fifth } \\
\text { half- } \\
\text { hour. }\end{array}$ \\
\hline 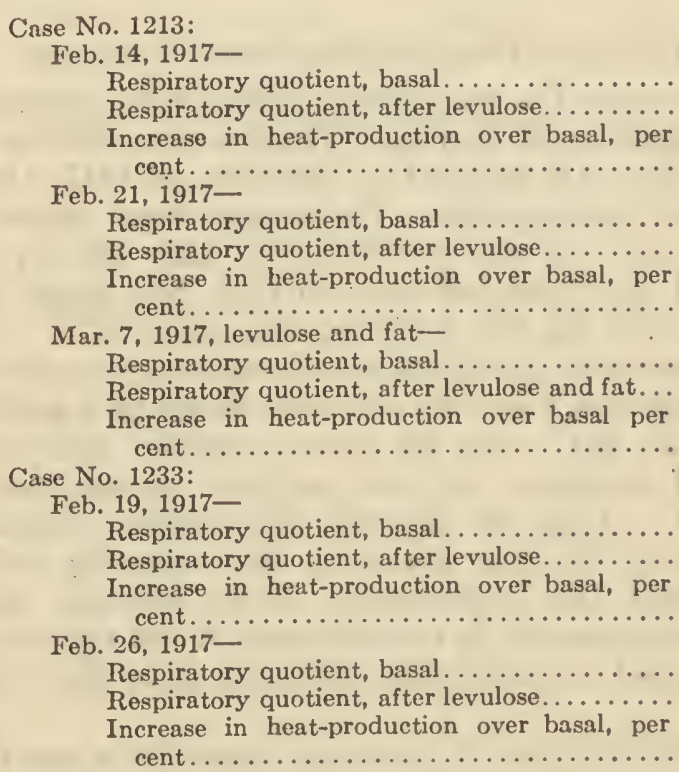 & $\begin{array}{c}0.94 \\
14 \\
\ldots \ldots .9 \\
0.98 \\
22 \\
0.85 \\
1.08 \\
5\end{array}$ & $\begin{array}{c}0.81 \\
0.83 \\
31 \\
0.88 \\
1.01 \\
16 \\
0.83 \\
1.07 \\
7 \\
\\
0.89 \\
0.96 \\
16 \\
0.85 \\
1.08 \\
9\end{array}$ & $\begin{array}{c}0.80 \\
1.02 \\
17 \\
0.81 \\
1.04 \\
9 \\
0.87 \\
0.90 \\
29\end{array}$ & $\begin{array}{c}0.80 \\
0.73 \\
42 \\
0.92 \\
0.86 \\
16 \\
\\
0.81 \\
0.99 \\
10\end{array}$ \\
\hline
\end{tabular}

The quantities of levulose ingested by these two patients were considerable (1.55 to 1.90 grams per kilogram of body-weight), though by no means the highest amounts given in the series. The quotients with both of these patients in all but one of the experiments after levulose alone followed the general rule observed in table 101 with the entire group of cases and in table 102 with the smaller group in demonstrating that the respiratory quotient reverts to its basal value during the fifth half-hour after the levulose is taken. They differ somewhat from the other two series of cases, however, in that the high respiratory quotients obtained in the second half-hour persisted throughout the third and fourth half-hour periods. In fact, the highest quotient for Case No. 1213 was found in both experiments in the fourth half-hour and of Case No. 1233 in one experiment in the third half-hour. That these quotients should temporarily rise so high and then fall in the fifth half-hour, not only to the basal quotient, but in three of the four experiments even below the basal, as was also observed in table 102, is supporting evidence of the accuracy of these observations.

Not only were the highest peaks in the respiratory quotient obtained with these two patients, but the average increases above the basal quotients were 
also among the highest noted; in fact, there were but five other patients (Cases Nos. 1049, 1066, 1085, 1196, and 1303) who showed an average rise in quotient on any day of 0.08 or more.

The patients with the highest respiratory quotients have various points in common. The data for these are collected in table 105. Paradoxical as it may seem, the case most below standard weight (Case No. 1213) had the highest basal respiratory quotients, not only of those used for the levulose experiments in this table, but also of those used for all of the other levulose experiments. The increase in quotient above basal after the administration of levulose was especially marked with this case.

Of the five patients with the highest quotients in the levulose experiments, one was a female (No. 1213) and the other four were males. The ages varied between 17 and 35 years. All were considered severe cases of diabetes at the time of the observations, and all were free from severe acidosis; in fact, only one patient (No. 1196) showed a moderate acidosis and one (No. 755 in the first two observations) a slight acidosis. The average loss in weight below the reported maximum weights was 31 per cent, while the average loss in weight below the standard normal weight was 30 per cent. Excluding the girl diabetic (Case No. 1213), whose metabolism is compared with that of the Girl Scouts, these cases agreed in having a low basal metabolism, although not the very lowest found in the series of observations. The values for blood sugar were distinctly low for diabetics. Out of 15 analyses there were but 6 above 0.20 per cent. The percentages for the 6 blood-fat analyses were definitely above normal, though not especially high. The values for the nonprotein nitrogen were known for the experimental day in but three cases, and two of these (with Case No. 1233) were high. Sugar was absent from the urine, or slight in amount, except with Case No. 1196, who had 35, 26, and 38 grams per 24 hours on the three successive days when the observations were made.

The similarity in severity, substandard weight, and low metabolism existing between the different individuals who had high respiratory quotients and a great rise in respiratory quotient after food suggests that these characteristics may be responsible for this behavior of the respiratory quotient. Whether the peculiarities of subnormal weight and low metabolism, if present in individuals who were not diabetics, would lead to the same changes in respiratory quotient is open to demonstration. Speculation as to the reason for these high quotients is easy. They are so high in the instance of Cases Nos. 1213 and 1233 that it would appear impracticable to explain them in any way other than by a conversion of carbohydrate to fat, strange as this may seem to be in diabetes. (See p. 170.)

Morgulis and Pratt ${ }^{a}$ showed that even when a dog is reduced in weight from 13.8 to 6.1 kilograms as a result of partial extirpation of the pancreas, with consequent failure to assimilate 42 per cent of the nitrogen and 73 per cent of the fat in the food, the change of carbohydrate to fat could go on undisturbed, as shown by the respiratory quotient of 1.06 and 1.04. Perhaps this result took place all the more readily because the dog was emaciated. It is certainly significant that the Russian investigators whom they cite obtained similar results with dogs which had first been subjected to a fast for several days. It would be desirable to observe whether in the presence of under-

C Morgulis and Pratt, Am. Journ. Physiol., 1913, 32, p. 200. 
TABLE 105.-Metabolism and clinical statistics of five cases of severe diabetes having the highest respiratory quotients in levulose experiments.

\begin{tabular}{|c|c|c|c|c|c|c|c|c|c|c|c|c|}
\hline \multirow{2}{*}{$\begin{array}{l}\text { Crse } \\
\text { No. }\end{array}$} & \multirow[t]{2}{*}{ Date. } & \multirow{2}{*}{ 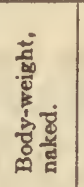 } & \multirow{2}{*}{ 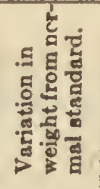 } & \multirow{2}{*}{ 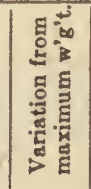 } & \multirow{2}{*}{\multicolumn{2}{|c|}{ 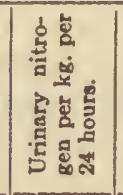 }} & $\begin{array}{l}\text { है } \\
\text { है } \\
\frac{8}{0} \\
\frac{8}{0}\end{array}$ & \multirow{2}{*}{\multicolumn{2}{|c|}{ 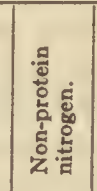 }} & \multirow{2}{*}{ 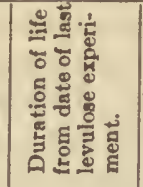 } & \multicolumn{2}{|c|}{$\begin{array}{l}\text { Levulose } \\
\text { ingested. }\end{array}$} \\
\hline & & & & & & & $\frac{\tilde{D}}{8}$ & & & & Total. & $\begin{array}{l}\text { Per } \\
\text { kg. }\end{array}$ \\
\hline \multirow{4}{*}{755} & & ko. & p. $c t$. & p. ct. & \multirow{4}{*}{$\begin{array}{c}g m . \\
0.080 \\
.135 \\
.110 \\
\ldots \ldots\end{array}$} & $\begin{array}{l}\text { p. } c t . \\
0.13\end{array}$ & $\begin{array}{l}\text { p. ct. } \\
\ldots \ldots\end{array}$ & $\begin{array}{l}m g . \\
122\end{array}$ & \multicolumn{2}{|c|}{ years. } & $g m$. & om. \\
\hline & May $7,1917 .$. & 52.4 & -20 & $\begin{array}{l}-21 \\
-24\end{array}$ & & & $14 \mid \cdots$ & \begin{tabular}{l|c}
$\cdots$ & 2 \\
$\ldots$ & $\ldots$
\end{tabular} & $\ldots$ & $\ldots \ldots$ & 30 & $\begin{array}{r}0.90 \\
.95\end{array}$ \\
\hline & May 14, 1917.. & 51.5 & -21 & -25 & & & $12 \ldots$ & $\ldots \ldots$ & $\ldots$. & & 50 & .95 \\
\hline & May $21,1917 .$. & 51.0 & -22 & -26 & & ... & \multirow{2}{*}{$\ldots \ldots$} & $\ldots \ldots$ & \multicolumn{2}{|r|}{0.4} & 50 & 1.00 \\
\hline \multirow[t]{2}{*}{1049} & May $19,1916$. & 41.0 & -26 & -28 & .185 & .21 & & $\ldots \mid \ldots$ & $\ldots$. & & 41 & .95 \\
\hline & May 27, 1916. & 41.3 & -30 & -32 & (2) & \multirow{2}{*}{$\begin{array}{l}.22 \\
.15\end{array}$} & $\ldots$ &.$\ldots$ & $\cdots$ & 0.3 & 82 & 2.00 \\
\hline \multirow[t]{3}{*}{1196} & Dec. $14,1916$. & 48.6 & -27 & -33 & .18 & & 1.1 & 60 & . . & . & 100 & 2.05 \\
\hline & Dec. $15,1916$. & 51.9 & -23 & -29 & .115 & . & $\ldots \ldots$ & $\cdots$ & .1. & & 100 & 1.95 \\
\hline & Dec. 16, 1916. . & 51.9 & -23 & -29 & .12 & .2 & 1.0 & $01 \mid \ldots$ & $\cdots$ & 1.0 & 100 & 1.95 \\
\hline 41213 & Feb. $7,1917$. & 31.2 & -45 & -39 & .18 & & $21 \ldots$ & $\ldots \ldots$ & .1. & & 60 & 1.90 \\
\hline & Feb. 14, 1917.. & 31.2 & -45 & -39 & .120 & & $23 \mid \ldots$ & .. & .1. & & 60 & 1.90 \\
\hline & Feb. $21,1917$. & 31.8 & -45 & -38 & .150 & & $15 \mid \ldots$ & $\ldots \ldots$ &. & & 60 & 1.90 \\
\hline & Feb. $28,1917 .$. & 33.2 & -42 & -35 & .240 & & \begin{tabular}{l|l}
28 & 1.4
\end{tabular} & $15 \ldots$ & & & 60 & 1.80 \\
\hline & Mar. 28, 1917.. & 32.5 & -43 & -36 & .140 &. & 01.4 & $12 \ldots$ & & 2.9 & 60 & 1.85 \\
\hline 1233 & Feb. $19,1917$. & 48.3 & -22 & -30 & .210 & & 1.5 & 110 & & $\cdots$ & 75 & 1.55 \\
\hline & Feb. 26. 1917.. & 48.3 & -22 & -30 & .090 & & 1.3 & 120 & & 1.3 & 75 & 1.55 \\
\hline Case & Date. & 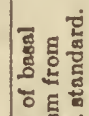 & 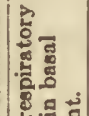 & 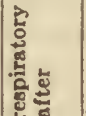 & & $\begin{array}{l}\text { opirato } \\
\text { or each } \\
\text { after le }\end{array}$ & $\begin{array}{l}\text { y quoti } \\
\text { half hou } \\
\text { evulose. }\end{array}$ & ent & $\begin{array}{r}\text { Incres } \\
0 \\
\text { balf }\end{array}$ & $\begin{array}{l}\text { use in he } \\
\text { ver basa } \\
\text { hour af }\end{array}$ & $\begin{array}{l}\text { t-prod } \\
\text { for eac } \\
\text { er levul }\end{array}$ & $\begin{array}{l}\text { action } \\
\mathrm{h} \\
\text { ose. }\end{array}$ \\
\hline No. & & 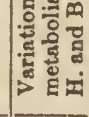 & 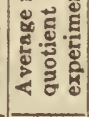 & 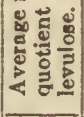 & $\begin{array}{c}2 \mathrm{~d} \\
\text { half- } \\
\text { hour.? }\end{array}$ & $\begin{array}{l}\text { 3d } \\
\text { half- } \\
\text { hour. }\end{array}$ & $\begin{array}{l}\text { 4th } \\
\text { half- } \\
\text { hour. }\end{array}$ & $\begin{array}{l}\text { sth } \\
\text { half- } \\
\text { hour. }\end{array}$ & $\begin{array}{l}2 \mathrm{~d} \\
\text { half- } \\
\text { bour. }\end{array}$ & $\begin{array}{c}\text { 3d } \\
\text { half- } \\
\text { hour. }\end{array}$ & $\begin{array}{l}\text { eth } \\
\text { half- } \\
\text { hour. }\end{array}$ & $\begin{array}{l}\text { 5th } \\
\text { half- } \\
\text { hour. }\end{array}$ \\
\hline 755 & Apr, 30,1917 & $\begin{array}{l}\text { p. } c t . \\
-21\end{array}$ & 0.78 & & & & & & p. ct. & p. ct. & p. ct. & p.et. \\
\hline & May $7,1917 \ldots$ & -23 & .81 & $\begin{array}{r}.80 \\
.83\end{array}$ & $\begin{array}{r}.88 \\
.88\end{array}$ & $\begin{array}{r}.01 \\
.81\end{array}$ & $\begin{array}{r}.78 \\
.79\end{array}$ & $\begin{array}{r}.84 \\
.83\end{array}$ & $\begin{array}{l}11 \\
13\end{array}$ & $\begin{array}{r}9 \\
19\end{array}$ & $\begin{array}{l}13 \\
16\end{array}$ & $\begin{array}{l}9 \\
9\end{array}$ \\
\hline & May $14,1917 \ldots$ & -18 & .81 & .85 & .90 & .84 & .82 & .83 & 12 & 15 & 13 & 10 \\
\hline & May 21, 1917... & -17 & .81 & .86 & .92 & .88 & .85 & .78 & 4 & 5 & 4 & 7 \\
\hline 1049 & May $19,1916 \ldots$ & -20 & .80 & .80 & .82 & .86 & .80 & .72 & 36 & 17 & 9 & 25 \\
\hline & May $27,1916 \ldots$ & -18 & .82 & .88 & .91 & .94 & .85 & .81 & 26 & 26 & 34 & 41 \\
\hline 1196 & Dec. $14,1916 \ldots$ & -19 & .76 & .81 & .88 & .88 & .77 & .72 & 29 & 29 & 22 & 30 \\
\hline & Dec. $15,1916 \ldots$ & -27 & .80 & .78 & .91 & .85 & .91 & .69 & 41 & 40 & 20 & 36 \\
\hline & Dec. 16, 1916... & -22 & .72 & .83 & .92 & .93 & .83 & .71 & 29 & 21 & 24 & 25 \\
\hline 41213 & Feb. $7,1917 \ldots$ & $\ldots \ldots$ & .85 & .85 & .95 & .90 & .80 & .74 & 18 & 19 & 35 & 41 \\
\hline & Feb. 14, 1917 ... & $\ldots \ldots$ & .80 & .88 & .94 & .83 & 1.02 & .73 & 14 & 31 & 17 & 42 \\
\hline & Feb. $21,1917 \ldots$ & $\ldots \ldots$ & .87 & .97 & .98 & 1.01 & 1.04 & .86 & 22 & 16 & 9 & 16 \\
\hline & Feb. $28,1917 \ldots$ & & .91 & .92 & .96 & .95 & .87 & .91 & 24 & 25 & 35 & 11 \\
\hline & Mar. 28, 1917... & & .91 & .89 & .90 & .82 & .90 & .93 & 7 & 17 & 22 & 14 \\
\hline 1233 & Feb. $19,1917 \ldots$ & -33 & .86 & .95 & 1.00 & .96 & .93 & .90 & 14 & 16 & 14 & 14 \\
\hline & Feb. $26,1917 \ldots$ & -28 & .87 & .95 & .93 & 1.08 & .99 & .82 & 25 & 9 & 17 & 23 \\
\hline
\end{tabular}

1 Determined on Mar. 1, 1917.

2 Nitrogen on preceding day was 0.155 gram.

- Blood fat determined 5 days before the experiment.

- Case No. 1213 was a girl diabetic, 17 years of age.

- Blood fat determined on the following day.

- Blood fat determined 7 days before the experiment.

7 The beginning of this second half-hour in levulose experiments was on the average about 35 minutes after the taking of levulose.

- Additional respiratory quotients after levulose were obtained with Case No. 1196; Dec. 15, 1916, sixtb half-hour, 0.74; eighth half-hour, 0.70; ninth half-hour, 0.72 ; tenth balf hour, $0.69 ;$ Dec. 16, 1916, sixth halfhour, 0.74. The increases in heat-production over basal for these additional half-hours were 25, 13, 10, 10, and 10 per cent, respectively. 
nutrition carbohydrate given in temporary excess might be transformed to fat with especial readiness, and particularly if levulose were the carbohydrate used. If this were the case, Morgulis and Pratt's emaciated "Flora" would help explain the high quotients obtained with emaciated diabetics after levulose administration.

Effect of Levulose Given on Different Occasions to the Same Patient.

When levulose was given to the same diabetic patient upon different days, the effect upon the respiratory quotient was not always identical. The data illustrating this are collected in table 106, and are so arranged that they represent the period for the first two hours following the ingestion of the carbohydrate instead of the whole experimental period as in table 105.

After levulose the fluctuations in the average respiratory quotient of the same patient above basal on 2 different days were 0.01 for Case No. 1160, and 0.11 for Case No. 1213 . In two cases there was actually a fall. With four patients the maximum fluctuation in the increase over basal was not over 0.04 , and with a like number it amounted to 0.08 or more. One of these latter instances occurred with Case No. 1196, who was the only case to receive levulose upon three successive days. With this patient the increases in the quotient over basal after similar quantities of levulose per kilogram of bodyweight were $0.08,0.09$, and 0.17 , respectively. These lend support to the statements of Bernstein and Falta, that repeated administration of carbohydrate on successive days leads to better utilization. Case No. 1196 is further discussed on page 229. There was also a rise upon the third successive oatmeal day in a case of Allen and Du Bois. ${ }^{b}$

Case No. 1213 received practically the same quantity of levulose on four different days. The variations in quotient from basal on these days were, respectively, $0.03,0.13,0.14$, and 0.02 . A fifth experiment was also made with Case No. 1213 on March 28, after the ingestion of the same amount of levulose as in the four preceding experiments. The average respiratory quotient for the second, third, and fourth half-hours after the ingestion of the levulose was 0.87. (See table 105.) This was 0.04 below the equal basal values obtained 7 days before and 7 days after the test. It so happened that about 4 hours before the levulose test was begun on this day, the patient took 60 grams of olive oil. The average respiratory quotient for this oliveoil experiment was 0.86 , so that the average value of 0.87 for the respiratory quotient in the first three half-hour periods of the subsequent levulose experiment, which registers a rise of only 0.01 , may be explained as due to the temporary inhibitory influence of the oil, especially as in the last two periods of the levulose experiment, the respiratory quotients were 0.90 and 0.93 . Obviously a single experiment of this character is not conclusive. With Case No. 1213, the diabetes was very severe (see p. 231), and quotients of 1.00 or more were obtained after levulose in eight single periods on five different days during her stay in the hospital. Case No. 1233, whose quotients were also above 1.00 at times, had increases of 0.10 and 0.13 in first two hours after the ingestion of the levulose during an interval of one week. (See table 106.)

- Bernstein and Falta, Deutsch Arch. f. klin. Med., 1916, 121, p. 95.

- Allen and Du Bois, Arch. Intern. Med., 1916, 17, p. 1010. 
There was no essential change in the quotient with Case No. 1085 after 1.65 and 1.60 grams levulose per kilogram body-weight in the first and second experiments, but an increase of 0.09 after 2.35 grams in the third observation.

TABLE 106.- Rise in average respiratory quotient above basal following the ingestion of levulose on different days with the same diabetic patient.

[Respiratory quotient obtained in the first 2 hours after the taking of levulose.]

\begin{tabular}{|c|c|c|c|c|c|c|}
\hline \multirow[b]{2}{*}{$\begin{array}{l}\text { Case } \\
\text { No. }\end{array}$} & \multicolumn{3}{|c|}{ First experiment. } & \multicolumn{3}{|c|}{ Second experiment. } \\
\hline & Date. & $\begin{array}{c}\text { Levulose } \\
\text { per } \\
\text { kilogram } \\
\text { of body- } \\
\text { weight. }\end{array}$ & $\begin{array}{c}\text { Rise in } \\
\text { average } \\
\text { quotient } \\
\text { above basal. }\end{array}$ & Date & $\begin{array}{l}\text { Levulose } \\
\text { per } \\
\text { kilogram } \\
\text { of body- } \\
\text { weight. }\end{array}$ & $\begin{array}{c}\text { Rise in } \\
\text { average } \\
\text { quotient. } \\
\text { above basal. }\end{array}$ \\
\hline $\begin{array}{r}610 \\
632 \\
755 \\
1011 \\
1049 \\
1085 \\
1160 \\
1196 \\
1213 \\
1233 \\
1303 \\
1307\end{array}$ & $\begin{array}{lr}\text { May } & 15,1916 \\
\text { Mar. } & 8,1916 \\
\text { Apr. } & 30,1917 \\
\text { Mar. } 30,1916 \\
\text { May } 19,1916 \\
\text { Oct. } 19,1916 \\
\text { Oct. } 28,1916 \\
\text { Dec. } 14,1916 \\
\text { Feb. } 7,1917 \\
\text { Feb. } 19,1917 \\
\text { May } 28,1917 \\
\text { June } 7,1917\end{array}$ & $\begin{array}{r}\text { am. } \\
1.05 \\
1.60 \\
.90 \\
1.55 \\
.95 \\
1.65 \\
1.45 \\
2.05 \\
1.90 \\
1.55 \\
1.20 \\
1.00\end{array}$ & $\begin{array}{r}0.01 \\
.00 \\
.01 \\
.00 \\
.03 \\
.03 \\
.03 \\
.08 \\
.03 \\
.10 \\
.08 \\
.05\end{array}$ & $\begin{array}{lr}\text { Mar. } 15,1917 \\
\text { Mar. } 15,1916 \\
\text { May } 7,1917 \\
\text { Apr. } 4,1916 \\
\text { May } 27,1916 \\
\text { Oct. } 23,1916 \\
\text { Nov. } 4,1916 \\
\text { Dec. } 15,1916 \\
\text { Feb. } 14,1917 \\
\text { Feb. } 26,1917 \\
\text { June } 4,1917 \\
\text { June } 14,1917\end{array}$ & $\begin{array}{l}g m . \\
1.00 \\
1.60 \\
.95 \\
1.60 \\
2.00 \\
1.60 \\
1.45 \\
1.95 \\
1.90 \\
1.55 \\
1.20 \\
1.05\end{array}$ & $\begin{array}{r}-0.01 \\
.05 \\
.02 \\
-.02 \\
.08 \\
.00 \\
.02 \\
.09 \\
.13 \\
.13 \\
.00 \\
.03\end{array}$ \\
\hline \multirow[b]{2}{*}{$\begin{array}{c}\text { Case } \\
\text { No. }\end{array}$} & \multicolumn{3}{|c|}{ Third experiment. } & \multicolumn{3}{|c|}{ Fourth experiment. } \\
\hline & Date. & $\begin{array}{l}\text { Levulose } \\
\text { per } \\
\text { kilogram } \\
\text { of body- } \\
\text { weight. }\end{array}$ & $\begin{array}{c}\text { Rise in } \\
\text { average } \\
\text { quotient } \\
\text { above basal. }\end{array}$ & Date. & $\begin{array}{l}\text { Levulose } \\
\text { per } \\
\text { kilogram } \\
\text { of body- } \\
\text { weight. }\end{array}$ & $\begin{array}{c}\text { Rise in } \\
\text { average } \\
\text { quotient } \\
\text { above basal. }\end{array}$ \\
\hline 610 & & om. & & & $g m$. & \\
\hline 632 & Mar. 22,1916 & 1.65 & 0.06 & & & $\cdots \cdots$ \\
\hline 755 & May 14,1917 & .95 & .04 & May 21,1917 & 1.00 & 0.07 \\
\hline 1011 & May 10,1917 & .90 & .06 & $\ldots \ldots \ldots \ldots$ & $\ldots \ldots \ldots$ & $\ldots \ldots \ldots$ \\
\hline 1085 & Oct. 30,1916 & $\begin{array}{l}\cdots 35 \\
2.35\end{array}$ & $\begin{array}{c}\cdots \cdots \\
.09\end{array}$ & ${ }_{\cdots \cdots \cdots \cdots} \cdots \cdots$ & $\begin{array}{l}\ldots \ldots \ldots \ldots \\
\ldots \ldots \ldots \ldots\end{array}$ & \\
\hline 1160 & $\ldots \ldots \ldots$ & $\ldots \ldots \ldots$ & $\ldots \ldots \ldots \ldots$ & $\ldots \ldots \ldots \ldots \ldots$ & $\ldots \ldots \ldots$ & $\ldots \ldots \ldots$ \\
\hline 1196 & Dec. 16,1916 & 1.95 & .17 & & $\ldots \ldots \ldots \ldots$ & $\ldots \ldots$ \\
\hline 1213 & Feb. 21,1917 & 1.90 & .14 & Feb. 28,1917 & 1.80 & .02 \\
\hline 1233 & ….......... & $\cdots \cdots \cdots$ & $\cdots \cdots$ & $\ldots \ldots \ldots \ldots$ & $\ldots \ldots \ldots$ & $\ldots \ldots \ldots$ \\
\hline 1303 & June 11,1917 & 1.15 & .03 & $\ldots \ldots \ldots$ & . & $\ldots \ldots \ldots$ \\
\hline 1307 & June 25,1917 & 1.20 & .02 & 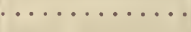 & & $\cdots$ \\
\hline
\end{tabular}

There was a difference of 0.08 in the reaction of the respiratory quotient to the food with Case No. 1303 although the amount of levulose given per kilogram of body-weight did not change essentially for the three experiments.

The average rise in the respiratory quotient for eight cases receiving levulose on 3 days, though in only one instance on successive days, amounted in the first levulose experiment to 0.03 on the first day, 0.04 on the second, and 0.08 
on the third. This indicates a progressive gain in tolerance for carbohydrate while under treatment. A further increase is to be seen with one of the two cases receiving levulose for a fourth time, Case No. 755 showing a progressive rise in the quotient of that case of $0.01,0.02,0.04$, and 0.07 .

The demonstration of improvement in toleration of levulose with diabetics by observations of the respiratory quotient subsequent to test meals has thus been achieved. Their occurrence with these 8 cases of diabetes illustrates not only the inherent possibility for improvement in the disease which is not widely enough recognized, but also another means by which such improvement can be measured.

\section{Carbohydrate Balance in Levulose Experiments.}

Carbohydrate balances are available both for the day preceding the levulose experiment and for the day of the levulose test as well. On both of these days it will be found that the carbohydrate balances were usually positive, but from this circumstance it should not be inferred that these cases were mild in character. Far from it. The cases whose carbohydrate balances are known were nearly all severe cases, their permanent tolerance for carbohydrate was low, they were usually receiving quantities of carbohydrate far less in amount than that represented by the levulose. given on experimental days, and they were often on diets which now one more easily recognizes represented undernutrition. It would be much better to compare the results obtained with the actual total glucose balance as recently urged by Woodyatt, or even with the carbohydrate balance based on carbohydrate and protein as urged some years ago by Falta. Even these latter two methods would not be wholly satisfactory because they would not take account of the actual amount of carbohydrate, protein, and fat burned as shown from calculations based upon the total metabolism and non-protein respiratory quotient. For such a close analysis these experiments were not designed and it seems best not to attempt it. (See p. 47 for discussion of non-protein respiratory quotient.) Though the limitations of the data here assembled are fully recognized, deductions are drawn.

Frequently great variations in the carbohydrate balances took place from day to day, particularly in the early experiments. A study of the protocols shows that these variations were not closely related to the metabolism. One of the chief reasons for this is that the positive or negative carbohydrate balances may or may not have simultaneously represented essential changes in the total caloric value of the diet. One should also remember that a change even as great as 50 grams in the carbohydrate balance represents but 200 calories, and this would be divided throughout the entire day, thus amounting to less than 10 calories per hour. Contrast with these meager calories the results obtained when 100 grams of levulose representing 400 calories were given to the subject in one minute.

The carbohydrate balance for the 24 hours preceding the tests with levulose was known for 49 experiments. These balances have been arranged in sequence in the upper part of table 107 and compared with the corresponding figures for the metabolism and the respiratory quotients obtained after levulose had been ingested. The table shows a similar rise of metabolism and of quotient after the levulose, irrespective of whether the carbohydrate balance 
was -20 to -5 or +55 to +75 grams. This holds true both for the average figures of the experiments and for the ranges of increase. A single experiment when the carbohydrate balance was +95 grams gives an increase in the respiratory quotient of 0.06 , but of only 8 per cent in the metabolism.

The relation of the carbohydrate balance of the experimental day to the metabolism and to the respiratory quotient on the same day that the levulose was taken is made clear in the lower part of table 107. When the carbohydrate balance of the experimental day varied between 25 and 60 grams, the respiratory quotient increased in 21 of the 30 experiments with an average increase of 0.02 for the group. When the carbohydrate balance of the experimental day was between 61 and 100 grams, the quotient increased in 14 of 17 experiments, with an average increase for the group of 0.04 . The average increases in heat-production were 15 and 20 per cent, respectively. The greater increases in respiratory quotient were observed with the higher carbohydrate balances, and it so happens that the greater increases in metabolism were also observed with the higher balances. These are results which one might expect as a consequence of the larger quantity of carbohydrate utilized.

TABLE 107.-Relation of heat-production and respiratory quotient of diabetics in levulose experiments to the carbohydrate balance.

\begin{tabular}{|c|c|c|c|c|c|}
\hline \multirow[b]{2}{*}{$\begin{array}{c}\text { Carbohydrate } \\
\text { balance (grams). }\end{array}$} & \multirow{2}{*}{$\begin{array}{l}\text { No. of } \\
\text { experi- } \\
\text { ments. }\end{array}$} & \multicolumn{2}{|c|}{ Respiratory quotient. } & \multicolumn{2}{|c|}{ Heat-production. } \\
\hline & & $\begin{array}{c}\text { Average } \\
\text { increase over } \\
\text { basal. }\end{array}$ & $\begin{array}{l}\text { Range of } \\
\text { increase. }\end{array}$ & $\begin{array}{c}\text { Average } \\
\text { increase over } \\
\text { basal. }\end{array}$ & $\begin{array}{l}\text { Range of } \\
\text { increase. }\end{array}$ \\
\hline $\begin{array}{l}\text { On preceding day. } \\
-20 \text { to }-5 \\
0+25 \\
+30+50 \\
+55+75 \\
+95\end{array}$ & $\begin{array}{r}9 \\
28 \\
6 \\
5 \\
1\end{array}$ & $\begin{array}{r}0.03 \\
.02 \\
.03 \\
.03 \\
.06\end{array}$ & $\begin{array}{ll}-0.02 \text { to } & +0.09 \\
-0.03 & +0.10 \\
-0.05 & +0.08 \\
-0.02 & +0.11 \\
\ldots \ldots \ldots \ldots\end{array}$ & $\begin{array}{l}\text { p. } c t . \\
16 \\
16 \\
16 \\
18 \\
8\end{array}$ & \begin{tabular}{rr}
\multicolumn{2}{c}{$p . c t}$. \\
6 & to 27 \\
5 & 28 \\
6 & 32 \\
13 & 24 \\
$\ldots \ldots$ & $\ldots$
\end{tabular} \\
\hline $\begin{array}{l}\text { On experimental day. } \\
\quad+25 \text { to }+60 \\
+61+100\end{array}$ & $\begin{array}{l}30 \\
17\end{array}$ & $\begin{array}{l}.02 \\
.04\end{array}$ & $\begin{array}{l}-0.02 \text { to }+0.09 \\
-0.05+0.11\end{array}$ & $\begin{array}{l}15 \\
20\end{array}$ & $\begin{array}{l}6 \text { to } 28 \\
8 \quad 32\end{array}$ \\
\hline
\end{tabular}

I Levulose was the only carbohydrate ingested during the day.

\section{Relation Between Metabolism and Variations in Excretion of Sugar in Urine of Diabetics After Levolose.}

Still another method is available for studying the effect of levulose. In table 108 are grouped the data for experiments with severe cases of diabetes in which the carbohydrate excreted in the urine on the experimental days was more than 10 per cent of the levulose administered, also, for comparison, the data are included for the experiments in which no carbohydrate at all was excreted on the levulose days. The amount of sugar excreted, the carbohydrate balance, and the increase over basal of both the heat-production and the respiratory quotient are likewise given in table 108. 
Upon study of the data it will be found that the average carbohydrate balances for these two groups were essentially identical, being +53 grams in the group showing urinary sugar and +56 grams in the group free from sugar. The effect of the levulose on the metabolism and respiratory quotient

TABLE 108.-Comparison of metabolism in levulose experiments with cases of severe diabetes in relation to widely varying excretions of sugar in urine.

[Levulose the only carbohydrate ingested during the day.]

Excretion of Sugar per 24 Hours in Amounts more than 10 per cent of the LEVULOSE TAKEN.

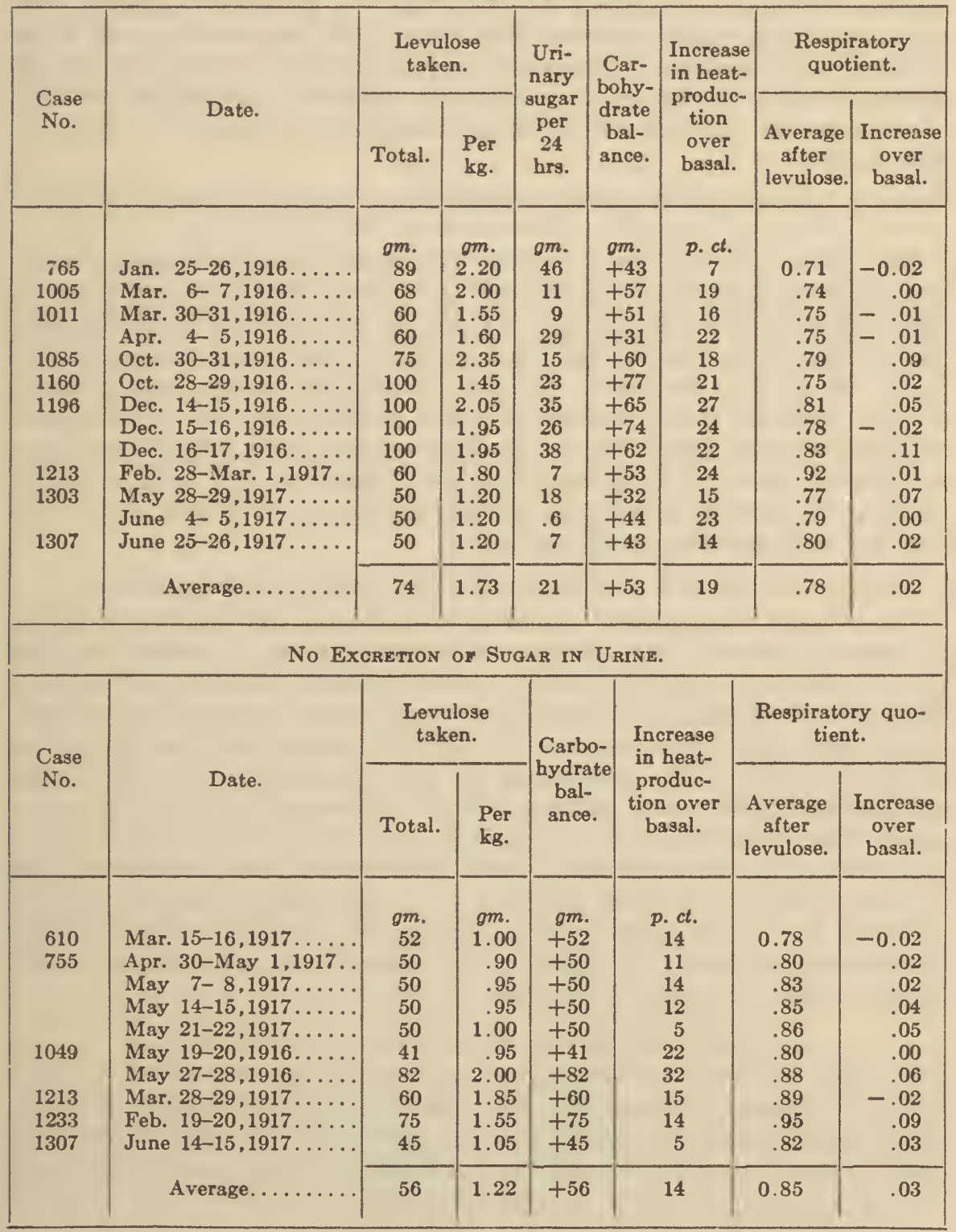


was likewise similar. The group excreting sugar took on the average 1.73 grams of levulose per kilogram of body-weight and the metabolism rose 19 per cent; the other group took about one-third less levulose, i. e., 1.22 grams per kilogram of body-weight, and the metabolism rose 14 per cent. The average increases in the respiratory quotient were 0.02 and 0.03 , respectively. Thus the complete or incomplete utilization of the levulose as measured by the subsequent excretion of sugar in the urine shows no effect upon the metabolism or the respiratory quotient.

Incidentally, the table is of use for another purpose. The data discussed above show that the ingestion of levulose by two groups of diabetics, with differing average basal quotients of 0.76 and 0.82 , respectively, and a like average basal metabolism of 16 per cent below standard, produced essentially the same effect with each group on both the respiratory quotient and the heatproduction. It confirms the results reached by another method of analysis. (See p. 220.)

Effect of Severity of Diabetics on Respiratory Quotient after Ingestion of LEVULOSE.

The relation between the severity of the diabetes and the response of the respiratory quotient to levulose can not be determined satisfactorily from the results of our experiments, because of the scant number of mild cases for comparison with the severe. With the 6 moderate cases there was an average rise in the quotient for the six experiments over the average basal quotient of 0.04 . The rise of the average maximum quotient over the corresponding basal quotient was 0.06 . There were 43 experiments with the 21 severe cases of diabetes, these exhibiting an average rise in quotient after levulose for the whole group of 0.02 , and for the average maximum quotient a rise of 0.05 over the corresponding basal quotient.

Effect of Acidosis on Respiratory Qdotient After Ingestion of Levolose.

The effect of the presence or absence of acidosis upon the response of the respiratory quotient to the ingestion of levulose is shown in table 97 on page 217. It will be seen that the increase in the respiratory quotient was the greatest when acidosis was absent, being 0.04 ; when acidosis was slight or moderate, the increase in the quotient was 0.02 and 0.03 , respectively, and there is no increase whatever in the quotient in the five experiments when the acidosis was severe, but an actual decrease of 0.01 . If the period is limited to two hours, these increases in the respiratory quotient after levulose would be somewhat higher in some instances, in that the increase with no acidosis would be raised from 0.04 to 0.05 , and with moderate acidosis from 0.03 to 0.05 . Although the total metabolism after levulose was apparently unaffected by the absence or presence of acidosis, it is evident that acidosis had a very definite influence upon the respiratory quotient.

\section{BLOOD SUGAR AND INGESTION OF LEVULOSE.}

Levulose produced no hyperglycemia in the normal individual to whom Folin and Berglund ${ }^{a}$ gave 200 grams. These results are of so much significance in diabetes that their table is here reproduced as table 109 . From the results therein recorded, they conclude and infer:

\footnotetext{
a Folin and Berglund, Journ. Biol. Chem., 1922, 51, p. 213.
} 
(1) That levulose is not directly converted into glucose by the liver, or else the blood sugar would have risen.

(2) That levulose did not appear in the urine because, like glucose, it also has a renal threshold which the rare cases of harmless levulosuria illustrate.

(3) That the rapidity of its disappearance from the blood is "beyond possibility of plausible explanation in terms of metabolism processes."

(4) That the interpretation of the fate of absorbed levulose is as follows:

"The liver retains fructose as well as every other usable sugar to a greater extent in proportion to its weight than do the general tissues such as the muscles. But such retentions by the liver are never even approximately quantitative, and a large fraction of absorbed sugars, possibly the greater part, gets by this organ. Other tissues, such as the muscles, take up sugars from the plasma of arterial blood, and it is this general absorption which prevents excessive accumulations of sugar in the blood. But tissue sugar like blood sugar is normally and predominantly glucose, partly because the major part of our carbohydrate food is made up of glucose, partly because all other usable sugars are gradually converted into this essential sugar. The tissues being relatively well stored with glucose and empty of other sugars, such as fructose, may well be able to absorb these other sugars from the blood so nearly completely that the venous blood used for our analyses shows only traces. The glycogen formation may or may not begin immediately, and at all events need not be the immediate cause for the rapid disappearance of levulose from the blood. Levulose happens to be an excellent glycogen former, but that this is not the immediate cause of its disappearance from the blood is strongly indicated by the results which we have obtained with a much poorer glycogen former-galactose."

TABLE 109.-Effect of ingestion of 200 grams of levulose by normal individual on blood and urine. (Folin and Berglund.)

[Subject, H. B-d. Age, 34 years. Weight, $90 \mathrm{~kg}$. Fasting.]

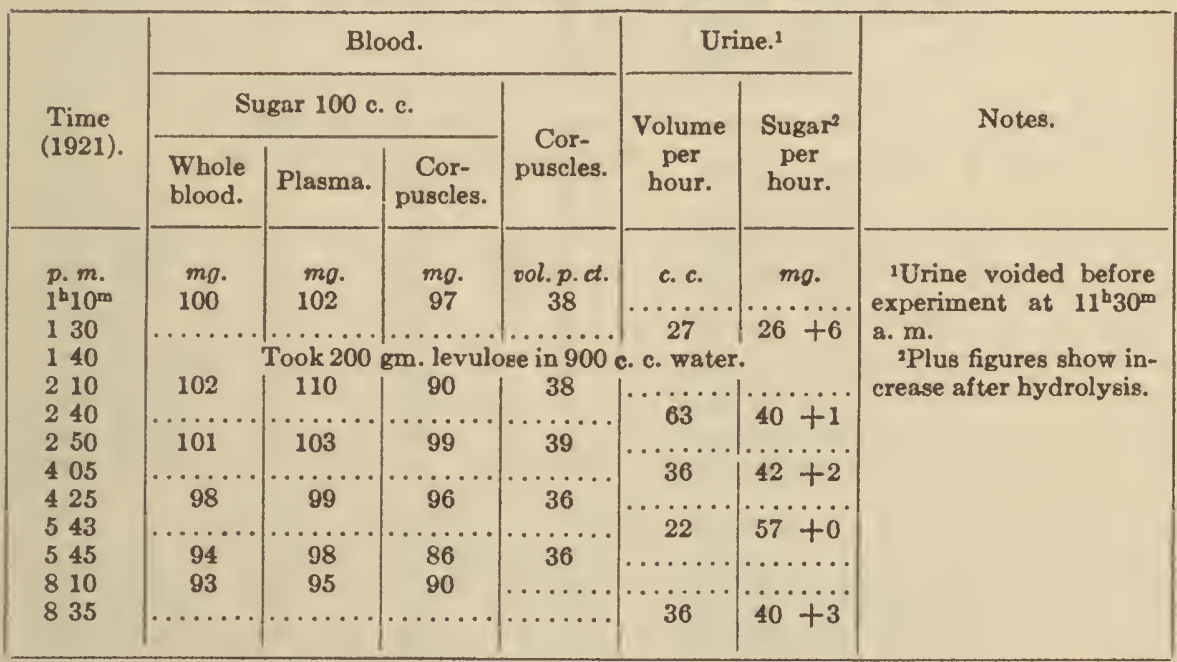

(5) That the above facts and interpretations suggest the possibility of making more extensive use of levulose in diabetes, since past failures may have been due to impurities in the levulose which the early experiments avoided because based on the purest obtainable brands. 
(6) That "the tissues of the diabetic person should contain much higher concentrations of glucose than tissues of normal persons, and this is the immediate reason why the blood sugar rises so high after the intake of glucose in any form. The high concentration of glucose in the tissues would probably have little or no effect on their absorption of fructose. From the giving

TABLE 110.- Comparison of blood sugar before ingestion of levulose with that found on following morning.

\begin{tabular}{|c|c|c|c|c|c|c|}
\hline \multirow{2}{*}{$\begin{array}{l}\text { Levulose in } \\
\text { grams per } \\
\text { kilogram of } \\
\text { body-weight. }\end{array}$} & \multirow[b]{2}{*}{$\begin{array}{l}\text { Case } \\
\text { No. }\end{array}$} & \multirow[b]{2}{*}{ Date. } & \multirow{2}{*}{$\begin{array}{c}\text { Levulose } \\
\text { per kilo- } \\
\text { gram of } \\
\text { body- } \\
\text { weight. }\end{array}$} & \multicolumn{2}{|c|}{ Blood sugar. } & \multirow[b]{2}{*}{$\begin{array}{c}\text { Time of taking } \\
\text { levulose. }\end{array}$} \\
\hline & & & & $\begin{array}{l}\text { Before } \\
\text { levulose } \\
\text { on morn- } \\
\text { ing of ex- } \\
\text { periment. }\end{array}$ & $\begin{array}{l}\text { On } \\
\text { following } \\
\text { morning. }\end{array}$ & \\
\hline \multirow{16}{*}{0.90 to 1.25} & \multirow{2}{*}{610} & & om. & p. ct. & p. ct. & \multirow{15}{*}{ 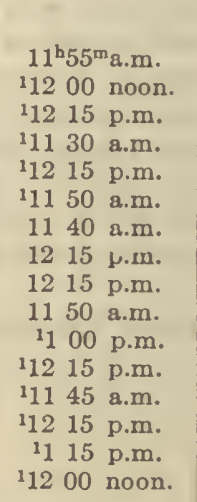 } \\
\hline & & Mar. 15,1917 & $\begin{array}{l}1.05 \\
1.00\end{array}$ & $\begin{array}{r}0.11 \\
.20\end{array}$ & $\begin{array}{r}0.12 \\
.21\end{array}$ & \\
\hline & 755 & Apr. 30,1917 & .90 & .13 & .14 & \\
\hline & & May 7,1917 & .95 & .14 & .11 & \\
\hline & & May 21, 1917 & 1.00 & .10 & .10 & \\
\hline & 1011 & May 10,1917 & .90 & .15 & .16 & \\
\hline & 1051 & May 25, 1916 & 1.00 & .14 & .22 & \\
\hline & 1058 & May 23, 1916 & 1.00 & .16 & .15 & \\
\hline & 1059 & May 31,1916 & 1.00 & .16 & .16 & \\
\hline & 1066 & May 26, 1916 & 1.00 & .21 & .19 & \\
\hline & \multirow[t]{2}{*}{1303} & May 28, 1917 & 1.20 & .17 & .15 & \\
\hline & & $\begin{array}{l}\text { June } 4,1917 \\
\text { June } 11,1917\end{array}$ & $\begin{array}{l}1.20 \\
1.15\end{array}$ & .13 & .15 & \\
\hline & \multirow{4}{*}{1307} & June 7,1917 & 1.00 & .13 & .12 & \\
\hline & & June 14,1917 & 1.05 & .17 & .17 & \\
\hline & & June 25,1917 & 1.20 & .19 & .22 & \\
\hline & & Average. . & 1.05 & 0.15 & 0.16 & \\
\hline \multirow[t]{11}{*}{1.30 to 1.75} & \multirow[t]{3}{*}{632} & Mar. 8, 1916 & 1.60 & 0.20 & 0.24 & \multirow{10}{*}{ 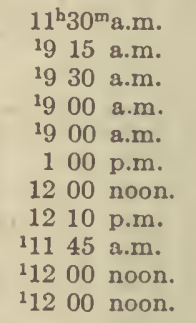 } \\
\hline & & Mar. 15, 1916 & 1.60 & $\therefore 13$ & .14 & \\
\hline & & Mar. 22, 1916 & 1.65 & .19 & .24 & \\
\hline & 1011 & Mar. 30, 1916 & 1.55 & .29 & .31 & \\
\hline & \multirow{2}{*}{1085} & Apr. $\quad 4,1916$ & 1.60 & .27 & .31 & \\
\hline & & Oct. 19,1916 & 1.65 & .26 & .21 & \\
\hline & \multirow[t]{2}{*}{1160} & $\begin{array}{l}\text { Oct. } 23,1916 \\
\text { Oct. } 28,1916\end{array}$ & $\begin{array}{l}1.60 \\
1.45\end{array}$ & $\begin{array}{l}.29 \\
.26\end{array}$ & $\begin{array}{l}.22 \\
.24\end{array}$ & \\
\hline & & Nov. 4,1916 & 1.45 & .20 & .25 & \\
\hline & 1233 & Feb. 26,1917 & 1.55 & .14 & .11 & \\
\hline & 1259 & Mar. 31, 1917 & 1.50 & .22 & .21 & \\
\hline & & Average. . & 1.55 & 0.22 & 0.23 & . \\
\hline \multirow[t]{5}{*}{1.80 to 2.00} & \multirow{5}{*}{$\begin{array}{l}1005 \\
1159 \\
1213\end{array}$} & Mar. 6, 1916 & 2.00 & 0.33 & 0.24 & \multirow{5}{*}{$\begin{array}{l}11^{\mathrm{b}} 45^{\mathrm{m}} \text { a.m. } \\
{ }^{1} 1200 \text { noon. } \\
{ }^{1} 1130 \text { a.m. }\end{array}$} \\
\hline & & Oct. 27,1916 & 1.90 & .24 & .34 & \\
\hline & & Mar. 28, 1917 & 1.85 & .19 & .20 & \\
\hline & & Average. . & 1.90 & 0.25 & 0.26 & \\
\hline & & $\begin{array}{c}\text { Average of } \\
\text { all...... }\end{array}$ & 1.30 & 0.19 & 0.19 & \\
\hline
\end{tabular}

Approximate. 
of fructose we should, therefore, get a much higher concentration of total sugar (glucose plus fructose) in the tissues without any material increase in the sugar of the blood. Because of this higher concentration an increased utilization might well take place. Continuous or excessive use of fructose would, of course, defeat the purpose of the treatment, because gradually this would become equivalent to the loading of all the tissues with glucose, and, because of the large bulk of the tissues, an excessive amount of glucose would pour into the blood and be eliminated with the urine. Such a series of results has, however, no bearing on what would happen from small doses of pure fructose given at carefully regulated intervals. For under such conditions there is not only a larger concentration of sugar in the tissues in relation to the level of the blood sugar, but there is also the possibility that nascent glucose is more easily utilized than ordinary, preformed glucose. At least it seems safe to say that until the effects of pure fructose on diabetics have been carefully investigated from this standpoint the subject has not been exhausted."

For 30 experiments with 17 of the diabetics in our research, the blood sugar was determined early in the morning of the experimental day, before the levulose was given, and again 24 hours later. On both days the blood sugar averaged 0.19 per cent. The detailed results are given in table 110 , grouped according to the amount of levulose given. As a rule, the levulose was administered in the forenoon, and in no experiment included in table 110 was it given after $2 \mathrm{p} . \mathrm{m}$. An examination of the blood-sugar values on the levulose day and on the following morning shows that the average percentage of 0.19 for the two days was by no means an accidental compensatory average, but that the individual differences in blood sugar for the two days with any one case were usually very slight. When the percentages of blood sugar were highest, the alterations were proportionately greater, as would be expected since there is always less accuracy in the determinations of a high blood sugar. So far as the blood is concerned, therefore, the effect of the administration of the levulose, whether in smaller or larger quantities, passed off over night.

Since with the mild cases none of the levulose administered appeared as glucose in the urine, with the moderate cases not over 1.0 per cent, and with the severe cases but 12.0 per cent (see footnote 1 , table 94, p. 213), it is plain that the levulose must either have been oxidized or stored in the body in some form. The return of the respiratory quotient to normal at the end of two hours after the administration of the levulose, together with the absence of sugar in the urine in so many of the experiments and the return of the blood sugar to normal, also supports the contention that considerable portions of the levulose must have been stored directly as glycogen, or in some other form, or very, very slowly oxidized. The conversion of levulose into fat, as indicated by a respiratory quotient over 1.00 , appears probable in many of the experiments, but positive in five experiments and with two individuals. (See table 104, p. 232.)

Yet upon this point one must not be too positive. Case No. 1213 upon February 21-22, 1917, had a basal respiratory quotient of 0.87 . As a result of the ingestion of 60 grams of levulose, of which not more than 1 gram was 
excreted as sugar in the urine, the respiratory quotient rose to 0.97 for an average of 2 hours and 7 minutes. The total computed carbon-dioxide excretion during this period was 13,855 c. c. and the total oxygen consumption was 14,260 c. c. The carbon-dioxide excretion corresponding to this quantity of oxygen as calculated for a basal respiratory quotient of 0.87 would be 12,404 c. c. Subtracting this from the carbon dioxide produced after levulose $(13,855$ c. c.), we have an excess carbon-dioxide excretion of 1,451 c. c. Using Bleibtreu's formula that 270 grams of dextrose (and presumably levulose) sets free 115.45 grams of carbon dioxide in the conversion to 100 grams of fat, this excess of carbon dioxide, which has raised the respiratory quotient from 0.87 to 0.97 , would represent the conversion of 6.6 grams of levulose to fat. Since the combustion of 1 gram of cane sugar produces 1.54 grams of carbon dioxide, the combustion of levulose as carbohydrate to account for the excess of carbon dioxide found in the experiment would amount to about 1.8 grams of levulose. Such calculations obviously disregard other changes taking place in the intermediary metabolism during the period under discussion.

TABLE 111.-Comparison of blood-sugar determinations before and after the ingestion of levulose.

\begin{tabular}{|c|c|c|c|c|c|c|c|c|c|c|}
\hline \multirow{2}{*}{$\begin{array}{l}\text { Case } \\
\text { No. }\end{array}$} & \multirow{2}{*}{ Dete. } & \multicolumn{2}{|c|}{$\begin{array}{l}\text { Blood sugar before } \\
\text { levulose. }\end{array}$} & \multicolumn{2}{|c|}{$\begin{array}{l}\text { Levulose ingested per } \\
\text { kg. of body-weight. }\end{array}$} & \multicolumn{2}{|c|}{$\begin{array}{l}\text { Increase after } \\
\text { levulose. }\end{array}$} & \multicolumn{2}{|c|}{$\begin{array}{l}\text { Blood sugar after } \\
\text { levulose. }\end{array}$} & \multirow{2}{*}{$\begin{array}{l}\text { Blood } \\
\text { sugar on } \\
\text { follow- } \\
\text { ing } \\
\text { morn- } \\
\text { ing. }\end{array}$} \\
\hline & & $\begin{array}{l}\text { Time of } \\
\text { determina. } \\
\text { tion. }\end{array}$ & $\begin{array}{l}\text { Per- } \\
\text { cent- } \\
\text { age. }\end{array}$ & Time. & Amount. & $\begin{array}{l}\text { In heat- } \\
\text { produc- } \\
\text { tion. }\end{array}$ & $\begin{array}{l}\text { In average } \\
\text { respiratory } \\
\text { quotient. }\end{array}$ & $\begin{array}{l}\text { Time of } \\
\text { determins- } \\
\text { tion. }\end{array}$ & $\begin{array}{l}\text { Per- } \\
\text { cent- } \\
\text { age. }\end{array}$ & \\
\hline \multirow[t]{9}{*}{632} & Mar. 81916 & $8^{\mathrm{h}} 00^{\mathrm{m}}$ a.m. & 0.20 & $11^{\mathrm{b}} 30^{\mathrm{m}}$ a.m. & $\begin{array}{l}\mathrm{gm} . \\
1.60\end{array}$ & $\begin{array}{c}\text { p. } c t . \\
13\end{array}$ & 0.00 & $2^{\text {hoom }}$ p.m. & 0.24 & $\begin{array}{l}\text { p. ct. } \\
0.24\end{array}$ \\
\hline & Mar. 151916. & $900 \mathrm{a.m}$. & .13 & 1915 a.m. & 1.60 & 19 & +.05 & 1200 noon & .18 & .14 \\
\hline & Mar. 221916 & ........... & .19 & 1930 a.m. & 1.63 & 19 & +.06 & 100 p.m. & .16 & .24 \\
\hline & Jan. 251916. & & .26 & 240 p.m. & 2.20 & 8 & -.03 & 600 p.m. & .24 & \\
\hline & Dec. 151914 . & 755 a.m. & .24 & ${ }^{11245}$ p.m. & 1.95 & 9 & .00 & 445 p.m. & .34 & 8.29 \\
\hline & Jan. 111916 & . $\ldots \ldots \ldots \ldots$ & .22 & 853 a.m. & 1.85 & 18 & -.01 & 1140 a.m. & .43 & \\
\hline & Mar. 61916. & 1130 a.m. & .33 & 1145 a.m. & 2.00 & 15 & +.02 & 100 p.m. & .43 & .24 \\
\hline & Mar. 301916 & …........ & .29 & 1900 a.m. & 1.55 & 16 & .00 & 1210 p.m. & .40 & .31 \\
\hline & Average. & & 0.23 & & & 15 & +.01 & & 0.30 & \\
\hline
\end{tabular}

1 Approximate.

8 Other carbohydrates eaten after the second blood-sugar determination on Dec. 15, 1914 .

Although it has been brought out in previous discussions that the respiratory quotient returned to the basal value two hours after the levulose was administered, the blood sugar did not return to its basal level in the same length of time so far as our data permit us to infer. But eight observations were made upon the percentage of sugar in the blood within $2 \frac{1}{2}$ to 4 hours after the levulose was given. The results of these are gathered together in table 111. The percentage of sugar in the blood before the levulose was taken averaged 0.23 per cent. The average blood-sugar percentage $21 / 2$ to 4 hours after the food, when the patient had left the respiration chamber, was 0.30 per cent. There were two instances (with Cases Nos. 632 and 765) in which the blood-sugar percentage returned to approximately the basal values during this period, but the utilization of levulose as shown by the respiratory quotient was not remarkable. In several of the experiments the rise in the blood sugar was 0.10 per cent or more, and in one experiment (with Case No. 
966) 0.21 per cent. The increases in sugar after levulose with diabetics are in marked contrast to what occurs with normal individuals.

The fact that there is no hyperglycemia after the administration of levulose to normals as demonstrated by Folin and Berglund is explained by its transformation into fat. This is in line with the unusually high respiratory quotient found with normal individuals and diabetics after its administration. If the levulose were transformed into glycogen, the respiratory quotient would not rise, and if into glucose, it would give an increase in the blood sugar which Folin and Berglund have shown does not take place normally. The possibility should be entertained that the increased metabolism following the administration of levulose, which continues after the respiratory quotient has fallen to the basal value, might be due to the levulose continuing to be burned as fat; and for this theory there is some support because after this period the respiratory quotient falls even below the basal value.

\section{EFFECT OF LEVULOSE ON METABOLISM AND RESPIRATORY QUOTIENT WITH VARYING PERCENTAGES OF SUGAR IN THE BLOOD.}

If a study is made of the effect of the levulose upon the metabolism and the respiratory quotient with the percentage of sugar in the blood at different levels, we find (table 112) that when the percentage of sugar in the blood before the experiment was within normal limits, 0.05 to 0.11 per cent, levulose increased the heat-production 10 per cent. But the quantity of levulose administered in experiments with this percentage of blood sugar averages only 1.15 grams per kilogram of body-weight. As the blood-sugar values rose, the heat-production also rose, but to a considerable extent the interrelation of the two phenomena is negative because the quantities of levulose per kilogram of body-weight simultaneously advanced.

TABLE 112.-Effect of levulose upon the metabolism and the respiratory quotient in experiments with diabetics with various post-absorptive blood-sugar values.

\begin{tabular}{|c|c|c|c|c|c|c|}
\hline \multirow{3}{*}{$\begin{array}{l}\text { Percentage of } \\
\text { blood sugar. }\end{array}$} & \multirow{3}{*}{$\begin{array}{l}\text { No. of ex- } \\
\text { periments. }\end{array}$} & \multirow{3}{*}{$\begin{array}{l}\text { Increase in } \\
\text { heat-pro- } \\
\text { duction over } \\
\text { basal. }\end{array}$} & \multicolumn{3}{|c|}{ Respiratory quotient. } & \multirow{3}{*}{$\begin{array}{l}\text { Average } \\
\text { levulose } \\
\text { per kg. } \\
\text { of body- } \\
\text { weight. }\end{array}$} \\
\hline & & & \multirow{2}{*}{ Basal. } & \multicolumn{2}{|c|}{ After levulose. } & \\
\hline & & & & Average. & $\begin{array}{l}\text { Average } \\
\text { maximum. }\end{array}$ & \\
\hline 0.05 to 0.11 & 3 & $\begin{array}{l}\text { p. } c t . \\
10\end{array}$ & 0.79 & 0.83 & 0.88 & $\begin{array}{c}\text { grams. } \\
1.15\end{array}$ \\
\hline $.12 \quad .20$ & 23 & 16 & .79 & .82 & .86 & 1.25 \\
\hline $.21 \quad .30$ & 16 & 18 & .79 & .80 & .86 & 1.70 \\
\hline .33 & 1 & 19 & .74 & .74 & .82 & 2.00 \\
\hline
\end{tabular}

The average rise in respiratory quotient for the experiments with normal blood-sugar values ( 0.05 to 0.11 per cent) was 0.04 , but the average maximum rise was 0.09 . When the percentage of sugar in the blood was slightly greater, namely, between 0.12 per cent and 0.20 per cent, the respiratory quotient increased on the average but 0.03 , and the maximum rise was also less than the normal blood-sugar values, being 0.07 . When the blood-sugar percentage was between 0.21 per cent and 0.30 per cent, the average respiratory quotient 
for the combined periods of these experiments rose only 0.01 above the basal, though the average maximum value still increased as much as 0.07 . There was but one experiment in which the blood sugar was as high as 0.33 per cent. The quantity of levulose given before this experiment was 2 grams per kilogram of body-weight. There was no change in the average respiratory quotient, but the maximum quotient rose 0.08 .

The results of these experiments therefore show that increasing percentages of sugar in the blood are accompanied by constantly advancing increases over basal in the heat-production, though it must be added that the quantities of levulose administered in these experiments were also being increased. Furthermore, the nearer the blood-sugar values are to normal, the higher will the respiratory quotient rise after levulose, this being true for the average quotient for the whole experiment, but not true for the maximum quotient.

\section{RELATION OF URINARY NITROGEN TO METABOLISM AND RESPIRATORY QUOTIENT OF DIABETICS IN LEVULOSE EXPERIMENTS.}

Subsequent to June, 1914, the urinary nitrogen was determined for the day preceding 44 of the levulose experiments and for the 44 experimental days as well. The results are given in table 113, grouped according to the amount of levulose ingested. The only data obtained before June, 1914, were for

TABLE 113.-Relation between urinary nitrogen and metabolism of diabetics in 44 experiments with levulose after June 1914.

\begin{tabular}{|c|c|c|c|c|}
\hline \multirow{2}{*}{$\begin{array}{l}\text { Levulose in } \\
\text { grams per kg. of } \\
\text { body-weight. }\end{array}$} & \multicolumn{2}{|c|}{$\begin{array}{l}\text { Urinary nitrogen per } \mathrm{kg} \text {. body- } \\
\text { weight per } 24 \text { hours. }\end{array}$} & \multirow{2}{*}{$\begin{array}{l}\text { Average increase } \\
\text { in heat-produc- } \\
\text { tion above basal. }\end{array}$} & \multirow{2}{*}{$\begin{array}{l}\text { Average increase } \\
\text { in respiratory } \\
\text { quotient } \\
\text { above basal. }\end{array}$} \\
\hline & Preceding day. & $\begin{array}{l}\text { Experimental } \\
\text { day. }\end{array}$ & & \\
\hline 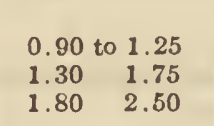 & $\begin{array}{c}\text { grams. } \\
0.150 \\
.235 \\
.205\end{array}$ & $\begin{array}{l}\text { grams. } \\
0.110 \\
.155 \\
.150\end{array}$ & $\begin{array}{l}\text { p. } c t . \\
14 \\
15 \\
21\end{array}$ & $\begin{array}{r}0.02 \\
.03 \\
.03\end{array}$ \\
\hline Average.. & .190 & .135 & 17 & .03 \\
\hline
\end{tabular}

Cases Nos. 332 and 552, but these have not been included in the summary. On the day preceding the experiment, the excretion of urinary nitrogen per kilogram of body-weight averaged 0.190 gram, and on the experimental day 0.135 gram. The decrease can be attributed to the reduction of food upon the experimental day, rather than to any sparing action which might result from the oxidation of levulose. Upon that day the only food given in the majority of the experiments was the levulose itself. It would be purely speculative to say that if no levulose had been ingested, the nitrogen excretion would not have fallen so much, and indeed there is no justification for this statement, as there are as many as 32 fasting days with these patients within four days of the experiment and the average nitrogen excretion upon these days was 0.135 gram.

Here as elsewhere, however, the urinary nitrogen excretion bears no relation to the metabolism. When the average nitrogen excretion on the preceding day was the lowest ( $0.150 \mathrm{gram})$, the increase in the metabolism after levulose was 14 per cent, whereas when the nitrogen excretion was highest 
( 0.235 gram), the increase in the heat-production was but 15 per cent, despite the fact that the quantity of levulose given was larger. The nitrogen values for the experimental day also bore no direct relation to the percentage increase in the metabolism after levulose. These general statements likewise apply to the relation of the urinary nitrogen to the increase in the respiratory quotient.

RELATION OF NON-PROTEIN NITROGEN IN THE BLOOD TO TOTAL METABOLISM AND RESPIRATORY QUOTIENT OF DIABETICS IN LEVULOSE EXPERIMENTS.

The non-protein nitrogen was determined in six of the experiments with subjects to whom levulose was given. Fortunately, these experiments were conducted under fairly uniform conditions. Thus, all of the cases were severe

$T_{\triangle B L E} 114$. -The relation of non-protein nitrogen in the blood to total metabolism and respiratory quotient after administration of levulose to diabetics.

\begin{tabular}{|c|c|c|c|c|c|c|c|c|c|}
\hline \multirow[b]{2}{*}{$\begin{array}{l}\text { Case } \\
\text { No. }\end{array}$} & \multirow{2}{*}{$\begin{array}{l}\text { Non- } \\
\text { protein } \\
\text { nitro- } \\
\text { gen in } \\
\text { the } \\
\text { blood. }\end{array}$} & \multicolumn{2}{|c|}{$\begin{array}{l}\text { Carbohydrate } \\
\text { balance. }\end{array}$} & \multirow{2}{*}{$\begin{array}{l}\text { Levulose } \\
\text { per kg. } \\
\text { body- } \\
\text { weight. }\end{array}$} & \multicolumn{2}{|c|}{$\begin{array}{l}\text { Respiratory } \\
\text { quotient. }\end{array}$} & \multicolumn{2}{|c|}{ Heat-output. } & \multirow{2}{*}{$\begin{array}{c}\text { Date of } \\
\text { levulose } \\
\text { experiment. }\end{array}$} \\
\hline & & $\begin{array}{l}\text { Preced- } \\
\text { ing day. }\end{array}$ & $\begin{array}{l}\text { Experi- } \\
\text { mental } \\
\text { day. }\end{array}$ & & Basal. & $\begin{array}{c}\text { After } \\
\text { levulose. }\end{array}$ & $\begin{array}{l}\text { Variation from } \\
\text { H. and } B \text {. } \\
\text { standard in } \\
\text { basal } \\
\text { experiment. }\end{array}$ & $\begin{array}{l}\text { Increase } \\
\text { in heat- } \\
\text { production } \\
\text { over } \\
\text { basal. }\end{array}$ & \\
\hline $\begin{array}{r}755 \\
1160 \\
610 \\
1196 \\
1233\end{array}$ & $\begin{array}{r}m o . \\
22 \\
30 \\
31 \\
60 \\
110 \\
120\end{array}$ & $\begin{array}{r}\text { orams. } \\
0 \\
+20 \\
+10 \\
-15 \\
0 \\
+10\end{array}$ & $\begin{array}{l}\text { orams. } \\
+50 \\
+90 \\
+50 \\
+65 \\
+75 \\
+75\end{array}$ & $\begin{array}{l}\text { orams. } \\
0.90 \\
1.45 \\
1.00 \\
2.05 \\
1.55 \\
1.55\end{array}$ & $\begin{array}{r}0.78 \\
.78 \\
.80 \\
.76 \\
.86 \\
.87\end{array}$ & $\begin{array}{r}0.80 \\
.79 \\
.78 \\
.81 \\
.95 \\
.95\end{array}$ & $\begin{array}{l}\text { p. ct. } \\
-21 \\
-11 \\
+2 \\
-19 \\
-33 \\
-28\end{array}$ & $\begin{array}{l}\text { p. } c t . \\
11 \\
17 \\
14 \\
27 \\
14 \\
19\end{array}$ & $\begin{array}{lr}\text { Apr. } 30,1917 \\
\text { Nov. } 4,1916 \\
\text { Mar. } 15,1917 \\
\text { Dec. } 14,1916 \\
\text { Feb. } 19,1917 \\
\text { Feb. } 26,1917\end{array}$ \\
\hline
\end{tabular}

and none showed severe acidosis, only one of the six, in fact, having even moderate acidosis. The carbohydrate balances for the preceding day with the six cases ranged between -15 and +20 grams, and for the experimental day between +50 and +90 grams. (See table 114.) As previously noted, the stimulating effect of the levulose upon the metabolism varied with the amount given per kilogram of body-weight. A comparison of the non-protein nitrogen in the blood with the metabolism discloses no general relation between the two in this small series. The picture with the respiratory quotient is quite different. Excluding, first, those experiments when there was a variation in the amount of levulose given, which are therefore unsuitable for comparison, three experiments remain in which the quantity of levulose taken was essentially the same, i. e., 1.45 and 1.55 grams per kilogram of body-weight. With these patients the amounts of non-protein nitrogen in the blood were 30,110 , and $120 \mathrm{mg}$. per $100 \mathrm{c}$. c., respectively. Comparison of these figures with the respiratory quotients for the same experiments shows very clearly that the higher the non-protein nitrogen in the blood rises, the greater is the rise in the quotient after levulose. Thus, when the non-protein nitrogen was $30 \mathrm{mg}$. per $100 \mathrm{c}$. c. of blood, the change in quotient after levulose was but 0.01 , but when the non-protein nitrogen was $110 \mathrm{mg}$. and $120 \mathrm{mg}$. per $100 \mathrm{c}$. c. of blood, the changes in quotient after levulose were 0.09 and 0.08 , respectively. In one other observation, when the non-protein nitrogen in the blood 
was $60 \mathrm{mg}$., there was also a marked increase in quotient of 0.05 . These last three results, therefore, show that when levulose is given to emaciated, severe cases of diabetes with an abnormally high percentage of non-protein nitrogen in the blood, the respiratory quotient rises to an unusual extent. The number of observations upon which this statement is based are too few to allow broad inferences. If confirmed they would favor the idea that with these patients the carbohydrate portion of the protein molecule is either being burned or converted into fat, and that the non-carbohydrate portion is being retained. This is in line with an earlier statement made in the discussion of the high respiratory quotients noted with severe cases of diabetes in the severe stage of inanition.

\section{RELATION OF BLOOD FAT TO TOTAL METABOLISM AND RESPIRATORY QUOTIENT AFTER ADMINISTRATION OF LEVULOSE TO DIABETICS.}

The percentage of fat in the blood was determined in connection with a number of the levulose tests. Data were obtained on experimental days for ten patients with whom the diabetes was severe and acidosis generally present. The results given in table 115 indicate that the percentage of fat in the blood bears no relation whatever to the increase over basal in heat-production when levulose is given.

A large percentage of fat in the blood has no deterrent action upon the increase in the respiratory quotient after the administration of levulose. In fact, so far as the data in the table are concerned, the contrary appears to be the rule, because when the percentage of fat in the blood was high, the increase

\section{TABLE 115.-The relation of fat in the blood to tota' metabolism and res'piratory quotient after} administration of levulose to diabetics.

\begin{tabular}{|c|c|c|c|c|c|c|c|c|c|c|}
\hline \multirow{2}{*}{$\begin{array}{l}\text { Case } \\
\text { No. }\end{array}$} & \multirow{2}{*}{$\begin{array}{c}\text { Fat } \\
\text { in } \\
\text { blood. }\end{array}$} & \multirow{2}{*}{$\begin{array}{l}\text { Aci- } \\
\text { dosis. }\end{array}$} & \multicolumn{2}{|c|}{$\begin{array}{c}\text { Carbohydrate } \\
\text { balance. }\end{array}$} & \multirow{2}{*}{$\begin{array}{l}\text { Levulose } \\
\text { per kg. } \\
\text { body- } \\
\text { weight. }\end{array}$} & \multicolumn{2}{|c|}{$\begin{array}{l}\text { Respiratory } \\
\text { quotient. }\end{array}$} & \multicolumn{2}{|c|}{ Heat-output. } & \multirow[b]{2}{*}{$\begin{array}{l}\text { Date of levulose } \\
\text { experiment. }\end{array}$} \\
\hline & & & $\begin{array}{c}\text { Pre- } \\
\text { ceding } \\
\text { day. }\end{array}$ & $\begin{array}{c}\text { Experi- } \\
\text { mental } \\
\text { day. }\end{array}$ & & Babal. & $\begin{array}{l}\text { After } \\
\text { levu- } \\
\text { lose. }\end{array}$ & $\begin{array}{l}\text { Variation from } \\
\mathrm{H} \text {. and } \mathrm{B} \text {. } \\
\text { atandard in ba- } \\
\text { sal experiment. }\end{array}$ & $\begin{array}{l}\text { Increase in } \\
\text { hest-produc- } \\
\text { tion over } \\
\text { basal. }\end{array}$ & \\
\hline Severe: & p. ct. & & grams. & grams. & grams. & & & p. ct. & p. ct. & \\
\hline 966 & 0.62 & ++ & & $\ldots \ldots$ & 1.85 & 0.72 & 0.71 & -5 & 14 & Jan. 11,1916 \\
\hline 1005 & .75 & $++t$ & +5 & +55 & 2.00 & .74 & .74 & -14 & 19 & Mar. 6, 1916 \\
\hline 632 & .83 & + & +25 & +95 & 1.65 & .75 & .80 & -4 & 22 & Mar. 22, 1916 \\
\hline 1160 & .96 & ++ & -20 & +75 & 1.45 & .73 & .75 & -5 & 21 & Oct. 28,1916 \\
\hline & 1.08 & + & +20 & +90 & 1.45 & .78 & .79 & -11 & 17 & Nov. 4,1916 \\
\hline 610 & 1.03 & + & +10 & +50 & 1.00 & .80 & .78 & +2 & 14 & Mar. 15,1917 \\
\hline 765 & 1.05 & +++ & -15 & +45 & 2.20 & .73 & .71 & -14 & 7 & Jan. 25,1916 \\
\hline 1196 & 1.01 & ++ & +75 & +60 & 1.95 & .72 & .83 & -22 & 22 & Dec. 16,1916 \\
\hline & 1.18 & $+t$ & -15 & +65 & 2.05 & .76 & .81 & -19 & 27 & Dec. 14,1916 \\
\hline 1233 & 1.39 & 0 & +10 & +75 & 1.55 & .87 & .95 & -28 & 19 & Feb. 26,1917 \\
\hline & 1.51 & 0 & 0 & +75 & 1.55 & .86 & .95 & -33 & 14 & Feb. 19,1917 \\
\hline 1213 & 1.42 & 0 & +20 & +60 & 1.85 & .91 & .89 & +8 & 15 & Mar. 28, 1917 \\
\hline & 1.45 & 0 & 0 & +55 & 1.80 & .91 & .92 & -6 & 24 & Feb. 28,1917 \\
\hline $\begin{array}{c}1085 \\
\text { Moderate: }\end{array}$ & 2.94 & ++ & -15 & +60 & 2.35 & .70 & .79 & -30 & 18 & Oct. 30,1916 \\
\hline 1058 & 1.03 & $+t$ & +30 & +55 & 1.00 & .76 & .77 & -12 & 15 & May 23,1916 \\
\hline 1182 & 1.05 & 0 & +95 & +100 & 1.35 & .77 & .83 & -3 & 8 & Nov. 20,1816 \\
\hline 610 & 1.12 & 0 & +55 & +55 & 1.05 & .79 & .81 & -7 & 16 & May 15,1916 \\
\hline $\begin{array}{l}\text { Mata: } \\
1059\end{array}$ & .85 & + & +60 & +60 & 1.00 & .83 & .82 & -5 & 13 & May 31,1916 \\
\hline 1051 & .99 & 0 & +30 & +40 & 1.00 & .75 & .76 & 0 & 15 & May 25, 1916 \\
\hline
\end{tabular}


in the respiratory quotient after levulose also tended to be high, though individual exceptions are to be noted. (See Case No. 1213.) It even suggests that when a large quantity of fat in the blood is found, carbohydrate is being freely burned or carbohydrate is being changed to fat.

\section{Effect of Ingestion of Various Carbohydrates.}

The effect of the ingestion of various kinds of carbohydrate foods by diabetics, namely, orange juice, dextrose, sucrose, and levulose, the last already discussed (pp. 211 to 248) are compared in table 116. It will be observed that in all of the experiments the diabetes was severe except in a single experiment with sucrose and in three experiments with levulose. Acidosis was absent, save in one instance in an experiment with orange juice, when it was of moderate degree. The total carbohydrate ingested varied a good deal in the different experiments, but it will be seen that the variation is less when the amount is recorded on the basis of grams per kilogram of body-weight.

TABLE 116.-Effect of ingestion of various carbohydrates in experiments with diabetics.

\begin{tabular}{|c|c|c|c|c|c|c|c|c|c|c|}
\hline \multirow{3}{*}{ Kind of experiment. } & \multirow{3}{*}{ Severity. } & \multirow{3}{*}{$\begin{array}{l}\text { Acido- } \\
\text { sis. }\end{array}$} & \multirow{2}{*}{\multicolumn{2}{|c|}{$\begin{array}{l}\text { Carbohydrate in- } \\
\text { gested before ex- } \\
\text { periment. }\end{array}$}} & \multirow{2}{*}{\multicolumn{2}{|c|}{$\begin{array}{l}\text { Carbohydrate } \\
\text { balance. }\end{array}$}} & \multirow{3}{*}{$\begin{array}{l}\text { Increase } \\
\text { in heat- } \\
\text { produc- } \\
\text { tion } \\
\text { over } \\
\text { basal. }\end{array}$} & \multicolumn{3}{|c|}{ Respiratory quotient. } \\
\hline & & & & & & & & \multirow[b]{2}{*}{ Bassl. } & \multicolumn{2}{|c|}{$\begin{array}{l}\text { After carbo- } \\
\text { hydrate. }\end{array}$} \\
\hline & & & Total. & $\begin{array}{l}\text { Per } \\
\text { kilo- } \\
\text { gram. }\end{array}$ & $\begin{array}{l}\text { Preced- } \\
\text { ing day. }\end{array}$ & $\begin{array}{l}\text { Experi- } \\
\text { mental } \\
\text { day. }\end{array}$ & & & $\begin{array}{l}\text { Aver- } \\
\text { age. }\end{array}$ & $\begin{array}{l}\text { Marj- } \\
\text { mum. }\end{array}$ \\
\hline \multirow{2}{*}{$\begin{array}{r}\text { Orange juice }(10 \text { per } \\
\text { ct. carbohydrate) } \\
\text { Case } 610 \ldots \ldots \\
\text { Case } 1011 \ldots \ldots \\
\text { Case } 1213 . \ldots . \\
\text { Case } 1233 . . . \\
\text { Average....... }\end{array}$} & $\begin{array}{l}\text { S. } \\
\text { S. } \\
\text { S. } \\
\text { S. }\end{array}$ & $\begin{array}{r}0 \\
++ \\
0 \\
0\end{array}$ & $\begin{array}{l}\text { grams. } \\
60 \\
28 \\
60 \\
42 \\
\end{array}$ & $\begin{array}{c}\text { orams. } \\
1.20 \\
.95 \\
1.80 \\
.85 \\
\end{array}$ & $\begin{array}{c}\text { grams. } \\
+10 \\
0 \\
+15 \\
\cdots\end{array}$ & $\begin{array}{l}\text { grams. } \\
+59 \\
+24 \\
+54 \\
+42 \\
\end{array}$ & $\begin{array}{l}\text { p. } c t . \\
11 \\
13 \\
21 \\
1\end{array}$ & $\begin{array}{r}0.82 \\
.81 \\
.91 \\
.84\end{array}$ & $\begin{array}{r}0.80 \\
.84 \\
.97 \\
.89\end{array}$ & $\begin{array}{r}0.85 \\
.93 \\
1.04 \\
.93\end{array}$ \\
\hline & $\mathrm{S}$. & $\ldots \ldots \ldots$ & 48 & 1.20 & $\ldots \ldots \ldots$ & +45 & 12 & .85 & .88 & .94 \\
\hline $\begin{array}{l}\text { Dextrase: } \\
\quad \text { Case } 632 \ldots . . . \\
\text { Levulose }(100 \text { gms. }):\end{array}$ & $\begin{array}{c}\text { S. } \\
\text { Severe (6 }\end{array}$ & 0 & 100 & 1.70 & +25 & +87 & 10 & .75 & .77 & .78 \\
\hline & $\begin{array}{c}\text { expts.) } \\
\text { Moderste } \\
\text { (3 cases, } \\
3 \text { expts.) }\end{array}$ & . $\ldots \ldots \ldots$ & 100 & 1.80 & $1+20$ & +84 & 22 & .76 & .79 & .85 \\
\hline $\begin{array}{l}\text { Sucrose: } \\
\text { Case 1134... }\end{array}$ & Mild. & 0 & 100 & 1.55 & +305 & (4) & 3 & .86 & 1.02 & 1.05 \\
\hline
\end{tabular}

1 Average of preceding day values for 9 out of 11 experiments.

2 Average of 10 out of 11 expcriments.

3 Average of 2 out of 3 experiments. On the day of the third experiment the balance was +123 grams, 30 grams additional carbohydrate being eaten after the experiment was finished.

- The carbohydrate balance on the experimental day with Case No. 1134 was +404 grans, 307 grams additional carbohydrate being eaten after the experiment was finished.

\section{ORANGE JUICE.}

As the proportion of carbohydrate in orange juice varies considerably, it was decided to accept an arbitrary value of 10 per cent. There are three different sugars found in orange juice-sucrose, dextrose, and levulose. ${ }^{a}$ Sucrose usually makes up a little over one-half of the total sugar. After the fruit is

- Collison, Florida Agr. Exp. Sta. Bull. No. 115, 1913. 
removed from the tree, there is a gradual decrease in the amount of sucrose, with a corresponding increase in the other two sugars, indicating that sucrose is changed into the other two. One group of analyses of California oranges shows variation in content of sucrose between 4.93 and 5.35 per cent, of fruit sugars 4.36 to 6.80 per cent.

Acid is present in oranges almost entirely as citric acid. In the group of analyses above cited it varied beween 1.26 and 1.51 per cent. Since citric acid is oxidized in the body, it is desirable to remember that its respiratory quotient is 1.33. Fortunately its percentage and quantity in orange juice is so low as not to interfere with our experiments.

In the four experiments with orange juice the average amount of carbohydrate per kilogram of body-weight was estimated at 1.20 grams. The carbohydrate balances for the preceding day varied from 0 to 15 grams, but upon the day of the experiment the carbohydrate balances averaged +45 grams. This shows well the excellent utilization of the amount given, which averaged 48 grams. The increase in heat-production varied from 1 to 21 per cent, with an average of 12 per cent. As was found with levulose, the increase in the respiratory quotient was distinct, for although the average increase was but 0.03 , the peak increase was considerable, and the average maximum increase above the basal was 0.09 .

\section{DEXTROSE.}

In contrast to this series of experiments with orange juice is one experiment with dextrose in which 1.70 grams per kilogram of body-weight were given the patient. Here the carbohydrate balance on the experimental day showed a utilization of 87 per cent of the 100 grams given. The increase in the heatproduction was slightly less than that found after the ingestion of orange juice, and the increase in respiratory quotient distinctly less, being but 0.02 , with a maximum increase of but 0.03 .

\section{LEVULOSE.}

The average results of 11 experiments with six severe cases of diabetes to whom 100 grams of levulose were given are included in the table for comparison with the results obtained in the experiments with orange juice and with dextrose. As with the dextrose and the orange juice, the utilization of the levulose was excellent, being 84 per cent in ten of the experiments. In contrast to the increase in heat-production of 12 per cent for orange juice and 10 per cent for dextrose, in the levulose experiments the heat-production increased on the average 22 per cent. The increase in the average respiratory quotient, however, was but 0.03 , although the average maximum increase in the respiratory quotient was 0.09 .

Results are also included in table 116 of 3 experiments with 3 moderate cases of diabetes who were given the same amount of levulose as the severe cases. These showed much less increase in heat-production than the diabetics in a more advanced stage of the disease, the increase with the moderate cases averaging but 12 per cent in contrast to 22 per cent with the severe cases, notwithstanding the fact that in two of the experiments, none of the carbohydrate ingested as levulose appeared in the urine. The increase in the 
respiratory quotient with the moderate cases was 0.05 , and the maximum increase 0.09 .

\section{SUCROSE.}

A single experiment is likewise included in table 116, in which 100 grams of sucrose were given to a mild case of diabetes. The patient tolerated sucrose well and, in fact, received additional carbohydrate during the day, which increased the total ingestion of carbohydrate for the 24 hours to 407 grams, yet the sugar in the urine was but 3 grams. Nevertheless, directly following the ingestion of 100 grams of sucrose, the patient's metabolism rose but 3 per cent. His respiratory quotient, however, behaved quite like that of a normal individual, as it rose to 1.02 on the average and to a maximum of 1.05. With the slight increase in metabolism following sucrose and the marked rise in respiratory quotient, it would seem that the sucrose may have been transformed to fat. ${ }^{a}$

\section{EFFECT OF DEXTROSE AND BREAD ON THE METABOLISM OF DIABETICS.}

During the first year of experimentation (1908-1909), the effect of the ingestion of dextrose and bread upon the metabolism of diabetics was determined in 4 experiments. These were the first food experiments and were suggested by Falta, who was then visiting Boston. The quantity of bread given was 75 grams and of dextrose 25 grams, and the total amount of carbohydrate ingested was estimated at 70 grams. Three of these four experiments are excluded because the basal metabolism was determined upon other days than the food experiments or with different apparatus. The remaining experiment was with Case No. 220 on March 13, 1909. He was a severe diabetic and in a stage of severe acidosis at this time. The quantity of carbohydrate given amounted to 1.35 grams per kilogram of body-weight. During this experiment the metabolism fell 3 per cent below the basal value, but strangely enough the average respiratory quotient rose 0.06 , and the maximum was 0.07 above the basal quotient. The experiment is reported more for historical interest than for its scientific value.

\section{EFFECT ON DIABETICS OF INGESTION OF CARBOHYDRATE WITH BUTTER OR OLIVE OIL.}

The results of 8 experiments with 4 severe cases of diabetes free from acidosis, which were obtained after the patients had taken levulose and fat, are set forth in table 117. It will be observed that the quantity of carbohydrate per kilogram of body-weight varied between 0.75 gram and 1.85 grams. The range in the amounts of fat was essentially the same. The average amount of carbohydrate per kilogram of body-weight was 1.25 grams and of fat 1.15 grams. The carbohydrate balances on both the preceding and the experimental days were positive. As a matter of fact, the urines of the patients upon both of these days were nearly sugar-free. No sugar was excreted on the preceding days, and but 2 grams on two of the experimental days (with Cases Nos. 1213 and 1259); no data for sugar excretion were obtained for three of the experimental days with Case No. 610 .

- Despite the favorable tolerance for carbohydrate which this patient showed on October 20 , 1916, he died of diabetic coma November 1, 1918. It is perhaps needless to add that he disregarded diet immediately upon leaving the hospital. He entered the army, but died the day before he was to have sailed for France. 
As a result of the ingestion of these quantities of carbohydrate and fat, the metabolism rose on an average 16 per cent. Comparing this increase with that observed when levulose was given alone to these four patients (19 per cent), it will be seen that despite the addition of fat, the metabolism rose slightly less during the actual period of experimentation. The average basal respiratory quotient in the eight experiments was 0.83 , and during the test this was increased on the average to 0.88 , which corresponds closely with the values observed when levulose was given alone. The average maximum quotient was 0.92 , thus indicating that even the peak effects of these levulose and fat meals correspond with the levulose meals without fat.

TABLE 117.--Effect of ingestion of carbohydrate and fat and of olive oil in experiments with diabetics.

[Severe cases without acidosis.

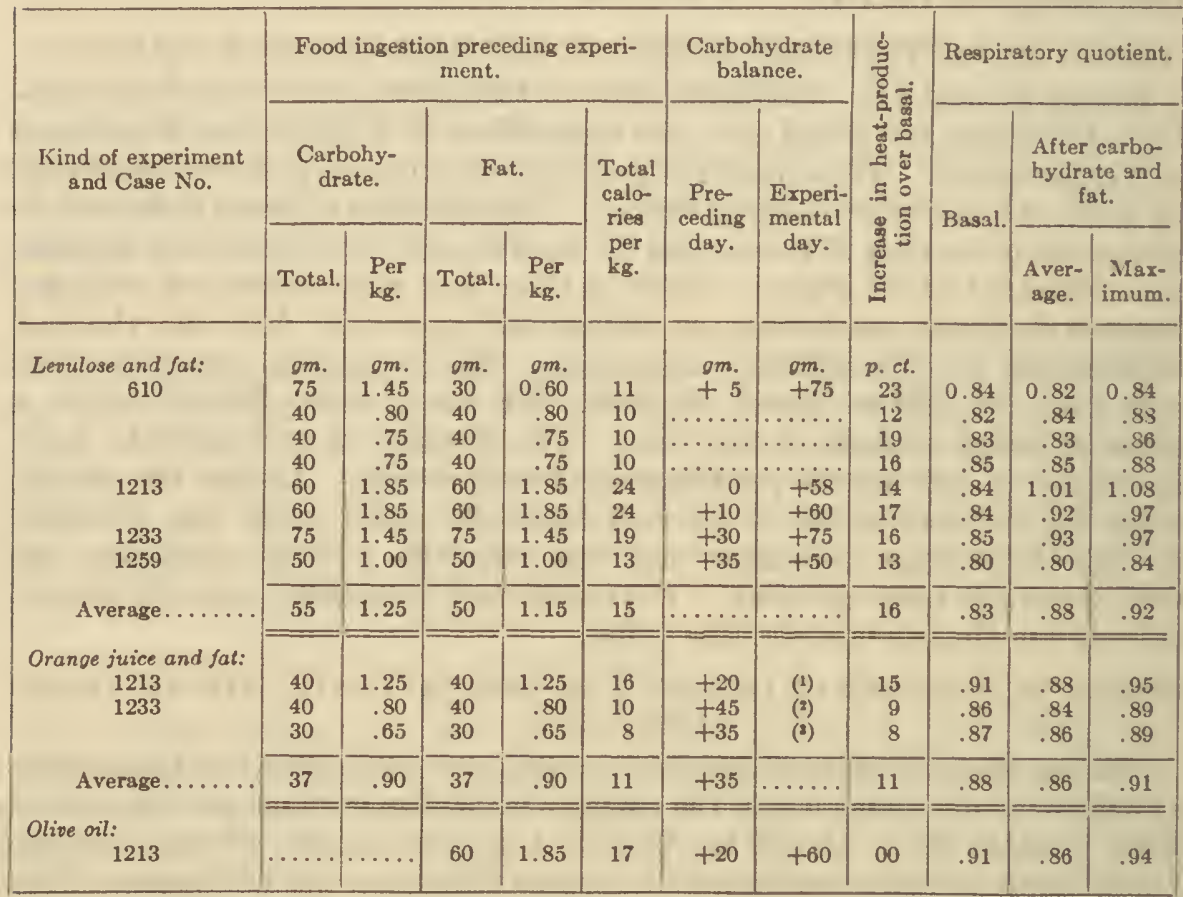

1 The carbohydrate balance on the day of the experiment with Case No. 1213 was +54 grams, 20 grams additional carbohydrate being eaten after experinent was finished.

'The carbohydratc balance on this day with Case No. 1233 was +75 grams, 35 grams additional carbohydrate being eaten after experiment was finished.

The carbohydrate balance on this day with Case No. 1233 was +60 grams, 30 grams additional carbohydrate being eaten after the experiment was finished.

These experiments show beautifully the selective action of the body for carbohydrate when carbohydrate and fat are ingested simultaneously, the respiratory quotient rising as high when the two food elements were given as when carbohydrate was given alone; in one instance the respiratory quotient rose even above unity. On the other hand, there was no increase in the metabolism over those experiments in which levulose was given alone, although the blood must have contained a far greater number of food molecules. In 
these experiments only good effects, so far as the metabolism and respiratory quotient were concerned, came from the addition of the fat to the levulose, and the patients obtained additional calories.

These data regarding the levulose and fat experiments are of service in another direction in that they offer a comparison of the effect of variation in the number of calories given in the food at one time per kilogram of bodyweight. If one examines table 117 from this point of view, it will be seen that when the number of calories was lowest, i. e., 10 calories per kilogram of body-weight, the increase in metabolism varied between 12 and 19 per cent, and when the number of calories was over twice as large per kilogram of bodyweight, the increases in the metabolism were 14 and 17 per cent. A variation in the number of calories per kilogram of body-weight caused no change in the metabolism. Attention is again called to the large number of calories per kilogram of body-weight given in a brief period. In the course of a few minutes one patient (Case No. 1213) received 24 calories per kilogram of body-weight, sufficient to supply the basal needs of the body for 24 hours. The benefits to be derived from the administration of repeated small meals to diabetics have recently been set forth by Gray and Murayama. ${ }^{b}$ Their work, however, was not based upon levulose, but was related to the activating influence of small doses of carbohydrate given one hour or more preceding larger meals.

Corresponding to these experiments with levulose and fat, three experiments with two of the same patients were made after the ingestion of orange juice and fat. The comparative results are strikingly similar. The average increase in metabolism was 11 per cent, and this is essentially the same as when orange juice was given alone. (See table 116, p. 249.) The rise in metabolism here, however, varied directly with the calories administered. In these three experiments the respiratory quotient did not show a rise save for the maxima, which were on the average 0.03 above the basal level. The total amount of carbohydrate given was but 30 to 40 grams, corresponding to 0.65 to 1.25 grams per kilogram of body-weight.

A single experiment was made with Case No. 1213 after 60 grams of olive oil had been given, or 1.85 grams per kilogram of body-weight. No change was noted in the metabolism as a result of the oil, thus supporting the results already noted when fat was added to levulose or orange juice. This lack of increase in the metabolism is the more noteworthy, because the patient received 17 calories per kilogram of body-weight in the course of one or two moments-a quantity of food sufficient to supply the basal needs for 18 hours. The average respiratory quotient fell 0.05 , though in the first period there was a rise of 0.03 , with successive decreases thereafter.

\section{EFFECT ON DIABETICS OF INGESTION OF PROTEIN.}

The effect of the ingestion of protein was studied in four experiments with three diabetics, all of whom exhibited slight or moderate acidosis. The results are given in table 118. At this time these patients were receiving no carbohydrate and a negligible amount of fat. Practically all of their urines were sugar-free. The meals eaten before the experiment consisted of fish, vege-

a Gray, Boston Med. and Surg. Journ., 1922, 186, p. 763.

Murayama, Boston Med. and Surg. Journ., 1922, 186, p. 768. 
tables (three times washed), and tea or coffee. Case No. 1012 on November 9, 1917, and Case No. 1181 on November 18, 1916, had coffee jelly in addition.

The quantity of protein given was very small ranging only from 9 to 24 grams, but if this amount was given at each of the 3 meals during the day, the values would be 27 to 72 grams, which with these thin patients equal half a gram or a gram and more per kilogram of body-weight. Too often with thin patients in every-day treatment one overlooks the relatively large quantities of food which they receive. With the smallest amount there was a rise in metabolism of 6 per cent over basal, but when the quantity of protein was sufficient to provide 0.4 gram per kilogram of body-weight at this meal, the increase in the metabolism reached 20 to 32 per cent. Case No. 1012, who showed the values 21 and 32 per cent, was a diabetic girl.

TABLE 118.-Effect on diabetics of ingestion of protein without carbohydrate or fat.

\begin{tabular}{|c|c|c|c|c|c|c|c|c|c|c|}
\hline \multirow{2}{*}{$\begin{array}{l}\text { Case } \\
\text { No. }\end{array}$} & \multirow{2}{*}{ Date. } & \multirow{2}{*}{$\begin{array}{c}\text { Body- } \\
\text { weight, } \\
\text { naked. }\end{array}$} & \multicolumn{2}{|c|}{$\begin{array}{l}\text { Protein in- } \\
\text { gested. }\end{array}$} & \multirow{2}{*}{$\begin{array}{c}\text { Increase } \\
\text { in heat- } \\
\text { produc- } \\
\text { tion } \\
\text { over } \\
\text { basal. }\end{array}$} & \multirow{2}{*}{$\begin{array}{c}\text { Varia- } \\
\text { tion of } \\
\text { basal } \\
\text { hest- } \\
\text { produc- } \\
\text { tion from } \\
\text { stand- } \\
\text { ard. }\end{array}$} & \multirow{2}{*}{$\begin{array}{l}\text { Average } \\
\text { respira- } \\
\text { tory } \\
\text { quotient } \\
\text { in } \\
\text { experi- } \\
\text { ment. }\end{array}$} & \multirow{2}{*}{$\begin{array}{c}\text { Basal } \\
\text { respira- } \\
\text { tory } \\
\text { quo- } \\
\text { tient. }\end{array}$} & \multicolumn{2}{|c|}{$\begin{array}{l}\text { Urinary nitro- } \\
\text { gen per kg. } \\
\text { per } 24 \text { hours. }\end{array}$} \\
\hline & & & Total. & Per kg. & & & & & $\begin{array}{l}\text { Preced- } \\
\text { ing } \\
\text { day. }\end{array}$ & $\begin{array}{l}\text { Experi- } \\
\text { mental } \\
\text { day. }\end{array}$ \\
\hline $\begin{array}{r}821 \\
21012 \\
1181\end{array}$ & $\begin{array}{l}\text { Mar. } 28-29,1916 \\
\text { Nov. } 1-2,1917 \\
\text { Nov. } 9-10,1917 \\
\text { Nov. } 18-19,1916\end{array}$ & $\begin{array}{l}k g . \\
50.6 \\
26.0 \\
26.2 \\
55.7\end{array}$ & $\begin{array}{r}o m . \\
19 \\
10 \\
110 \\
\cdot 24\end{array}$ & $\begin{array}{r}g m . \\
0.2 \\
.4 \\
.4 \\
.4\end{array}$ & $\begin{array}{c}\text { p. ct. } \\
6 \\
21 \\
32 \\
20\end{array}$ & $\begin{array}{l}\text { p. ct. } \\
-27 \\
(3) \\
(3) \\
-19\end{array}$ & $\begin{array}{l}0.79 \\
.84 \\
.84 \\
.75\end{array}$ & $\begin{array}{l}0.81 \\
.84 \\
.81 \\
.73\end{array}$ & $\begin{array}{r}g m . \\
0.170 \\
.290 \\
.275 \\
\ldots \ldots\end{array}$ & $\begin{array}{c}0 m . \\
0.200 \\
.300 \\
.340 \\
\ldots \ldots\end{array}$ \\
\hline & Average.... & 39.6 & 13 & .3 & 20 & & .81 & .80 & .245 & .280 \\
\hline
\end{tabular}

1 About $61 / 2$ hours earlier, patient had eaten a breakfast of vegetables and coffee.

2 Girl diabetic.

- Variations in heat-production from Girl Scout values in the basal experiments with Care No. 1012 were +31 p. ct. and +18 p. ct., respectively.

4 About 5 hours earlier patient had esten a breakfast consisting of C. 0, P. 10, F. 0 grams. Coffee jelly was taken with the test meal.

s About $51 / 2$ hours earlier patient had eaten a breakfast consisting of C. 0, P. 16, F. 10 grams. Coffee jelly was taken with the test meal.

As would be expected, the average respiratory quotients for the basal period and the period after the ingestion of the protein were essentially the same. In fact, they serve as a control on the accuracy of the observations. In all of the experiments the carbohydrate balance of the preceding day was 0 . The urinary nitrogen, both for the preceding day and the day of the experiment, tended to be moderately elevated, being higher upon the experimental day.

\section{EFFECT OF INGESTION OF PROTEIN AND FAT.}

A group of 10 experiments was made with 5 patients in which the diet contained protein and fat, and was entirely without carbohydrate. The results are given in table 119. The quantities of protein given averaged 18 grams, and of fat 16 grams, making 7 calories per kilogram of body-weight for this single meal. All but one of the experiments recorded in this table were after dinner as the second meal of the day, only the experiment with Case No. 767 being after breakfast. In the eight instances in which the breakfast preceding the diet for the experiment was recorded, the food was free from carbo- 
hydrate, contained 6 to 12 grams of protein and from 6 to 25 grams of fat, evidence that these patients were being treated upon a low calorie basis.

The average increase in metabolism in these 10 experiments was 23 per cent. This was about one-third greater than the average increase in the levulose experiments (see p. 214), but not essentially greater than when smaller quantities of protein alone were given in the somewhat unsatisfactory series just discussed. (See table 118.) In fact, these protein and fat experiments bear the same relation to the experiments with protein as do the experiments with carbohydrate (levulose or orange juice; see p. 251) and fat to the experiments

TABLE. 119.-Effect of ingestion of protein and fat without carbohydrate in experiments with diabetics.

\begin{tabular}{|c|c|c|c|c|c|c|c|c|c|c|c|c|c|c|c|}
\hline \multirow{3}{*}{$\begin{array}{l}\text { Case } \\
\text { No. }\end{array}$} & \multirow{3}{*}{ Date. } & \multirow{3}{*}{ 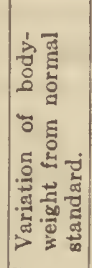 } & \multicolumn{2}{|c|}{$\begin{array}{l}\text { Protein } \\
\text { and fat } \\
\text { breakfast. }\end{array}$} & \multicolumn{4}{|c|}{$\begin{array}{l}\text { Protein and fat dinner } \\
\text { immediately preceding } \\
\text { the experiment. }\end{array}$} & \multirow{3}{*}{ 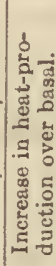 } & \multirow{3}{*}{ 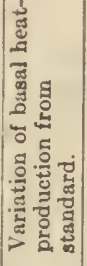 } & \multirow{3}{*}{ 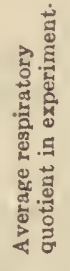 } & \multirow{3}{*}{ 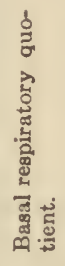 } & \multirow{2}{*}{\multicolumn{2}{|c|}{$\begin{array}{l}\text { Uirinary nitro- } \\
\text { gen per kilo- } \\
\text { gram of body- } \\
\text { weight per } 24 \\
\text { hours. }\end{array}$}} & \multirow[b]{3}{*}{$\frac{\frac{0}{0}}{\frac{0}{0}}$} \\
\hline & & & \multirow[b]{2}{*}{$\begin{array}{l}\text { Pro- } \\
\text { tein. }\end{array}$} & \multirow{2}{*}{ Fat. } & \multirow[b]{2}{*}{$\begin{array}{l}\text { Pro- } \\
\text { tein. }\end{array}$} & \multirow{2}{*}{ Fat } & \multicolumn{2}{|c|}{ Calories. } & & & & & & & \\
\hline & & & & & & & $\begin{array}{l}\text { To- } \\
\text { tal. }\end{array}$ & $\begin{array}{l}\text { Per } \\
\mathrm{kg} \text {. }\end{array}$ & & & & & $\begin{array}{l}\text { Pre- } \\
\text { ceding } \\
\text { day. }\end{array}$ & $\begin{array}{l}\text { Experi- } \\
\text { mental } \\
\text { day. }\end{array}$ & \\
\hline 767 & $\begin{array}{l}1914 \\
\text { Sept. } 26 \\
1917\end{array}$ & $\begin{array}{l}\text { p. } c t . \\
+14\end{array}$ & om. & $\begin{array}{l}o m . \\
(1)\end{array}$ & $\begin{array}{l}o m . \\
115\end{array}$ & $\begin{array}{l}g m . \\
120\end{array}$ & 1240 & 3.4 & $\begin{array}{c}p . c t . \\
16\end{array}$ & $\begin{array}{l}\text { p. ct. } \\
-3\end{array}$ & 0.75 & 0.77 & $\begin{array}{c}g m . \\
0.075\end{array}$ & 0.115 & + \\
\hline \multirow[t]{2}{*}{792} & Nov. 14 & -29 & 212 & 212 & 16 & 10 & 155 & 4.4 & 8 & -14 & .80 & .76 & & .255 & + \\
\hline & $\begin{array}{c}\text { Nov. } 16 \\
1916\end{array}$ & -28 & 212 & ${ }^{\prime} 12$ & 16 & 10 & 155 & 4.3 & 8 & -14 & .79 & .76 & .195 & .225 & 0 \\
\hline 821 & $\underset{1917}{\operatorname{Mar} .14}$ & -9 & ${ }^{2} 10$ & 225 & 24 & 23 & 305 & 5.5 & 22 & -25 & .77 & .78 & .125 & .205 & + \\
\hline \multirow[t]{4}{*}{1012} & Oct. 18 & -32 & 28 & 214 & 16 & 18 & 225 & 7.8 & 20 & (4) & .81 & .83 & .265 & .225 & ++ \\
\hline & Oct. 25 & $\begin{array}{l}-39 \\
-38\end{array}$ & $\begin{array}{l}26 \\
26\end{array}$ & $\begin{array}{l}26 \\
28\end{array}$ & 24 & 23 & 305 & 11. & 26 & (4) & .8 & .85 & .21 & .280 & ++ \\
\hline & $\begin{array}{l}\text { Nov. } 15 \\
\text { Nov. } 21\end{array}$ & $\begin{array}{l}-38 \\
-36\end{array}$ & $\begin{array}{l}26 \\
26\end{array}$ & $\begin{array}{r}28 \\
210\end{array}$ & $\begin{array}{l}16 \\
16\end{array}$ & $\begin{array}{l}12 \\
15\end{array}$ & $\begin{array}{l}170 \\
200\end{array}$ & $\begin{array}{l}6.5 \\
7.4\end{array}$ & $\begin{array}{l}21 \\
34\end{array}$ & $\begin{array}{l}\text { (4) } \\
\text { (4) }\end{array}$ & $\begin{array}{l}.9 \\
.8\end{array}$ & $\begin{array}{l}.85 \\
.85\end{array}$ & $\begin{array}{l}.200 \\
.285\end{array}$ & $\begin{array}{l}.325 \\
.335\end{array}$ & ${ }_{0}^{+}$ \\
\hline & Nov. 27 & -40 & 26 & 210 & 20 & 20 & 260 & 10.3 & 31 & (d) & .81 & .85 & .305 & .340 & 0 \\
\hline \multirow[t]{2}{*}{1378} & Dec. 5 & -44 & (3) & (3) & 16 & 10 & 155 & 5.0 & 40 & -29 & .84 & .88 & ... & $\ldots \ldots$ & 0 \\
\hline & Avg... & -28 & & & 18 & 16 & 215 & 6.6 & 23 & & .81 & .82 & .210 & ${ }^{5} .255$ & \\
\hline
\end{tabular}

1 Breakfast, instead of dinner, immediately preceded the experiment on this date.

2 From 5 to 6 hours before experiment.

- Composition of breakfast not known.

- Variations in heat-production from Girl Scout values in basal experiments with Case No. 1012 were $+13,+22,+21,+8$, and +12 per cent, respectively.

Does not include 0.255 for Case No. 792 on Nov. 14-15, 1917.

with pure carbohydrate. In other words, so far as the limits of these experiments go, there appears to be no tendency for fat to increase the metabolism, either when given with carbohydrate or with protein. The ingestion of fat in these experiments, therefore, produced as little effect on the metabolism as the oxidation of body fat did in the experiments with the overweight normals and diabetics, for which the data are collected in table 64, page 154 .

The average respiratory quotient did not essentially change in these experiments. The increase in these experiments ranged from 0.03 to 0.06 , and in seven there was a decrease ranging from 0.01 to 0.04 . The average urinary nitrogen was greater on the experimental day than on the preceding day, as was also the case in the series of experiments in which protein alone was given. In other words, the calories here given and during the remainder of 
the day were not sufficient to prevent these undernourished patients from drawing very freely upon body protein to maintain life.

Acidosis was absent for four days, of slight extent on four, and present to a moderate degree on two, but the presence or absence of acidosis exerted no influence upon the increase in heat-production as a result of the ingestion of protein and fat.

EFFECT OF INGESTION OF BEEFSTEAK (PROTEIN) AND FAT BY DIABETICS.

The results of 12 observations with 6 patients, after a meal of beefsteak and butter, are given in table 120 . The conditions of the experiments resemble

TABLE 120.- Effect of ingestion of beefsteak (protein) and fat in experiments with diabetics.

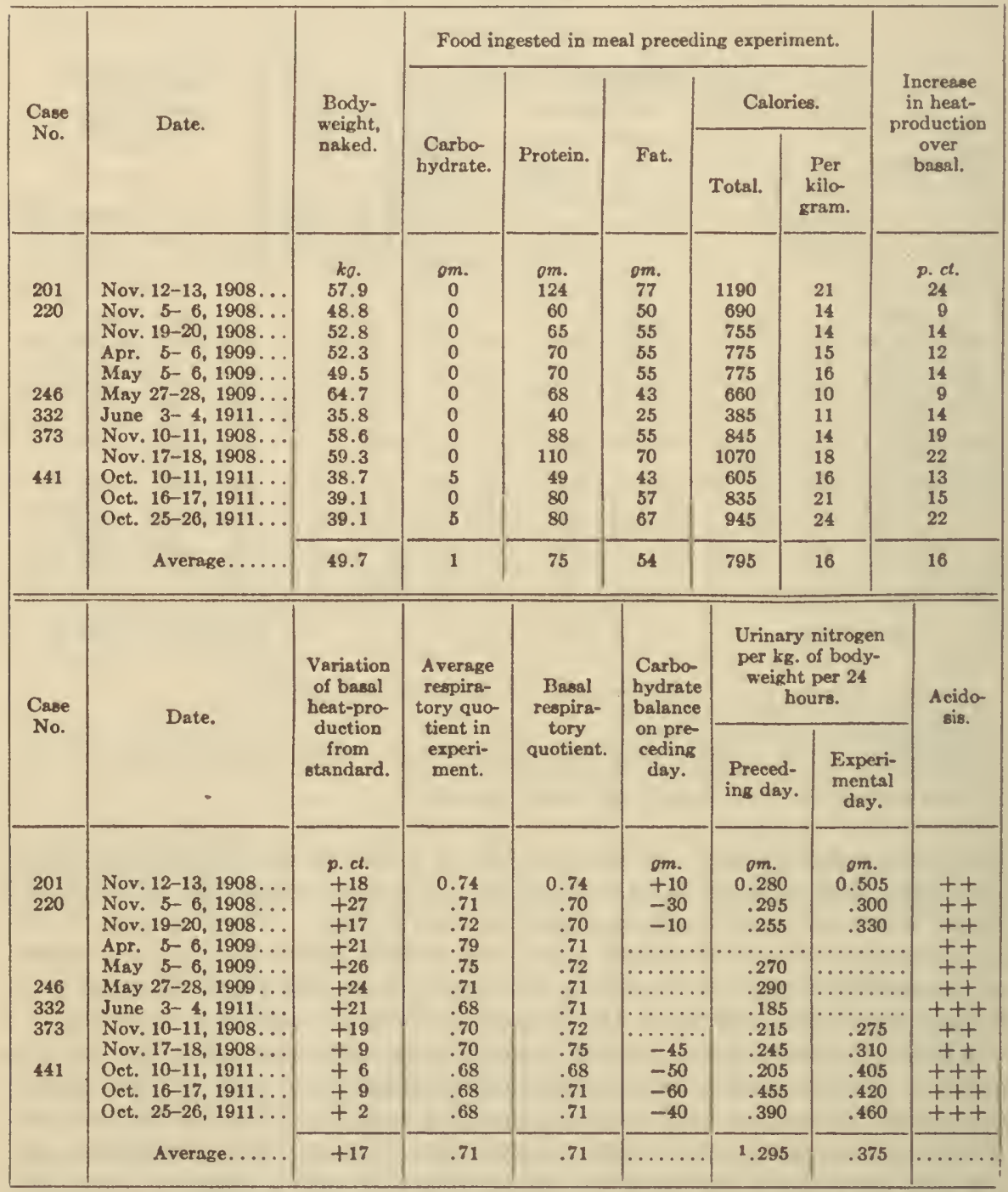

${ }_{1}^{1}$ Not including 0.270 for May 5-6, 1909, with Case No. 220; 0.290 for May 27-28, 1909, with Crse No. 246 and 0.185 for June $3-4,1911$, with Case No. 332. 
those in table 119, except that in this group the amounts of protein and fat were very much larger, and the protein was exclusively in the form of meat. Of special interest is the fact that the observations in table 120 were made between 1908 and 1911, inclusive, with patients whose basal metabolism averaged 17 per cent above standard, while those given in table 119 were carried out between 1914 and 1917, inclusive, and with 5 patients, of whom 4 showed a basal metabolism averaging 17 per cent below standard. In general, therefore, the experiments in table 120 represent the period in which the metabolism was above the normal standard, ${ }^{a}$ and those in table 119 the later period when the metabolism was below the normal standard.

If we compare the average increase after food in the period of high metabolism with the average increases in the period of low metabolism and, to make them comparable, exclude the values for the girl diabetic (Case No. 1012) for whom a different standard was used, we find that the increase in metabolism after beefsteak in the high-metabolism period was much the same as that after protein in the low-metabolism period. When the data for Case No. 1012 are thus excluded, the average increase in the metabolism above basal was 19 per cent after protein and fat (see table 119) and after very small quantities of protein alone it was 13 per cent (see table 118), whereas in the twelve observations after the ingestion of beefsteak and butter in the years 1908 and 1911, recorded in table 120, there was an average increase of 16 per cent.

Corresponding to this average increase in the metabolism of 16 per cent after beefsteak and butter, the respiratory quotients were low. The average basal respiratory quotient was but 0.71 , and fell or remained constant in all cases, save with Case No. 220, and with him rose an average of 0.03 in four experiments. With such results it is not surprising to find that the carbohydrate balance on the day preceding the experiment, so far as recorded, was almost invariably minus, and that the acidosis was either moderate or severe in degree. That the nitrogen excretion was high for the preceding day and still higher for the experimental day would be expected, as the patients were being liberally fed.

\section{INCREASES IN HEAT-PRODUCTION IN VARIOUS FOOD EXPERIMENTS AT} DIFFERENT LEVELS OF BASAL METABOLISM.

To determine whether there was any relationship between the increase in the heat-production after food and the variation of the basal metabolism above and below standard, comparison has been made in table 121 of the increases obtained in the food experiments with diabetics at different levels of basal metabolism.

When the results for all the basal experiments used for the food observations are compared with the increases in the heat-production found in all of the food experiments, it is seen that the average increases ranged from 13 to 19 per cent, with no regular relation between them and the level of the basal metabolism. The group with a basal metabolism of 32 to 21 per cent includes 8 experiments after oatmeal, levulose, or beefsteak. Two experiments after dextrose and bread, showing a fall in metabolism after food, have been

a The values in eight of the first nine experiments in table 120 were obtained with the chair calorimeter, but the excess metabolism due to difference in position and other experimental conditions, if corrected for, would not reduce the percentage variation from standard in most of the individual experiments to below +17 per cent. 
excluded from this group. (See footnote 3 of table 121.) If they had been included, the average increase after food for the 10 experiments would have been 9 per cent. Of interest in this connection is the fact that of the 174

TABLE 121.-Comparison of variation of basal metabolism from standard with the increase in heat-production in various food experiments.

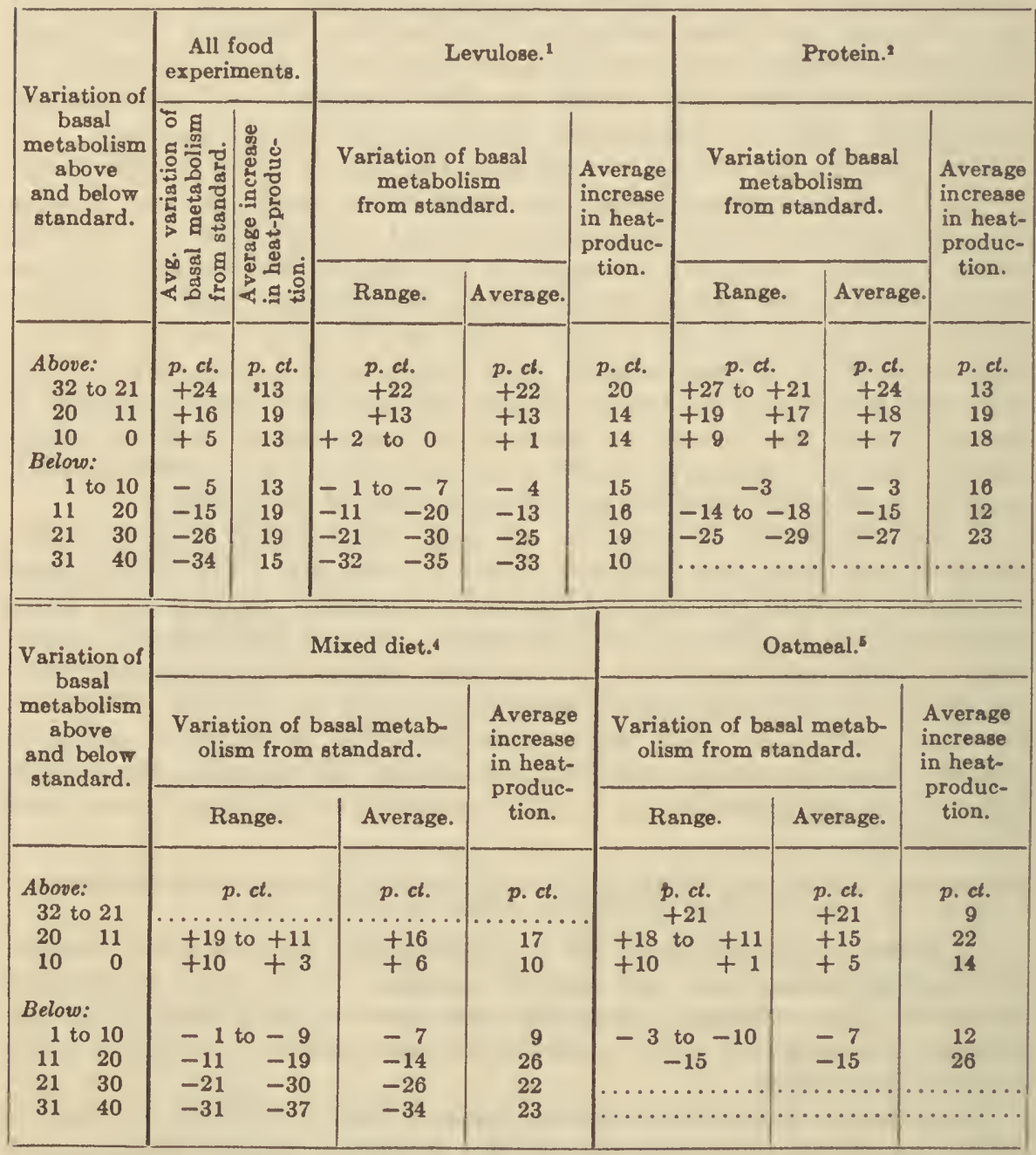

1 Experiments in which levulose alone was given.

2 Protein, protein and fat, and protein (meat) and fat included in this group.

- Two experiments with dextrose and bread, with a fall in metabolism after food of 3 and 9 per cent, respectively, have been excluded from this average. These two experiments were made early in the research and the basal values used, which were determined on other days, were not especially satisfactory. If these experiments are included, the average percentage increase after food for this group with a basal metabolism of 32 to 21 per cent above standard would be reduced from 13 to 9 per cent.

- All of the mixed diet experiments are included in this group except mixed dinner and levulose combinations.

- Oatmeal, oatmeal with fat, ostmeal day (single meal and multiple meals) included in this group. 
experiments in this table, all but 7 showed an increase in metabolism after food. Of these 7 experiments, there was a fall in 1 experiment each of 9 and 3 per cent, respectively, of 1 per cent in 4 experiments, and no change in 1 experiment.

The same lack of relation between the level of basal metabolism and the heat-production after food is to be found when the results of observations after some of the individual foods and diets are examined. After levulose, the highest increment in the metabolism occurred when the basal metabolism was highest ( 32 to 21 per cent above standard), but approximately the same value was secured when the basal value was 21 to 30 per cent below standard. Like results are found for the observations after protein and mixed diets, as well as for the oatmeal experiments, later described, unless importance is attached to the one experiment with oatmeal when the basal metabolism was 21 per cent above standard and the increment was but 9 per cent. Although it might be supposed that the stimulus of food would be less on an already stimulated body-metabolism (i. e., with acidosis and high metabolic state), it would appear from these results that there is no especial relation between the level of the basal metabolism and the degree of reaction of the body to food.

Coleman and $\mathrm{Du}$ Bois* have found that food given to patients with fever, whose metabolism was 40 per cent above normal, caused far less increase in the metabolism than when the metabolism was nearer the normal level. With the diabetics, however, the observations made with food, as shown in table 121, do not indicate this. Food stimulated the metabolism almost equally well when the basal metabolism was above as when it was below standard.

After food the metabolism of certain diabetics of the severest type rose to an extraordinarily high point. Case No. 561, whose basal metabolism was +18 per cent above normal, presented a metabolism on an "oatmeal day" (February 8-9, 1913) following three feedings of oatmeal and butter, of 61 per cent above the normal standard and 37 per cent above his basal value. Case No. 591 , whose basal metabolism was +15 per cent, showed a metabolism after the fourth meal on an oatmeal day (April 12-13, 1913) of 50 per cent above the normal standard and 30 per cent above the basal metabolism. After the fifth meal on the same day the metabolism was 63 per cent above standard and 42 per cent above basal. On the following oatmeal day the metabolism of this patient after three meals was 53 per cent above standard and 40 per cent above basal. With Case No. 430, whose basal metabolism was +11 per cent, the metabolism after a mixed breakfast on September 14-15, 1914, rose to 55 per cent above the normal standard and to 39 per cent above his basal metabolism.

Similar values, though not quite so high, have been found with normal individuals. Benedict and Carpenter, ${ }^{b}$ in an observation on a normal man (A. H. M.) at Wesleyan University on February 19, 1906, obtained a basal metabolism of 1,704 calories per 24 hours. or, in terms of normal standard, +2 per cent. Following a heavy breakfast with an energy content of 3,936 calories (protein, 13 per cent; fat, 54 per cent; carbohydrate, 33 per cent), the metabolism rose in the period from $1 \frac{1}{2}$ to $91 / 2$ hours after breakfast 40 per cent above the basal level. This was equivalent to 41 per cent above

- Coleman and Du Bois, Arch. Intern. Med., 1914, 14, p. 168.

'Benedict and Carpenter, Carnegie Inst. Wash. Pub. No. 261, 1918, p. 316. 


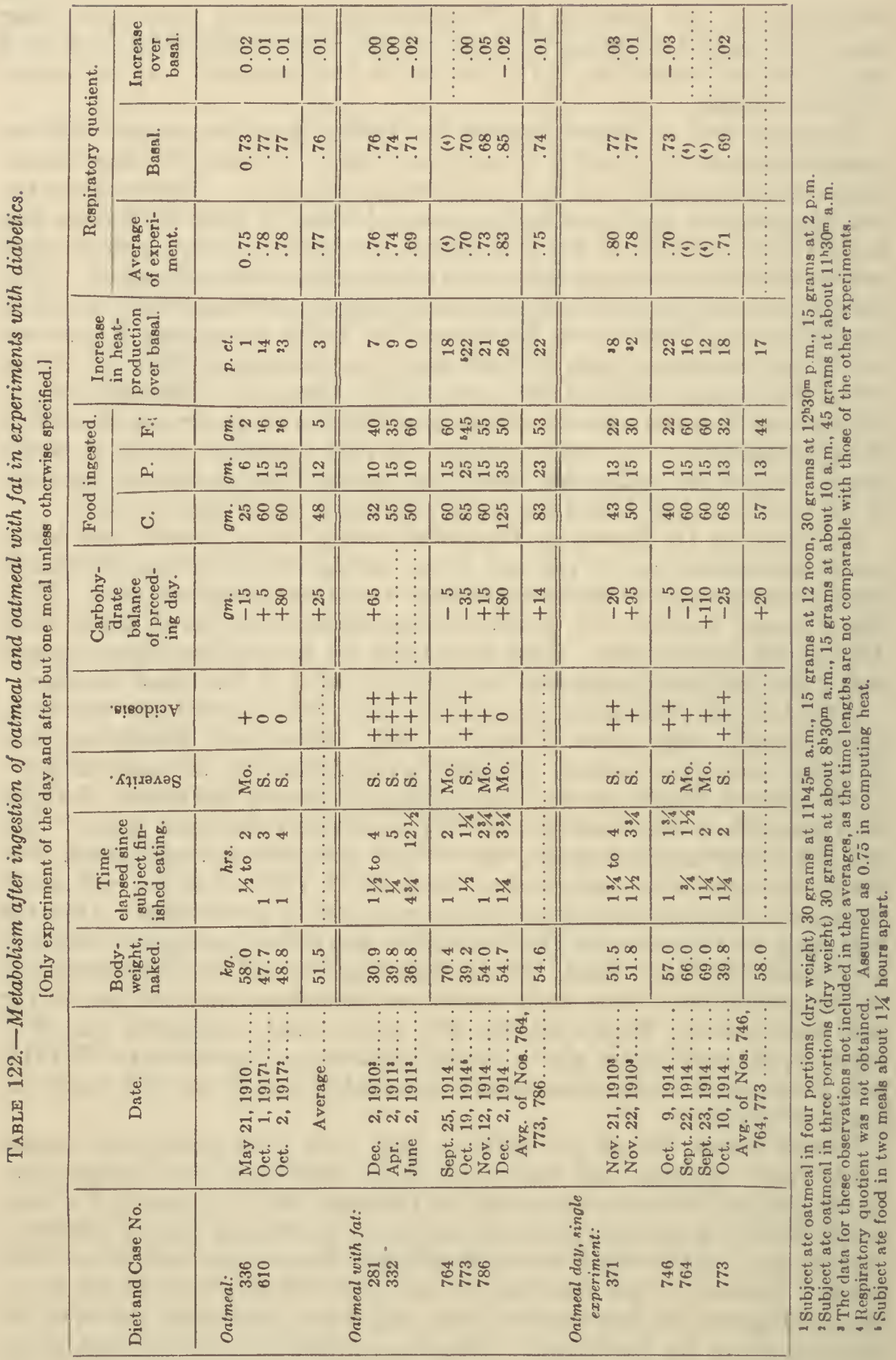


the normal standard for this man. During the interval between $11 / 2$ and $51 / 2$ hours after the breakfast, the metabolism rose to 45 per cent above basal, which was equivalent to 46 per cent above the normal standard.

\section{EFFECT OF OATMEAL ON METABOLISM OF DIABETICS.}

Oatmeal, both alone and with fat, was given to the patients studied in this series in varying amounts and at varying times of the day. In many of the tests the oatmeal was given in accordance with the "oatmeal cure," originally suggested by von Noorden, ${ }^{a}$ but the individual observations with oatmeal and oatmeal and fat in table 122 , which were obtained on other than oatmeal days, are first considered.

\section{Oatmeal Without Fat.}

Oatmeal, unmixed with other food, was taken in only three experiments by two patients. In this series, as in all subsequent series of experiments with this cereal, the amount of oatmeal used as a basis of calculation was 30 grams, weighed dry. The composition of this quantity was estimated to be carbohydrate 20 grams, protein 5 grams, fat 2 grams, energy content, 118 calories.

In the experiments with oatmeal alone, the carbohydrate represented by the amounts taken varied from 25 to 60 grams, the protein from 6 to 15 grams, and the fat a negligible quantity of 2 to 6 grams. In the first experiment the metabolism was determined during a period of one-half hour to two hours after the ingestion of the oatmeal, with practically no rise in metabolism or quotient. In the remaining two experiments, which continued from one to three and from one to four hours after the patient had finished eating 75 and 90 grams of oatmeal, respectively, in several portions, the change in heatproduction was negligible and the respiratory quotient remained essentially unaltered. The only conclusion, therefore, to be drawn from these three experiments is that the metabolism of these two diabetic patients at the expiration of a period of two to four hours after the taking of a small quantity of carbohydrate in the form of oatmeal is not appreciably increased and that there is no essential change in the respiratory quotient.

\section{Oatmeal With Fat.}

Oatmeal in varying quantities, together with fat, was given in 7 experiments to 5 of the diabetic patients on other than oatmeal days. The quantity of carbohydrate represented by the oatmeal varied between 32 and 125 grams; the protein between 10 and 35 grams; and the fat between 35 and 60 grams. The observations were made at varying periods after the ingestion of the oatmeal and fat. In the first two experiments of the series, which were begun one-quarter hour and $11 / 2$ hours after the food was taken, but continued until 4 or 5 hours after food, the rise in the metabolism was 7 and 9 per cent, respectively, but in the experiment which commenced $43 / 4$ hours after the ingestion of the food, no increase in metabolism was found. In the experiments which were concluded within $1 \frac{1}{4}$ to $33 / 4$ hours after the food was given, the rise in metabolism was greatest, varying between 18 and 26 per cent. Only these last 4 experiments are included in the averages, as the others

a von Noorden, Berl. klin. Wochenschr., 1903, 40, p. 817. 
are not comparable in length of period and time elapsed after the taking of the food.

Three of the experiments were made with cases of moderate severity, but the rise in metabolism with these was fully equaled by one of the severe cases who received the oatmeal in a similar period of time.

The average respiratory quotient was unaffected by the feeding of the oatmeal and fat and the individual quotients varied in a negligible degree, save in one case there was a rise of 0.05 .

The increase in metabolism following the taking of the oatmeal and fat should not be attributed alone to the effect of the carbohydrate or to the carbohydrate and fat because the 10 to 35 grams of protein in the oatmeal, and the greater caloric value of the meal must be considered. The lack of effect on the respiratory quotient may in part be explained by the interval which ensued between the ingestion of the oatmeal and the beginning of the experiment and by the duration of the experimental period and not necessarily considered to be due entirely to lack of oxidation.

The evidence here, therefore, is more conclusive than that obtained from the experiments with oatmeal alone and shows that oatmeal, when combined with fat, is capable of increasing the metabolism of moderate and severe diabetics 18 to 26 per cent if the observations are concluded within two or three hours of the ingestion of the food, but to a lesser degree if continued longer, and that the influence disappears if the beginning of the observation is deferred for 5 hours. The experiments as conducted provide no evidence of change in the respiratory quotient.

\section{Metabolism on "Oatmeal Days"-Single Observations.}

A number of determinations of the metabolism after the ingestion of oatmeal and fat were made with patients who were undergoing the "oatmeal cure." In some instances but a single observation was made on the oatmeal day, while on other days several experiments were made after the various feedings with oatmeal and fat. The single determinations on the oatmeal days, which were made with 4 patients on 6 days, are included in table 122 . In these experiments there was a considerable variation in the interval between the ingestion of the oatmeal and fat and the conclusion of the experiment.

The first two experiments began $11 / 2$ to $13 / 4$ hours after the ingestion of the oatmeal and fat and continued to $3 \frac{3}{4}$ or 4 hours after food, the rise in metabolism being but 8 per cent and 2 per cent, respectively. These two experiments are not included in the averages, since they are not comparable in time with the others in the series, as they were begun later and were continued longer. In the last four experiments, the period of observation began from 45 minutes to $1 \frac{1}{4}$ hours after the ingestion of food and ended in 2 hours or less after food. It will be observed that in these four experiments the rise in metabolism varied from 12 to 22 per cent.

Of these last four experiments, in which the rise in metabolism was considerable, two were with patients having severe diabetes and two were with a patient with moderate diabetes. Thus, the severity of the diabetes played no part in the increase of the metabolism in this series, which corresponds to observations made in the series of experiments with oatmeal and fat just discussed. There was no essential change in the respiratory quotient, but it 
must be remembered that in these oatmeal experiments an hour, more or less, elapsed between the taking of the oatmeal and the beginning of the experiment. This first hour was shown in the levulose experiments to have been the hour in which the rise in quotient was greatest.

\section{Metabolism on "Oatmeal Days"-Moltiple Observations.}

By far the larger series of experiments with oatmeal and fat were carried out during the course of typical oatmeal days. In table 123 are collected the results of observations after the first, second, third, fourth, fifth, sixth, and seventh meals upon such days. The percentage increases in heat-production after these successive meals are also grouped for ready comparison in table 124, page 267. Table 123 is so arranged that not only the constituents of the individual meals of oatmeal and fat are given, but the summation of the composition of all previous meals in the day is recorded, including that immediately preceding the respective observations. It may be noted that the values obtained in the experiments after the first meal are comparable with those given in table 122 .

Fortunately the times which elapsed after the subject finished eating the meal immediately preceding the experiment were comparatively uniform. This interval varied from approximately one-half hour to $11 / 2$ hours in most of the observations. A single experiment which began $51 / 2$ hours after food and continued to $131 / 2$ hours after food appears among the observations after the third meal, but the results are not included in the averages. This experiment is the only one in the series in which a rise in the metabolism did not take place, and consequently affords some evidence that when such a rise in metabolism does not take place after the ingestion of oatmeal and fat on a typical oatmeal day, it is due to the prolonged interval after the food is taken before the experiment begins or ends.

First of all, it will be observed that all of these experiments were made with severe cases, who, except in 4 out of the 35 experiments, presented the severest type of acidosis. The carbohydrate balance of the preceding day was minus in 25 experiments and positive in 10 experiments. After the first meal, which contained on the average carbohydrate, 41 grams; protein, 12 grams; and fat, 49 grams, there was an average rise of the metabolism in 9 experiments of 14 per cent. In general, the rise was greater or less with the increase or decrease in the quantity of food, the least rise in the metabolism occurring when the diet was least. The average respiratory quotients for the basal period and the period of the experiment were identical, namely, 0.73. In fact, the variation in quotient for the different experiments ranged only between -0.03 and +0.03 .

The results of the 8 experiments after the second feeding of oatmeal and fat differed from the first simply in a slightly greater increase in metabolism above basal, being 19 per cent as compared with the increase of 14 per cent after the first meal. In but two cases was the increase in the metabolism below 15 per cent, these being with the same patient. The greatest increase in metabolism was 31 per cent, but this was only 3 per cent above the results obtained in two experiments after the first meal. The composition of the second meal was almost identical with that of the first; consequently, the only exflanation of the increase in the metabolism after this meal must be attrib- 


\begin{tabular}{|c|c|c|c|c|c|c|}
\hline \multirow{4}{*}{ 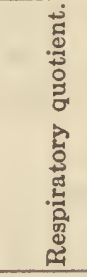 } & \multirow{2}{*}{\multicolumn{2}{|c|}{ 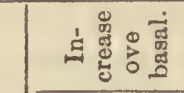 }} & 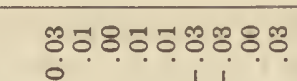 & 8 & ซㅇํㅇํํㅇํㅇํำ & 8 \\
\hline & & & $\begin{array}{l}11 \\
\end{array}$ & & $1 \quad 1$ & \\
\hline & \multicolumn{2}{|c|}{$\begin{array}{l}\text { 荡 } \\
\text { m } \\
\end{array}$} & ํํำกำกำ & $?$ & 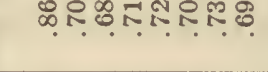 & $\frac{1}{N}$ \\
\hline & \multicolumn{2}{|c|}{ 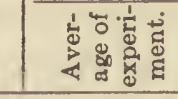 } & ㄲํํำฺํำ & ?ִ & ๓유ํํํํํํํํ. & $\stackrel{\mathfrak{N}}{\mathfrak{N}}$ \\
\hline \multicolumn{3}{|c|}{ 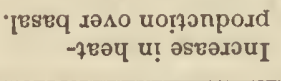 } & 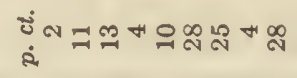 & \pm & 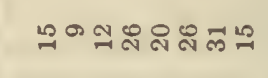 & $\stackrel{2}{-1}$ \\
\hline \multirow{7}{*}{ 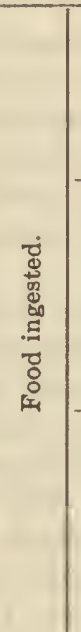 } & \multicolumn{2}{|c|}{ 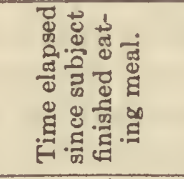 } & 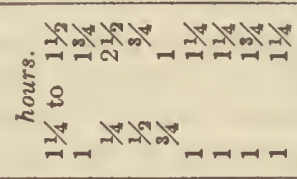 & & 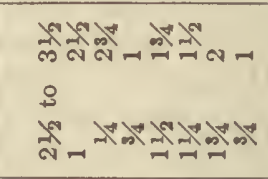 & \\
\hline & \multirow{3}{*}{ 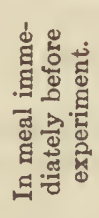 } & 庄 & కై & F & 붕용ำ & $\stackrel{\infty}{*}$ \\
\hline & & i & 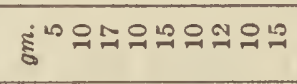 & $\cong$ & 유 $\infty \propto ⿻ 上 丨$ & $\approx$ \\
\hline & & $\dot{0}$ & 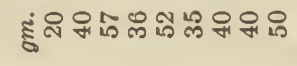 & F & 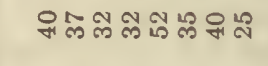 & กิ \\
\hline & \multirow{3}{*}{ 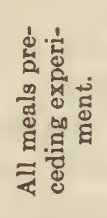 } & $\dot{5 i}$ & & & 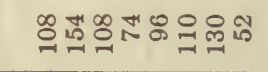 & 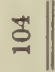 \\
\hline & & i & ह் & & 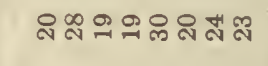 & ฉ్ \\
\hline & & ن & : : : : : : : & & ஓ & $\infty$ \\
\hline \multicolumn{3}{|c|}{ 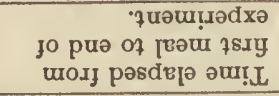 } & 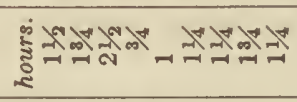 & & 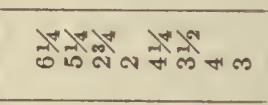 & \\
\hline \multicolumn{3}{|c|}{ 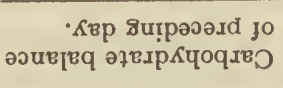 } & 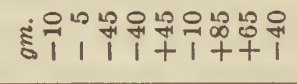 & & 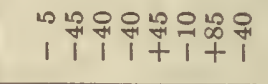 & $\vdots$ \\
\hline \multicolumn{3}{|c|}{ •s!sop!̣ } & $\begin{array}{l}+++++++ \\
++++++++ \\
++++++\end{array}$ & & & \\
\hline \multicolumn{3}{|c|}{ 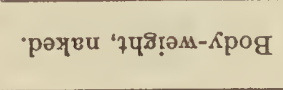 } & 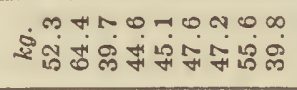 & $\begin{array}{l}10 \\
\infty \\
1+\infty\end{array}$ & 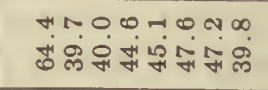 & 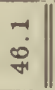 \\
\hline \multicolumn{3}{|c|}{ 离 } & 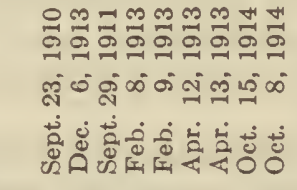 & 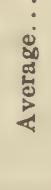 & 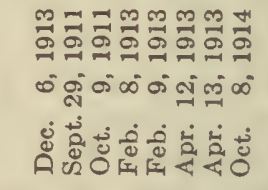 & 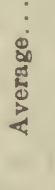 \\
\hline \multicolumn{3}{|c|}{ 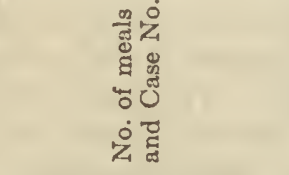 } & 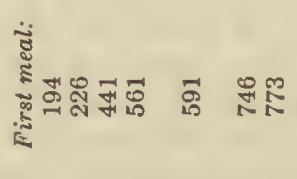 & \multicolumn{2}{|r|}{ 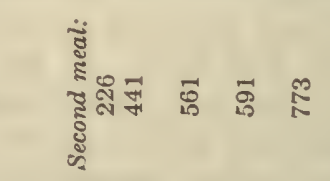 } & \\
\hline
\end{tabular}




\begin{tabular}{|c|c|c|c|c|c|c|}
\hline 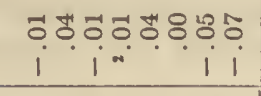 & क् & จำ: & 尺े & ㄸํำ? & i & \% \\
\hline 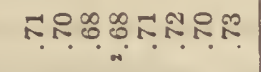 & 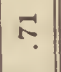 & 도ำก & $\stackrel{N}{\sim}$ & 즈준 & $\approx$ & 구 \\
\hline 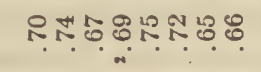 & ㅇ․ & 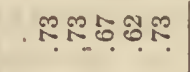 & $R$ & 욤ำ & 5 & $\pi$ \\
\hline 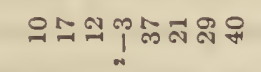 & जี & 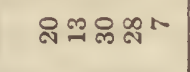 & ฉి & 워요 & $\stackrel{N}{2}$ & $\approx$ \\
\hline 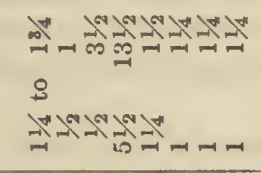 & $\vdots \vdots$ & 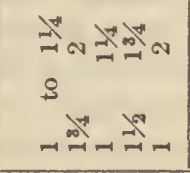 & : & 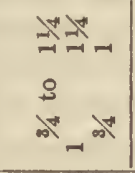 & $\begin{array}{l}\vdots \\
\vdots \\
\vdots \\
\vdots\end{array}$ & $\begin{array}{l}\Rightarrow+ \\
\Rightarrow \\
\Rightarrow \\
\Rightarrow\end{array}$ \\
\hline 이요연 & H & 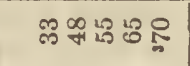 & 萿 & $\stackrel{9}{9}$ & $\stackrel{\infty}{*}$ & 92 \\
\hline 윽 & 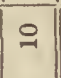 & $0 \div 20 \div$ & $\stackrel{\circ}{=}$ & 900 & $\Rightarrow$ & $\pi 4$ \\
\hline 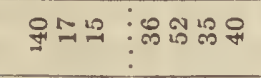 & ले & 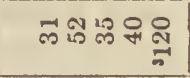 & 呙 & 유즐ำ & ผ్ల & $\stackrel{-}{-}$ \\
\hline ৪æ & \pm & 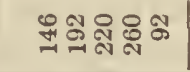 & 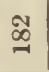 & 曷导总 & : & $\underset{\infty}{\infty} \stackrel{\infty}{\circ}$ \\
\hline ష & ๑ి & $\infty$ & $\mathscr{O}$ & "⿹弋 & พี & कृ \\
\hline 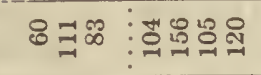 & 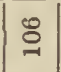 & 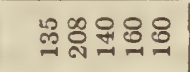 & $\overline{0}$ & 엄 & $\exists$ & $\underset{-1}{N} \infty$ \\
\hline 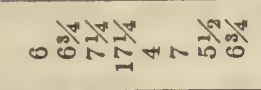 & $\vdots$ & 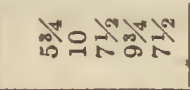 & & ฮ゙ミ゙ず & $\vdots$ & ळँ $=$ \\
\hline 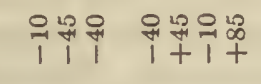 & $\vdots \vdots$ & 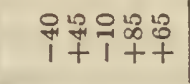 & $\vdots$ & 욱유유 & $\vdots \vdots$ & 유 유 \\
\hline $\begin{array}{l}+++\quad+++ \\
+++\quad+++t \\
+++\quad+++t\end{array}$ & \begin{tabular}{c|}
$\vdots$ \\
$\vdots$
\end{tabular} & $\begin{array}{l}+++t \\
+++t+ \\
++t\end{array}$ & $\vdots$ & $\begin{array}{l}+++ \\
+++ \\
+++\end{array}$ & $\begin{array}{c}\vdots \\
\vdots \\
\vdots\end{array}$ & $\begin{array}{l}++ \\
++ \\
+\end{array}$ \\
\hline mกำ & 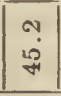 & 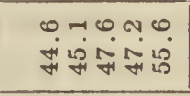 & $\begin{array}{l}0 \\
\infty \\
+ \\
+\end{array}$ & 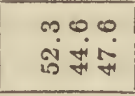 & 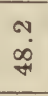 & 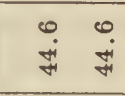 \\
\hline 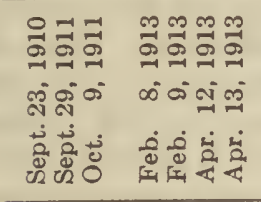 & 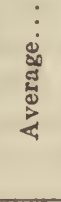 & 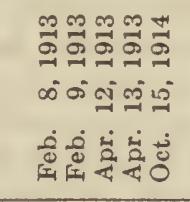 & 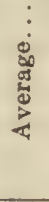 & 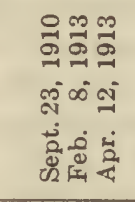 & 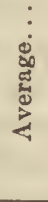 & 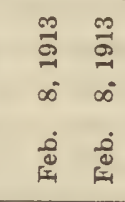 \\
\hline 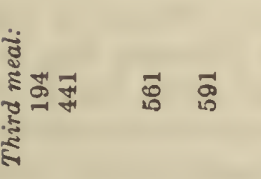 & & 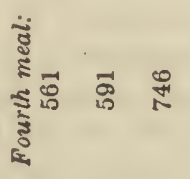 & & 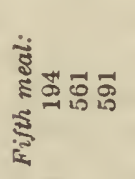 & & 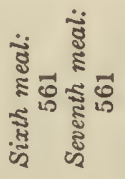 \\
\hline
\end{tabular}


uted to a summation effect of the two meals. Here, again, the average basal respiratory quotient and the respiratory quotient during the experiment averaged the same.

Following the third meal, which, as a matter of fact, was a trifle less in amount than either the first or second meal, the rise in metabolism was 24 per cent. Exclusive of the long experiment on October 9, the lowest increase in metabolism was 10 per cent, but in two experiments the increases in metabolism were 37 and 40 per cent, respectively, these being materially greater than any increases noted after the first or second meals. Since this meal was smaller than the first and second meals, the greater increase in metabolism must again be attributed to a summation effect. It is notable that there was practically no difference between the average basal respiratory quotient and that found after the third meal.

There were but 5 experiments after the fourth meal which were made with three cases. As a result of this feeding, the average rise in metabolism was maintained at 20 per cent above the basal, though in two experiments it showed further stimulation. The respiratory quotient fell on the average 0.02 , but this was due to an unusual fall of 0.11 in an experiment on April 13, 1913, with Case No. 591. In the past doubt has been thrown upon an experiment of this type because of the low quotient obtained of 0.62 . Attention is here called to the following facts: (1) that in the series of oatmeal experiments thus far recorded there has been no clear tendency to a rise in quotient; (2) that these low quotients were secured on two successive days and are supported by similar quotients; (3) that they were secured after the patient had taken 220 and 260 grams of fat, respectively; (4) that with the carbohydrate and protein the total calories were equivalent to 57 and 67 calories per kilogram of body-weight in the preceding $71 / 2$ and $93 / 4$ hours, although the patient was taking no active exercise.

Three experiments with three patients were made after a fifth feeding of oatmeal. The amount of food taken at this meal was, on the average, less than the average feeding in any of the preceding four meals. The average rise in the metabolism was 26 per cent, which is the greatest thus far noted in this oatmeal series. The respiratory quotient, on the other hand, fell 0.04. This considerable fall must be attributed to the single experiment with Case No. 591 in which the unusually low value for respiratory quotient of 0.58 was obtained. This is the same patient with whom the low quotient of 0.62 was obtained after the fourth meal, although the latter was not obtained on the same day as the quotient of 0.58 , but on the day following. These unusually low quotients with Case No. 591 can not be disregarded. The subject was an ideal one, a severe diabetic with severe acidosis who died in coma six months after these observations. He was given 55 grams of fat at each of 5 successive meals with but little protein (10 grams) and carbohydrate (35 grams) each. Confirmation of the reliability of these quotients is supplied by the quotients obtained in a similar experiment the following day and the basal experiment and mixed diet experiment the day after (April 14-15). The rise in his metabolism after the third meal on April 13 was 40 per cent and after the fifth meal on April 12, 42 per cent. This is exactly in line with what has already been noted about the metabolism and respiratory quotient, namely, that the lower the quotient, the higher the metabolism. (See p. 165.) 
There was a single experiment after the sixth meal and but one after the seventh meal. Fortunately, these were made with the same patient (Case No. 561) and on the same day. The rise in metabolism was essentially the same, i. e., 13 and 14 per cent, respectively, with an increase in the respiratory quotient in both of 0.03 . Comparing the earlier experiments with this patient on the same day (February 8,1913 ), we may note that after the fifth and fourth meals the increases in metabolism were 19 and 20 per cent and the rise in the respiratory quotient 0.02 . After the third meal there was an extraordinary increase in the metabolism of 37 per cent and an increase in the respiratory quotient of 0.04 . After the second meal, the rise in the metabolism was 26 per cent and the increase in the respiratory quotient 0.07 , but after the first meal the increase in metabolism was but 4 per cent and in the respiratory quotient only 0.01 . It is notable that on the following day, which was also

TABLE. 124-Comparison of percentage increases over basal in heat-production of diabetics after successive meals on oatmeal days.

\begin{tabular}{|c|c|c|c|c|c|c|c|c|}
\hline $\begin{array}{l}\text { Case } \\
\text { No. }\end{array}$ & Date. & $\begin{array}{l}\text { First } \\
\text { meal. }\end{array}$ & $\begin{array}{c}\text { Second } \\
\text { meal. }\end{array}$ & $\begin{array}{l}\text { Third } \\
\text { meal. }\end{array}$ & $\begin{array}{c}\text { Fourth } \\
\text { meal. }\end{array}$ & $\begin{array}{l}\text { Fifth } \\
\text { meal. }\end{array}$ & $\begin{array}{l}\text { Sixth } \\
\text { meal. }\end{array}$ & $\begin{array}{c}\text { Seventh } \\
\text { meal. }\end{array}$ \\
\hline 194 & Sept. 23, 1910 & 2 & & 10 & & 16 & & \\
\hline 226 & Dec. 6,1913 & 11 & 15 & $\cdots$ & 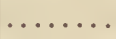 & $\cdots$ & & - \\
\hline \multirow[t]{2}{*}{441} & Sept. 29, 1911 & 13 & 9 & 17 & , & . & .. & \\
\hline & Oct. $\quad 9,1911$ & $\ldots \ldots$ & 12 & 12 & $\ldots \ldots$ & $\ldots \ldots$ & $\ldots$ & $\cdots$ \\
\hline \multirow[t]{2}{*}{561} & Feb. $\quad 8,1913$ & 4 & 26 & 37 & 20 & 19 & 13 & 14 \\
\hline & Feb. 9,1913 & 10 & 20 & 21 & 13 & $\ldots \ldots$ & ....... & $\ldots \ldots \ldots$ \\
\hline \multirow[t]{2}{*}{591} & Apr. 12,1913 & 28 & 26 & 29 & 30 & 42 & $\ldots \ldots \ldots$ & $\ldots \ldots \ldots$ \\
\hline & Apr. 13,1913 & 25 & 31 & 40 & 28 & $\ldots \ldots$ & $\ldots \ldots \ldots$ & $\ldots \ldots \ldots$ \\
\hline \multirow{3}{*}{$\begin{array}{l}746 \\
773\end{array}$} & Oct. 15,1914 & 4 & $\cdots$ & $\cdots$ & 7 & $\ldots \ldots \ldots$ & $\ldots \ldots \ldots$ & $\ldots \ldots \ldots$ \\
\hline & Oct. 8,1914 & 28 & 15 & $\cdots$ & $\cdots \cdots$ & $\cdots$ & $\ldots \ldots \ldots$ & $\cdots \cdots$ \\
\hline & Average increase. & 14 & 19 & 24 & 20 & 26 & 13 & 14 \\
\hline
\end{tabular}

an oatmeal day for this patient, the rise in metabolism after the first meal was 10 per cent, after the second meal 20 per cent, after the third meal 21 per cent, and after the fourth meal 13 per cent. This case, therefore, shows particularly well the increase in metabolism after oatmeal. Furthermore, the results with this patient give evidence that the rise in metabolism upon a second oatmeal day is not greater than on the first oatmeal day and second, that the respiratory quotient had an even less tendency to rise on the second oatmeal day than on the first one. The percentage increases in the heat-production due to the ingestion of the several meals on the oatmeal days are summarized for comparison in table 124. The increases in the respiratory quotient, being small in most cases, are not included.

\section{Conclusions upon Experiments with Oatmeal.}

The whole series of experiments above cited shows that upon the typical von Noorden oatmeal days, the metabolism had a general tendency to rise from 14 per cent after the first meal to as much as 26 per cent after the fifth meal The progressive increase in metabolism throughout the day must be attributed to a summation effect. This increase in metabolism took place although the protein in the diet was low. On the other hand, with the type of experiment here employed, the respiratory quotient gave slight evidence of a tendency 
to rise. Whether such a tendency with the quotient would be manifest if the experiments were made in half-hour periods, as in the experiments with levulose, is a matter of speculation, since the size of the meal tended to decrease somewhat as the successive meals were given. With one patient who received extraordinary quantities of oatmeal and butter for an individual of his body-weight (Case No. 591), extraordinarily low quotients were obtained, with extraordinarily great increases in the metabolism, particularly after meals which contained comparatively little protein.

\section{METABOLISM OF DIABETICS AFTER INGESTION OF MIXED DIETS.}

In connection with the routine post-absorptive observations and observations upon the effect of levulose, orange juice, and oatmeal, opportunity often arose to utilize the clinical respiration chamber for determining the metabolism after mixed meals. The results are recorded in tables 125 to 128 .

The experiments have been grouped into those following: (1) the first meal of the day (either breakfast or dinner); (2) a dinner preceded by breakfast; (3) two and three meals taken at various times in the day; and finally (4) a dinner consisting exclusively of carbohydrate and protein. Experiments in each table are further grouped according to whether the diabetes was severe, moderate, or mild. The carbohydrate, protein, and fat contents of these meals have been recorded in each case.

Metabolism of Diabetics after First Meal of Day (Breakfast or Dinner).

In the first group of table 125, the results are given for 14 observations with patients having severe diabetes, in which a study was made of the effect of a mixed diet taken as the first meal of the day and from one to $23 / 4$ hours previous to the beginning of the test. In nearly all of the observations the acidosis was moderate to severe. The diet for the day preceding the experiment was not accurately known in many cases, but the composition and caloric value of the meal preceding the experiment are recorded in the table.

The largest amount of energy per kilogram of body-weight in the meal immediately preceding the observations with the severe cases was 11 calories, which represents about the normal quantity of food required by a normal individual at one of three equal meals in 24 hours. The least quantity given was 2 calories, which would be about one-fifth of the normal intake. The average constituents of the meal were: carbohydrate, 16 grams; protein, 12 grams; fat, 16 grams; the average energy per kilogram of body-weight was 7.1 calories.

In the interpretation of these observations it is essential to bear in mind that the increases in metabolism do not represent the total increase in metabolism after the given quantity of food, but simply the increase in metabolism for the period of the observation, which was from 15 minutes to $21 / 4$ hours. Furthermore, this period began from approximately 1 to 2 hours after the food was ingested. It is reasonable to suppose that if a study had been made of the entire period in which the metabolism was affected by the food, somewhat different results would have been obtained. Thus, if the experiment had begun promptly after the ingestion of the food, the metabolism would probably have been higher. If the experiment had continued longer, the increases in the metabolism would have gradually diminished, and the figures would h\&ve been reduced. 
The average increase in heat-production over the basal was 15 per cent, with variations from -1 to +39 per cent. It will be observed that the presence or absence of acidosis had comparatively little effect upon the heatproduction. Thus, the average increase in metabolism of the patients without acidosis was +17 per cent, which was essentially the average figure for all the cases. Furthermore, there were experiments. with practically no rise in the metabolism, in which the acidosis was, respectively, ++ , and +++ ; on the other hand, there were experiments in which the rise of metabolism was between 29 and 39 per cent, in which the acidosis was $0,+$, and ++ . Acidosis, therefore, according to these results, as elsewhere shown, did not prevent a rise in metabolism after food. The individuals who showed the higher increments in metabolism were those who received the most protein, though this rule has exceptions. Likewise, the individuals who showed the

TABLE 125.-Metabolism of diabetics in experiments after breakfast or dinner as the first meal of the day.

\begin{tabular}{|c|c|c|c|c|c|c|c|c|c|c|c|c|c|c|}
\hline \multirow{3}{*}{$\begin{array}{l}\text { Case No. } \\
\text { and } \\
\text { severity. }\end{array}$} & \multirow{3}{*}{ Date. } & \multirow{3}{*}{$\begin{array}{c}\text { Time elasped } \\
\text { since subject } \\
\text { fnished } \\
\text { eating. }\end{array}$} & \multirow{3}{*}{ 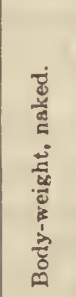 } & \multirow{3}{*}{ 密 } & \multirow{3}{*}{ 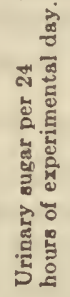 } & \multirow{3}{*}{ 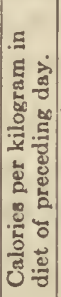 } & \multicolumn{4}{|c|}{$\begin{array}{l}\text { Food ingested in } \\
\text { meal preceding } \\
\text { experiment. }\end{array}$} & \multirow{3}{*}{ 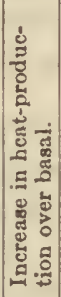 } & \multicolumn{3}{|c|}{ Respiratory quotient. } \\
\hline & & & & & & & \multirow{2}{*}{ C. } & \multirow{2}{*}{ P. } & \multirow{2}{*}{ F. } & \multirow{2}{*}{ 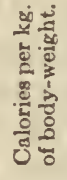 } & & \multirow{2}{*}{ Basal. } & \multicolumn{2}{|c|}{$\begin{array}{l}\text { During ex- } \\
\text { periment. }\end{array}$} \\
\hline & & & & & & & & & & & & & $\begin{array}{l}\text { Maxi- } \\
\text { mum. }\end{array}$ & $\begin{array}{l}\text { Aver- } \\
\text { age. }\end{array}$ \\
\hline \multirow{3}{*}{$\begin{array}{r}332 \\
332\end{array}$} & & hours. & ko. & & gm. & & $a m$. & om. & om. & & p.ct. & & & \\
\hline & May 14,1910 & $13 / 4$ to 2 & 39.0 & $++t$ & $\ldots$ & & 15 & 6 & 6 & 3.6 & 2 & 0.76 & 0.74 & 0.74 \\
\hline & May 19,1910 & $21 / 4$ & 39.3 & $+t+$ & & & 20 & 15 & 30 & 10.4 & 5 & .76 & .74 & .73 \\
\hline 430 & Sept. 14, 1914 & $13 / 4$ & 54.1 & + & 86 & 132 & 30 & 20 & 27 & 8.2 & 39 & .75 & 69 & .69 \\
\hline 746 & Oct. 7,1914 & $8 \%$ & 56.0 & ++ & 93 & 128 & 30 & 10 & 15 & 5.3 & 13 & .71 & .73 & .73 \\
\hline \multirow[t]{2}{*}{806} & Dec. 21,1914 ? & 23 & 61.9 & $+t$ & 0 & 0 & 10 & 10 & 10 & 2.7 & -1 & .71 & .71 & .70 \\
\hline & Dec. 23,1914 & 28 & 62.7 & $+t$ & 0 & 12 & 5 & 10 & 10 & 2.4 & 2 & .68 & .84 & .78 \\
\hline \multirow[t]{5}{*}{1011} & Nov. $3,1916^{2}$ & $13 \frac{1}{4}$ & 29.9 & ++ & 0 & 4 & 3 & 18 & 26 & 10.7 & 29 & .78 & .80 & .75 \\
\hline & Oet 26,1917 & 3 & 27.0 & ++ & 95 & 42 & 40 & 10 & 10 & 10.7 & 17 & .84 & .95 & .88 \\
\hline & Nov. 2,1917 & 1 & 27.6 & $+t$ & 94 & 42 & 40 & 10 & 10 & 10.5 & 25 & .83 & .93 & .87 \\
\hline & Nov. 15,1917 & 3 & 27.4 & $+t$ & 74 & 30 & 18 & 15 & 10 & 8.0 & 6 & .80 & 1.09 & .91 \\
\hline & Nov. 27,1917 & $i$ & 26.3 & $+t$ & 0 & 18 & 3 & 10 & 15 & 7.0 & 15 & .88 & .99 & .89 \\
\hline \multirow{4}{*}{$\begin{array}{l}1213 \\
1378\end{array}$} & Apr. 11,1917 & 114 & 32.3 & 0 & 0 & 16 & 2 & 10 & 15 & 5.7 & 0 & .91 & 1.05 & .98 \\
\hline & Oct. 25,1917 & 1 & 31.2 & 0 & 3 & 32 & 4 & 14 & 16 & 6.9 & 15 & .84 & .90 & .85 \\
\hline & Nov. 16,1917 & 1 & 31.0 & 0 & $\ldots \ldots$ & $\cdots$ & 2 & 14 & 18 & 7.3 & 36 & .88 & .83 & .82 \\
\hline & Average & $\ldots \ldots \ldots \ldots$ & 39.0 & .. & 40 & 23 & 16 & 12 & 16 & 7.1 & 15 & .80 & .86 & .81 \\
\hline \multirow{5}{*}{$\begin{array}{c}\text { Moderate: } \\
226 \\
767 \\
1414 \\
1422\end{array}$} & Scot. 27,1910 & $3 / 2$ to $18 \%$ & 66.5 & + & 0 & & 34 & & 50 & 9.9 & 19 & 73 & 80 & 75 \\
\hline & Nov. $9,1914^{2}$ & $1^{7 / 2} \quad 3 \%$ & 66.7 & ${ }_{0}^{\top}$ & 0 & 14 & 76 & $\begin{array}{l}10 \\
10\end{array}$ & 30 & $\begin{array}{l}9.9 \\
9.2\end{array}$ & 22 & .81 & .82 & .80 \\
\hline & Dec. 4, 1917 & $2 \%$ & 41.8 & 0 & 0 & 36 & 28 & 45 & 45 & 16.6 & 19 & .85 & .89 & .85 \\
\hline & Nov. 28,1917 & & 59.2 & 0 & 0 & 23 & 20 & 25 & 40 & 9.1 & 15 & .77 & .83 & .80 \\
\hline & Average & $\ldots \ldots \ldots$ & 58.6 & .. & 0 & 24 & 40 & 25 & 41 & 11.2 & 19 & .79 & .84 & .80 \\
\hline \multirow{6}{*}{$\begin{array}{l}\text { Mild: } \\
\quad 810\end{array}$} & & & & & & & & & & & & & & \\
\hline & Dec. $17,1914^{8}$ & $51 / 2$ to 8312 & 44.2 & + & 0 & 1 & 5 & 3 & 410 & 2.7 & $:-9$ & .76 & .86 & .79 \\
\hline & Dec. $18,1914^{8}$ & $5 \%$ & 43.6 & 0 & 0 & 6 & 8 & 10 & 6 & 2.9 & 3 & .72 & .74 & .73 \\
\hline & Dec. 19,1914 & $13 / 4 \quad 13 / 4$ & 44.7 & 0 & 0 & 10 & 5 & 15 & 20 & 5.8 & 14 & .72 & .86 & .85 \\
\hline & Dec. 21,1914 & $21 / 4$ & 44.6 & 0 & 0 & 21 & 8 & 15 & 36 & 9.3 & 8 & .72 & .77 & .75 \\
\hline & Average & $\ldots \ldots \ldots \ldots$ & 44.3 & & 0 & 10 & 7 & 11 & 18 & 5.2 & 4 & .73 & .81 & .78 \\
\hline
\end{tabular}

1 Approximate. Estimate is, if anything, too low.

2 Experiments with Case No. 806, Dec. 21, 1914, Case No. 1011, Nov, 3, 1916, and Case No. 767, Nov. 9 , 1914, were after dinner which was the frst meal of the day.

3 Experiments with Case No. 810, Dec. 17, and Dec. 18, 1914, were practically post-sbsorptive.

- Approximate amount of fat. 
greatest increases in metabolism were, in general, those who received the higher calories per kilogram of body-weight.

The average respiratory quotient remained essentially the same, being 0.80 for the basal, and 0.81 for the experimental period. The average for the maximum quotients was 0.06 higher than the basal.

With the moderate cases of diabetes, there were 4 observations; these individuals received rather more food than the severe cases. Their metabolism was likewise increased, averaging 19 per cent above the basal value. The respiratory quotients did not change essentially from those obtained with the severe cases, for the whole experiment, or for the average of the maximum quotients.

There were likewise 4 observations with one mild case of diabetes. The quantities of food given this patient were decidedly smaller than those ingested by the other two groups. The rise in metabolism was slight, averaging but 4 per cent. The respiratory quotient increased noticeably, rising from an average basal quotient of 0.73 to an average experimental quotient of 0.78 , and an average maximum quotient of 0.81 .

\section{Mftabolism of Diabetics after Noon Meal Preceded by Breakfast.}

The observations recorded in table 126 are similar to those in table 125 save that they were made after the noon meal when the patients had also had breakfast. With the severe cases of diabetes, 11 observations were made which began from 1 to $2 \frac{1}{4}$ hours after the end of the meal. With no patient was there severe acidosis, the acidosis being moderate or mild or absent altogether. The calories per kilogram of body-weight given these individuals averaged less than in the series recorded in table 125, and varied from 1.1 to 8.9 calories, with an average of 4 calories per kilogram of body-weight. The average amount of protein, however, was comparatively high, being 20 grams. The reduction in the energy content of the food was thus brought about by lowering the amounts of carbohydrate and fat.

The observations show an average increase in metabolism over basal of 25 per cent. This corresponds with the higher quantity of protein and would appear to be directly connected with it, since the caloric value of the diet was decidedly lower than that of the diet used in the experiments in table 125. This diet, therefore, presents an excellent demonstration of the ability of the diabetic to respond to protein. The average respiratory quotient was unchanged by the taking of the food, though there was a slight increase (0.04) in the average of the maximum quotients.

There were 4 observations upon moderate cases. The caloric intake averaged 5.9 calories and the amount of protein was essentially the same as with the severe cases, yet the increase in heat-production was but 16 per cent. This is due primarily to the low values obtained with Case No. 924. Except for these low values, the increase in heat-production would have been essentially the same as with the severe cases. The respiratory quotient fell on the average 0.01 , which corresponds with the low amount of carbohydrate in the diet ( 5 grams). The increase in the average of the maximum quotients was 0.06 .

Three observations were made upon two mild cases. These individuals received the most liberal diet of any of the three groups studied, with a higher caloric content, and larger amounts of protein, carbohydrate, and fat. 
The results of the experiments correspond to the character of the food ingested. Thus, the rise in the metabolism was 20 per cent, which is about what one would expect with normal individuals. The rise in the average quotient was 0.03 , which corresponds to the larger quantity of carbohydrate in the diet. The increase in the average maximum quotients was 0.07 . It is noticeable that with Case No. 1134, who received 100 grams of carbohydrate, there was no rise in the average quotient, but there was a noticeable rise in the maximum quotient.

TABLE 126.-Metabolism of diabeties in experiments after dinner when subjects had had breakfast.

\begin{tabular}{|c|c|c|c|c|c|c|c|c|c|c|c|c|c|c|}
\hline \multirow{3}{*}{$\begin{array}{c}\text { Case No. } \\
\text { and } \\
\text { severity. }\end{array}$} & \multirow{3}{*}{ Date. } & \multirow{3}{*}{ 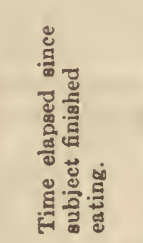 } & \multirow{3}{*}{ 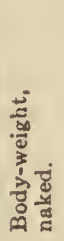 } & \multirow{3}{*}{ 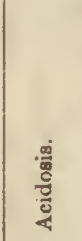 } & \multirow{3}{*}{ 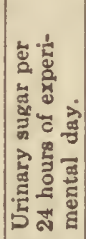 } & \multirow{3}{*}{ 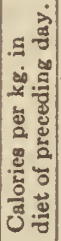 } & \multicolumn{4}{|c|}{$\begin{array}{c}\text { Dinner preceding } \\
\text { experiment. }\end{array}$} & \multirow{3}{*}{ 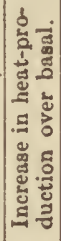 } & \multicolumn{3}{|c|}{$\begin{array}{l}\text { Respiratory } \\
\text { quotient. }\end{array}$} \\
\hline & & & & & & & \multirow{2}{*}{ C. } & \multirow{2}{*}{ P. } & \multirow{2}{*}{ F. } & \multirow{2}{*}{ 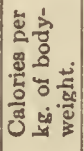 } & & \multirow{2}{*}{ Basal. } & \multicolumn{2}{|c|}{$\begin{array}{l}\text { During ex- } \\
\text { periment. }\end{array}$} \\
\hline & & & & & & & & & & & & & Max. & Avg. \\
\hline Sevore: & & hours. & $k g$. & & $\mathrm{gm}$. & & $\mathrm{gm}$. & $o m$. & om. & & p.ct. & & & \\
\hline 610 & Oct. $\quad 5,1917$ & $11 / 4$ to $31 / 4$ & 46.9 & + & 0 & 9 & 4 & 15 & 18 & 4.7 & 28 & 0.78 & 0.80 & 0.74 \\
\hline 806 & Dec. 22,1914 & $21 / 4$ & 61.8 & $+t$ & 3 & 7 & 5 & 10 & 5 & 1.7 & 2 & .68 & .73 & .71 \\
\hline \multirow[t]{3}{*}{1011} & Oct. 19,1917 & & 27.4 & $+t$ & 77 & 37 & 30 & 25 & 15 & 1.3 & 31 & .84 & .87 & .82 \\
\hline & Nov. 8,1917 & & 27.4 & $+t$ & 84 & 44 & 50 & 30 & 15 & 1.7 & 25 & .75 & .84 & .81 \\
\hline & Nov. 19,1917 & 3 & 28.7 & $+t$ & 51 & 29 & 30 & 25 & 10 & 1.1 & 20 & .87 & .94 & .90 \\
\hline 1025 & May 9,1916 & 2 & 39.9 & 0 & 0 & 35 & 5 & 20 & 14 & 5.6 & 23 & .76 & .80 & .77 \\
\hline 1049 & May 8,1916 & $41 / 4$ & 41.5 & $+t$ & Tr. & 11 & 10 & 37 & 20 & 8.9 & 38 & .77 & .82 & .74 \\
\hline 1213 & Apr. 11,1917 & $31 / 4$ & 32.3 & 0 & 0 & 16 & 2 & 10 & 25 & 2.9 & 29 & .91 & .83 & .80 \\
\hline \multirow[t]{4}{*}{1378} & Oct. 17,1917 & $31 / 4$ & 32.0 & + & $\ldots$ & 29 & 4 & 20 & 15 & 7.2 & 31 & .78 & .92 & .88 \\
\hline & Nov. 1,1917 & 1 & 31.5 & 0 & 0 & 18 & 2 & 10 & 5 & 3.0 & 20 & .90 & .88 & .81 \\
\hline & Nov. 7,1917 & $23 / 4$ & 30.6 & 0 & 0 & 24 & 2 & 17 & 10 & 5.4 & 23 & .90 & .92 & .88 \\
\hline & Average & & 36.4 & & 22 & 24 & 13 & 20 & 11 & 4.0 & 25 & .81 & .85 & .81 \\
\hline \multirow{3}{*}{$\begin{array}{c}\text { Moderate: } \\
924\end{array}$} & & & & & & & & & & & & & & \\
\hline & Nov. 22,1917 & to 3 & 43.2 & 0 & 0 & 15 & 2 & 17 & 14 & 4.6 & -1 & .78 & .86 & .80 \\
\hline & Nov. 28,1917 & 3 & 43.7 & 0 & Tr. & 19 & 2 & 17 & 17 & 5.3 & 3 & .78 & .82 & .77 \\
\hline \multirow[t]{3}{*}{1265} & Nov. 20,1917 & $31 / 4$ & 41.7 & 0 & 0 & 15 & 7 & 20 & 16 & 6.0 & 26 & .84 & .91 & .82 \\
\hline & Nov. 26,1917 & $23 / 4$ & 41.7 & 0 & 0 & 13 & 7 & 20 & 24 & 7.8 & 34 & .84 & .88 & .79 \\
\hline & Average & . & 42.6 & . & 0 & 16 & 5 & 19 & 18 & 5.9 & 16 & .81 & .87 & .80 \\
\hline \multirow{3}{*}{$\begin{array}{l}\text { Mild: } \\
810\end{array}$} & & & & & & & & & & & & & & \\
\hline & Dec. 19,1914 & 2 to $31 / 4$ & 44.7 & 0 & 0 & 10 & 10 & 15 & 26 & 3.5 & 19 & .72 & .76 & .72 \\
\hline & Dec. 21,1914 & $11 / 2$ & 44.6 & 0 & 0 & 21 & 10 & 15 & 225 & 7.3 & 21 & .72 & .83 & .81 \\
\hline \multirow[t]{2}{*}{1134} & Oct. 16,1916 & $3 / 4$ & 64.6 & 0 & 0 & 37 & 100 & 45 & 30 & 13.2 & 21 & .84 & .89 & .84 \\
\hline & Average & & 51.3 & & 0 & 23 & 23 & 25 & 20 & 8.0 & 20 & .76 & .83 & .79 \\
\hline
\end{tabular}

1 Dinner eaten by Case No. 610 on Oct. 5, 1917, included 10 grams of alcohol.

- Breakfast eatcn by Case No. 1213, Apr. 11, 1917, consisted of C. 2, P. 10, F. $15 \mathrm{gms}$.

Breakfasts eaten by Case No. 810, Dec. 19 and Dec. 21, 1914, consisted of C. 5, P. 15, F. 20 gms., and C. 8, P. 15 , and F. 36 gms., respectively.

\section{Metabolism of Diabetics after Two or Three Meals.}

Between September 22, 1910, and October 27, 1914, the metabolism of 3 cases of severe diabetes, all of whom showed acidosis, was observed after they had received two or three mixed meals. The experiments began from 30 minutes to $21 / 2$ hours after the patient had finished eating the last meal. The average caloric value for the food taken in the meals before the 5 experiments was 20 calories per kilogram of body-weight or the same as would be taken in two meals by normal individuals with normal activity. The protein 
averaged 34 grams, also a normal amount for two meals with individuals whose average body-weight was but $48.5 \mathrm{~kg}$. The carbohydrate in the diet was comparatively low (39 grams) and the fat comparatively high (76 grams). The results of the observations are given in table 127.

Following these meals, the metabolism increased between 19 and 28 per cent. The highest figure was obtained after three meals, though as a matter of fact an increase of 27 per cent was also obtained after two meals, though this marked rise may have been due to the shorter period between the time of eating and the beginning of the experiment. The average increase in metabolism for the five observations was 24 per cent.

TABLE 127.-Metabolism of diabetics in experiments after two or three meals. (All cases severe.)

\begin{tabular}{|c|c|c|c|c|c|c|c|c|c|c|c|c|c|c|}
\hline \multirow{3}{*}{$\begin{array}{l}\text { Case No. } \\
\text { and } \\
\text { meals. }\end{array}$} & \multirow{3}{*}{ Date. } & \multirow{3}{*}{ 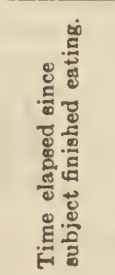 } & \multirow{3}{*}{ 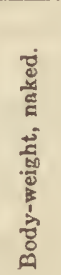 } & \multirow{3}{*}{ } & \multirow{3}{*}{ 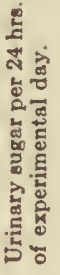 } & \multirow{3}{*}{ 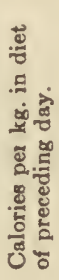 } & \multicolumn{4}{|c|}{$\begin{array}{l}\text { Food ingcsted in the } \\
\text { meals preceding the } \\
\text { experiment. }\end{array}$} & \multirow{3}{*}{ 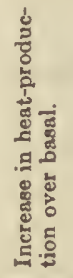 } & \multicolumn{3}{|c|}{ Respiratory guotient. } \\
\hline & & & & & & & \multirow{2}{*}{ C. } & \multirow{2}{*}{ P. } & \multirow{2}{*}{ F. } & \multirow{2}{*}{ 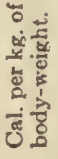 } & & \multirow{2}{*}{ Basal. } & \multicolumn{2}{|c|}{$\begin{array}{c}\text { During } \\
\text { experiment. }\end{array}$} \\
\hline & & & & & & & & & & & & & Max. & Avg. \\
\hline I meals: & Sent. 22 & hours. & $k_{0 .}$ & + & $g m$. & 40 & gm. & om. & $\underset{1100}{g m .}$ & 20 & p. cl. & 0.74 & 0.74 & 0.73 \\
\hline 591 & A pr. 10,1913 & $23 / 23$ & 47.2 & $+t+$ & 64 & & 40 & 50 & 110 & 29 & 19 & .7 & .71 & .70 \\
\hline & Apr. $14,1913 \ldots$ & $21 / 4$ & 47.2 & $++t$ & 48 & 69 & 50 & 35 & 250 & 17 & 19 & .6 & .63 & .62 \\
\hline 765 & Oct. $27,1914 \ldots$ & & 48.4 & & 29 & 27 & 65 & 20 & 55 & 17 & 27 & .73 & .75 & .75 \\
\hline \multirow{3}{*}{$\begin{array}{l}S \text { meals: } \\
591\end{array}$} & Average.... & $\ldots \ldots \ldots$ & 48.9 & & 46 & 45 & 42 & 34 & 79 & 21 & 23 & .72 & .71 & .70 \\
\hline & Apr. 11, 1913... & $13 / 2$ to $21 / 4$ & 47.1 & $+t+$ & 37 & 29 & 30 & 35 & 465 & 18 & 28 & .72 & .74 & .72 \\
\hline & $\begin{array}{l}\text { Average of all } \\
\text { five experiments. }\end{array}$ & & 48.5 & & 44 & 41 & 39 & 34 & 76 & 20 & 24 & .72 & .71 & .70 \\
\hline
\end{tabular}

1 Breakfast and dinner in 5 hours preceding experiment. Eaten in 6 hours preceding the experiment.

Breakfast and dinner in $31 / 2$ hours preceding experiment. - Eaten in 10 hours preceding the experiment.

The basal respiratory quotients averaged 0.72 , but following the last meal the average fell to 0.70 ; even the maximum quotients averaged only 0.71 . As elsewhere stated, the experiments began at a period when the effect of the carbohydrates in the two or three meals might be considered to have largely passed away. On the other hand, the effect of the carbohydrate formed from protein might still exert an influence, though it is questionable as to how much of this was utilized.

Metabolism of Diabetics after Noon Meal of Carbohydrate and Protein.

Between December, 1914, and October, 1917, 7 observations were made upon 7 patients following a noon meal consisting of carbohydrate and protein with no fat. The caloric value of the meals was slight, not being in excess of 6 calories per kilogram of body-weight, and in one experiment it was as low as 0.9 calories per kilogram of body-weight. The series shows, therefore, quite as much the effect of the ingestion of small quantities of food as it does the ingestion of carbohydrate and protein. In all save two of the experiments, the carbohydrate varied between 15 and 60 grams. The protein varied between 5 and 13 grams. The results obtained are given in table 128 . 
With the 3 severe cases of diabetes whose noon meal was not preceded by a breakfast, there was an almost uniform increase in heat-production over basal of 12 per cent. The average basal and experimental respiratory quotients were identical, and even the maximum quotient was unchanged.

The second group in table 128 represents results obtained with two severe cases who had received a breakfast several hours before the noon meal. The metabolism was practically the same as that just recorded for the breakfastless cases. The average basal and experimental quotients were essentially alike.

TABLE 128.-Metabolism of diabetics in experiments after meals consisting of carbohydrate and protein.

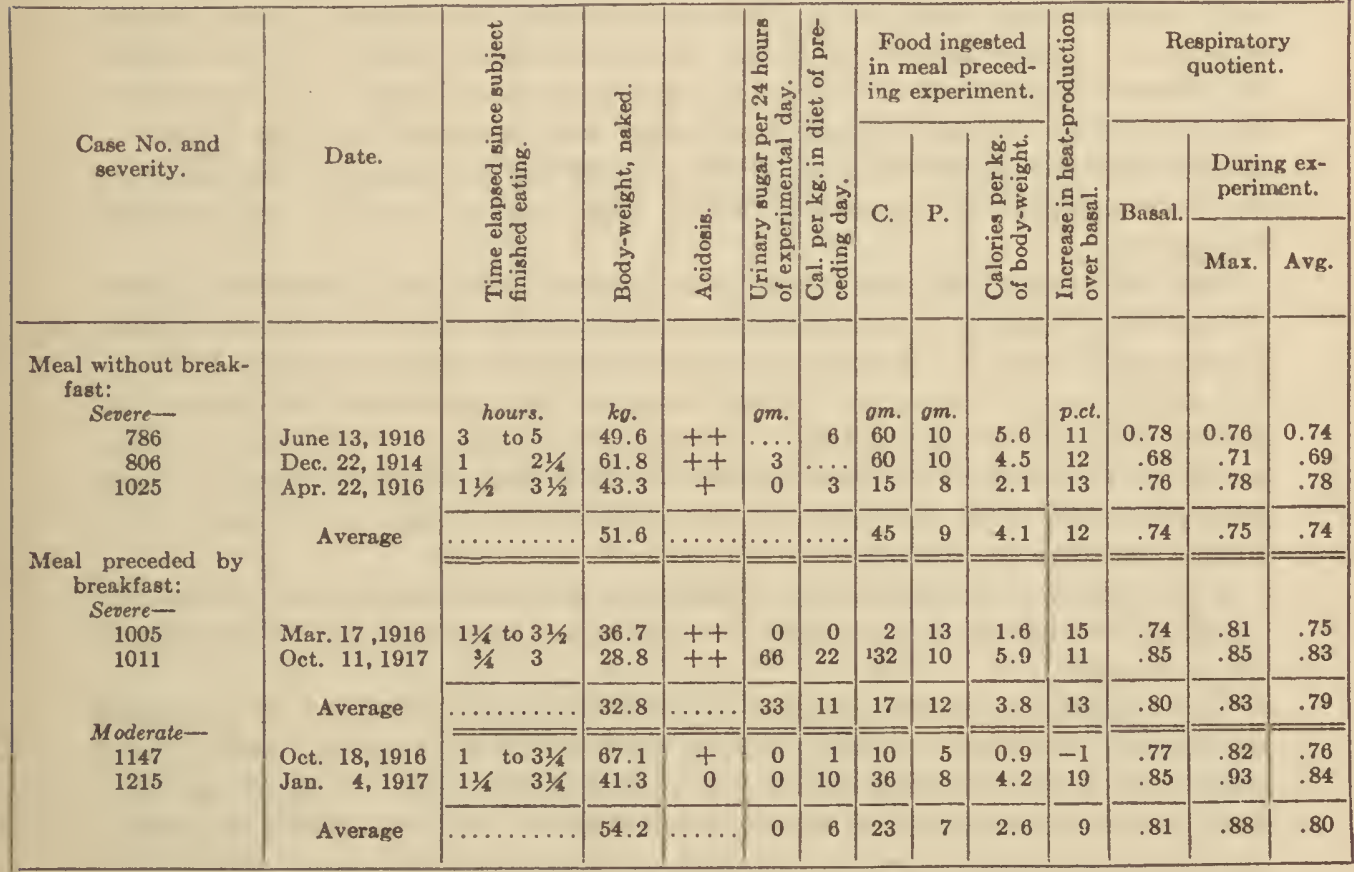

1 Six hours earlier subject had eaten breakfast consisting of C. 35, P. 10, F. 0 .

Experiments with 2 moderate cases are included in this series. In one the metabolism remained unchanged, but in the other there was an increase of 19 per cent. The maximum respiratory quotients definitely rose in each case, but the average quotients for the entire periods were essentially without change. The value of these observations with small meals of carbohydrate and protein lies chiefly in their serving for comparison with heavier meals in which pronounced results were obtained. 


\section{SUMMARY.}

Two monographs upon the metabolism in diabetes have been published by the Nutrition Laboratory, the first in 1910 containing a report of investigations based upon 13 cases and the second in 1912 dealing particularly with metabolism in severe diabetes. Between 1912 and 1917, 89 more patients were studied and in the present publication an attempt has been made to correlate the data of the entire series. The cases observed were private patients and these proved to be especially desirable subjects for scientific investigation.

The earlier observations related chiefly to the study of the metabolism in the post-absorptive state, but since June, 1914, records of the metabolism have been secured under varying conditions of fasting and feeding. This date is important because upon it rests the interpretation of results. Prior to 1914 the patients were overfed with a low carbohydrate and high protein-fat diet. In June, 1914, fasting and undernutrition were introduced. The change in the method of treatment so profoundly affected the metabolism of the diabetics as to necessitate the separation of the observations upon the patients into two groups.

The observations of the metabolism between 1908 and 1915 were carried on mainly at the Nutrition Laboratory and after that time at the New England Deaconess Hospital. In somewhat over two-thirds (456) of the experiments the patient was in the post-absorptive state; the remainder (205) were conducted after the administration of food. In addition, 19 experiments were made with a nurse, who assumed the rôle of a diabetic for a period of three weeks in order that the effect of the diabetic diet could be studied with a healthy subject.

The apparatus employed for determining the metabolism was at first the chair or bed calorimeter, and later the respiration apparatus and clinical respiration chamber.

The longest duration of diabetes in the Laboratory series was 26 years and the patient is still alive. The average duration of the 88 fatal cases was 4.6 years and of the 24 cases living in June, 1921, 11.8 years. Most of the cases were of the severe type, but the degree of severity and of acidosis frequently altered in the same patient. The early patients appeared tense and ill, but fairly strong, while the later cases were more often frail and weak. Coma was responsible for 67 of the 88 deaths.

The pulse-rate was found to be surprisingly prophetic of the results obtained later by measurements of the respiratory metabolism. The average pulserate was increased. For the 31 diabetics prior to June, 1914, it was 73, and for 69 cases after June, 1914, it was 65, as compared with 64, the average pulse-rate of 210 normals. Diabetics both before and after June, 1914, with a much greater loss in weight than undernourished normals had higher pulserates than the latter. Increasing severity raised the pulse-rate before June, 1914, but lowered it after June, 1914. The 45 patients who were free from acidosis had an average pulse-rate of 63 beats, while the 24 cases with severe acidosis showed an average pulse-rate of 73 beats.

In the former publications from this Laboratory upon diabetes, the data reported showed an increase in the metabolism of the patients whose diabetes was severe. The cases more recently under observation have shown a 
subnormal metabolism. In the whole group of diabetics the average postabsorptive metabolism was 12 per cent above normal prior to June, 1914, and 11 per cent below normal after June, 1914. (See table 20, p. 49.) The metabolism values included in these averages ranged between 32 per cent above and 40 per cent below standard. ${ }^{\circ}$ (See table 21, p. 52.)

The metabolism in diabetes approximates normal in the mild and moderate types.

The variations in metabolism are considerable, not only between different diabetics, but also with individual diabetics, in one instance amounting to 36 per cent.

The average loss in weight from maximum of five patients with an exceptionally high metabolism was 21 per cent, and of seven with exceptionally low metabolism was 37 per cent.

Prior to June, 1914, the severe types of diabetics gave a higher metabolism than mild cases, while subsequent to that date the severest type of the disease presented a lower metabolism than that of the mild and moderate forms. The factors which appeared to be of the greatest influence in the production of these variations in metabolism were the diet and acidosis.

Acidosis was present on 85 per cent of the experimental days before June, 1914, and severe acidosis on 40 per cent. After June, 1914, acidosis was present on 67 per cent of the experimental days, and severe acidosis on but 5 per cent.

The relation between acidosis and metabolism was also studied in the group of individuals showing various degrees of acidosis on different days, and the conclusion reached that acidosis increases the metabolism.

Changes in body-weight due to edema may lead to errors in the interpretation of the metabolism. With one patient, when the actual body-weight was used for calculating the percentage variation of the metabolism from standard, the heat-production apparently rose from +7 per cent to +31 per cent. If, however, use is made of the presumably more accurate body-weight of an earlier date before the edema occurred, the metabolism during the same period would vary in the inverse direction, and fall from +31 to +7 per cent.

A study of the metabolism of 6 girl diabetics mirrors the metabolism of the adult diabetics, but if one attempts to discuss the metabolism in terms of standards, based on normal individuals, the need for a standard based upon observations of normal girls awake, and an auxiliary series for girls, abnormal alone in height and weight, is evident.

The nitrogen excretion per kilogram of body-weight prior to June, 1914, was 0.265 gram and subsequent to June, 1914, averaged about one-third less or $0.185 \mathrm{gram}$. Individual variations in the nitrogen excretion were considerable in both periods. Prior to June, 1914, the lowest excretion of urinary nitrogen per kilogram of body-weight was 0.080 gram, and the highest excretion was 0.835 gram. After June, 1914, the lowest nitrogen excretion was 0.050 gram per kilogram of body-weight and the highest 0.515 gram. If is of particular interest that the latter result was obtained with a patient who showed on another day a nitrogen excretion of 0.055 gram per kilogram of body-weight. The nitrogen metabolism and the total metabolism did not

- Case No. 1412, with a metabolism of 33 per cent above standard, is not included in this range, as his values were not included in the averages. (See footnote 2 of table 20, p. 49.) 
vary simultaneously. Prior to June, 1914, the metabolism tended to rise with the increasing quantities of nitrogen per kilogram of bodv-weight and after June, 1914 , when the metabolism reached -20 per cent and below, the nitrogen excretion rose.

Of the 113 diabetics included in this study, 2 died when they were in the hospital; 8 others died within an average period of 22 days from the date of the last metabolism test. The cause of death in 9 of the 10 cases was coma. The metabolism with 8 of the cases was above normal. The case dying of inanition had a metabolism of -40 per cent. The respiratory quotients of the patients who died in coma were low, but that of the case who died of inanition was high.

Acidosis has an unfavorable influence, but from the severest acidosis a patient may recover. Case No. 983 with severe acidosis in February, 1916, was alive in July, 1922.

In June, 1916, a healthy young woman underwent for 20 days the treatment in vogue at that time employed in diabetes. During this period the subject lost 4.1 kilograms of body-weight. The blood sugar decreased from 0.12 per cent at the beginning of the experiment to 0.08 per cent on the eighth day. Acidosis developed, which did not begin to subside until the subject had taken 15 per cent in carbohydrate of the estimated total day's metabolism. For the first four days of the experiment the subject was without food, and thereafter the carbohydrate was gradually increased to 55 grams, the protein to 85 grams, and the energy to 30 calories per $\mathrm{kg}$. of bodyweight. The total calories lost by the subject during the four days of fasting, computed from the basal metabolism, plus an allowance of 20 per cent for activity, amounted to 6,250 calories, or 1,560 calories per day. An even greater loss of calories must, therefore, be expected with a diabetic patient showing acidosis. The metabolism of this subject was as high during the first four days of fasting as during the fourteenth to eighteenth days when she was receiving an adequate supply of food.

It is a curious coincidence that the range in metabolism of L., the normal subject who fasted for 31 days, as determined at the beginning and end of the fasting period, closely approximates that of the diabetic patients before and after June, 1914. Before the fast his metabolism averaged +5 per cent, and upon its completion, -14 per cent. Even at the end of 31 days he had not reached the point when body fat was insufficient to supply the necessary calories, because the lowest quantity of nitrogen in the urine for the 31 days was 6.94 grams upon the thirty-first day.

The influence of age upon the metabolism of the diabetic patient is definite. Patients between 51 and 70 years showed an approximately normal metabolism. The metabolism in the second decade was likewise within the normal zone. For the three decades between 21 and 50 years there is an average increase above normal of 17 per cent before 1914 and a decrease of 10 per cent after that date.

A comparison of the figures for the metabolism with the pulse-rate, both before and after June, 1914, showed that the pulse-rate registers with considerable accuracy the changes in metabolism. It may be noted here that the average pulse-rate of all subjects used in establishing the $\mathrm{Du}$ Bois and Harris and Benedict standards are the same, being 61 beats. 
The average respiratory quotient before June, 1914, was 0.73 and after June $1914,0.77$. The average metabolism was 13 per cent above standard in the earlier period and 10 per cent below standard in the later period. ${ }^{\circ}$ The respiratory quotient in diabetes appears to bear a definite relation to the metabolism in that it is low when the metabolism is high, and higher when the metabolism is low. The average of three experiments before June, 1914, gives a respiratory quotient of 0.70 , corresponding to a metabolism 35 to 30 per cent above standard, and the average respiratory quotient for 4 observations after June, 1914, was 0.84 when the metabolism was 35 to 40 per cent below standard. Between these two extremes a general tendency is seen for the quotient to rise as the metabolism falls. Case No. 591, a severe diabetic with extreme acidosis, showed upon a diet with excessive quantities of fat, an increase in metabolism over basal of 40 per cent and a respiratory quotient of 0.66 .

Although a high respiratory quotient is welcome in diabetes, because it suggests the ability of the patient to burn carbohydrate, it is obtained only through a metabolism of threateningly low degree.

Extremely low respiratory quotients in diabetes have been looked upon with suspicion, but analysis of the clinical data accompanying such quotients both in the literature and in this series indicates that these extremely low quotients must not be disregarded. The conclusion is reached that such low quotients are forced quotients, due to the ingestion of much protein and fat with little carbohydrate.

On the other hand, extremely high respiratory quotients were found with severe diabetics, and there is some evidence to indicate that these occurred when lack of available fat necessitated unusual katabolism of body protein, or even the transformation of carbohydrate into fat. Patients with these high quotients are often in extremis, without acidosis, show a high excretion of urinary nitrogen, and have an unusually low metabolism. One such patient gave a respiratory quotient of 0.94 when the metabolism was -37 per cent, values well supported by other data obtained with this individual. The average minimum weight of all the diabetics was 18 per cent below the normal standard, but the 22 adult severe cases with high quotients had an average minimum weight below standard of 29 per cent, while that of the severe cases among the girl diabetics with high quotients was 41 per cent below standard.

Fifty-one observations upon the effect of levulose were made. As a rule the quantities ingested were well utilized, though of 41 experiments with 19 severe cases, in only 9 did the urines remain sugar-free.

Levulose increased the metabolism of the diabetic patients from 5 to 32 per cent, and on the average 17 per cent. This was slightly greater than that found in this Laboratory with normals under similar conditions, and persisted at a higher level for a greater period of time. In part, the wide variation in response of the diabetics to levulose is explained by the quantity of levulose given, since this varied between 28 and 100 grams or 0.90 and 2.50 grams per kilogram of body-weight. While variations in the quantity of levulose sdministered per kilogram of body-weight affected the metabolism, the quotient was affected to a much less degree.

- These figures represent only those experimental days on which the respiratory quotient was determined in contrast to the percentages given for the post-absorptive metabolism earlier in the vummary. (See p. 275.) 
The increase in metabolism following the ingestion of levulose with severe cases was greater than with moderate or mild cases or with normal individuals.

The post-absorptive quotients obtained in the experiments which served as basal for the levulose experiments varied between 0.70 and 0.91 , but levulose produced the same effect upon the respiratory quotient and metabolism when the basal quotients of the patients were low as when they were high.

The average quotient of the diabetics for the second half-hour after levulose was 0.84 and thereafter it fell steadily and for the most part uniformly to the basal quotient 0.79 in the fifth half-hour. Subsequently it was below the standard, in contrast to normals in which the increase in the quotient continued into the ninth half-hour.

The respiratory quotient rose considerably above 1.00 in 4 experiments with 2 cases after the ingestion of 1.55 to 1.90 grams of levulose per kilogram of body-weight. The two patients with the highest respiratory quotients after levulose were among those patients whose post-absorptive respiratory quotients were also high.

It appears impracticable to explain the quotients above unity other than as due to a conversion of carbohydrate to fat, though such a conversion may take place at lower levels.

One patient receiving similar quantities of levulose upon three successive days showed average increases in quotient above basal of $0.08,0.09$, and 0.17 , respectively.

The average percentages of blood sugar before taking levulose and 24 hours later were the same, 0.19 per cent. In 8 experiments the blood sugar averaged 0.23 per cent before levulose was given; about three or four hours after the levulose was taken, it was 0.30 per cent, increasing values being found in all but two experiments.

Orange juice acted similarly to levulose, the average increase in heat-production in 4 experiments being 12 per cent, and the average increase in respiratory quotient 0.03 and the average maximum increase 0.09. Smaller though distinct increases were obtained after dextrose. A single experiment upon a mild diabetic with sucrose increased the metabolism 3 per cent, and the respiratory quotient reached 1.02 .

In eight experiments levulose and fat were taken by four severe cases free from acidosis and the metabolism increased 16 per cent. The respiratory quotient rose from 0.83 to 0.88 , with an average maximum quotient of 0.92 . Three similar experiments after the ingestion of orange juice with fat gave results like those when orange juice was taken alone.

In a series of experiments with beefsteak and butter, between 1908 and 1911, when the basal metabolism was high, the average increase in metabolism was 17 per cent and the respiratory quotient fell or remained constant with all but one case, and in a series of experiments after protein and fat between 1914 and 1917; when the basal metabolism was low the metabolism rose 23 per cent, with but slight change in the respiratory quotient.

An analysis of all the food experiments according to the height of the basal metabolism shows no special relation between the level of the basal metabolism and the degree of reaction of the body to food.

The effect of oatmeal alone and with fat, in single and in multiple meals, and upon von Noorden's oatmeal days, was determined. The increase.in 
heat-production after oatmeal and fat was 22 per cent, but the respiratory quotient was unaffected, perhaps due to the lapse of time between the ingestion of the oatmeal and the beginning of the experiment, and its completion. Upon typical "oatmeal days," the metabolism rose from 14 per cent after the first meal to 26 per cent after the fifth meal. One patient who received extraordinarily large quantities of oatmeal and butter developed correspondingly low quotients.

Observations were also made after one, two, and three meals, such as were customarily given diabetic patients undergoing treatment. The average increase in heat-production over the basal with severe cases was 15 per cent after the first meal. In general the rise in metabolism was related to the quantities of protein, and the calories per kilogram of body-weight given. After the second meal, containing a larger quantity of protein, the increase in metabolism was 25 per cent. Acidosis did not prevent a rise in metabolism after these meals. 



\section{APPENDIX I.}

\section{ABSTRACT OF CLINICAL DATA AND PROTOCOLS OF EXPERI- MENTS WITH 113 CASES OF DIABETES MELLITUS.}

Key to Abbreviations, etc.

\section{Experimental conditions:}

P. A., post-absorptive, i. e., without food 12 hours.

C. P. F., carbohydrate, protein, fat; figures represent grams eaten.

Apparatus:"

I, chair calorimeter.

II, bed calorimeter.

III, Benedict universal respiration apparatus.

IV, clinical respiration chamber.

$\mathrm{V}$, respiratory-valve apparatus.

Sex and age:

M., male; F., female. Age is given in years.

Total heat greater or less than predicted:

H. and B., Harris and Benedict normal standard for basal metabolism.?

Degree of severity:

Mi., mild diabetes. Mo., moderate diabetes. S., severe diabetes.

For cases reported in previous publications, ${ }^{3}$ see table 3 , footnote 1 , page 8 , in which the numbers of these cases are accompanied by the original alphabetical designations.

I For a description of the chair calorimeter and the bed calorimeter, see Benedict and Carpenter, Carnegio Inst. Wash. Pub. No. 123, 1910. For the Benedict universal respiration apparatus, see Benedict, Am. Journ. Physiol., 1909, 24, p. 345; ibid., Deutsch. Arch. f. klin. Med., 1912, 107, p. 156; and Carpenter, Carnegie Inst. Wash. Pub. No. 216, 1915, pp. 21-53. For the respiratory-valve apparatus, see Hendry, Carpenter, and Emmes, Boston Med. and Surg. Journ., 1919, 181, pp. 287-289. For the clinical respiration chamber, seo Benedict and Tompkins, Boston Med. and Suro. Journ., 1916, 174, pp. 898 and 939.

2 Harris and Benedict, Carnegie Inst. Wash. Pub. No. 279, 1919, p. 227, and Appendix. See, also, Harris and Benedict, Sci. Mo., 1919, 8, p. 385. In the latter paper, the first factor in the formula for women should be corrected to 655.096 .

Benedict and Joslin, Carnegie Inst. Wash.Pub. No. 136, 1910; ibid., Pub. No. 176, 1912. 


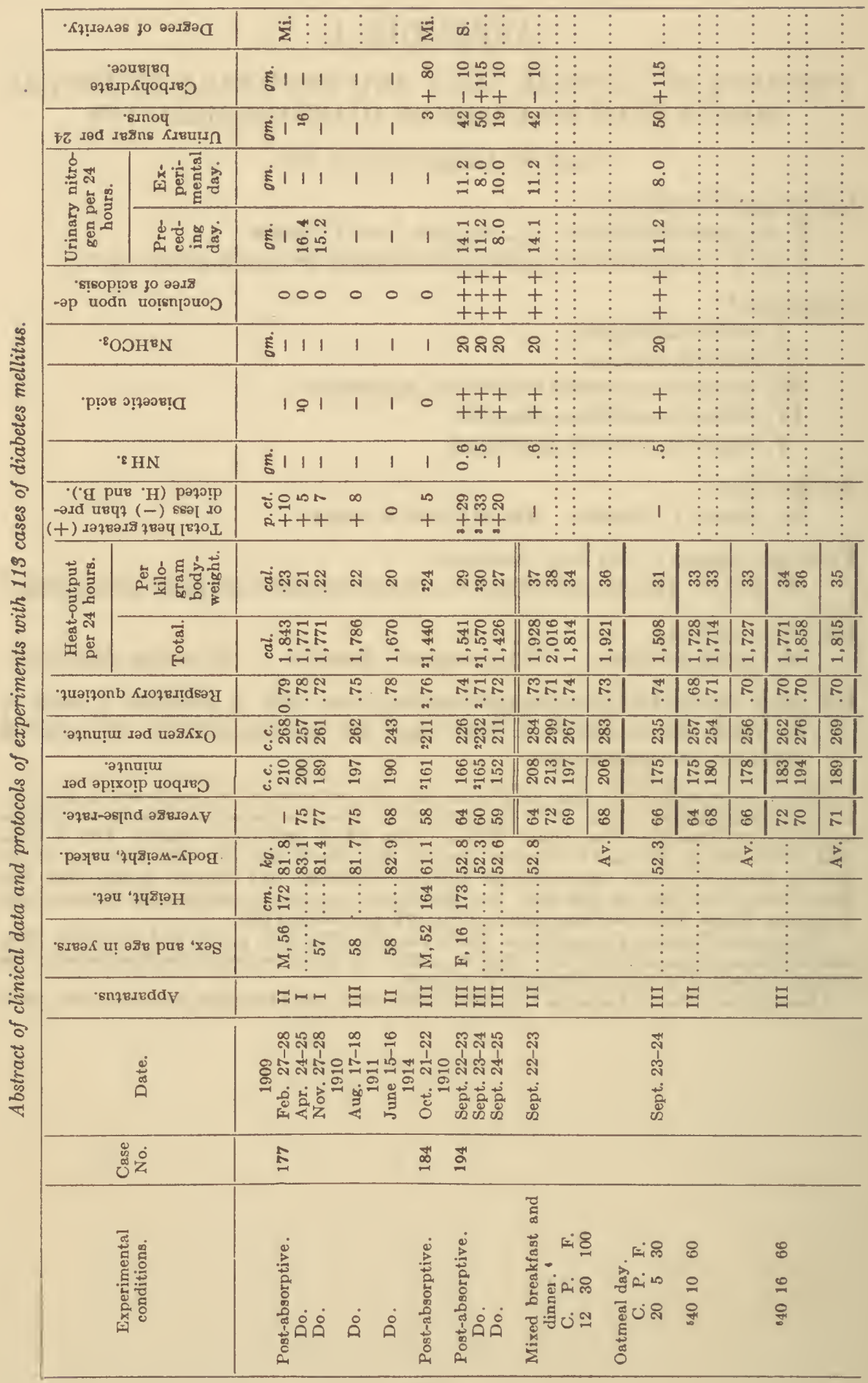




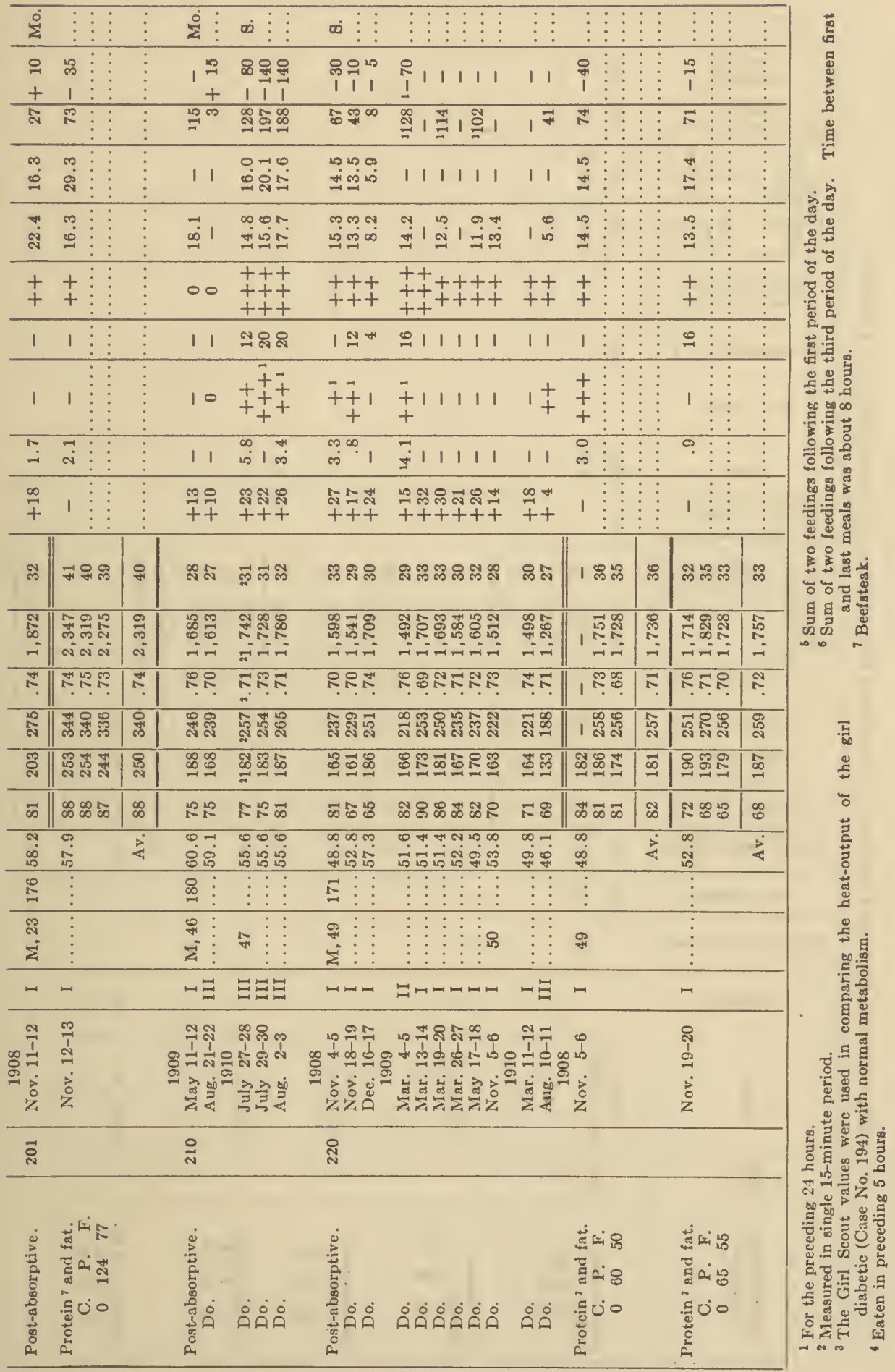




\begin{tabular}{|c|c|c|c|c|c|c|c|c|c|c|c|}
\hline \multicolumn{2}{|c|}{ 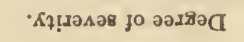 } & is & & & & & & & & & \\
\hline \multicolumn{2}{|c|}{ 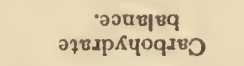 } & $\varepsilon^{\circ}$ & & 0 & & 1 & & 1 & & 1 & \\
\hline \multicolumn{2}{|c|}{ 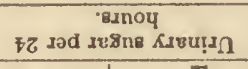 } & $\varepsilon^{\infty}$ & & $\infty$ & & 1 & & & & $\stackrel{20}{=}$ & \\
\hline \multirow{2}{*}{ 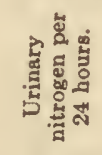 } & 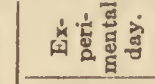 & ह & & $\stackrel{\sim}{\mathscr{m}}$ & : & I & & 1 & & 1 & \\
\hline & 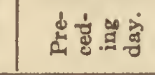 & $\dot{g} \stackrel{0}{\dot{m}}$ & : & $\stackrel{\ddot{g}}{\leftrightarrows}$ & & 1 & & 1 & & $\ddot{m}$ & \\
\hline \multicolumn{2}{|c|}{ 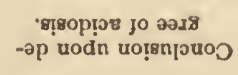 } & + & & \pm & & $\begin{array}{l}+ \\
+ \\
+\end{array}$ & & + & & + & \\
\hline \multicolumn{2}{|c|}{ 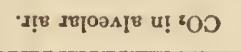 } & है। & o & 1 & $\vdots$ & 1 & & 1 & & 1 & \\
\hline \multicolumn{2}{|c|}{ 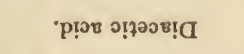 } & 1 & & + & & 1 & & I & & 1 & \\
\hline \multicolumn{2}{|c|}{ 'HN } & 50 & : & 1 & $\vdots$ & 1 & . & 1 & & 1 & \\
\hline \multicolumn{2}{|c|}{ 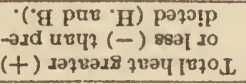 } & $\begin{array}{ll}\dot{\vdots} \\
\dot{R}\end{array}$ & & 1 & & 1 & & 1 & & 1 & \\
\hline \multirow{2}{*}{ 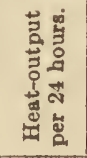 } & 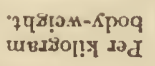 & కేี & ลิ & ตే & 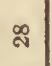 & న్ల ణ్ల & 凩 & हేల్లో है & ले & $\begin{array}{llll}1 & 1 & 1 & 1\end{array}$ & के \\
\hline & 离 & 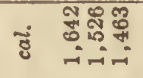 & Tี & 员突兽 & : & 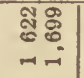 & $\mid$ & mån్ & $\sqrt{5}$ & $\begin{array}{llll}1 & 1 & 1 & 1 \\
\end{array}$ & $\mid \begin{array}{l}\mathscr{B} \\
\infty \\
0 \\
-1\end{array}$ \\
\hline \multicolumn{2}{|c|}{ 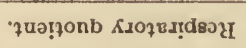 } & ำกㄴ. & त. & 유뮨? & จ. & กः & 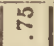 & क. & $\pi$ & $?$ & 19 \\
\hline \multicolumn{2}{|c|}{ 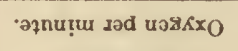 } & $\because$ ํํำ & สิ & ลึลสัส & สู้ & ขึล & की & 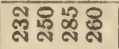 & มู & 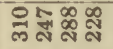 & $\begin{array}{c}\infty \\
\vdots \\
\approx\end{array}$ \\
\hline \multicolumn{2}{|c|}{$\begin{array}{l}\text { "วิnu!u dad } \\
\text { әр!xo!p uoqsio }\end{array}$} & 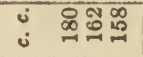 & $\stackrel{5}{\circ}$ & $\stackrel{9-9}{0}$ & 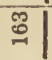 & 交 & $\infty$ & 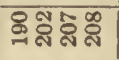 & ริ & స్ & 焉 \\
\hline \multicolumn{2}{|c|}{ 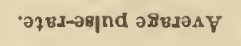 } & ヘ®๐ & $\stackrel{\infty}{\infty}$ & กิธี & $\hat{0}$ & $\infty$ & $\bowtie$ & 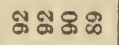 & పే & ஜํㅀㅀ & \& \\
\hline \multicolumn{2}{|c|}{ 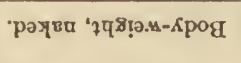 } & $\dot{8} \stackrel{\infty}{\infty}$ & $\dot{8}$ & $\ddot{8}$ & $\dot{z}$ & $\frac{7}{4}$ & $\dot{4}$ & ช్ & 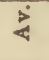 & की & 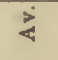 \\
\hline \multicolumn{2}{|c|}{ 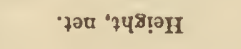 } & $\Xi$ & & & & & & & & $\vdots$ & \\
\hline \multicolumn{2}{|c|}{ 'Аะซอ } & 우 & & & & & & & & & \\
\hline \multicolumn{2}{|c|}{ 'gnวษ } & $m$ & & - & & & & - & & $m$ & \\
\hline \multicolumn{2}{|r|}{ 岕 } & 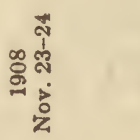 & \multicolumn{2}{|r|}{ 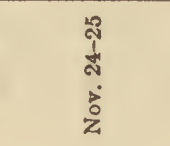 } & \multicolumn{3}{|c|}{ 通泀 } & $\begin{array}{l}\infty \\
b \\
\dot{0} \\
\dot{\alpha}\end{array}$ & & $\begin{array}{l}\infty \\
b \\
b \\
c\end{array}$ & \\
\hline \multicolumn{2}{|c|}{ 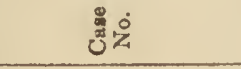 } & \multicolumn{6}{|l|}{ สํี่ } & & & & \\
\hline & 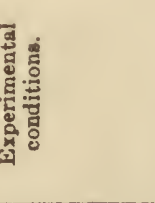 & 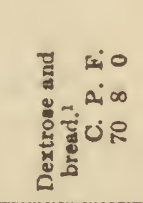 & & 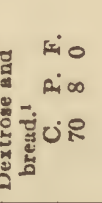 & & 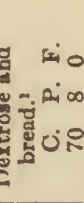 & & 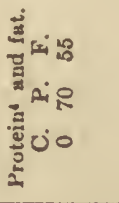 & & 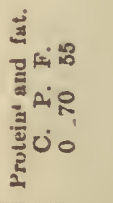 & \\
\hline
\end{tabular}




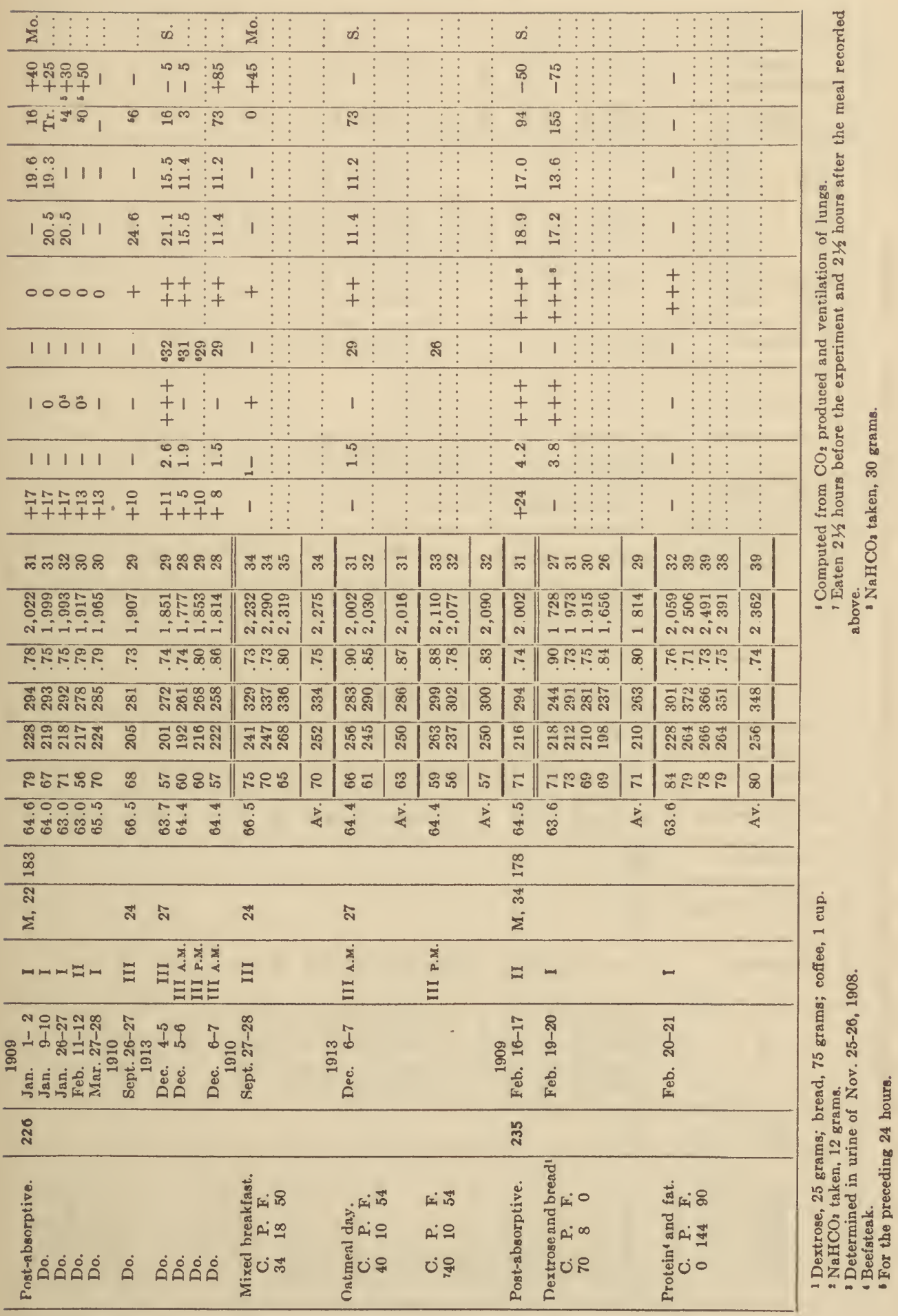




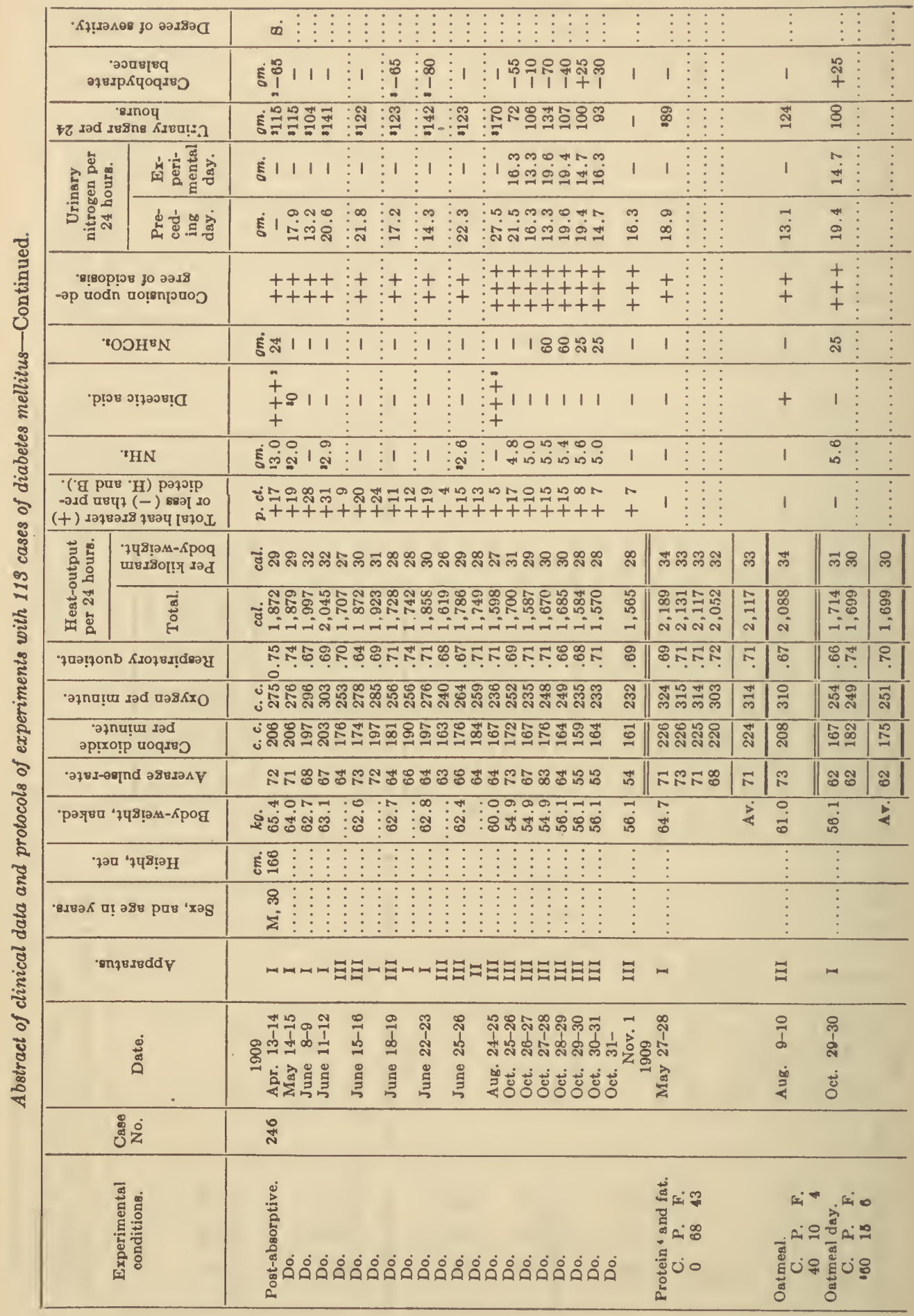




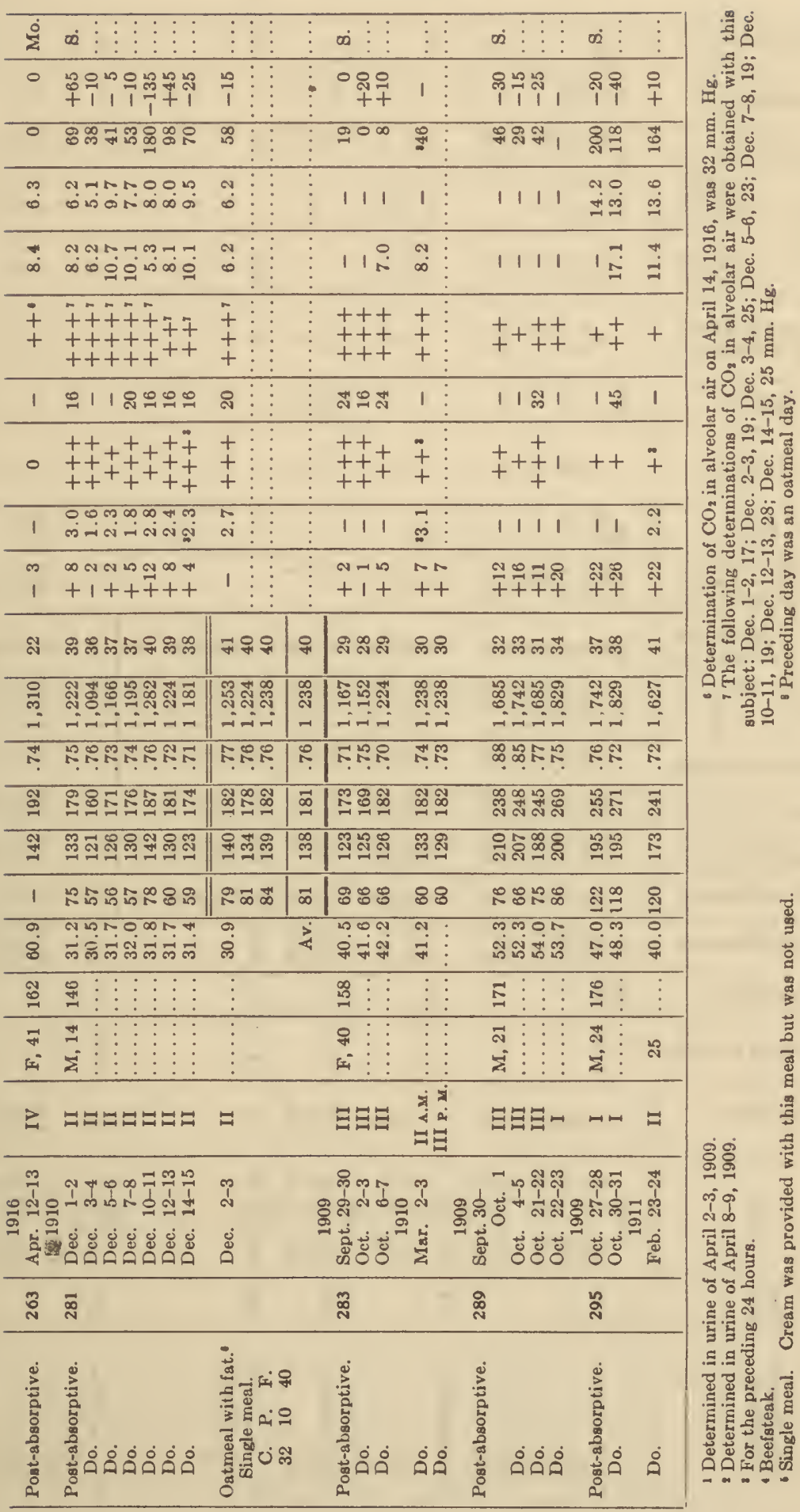




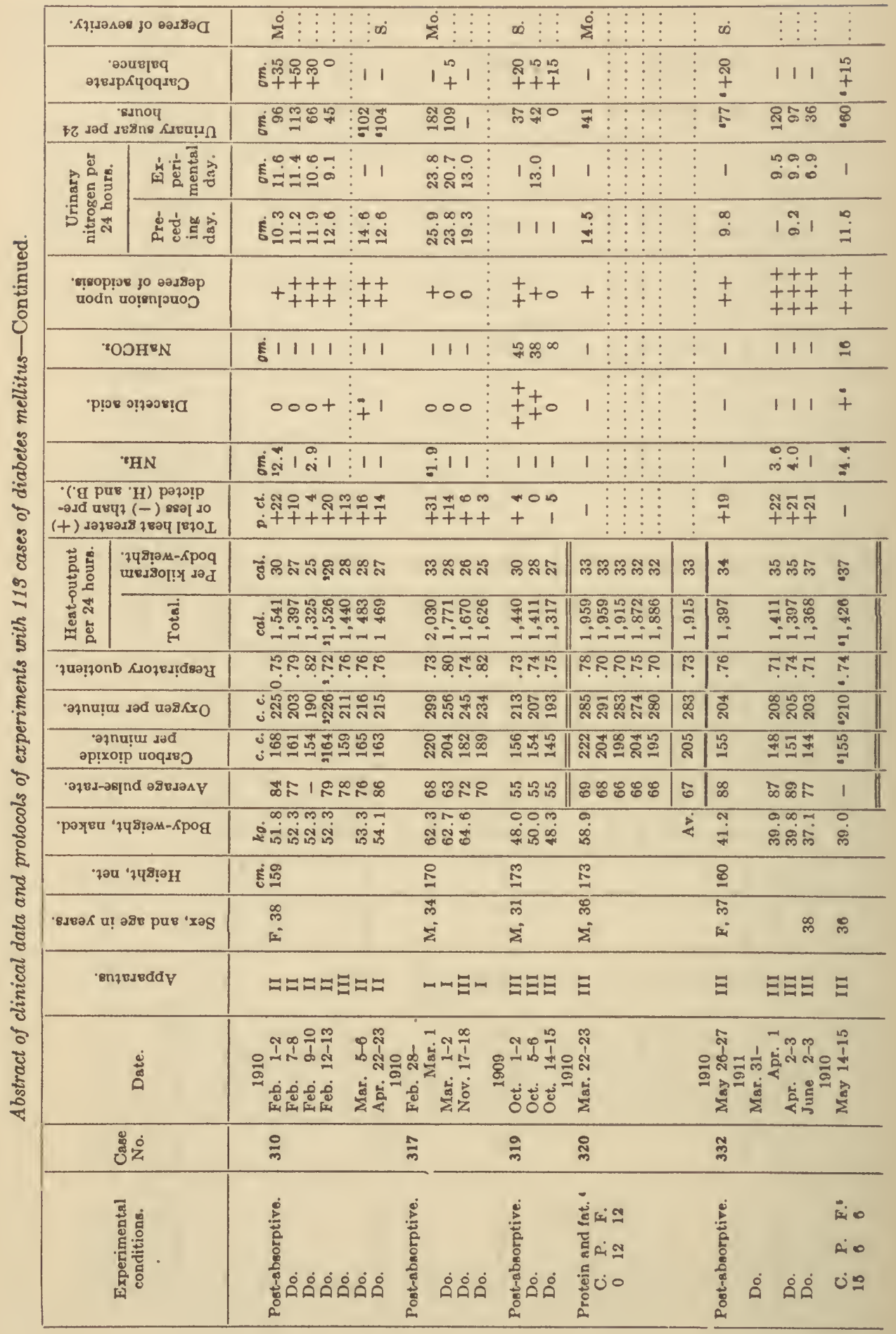




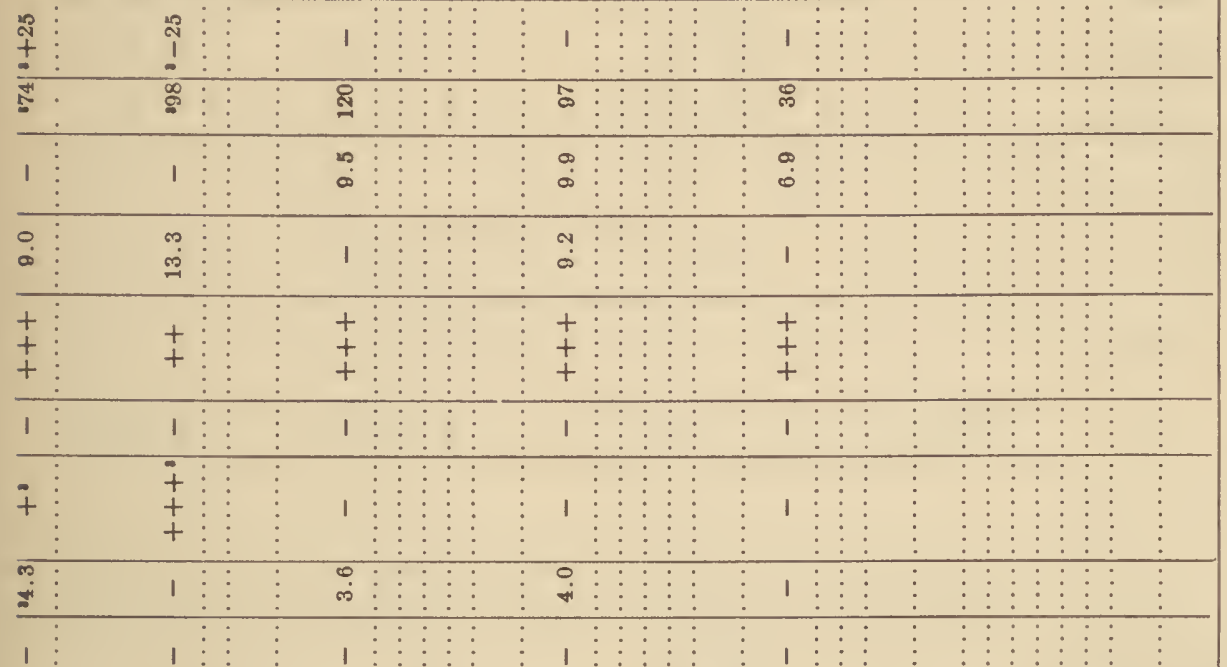

\begin{tabular}{|c|c|c|c|c|c|c|c|c|c|c|c|}
\hline 需命 & के & હే & म̈ & 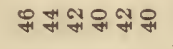 & $\mathscr{F}$ & 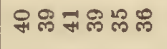 & $\infty$ & $\begin{array}{llll}1 & 1 & 1 & 1\end{array}$ & 1 & 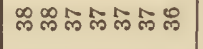 & $\tilde{m}$ \\
\hline
\end{tabular}

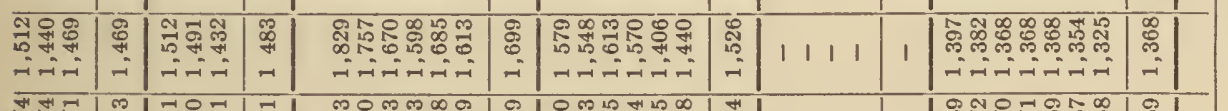

\begin{tabular}{|c|c|c|c|c|c|c|c|c|c|c|}
\hline 존다. & ? & 주유 & F & 무뮤: & $\%$ & 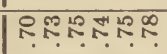 & 는. & $\begin{array}{llll}1 & 1 & 1 & 1\end{array}$ & 1 & 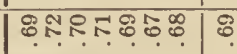 \\
\hline
\end{tabular}
สูสส $\mid$ สี $\mid$ สี่สี

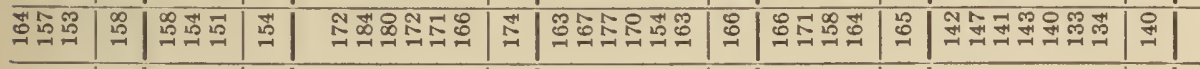

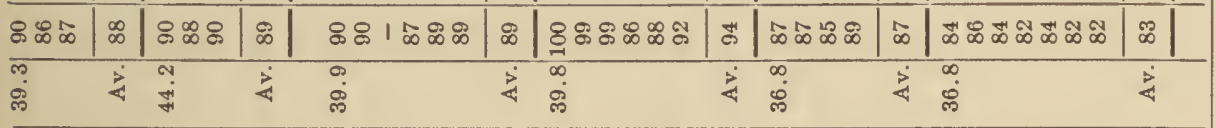
$\infty$

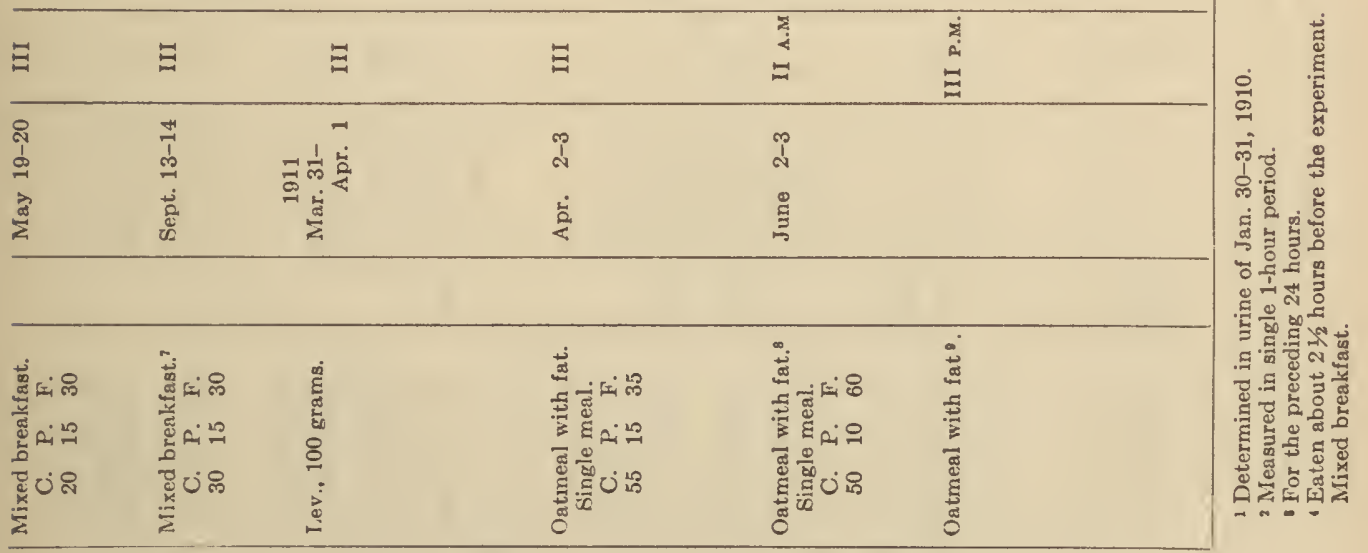




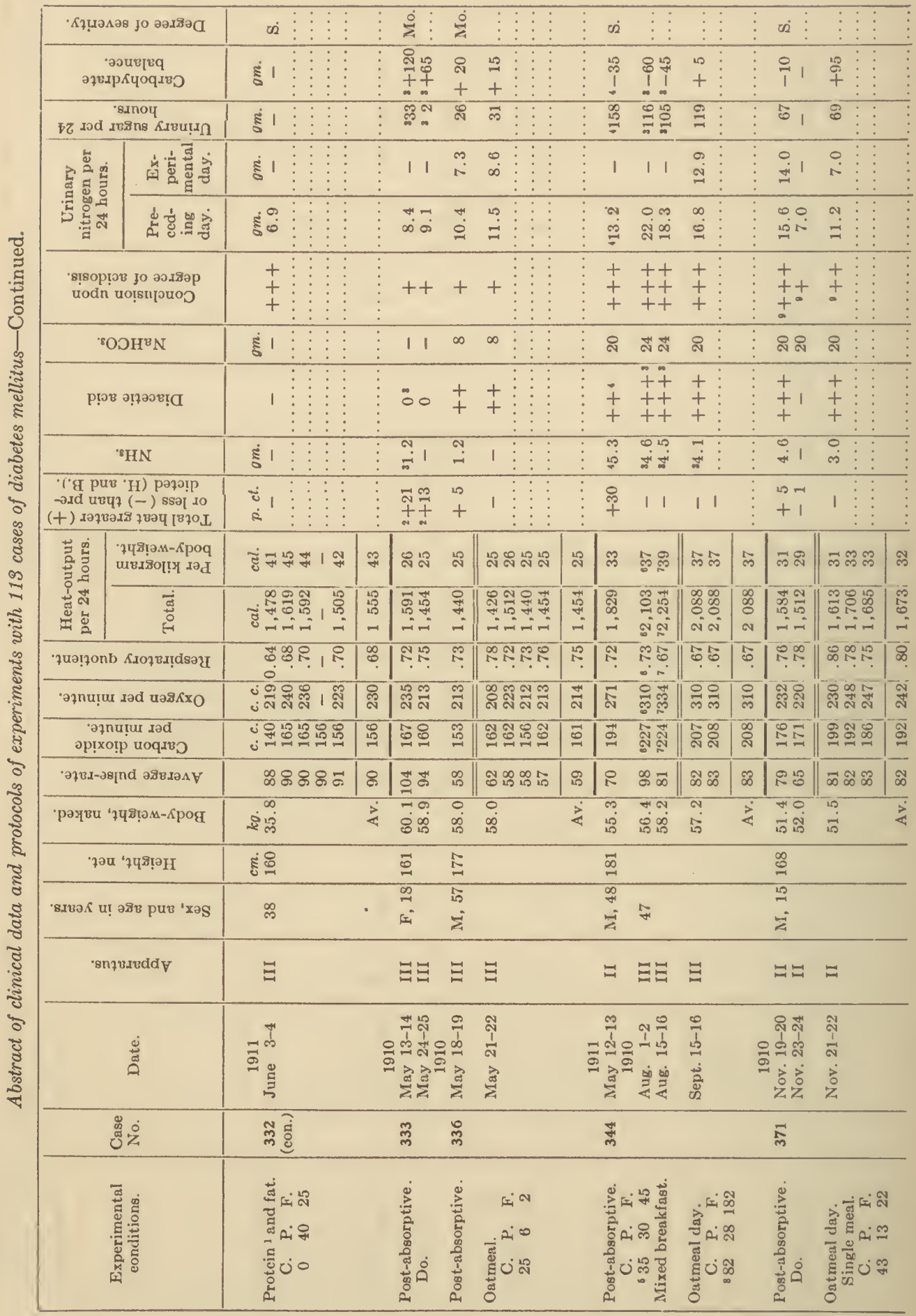




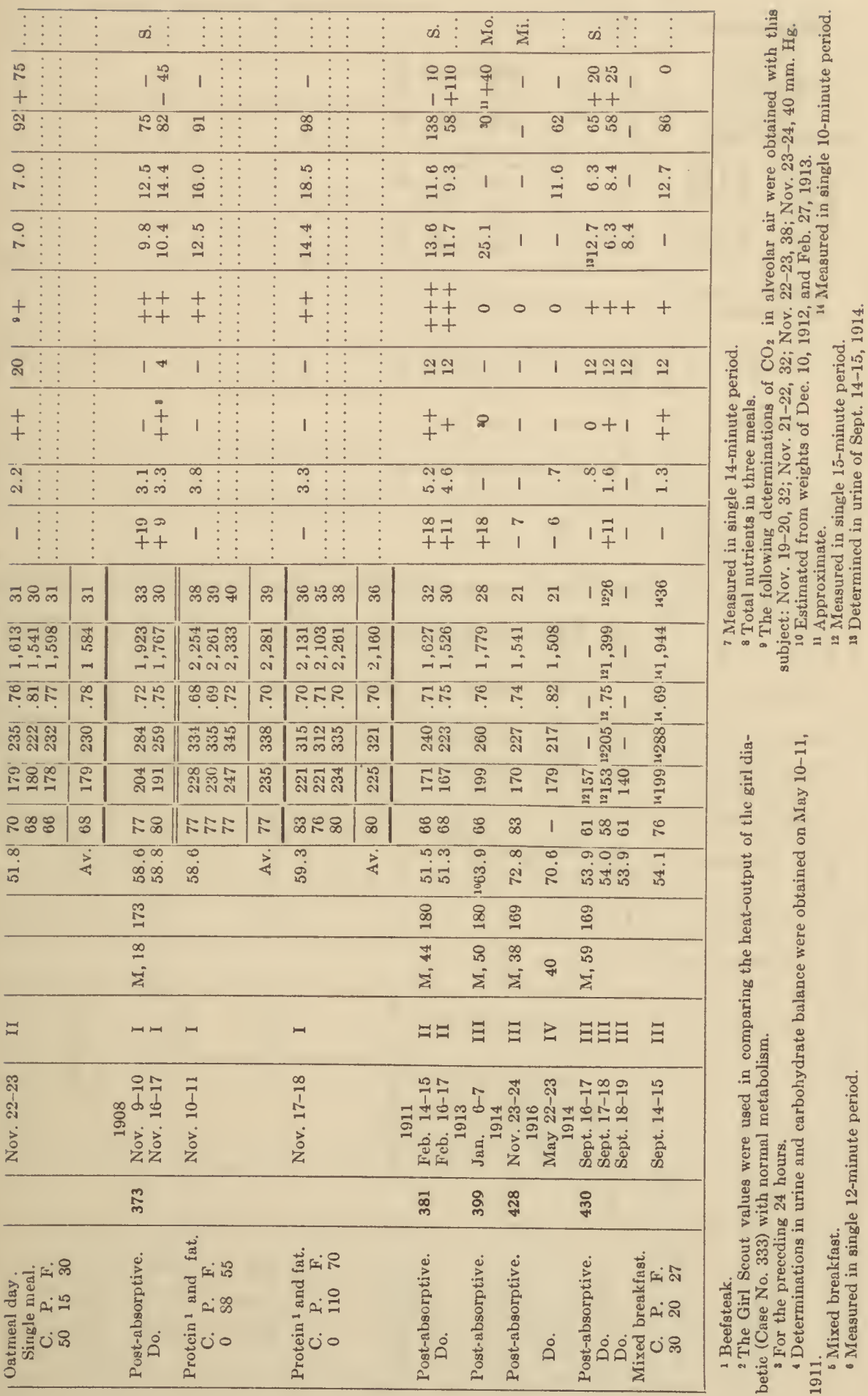




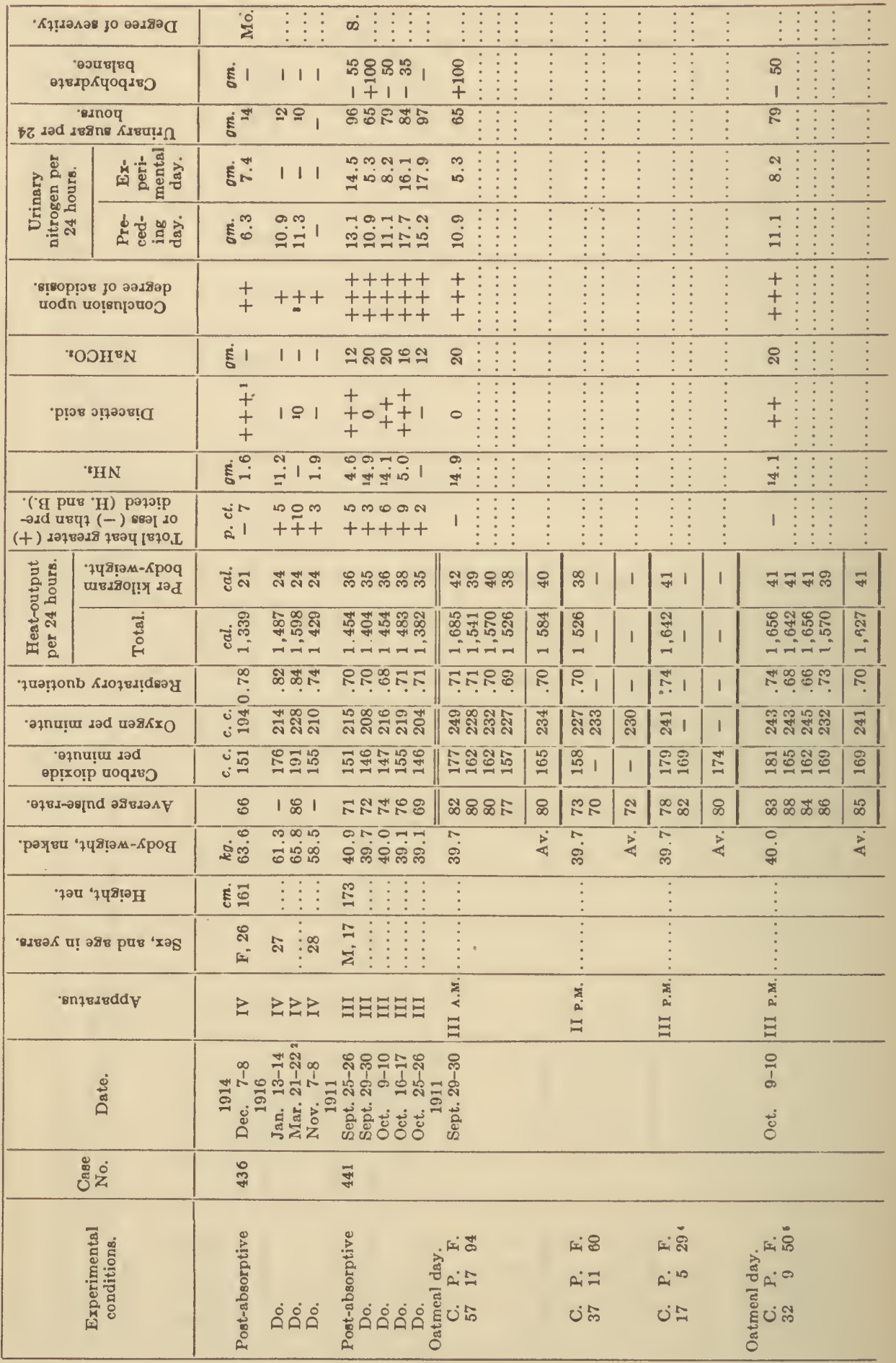




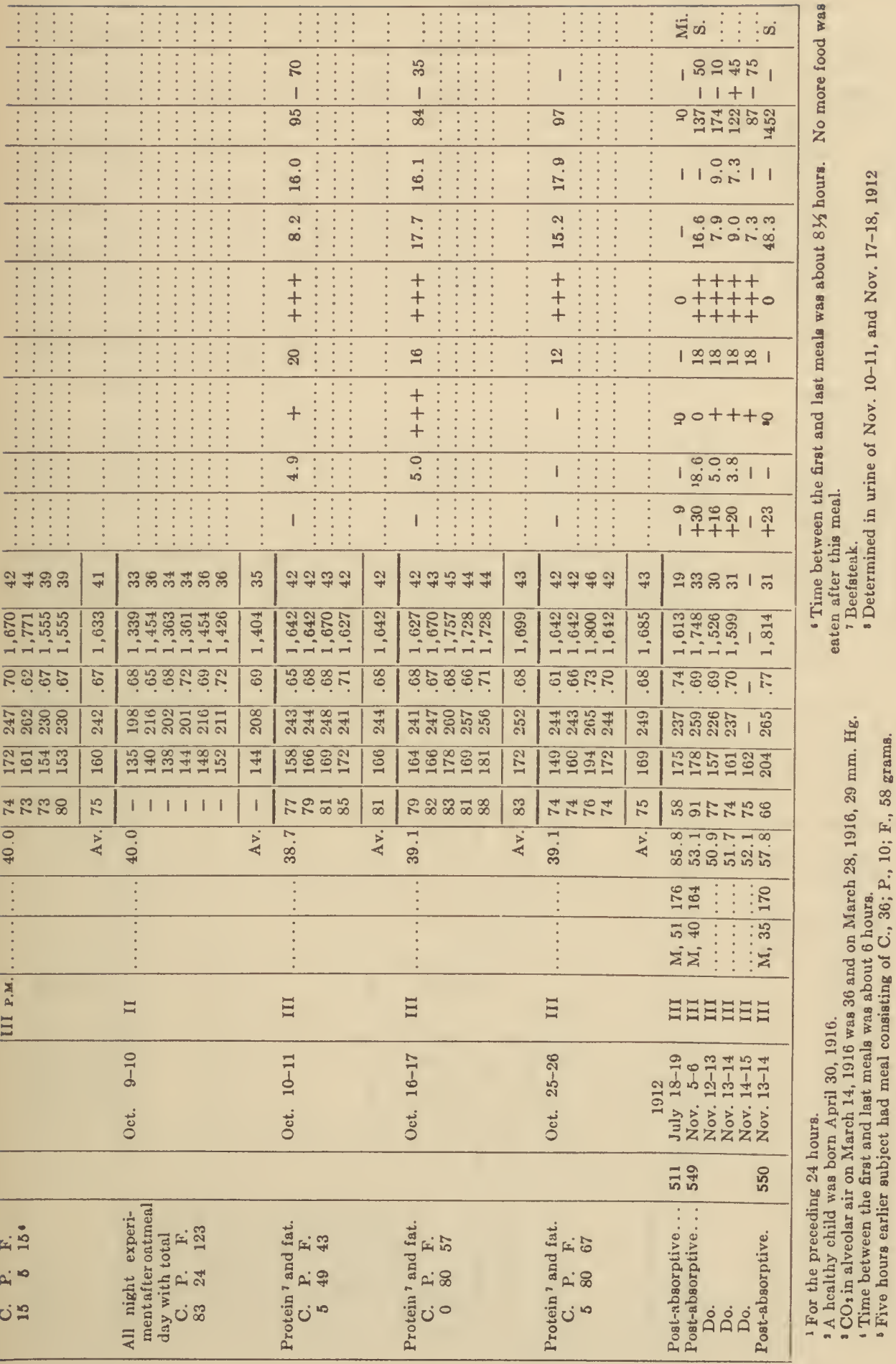




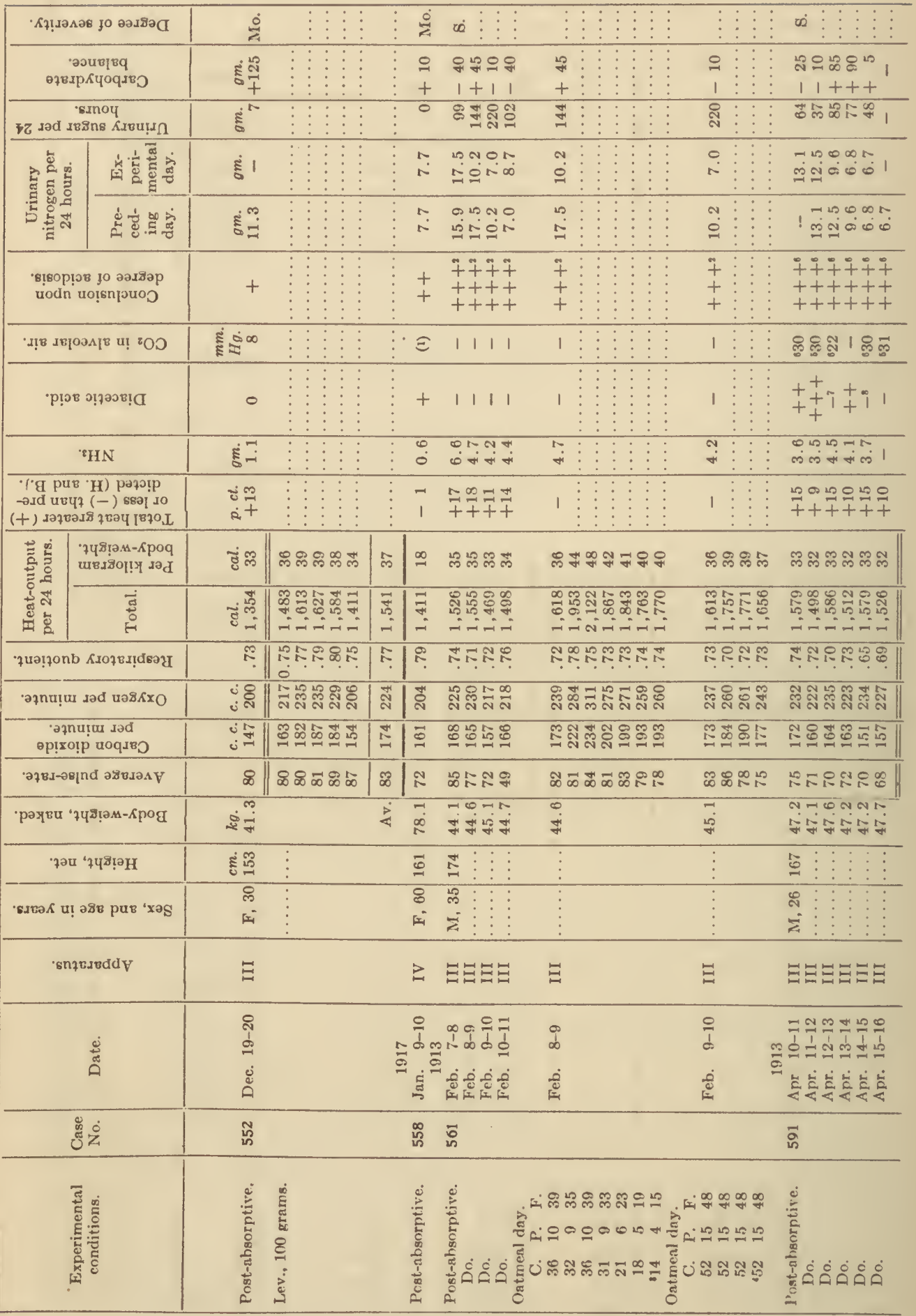




\begin{tabular}{|c|c|c|c|c|c|c|c|c|}
\hline$\vdots$ & & $\vdots$ & & & & & $\vdots \dot{a}$ & $\vdots \vdots \vdots$ \\
\hline เ & & $\because$ & & 18 & 8 & 10 & 108 & ㅇำ \\
\hline नें & & $\frac{1}{n}$ & & $\begin{array}{l}+ \\
\text { L } \\
\infty\end{array}$ & $\frac{+}{N}$ & $\begin{array}{l}+ \\
\stackrel{\infty}{*}+ \\
+\end{array}$ & $1^{++}$ & $\frac{+++}{00-1}, \frac{++}{0^{-1}}$ \\
\hline 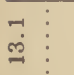 & & $\stackrel{\mathscr{L}}{\mathrm{I}}$ & & $\dot{0}$ & $\stackrel{\infty}{\infty}$ & $\stackrel{0}{\infty}$ & 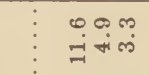 & 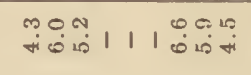 \\
\hline 1 & & $\overrightarrow{\dot{m}}$ & & $\stackrel{\mathscr{L}}{\mathrm{I}}$ & $\stackrel{0}{0}$ & $\stackrel{\infty}{i}$ & 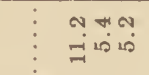 & 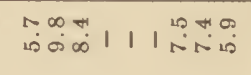 \\
\hline $\begin{array}{l}\dot{5}+ \\
+ \\
+\end{array}$ & & $\begin{array}{l}\vdots \\
+ \\
+ \\
+\end{array}$ & & $\begin{array}{l}\dot{i} \\
+ \\
+\end{array}$ & $\begin{array}{l}\dot{+} \\
+ \\
+\end{array}$ & $\begin{array}{l}\dot{+}+ \\
+ \\
+\end{array}$ & +oo & to0000000 \\
\hline $\mathscr{8}$ & & \$ & & $\mathscr{్}$ & 1 & $\%$ & 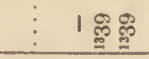 & 111111111 \\
\hline+ & & $\begin{array}{l}+ \\
+ \\
+\end{array}$ & & $\mathbf{i}$ & + & i & 100 & to0111000 \\
\hline $\begin{array}{l}\overline{0} \\
\dot{\infty}\end{array}$ & & 点 & & 25 & $\vec{j}$ & $\tilde{\infty}$ & 111 & 111111111 \\
\hline 1 & & 1 & & 1 & 1 & 1 & $\begin{array}{l}\infty 10 n \\
+11\end{array}$ & $\begin{array}{l}N N+N O N O F N \\
+11111111\end{array}$ \\
\hline พู & 우 & 아구 & $F$ & 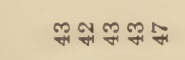 & 유곽여구 & 요 요 & ㅇำสีสี สี & ส สฐ ส ส สฐ \\
\hline 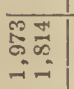 & $\begin{array}{l}0 \\
\infty \\
\infty \\
-1 \\
-1\end{array}$ & $\begin{array}{l}\infty \\
\infty \\
\infty \\
\infty \\
-\infty \\
-1 \\
-1\end{array}$ & $\stackrel{20}{9}$ & 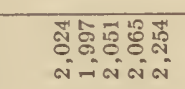 & 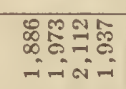 & 要 & 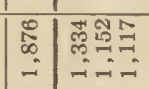 & 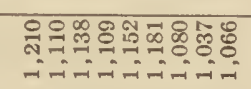 \\
\hline 8ृत्र & 8 & 158 & T? & 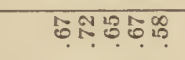 & 유유. & 80 & \begin{tabular}{l|l}
0 & $\infty$ \\
\end{tabular} & \& \\
\hline बू. & $\left|\begin{array}{l}\infty \\
\text { a }\end{array}\right|$ & 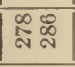 & 岕 & 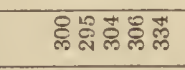 & S్ & कित्र & 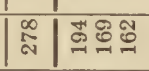 & 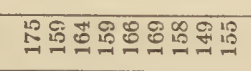 \\
\hline 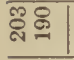 & $|\nsubseteq|$ & 造 & 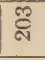 & 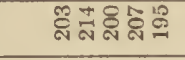 & 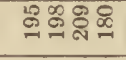 & $\stackrel{\infty}{\infty}$ & 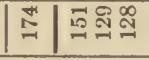 & 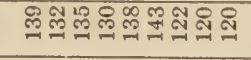 \\
\hline$-\infty$ & $\infty$ & $|+\infty|$ & 央 & さேேロ怘 & $\approx \sim \infty \& \infty$ & $\operatorname{lig}$ & $|\leqslant| 81$ 会 & 㶽 \\
\hline 梦 & $\dot{4}$ & $\bar{n}$ & $\dot{4}$ & \begin{tabular}{l}
0 \\
\multirow{4}{*}{}
\end{tabular} & & 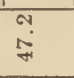 & 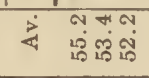 & 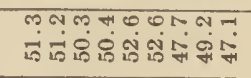 \\
\hline : & & $\vdots$ & & $\vdots$ & & & 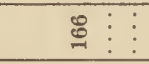 & 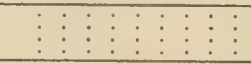 \\
\hline$\vdots$ & & : & & & & & 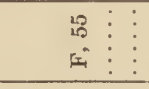 & 品 \\
\hline$\Xi$ & & $\Xi$ & & $\Xi$ & $\Xi$ & $\Xi$ & 를 & 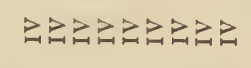 \\
\hline $\bar{\Xi}$ & & $\stackrel{\cong}{I}$ & & $\stackrel{m}{I}$ & $\stackrel{\pi}{\frac{\pi}{\sigma}}$ & $\stackrel{29}{I}$ & 象 & 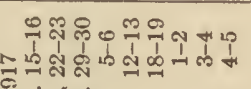 \\
\hline 宽 & & 定 & & 芶 & $\dot{\overrightarrow{0}}$ & 芶 & (x) & 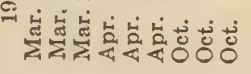 \\
\hline & & & & - & & & $\because$ & \\
\hline 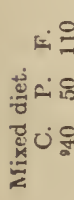 & & 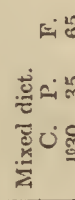 & & 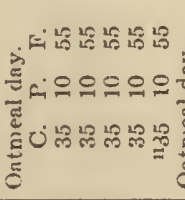 & 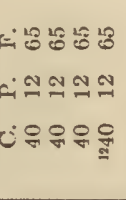 & 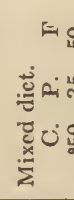 & 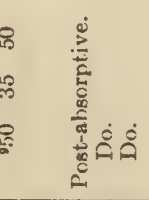 & 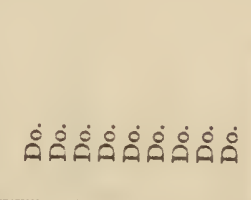 \\
\hline
\end{tabular}

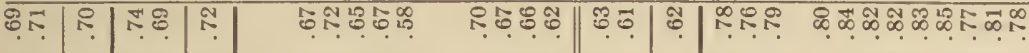

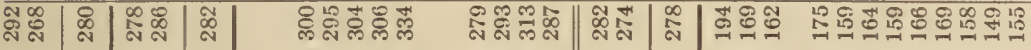
ర్సి.

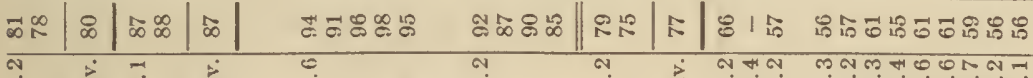

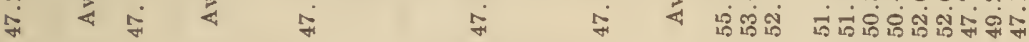




\begin{tabular}{|c|c|c|c|c|c|c|c|c|c|c|c|}
\hline \multicolumn{2}{|c|}{ 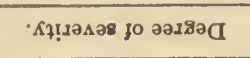 } & $\stackrel{1}{3}$ & & $\infty$ & & & & & & & \\
\hline \multicolumn{2}{|c|}{ 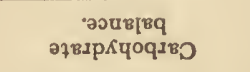 } & s: $_{+}^{2}$ & & $\begin{array}{l}8 \\
+\vdots \\
+\vdots\end{array}$ & & $\begin{array}{l}\approx \vdots \\
+\vdots \\
+\vdots\end{array}$ & & $\begin{array}{l}8 \\
+\end{array}$ & & 1 & \\
\hline \multicolumn{2}{|c|}{ 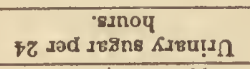 } & $\xi^{\circ}$ & & 0 & & $0 \vdots$ & & -1 & & 1 & \\
\hline \multirow{2}{*}{ 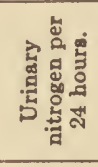 } & 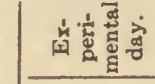 & हूँ & & $\stackrel{m}{*}$ & & $\stackrel{0}{\circ}$ & & 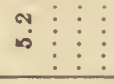 & & 1 & \\
\hline & 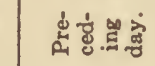 & हิ & & is & & $\stackrel{\infty}{\infty}$ & & $\underset{\infty}{*}$ & & 1 & \\
\hline \multicolumn{2}{|c|}{ 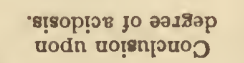 } & ○ & & + & & $\circ$ & & 。 & & 0 & \\
\hline \multicolumn{2}{|c|}{ 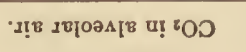 } & हूं & : & 1 & : & 1 & : & 1 & & 1 & \\
\hline \multicolumn{2}{|c|}{ 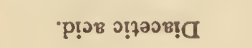 } & ○ & & + & & 0 & & ○ & & 1 & \\
\hline \multicolumn{2}{|r|}{ 'zHN } & हो 1 & : & 1 & & 1 & : & 1 & & 1 & : \\
\hline \multicolumn{2}{|c|}{ 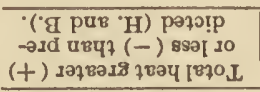 } & $\begin{array}{l}\dot{0} \\
\dot{R}\end{array}$ & & 1 & & 1 & & 1 & & 1 & \\
\hline \multirow{2}{*}{ 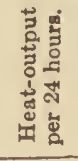 } & 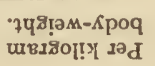 & 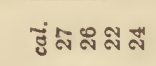 & ผ & ลิลัญล & ลิ & ลลลั & ลิ & 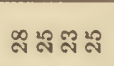 & ผ & สี జึะส & ผ \\
\hline & एँّ & 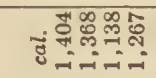 & \&్స & 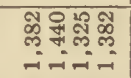 & 商 & 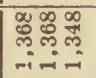 & ब্: & 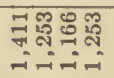 & స్ & 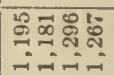 & $\underset{\sim}{\infty}$ \\
\hline \multicolumn{2}{|c|}{ 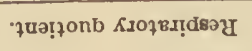 } & 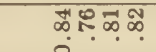 & $\bar{\infty}$ & דיא & $\infty$ & 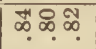 & $\infty$ & - & $\infty$ & $\infty \infty \infty \infty$ & क. \\
\hline \multicolumn{2}{|c|}{ 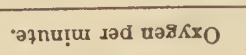 } & 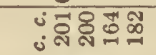 & $\underset{\sim}{\Gamma}$ & 承霝司 & $\overline{\mathrm{\sigma}}$ & 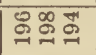 & $\stackrel{\circ}{\mathscr{2}}$ & 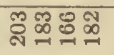 & $\stackrel{\infty}{\infty}$ & R. & 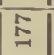 \\
\hline \multicolumn{2}{|c|}{ 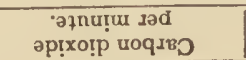 } & 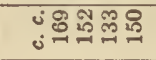 & $\overline{2}$ & 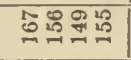 & is & 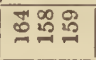 & $\stackrel{8}{\circ}$ & 몀웍원 & \pm & 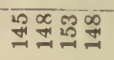 & $\mid \begin{array}{l}\infty \\
0 \\
\sim \\
\sim\end{array}$ \\
\hline \multicolumn{2}{|c|}{ 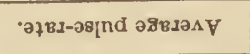 } & 11111 & 1 & 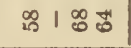 & $\approx$ & 도용 & $\overrightarrow{0}$ & 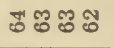 & $\mathscr{\Xi}$ & ส 118 & 1 \\
\hline \multicolumn{2}{|c|}{ 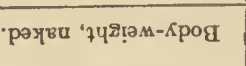 } & इลู่ & $\dot{q}$ & $\stackrel{m}{-10}$ & $\frac{8}{4}$ & मे & 8 & m & 4 & : & 8 \\
\hline \multicolumn{2}{|c|}{ 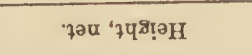 } & है: & & $\vdots$ & & : & & $\vdots$ & & $\vdots$ & \\
\hline \multicolumn{2}{|c|}{ 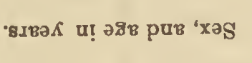 } & 号 & & : & & : & & : & & $\vdots$ & \\
\hline \multicolumn{2}{|c|}{-8mభ̨redd } & $\geq$ & & $\geqq$ & & $\geq$ & & $\geq$ & & $z$ & \\
\hline \multicolumn{2}{|r|}{ هّ } & م) & & 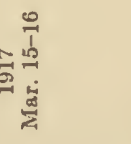 & & 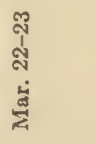 & & 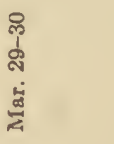 & & 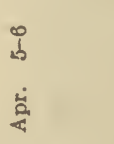 & \\
\hline \multicolumn{2}{|c|}{ 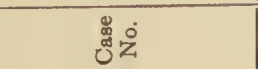 } & 영 & & & & & & . & & & \\
\hline \multicolumn{2}{|c|}{ 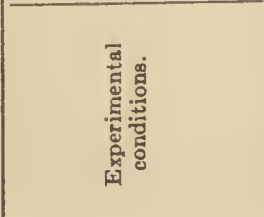 } & 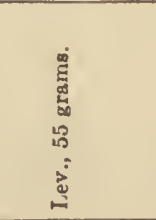 & & 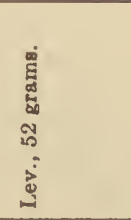 & & 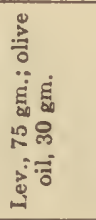 & & 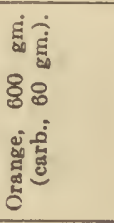 & & 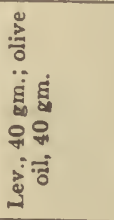 & \\
\hline
\end{tabular}




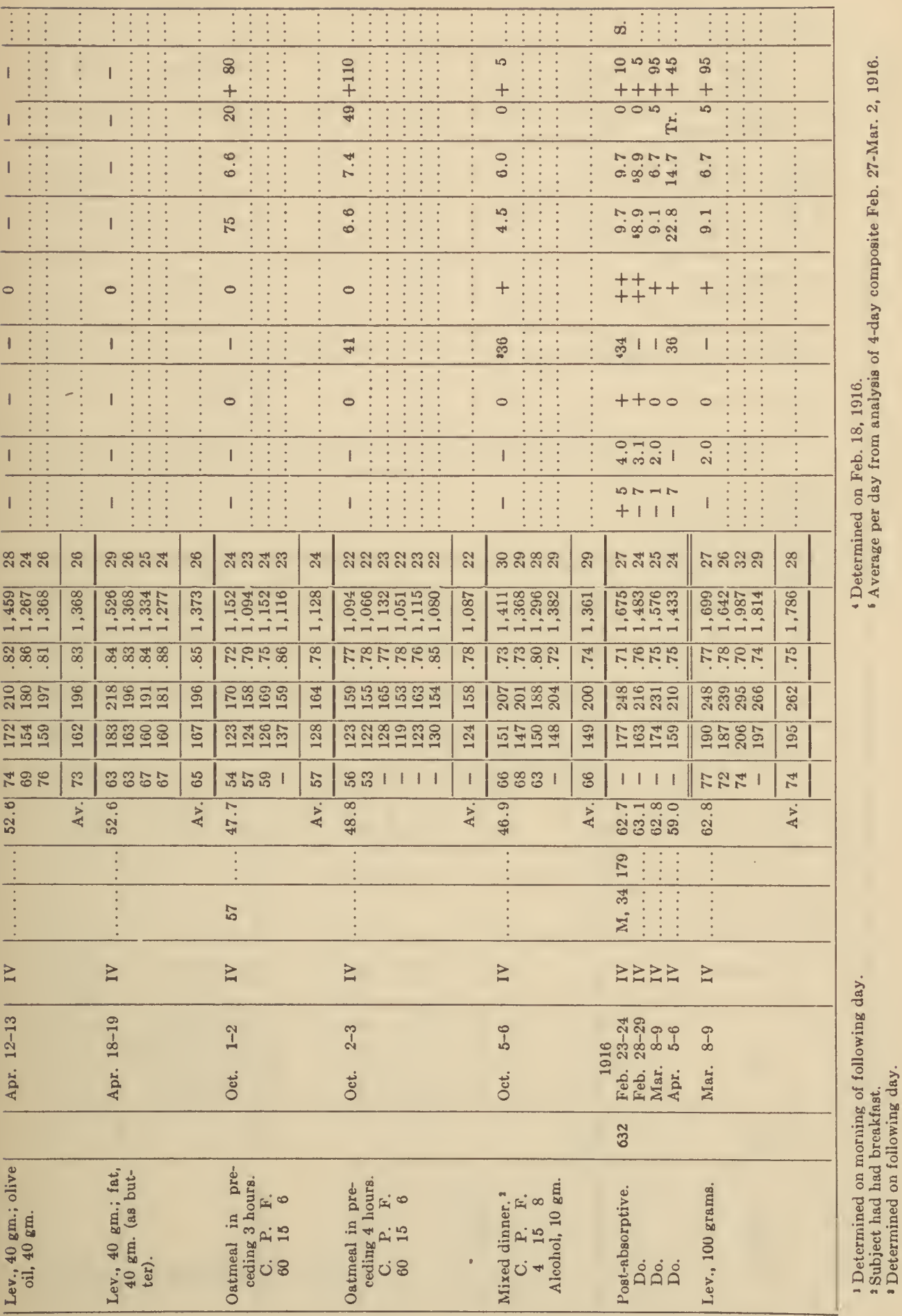


DIABETIC METABOLISM WITH HIGH AND LOW DIETS.

\begin{tabular}{|c|c|c|c|c|c|c|c|c|}
\hline \multicolumn{2}{|c|}{ 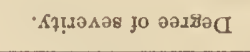 } & $\dot{\theta}$ & & & & & 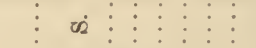 & $\stackrel{1}{2}$ \\
\hline \multicolumn{2}{|c|}{ 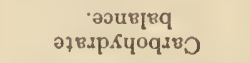 } & $\varepsilon^{20}$ & & $\stackrel{p}{+}$ & & $\stackrel{\infty}{+\infty}$ & 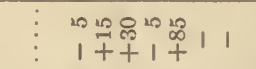 & 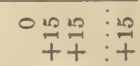 \\
\hline \multicolumn{2}{|c|}{ 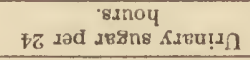 } & $\mathrm{E}^{\mathrm{N}}$ & & क & & $\stackrel{m}{=}$ & समसं। & 800 \\
\hline \multirow{2}{*}{ 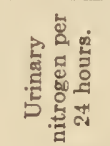 } & 㤐它总完 & 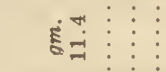 & & $\stackrel{\infty}{\sim}$ & & $\stackrel{\sim}{\mathscr{2}}$ & 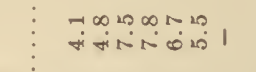 & $1 \stackrel{0=}{=}=\stackrel{n}{=}$ \\
\hline & 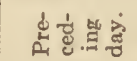 & $E^{\circ}$ & $\vdots$ & تُ & & $\ddot{0}$ & 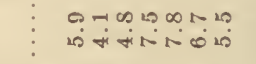 & $\stackrel{0}{0} 1 \stackrel{0}{=}$ \\
\hline \multicolumn{2}{|c|}{ 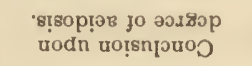 } & + & & + & & 0 & $\begin{array}{l}+++++++ \\
++++++\end{array}$ & +++ \\
\hline \multicolumn{2}{|c|}{ ' } & 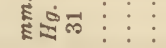 & : & ణี & & 운 & $\begin{array}{lllllll}1 & 1 & 1 & 1 & 1 & 1 & 1\end{array}$ & 111 \\
\hline \multicolumn{2}{|c|}{ 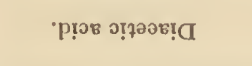 } & 0 & & + & & 1 & $\begin{array}{l}++++ \\
++++ \\
++++ \\
++11\end{array}$ & $0++$ \\
\hline \multicolumn{2}{|c|}{ 'EN } & हूँ & & $\infty$. & & ? & 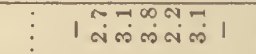 & 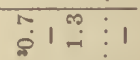 \\
\hline \multicolumn{2}{|c|}{ 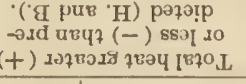 } & $\begin{array}{l}\dot{0} \\
\dot{2} \\
\dot{8}\end{array}$ & & 1 & & 1 & $\begin{array}{l}\infty \pi 0-\infty 0 N \\
11+111\end{array}$ & $\begin{array}{l}0 m-\infty-1 \\
+1+1\end{array}$ \\
\hline \multirow{2}{*}{ 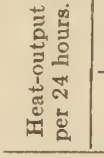 } & 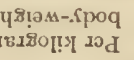 & జ్లై & ஜ̊ & สำ ลี & $\overrightarrow{~ ह ै ~}$ & สำล & 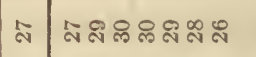 & 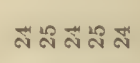 \\
\hline & $\underset{\substack{5 \\
0}}{+}$ & 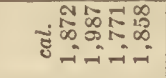 & $\begin{array}{l}\mathbb{N} \\
\substack{\mathbb{N} \\
-1}\end{array}$ & 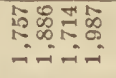 & $\begin{array}{l}\substack{\infty \\
\infty} \\
-\infty\end{array}$ & 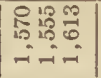 & 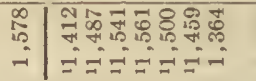 & 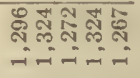 \\
\hline \multicolumn{2}{|c|}{ 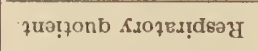 } & $\infty$ & $\infty$ & 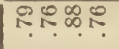 & $\infty$ & 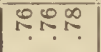 & $\vDash 1111111 \%$ & คำ \\
\hline \multicolumn{2}{|c|}{ 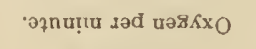 } & 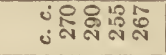 & : & ลี่งิสี & 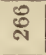 & สิสี่อี & 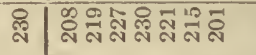 & .0000 \\
\hline \multicolumn{2}{|c|}{ 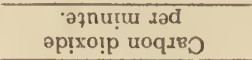 } & 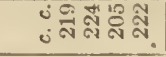 & $\overline{\mathrm{N}}$ & ลั้สสำ & ลี & 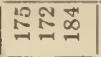 & $\approx 1111110$ & 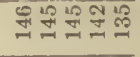 \\
\hline \multicolumn{2}{|c|}{ 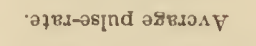 } & か゚゚ト & ז & 용 1 & 8 & 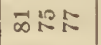 & 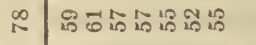 & タะถ์ำำ \\
\hline \multicolumn{2}{|c|}{ 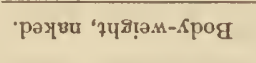 } & ₹i் & \& & $\dot{8}$ & $\frac{8}{4}$ & min & 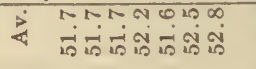 & 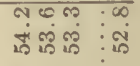 \\
\hline \multicolumn{2}{|c|}{ 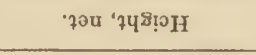 } & E⿱尺⺀ & & $\vdots$ & & : & $\stackrel{8}{g}$ & $\ddot{\mathscr{E}}$ \\
\hline \multicolumn{2}{|c|}{ 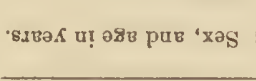 } & ले & & $\vdots$ & & & $\begin{array}{l}\bar{z} \\
\dot{z}\end{array}$ & ஜ̊ \\
\hline \multicolumn{2}{|c|}{ 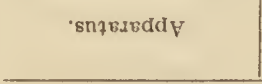 } & $\geq$ & & $\geq$ & & $\geq$ & $\Xi \Xi \Xi \Xi \Xi \Xi ぇ$ & 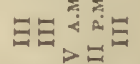 \\
\hline \multicolumn{2}{|c|}{ 离 } & 离 & & 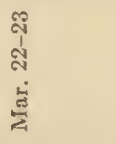 & & 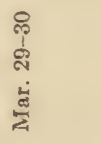 & 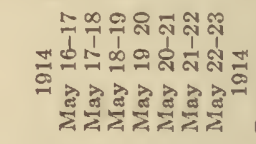 & 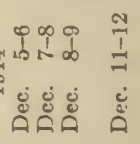 \\
\hline \multicolumn{2}{|c|}{ 造离 } & 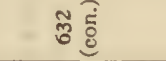 & & & & & 홍 & $\frac{\pi}{\Sigma}$ \\
\hline \multicolumn{2}{|c|}{ 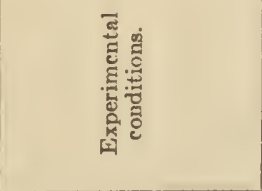 } & 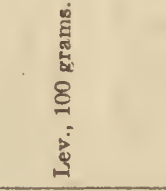 & & 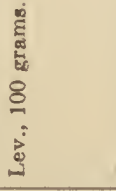 & & 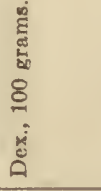 & 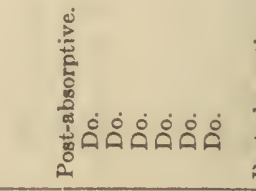 & 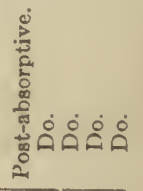 \\
\hline
\end{tabular}




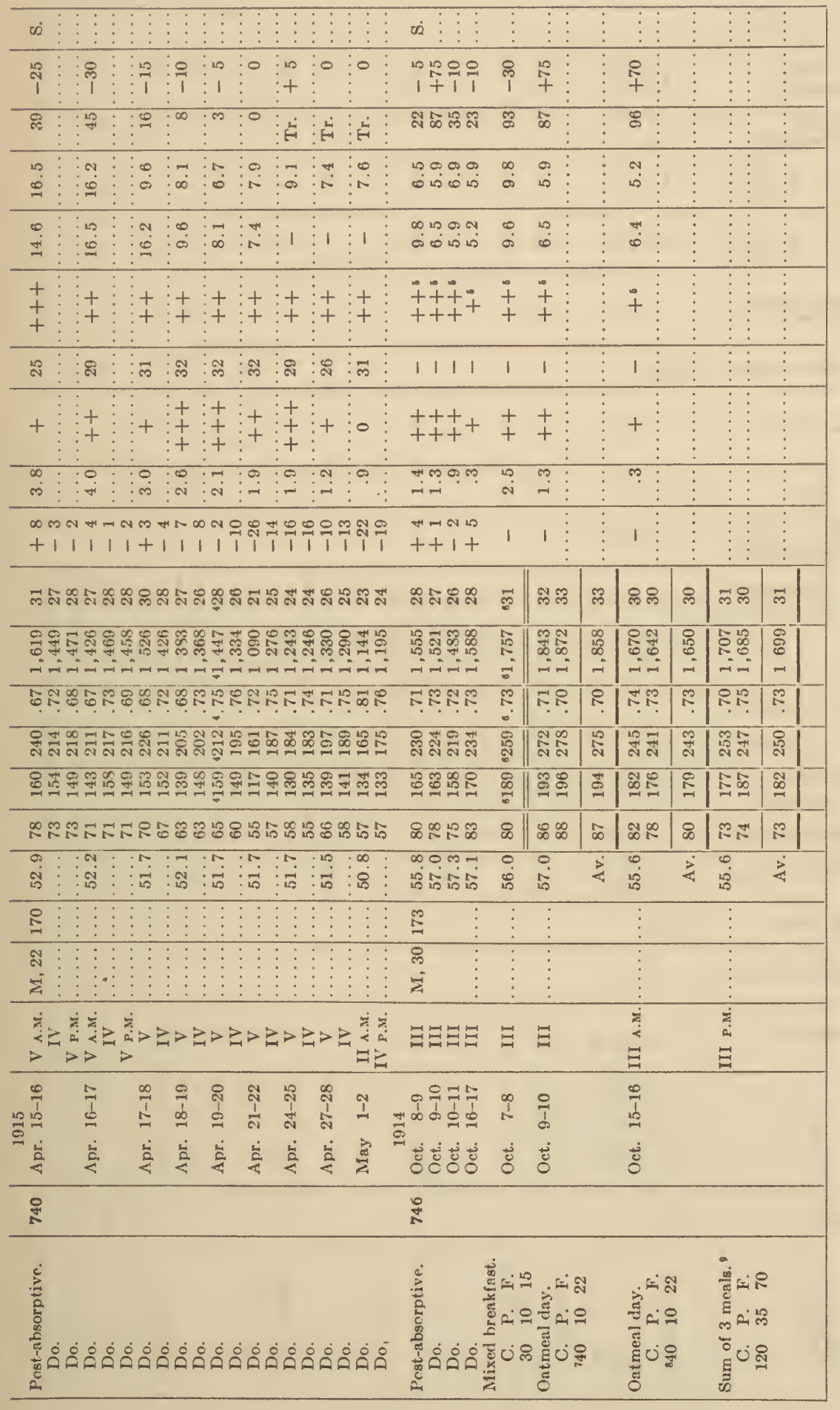




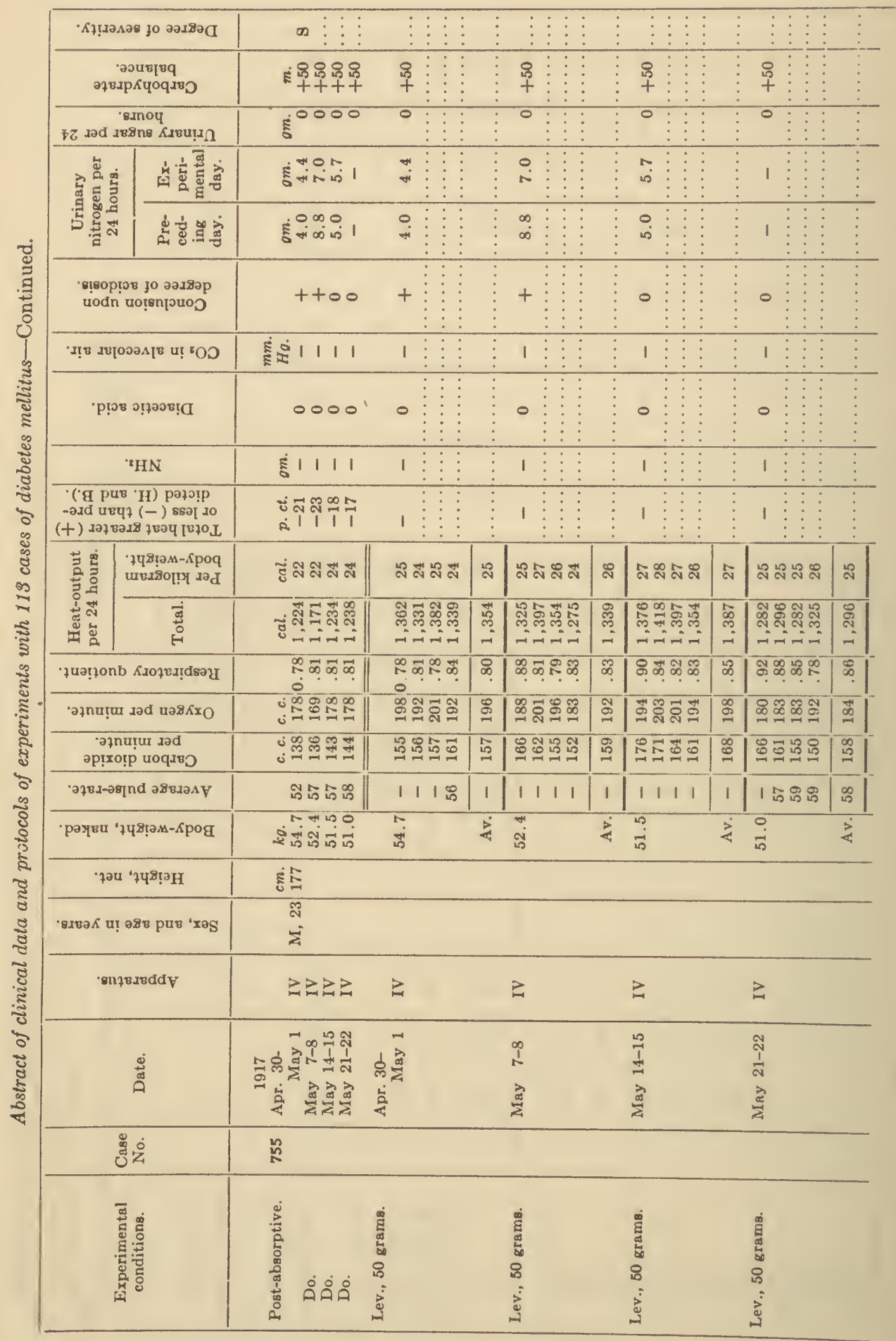




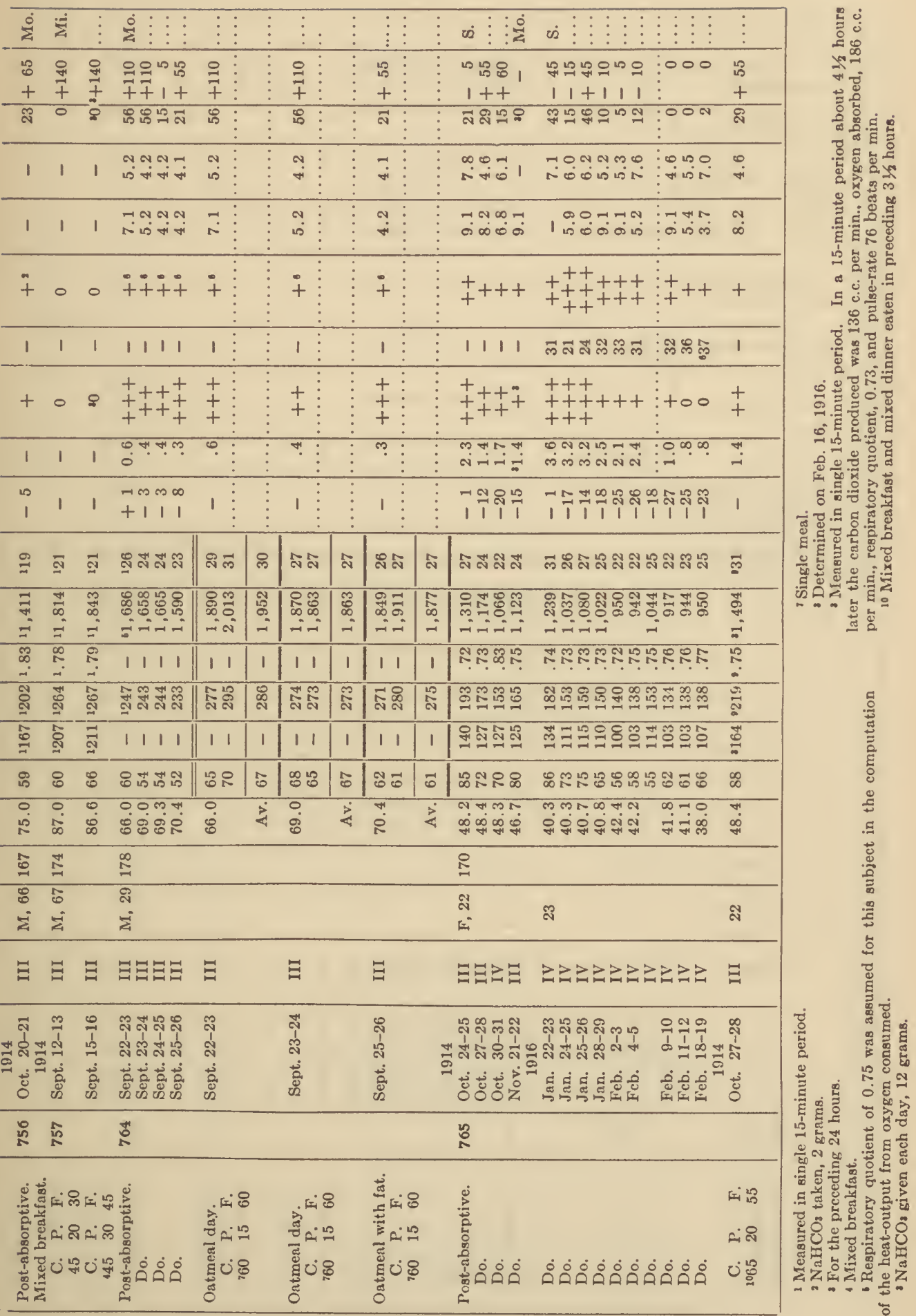




\begin{tabular}{|c|c|c|c|c|c|c|c|c|c|c|c|c|}
\hline \multicolumn{2}{|c|}{ 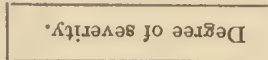 } & कर & & $\dot{s}$ & & & & & & $\dot{s}$ & : & \\
\hline \multicolumn{2}{|c|}{ 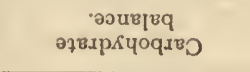 } & हैं & & 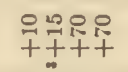 & 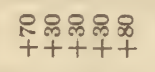 & $\begin{array}{l}20 \\
+\end{array}$ & & $\stackrel{\varnothing}{+}$ & & $\begin{array}{l}\text { 3요요 } \\
+1+\end{array}$ & 0 & \\
\hline \multicolumn{2}{|c|}{ 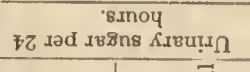 } & $\dot{\Sigma}^{\circ}$ & & $20=00$ & 00000 & 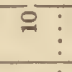 & & 0 & & ஃேே & $\stackrel{-8}{0}$ & \\
\hline \multirow{2}{*}{ 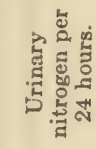 } & 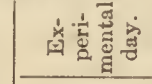 & ริ & & $\stackrel{0}{\infty} 11 \stackrel{0}{0}$ & 우 & $\underset{\infty}{\infty}$ & & क & & 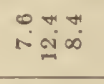 & $\dddot{\infty}$ & \\
\hline & 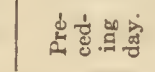 & 今் & & $\stackrel{0}{\sim} \infty{ }_{\infty}^{\infty} \stackrel{\infty}{\infty}$ & 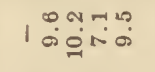 & is & & $\stackrel{?}{\infty}$ & & कृष & $\stackrel{\circ}{\cong}$ & \\
\hline \multicolumn{2}{|c|}{ 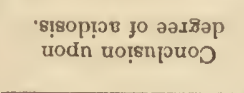 } & $\begin{array}{l}+ \\
+ \\
+\end{array}$ & & $-\ddot{0}$ & 00000 & + & & 0 & & $\begin{array}{l}+\infty \\
+++ \\
+++ \\
+++\end{array}$ & $\begin{array}{l}+ \\
+ \\
+\end{array}$ & \\
\hline \multicolumn{2}{|c|}{ 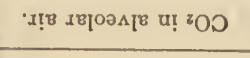 } & E & & 1111 & 11111 & 1 & & 1 & & 111 & 1 & \\
\hline \multicolumn{2}{|c|}{ •рణюษ ә!ұәәв! } & + & & & o & + & & o & & $\begin{array}{l}+++ \\
++ \\
+++\end{array}$ & $\begin{array}{l}+ \\
+ \\
+\end{array}$ & \\
\hline \multicolumn{2}{|r|}{ 'हHN } & $\Sigma_{\infty}^{N}$ & & 궁 & $111^{\circ} 0$ & 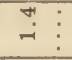 & & \% & & Tin & is & \\
\hline \multicolumn{2}{|c|}{ 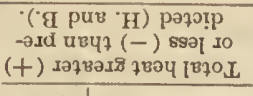 } & $\begin{array}{l} \\
\dot{2} \\
\dot{2}\end{array}$ & & $\begin{array}{c}n-\infty \infty \\
11++\end{array}$ & 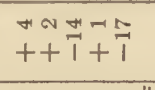 & 1 & & 1 & & 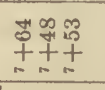 & 1 & \\
\hline \multirow{2}{*}{ 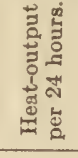 } & 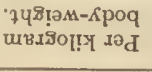 & 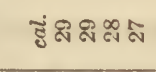 & $\stackrel{\infty}{\infty}$ & สล๊ ฒั & 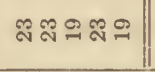 & ลี & มี & ฆึ สึ & $\Re$ & ఇ & $\mathscr{F}$ & $F$ \\
\hline & 焉 & 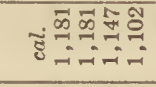 & $\mid \begin{array}{l}0 \\
0 \\
-1 \\
-1\end{array}$ & 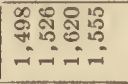 & 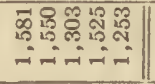 & 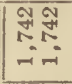 & 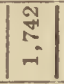 & 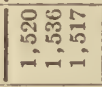 & : & 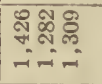 & & 跅 \\
\hline \multicolumn{2}{|c|}{ 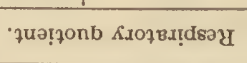 } & ๑ำ & $F$ & 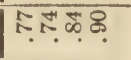 & 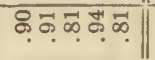 & R? & $\stackrel{R}{?}$ & 必 & \&. & कृ? & $\stackrel{7}{7}$ & \% \\
\hline \multicolumn{2}{|c|}{ 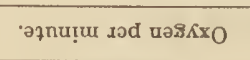 } & 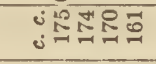 & R & 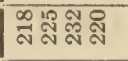 & 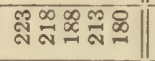 & เก้า & 旅 & สีสีส & $\overline{\mathbb{N}}$ & 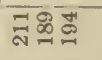 & : & สี \\
\hline \multicolumn{2}{|c|}{ 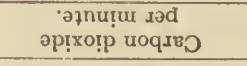 } & ن.్ำส & $\overrightarrow{\mathrm{N}}$ & 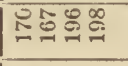 & 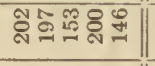 & 渠。 & ฮू & 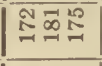 & $\frac{10}{10}$ & 焉省 & $\stackrel{\Xi}{-}$ & $\underline{6}$ \\
\hline \multicolumn{2}{|c|}{ 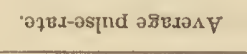 } & ゚ヘボ゚ & N & 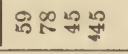 & 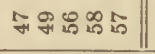 & 18 & I & Bกำ & 요 & $\infty \infty$ & 苍 & 8 \\
\hline \multicolumn{2}{|c|}{ 'рәччи '7ч } & só & $\frac{3}{4}$ & $\begin{array}{l}\text { F⿻ㅇ․ } \\
\text { Fiㅇํㅇ }\end{array}$ & 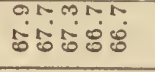 & i & $\dot{4}$ & $\ddot{8}$ & $\dot{8}$ & कृं हें & $\infty$ & \\
\hline \multicolumn{2}{|c|}{ 'วәч 'วч } & हู유 & & $\underset{N}{\sim}$ & & $\vdots$ & & & & $\stackrel{\infty}{\rightarrow}$ & & \\
\hline \multicolumn{2}{|c|}{ 'sıвә } & ฆ & & $\begin{array}{l}\text { ๙ิ } \\
\text { si }\end{array}$ & & $\vdots$ & & & & $\stackrel{\infty}{\stackrel{\infty}{-}}$ & & \\
\hline \multicolumn{2}{|c|}{ 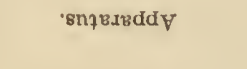 } & $\geq$ & & 沁ヨヨ & 晗きヨ己 & $\Xi$ & & $Z$ & & $\Xi \Xi \Xi$ & $\Xi$ & \\
\hline \multicolumn{2}{|r|}{ 亗 } & 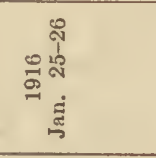 & & 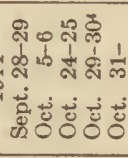 & 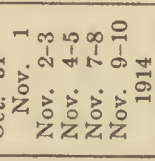 & 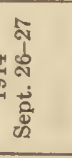 & & $\begin{array}{l}\text { 음 } \\
\text { dे } \\
\text { zे }\end{array}$ & & 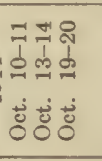 & $\begin{array}{l}\infty \\
\infty \\
\dot{0}\end{array}$ & \\
\hline \multicolumn{2}{|c|}{ 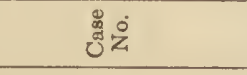 } & 응 & & 요 & & & & & & 点 & & \\
\hline \multicolumn{2}{|c|}{ 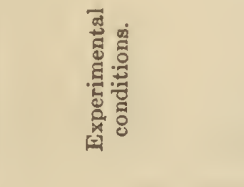 } & 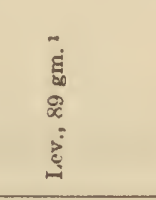 & & 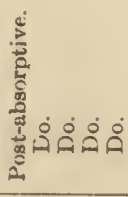 & ค่ํํㅇㅇํํ & 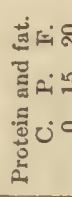 & & 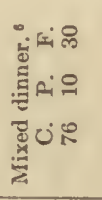 & & 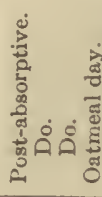 & 20 & 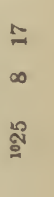 \\
\hline
\end{tabular}




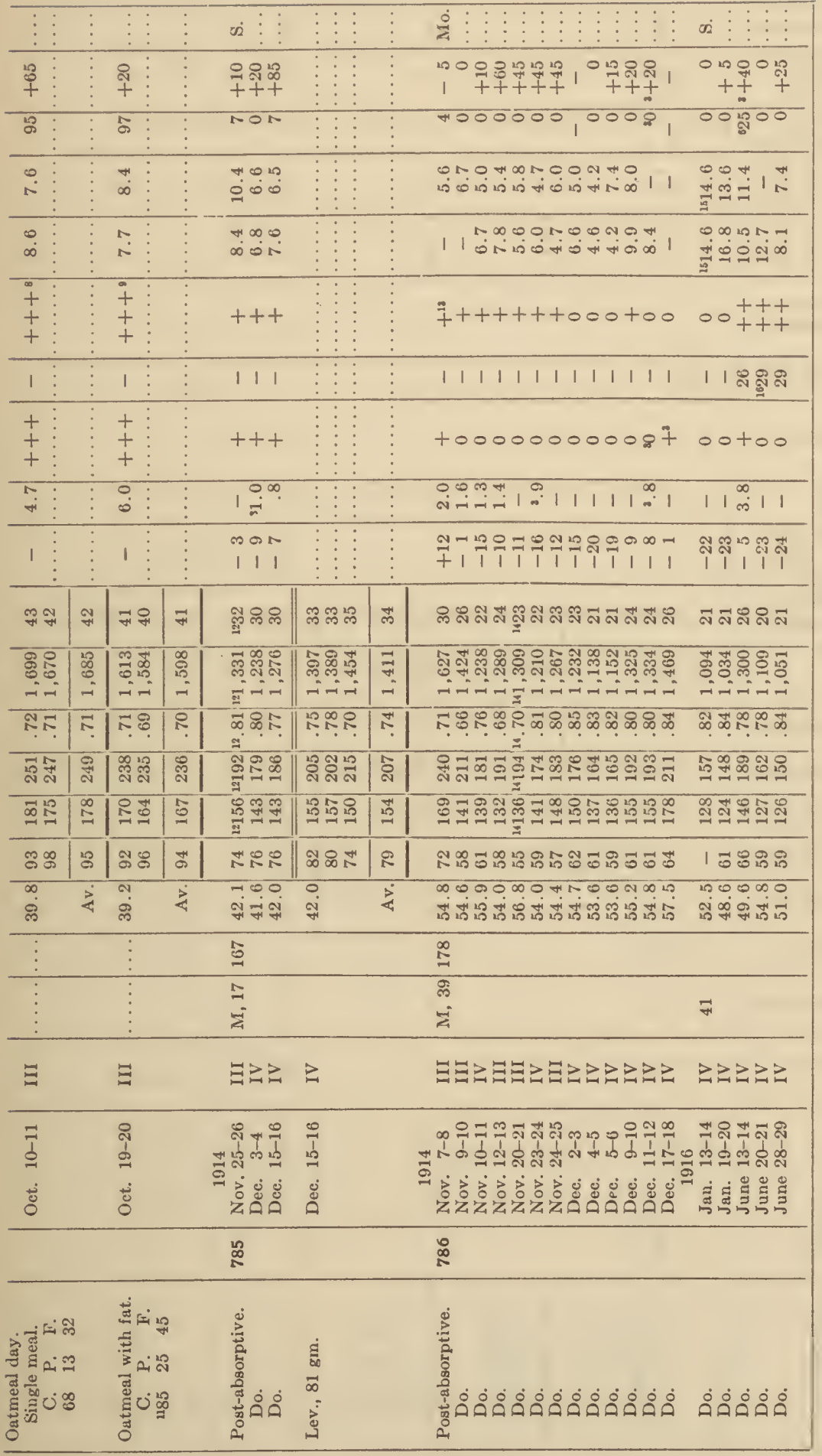

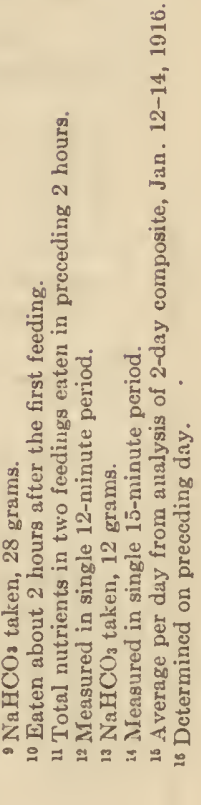


DIABETIC METABOLISM WITH HIGH AND LOW DIETS.

\begin{tabular}{|c|c|c|c|c|c|c|c|c|c|c|c|c|}
\hline \multicolumn{2}{|c|}{ 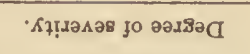 } & ¿ & & & & $\dot{\theta}$ & & हो & & के & : & \\
\hline \multicolumn{2}{|c|}{ 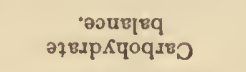 } & $\begin{array}{l}8 \\
+ \\
+\end{array}$ & & 1 & & 1 & & $\begin{array}{l}00 \\
+\end{array}$ & + & $\begin{array}{c}1 \\
1\end{array}$ & & \\
\hline \multicolumn{2}{|c|}{ 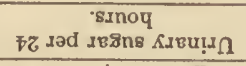 } & $\dot{5}^{\circ}$ & & 1 & & 1 & & 00 & 0 & men & & \\
\hline \multirow{2}{*}{ 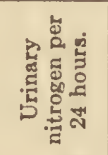 } & 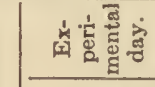 & ह5. & & $\stackrel{0}{\text { is }}$ & & $\stackrel{\square}{=}$ & & $\stackrel{0}{\circ 1}$ & $\stackrel{\leftrightarrow}{\sim}$ & $1 \stackrel{\circ}{0}$ & & \\
\hline & 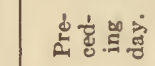 & $\dot{E}_{0}^{\infty}$ & & $\stackrel{\circ}{\circ}$ & & 电 & & $1 \stackrel{\circ}{n}$ & $\stackrel{\circ}{\infty}$ & 11 & 1 & \\
\hline \multicolumn{2}{|c|}{ 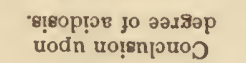 } & + & & 0 & & + & & of & 0 & $+t$ & + & \\
\hline \multicolumn{2}{|c|}{ ' } & है। & & 1 & & A & & 11 & 1 & ది స్ట్ & 1 & \\
\hline \multicolumn{2}{|c|}{ 'р!ฺв จ!ฺจ०в!ด } & 0 & & 。 & & + & & ot & $\circ$ & $t+$ & ○ & \\
\hline \multicolumn{2}{|r|}{${ }^{\mathrm{I}} \mathrm{HN}$} & हूँ & & 1 & & $\begin{array}{l}\infty \\
\dot{\infty}\end{array}$ & & 11 & 1 & 11 & 1 & \\
\hline \multicolumn{2}{|c|}{ 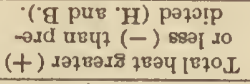 } & $\begin{array}{l}\dot{U} \\
\dot{8}\end{array}$ & & 1 & & 1 & & $\begin{array}{l}-\infty \\
0 \\
+ \\
+\end{array}$ & $\overrightarrow{\text { I }}$ & $\frac{107}{11}$ & & \\
\hline \multirow{2}{*}{ 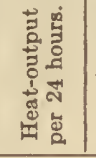 } & 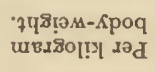 & కేં สీ జิ & สิ & ลิ ลี ล & $\stackrel{\infty}{\infty}$ & ๙ ๙ & ลิ & 赵些 & : & $\hat{\sim} \stackrel{\infty}{*}$ & 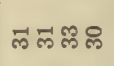 & ले। \\
\hline & 离 & 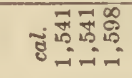 & in & 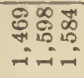 & 学 & 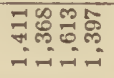 & 亲 & 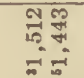 & : & 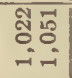 & $\begin{array}{l}8_{0}^{0} 008 \\
7=0\end{array}$ & $\stackrel{\infty}{=}$ \\
\hline \multicolumn{2}{|c|}{ 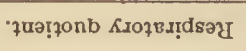 } & №ㄴ? & $?$ & ळळం. & $\infty$ & 담유? & 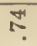 & 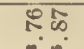 & $\vec{\infty}$ & $\stackrel{\infty}{ヘ}$ & 舟 & $\notin$ \\
\hline \multicolumn{2}{|c|}{ •əุnu!̣u } & نส & स్ & ำสิสิ & สึ్ & 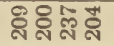 & $\stackrel{\text { ส }}{\pi}$ & สู้ జ & $\stackrel{m}{\mathfrak{m}}$ & 栾茪 & 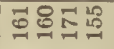 & ฮ్ \\
\hline \multicolumn{2}{|c|}{ 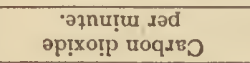 } & ن영 & 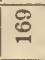 & : & $\stackrel{\infty}{\infty}$ & 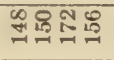 & เ2 & $\sum_{0}^{\infty} \frac{\infty}{-1}$ & $\cong$ & $\stackrel{\Xi}{=}$ & 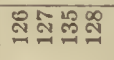 & क्ज \\
\hline \multicolumn{2}{|c|}{ 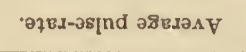 } & 요용 & $\hat{\circ}$ & 퐁잉 눙 & के & 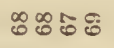 & $\ddot{\infty}$ & 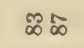 & 1 & $\because 1$ & 11111 & 11 \\
\hline \multicolumn{2}{|c|}{ 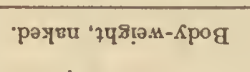 } & $\dot{2} \dot{0}$ & $\dot{8}$ & $\overrightarrow{7 i}$ & $\frac{8}{4}$ & : & $\frac{8}{4}$ & कर & $\vec{\infty}$ & 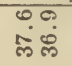 & & $\dot{8}$ \\
\hline \multicolumn{2}{|c|}{ 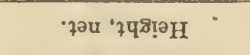 } & हี่ & & & & & & 疍 & $\vdots$ & 萑 & & \\
\hline \multicolumn{2}{|c|}{ 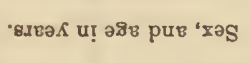 } & हి & & & & F & & $\stackrel{\infty}{=}$ & 요 & $\overline{4}$ & & \\
\hline \multicolumn{2}{|c|}{-snวยsвdd } & $\Xi$ & & $z$ & & $z$ & & $\Xi \Xi$ & $z$ & 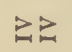 & $z$ & \\
\hline \multicolumn{2}{|r|}{ ڤัँ } & 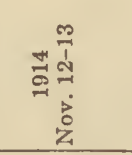 & & $\begin{array}{l}\not{m} \\
\text { ஸे } \\
\dot{0} \\
\stackrel{0}{0}\end{array}$ & & 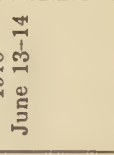 & & م & $\AA$ & 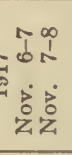 & $\begin{array}{l}\frac{20}{1} \\
\frac{1}{4} \\
\dot{0} \\
\dot{2}\end{array}$ & \\
\hline \multicolumn{2}{|r|}{ 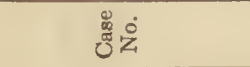 } & 을 & & & & & & ฉ̊ & & & & \\
\hline \multicolumn{2}{|r|}{ 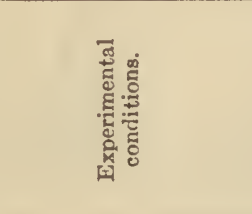 } & 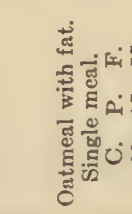 & & 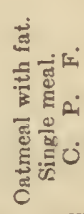 & & 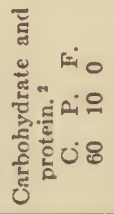 & & คे & $\dot{\AA}$ & $\dot{\circ} \dot{\circ}$ & 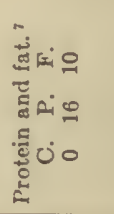 & \\
\hline
\end{tabular}




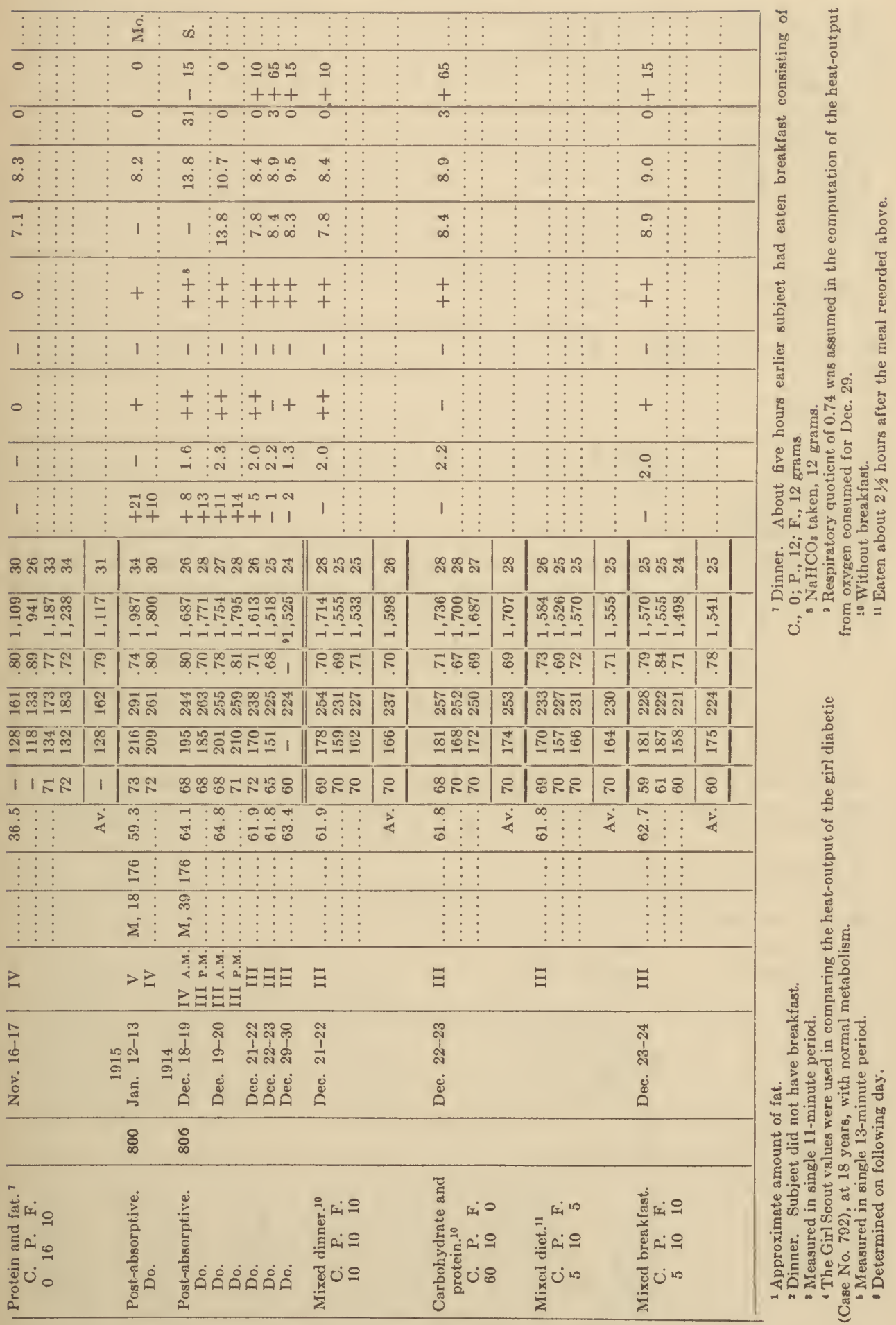




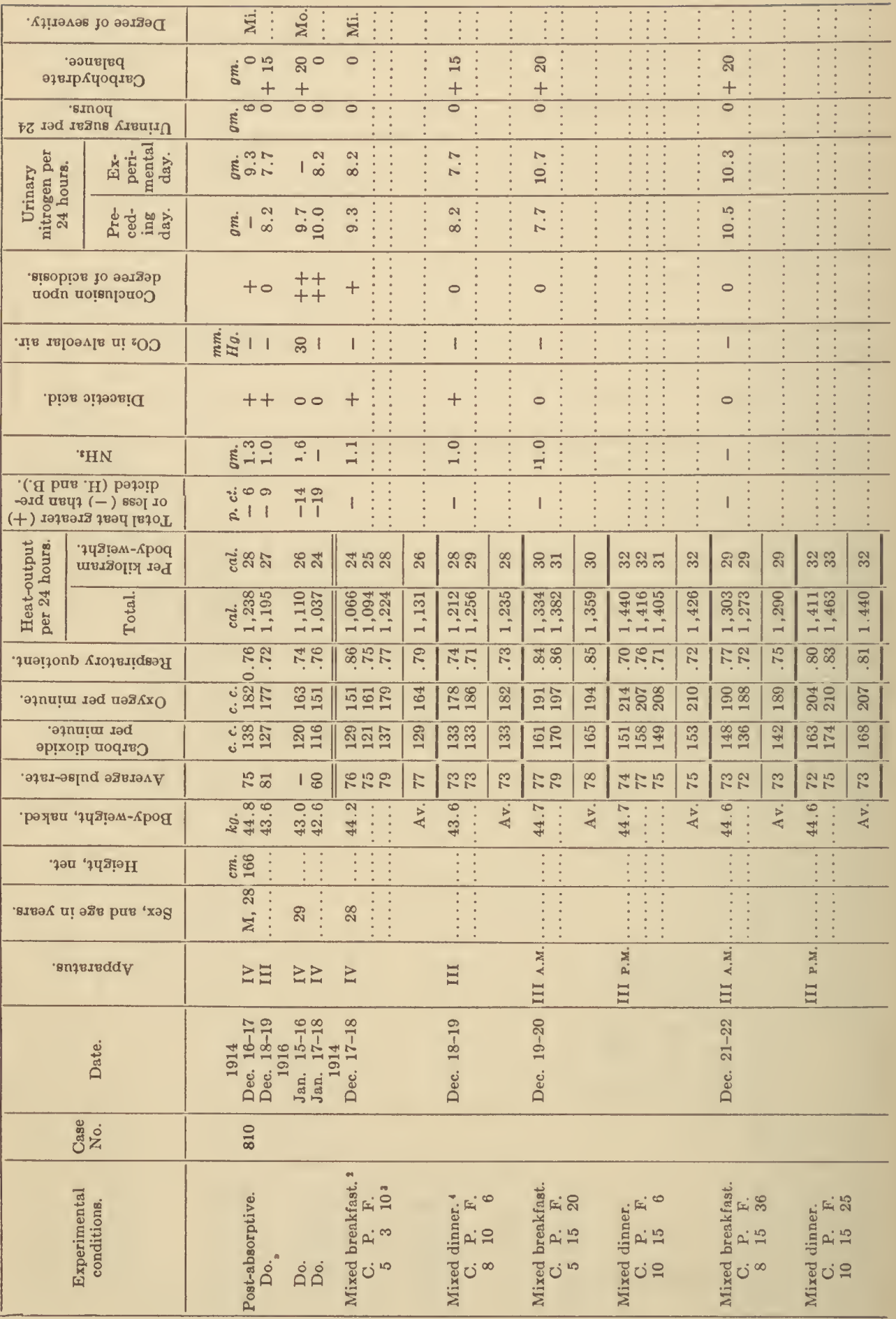




\begin{tabular}{|c|c|c|c|c|c|c|c|c|}
\hline$\dot{\infty}$ & $\vdots \vdots \vdots$ & & : & & : & & & \\
\hline $\begin{array}{l}\text { ผูก } 200000000000 \\
11111\end{array}$ & $\begin{array}{l}0 \\
\\
\vdots \\
\vdots\end{array}$ & & $\begin{array}{l}8 \\
+\end{array}$ & & $\begin{array}{r}8 \vdots \\
+\vdots \\
+\end{array}$ & & $\circ$ & \\
\hline Q $=0000000000$ & $\begin{array}{l}\dot{\mu} \\
\vdots \vdots\end{array}$ & & कृ & & $\infty:$ & & 0 & \\
\hline 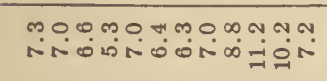 & $\stackrel{\infty}{=}$ & & $\stackrel{\infty}{\circ}$ & & $\stackrel{0}{\circ}$ & & $\stackrel{\sim}{\dddot{N}}$ & $\vdots$ \\
\hline 幺no & $\stackrel{0}{\circ}$ & & $\stackrel{\infty}{=}$ & & $\dddot{m}$ & & $\stackrel{\infty}{\infty}$ & $\vdots$ \\
\hline 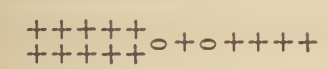 & + & & + & & + & & + & $\vdots$ \\
\hline 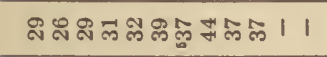 & జొ & & กิ & & 1 & $\vdots$ & 1 & : \\
\hline $\begin{array}{l}++t \\
++++00000000 \\
++t\end{array}$ & 0 & & 0 & & ○ & & $\circ$ & $\vdots$ \\
\hline 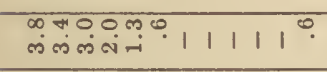 & 1 & $\bar{\vdots}$ & $\stackrel{26}{-1}$ & & $\because$ & : & 1 & $\vdots$ \\
\hline N & 1 & : & । & & । & & । & $\vdots$ \\
\hline 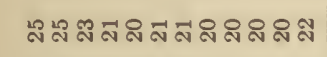 & ลำลี & $\sqrt[4]{5}$ & 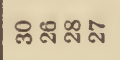 & $\stackrel{\infty}{\sim}$ & ลี心ే心્ล & \& & ็ุลสัส & สี \\
\hline 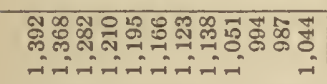 & 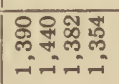 & $\begin{array}{l}\infty \\
\infty \\
\infty \\
-1\end{array}$ & 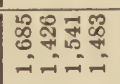 & 䠇 & 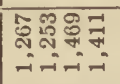 & 焉 & 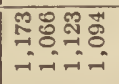 & $\begin{array}{l}\cong \\
\exists\end{array}$ \\
\hline 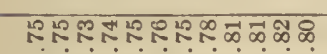 & क⿻上丨 & T & ก⿻上丨 & ळ. & 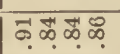 & क & గ⿻上丨 & ? \\
\hline 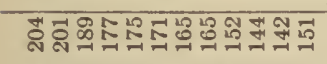 & 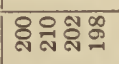 & สू & 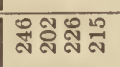 & สู & शำส을 & $\stackrel{\sim}{\sim}$ & 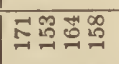 & ब্ত্] \\
\hline 茎 & 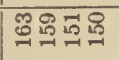 & 总 & 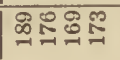 & E & 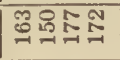 & 2 & 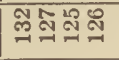 & 걱 \\
\hline 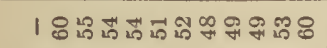 & 的战品品 & 战 & 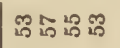 & เี่ & 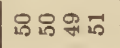 & in & 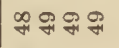 & \& \\
\hline 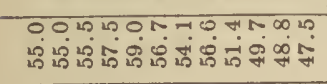 & & $\frac{1}{4}$ & $\begin{array}{l}0 \\
0 \\
\text { in } \\
\text { in }\end{array}$ & 安 & 药 & $\frac{1}{4}$ & $\stackrel{0}{\circ}$ & $\frac{1}{\dot{z}}$ \\
\hline 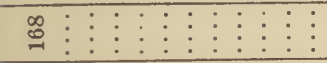 & $\vdots$ & & $\vdots$ & & $\vdots$ & & $\vdots$ & \\
\hline 旅 & $\bar{\vdots}$ & & & & & & & \\
\hline 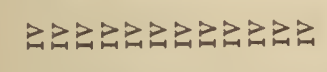 & $\gtrsim$ & & $\geq$ & & 2 & & $\geq$ & \\
\hline 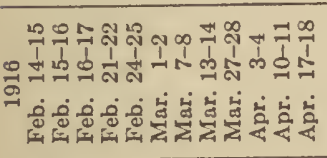 & 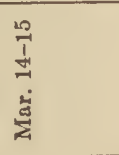 & & $\sum_{\substack{\pi\\
}}^{2}$ & & 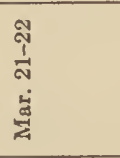 & & 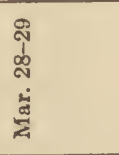 & \\
\hline สี & & & & & & & & \\
\hline 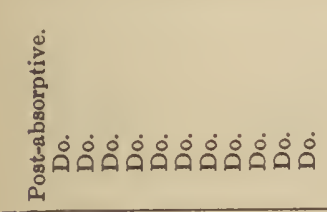 & 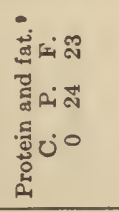 & & 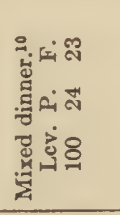 & & 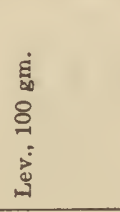 & & 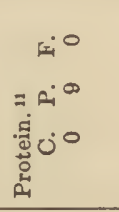 & \\
\hline
\end{tabular}




\begin{tabular}{|c|c|c|c|c|c|c|c|c|c|c|c|c|}
\hline \multicolumn{2}{|c|}{ 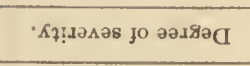 } & $\stackrel{0}{2}$ & $\stackrel{0}{*}$ & & & & & $\stackrel{0}{2}$ & & & & \\
\hline \multicolumn{2}{|c|}{ 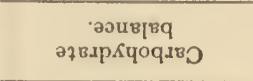 } & $\mathrm{E}^{\circ}$ & 10 & $\begin{array}{l}10 \\
+\end{array}$ & & 0 & & $\begin{array}{l}0 \cong 20 \\
++\end{array}$ & $\frac{10}{7}$ & & $\frac{40}{7}$ & \\
\hline \multicolumn{2}{|c|}{ 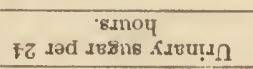 } & $5^{\circ}$ & $r$ & 0 & & $\dot{H}$ & & 000 & 0 & & h & \\
\hline \multirow{2}{*}{ 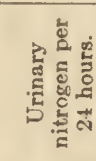 } & 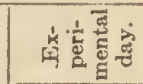 & हूं 1 & $\stackrel{4}{i}$ & $\overline{0}$ & & $\ddot{0}$ & & $\begin{array}{l}n: 0 \\
\infty \infty \\
\infty\end{array}$ & 1 & & 1 & \\
\hline & 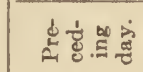 & है 1 & 1 & $\stackrel{\circ}{\infty}$ & & 1 & & $\begin{array}{l}\because \because 0 \\
\because=0\end{array}$ & 1 & & 1 & \\
\hline \multicolumn{2}{|c|}{ 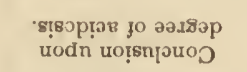 } & + & + & $\circ$ & & ○ & & $\begin{array}{l}+++ \\
+++\end{array}$ & o & & o & \\
\hline \multicolumn{2}{|c|}{. } & $\sum_{\Xi 1}$ & $\stackrel{\infty}{\dddot{2}}$ & 1 & . & 1 & & ले ले & 1 & & 1 & \\
\hline \multicolumn{2}{|c|}{ - } & + & + & 0 & & o & & 000 & o & & o & \\
\hline \multicolumn{2}{|c|}{ เHN } & हैं: & 1 & 1 & & 1 & & 111 & 1 & & 1 & \\
\hline \multicolumn{2}{|c|}{ 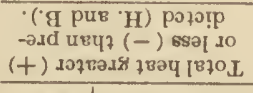 } & $\begin{array}{l}\dot{i} \infty+ \\
\dot{8}++\end{array}$ & $\begin{array}{l}\infty \\
+\end{array}$ & 1 & & 1 & & 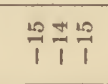 & 1 & & 1 & \\
\hline \multirow{2}{*}{ 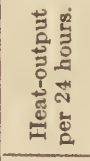 } & 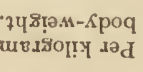 & 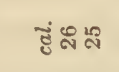 & $\stackrel{\infty}{\sim}$ & ผึณัณล & $\hat{\mathrm{N}}$ & 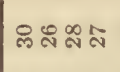 & ลิ & ๓ฒฒ & ぶざ ๙ & $\vec{a}$ & ลี สั ส & $\approx$ \\
\hline & 焉 & 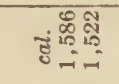 & $\begin{array}{l}8 \\
: \\
= \\
=\end{array}$ & 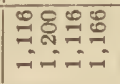 & : & 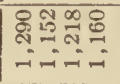 & 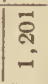 & 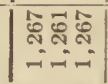 & 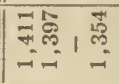 & 趈 & 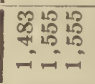 & 总 \\
\hline \multicolumn{2}{|c|}{ 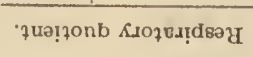 } & 武? & $\stackrel{\infty}{\uparrow}$ & $\infty$ & $\infty$ & 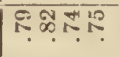 & F & $\infty_{\infty}^{\infty} \leqslant$ & $\infty \stackrel{\infty}{\infty} \stackrel{\infty}{\infty}$ & 9 & WNF? & $\infty$ \\
\hline \multicolumn{2}{|c|}{ 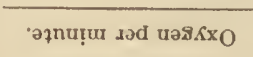 } & ن & 요 & 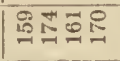 & $\because$ & 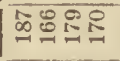 & $\stackrel{10}{=}$ & $\mid \begin{array}{l}\infty \\
\infty \\
\infty\end{array} \infty$ & 薃 & हี & สีล్ส สิ & $\overrightarrow{\text { สี }}$ \\
\hline \multicolumn{2}{|c|}{ 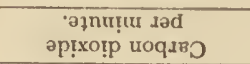 } & 政包 & $\stackrel{m}{m}$ & 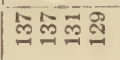 & ले & $\stackrel{\infty}{=}$ & $\stackrel{\infty}{\dddot{m}}$ & | 采守是 & 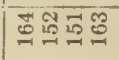 & 5 & 央央 & $\underline{E}$ \\
\hline \multicolumn{2}{|c|}{ 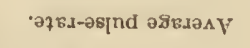 } & ชี & 1 & 菏 1111 & 1 & \& & I & 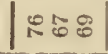 & แลกั & $\pi$ & |R゚ト & $\Re$ \\
\hline \multicolumn{2}{|c|}{ 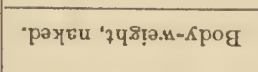 } & $\stackrel{0}{\circ}$ & $\dddot{q}$ & $\stackrel{a}{3}$ & $\dot{s}$ & $\hat{q}$ & $\dot{8}$ & 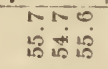 & $\begin{array}{l}a \\
\infty \\
b\end{array}$ & $\dot{8}$ & $\vec{\circ}$ & $\stackrel{2}{2}$ \\
\hline \multicolumn{2}{|c|}{ 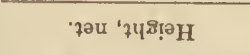 } & हี่ำ & 象 & & & & & $\cong$ & & & & \\
\hline \multicolumn{2}{|c|}{ 'вдва $K$ u! อรв рив 'хаS } & $\begin{array}{l}0 \\
\text { in } \\
=\end{array}$ & 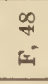 & & & & & ت̆ & & & & \\
\hline \multicolumn{2}{|c|}{ 'snzвI8ddV } & $>\geq$ & $\geq$ & $\geq$ & & $\geq$ & & $\geq \geq \geq$ & $\geq$ & & \multicolumn{2}{|l|}{$z$} \\
\hline \multicolumn{2}{|r|}{ 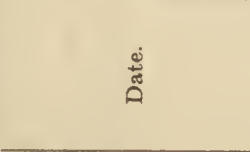 } & 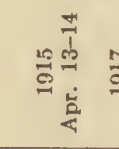 & 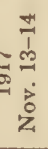 & 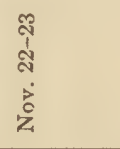 & & 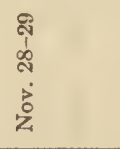 & & 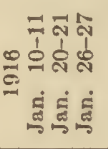 & $\begin{array}{l}m \\
\stackrel{m}{\tilde{N}} \\
\dot{8} \\
\dot{8}\end{array}$ & & \multicolumn{2}{|l|}{ 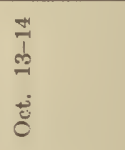 } \\
\hline \multicolumn{2}{|c|}{ 聯 } & \# & ふूँ & & & & & $\overrightarrow{\text { มี }}$ & & & & \\
\hline \multicolumn{2}{|c|}{ 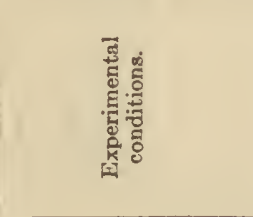 } & 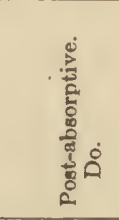 & 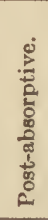 & 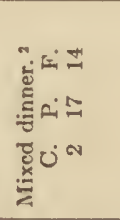 & & 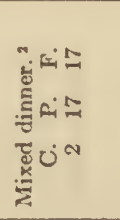 & & 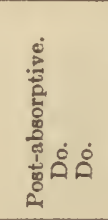 & 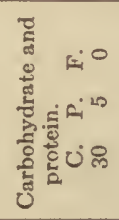 & & \multicolumn{2}{|c|}{ 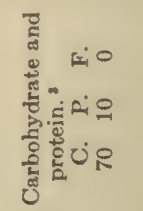 } \\
\hline
\end{tabular}




\begin{tabular}{|c|c|c|c|c|c|c|c|c|c|c|c|}
\hline i & $\dot{s}$ & & & $\vdots \frac{1}{4}$ & $\dot{\infty}$ & $\dot{\vec{z}}$ & $\dot{\infty}$ & $\dot{\bar{z}} \quad \vdots \infty \vdots \vdots \vdots$ & $\dot{s}$ & & \\
\hline $\begin{array}{l}\text { p } \\
+\end{array}$ & $\frac{00010}{1+}$ & 1 & & 20 & 00 & 虾 & 0 & 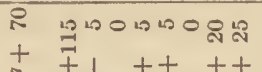 & $\begin{array}{l}\text { : } 10000 \\
+t+\end{array}$ & : & \\
\hline & श्रन ${ }_{\mathrm{H}^{\circ}}^{\circ}$ & 1 & & 00 & 00 & 0 & $\dot{H}$ & $=00_{400} \mathrm{~F}^{000}$ & $=\mathrm{Fin}^{\circ 0}$ & $=$ & \\
\hline$\stackrel{\sim}{\stackrel{\sim}{\sim}}$ & is & 1 & & $1 \stackrel{0}{0}$ & $\infty_{\infty}^{-1}+\infty$ & $\ddot{\circ}$ & 1 & $\stackrel{\infty}{\infty} \quad \stackrel{\text { Na }}{=}$ & 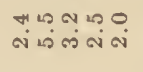 & $\overrightarrow{\dot{H}}$ & \\
\hline 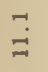 & 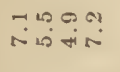 & is & & 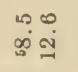 & $\stackrel{0}{\infty}$ & $\stackrel{\infty}{=}$ & $\stackrel{\sim}{\infty}$ & N. लำ & $\ddot{n}$ & $\ddot{n}$ & \\
\hline+ & & + & & 00 & 00 & $\stackrel{+}{+}$ & + & 00 & & $\begin{array}{l}+ \\
+ \\
+\end{array}$ & \\
\hline 1 & 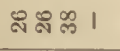 & 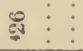 & & $1 ळ$ & 11 & \&̊ำ & ลิ & 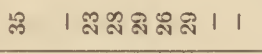 & 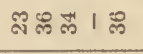 & 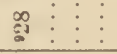 & \\
\hline+ & & + & & 00 & 0 & 0 & $\begin{array}{l}+ \\
+ \\
+\end{array}$ & $=1+$ & 100 & 8 & \\
\hline 1 & कृत्य & 1 & & 11 & 11 & 1 & $\stackrel{\infty}{\infty}$ & 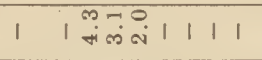 & 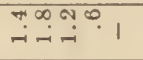 & $\stackrel{4}{-i}$ & \\
\hline $\begin{array}{l}\text { N } \\
+\end{array}$ & $\begin{array}{l}+1711 \\
+11\end{array}$ & 1 & & 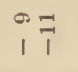 & 11 & $\begin{array}{l}\infty \\
+\end{array}$ & $\vec{i}$ & 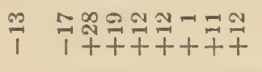 & けテプ & 1 & \\
\hline สิ & 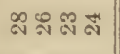 & ్ㅣㅇㅀ స్ & ఃे & สี & ล & $\stackrel{-}{-1}$ & สิ & 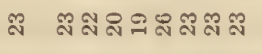 & ลัลละสล & 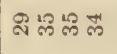 & $\infty$ \\
\hline $\begin{array}{l}\infty \\
\infty \\
\infty \\
-1 \\
-1\end{array}$ & 年 & 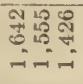 & 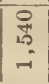 & 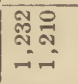 & స: & 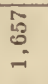 & 菊 & 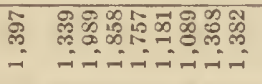 & 舫 & 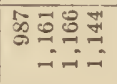 & $\begin{array}{l}\stackrel{0}{=} \\
=1\end{array}$ \\
\hline$\stackrel{7}{?}$ & NNㄴ & ำก & $\because$ & 꽁 & $i \vec{\infty}$ & $\stackrel{\infty}{?}$ & T & 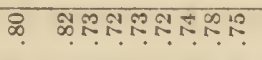 & 꼬ำ & 오ㅇㅠㅠ. & ㄴ. \\
\hline న్ & สิ స్తి & mูง & 舟 & $\overline{0}=$ & $\begin{array}{ll}\infty & 0 \\
5 & 0 \\
1 & 10\end{array}$ & సี & $\stackrel{\infty}{\infty}$ & 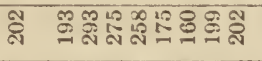 & 包导 & 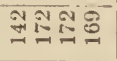 & $\stackrel{\overrightarrow{0}}{-1}$ \\
\hline ڤे & 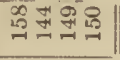 & 도윰요 & gू & 票余 & कิ & $\stackrel{\infty}{\infty}$ & 焉 & 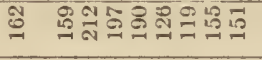 & 훙ㅎㅇ요요 & 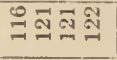 & a \\
\hline$\$$ & 我只我: & ஜøః & $\Xi$ & 央芯 & 동ํำ & 1 & 1 & 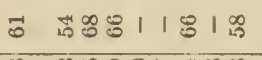 & 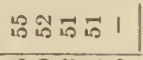 & | & 11 \\
\hline$\stackrel{\infty}{\infty}$ & 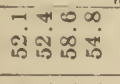 & $\frac{9}{10}$ & $\frac{3}{4}$ & 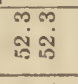 & 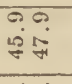 & $\ddot{\infty}$ & is & 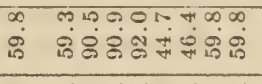 & 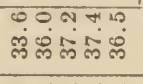 & $\ddot{\circ}$ & $\dot{z}$ \\
\hline$\stackrel{\infty}{=}$ & $\Phi$ & $\vdots$ & & $\stackrel{\infty}{=}$ & & $\Phi$ & $\mathscr{:}$ & 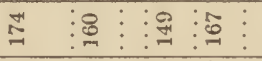 & 을 & : & \\
\hline दे & 离 & & & $\begin{array}{l}\infty \\
+1 \\
\dot{z}\end{array}$ & से & $\begin{array}{l}\text { की } \\
\text { के }\end{array}$ & $\begin{array}{l}\text { in } \\
\text { if }\end{array}$ & 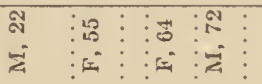 & 茴 & & \\
\hline$\geq$ & $Z \geq$ & $z$ & & $\geq \geq$ & 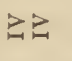 & $\geq$ & $z$ & 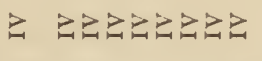 & 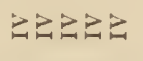 & 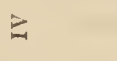 & \\
\hline \%ి & 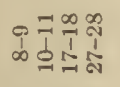 & $\stackrel{\text { I }}{\Rightarrow}$ & & 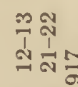 & & & 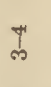 & 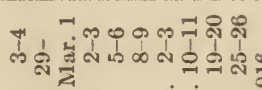 & 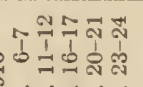 & $\hat{\jmath}$ & \\
\hline 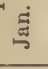 & 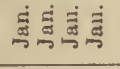 & تر & & 哥良 & & 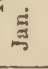 & 离 & 递 & 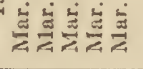 & $\frac{\dot{J}}{\bar{z}}$ & \\
\hline ஜू & $\stackrel{\circ}{\circ}$ & & & \&े & & 옴 & 今ิ & ஃ ஃ ஃ & 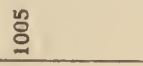 & & \\
\hline 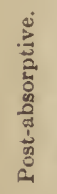 & 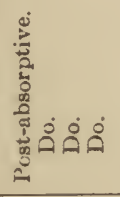 & 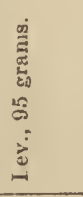 & & 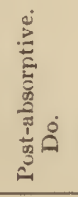 & $\dot{\circ} \dot{\circ}$ & 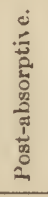 & 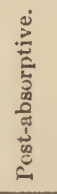 & 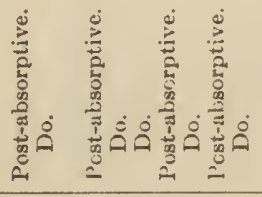 & 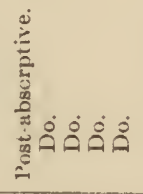 & 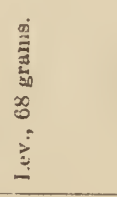 & \\
\hline
\end{tabular}




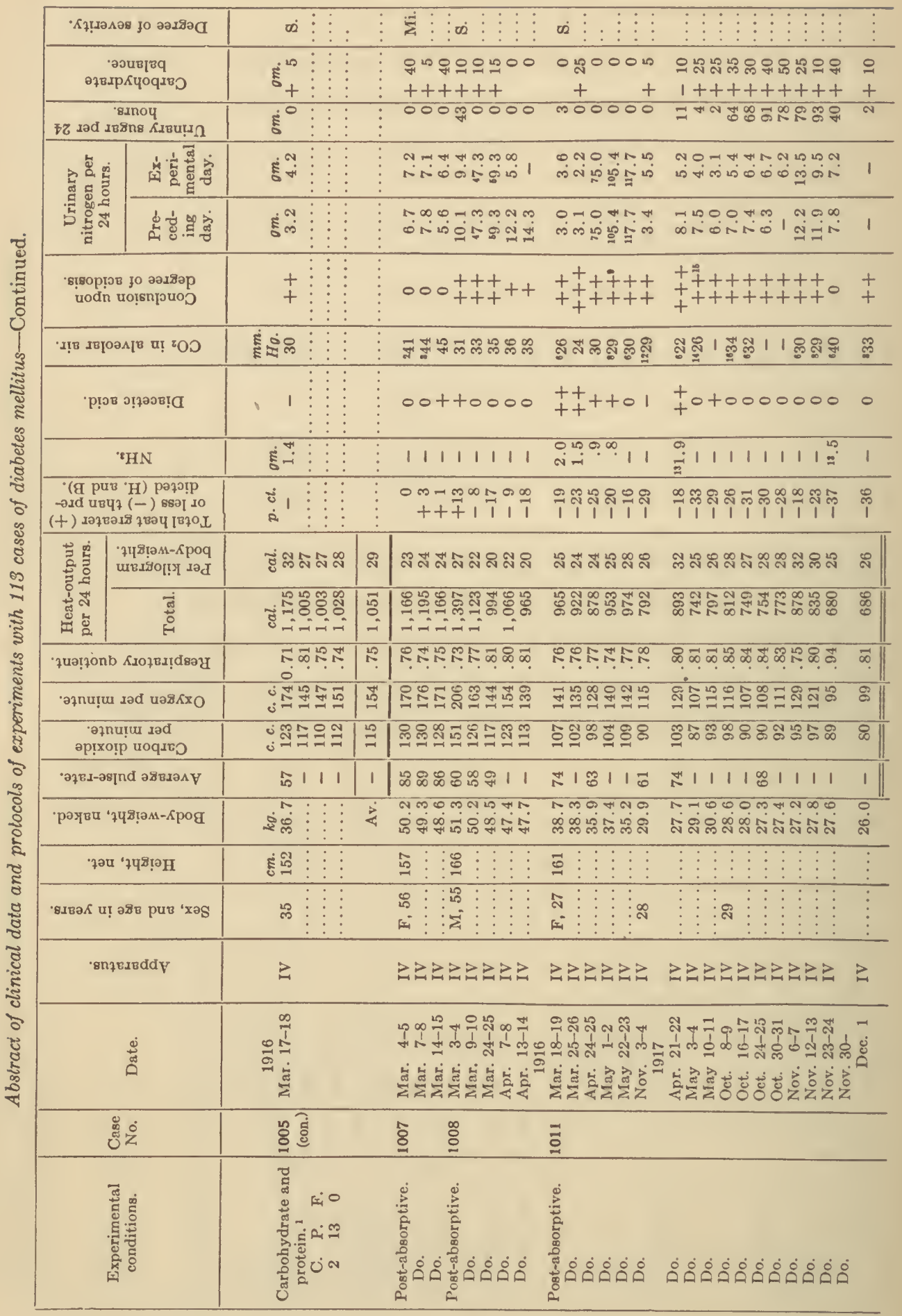




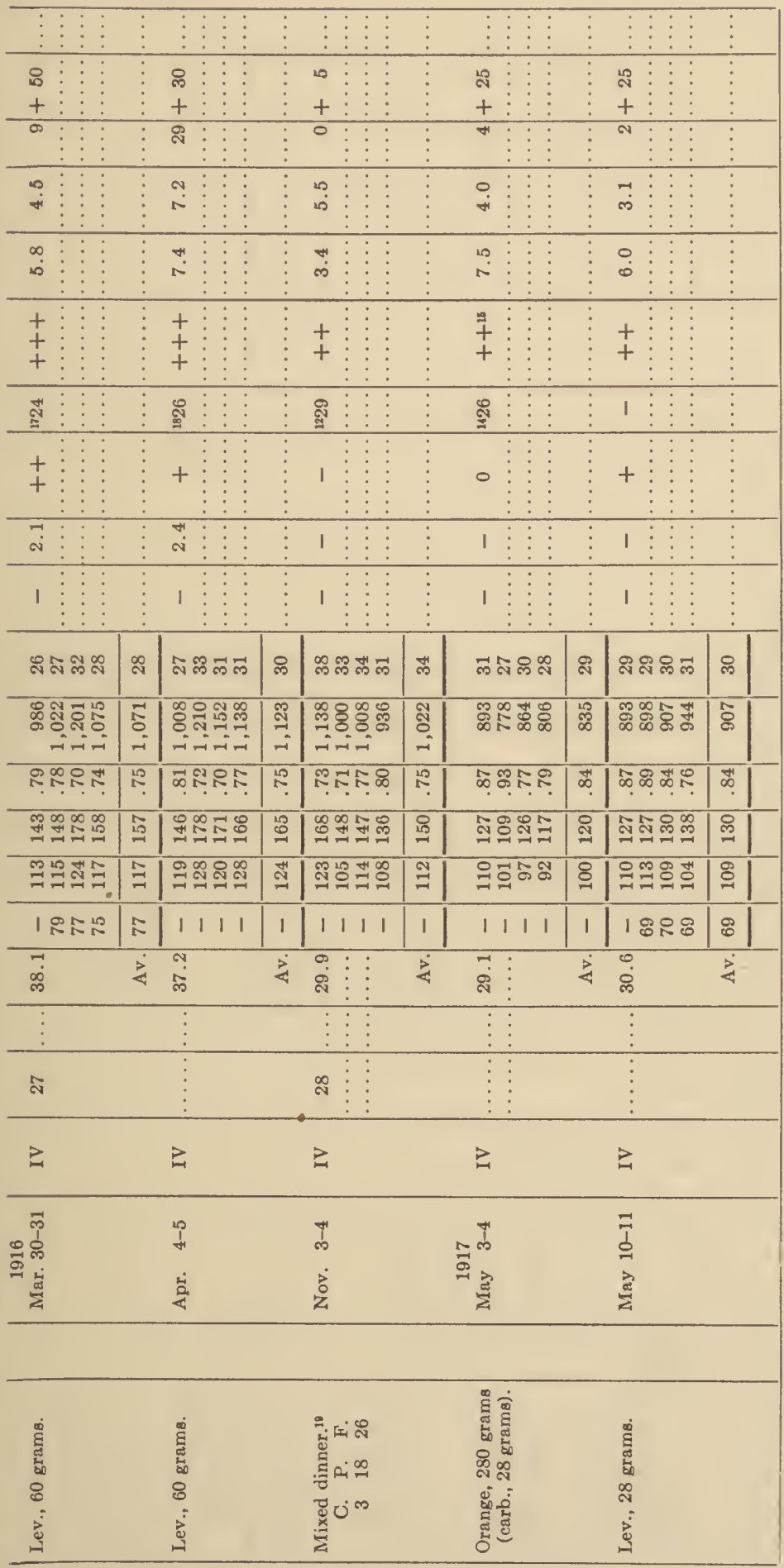

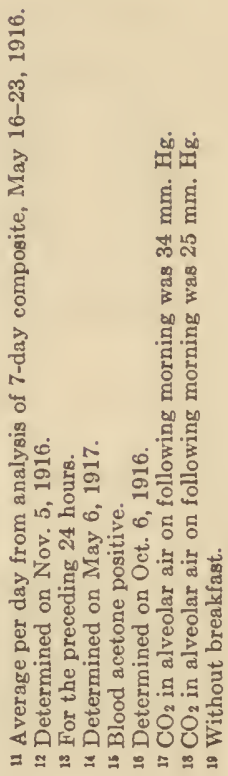

분

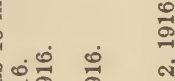

क्न क्न

ㅇำ

क्षंत्न के ले

芯芯莕

औั 5

홍ㅇㅇㅇ

\& हี ह

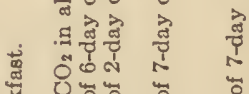

प्रु 0 पे पू

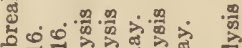

ธี

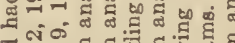
ॠ

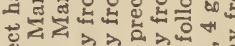

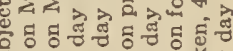

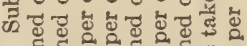

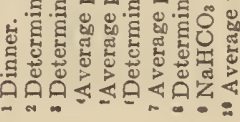




\begin{tabular}{|c|c|c|c|c|c|c|c|c|c|c|c|}
\hline \multicolumn{2}{|c|}{ 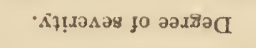 } & $\dot{\theta}$ & & & & & & & & & \\
\hline \multicolumn{2}{|c|}{ 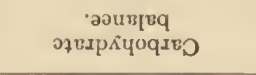 } & हूँ & & $\begin{array}{l}8 \\
+ \\
+\end{array}$ & & $\begin{array}{l}10 \\
+ \\
+\end{array}$ & & $\begin{array}{l}\text { मृ } \\
+ \\
+\end{array}$ & & $\begin{array}{l}\text { ล } \\
+\end{array}$ & \\
\hline \multicolumn{2}{|c|}{ 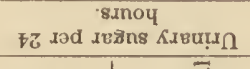 } & $\Sigma^{\circ}$ & & N & & 8 & & है & & $\ddot{\infty}$ & \\
\hline \multirow{2}{*}{ 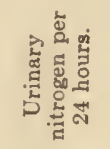 } & 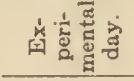 & हิें & & $\overrightarrow{0}$ & & $\dddot{0}$ & & \%. & & & \\
\hline & 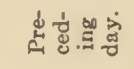 & हू 1 & & $\stackrel{\infty}{i \infty}$ & & $\stackrel{\circ}{i}$ & & $\begin{array}{l}\infty \\
\text { is }\end{array}$ & & $\stackrel{\infty}{=}$ & \\
\hline \multicolumn{2}{|c|}{ 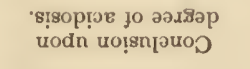 } & $\begin{array}{l}+ \\
+\end{array}$ & & + & & + & & + & & + & \\
\hline \multicolumn{2}{|c|}{ 'ג!̣ дв[оәА } & हूँ & & ॠ & & 1 & & 1 & & है & \\
\hline \multicolumn{2}{|c|}{ ·pเุษ อุววอษ! } & 0 & & 0 & & 0 & & 0 & & 0 & \\
\hline \multicolumn{2}{|c|}{ 'HN } & हूं। & & 1 & : & 1 & & 1 & & 1 & \\
\hline \multicolumn{2}{|c|}{ 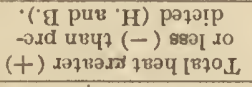 } & $\begin{array}{l}\dot{0} \\
\dot{2}\end{array}$ & & 1 & & 1 & & 1 & & 1 & \\
\hline \multirow{2}{*}{ 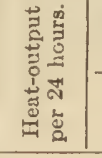 } & 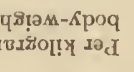 & 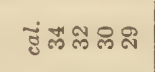 & $\bar{m}$ & ద్లె & $\stackrel{\infty}{\infty}$ & 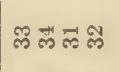 & 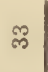 & 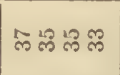 & 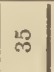 & F平然占 & 악 \\
\hline & क्ञ & 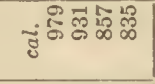 & 恋 & 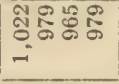 & 尺̊. & 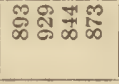 & $\infty$ & 总踏命 & 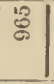 & 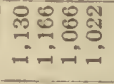 & \begin{tabular}{r|}
2 \\
0 \\
0 \\
-1
\end{tabular} \\
\hline \multicolumn{2}{|c|}{ 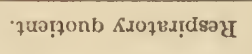 } & 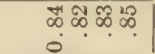 & $\infty$ & 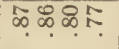 & $\infty$ & 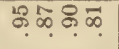 & $\begin{array}{l}\infty \\
\infty \\
\infty\end{array}$ & Øุ: & $\infty$ & $\infty$ & $\vec{\infty}$. \\
\hline \multicolumn{2}{|c|}{ 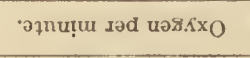 } & ن커표 & స్తి & 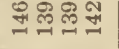 & $\exists$ & 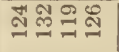 & $\stackrel{+1}{-1}$ & 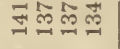 & 勻 & 䲩只㖞式 & \begin{tabular}{l}
$\infty$ \\
$:$ \\
\hdashline
\end{tabular} \\
\hline \multicolumn{2}{|c|}{ 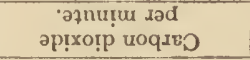 } & 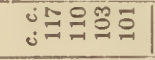 & $\stackrel{\infty}{\circ}$ & 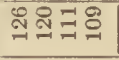 & $\approx$ & $\stackrel{\infty}{=} \stackrel{\infty}{=} \underset{0}{0} \stackrel{0}{0}$ & $\exists 1$ & 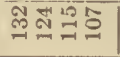 & $=1$ & 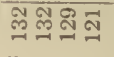 & $\underset{\sim}{\infty} \mid$ \\
\hline \multicolumn{2}{|c|}{ 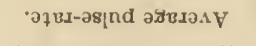 } & 我的 88 & 品 & 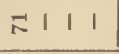 & 1 & $\begin{array}{llll}1 & 1 & 1 & 1\end{array}$ & 11 & $\begin{array}{llll}1 & 1 & 1 & 1\end{array}$ & 11 & 11111 & 1 \\
\hline \multicolumn{2}{|c|}{ рәчви 'РЧఖ!әм-Крод } & 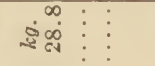 & $\frac{\overrightarrow{4}}{4}$ & ลั & $\dot{4}$ & 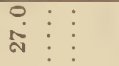 & $\dot{\overrightarrow{4}}$ & 离 & $\frac{1}{4}$ & $\stackrel{n}{\pi}$ & $\frac{3}{4}$ \\
\hline \multicolumn{2}{|c|}{ 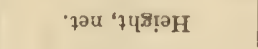 } & हูं & & & & & & & & $\vdots$ & \\
\hline \multicolumn{2}{|c|}{ 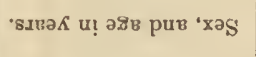 } & ลి & & & & & & & & $\mathscr{2}$ & \\
\hline \multicolumn{2}{|c|}{ 'snz̧rseddV } & $\geq$ & & $\geq$ & & $\dot{z}$ & & $\geq$ & & $\geq$ & \\
\hline \multirow{2}{*}{\multicolumn{2}{|c|}{ هัّ }} & $\stackrel{\frac{7}{I}}{\frac{1}{1}}$ & & $\begin{array}{l}\text { จ } \\
\text { ఏ }\end{array}$ & & 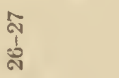 & & $\stackrel{p}{\sim}$ & & $\dot{b}$ & \\
\hline & & ن & & $\dot{\Xi}$ & & $\dot{8}$ & & : & & خे & \\
\hline \multicolumn{2}{|c|}{ 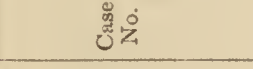 } & $\overline{\bar{\partial}}$ & & & & & & & & & \\
\hline \multicolumn{2}{|c|}{ 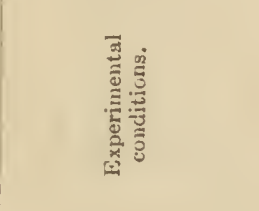 } & 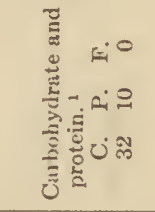 & & 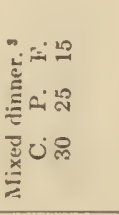 & & 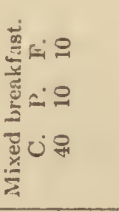 & & 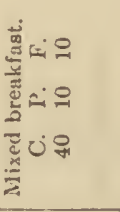 & & 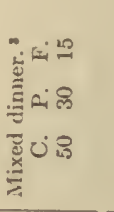 & \\
\hline
\end{tabular}




\begin{tabular}{|c|c|c|c|c|c|c|c|c|c|c|}
\hline תמג & . & คి & : & $\stackrel{9}{1}$ & : & $000 \mathrm{LO} 000 \mathrm{M}$ & $\infty$ & $\vdots$ & 우 & : \\
\hline+ & : & $+\vdots \vdots \vdots$ & : & $+\vdots \vdots \vdots$ & 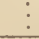 & + & 1 & $\vdots$ & 1 & : \\
\hline 点 & & 50 & $\cdot$ & 0 & ; & $000+0000$ & + & $\vdots$ & 0 & \\
\hline$\ddot{\circ}$ & $\vdots$ & $\underset{\infty}{-1} \vdots \vdots \vdots$ & $\vdots$ & $\begin{array}{l}\text { थs } \vdots \vdots \vdots \\
\text { - } \vdots \vdots\end{array}$ & $\vdots$ & a & œ & $\vdots$ & $\stackrel{\infty}{\sim} \vdots \vdots \vdots \vdots$ & $\vdots \vdots$ \\
\hline $\begin{array}{l}\infty \\
\infty\end{array}$ & $\vdots$ & ก $\vdots \vdots \vdots \vdots$ & $\vdots$ & $\stackrel{\infty}{\varrho}$ & $\vdots$ & 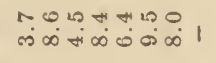 & ㄴ: & $\vdots$ & $\begin{array}{l}\infty \vdots \vdots \vdots \\
\infty \vdots \vdots \\
\infty\end{array}$ & $\vdots$ \\
\hline $\begin{array}{l}+\vdots \\
+\vdots\end{array}$ & $\vdots$ & + & : & + & $\vdots$ & $\begin{array}{l}++++ \\
++++t+00\end{array}$ & $\begin{array}{l}+\vdots \vdots \\
+\vdots\end{array}$ & $\vdots$ & $\begin{array}{l}+\vdots \vdots \vdots \\
+\vdots\end{array}$ & \\
\hline స్ & $\vdots$ & $\overrightarrow{5}$ & $\vdots$ & $\vdots \vdots$ & $\vdots$ & స్తి & ๙ิ઼ & $\vdots$ & 1 & $\vdots$ \\
\hline ○ & $\vdots$ & ○ & : & 0 & $\vdots$ & 00000000 & 0 & $\vdots$ & ○ & $\vdots$ \\
\hline$\dot{0} \vdots \vdots \vdots \vdots$ & $\vdots$ & ? & . & I $\vdots \vdots \vdots$ & $\vdots$ & $\begin{array}{llllllll}1 & 1 & 1 & 1 & 1 & 1 & 1 & 1\end{array}$ & 1 $\vdots$ & $\vdots$ & $1 \vdots$ & $\vdots$ \\
\hline 1 & : & I & $\vdots$ & 1 & $\vdots$ & 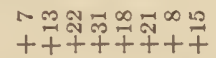 & 1 & $\vdots$ & 1 & : \\
\hline 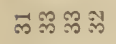 & है & 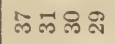 & జ్ & ిల్లెల్లి & ణ్ల & 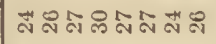 & 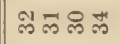 & ฆి & 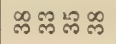 & ஜ \\
\hline 交 & $\stackrel{\infty}{\infty}$ & 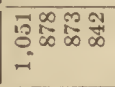 & 危 & 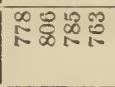 & $\stackrel{10}{\infty}$ & 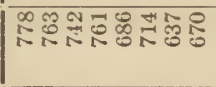 & 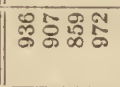 & के & 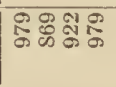 & ळొ \\
\hline कृळ\% & $\bar{\sigma}$ & बैळ $\infty \infty_{\infty}^{\infty}$ & 8 & कెळ & $\infty$ & 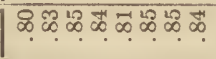 & 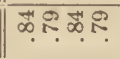 & $\infty$ & श용 & $\vec{\infty}$ \\
\hline 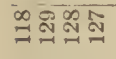 & जิ & 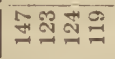 & $\stackrel{\infty}{\stackrel{\infty}{N}}$ & 드ㅇㅖㅛ & $\Xi$ & 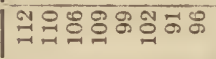 & 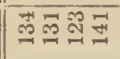 & ल् & 똟 & 里 \\
\hline N & $\Xi$ & 픔ㅇㅇㅇㅇㅇ & $\stackrel{2}{=}$ & हू요 & $\stackrel{\infty}{\infty}$ & 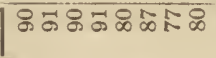 & 워유 & 5 & 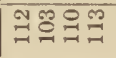 & 8 \\
\hline $\begin{array}{llll}1 & 1 & 1\end{array}$ & 1 & I I I 1 & 1 & 1111 & 1 & 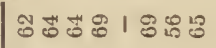 & | & 1 & ஜ5ㅇ & 吾 \\
\hline में & द & $\vec{\infty}$ & $\dot{4}$ & m & $\dot{3}$ & 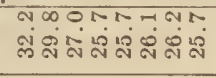 & के & 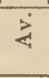 & : & 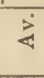 \\
\hline$\vdots$ & & & & & & $\vec{\exists} \vdots \vdots \vdots \vdots \vdots \vdots \vdots$ & & & $\vdots$ & \\
\hline$\vdots$ & & $\vdots$ & & & & 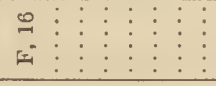 & & & & \\
\hline$\geq$ & & $\gtrsim$ & & $\geq$ & & 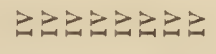 & $\gtreqless$ & & $z$ & \\
\hline $\begin{array}{l}\frac{9}{1} \\
20 \\
-1 \\
\vdots \\
z\end{array}$ & & 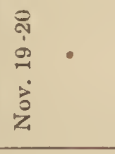 & & $\begin{array}{l}\infty \\
\text { 1 } \\
\frac{1}{N} \\
\vdots \\
\vdots \\
z\end{array}$ & & 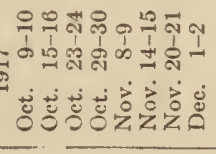 & $\begin{array}{l}\frac{0}{1} \\
\dot{0} \\
\dot{0} \\
0\end{array}$ & & 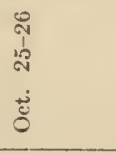 & \\
\hline & & & & & & $\stackrel{ }{0}$ & & & & \\
\hline 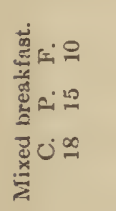 & & 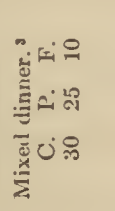 & & 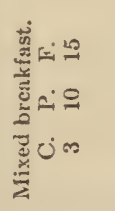 & & 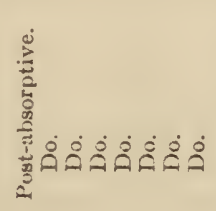 & 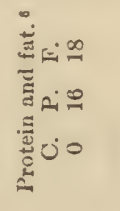 & & 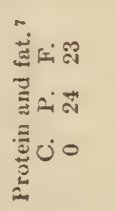 & \\
\hline
\end{tabular}


DIABETIC METABOLISM WITH HIGH AND LOW DIETS.

\begin{tabular}{|c|c|c|c|c|c|c|c|c|c|c|c|}
\hline \multicolumn{2}{|c|}{ 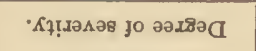 } & $\dot{\phi}$ & : & & & & & & & & \\
\hline \multicolumn{2}{|c|}{ 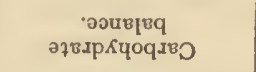 } & $\varepsilon^{\circ}$ & & 0 & & 0 & & + & & 0 & \\
\hline \multicolumn{2}{|c|}{ 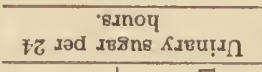 } & $\dot{5}^{\circ}$ & & 0 & & 0 & & 0 & & 0 & \\
\hline \multirow{2}{*}{ 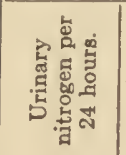 } & 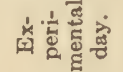 & $\Sigma_{0}^{\infty} \stackrel{\infty}{n}$ & & $\stackrel{\infty}{\infty}$ & & $\stackrel{\infty}{\infty}$ & & $\ddot{0}$ & & $\stackrel{0}{\infty}$ & \\
\hline & 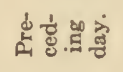 & $\dot{\varepsilon}$ & & 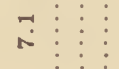 & & is & & $\stackrel{2}{\pi}$ & & & \\
\hline \multicolumn{2}{|c|}{ 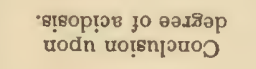 } & + & & + & & + & & 0 & & 0 & \\
\hline \multicolumn{2}{|c|}{ כזן } & हो & & I & & । & & 1 & & & \\
\hline \multicolumn{2}{|c|}{ 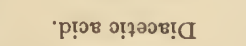 } & $\circ$ & & ○ & & o & & o & & o & \\
\hline \multicolumn{2}{|c|}{ 'HN } & हू & : & 1 & & 1 & & 1 & & 1 & \\
\hline \multicolumn{2}{|c|}{ 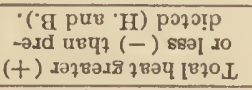 } & $\begin{array}{ll}\dot{0} \\
\dot{2}\end{array}$ & & 1 & & 1 & & 1 & & 1 & \\
\hline \multirow{2}{*}{ 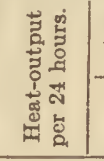 } & 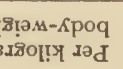 & తేં & 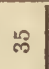 & లెల్లి దొ & 点 & 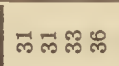 & $\infty$ & 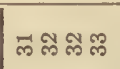 & 凩 & ๓ొణ ణ & 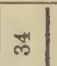 \\
\hline & 离 & 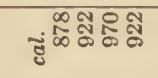 & สู | & 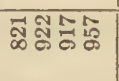 & \&े & 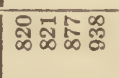 & 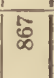 & W & 起 & $\begin{array}{llll}20 & 10 & 5 & 0 \\
\infty & \infty & \infty & \infty\end{array}$ & 象 \\
\hline \multicolumn{2}{|c|}{ 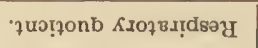 } & 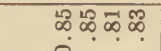 & $\$$ & दृश्. & क्ञ & ๑ొळळ & $\bar{a}$ & श๐ळ & क़ & œ & $\vec{\infty}$. \\
\hline \multicolumn{2}{|c|}{ 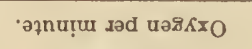 } & 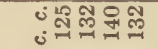 & ్ָతొ & 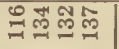 & \% & 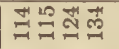 & ฐ & ్్స్తస్తి & 胥 & 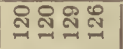 & 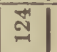 \\
\hline \multicolumn{2}{|c|}{ 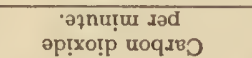 } & 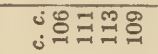 & 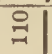 & 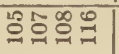 & $\stackrel{9}{g}$ & 윽윰웣 & 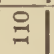 & "ాळ్ల & $\overrightarrow{0}$ & 웅ㅎㅁㅎㅁㅇㅇㅣ & $\stackrel{-1}{8}$ \\
\hline \multicolumn{2}{|c|}{ 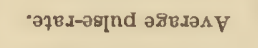 } & 1118 & 1 & ํㅛ8: & $\infty$ & ล & $\otimes 1$ & ำ & $: 8$ & タำล & 요 \\
\hline \multicolumn{2}{|c|}{ 'рәдви 'ячя!а.м-Кроя } & si் & $\dot{\vec{q}}$ & $\stackrel{n}{\mathscr{N}}$ & $\dot{8}$ & ֻั & $\stackrel{3}{4}$ & 离 & $\dot{z}$ & ลั่ & $\dot{s}$ \\
\hline \multicolumn{2}{|c|}{ 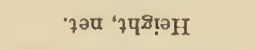 } & हू & & . & & & & & & & \\
\hline \multicolumn{2}{|c|}{ 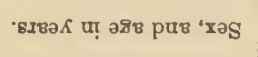 } & $\cong$ & & & & & & & & & \\
\hline \multicolumn{2}{|c|}{ 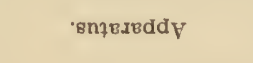 } & $z$ & & $z$ & & $z$ & & $z$ & & $z$ & \\
\hline \multicolumn{2}{|c|}{ تِّ } & $\stackrel{\frac{N}{\sigma}}{\stackrel{1}{a}}$ & & $\begin{array}{l}0 \\
\frac{1}{6} \\
\dot{0} \\
z \\
z\end{array}$ & & & & 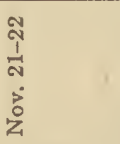 & & 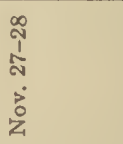 & \\
\hline \multicolumn{2}{|c|}{ 迆完 } & 옹 & & & & & & & & & \\
\hline \multicolumn{2}{|c|}{ 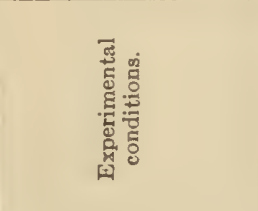 } & 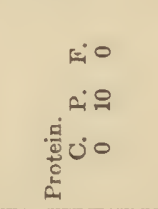 & & 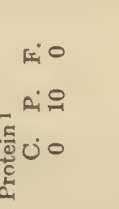 & & 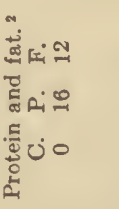 & & 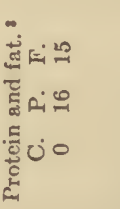 & & 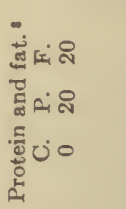 & \\
\hline
\end{tabular}




\begin{tabular}{|c|c|c|c|c|c|c|c|c|c|c|c|}
\hline$\infty \vdots \vdots \vdots$ & $\vdots \vdots$ & & $\vdots: \vdots:$ & : & 运: $\vdots \vdots$ & $\overbrace{1}^{\circ}$ & i் & 욜 & $\infty$ & $\vdots$ & $\vdots$ \\
\hline 이융 & ిల్ & : & 으: & : & 잉요 & 을 & 0 & 0 & ๒ం유아요 & జิ & $\vdots$ \\
\hline $1+$ & $+\vdots \vdots \vdots$ & $\vdots$ & $+\vdots \vdots \vdots$ & $\vdots$ & $++\overrightarrow{+}$ & + & & & $1+t+$ & + & $\vdots$ \\
\hline$\infty_{[-1}$ & $\circ \vdots \vdots \vdots$ & $\vdots$ & ० $\vdots \vdots \vdots \vdots$ & $\vdots$ & 0000 & 0 & 0 & 0 & 10000 H & F $\vdots \vdots \vdots$ & $\vdots$ \\
\hline "น & 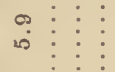 & $\vdots$ & $\vec{\infty} \vdots \vdots:$ & $\vdots$ & 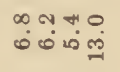 & 1 & 1 & $\stackrel{4}{4}$ & 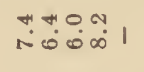 & 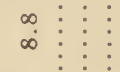 & : \\
\hline சं & 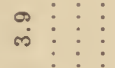 & $\vdots$ & $\stackrel{0}{\sim} \vdots:$ & $\vdots$ & ONO & 1 & 1 & in & 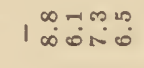 & 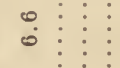 & : \\
\hline $\begin{array}{l}++ \\
++\end{array}$ & $+\vdots$ & : & 0 & $\vdots$ & $++\infty 0$ & o & 0 & + & & $\begin{array}{l}+ \\
+\end{array}$ & : \\
\hline నిని న్లి 1 & ల్ల : & $\vdots$ & $1 \vdots$ & $\vdots$ & న్లి હే స゙ ન゙ & 1 & 1 & $\widehat{\infty}$ & 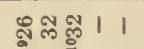 & స్ల & $\vdots$ \\
\hline $\begin{array}{l}++00 \\
+ \\
+\end{array}$ & o $\vdots \vdots \vdots \vdots$ & $\vdots$ & o : & $\vdots$ & tooo & 0 & 0 & + & tooo 1 & ० $\vdots \vdots \vdots \vdots$ & $\vdots$ \\
\hline ñil & $\begin{array}{l}2 \\
-\vdots\end{array} \vdots \vdots$ & $\vdots$ & $1 \vdots \vdots \vdots$ & $\vdots$ & मे 111 & 1 & 1 & $\stackrel{0}{-}$ & 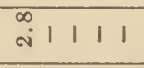 & क $\vdots \vdots \vdots \vdots$ & $\vdots$ \\
\hline 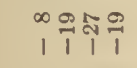 & 1 & $\vdots$ & $1 \vdots$ & $\vdots$ & $\infty=\frac{0}{1}$ & $\stackrel{2}{1}$ & $\frac{9}{1}$ & $\begin{array}{l}\infty \\
+\end{array}$ & 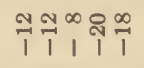 & $\vdots \vdots \vdots$ & $\vdots$ \\
\hline ลี๋ีลี & $\begin{array}{llll}1 & 1 & 1 & 1\end{array}$ & $\vec{N}$ & 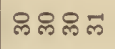 & 尺̊ & 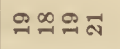 & ঙัง & జิ & ลี & 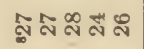 & 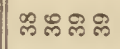 & $\infty$ \\
\hline $\begin{array}{l}\infty \\
= \\
=\end{array}$ & $\underbrace{\begin{array}{llll}1 & 1 & 1 & 1\end{array}}$ & $\stackrel{5}{\tilde{0}}$ & 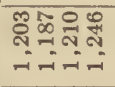 & ঐू & 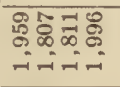 & न & $\stackrel{\mathfrak{7}}{-}$ & สั & 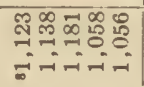 & 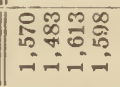 & 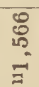 \\
\hline №R & & $\stackrel{\infty}{?}$ & 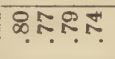 & $\approx$ & ำ & F & $\infty$ & $\stackrel{19}{?}$ & Nㅜㅇㅠ. & П๙ & N. \\
\hline 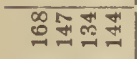 & 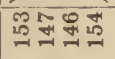 & $\stackrel{9}{9}$ & 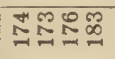 & $\stackrel{0}{=1}$ & 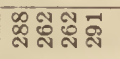 & ฮै & ช్త & $\infty$ & 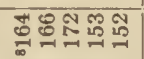 & 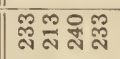 & ๙్లి \\
\hline సิ도워을 & 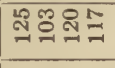 & $\cong$ & 음윰에 & 曽 & สํำ సิ & $\stackrel{\infty}{\mathbb{\#}}$ & $\vec{m}$ & ஸ్ & 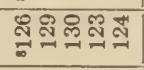 & 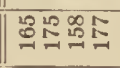 & 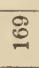 \\
\hline 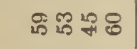 & 约年舟亦 & 7 & ஐ̊ஜே் & छ & 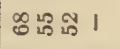 & 冓 & in & 1 & जै: 1 is 1 & $8: 068$ & 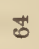 \\
\hline 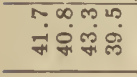 & m & 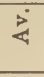 & क्ष & $\frac{3}{4}$ & $\begin{array}{l}\infty 010 \\
880 \\
0\end{array}$ & की & in & 迥 & 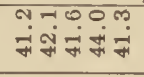 & $\frac{7}{4}$ & $\frac{3}{4}$ \\
\hline ฌั & $\vdots$ & & & & $\stackrel{\infty}{\bullet} \vdots \vdots \vdots$ & $\stackrel{\infty}{-1}$ & $\stackrel{N}{N}$ & $\stackrel{0}{8}$ & 今心 $\vdots \vdots \vdots \vdots$ & $\vdots$ & \\
\hline สิ $\vdots \vdots \vdots$ & $\vdots \vdots \vdots \vdots$ & & 80 & & ๙ $\vdots \vdots \vdots$ & ̊ి & ผิ & 8 & 怘 $\vdots \vdots \vdots \vdots$ & $\vdots$ & \\
\hline E $\vdots \vdots \vdots$ & $\vdots \vdots \vdots \vdots$ & & $\vdots \vdots \vdots$ & & $\Sigma \vdots \vdots \vdots$ & $\Sigma$ & 5 & si & 空 $\vdots \vdots \vdots:$ & $\vdots \vdots \vdots$ & \\
\hline 爫怘引 & $\geq$ & & 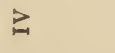 & & 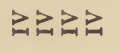 & $\geq$ & $\geqq$ & $\geqq$ & $\gtrsim \gtrsim \gtrsim \gtrsim \gtrsim$ & $\geq$ & \\
\hline 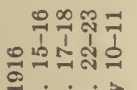 & 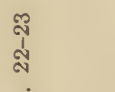 & & $\frac{0}{1}$ & & 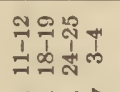 & \pm & సิ & 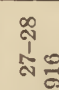 & 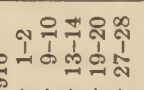 & $\tilde{\infty}$ & \\
\hline 会完客惫 & 苴 & & $\sum_{\bar{\Sigma}}^{\overrightarrow{\mathrm{m}}}$ & & 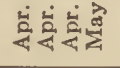 & $\stackrel{\text { L̊ }}{4}$ & 荌 & 客 & 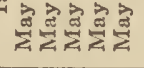 & है & \\
\hline$\stackrel{\text { ผ }}{0}$ & & & & & 을 & $\underset{\mathbb{C}}{\infty}$ & ळ్త్ర & ఫี & 월 & & \\
\hline 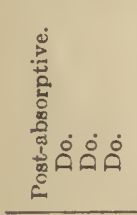 & 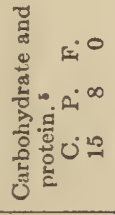 & & 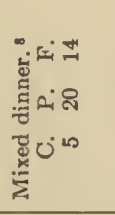 & & 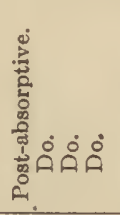 & 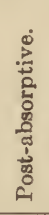 & 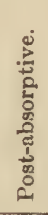 & 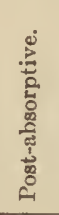 & 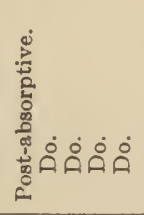 & 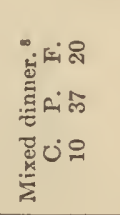 & \\
\hline
\end{tabular}




\begin{tabular}{|c|c|c|c|c|c|c|c|c|c|c|c|}
\hline \multicolumn{2}{|c|}{ 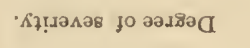 } & $\dot{\omega i}$ & & & & 竞 & & & 竎 & & \\
\hline \multicolumn{2}{|c|}{ 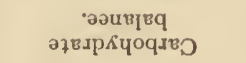 } & ำ & & $\stackrel{8}{+}$ & & 윰우 & $\stackrel{8}{+}$ & & $\begin{array}{l}100 \\
+10\end{array}$ & $\stackrel{80}{+}$ & \\
\hline \multicolumn{2}{|c|}{ 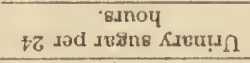 } & $\xi^{\circ}$ & & 出 & & 00 & 0 & & mo & $\infty$ & \\
\hline \multirow{2}{*}{ 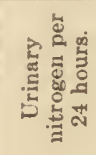 } & 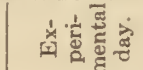 & ริ่ & & 1 & & $\begin{array}{l}700 \\
.00\end{array}$ & $\stackrel{9}{+2}$ & & $\stackrel{\infty}{+\infty}$ & $\stackrel{\infty}{+}$ & \\
\hline & 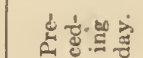 & है & & $\stackrel{4}{0}$ & & $\ddot{\sim}$ & $\ddot{\sim}$ & & $\begin{array}{ll}0.0 \\
+0\end{array}$ & $\because$ & \\
\hline \multicolumn{2}{|c|}{ 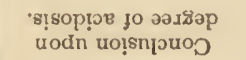 } & 0 & & c & & 00 & ○ & & ++ & + & \\
\hline \multicolumn{2}{|c|}{ ' } & हैं & & 1 & & 11 & 1 & & స్ల్ జ్ల & $\Phi$ & \\
\hline \multicolumn{2}{|c|}{ 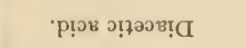 } & 0 & 8 & 1 & & 00 & ○ & & +0 & + & \\
\hline \multicolumn{2}{|c|}{${ }^{8} \mathrm{HN}$} & हैं। & & 1 & & 11 & 1 & & $\stackrel{\infty}{\sim} 1$ & $\stackrel{\infty}{\sim}$ & \\
\hline \multicolumn{2}{|c|}{ 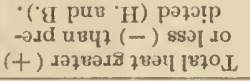 } & $\begin{array}{ll}\dot{8} \\
\dot{2}\end{array}$ & & 1 & & $\begin{array}{c}\text { om } \\
1\end{array}$ & 1 & & $\underset{1}{7} \frac{0}{1}$ & 1 & \\
\hline \multirow{2}{*}{ 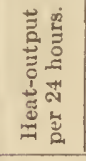 } & 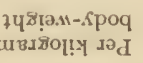 & 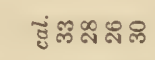 & \&ิ & స్లెల్లు స్లి & $\vec{m}$ & $\stackrel{\sim}{\infty} \underset{\infty}{\infty}$ & 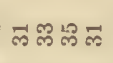 & $\mathscr{\varpi}$ & 오 & ส 1 สึ & ลี \\
\hline & 홍 & 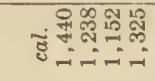 & 蓠 & 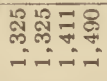 & 趈 & 슝을 & 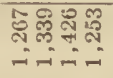 & 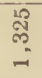 & 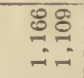 & 点 & 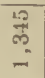 \\
\hline \multicolumn{2}{|c|}{ 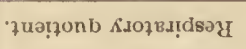 } & कू⿻ & $\$$ & 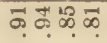 & $\infty$ & RR & ホNト\& & $?$ & 요 & 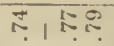 & 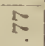 \\
\hline \multicolumn{2}{|c|}{ 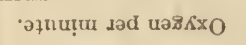 } & ن & $\stackrel{\infty}{\infty}$ & 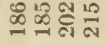 & 馬 & 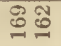 & 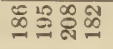 & $\cong$ & $\sqrt{50}$ & 莺 198 & $\stackrel{\Xi}{=}$ \\
\hline \multicolumn{2}{|c|}{ 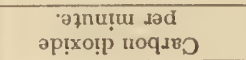 } & ن듀 & $\underset{-}{9}$ & 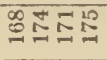 & $\frac{N}{2}$ & 赵奈 & 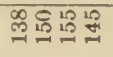 & \pm & कृ: & 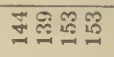 & \pm \\
\hline \multicolumn{2}{|c|}{ 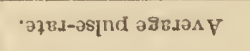 } & 11111 & 1 & 11111 & 1 & เด & ํㅗำ & 8 & 11 & 111111 & 1 \\
\hline \multicolumn{2}{|c|}{ 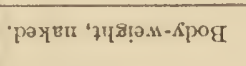 } & 운 & $\frac{8}{4}$ & $\stackrel{m}{=}$ & $\frac{\dot{b}}{4}$ & 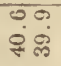 & $\begin{array}{l}0 \\
\dot{q}\end{array}$ & 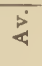 & - & $\overrightarrow{0}$ & $\frac{5}{4}$ \\
\hline \multicolumn{2}{|c|}{ 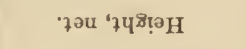 } & हूํํ. & & . & & \%) & & & : & & \\
\hline \multicolumn{2}{|c|}{ 'sมะว } & $\stackrel{+}{\infty}$ & & & & 7 & & & क्ల & & \\
\hline \multicolumn{2}{|c|}{ 'snวุвsвddy } & $z$ & & $\geq$ & & $\gtrsim \geq$ & $\geq$ & & 引 & $z$ & \\
\hline \multicolumn{2}{|r|}{ 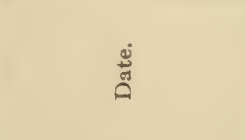 } & 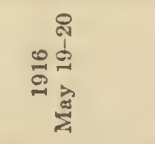 & & 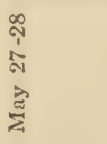 & & 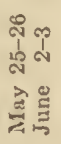 & $\begin{array}{l}\text { के } \\
\text { जे } \\
\text { के } \\
\text { है }\end{array}$ & & 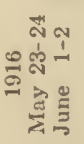 & 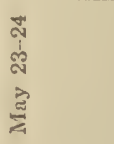 & \\
\hline \multicolumn{2}{|c|}{ 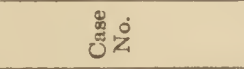 } & 㩆递 & & & & $\bar{\square}$ & & & $\stackrel{\infty}{\stackrel{\circ}{\leftrightarrow}}$ & & \\
\hline \multicolumn{2}{|c|}{ 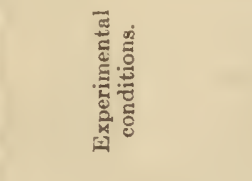 } & 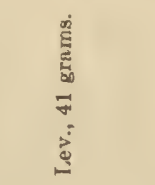 & & 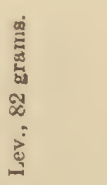 & & 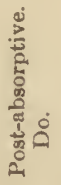 & 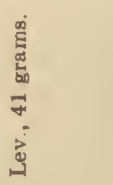 & & 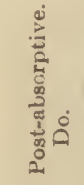 & 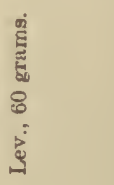 & \\
\hline
\end{tabular}




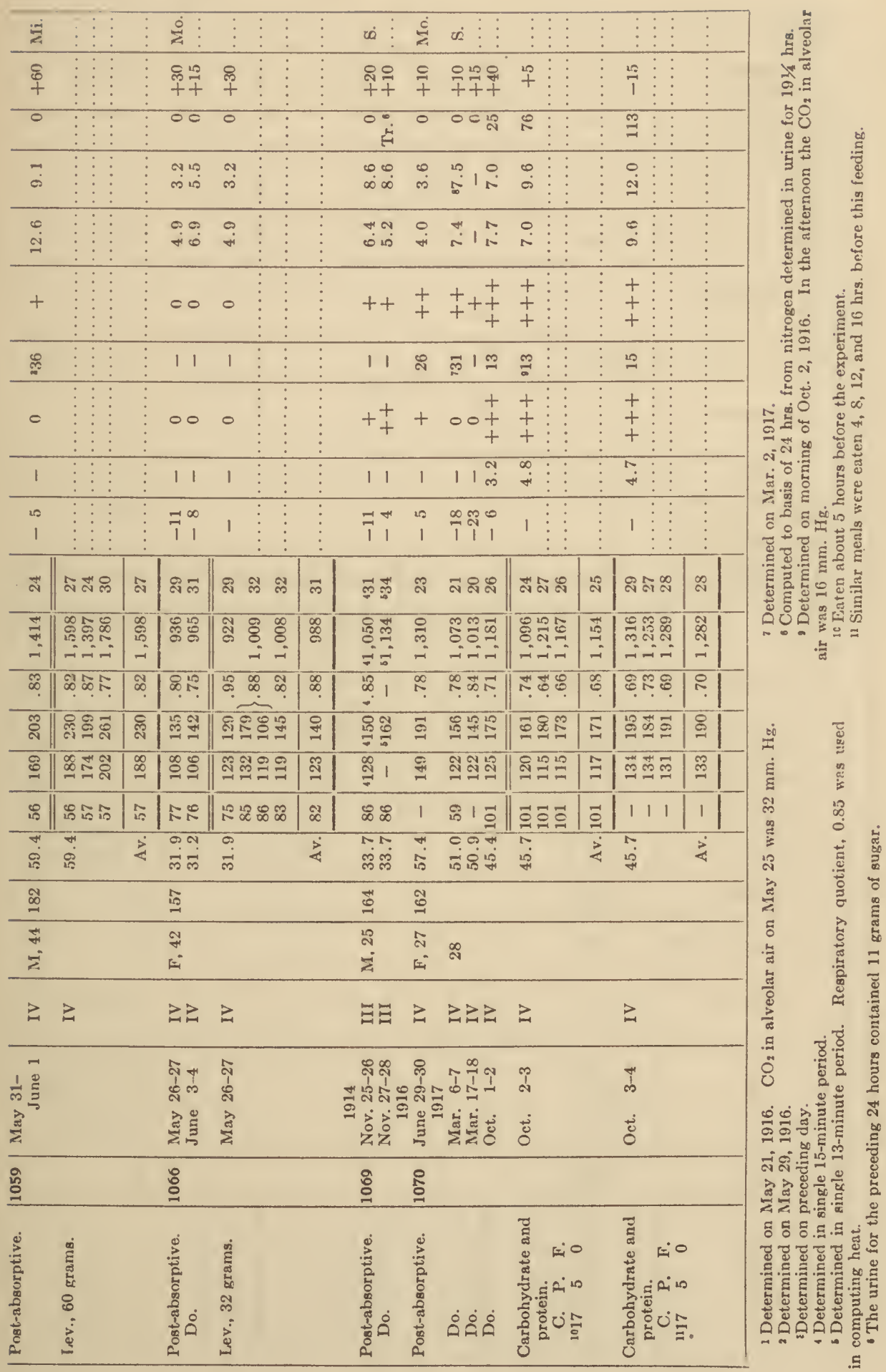




\begin{tabular}{|c|c|c|c|c|c|c|c|c|c|c|}
\hline \multicolumn{2}{|c|}{ 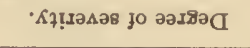 } & कs & & & & & & & & क \\
\hline \multicolumn{2}{|c|}{ 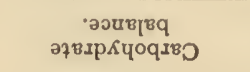 } & हैं & & $\frac{9}{4}$ & & ศิ & & i & & 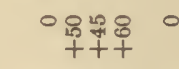 \\
\hline \multicolumn{2}{|c|}{ 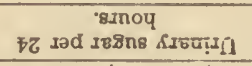 } & हूँ & & 8 & & $\infty$ & & $\infty$ & & ONक्य \\
\hline \multirow{2}{*}{ 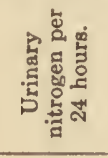 } & 我宫䓌密 & हิํำ & & $\stackrel{\circ}{\circ}$ & & $\stackrel{\leftrightarrow}{9}$ & & $\overline{\text { s. }}$ & & 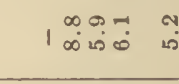 \\
\hline & 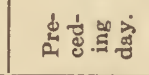 & కิં & & $\stackrel{\circ}{=}$ & & $\ddot{s}$ & & $\stackrel{2}{9}$ & & $\begin{array}{ll}0 & 0 \\
1 & 0\end{array}$ \\
\hline \multicolumn{2}{|c|}{ 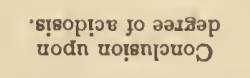 } & & & $\begin{array}{l}+ \\
+ \\
+\end{array}$ & $\therefore$ & $\begin{array}{l}+ \\
+ \\
+\end{array}$ & & $\begin{array}{l}+ \\
+ \\
+\end{array}$ & & $000_{+}^{+}+$ \\
\hline \multicolumn{2}{|c|}{ 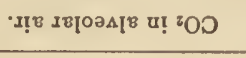 } & 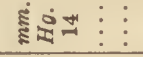 & & \pm & & I & & \pm & & 111 है \\
\hline \multicolumn{2}{|c|}{ 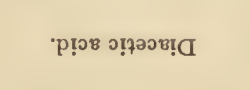 } & + & & $\begin{array}{l}+ \\
+ \\
+\end{array}$ & & $\begin{array}{l}+ \\
+ \\
+\end{array}$ & & $\begin{array}{l}+ \\
+\end{array}$ & & $000 i 0$ \\
\hline \multicolumn{2}{|c|}{${ }^{\imath} \mathrm{HN}$} & 5 & & $\hat{n}$ & & is & & in & & $111=1$ \\
\hline \multicolumn{2}{|c|}{ 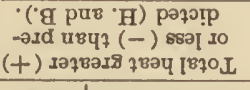 } & $\begin{array}{l}\dot{8} \\
\dot{2}\end{array}$ & & 1 & & 1 & & 1 & & 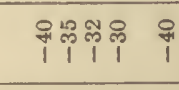 \\
\hline \multirow{2}{*}{ 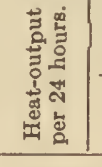 } & 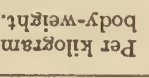 & కี่ ผึะั & สึ & ה゙ & ה & จำลล ลิ & $\widehat{ล}$ & ลลลล & เึ & 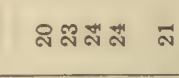 \\
\hline & 형 & 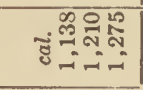 & ๙ิ & 泀 & $\ddot{0}$ & | & ¿্ণ & \begin{tabular}{l}
$\infty$ \\
\multirow{2}{*}{$\approx$} \\
$-=-1$
\end{tabular} & $\stackrel{5}{=}$ & 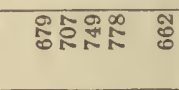 \\
\hline \multicolumn{2}{|c|}{ 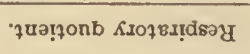 } & की: & $\stackrel{5}{\circ}$ & 羿 & $\because$ & 프토? & F & กฺก & 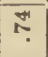 & దळळ\% \\
\hline \multicolumn{2}{|c|}{ 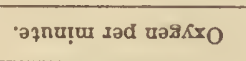 } & ن & 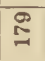 & : & ஜ & 유 & 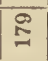 & 됴욤ㅇ & $\frac{1}{12}$ & 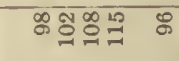 \\
\hline \multicolumn{2}{|c|}{ 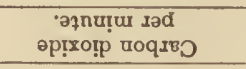 } & ن워유 & $\bar{\Xi}$ & $\cong \approx$ & $\cong$ & 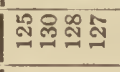 & ज & 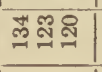 & 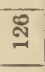 & ळ \\
\hline \multicolumn{2}{|c|}{ 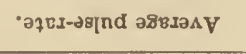 } & $18 \%$ & क & 150 & $\infty$ & 8111 & 1 & $\begin{array}{llll} & 1 & 1\end{array}$ & 1 & 1 ๓ \\
\hline \multicolumn{2}{|c|}{ 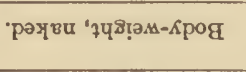 } & 25 & $\frac{3}{4}$ & मे & $\dot{8}$ & i & $\dot{4}$ & 뭄 & 安 & 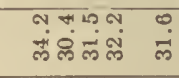 \\
\hline \multicolumn{2}{|c|}{ 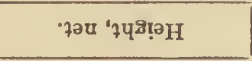 } & हुㅇ 으 & & & & & & & & 9 \\
\hline \multicolumn{2}{|c|}{ 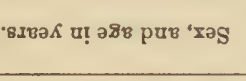 } & $\stackrel{\infty}{\sim}$ & & & & & & & & 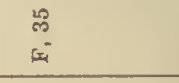 \\
\hline \multicolumn{2}{|c|}{ 'snุษรвdd } & $\geq$ & & $\geq$ & & $\geq$ & & $\geq$ & & $\geq \geq \geq \geq$ \\
\hline \multirow{2}{*}{\multicolumn{2}{|c|}{ 离 }} & $^{2}$ & & i & & $\$$ & & $\frac{0}{1}$ & \multirow{2}{*}{\multicolumn{2}{|c|}{ 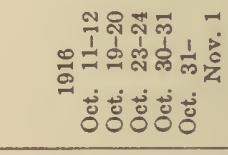 }} \\
\hline & & 远 & & $\dot{\Xi}$ & & $\dot{\delta}$ & & $\dot{8}$ & & \\
\hline \multicolumn{2}{|c|}{ 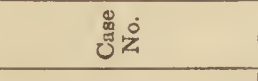 } & 윰 & & & & & & & & $\stackrel{\infty}{\stackrel{\infty}{=}}$ \\
\hline \multicolumn{2}{|c|}{ 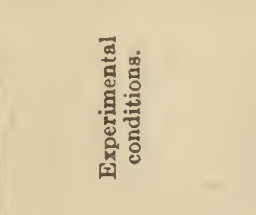 } & 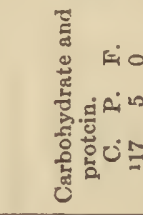 & & 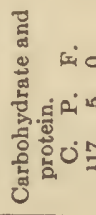 & & 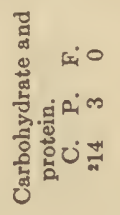 & & 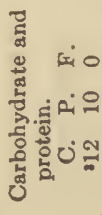 & & 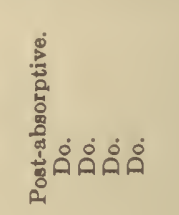 \\
\hline
\end{tabular}




\begin{tabular}{|c|c|c|c|c|c|}
\hline & & & 安 & : & 这 \\
\hline 章 & 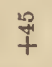 & $\stackrel{\square}{+}$ & 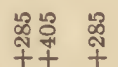 & 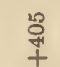 & 唱 \\
\hline $\bar{N}$ & is & $\stackrel{20}{=}$ & कल 0 & $m$ & बे $_{\text {स }}^{\circ}{ }^{\circ}$ \\
\hline $\begin{array}{c}\infty \\
\infty \\
\infty\end{array}$ & is & $\overrightarrow{0}$ & $\stackrel{\infty}{\infty} 1$ & 1 & 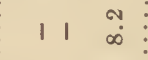 \\
\hline هـ & $\stackrel{0}{ \pm}$ & 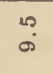 & 111 & 1 & $1_{\infty}^{\infty} \quad 1 \vdots \vdots$ \\
\hline & 。 & + & 000 & $\circ$ & ot $+\vdots$ \\
\hline 1 & 1 & $\ddot{\mathrm{s}}$ & 111 & 1 & $111 \vdots$ \\
\hline & - & 1 & 000 & 。 & $0_{+}^{+}+\vdots$ \\
\hline
\end{tabular}

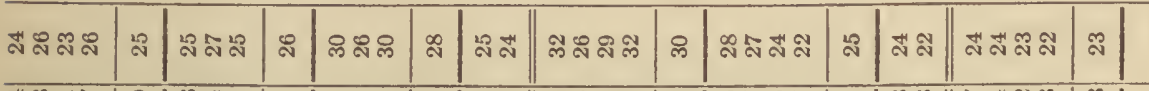

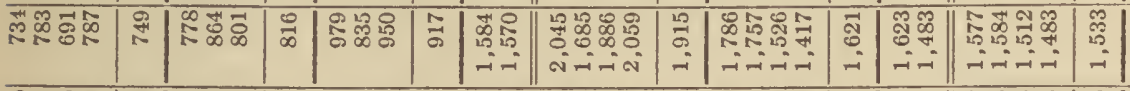

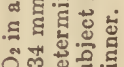

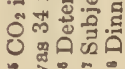
ळ

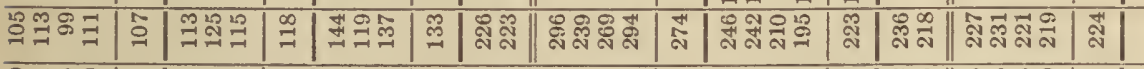
இढ் ద

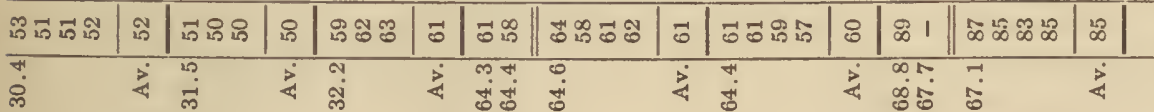

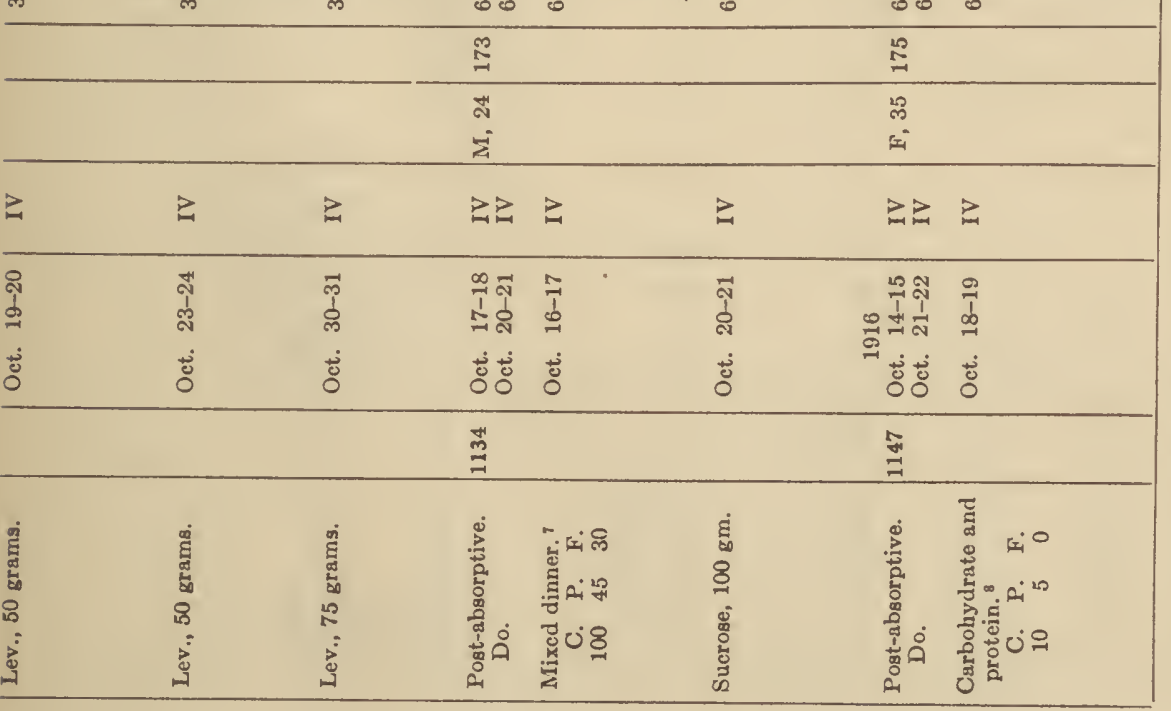


DIABETIC METABOLISM WITH HIGH AND LOW DIETS.

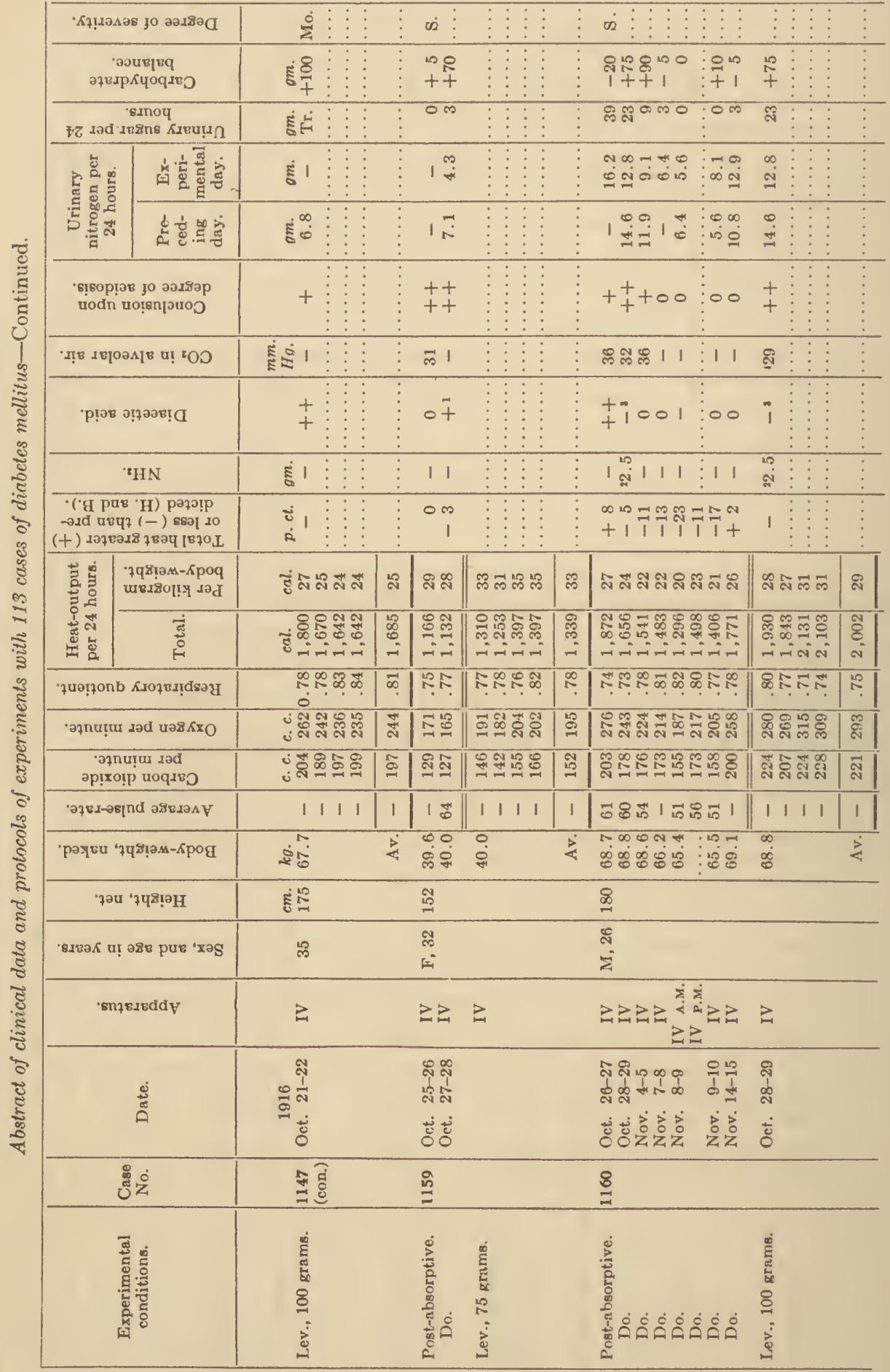




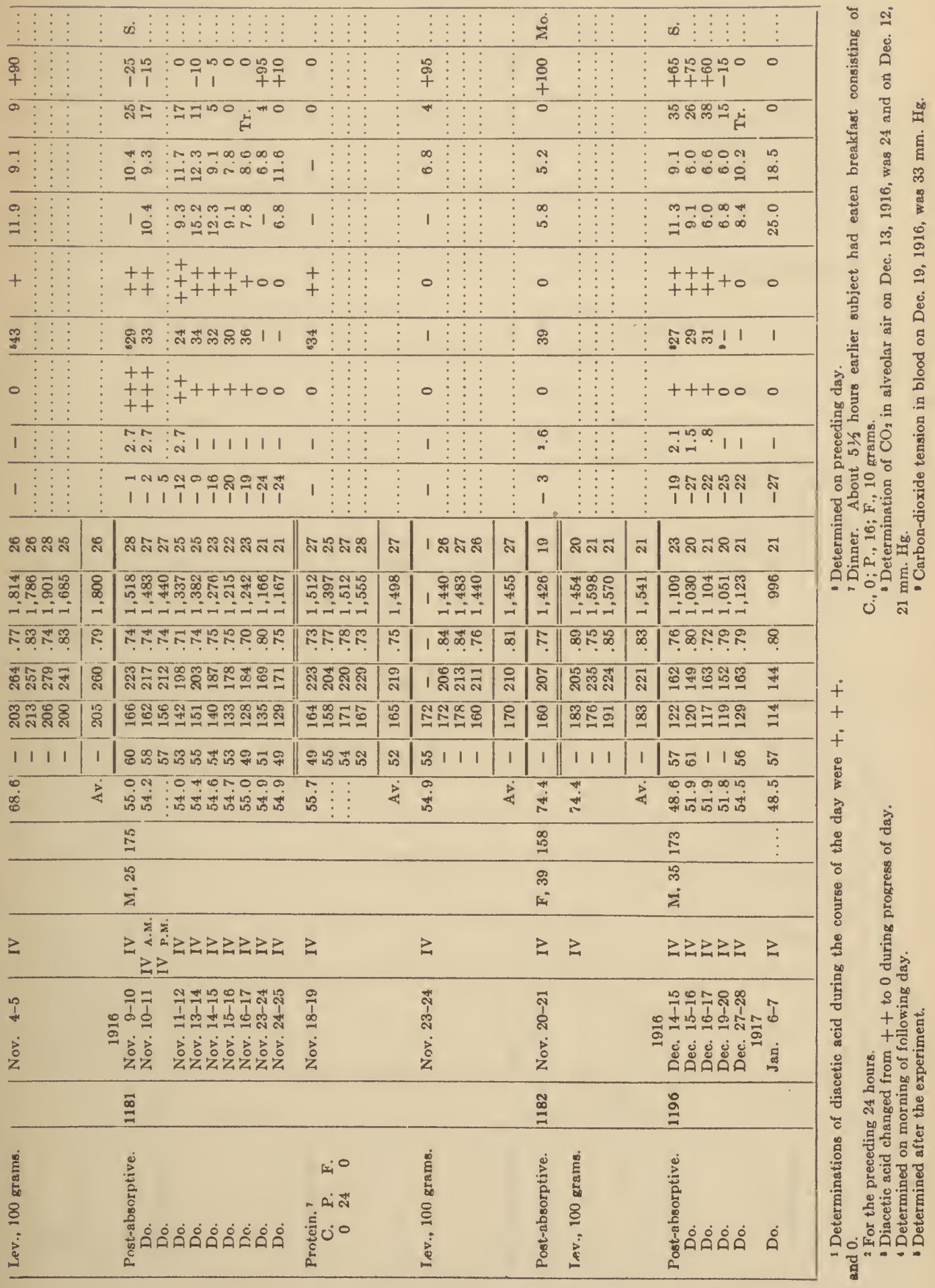




\begin{tabular}{|c|c|c|c|c|c|c|c|c|c|}
\hline \multicolumn{2}{|c|}{ 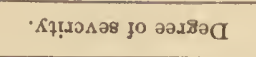 } & $\dot{\alpha}$ & & & & & & $\stackrel{3}{z}$ & $\dot{m}$ \\
\hline \multicolumn{2}{|c|}{ 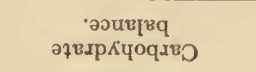 } & हैं & & $\stackrel{2}{+}$ & & $\stackrel{8}{+}$ & & 辛沽 & 章: \\
\hline \multicolumn{2}{|c|}{ 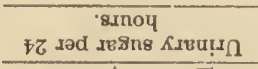 } & हूँ & & $\mathscr{2}$ & & $\stackrel{\infty}{\infty}$ & & 000 & $\omega=\pi$ \\
\hline \multirow{2}{*}{ 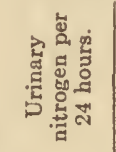 } & 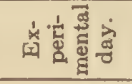 & हैं. & & $\because$ & & $\ddot{0}$ & & 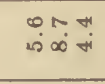 & 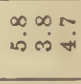 \\
\hline & 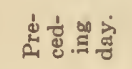 & $\Sigma^{\infty}=$ & & $\overrightarrow{0}$ & & $\dot{0}$ & & $1 \stackrel{0 \text { in }}{4}$ & $\stackrel{0}{\circ \infty} 00$ \\
\hline \multicolumn{2}{|c|}{ 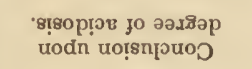 } & $\begin{array}{l}+ \\
+\end{array}$ & & + & & + & & $\begin{array}{l}+++ \\
+++\end{array}$ & 000 \\
\hline \multicolumn{2}{|c|}{ ' } & हี่: & & $\bar{m}$ & & ఇָ & & 1 ભ్లి శ్ & 111 \\
\hline \multicolumn{2}{|c|}{ 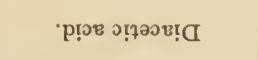 } & + & & + & & + & & +++ & 000 \\
\hline \multicolumn{2}{|c|}{ 'HN } & हुं & & $\stackrel{-10}{2}$ & & $\infty$ & & 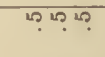 & 111 \\
\hline \multicolumn{2}{|c|}{ 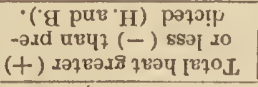 } & $\begin{array}{l}\dot{0} \\
\dot{2}\end{array}$ & : & 1 & & 1 & & ำ & $\begin{array}{r}8000 \\
+ \pm\end{array}$ \\
\hline \multirow{2}{*}{ 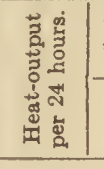 } & 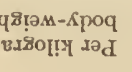 & 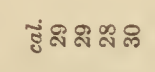 & ลิ & 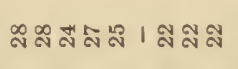 & มี & ลัละกลั สึ & สิ & $\stackrel{2}{\sim}:$ & สส สิ \\
\hline & 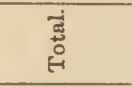 & 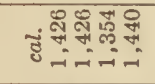 & $\bar{F}$ & 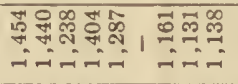 & $\mid$ & 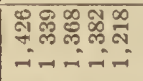 & लें & 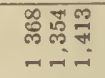 & 잉주용 \\
\hline \multicolumn{2}{|c|}{ 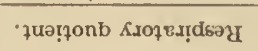 } & 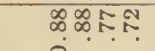 & $\bar{\infty}$ & పำ & $\stackrel{\infty}{?}$ & 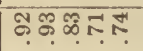 & $\infty$ & 유 & $\infty \not \infty$. \\
\hline \multicolumn{2}{|c|}{ 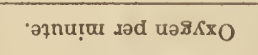 } & ن్ㅠ్ㅀㅇㅠ & : & 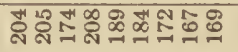 & $\underset{\infty}{\infty}$ & 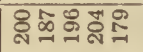 & $\stackrel{\mathscr{m}}{=}$ & 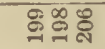 & 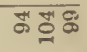 \\
\hline \multicolumn{2}{|c|}{ 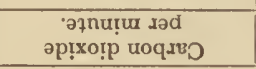 } & نक⿻心口𧘇 & 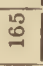 & 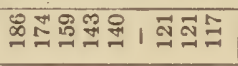 & $\exists$ & 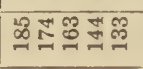 & 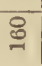 & 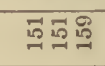 & $\varnothing \infty$ \\
\hline \multicolumn{2}{|c|}{ 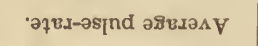 } & 8111 & 1 & 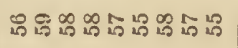 & is & 111111 & 1 & ఫึ่ \& & 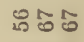 \\
\hline \multicolumn{2}{|c|}{ 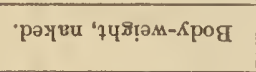 } & $\stackrel{\dot{0}}{\dot{s} \infty}$ & $\stackrel{\dot{4}}{4}$ & का & $\frac{8}{4}$ & $\frac{9}{15}$ & $\dot{4}$ & 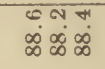 & 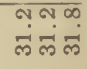 \\
\hline \multicolumn{2}{|c|}{ 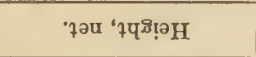 } & हูำ & & & & & & $\vec{\Xi}$ & $\stackrel{ }{=}$ \\
\hline \multicolumn{2}{|c|}{ 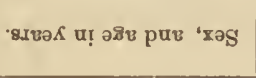 } & 足 & & & & & & $\begin{array}{l}\text { พี } \\
\text { Еँ }\end{array}$ & $=$ \\
\hline \multicolumn{2}{|c|}{ 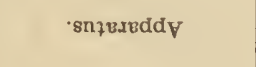 } & : & & $\geq$ & & $\geq$ & & $\geqq \geqq$ & 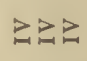 \\
\hline \multicolumn{2}{|r|}{ ஹू } & 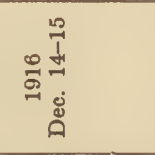 & & & & 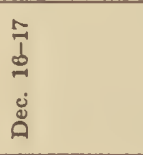 & & 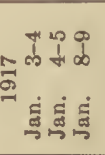 & 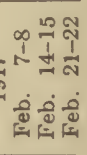 \\
\hline \multicolumn{2}{|c|}{ 遌完 } & ஃ & & & & & & 今్ & $\stackrel{m}{\beth}$ \\
\hline \multicolumn{2}{|c|}{ 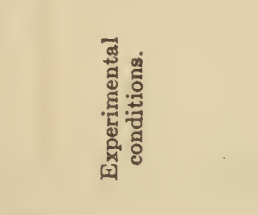 } & 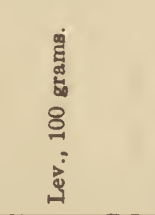 & & 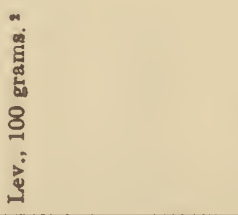 & & 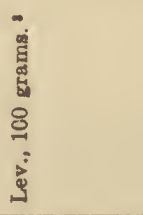 & & 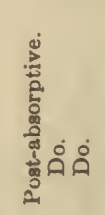 & 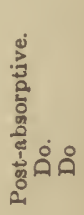 \\
\hline
\end{tabular}




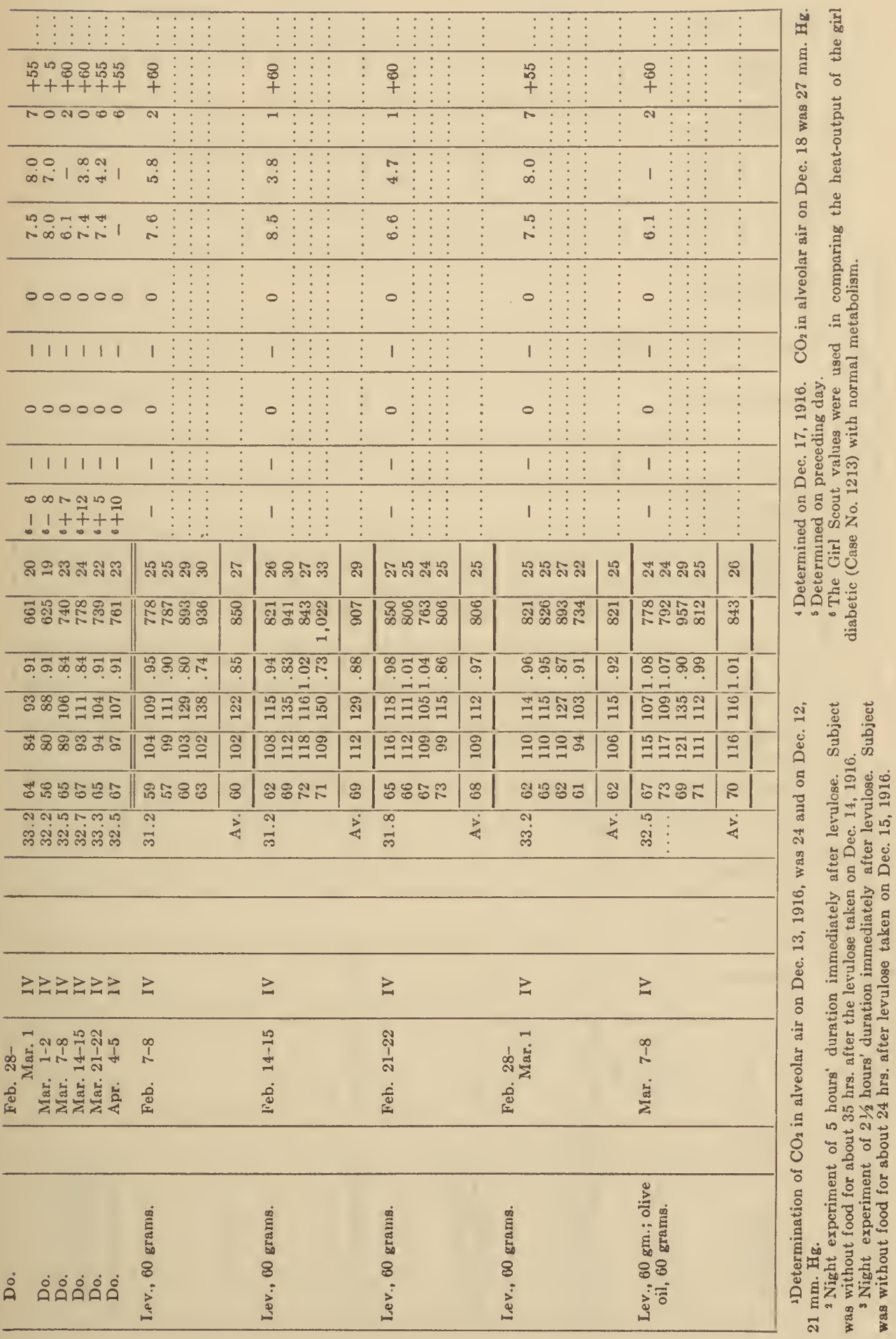




\begin{tabular}{|c|c|c|c|c|c|c|c|c|c|c|c|}
\hline \multicolumn{2}{|c|}{ 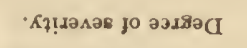 } & $\dot{\infty}$ & & $\vdots$ & & & & & & $\vdots$ & \\
\hline \multicolumn{2}{|c|}{ 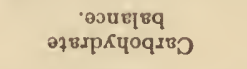 } & E⿱宀女口 & & $\stackrel{20}{+}$ & & $\stackrel{8}{+}$ & & & & $\stackrel{\infty}{+}$ & \\
\hline \multicolumn{2}{|c|}{ 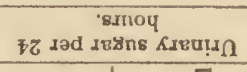 } & $E^{\circ}$ & & 0 & & 0 & & & & 0 & \\
\hline \multirow{2}{*}{ 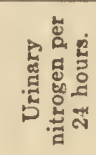 } & 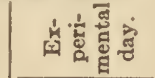 & $\dot{E}_{\infty}^{\infty} \dot{\infty}$ & & $\stackrel{4}{4}$ & & $\stackrel{\circ}{+}$ & & & & 1 & \\
\hline & 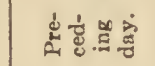 & E⿱宀⿻三丨口 & & $\ddot{n}$ & & $\vec{\infty}$ & & & & 1 & \\
\hline \multicolumn{2}{|c|}{ 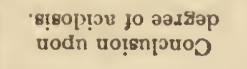 } & $\circ$ & & $\circ$ & & $\circ$ & & & & 0 & \\
\hline \multicolumn{2}{|c|}{ ' } & है। & $\vdots$ & 1 & $\vdots$ & 1 & & & : & 1 & \\
\hline \multicolumn{2}{|c|}{ 'р!ю8 э!ฺәวв! } & ○ & & 0 & & ○ & & & & o & \\
\hline \multicolumn{2}{|c|}{ 'HN } & हू 1 & $\vdots$ & 1 & $\vdots$ & 1 & $\vdots$ & & $\vdots$ & 1 & \\
\hline \multicolumn{2}{|c|}{ 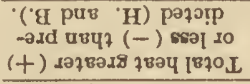 } & $\begin{array}{l}\dot{i} \\
\dot{a} \\
\end{array}$ & & I & & 1 & & & & 1 & \\
\hline \multirow{2}{*}{ 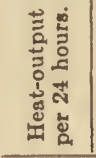 } & 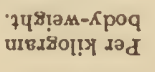 & కై సి & $\stackrel{\infty}{\pi}$ & ำ สి สి & ล & สีสุลี สే & รู & ณีล జึ & ล & สล 1 ณ & ล \\
\hline & ذ্ & 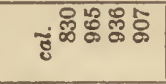 & $\overline{8}$ & 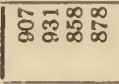 & ळ & 통్ㅀㅇㅛ & क्ष & 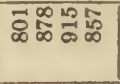 & 蒿 & 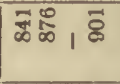 & 12 \\
\hline \multicolumn{2}{|c|}{ 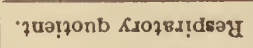 } & ธุक. & कू & 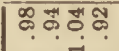 & 5. & "ౌాల్ & $\infty$ & ర్థ & $\Phi$ & న్రి & $\infty$ \\
\hline \multicolumn{2}{|c|}{ 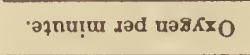 } & ن워 & 离 & 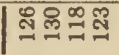 & I & 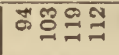 & 5 & 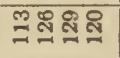 & I & $\stackrel{\infty}{=}$ I & $\Xi$ \\
\hline \multicolumn{2}{|c|}{ 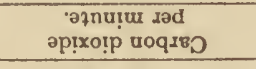 } & : & $1 \equiv$ & 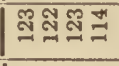 & \& & 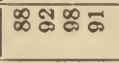 & क & 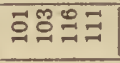 & $\stackrel{\infty}{=}$ & 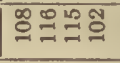 & 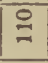 \\
\hline \multicolumn{2}{|c|}{ 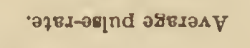 } & งะก์ & 2 & 於ล요 & ล & 모ㄴㅠㅛ & 8 & ஜீ- 18 & is & ニゅ๐ణ & $\approx$ \\
\hline \multicolumn{2}{|c|}{ 'рәуви '7чะ!э.А-Кроя } & इं્ल & $\frac{8}{4}$ & $\ddot{j}$ & $\overrightarrow{4}$ & वृ. & 8 & 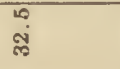 & $\frac{4}{4}$ & త్ల & $\ddot{z}$ \\
\hline \multicolumn{2}{|c|}{ "วอน " 74 ริเอH } & 통으 & & & & & & & & & \\
\hline \multicolumn{2}{|c|}{ 'ะגвว } & $=$ & & & & & & & & & \\
\hline \multicolumn{2}{|c|}{-snzededdV } & \multicolumn{2}{|l|}{$\geq$} & \multicolumn{2}{|l|}{$z$} & $\begin{array}{l}3 \\
2\end{array}$ & & 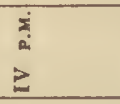 & & $\geq$ & \\
\hline \multicolumn{2}{|r|}{ هُ } & $=\frac{20}{\frac{I}{3}}$ & & $\begin{array}{l}\frac{\pi}{\pi} \\
\frac{1}{\pi} \\
\dot{\Phi} \\
\frac{\pi}{4}\end{array}$ & & $\begin{array}{l}\text { సे } \\
\text { के } \\
\dot{\tilde{\omega}} \\
\dot{\Xi}\end{array}$ & & & & $\begin{array}{l}\text { j } \\
\text { L }\end{array}$ & \\
\hline & ฮूّ & $\underset{3}{2}$ & & & & & & & & & \\
\hline & 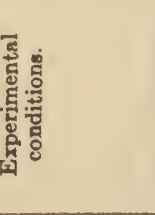 & 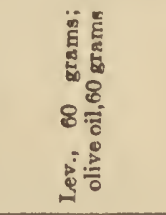 & & 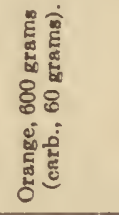 & & 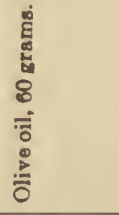 & & 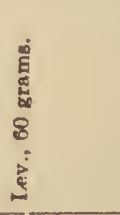 & & 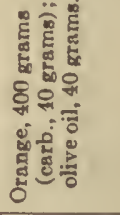 & \\
\hline
\end{tabular}




\begin{tabular}{|c|c|c|c|c|c|c|c|c|c|c|c|c|}
\hline & & & & $\infty \vdots$ & $\dot{3}$ & & & का & $\infty$ & & & \\
\hline מאו & & & & $\stackrel{\circ}{7}$ & $\stackrel{3}{+}$ & $\stackrel{\leftrightarrow}{+}$ & & $\stackrel{\circ}{7} \stackrel{8}{+}$ & $\frac{1}{1}$ & 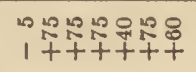 & $\stackrel{n}{+}$ & \\
\hline 0 & & & & 00 & 0 & ल & & 00 & 9 & $150=0000$ & 0 & \\
\hline 1 & & & & $\begin{array}{l}\infty \\
\text { in }\end{array}$ & $\stackrel{\infty}{n}$ & is & & $\begin{array}{ll}\dot{0} & \infty \\
\infty & \infty\end{array}$ & $\dot{0}$ & 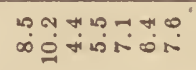 & $\stackrel{9}{9}$ & \\
\hline 1 & & & & $\stackrel{\infty}{\infty} 1$ & $\ddot{\infty}$ & 1 & & $\begin{array}{ll}\infty & m \\
\infty & 0\end{array}$ & $\ddot{9}$ & 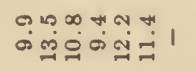 & $\ddot{m}$ & \\
\hline & & & & $\begin{array}{l}++ \\
++\end{array}$ & $\circ$ & ○ & & $\stackrel{t}{+}+$ & + & +000000 & $\circ$ & \\
\hline I & & & & ભ్లొ ్ఖ & 1 & 1 & & శ్ 1 & $\overrightarrow{\text { ตี }}$ & 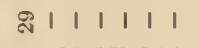 & 1 & \\
\hline & & & & ++ & 0 & $\circ$ & & ++ & 0 & 0 & $\circ$ & \\
\hline 1 & & & & 001 & 1 & 1 & $\vdots$ & 11 & 1 & 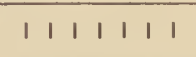 & 1 & \\
\hline 1 & & & & +1 & 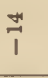 & 1 & : & $\begin{array}{ll}\pi & N \\
1 & 1\end{array}$ & $\stackrel{\infty}{i}$ & 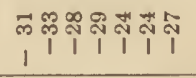 & 1 & \\
\hline สิ สี สี & $\mathfrak{N}$ & 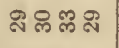 & రి & สี $\overrightarrow{\text { }}$ & ฉ & ని ని & จุ & $\vec{\sim}$ \&ั & $\vec{N}$ & 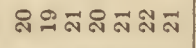 & สี สุล ส & ล \\
\hline 范染尔 & 용 & 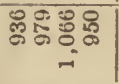 & 商 & 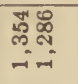 & ळ & 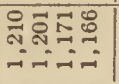 & $\begin{array}{l}-1 \\
= \\
=1\end{array}$ & 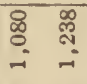 & $\stackrel{\infty}{0}$ & 尺. & 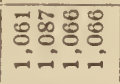 & 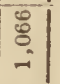 \\
\hline 20.8 & ? & 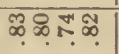 & 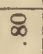 & ?ח & $\infty$ & लூ & का & क & 5 & 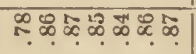 & 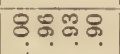 & $\$$ \\
\hline 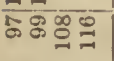 & $\cong$ & 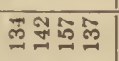 & $\mathbb{I}$ & $\stackrel{\infty}{\infty}$ & ฟु & 오종영 & 인 & 兽 & $\sqrt{2}$ & 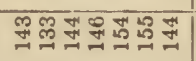 & 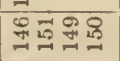 & $\stackrel{9}{-1}$ \\
\hline 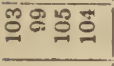 & $\stackrel{\circ}{\circ}$ & $\Xi \Xi ョ \Xi$ & $\stackrel{\infty}{=}$ & 票穿 & iี & 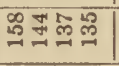 & 要1 & సี & $\cong$ & 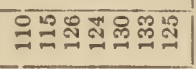 & 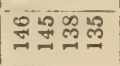 & $\equiv$ \\
\hline 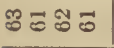 & 덩 & 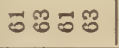 & ฮี & ஜே & $\pi$ & $\infty \begin{array}{llll}\infty & 1 & 1 & 1\end{array}$ & 1 & $\because 2$ & 舑 & 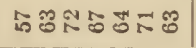 & ஜேもあ゙ & $\overrightarrow{0}$ \\
\hline बi & $\dot{3}$ & 㶾 & $\dot{4}$ & î̀ & $\begin{array}{l}c \\
\text { g }\end{array}$ & $\stackrel{m}{*}$ & $\dot{4}$ & $\begin{array}{ll}0 & 0 \\
\dot{0} & \dot{6}\end{array}$ & $\overrightarrow{8}$ & 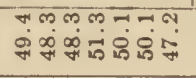 & $\begin{array}{l}\infty \\
\infty \\
\cdots\end{array}$ & 安 \\
\hline & & & & $\stackrel{尺}{=}$ & 昌 & & & 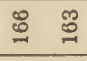 & $\stackrel{2}{1}$ & & & \\
\hline$\infty$ & & & & की & $\begin{array}{l}\text { ले } \\
\text { E }\end{array}$ & & & 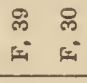 & $\frac{\hat{A}}{\mathrm{i}}$ & & & \\
\hline i & & $\begin{array}{l}\dot{\square} \\
\vdots \\
2\end{array}$ & & $\geq \geq$ & $\geq$ & $\geq$ & & $\geq z$ & $\geq$ & 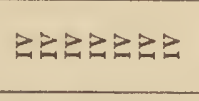 & $\geq$ & \\
\hline$\stackrel{2}{<}$ & & & & 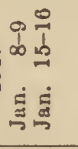 & 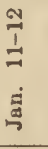 & $\begin{array}{l}0 \\
\vdots \\
\vdots\end{array}$ & & 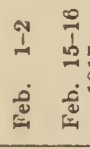 & 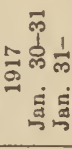 & 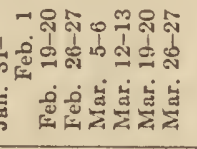 & 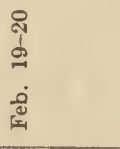 & \\
\hline & & & & $\stackrel{ \pm}{\underline{I}}$ & $\stackrel{n}{\Xi}$ & & & 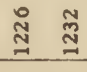 & $\stackrel{3}{\dddot{3}}$ & & & \\
\hline 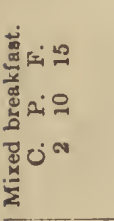 & & 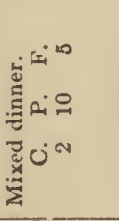 & & 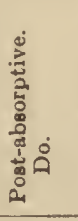 & 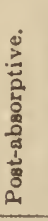 & 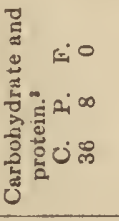 & & 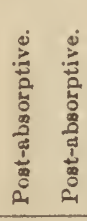 & 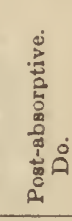 & ค்่̊ & 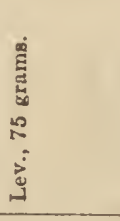 & \\
\hline
\end{tabular}




\begin{tabular}{|c|c|c|c|c|c|c|c|c|c|c|c|}
\hline \multicolumn{2}{|c|}{ 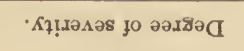 } & $\dot{2}$ & & & & & & & & & \\
\hline \multicolumn{2}{|c|}{ 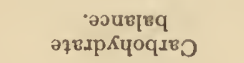 } & हैं & & $\stackrel{2}{+2}$ & & 욤 & & $\stackrel{2}{+}$ & & $\stackrel{8}{+}$ & \\
\hline \multicolumn{2}{|c|}{ 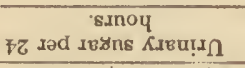 } & $\mathrm{E}^{-1}$ & & 0 & & 0 & & 0 & & 0 & \\
\hline \multirow{2}{*}{ 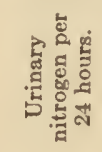 } & 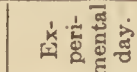 & हैं & & is & & $\bar{n}$ & & $\ddot{\circ}$ & & $\stackrel{\varphi}{\sim}$ & \\
\hline & 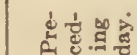 & $\varepsilon_{\square}^{\infty} \stackrel{\infty}{0}$ & & $\ddot{\infty}$ & & $\stackrel{\sim}{\sim}$ & & $\stackrel{\leftrightarrow}{=}$ & & । & \\
\hline \multicolumn{2}{|c|}{ 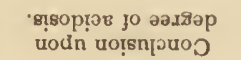 } & 0 & & 。 & & ○ & & 。 & & o & \\
\hline \multicolumn{2}{|c|}{ ' } & हैं। & $\vdots$ & 1 & & 1 & : & 1 & & I & \\
\hline \multicolumn{2}{|c|}{ 'р!юв эпฺюวв! } & 0 & : & 0 & & 0 & & 0 & & 0 & \\
\hline \multicolumn{2}{|c|}{ 'हHN } & हूं । & $\vdots$ & 1 & & 1 & & 1 & & 1 & \\
\hline \multicolumn{2}{|c|}{ 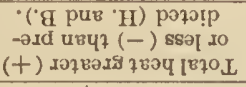 } & $\begin{array}{l}\text { षं। } \\
\dot{2}\end{array}$ & & 1 & & 1 & & 1 & & 1 & \\
\hline \multirow{2}{*}{ 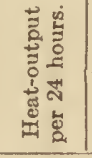 } & 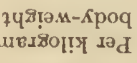 & 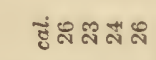 & $\stackrel{4}{4}$ & । สุณ & ๓ & ลีลสลส & สิ & ลีลสล & $\ddot{A}$ & ผีสูลส & ๓ \\
\hline & 愙 & 递要表 & đ: & 解哭 & 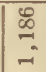 & 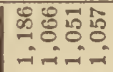 & 竞 & 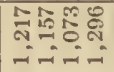 & $\stackrel{\infty}{=}$ & 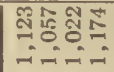 & $\begin{array}{l}\vec{E} \\
0 \\
-i\end{array}$ \\
\hline \multicolumn{2}{|c|}{ 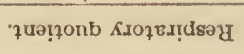 } & ๘ంळ & 2 & 1 कूळळ & \% & कळ & $\infty$ & 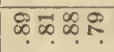 & 茂. & 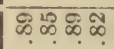 & $\infty$ \\
\hline \multicolumn{2}{|c|}{ 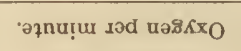 } & 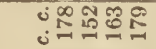 & $\ddot{\infty}$ & 1 이요요 & $\dddot{0}$ & 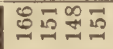 & 望 & 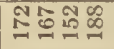 & 온 & 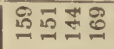 & 量 \\
\hline \multicolumn{2}{|c|}{ 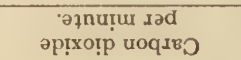 } & 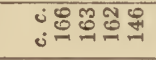 & 煦 & 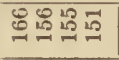 & 5 & 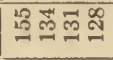 & 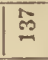 & 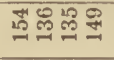 & $\stackrel{m}{-2}$ & 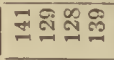 & $\bar{\Xi}$ \\
\hline \multicolumn{2}{|c|}{ 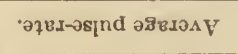 } & ト゚゚ジミ゙ & in & 1880 & $\mid \begin{array}{l}\infty \\
\theta\end{array}$ & $\mid \begin{array}{lllll}\infty & 1 & 1 & 0\end{array}$ & 1 & 이뉴 & ล & 5818 & $\mid t$ \\
\hline \multicolumn{2}{|c|}{ 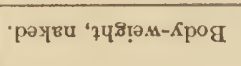 } & $\dot{\infty}$ & $\dot{s}$ & का. & $\dot{8}$ & $\overrightarrow{0}$ & $\dot{s}$ & $\overrightarrow{0}$ & $\dot{s}$ & a & $\dot{8}$ \\
\hline \multicolumn{2}{|c|}{ "วәน "7น } & 토ㅇㅛㅠ & & & & & & & & & \\
\hline \multicolumn{2}{|c|}{ 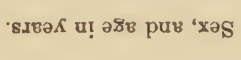 } & $\hat{\mathrm{N}}$ & & & & & & & & & \\
\hline \multicolumn{2}{|c|}{ 'snz̧eredd $V$} & $\geq$ & & $\geq$ & & $\geq$ & & $\geq$ & & $\geq$ & \\
\hline \multicolumn{2}{|r|}{ : } & 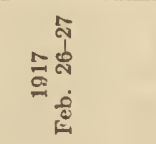 & & $\begin{array}{l}0 \\
\vdots \\
\dot{5} \\
\dot{5}\end{array}$ & & $\frac{m}{\stackrel{m}{a}}$ & & 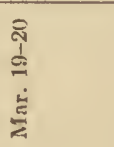 & & 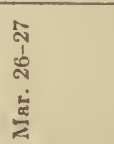 & \\
\hline \multicolumn{2}{|c|}{ 总完 } & 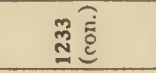 & & & & & & & & & \\
\hline \multicolumn{2}{|c|}{ 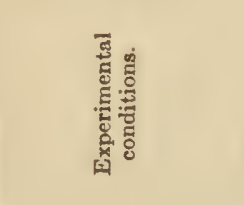 } & 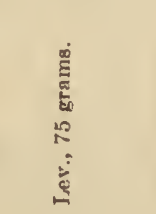 & & 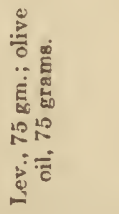 & & 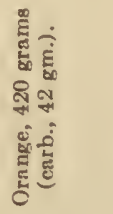 & & 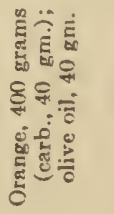 & & 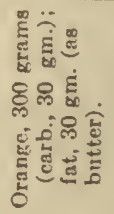 & \\
\hline
\end{tabular}




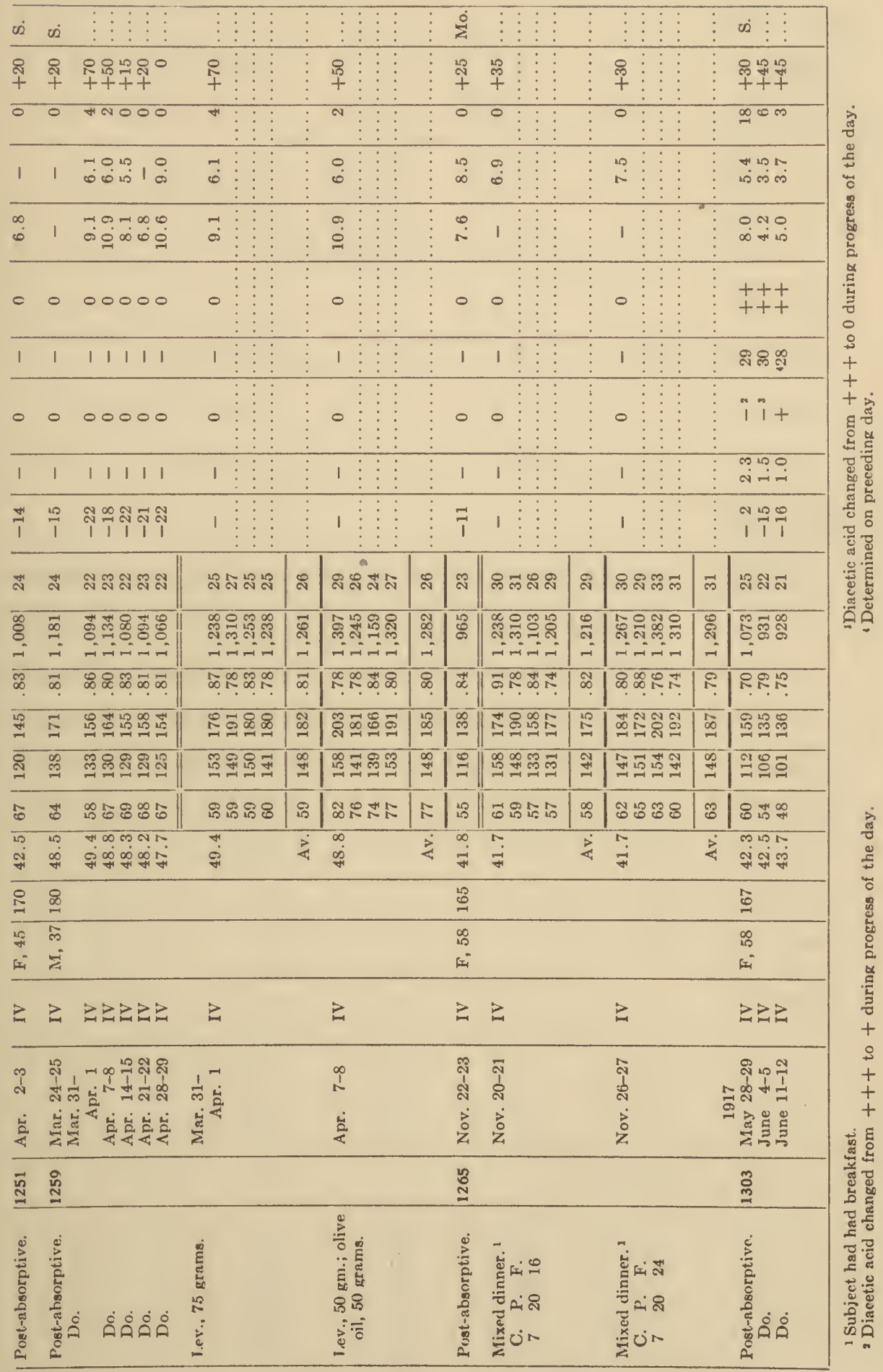




\begin{tabular}{|c|c|c|c|c|c|c|c|c|c|c|c|c|}
\hline \multicolumn{2}{|c|}{ 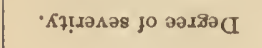 } & $\dot{s}$ & & & & & & $\dot{\theta}$ & & & & \\
\hline \multicolumn{2}{|c|}{ 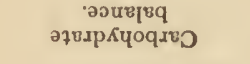 } & हूँ & & $\stackrel{\sharp}{+}$ & & t & & 유문군 & 욤 & & $\stackrel{2}{+}$ & \\
\hline \multicolumn{2}{|c|}{ 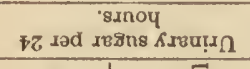 } & $\dot{\varepsilon}^{\infty}$ & & 0 & & क & & mon & $m$ & & 0 & \\
\hline \multirow{2}{*}{ 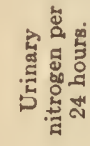 } & 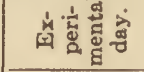 & हैं & & $\ddot{m}$ & & $\ddot{\infty}$ & & $\begin{array}{l}\text { His } \\
\text { His }\end{array}$ & $\stackrel{\circ}{+\infty}$ & & is? & \\
\hline & 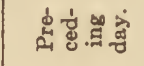 & $\dot{\varepsilon}_{\infty}^{\circ}$ & & $\stackrel{+}{\sim}$ & & is & & 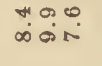 & $\infty$ & & $\stackrel{0}{\circ}$ & \\
\hline \multicolumn{2}{|c|}{ 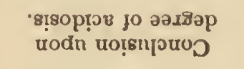 } & $\begin{array}{l}+ \\
+\end{array}$ & & $\stackrel{+}{+}$ & & + & & $+t_{+}$ & $\stackrel{+}{+}$ & & + & \\
\hline \multicolumn{2}{|c|}{ 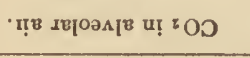 } & 於 & & ఫ̊ & & $\stackrel{\infty}{\infty}$ & & 吅 1 ह్ & $\mathscr{\Xi}$ & & 1 & \\
\hline \multicolumn{2}{|c|}{ 'p!ฺษ อ!ฺววษ!વ } & $i$ & & i & & + & & ioo & i & & $\circ$ & \\
\hline \multicolumn{2}{|c|}{ '?HN } & हूँ & & i? & & $\stackrel{0}{-i}$ & & $=11$ & $\stackrel{-1}{-}$ & & 1 & \\
\hline \multicolumn{2}{|c|}{ 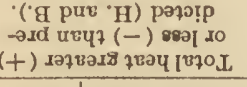 } & $\begin{array}{l}\dot{0} \\
\dot{R} \\
\end{array}$ & & 1 & & 1 & & $\stackrel{\infty}{1} \underset{7}{1}$ & 1 & & 1 & \\
\hline \multirow{2}{*}{ 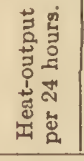 } & 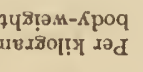 & 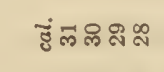 & 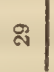 & ฉัละก & ล & ลลลลั & ลี & ボボ & ถักลลัล & $\hat{a}$ & ล2 ลิ สి & $\stackrel{4}{2}$ \\
\hline & 离 & 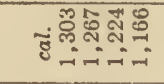 & 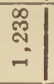 & 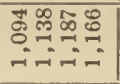 & $\stackrel{1}{101}$ & 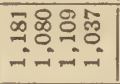 & 8 & 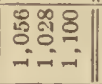 & 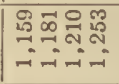 & 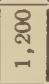 & 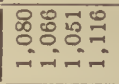 & $\begin{array}{l}0 \\
0 \\
- \\
-1\end{array}$ \\
\hline \multicolumn{2}{|c|}{ 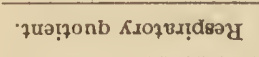 } & 뭉요 & $\because 1$ & 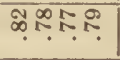 & $?$ & $\infty \underset{\infty}{\infty}$ & $\stackrel{\infty}{?}$ & 순? & 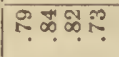 & $?$ & $\infty$ & $\infty$ \\
\hline \multicolumn{2}{|c|}{ 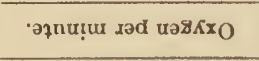 } & 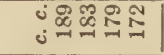 & $\stackrel{\vec{\infty}}{\rightarrow}$ & 垈 & 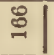 & 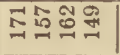 & $\stackrel{\square}{\circ}$ & 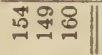 & 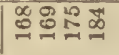 & \pm & 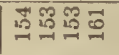 & 覀 \\
\hline \multicolumn{2}{|c|}{ 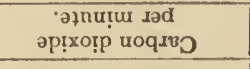 } & 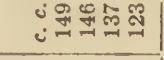 & 胥 & 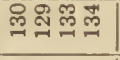 & $\vec{m}$ & 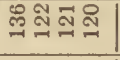 & $\stackrel{2}{-}$ & 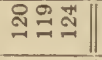 & 串 & 㐫 & 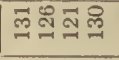 & \pm \\
\hline \multicolumn{2}{|c|}{ 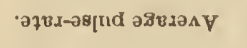 } & 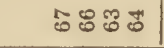 & $\because$ & ํํำ & is & 11111 & 1 & 180 & ฮี ซุ: 1 & $\approx$ & 占喫品 1 & : \\
\hline \multicolumn{2}{|c|}{ 'рәчви 'ту } & รึ่ & 4 & $\stackrel{4}{4}$ & $\frac{\dot{3}}{4}$ & $\stackrel{9}{\dot{m}}$ & $\frac{1}{4}$ & 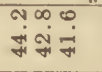 & $\frac{a}{y+j}$ & $\overrightarrow{4}$ & $\stackrel{\infty}{\stackrel{\infty}{*}}$ & $\frac{3}{4}$ \\
\hline \multicolumn{2}{|c|}{$7 ә 0$ ' } & हू요 & & & & & & 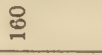 & & & & \\
\hline \multicolumn{2}{|c|}{ 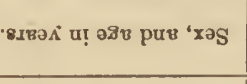 } & $\stackrel{\infty}{\circ}$ & & & & & & $\begin{array}{l}\vec{N} \\
\dot{E}\end{array}$ & & & & \\
\hline \multicolumn{2}{|c|}{-8nาช } & $\geq$ & & $\geq$ & & $z$ & & $\geqq \geq \geq$ & $z$ & & $\geq$ & \\
\hline \multicolumn{2}{|r|}{ ڤึं } & 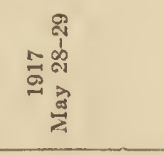 & & 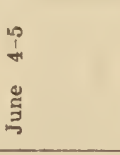 & & 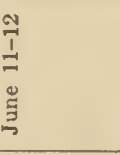 & & 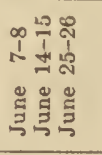 & 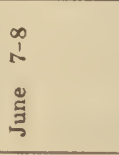 & & $\begin{array}{l}\frac{1}{1} \\
\frac{1}{2} \\
\frac{\pi}{3}\end{array}$ & \\
\hline \multicolumn{2}{|c|}{ 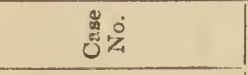 } & 兽 & & & & & & 今్ & & & & \\
\hline \multicolumn{2}{|c|}{ 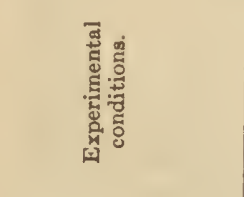 } & 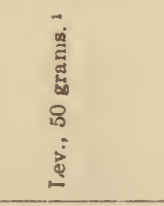 & & 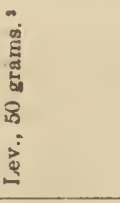 & & 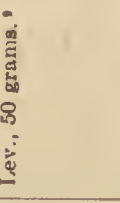 & & 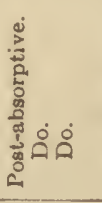 & 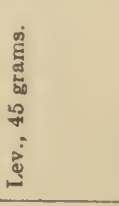 & & 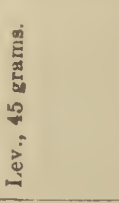 & \\
\hline
\end{tabular}


DIABETIC METABOLISM WITH HIGH AND LOW DIETS.

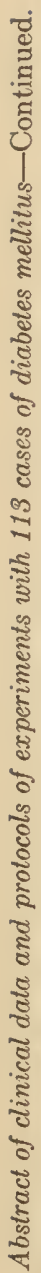

\begin{tabular}{|c|c|c|c|c|c|c|c|c|c|c|c|c|c|}
\hline \multicolumn{2}{|c|}{ 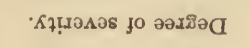 } & $\dot{s}$ & & & & $\dot{s}$ & ¿ & & & $\stackrel{8}{\circ}$ & & & $\dot{\theta}$ \\
\hline \multicolumn{2}{|c|}{ 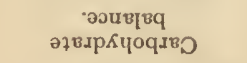 } & हूं । & & 1 & & 운 & $\circ$ & $\stackrel{2}{+}$ & & $\stackrel{8}{+}$ & $\stackrel{0}{0}$ & & 0 \\
\hline \multicolumn{2}{|c|}{ 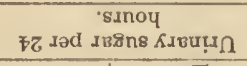 } & हैं & & 1 & & E़ी & 0 & 0 & & 0 & 0 & & 0 \\
\hline \multirow{2}{*}{ 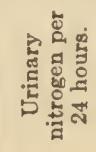 } & 离它䓌忽 & है। & & 1 & & $1 \stackrel{\infty}{=1}$ & $\stackrel{\infty}{\infty}$ & $\ddot{\infty}$ & & $\overrightarrow{\dddot{y}}$ & $\vec{\oplus}$ & & $\overrightarrow{5}$ \\
\hline & 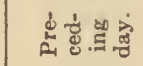 & है। & & 1 & & $11 \stackrel{0}{0}$ & $\overrightarrow{0}$ & 1 & & $\stackrel{\circ}{\text { I }}$ & $\ddot{\ddot{g}}$ & & $\vec{\infty}$ \\
\hline \multicolumn{2}{|c|}{ 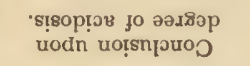 } & $\circ$ & & $\circ$ & & $\begin{array}{l}t+t \\
t+t \\
+t+\end{array}$ & $\circ$ & 0 & & 0 & 0 & & + \\
\hline \multicolumn{2}{|c|}{ 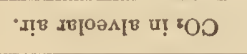 } & 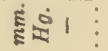 & & 1 & & สัส & 1 & 1 & & 1 & $\exists$ & & డ్ల \\
\hline \multicolumn{2}{|c|}{ 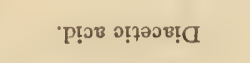 } & 1 & . & 1 & & $\begin{array}{l}+t+ \\
++t \\
++t\end{array}$ & $\circ$ & 。 & & 0 & ○ & & + \\
\hline \multicolumn{2}{|c|}{${ }^{2} \mathrm{HN}$} & हें 1 & $\vdots$ & 1 & & $1 \stackrel{\infty}{\infty} 1$ & 1 & 1 & & 1 & 1 & & 1 \\
\hline \multicolumn{2}{|c|}{ 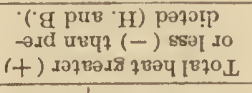 } & $\begin{array}{l}\dot{0} \\
\dot{2}\end{array}$ & & 1 & & 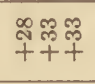 & $\infty$ & 1 & $\vdots$ & $\frac{29}{1}$ & 1 & & $\hat{1}$ \\
\hline \multirow{2}{*}{ 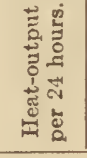 } & 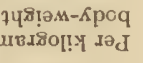 & हुं ले & $\bar{m}$ & స్లెల్లి ణొ & ల్ & 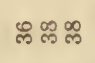 & $\vec{A}$ & ద్లి జి & ริ & $\approx$ & 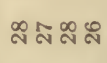 & ล & สี \\
\hline & 葋 & कृ: & 答 & 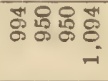 & ळ & 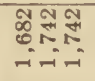 & జ్ & 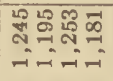 & $\underset{-\infty}{\stackrel{\infty}{\pi}}$ & 馬 & 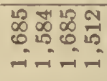 & - & ্ָণ్ \\
\hline \multicolumn{2}{|c|}{ 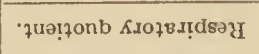 } & \&. & $\infty$ & का & $\vec{\infty}$ & 존 & $\stackrel{20}{\infty}$ & $\infty$ & $\infty$ & ₹ & 舟 & 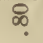 & $\stackrel{\infty}{?}$ \\
\hline \multicolumn{2}{|c|}{ 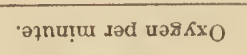 } & 证语 & 栗 & 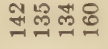 & $\stackrel{\text { F⿻ }}{\sim}$ & 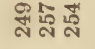 & I & 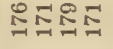 & $\stackrel{ \pm}{=}$ & สิ & สูกสิสำ & హึ & $\stackrel{\mathscr{-}}{-1}$ \\
\hline \multicolumn{2}{|c|}{ 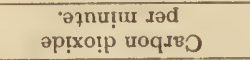 } & 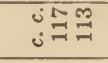 & $\Rightarrow$ & 크교 & ్ㅗ & $\stackrel{0}{\infty}$ & II & 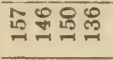 & F & 苞 & $\begin{array}{l}\infty \\
\mathscr{S}_{-\infty}^{\infty} \infty \\
\infty\end{array}$ & 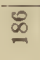 & 웜 \\
\hline \multicolumn{2}{|c|}{ 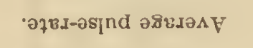 } & 11 & 1 & 1111 & 1 & $\stackrel{\infty}{\infty} \underset{\infty}{\infty} 1$ & ஜ & สำกำ & $\cong$ & : & 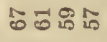 & $\overline{6}$ & 1 \\
\hline \multicolumn{2}{|c|}{ 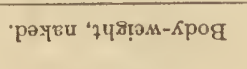 } & इं & $\dot{8}$ & $\stackrel{\text { ले }}{-1}$ & $\frac{3}{4}$ & 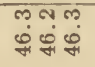 & ํํํ & $\stackrel{\infty}{-\infty}$ & $\frac{8}{4}$ & की & 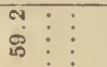 & $\dot{8}$ & 䐌 \\
\hline \multicolumn{2}{|c|}{ "วәน ‘า } & हี่ & & $\vdots$ & & $\stackrel{8}{0}$ & 曷 & & & $\stackrel{\infty}{\sim}$ & & & : \\
\hline \multicolumn{2}{|c|}{ 'SЈвכ } & $\stackrel{\infty}{\sharp}$ & & $\vdots$ & & ह્లీ & $\begin{array}{l}\text { i⿱ } \\
\text { 14 }\end{array}$ & & & ลี & & & 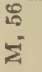 \\
\hline \multicolumn{2}{|c|}{ 'sกุвdยddV } & $\geq$ & & $z$ & & $\geq \geq \geq$ & $\geq$ & $z$ & & $z$ & $\geq$ & & $z$ \\
\hline \multirow{2}{*}{\multicolumn{2}{|c|}{ ڤّँ }} & $\approx \underline{\vec{b}}$ & & it & & 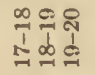 & $\hat{a ̂ ̃}$ & $i$ & & & $\begin{array}{l}\text { สิ } \\
\text { dे }\end{array}$ & & $\bar{d}$ \\
\hline & & 宫 & & $\stackrel{\mathscr{\delta}}{\circ}$ & & 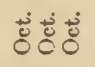 & ż & $\stackrel{\check{\nu}}{\circ}$ & & & $\dot{\vec{c}}$ & & ஹั \\
\hline \multicolumn{2}{|c|}{ 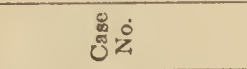 } & 悉 & & & & $\frac{7}{2}$ & $\frac{7}{2}$ & & & $\underline{\underline{Z}}$ & & & 竎 \\
\hline \multicolumn{2}{|c|}{ 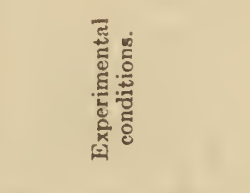 } & 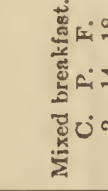 & & 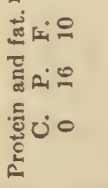 & & 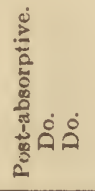 & 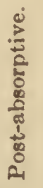 & 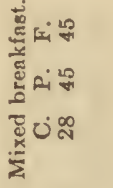 & & 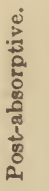 & 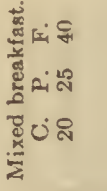 & & 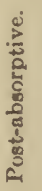 \\
\hline
\end{tabular}




\section{APPENDIX II.}

\section{SUGAR, FAT, AND NON-PROTEIN NITROGEN IN BLOOD OF DIABETICS IN POST-ABSORPTIVE CONDITION.}

TABLE A.-Determinations of sugar in the blood of diabetics in post-absorptive condition.

\begin{tabular}{|c|c|c|c|c|c|c|c|c|}
\hline $\begin{array}{l}\text { Case } \\
\text { No. }\end{array}$ & Date. & $\begin{array}{l}\text { Blood } \\
\text { sugar. }\end{array}$ & $\begin{array}{l}\text { Case } \\
\text { No. }\end{array}$ & Date. & $\begin{array}{l}\text { Blood } \\
\text { sugar. }\end{array}$ & $\begin{array}{l}\text { Case } \\
\text { No. }\end{array}$ & Date. & $\begin{array}{l}\text { Blood } \\
\text { sugar. }\end{array}$ \\
\hline & & p. ct. & & & p.ct. & & & p. ct. \\
\hline 263 & Apr. 12,1916 & 0.27 & 740 & Apr. 15,1915 & 0.26 & 786 & Nov. 6,1914 & 0.32 \\
\hline \multirow{2}{*}{428} & Nov. 23, 1914 & .25 & & Apr. 16,1915 & .43 & & Nov. 8,1914 & .31 \\
\hline & May 22, 1916 & .21 & & Apr. 17,1915 & .23 & & Nov. 10, 1914 & .21 \\
\hline \multirow[t]{8}{*}{436} & Dec. 7,1914 & .21 & & Apr. 18,1915 & .33 & & Nov. 12,1914 & .17 \\
\hline & Jan. 13,1916 & .20 & & Apr. 19,1915 & .29 & & Nov. 20, 1914 & .17 \\
\hline & Jan. 27, 1916 & .20 & & Apr. 20,1915 & .27 & & Nov. 23,1914 & .21 \\
\hline & Mar. 14, 1916 & .25 & & Apr. 21,1915 & .24 & & Dec. 2,1914 & .25 \\
\hline & Mar. 21, 1916 & .22 & & Apr. 24,1915 & .31 & & Dec. 3,1914 & .21 \\
\hline & Mar. 28, 1916 & .16 & & Apr. 27,1915 & .31 & & Dec. 4,1914 & .19 \\
\hline & Apr. $\quad 4,1916$ & .30 & & May 1,1915 & .28 & & Dec. 5,1914 & .14 \\
\hline & Oct. 24,1916 & .32 & 746 & Oct. 16,1914 & .30 & & Dec. 9,1914 & .17 \\
\hline \multirow[t]{2}{*}{558} & Jan. $\quad 6,1917$ & .26 & & Oct. 17,1914 & .30 & & Dec. 11,1914 & .15 \\
\hline & Jan. 15, 1917 & .14 & 755 & Apr. 12,1917 & .24 & & Dec. 17,1914 & .20 \\
\hline \multirow[t]{21}{*}{610} & Jan. 18, 1916 & .26 & & Apr. 16,1917 & .20 & & Dec. 30,1915 & .29 \\
\hline & May 11,1916 & .15 & & Apr. 25,1917 & .14 & & Jan. 19,1916 & .18 \\
\hline & Мау 15, 1916 & .11 & & Apr. 30,1917 & .13 & & June 13,1916 & .30 \\
\hline & May 16, 1916 & .12 & & May 1,1917 & .14 & & June 14,1916 & .30 \\
\hline & Mar. 13, 1917 & .20 & & May 7,1917 & .14 & & June 20,1916 & .31 \\
\hline & Mar. 15, 1917 & .20 & & May 8,1917 & .11 & & June 23,1916 & .25 \\
\hline & Mar. 16, 1917 & .21 & & May 13,1917 & .12 & & June 28,1916 & .15 \\
\hline & Mar. 22, 1917 & .20 & & May 15,1917 & .10 & & July $\quad 6,1916$ & .13 \\
\hline & Mar. 23, 1917 & .20 & & May 21,1917 & .10 & & July 10,1916 & .18 \\
\hline & Mar. 30, 1917 & .25 & & May 22, 1917 & .10 & & July 25,1916 & .20 \\
\hline & Apr. $\quad 5,1917$ & .18 & & May 28,1917 & .12 & 792 & Nov. 30,1914 & .22 \\
\hline & Apr. $\quad 6,1917$ & .19 & & May 29, 1917 & .11 & & Dec. 5,1914 & .25 \\
\hline & Apr. 12,1917 & .20 & & June 3,1917 & .10 & & Dec. 8,1914 & .22 \\
\hline & Apr. 13,1917 & .20 & 765 & Oct. 24,1914 & .24 & & Sept. 9,1916 & .17 \\
\hline & Apr. 18,1917 & .20 & & Oct. 26,1914 & .25 & & Dec. 5,1916 & .26 \\
\hline & Apr. 19,1917 & .17 & & Oct. 27,1914 & .18 & & Dec. 10,1916 & .17 \\
\hline & Sept. 28, 1917 & .23 & & Nov. 21, 1914 & .23 & & Nov. 8, 1917 & .21 \\
\hline & Oct. $\quad 1,1917$ & .25 & & Jan. 22, 1916 & .31 & & Nov. 13,1917 & .32 \\
\hline & Oct. 3,1917 & .37 & & Jan. 24,1916 & .25 & 800 & Jan. 12,1915 & .24 \\
\hline & Oct. $\quad 6,1917$ & .21 & & Jan. 25, 1916 & .26 & 806 & Dec. 18,1914 & .28 \\
\hline & Oct. 10,1917 & .19 & & Jan. 28, 1916 & .25 & & Dec. 21,1914 & .12 \\
\hline \multirow[t]{14}{*}{632} & Feb. 22, 1916 & .20 & & Jan. 30,1916 & .17 & & Dec. 22,1914 & .14 \\
\hline & Feb. 23, 1916 & .17 & & Feb. 2, 1916 & .20 & 810 & Dec. 15,1914 & .24 \\
\hline & Feb. 28, 1916 & .20 & & Feb. $\quad 4,1916$ & .22 & & Dec. 16,1914 & .33 \\
\hline & Mar. 8, 1916 & .20 & & Feb. $\quad 9,1916$ & .23 & & Dec. 18,1914 & .16 \\
\hline & Mar. 9, 1916 & .24 & & Feb. 10,1916 & .18 & & Dec. 22,1914 & .17 \\
\hline & Mar. 15,1916 & .13 & & Feb. 11,1916 & .21 & & Jan. 15,1916 & .16 \\
\hline & Mar. 16,1916 & .14 & & Feb. 14,1916 & .19 & 821 & Feb. 14,1916 & .33 \\
\hline & Mar. 22, 1916 & .19 & & Feb. 17,1916 & .25 & & Feb. 15,1916 & .33 \\
\hline & Mar. 23, 1916 & .24 & & Feb. 18,1916 & .17 & & Feb. 16,1916 & .31 \\
\hline & Mar. 27, 1916 & .20 & 767 & Oct. 29,1914 & .20 & & Feb. 19,1916 & .25 \\
\hline & Mar. 29, 1916 & .19 & & Nov. 2,1914 & .15 & & Feb. 21,1916 & .27 \\
\hline & Mar. 30,1916 & .22 & & Nov. 4,1914 & .20 & & Feb. 24,1916 & .27 \\
\hline & Apr. 5,1916 & .19 & & Nov. 9,1914 & .12 & & Mar. 1, 1916 & .22 \\
\hline & Apr. 13,1916 & .21 & 773 & Oct. 19,1914 & .27 & & Mar. 7,1916 & .25 \\
\hline \multirow[t]{4}{*}{714} & Dec. 5,1914 & .25 & 785 & Nov. 4,1914 & .20 & & Mar. 11, 1916 & .23 \\
\hline & Dec. 8,1914 & .22 & & Dec. 3, 1914 & .23 & & Mar. 13, 1916 & .13 \\
\hline & & & & Dec. 15,1914 & .24 & & Mar. 16, 1916 & .23 \\
\hline & & & & Dec. 16. 1914 & .29 & & Mar. 21, 1916 & .29 \\
\hline
\end{tabular}


TABLE A.-Determinations of sugar in the blood oj diabetics in post-absorptive condition-Continued.

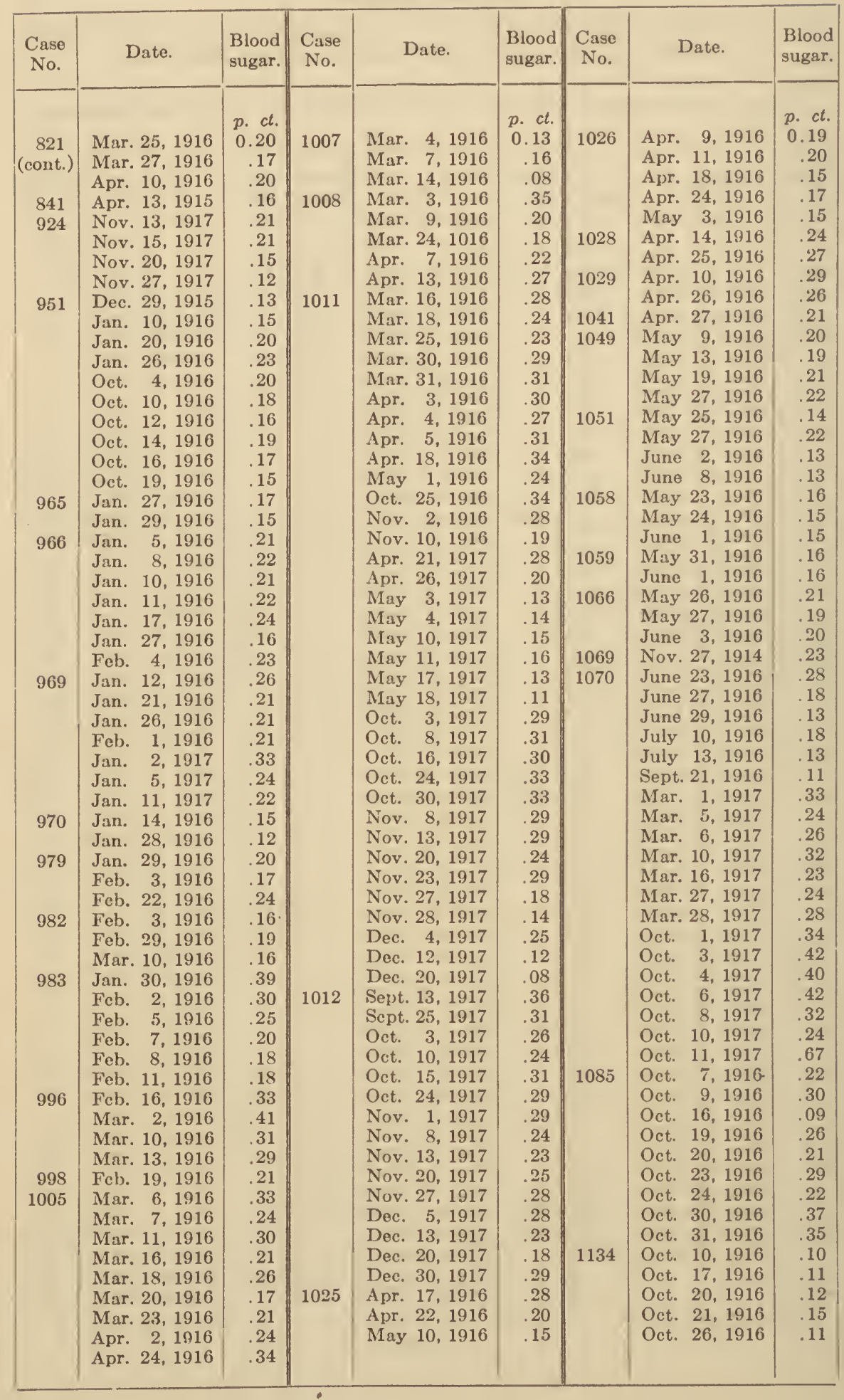


TABLE A.-Determinations of sugar in the blood oj diabetics in post-absorptive condition-Continued.

\begin{tabular}{|c|c|c|c|c|c|c|c|c|}
\hline $\begin{array}{l}\text { Case } \\
\text { No. }\end{array}$ & Date. & $\begin{array}{l}\text { Blood } \\
\text { sugar. }\end{array}$ & $\begin{array}{l}\text { Case } \\
\text { No. }\end{array}$ & Date. & $\begin{array}{l}\text { Blood } \\
\text { sugar. }\end{array}$ & $\begin{array}{c}\text { Case } \\
\text { No. }\end{array}$ & Date. & $\begin{array}{l}\text { Blood } \\
\text { sugar }\end{array}$ \\
\hline \multirow{5}{*}{1147} & & p. ct. & & & p. ct. & \multirow{14}{*}{1265} & & p. ct. \\
\hline & Oct. 14,1916 & 0.29 & 1213 & Mar. 21, 1917 & 0.20 & & Nov. 14, 1917 & 0.32 \\
\hline & Oct. 21,1916 & .15 & (cont.) & Mar. 22, 1917 &, 20 & & Nov. 20,1917 & .14 \\
\hline & Oct. 23,1916 & .17 & & Mar. 28, 1917 & .19 & & Nov. 26,1917 & .14 \\
\hline & Oct. 30,1916 & .18 & & Mar. 29, 1917 & .20 & & May 18,1917 & .22 \\
\hline & Nov. 1,1916 & .17 & & Apr. $\quad 4,1917$ & .22 & & May 26, 1917 & .16 \\
\hline \multirow[t]{10}{*}{1159} & Oct. 20,1916 & .34 & & Apr. $\quad 6,1917$ & .28 & & May 28, 1917 & .17 \\
\hline & Oct. 25,1916 & .33 & & Apr. $\quad 9,1917$ & .25 & & May 29, 1917 & .15 \\
\hline & Oct. 27,1916 & .24 & & Apr. 11,1917 & .20 & & June 4,1917 & .13 \\
\hline & Oct. 28,1916 & .34 & & Apr. 12,1917 & .17 & & June 5,1917 & .15 \\
\hline & Nov. 3, 1916 & .23 & & Apr. 16,1917 & .20 & & June 11, 1917 & .13 \\
\hline & Nov. 14, 1916 & .32 & \multirow[t]{5}{*}{1214} & Dec. 22,1916 & .31 & & June 12,1917 & .12 \\
\hline & Nov. 21, 1916 & .29 & & Dec. 27,1916 & .18 & & June 18,1917 & .13 \\
\hline & Nov. 28,1916 & .29 & & Jan. $\quad 2,1917$ & .18 & & June 19,1917 & .15 \\
\hline & Dec. 1,1916 & .25 & & Jan. $\quad 8,1917$ & .20 & \multirow[t]{11}{*}{1307} & May 23, 1917 & .20 \\
\hline & Dec. 2,1916 & .29 & & Jan. 18,1917 & .15 & & May 29,1917 & .19 \\
\hline \multirow[t]{10}{*}{1160} & Oct. 25,1916 & .40 & \multirow[t]{4}{*}{1215} & Jan. 1,1917 & .19 & & May 30,1917 & .19 \\
\hline & Oct. 28,1916 & .26 & & Jan. $\quad 5,1917$ & .16 & & June 4,1917 & .11 \\
\hline & Oct. 29,1916 & .24 & & Jan. 11, 1917 & .14 & & June 7.1917 & .12 \\
\hline & Nov. 2,1916 & .15 & & Jan. 15,1917 & .14 & & June 8,1917 & .12 \\
\hline & Nov, 4, 1916 & .20 & \multirow[t]{2}{*}{1226} & Jan. 22,1917 & .31 & & June 14,1917 & .17 \\
\hline & Nov. 5,1916 & .25 & & Feb. 13,1917 & .19 & & June 15,1917 & .17 \\
\hline & Nov. 8,1916 & .29 & \multirow[t]{3}{*}{1232} & Feb. $\quad 5,1917$ & .09 & & June 25, 1917 & .19 \\
\hline & Nov. 14,1916 & .17 & & Feb. 15,1917 & .08 & & June 26,1917 & .22 \\
\hline & Nov. 21,1916 & .20 & & Feb. 28,1917 & .09 & & June 30,1917 & .17 \\
\hline & Nov. 28,1916 & .17 & \multirow[t]{15}{*}{1233} & Jan. 30,1917 & .29 & & Sept. 8, 1917 & .05 \\
\hline \multirow[t]{6}{*}{1181} & Nov. 9, 1916 & .26 & & Feb. 19,1917 & .13 & \multirow[t]{4}{*}{1373} & Nov. 16,1917 & .37 \\
\hline & Nov. 13,1916 & .28 & & Feb. 21,1917 & .14 & & Nov. 20,1917 & .24 \\
\hline & Nov. 16,1916 & .24 & & Feb. 26,1917 & .14 & & Nov. 21, 1917 & .23 \\
\hline & Nov. 21, 1916 & .19 & & Feb. 27,1917 & .11 & & Nov. 27,1917 & .16 \\
\hline & Nov. 24,1916 & .20 & & Mar. 5,1917 & .16 & \multirow[t]{11}{*}{1378} & Sept. 14, 1917 & .24 \\
\hline & Nov. 28, 1916 & .22 & & Mar. 6,1917 & .14 & & Sept. 28, 1917 & .26 \\
\hline \multirow[t]{2}{*}{1182} & Nov. 13,1916 & .13 & & Mar. 12,1917 & .13 & & Oct. 3,1917 & .23 \\
\hline & Nov. 20,1916 & .09 & & Mar. 13, 1917 & .13 & & Oct. 10,1917 & .22 \\
\hline \multirow[t]{10}{*}{1196} & Dec. 9,1916 & .33 & & Mar. 19,1917 & .11 & & Oct. 16,1917 & .26 \\
\hline & Dec. 11,1916 & .31 & & Mar. 20, 1917 & .11 & & Oct. 24,1917 & .27 \\
\hline & Dec. 14,1916 & .15 & & Mar. 26, 1917 & .13 & & Nov. 2,1917 & .22 \\
\hline & Dec. 16,1916 & .37 & & Mar. 27, 1917 & .12 & & Nov. 8,1917 & .22 \\
\hline & Dec. 18,1916 & .31 & & Apr. 3,1917 & .14 & & Nov. 13,1917 & .24 \\
\hline & Dec. 21,1916 & .23 & & Apr. 10,1917 & .17 & & Nov. 27,1917 & .28 \\
\hline & Dec. 27,1916 & .24 & 1251 & Mar. 16,1917 & .29 & & Dec. 11,1917 & .26 \\
\hline & Jan. 2, 1917 & .22 & & Mar. 21, 1917 & .13 & 1412 & Oct. 17,1917 & .37 \\
\hline & Jan. 8, 1917 & 11 & & Mar. 24, 1917 & .16 & 1414 & Nov. 21, 1917 & .26 \\
\hline & Jan. 17, 1917 & .09 & & Apr. $\quad 2,1917$ & .14 & & Nov. 23, 1917 & .28 \\
\hline 1207 & Dec. 20,1916 & .22 & & Apr. $\quad 5,1917$ & .15 & & Nov. 26,1917 & .28 \\
\hline & Dec. 27,1916 & .17 & 1259 & Mar. 15, 1917 & .32 & & Nov. 27,1917 & .13 \\
\hline & Jan. $\quad 3,1917$ & .16 & & Mar. 19,1917 & .19 & & Dec. 5,1917 & .24 \\
\hline & Jan. $\quad 8,1917$ & .16 & & Mar. 22, 1917 & .19 & & Dec. 12,1917 & .17 \\
\hline & Jan. 12,1917 & .15 & & Mar. 31,1917 & .22 & 1422 & Nov. 17,1917 & .23 \\
\hline & $\operatorname{Jan} 15,1917$ & .14 & & Apr. 1,1917 & .21 & & Nov. 23,1917 & .16 \\
\hline 1213 & $\operatorname{Jan} 30,1917$ & .22 & & Apr. $\quad 7,1917$ & .24 & & Nov. 27,1917 & .15 \\
\hline & Feb $\quad 7,1917$ & .21 & & Apr. 8,1917 & .23 & & Nov. 30,1917 & .10 \\
\hline & Feb 14, 1917 & .23 & & Apr. 12,1917 & .20 & 1427 & Nov. 21,1917 & .20 \\
\hline & Feb 22, 1917 & .15 & & Apr. 14,1917 & .18 & & Nov. 26,1917 & .17 \\
\hline & Mar 1,1917 & .28 & & Apr. 15,1917 & .17 & & Dec. 3,1917 & .14 \\
\hline & Mar 7, 1917 & .26 & & Apr. 20,1917 & .19 & & Dec. 11,1917 & .15 \\
\hline & Mar 14, 1917 & .23 & & Apr. 28,1917 & .20 & & Dec. 14,1917 & .16 \\
\hline & Mar. 15,1917 & .22 & & May 5,1917 & .15 & & & \\
\hline
\end{tabular}


TABLE B.-Determinations of fat in the blood of diabetics in post-absorptive condition.

\begin{tabular}{|c|c|c|c|c|c|c|c|c|}
\hline $\begin{array}{l}\text { Case } \\
\text { No. }\end{array}$ & Date. & $\begin{array}{l}\text { Blood } \\
\text { fat. }\end{array}$ & $\begin{array}{l}\text { Case } \\
\text { No. }\end{array}$ & Date. & $\begin{array}{c}\text { Blood } \\
\text { fat. }\end{array}$ & $\begin{array}{l}\text { Case } \\
\text { No. }\end{array}$ & Date. & $\begin{array}{l}\text { Blood } \\
\text { fat. }\end{array}$ \\
\hline 428 & May 22,1916 & & 998 & Feb. 19,1916 & & 1160 & Oct. 25,1916 & $\begin{array}{l}\text { p. ct. } \\
0.96\end{array}$ \\
\hline 436 & Oct. 24,1916 & 1 & & [ar. 6,1916 & 5 & & Nov. 8,1916 & 1.08 \\
\hline & Jan. $\quad 6,1917$ & .78 & & Tar. 23,1 & .75 & 1181 & 9,1916 & .80 \\
\hline \multirow[t]{8}{*}{610} & Jan. 18,1916 & .83 & 1008 & Apr. 3,1916 & .98 & 1182 & Nov. 13,1916 & 1.05 \\
\hline & May 17,1916 & 1.12 & & Mar. 18,1916 & .84 & 1196 & Dec. 9,1916 & 1.18 \\
\hline & July 11,1916 & 1.56 & & Nov. 11,1916 & .77 & & Dec. 16,1916 & 1.01 \\
\hline & Mar. 13, 1917 & .97 & & Oct. $\quad 8,1917$ & 1.76 & & Jan. $\quad 8,1917$ & .79 \\
\hline & Mar. 15,1917 & 1.03 & & Oct. 24,1917 & 1.33 & 1207 & Dec. 20,1916 & 87 \\
\hline & Mar. 16,1917 & 1.22 & & ct. 30,1917 & 1.00 & & Jan. $\quad 3,1917$ & 68 \\
\hline & Oct. $\quad 1,1917$ & 1.20 & & Tov. 8,1917 & 1.16 & 1213 & 8,1917 & 74 \\
\hline & Oct. 3,1917 & 1.23 & & Nov. 13,1917 & 1.02 & & Mar. 1,1917 & 1.45 \\
\hline \multirow[t]{3}{*}{632} & Feb. 23,1916 & .72 & & Nov. 20,1917 & 1.01 & & Aar. 14, 1917 & 1.52 \\
\hline & 2 & .93 & & c. 4 , & 1. & & ar. 2 & 1.42 \\
\hline & Mar. 29 & .85 & & Dec. 12,1917 & 1.21 & 1214 & ec. 22, & .91 \\
\hline \multirow[t]{3}{*}{765} & Jan. 22, 1916 & 1.05 & 1012 & ct. 15,1917 & .82 & 1215 & Jan. 1, & .73 \\
\hline & $\mathrm{F}$ & 0 & & 8 & & 226 & an. 22 , & 88 \\
\hline & Feb. 17,1916 & 1.04 & & Nov. 20,1 & .88 & 1232 & eb. 15, & .81 \\
\hline \multirow[t]{9}{*}{786} & Jan. 11 & 0 & & ec. 5 & 1.03 & & eb. 2 & 83 \\
\hline & 12 & 7.36 & & Dec. 13 , & 1.25 & 123 & an. 30 , & 3.62 \\
\hline & e 14 & 8.90 & & Dec. 20 , & 1.00 & & eb. 1 & 1.51 \\
\hline & 1 & 9.5 & & 27 , & & & b. 2 & 1.39 \\
\hline & e 2 & 4.44 & & ec. 30 , & .9 & & b. 27 , & 1.36 \\
\hline & e 28 & 2.28 & 102 & 1 & 7 & & r. & 1.52 \\
\hline & $\mathrm{J}$ & 2.7 & & 1 & .0 & & 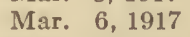 & 1.28 \\
\hline & 10 & 2.7 & & 1 & .7 & & r. 1 ? & 1.10 \\
\hline & 25 & & & 2 & 1.1 & & & 26 \\
\hline 792 & $\mathrm{D}$ & & & у 2 & & & & .09 \\
\hline 81 & 17,1 & 1.0 & & y 2 & 1.0 & 1251 & & 1.43 \\
\hline 82 & 1 & .7 & & 3 & & & & 75 \\
\hline 92 & 20 & .9 & & ne 29 & .8 & 1265 & & 1.81 \\
\hline & 10 & .9 & & 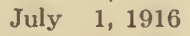 & .7 & & 7 & 1.81 \\
\hline \multirow[t]{3}{*}{966} & $\mathrm{~J}$ & .7 & & 1, & .6 & & 7 & .78 \\
\hline & 10 & .6 & & Mar. 6, & .0 & 13 & 7 & 1.49 \\
\hline & Feb. 4,1 s & .83 & & 1,1 & 1.07 & 1414 &.$\varepsilon$ & .81 \\
\hline \multirow[t]{2}{*}{969} & 21,1 & .98 & & 3,1 & 1.1 & & .2 & .74 \\
\hline & & 1.13 & & 8 & 1.0 & & ov. 2 & 68 \\
\hline 97 & Jan. 14, & 50 & 1085 & Oct. 30,1 & 2.9 & & 5 & .86 \\
\hline & $\mathrm{Ja}$ & & & Oct. 31,1 & 2.74 & & 20 & .0J \\
\hline 983 & Jan. 31 , & 1.06 & 1134 & Oct. 26,1916 & .64 & 1427 & Dec. 3 , & .93 \\
\hline 996 & Mar. 2,1916 & 65 & & & & & Dec. 11,1917 & .89 \\
\hline
\end{tabular}

TABLE C.-Determinations of non-protein nitrogen in the blood of diabetics in post-absorptive condition.

\begin{tabular}{|c|c|c|c|c|c|}
\hline $\begin{array}{c}\text { Case } \\
\text { No. }\end{array}$ & Date. & $\begin{array}{c}\text { Non- } \\
\text { protein } \\
\text { nitrogen. }\end{array}$ & $\begin{array}{l}\text { Case } \\
\text { No. }\end{array}$ & Date. & $\begin{array}{c}\text { Non- } \\
\text { protein } \\
\text { nitrogen. }\end{array}$ \\
\hline 610 & Mar. 13,1917 & p. ct. & 1214 & Dec. 22,1916 & $\begin{array}{l}\text { p. ct. } \\
16\end{array}$ \\
\hline 755 & May 1,1917 & & 1232 & Feb. 5,1917 & 34 \\
\hline 792 & Dec. 5,1916 & 40 & & Feb. 15,1917 & 60 \\
\hline 1011 & May 18,1917 & 28 & 1233 & Feb. 19,1917 & 110 \\
\hline 1070 & Oct. 3,1917 & 26 & & Feb. 21,1917 & 95 \\
\hline 1147 & Nov. 6,1916 & 30 & & Feb. 26,1917 & 120 \\
\hline 1159 & Nov. 14,1916 & 32 & & Mar. 5, 1917 & 28 \\
\hline \multirow[t]{2}{*}{1160} & Nov. 4,1916 & 30 & & Mar. 13, 1917 & 53 \\
\hline & Nov. 14,1916 & 22 & & Mar. 15, 1917 & 48 \\
\hline 1181 & Nov. 8,1916 & 20 & & Mar. 20, 1917 & 28 \\
\hline 1182 & Nov. 20,1916 & 16 & & Mar. 26, 1917 & 26 \\
\hline \multirow[t]{3}{*}{1196} & & 36 & & Mar. 27, 1917 & 28 \\
\hline & Dec. 14,1916 & 60 & 1259 & Mar. 15,1917 & 32 \\
\hline & Jan. 8,1917 & 43 & 1303 & May 18,1917 & 28 \\
\hline 1207 & Dec. 20,1916 & 54 & 1378 & Oct. 3,1917 & 50 \\
\hline
\end{tabular}






41120530R

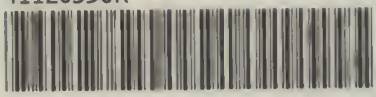

NLM 0520ьट99 8

NATIONAL LIBRARY OF MEDICINE 